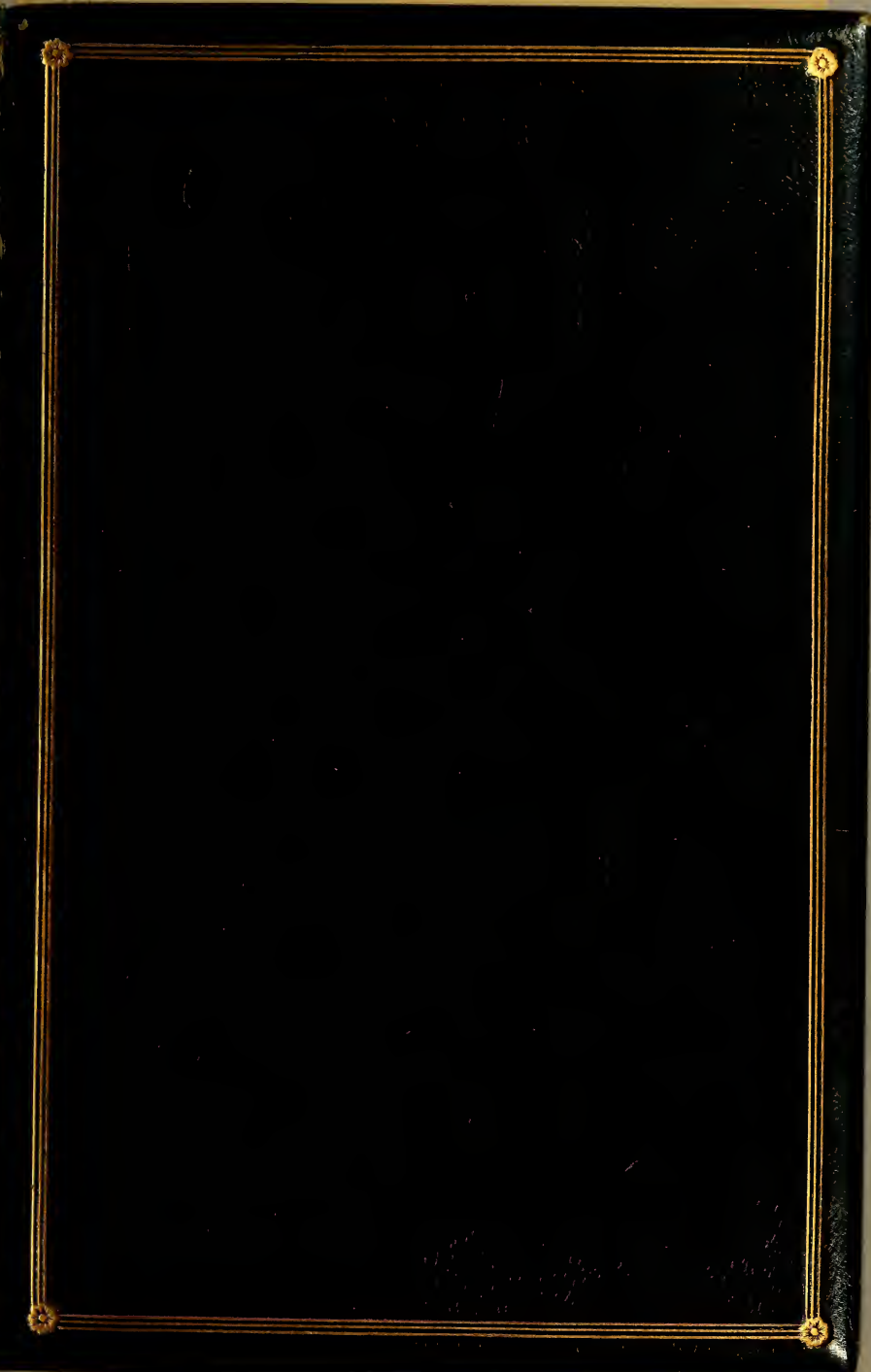




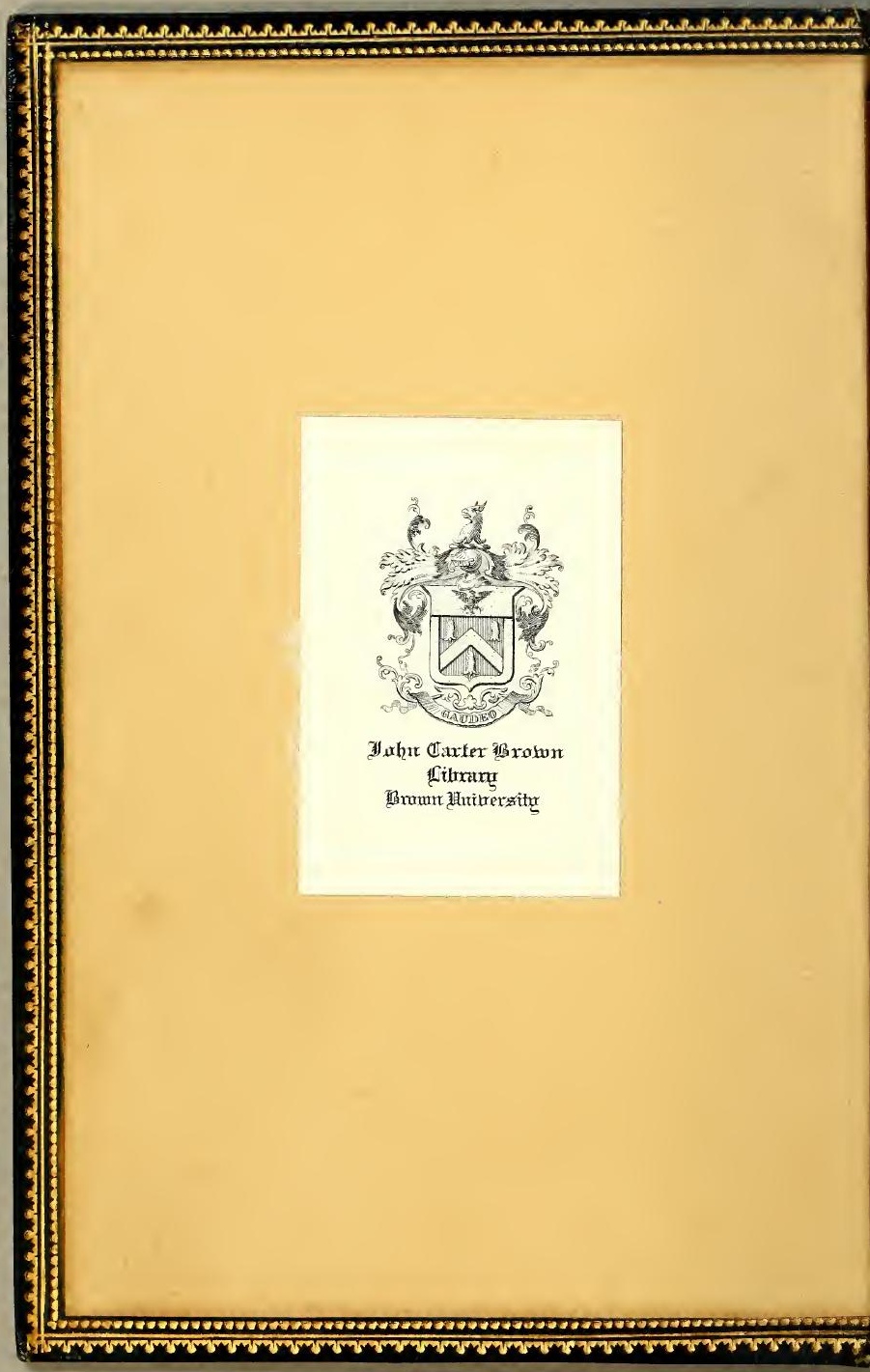




I O S E P H I

A C O S T A;

SOCIETATIS

IES V,

DE NATVRA NOVI ORBIS $L I B R I D V O$.

$\mathrm{E} \mathrm{T}$

DE PROMVLGATIONE

E V A G E L I I A P V D

B A R B A R O $s$,

fiue,

DE I'ROCVRANDA INDORVM Salute, Libri fex.
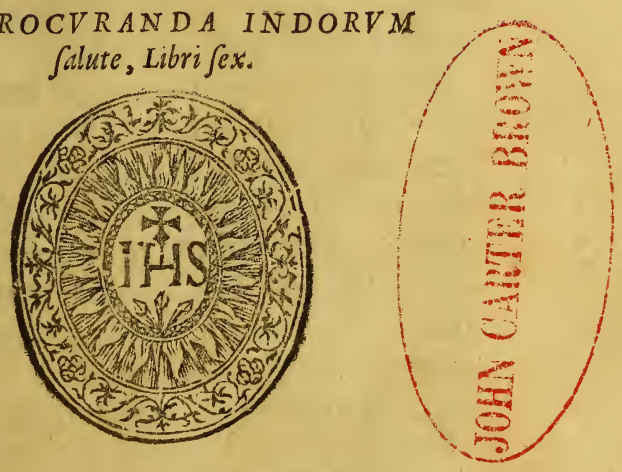

COLONIAE AGRIPPINAI, In officina Birckmannica, Sumpti-

bus Àrnoldi Mylij.

cIo. Io. XCV 1.

Cumgratitu Prinilegio S. Caf. Maieft. 



\section{P H ILIP PO \\ $S E C V N D O H I$}

$S P A N I A R V M A T Q V E$ I N D I A R M REG I Catholico

IOSEPHVS A COSTA SAlutem ef faclicitatem D.

3 VI diuturna peregrinationelongè pofitas regiones obicrunt, folent ij, cum ad patriam redeunt; rara aliqua atq; inufitata deferre fuis,quos vel ipfa noutate delectent. Quod fi felecta etiam ac pretiofa videantur, non aliâs putant melius collocari poffe, quàm oblata Principibus. Hortm potentifine R $\mathrm{cx}$, inftitutum mihi quoque imitandum exiftimaui:qui à maioribus ad Noui orbis noum excolendum Chrifti agrum iampridcmminus, vniucefam propemodum Indiam Occidentalem obicrim, imperijcertètui amplifinmi neq; mediocrem neq; parum locupleteni portionem. Itague inde in Europam relios ล⿱一𫝀口:- 


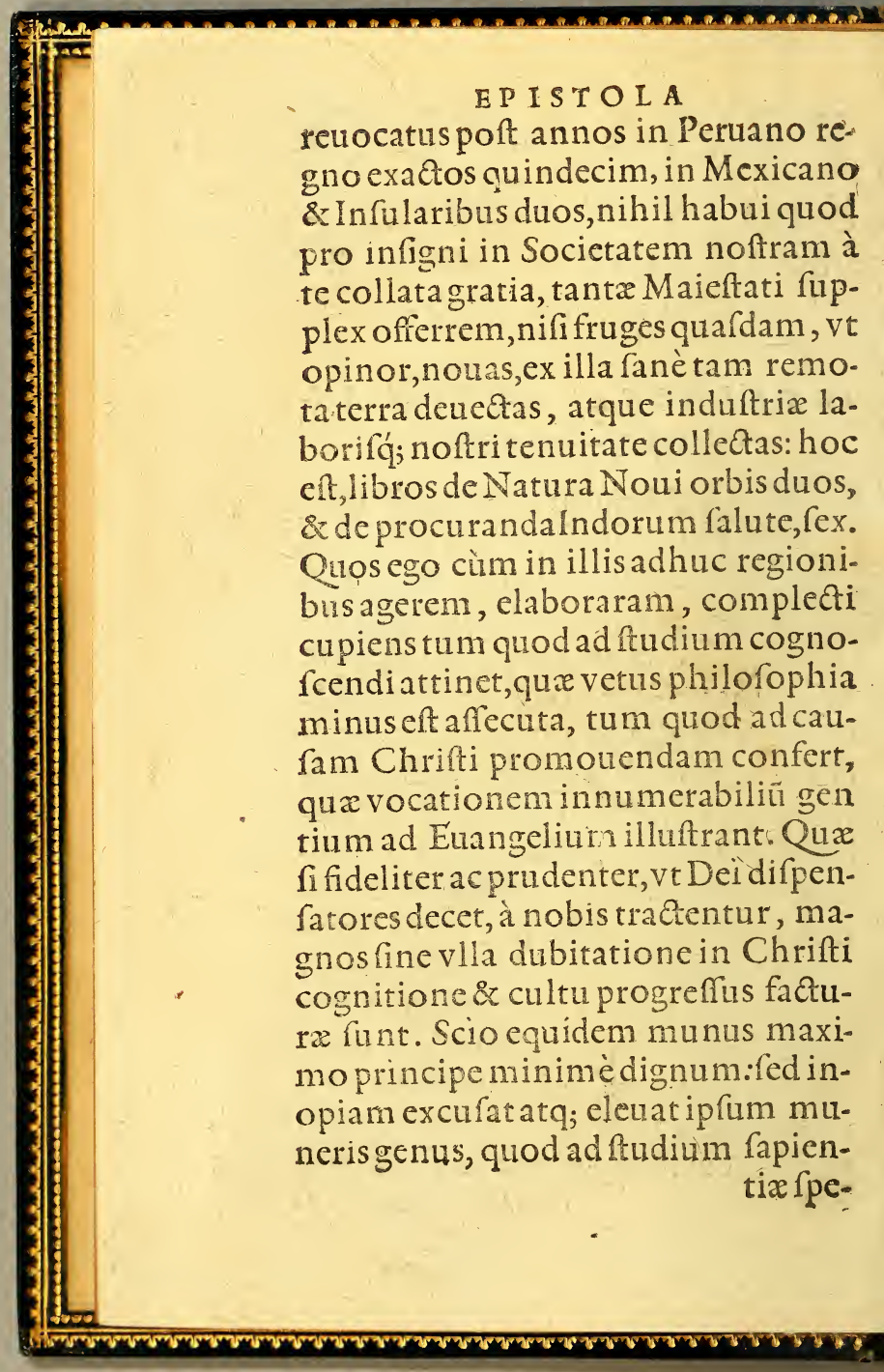




\section{DE D I C A TOR I A:} tix fpectat. Sapientix porrò vel exigua pars, quemadmodum beatus lob cenfet, non conferetur tinctis Indixe coloribus, neclapidi sardonyco pretiofiffimo, vel Saphyro, non adxquabitur ei aurum. Neque enim ad diuinam illam atque altiffimam fapientiam cognofcendam parum conferre putanda eft rerum admirabilium contemplatio, quarum authoreft ipfa: nequeverò fudium pietatis non vehementer accendet arque inflam. mabit falutis gentium bene explorata ratio, cùm conditor omnium idemq́; redemptor perfpicuè declaret, vellefe omnes faluos erfe, atque ad agnitionem fui fancti nominis peruenire. A qua tanta diuin $x$ bonitatis largitate, minimè aliena putandá eft gens. Indorum, hominum profectò genus do. cile, manfuetum,obfequens. Te verò, Rex maxime, tot auitis regnis cumulatum, etiam vtriufq; Indiæ Deus imperio auxit, totiufque orbis tanquam annuli gemmam effecit, vt Catholicætux Maieltatis \& fides fyncera, \& pietas inDeum ardens ad omnes mor-

$$
\dagger 3 \text { tales }
$$




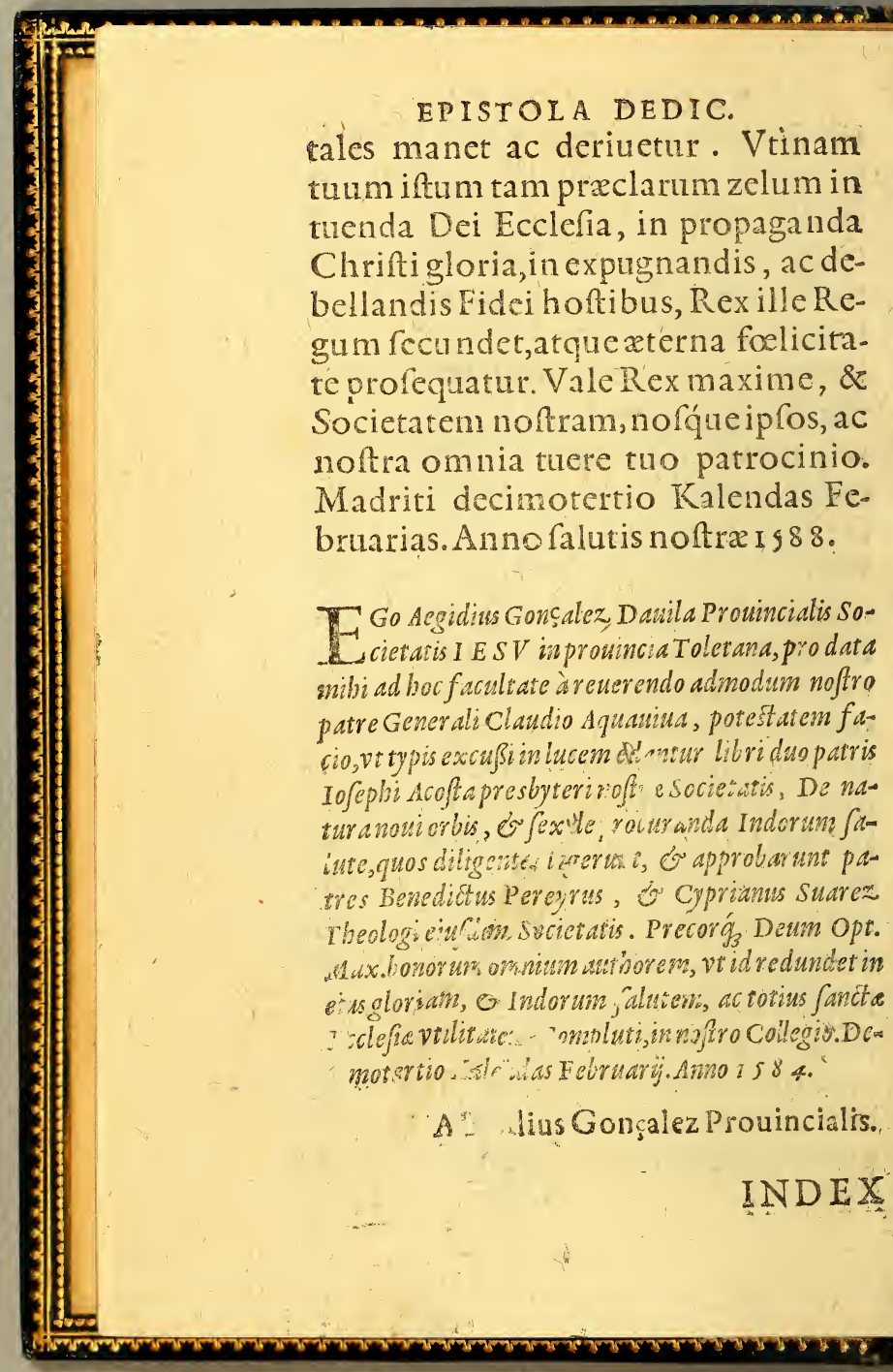




\section{N D E X.}

Quod quidam Ophir in acris literis efe noftrum $\mathrm{Pe}$ ru opinatifint.Cap.XIII.pag.31.

Quidnam Tharfis ơ Ophir in facris literis fignificèt. Cap.X I III.pag. 33.

Quid de boc nono orbe Abdias vaticinatus fit iuxta quofdam.Cap.XV.pag. 36 .

Quomodo primi bomines ad Indos venir cotuerint: o quod non venerint certä nauigatione. Cap. XVI.pag.39.

De Magnetis admir abili efficacia eं v vu ad nanigandum veteribus ignoto.Cap.XVII.pag. 43 .

Repponfio ad eos, qui volunt olim naurgatum Oceanum, vt boc tempore nauigatur. Cap. XV I I I. pag. 47 .

Probabile effe primos buins orbis babitatores tempeftate prater votum ad bas regiones eiectos. Cap.XIX.pag.48.

Longe probabilius effe primos buins noui orlis babitatores terreftrititinere bucperueniffe. Cap.XX. pag.5o.

Quomodobeftice \& pecudes ad buno noun orbem ex alteroperuenerint.Cap.XXI.pag. 54.

Quod nonvenerit genus Indortm per Atlantidem, vt quidam opinantur. Cap.XXII.pag.57.

Quod falfomilri Indos ex Iudaor um genere defcen dere affrment.Cap.XXIII.pag. 59 '.

Cur prima origo Indorum fciri non pogit. Cap. XXIIII.pag.62.

Quid de origime fua Indi tradant. Cap. XXV.pag. 63.

Capita 


\section{N D E X. \\ Capita Libri Secundi.}

\section{E aquinoctialis natur a differendum effe.Cap. I.jag. 66 .}

ur veteres Philofophi regionem Torridam effe inbabitabilem pro certo duxerint. Cap.II.pag. 66 . uod regio Torrida bumidifima fit contra veterum opinionem.Cap.III.pag. 68.

uod exir a Tropicos bumoris copiafolis receffu maximie fiat, contra quàm in regione Torrida. Cap. IIII.pag. 70.

uod intra Tropicos imbres aftivi fint, \& de ratione hyenris of aftatis.Cap.V.pag. 71 .

nod Torrida aquis,pabulifg abundet, quicquid Ariftoteles contradicat.Cap.VI.pag. 73 .

Redditur caufa, cur intra Tropicos folis prefentia bumorem efficiat, extra Tropicos ficcitatem.

Cap.VII.pag. 76.

uatemus, qua deTorrida dict a funt, accipienda fint. Cap.VIII.pag. 80.

Quod Torridaregio non fit vebementer calida, fed mediocriter calida.Cap.IX.pag. $8 I$.

Regionis Torrida aftum temperari tum multitudine imbrium, tum aftiuorum dierum breuitate. Cap. X.pag.83.

Alids quoğ efse peculiares caufas temper ande Torvide, atque in $̈$ s Oceani propinquitatem. Cap. Xl.pag.85.

Terras cuio altiores, è frigidiores effe, \&o que fit $b u-$ ius caufa. Cap.XII.pag.88.

$$
\text { ts Vento- }
$$




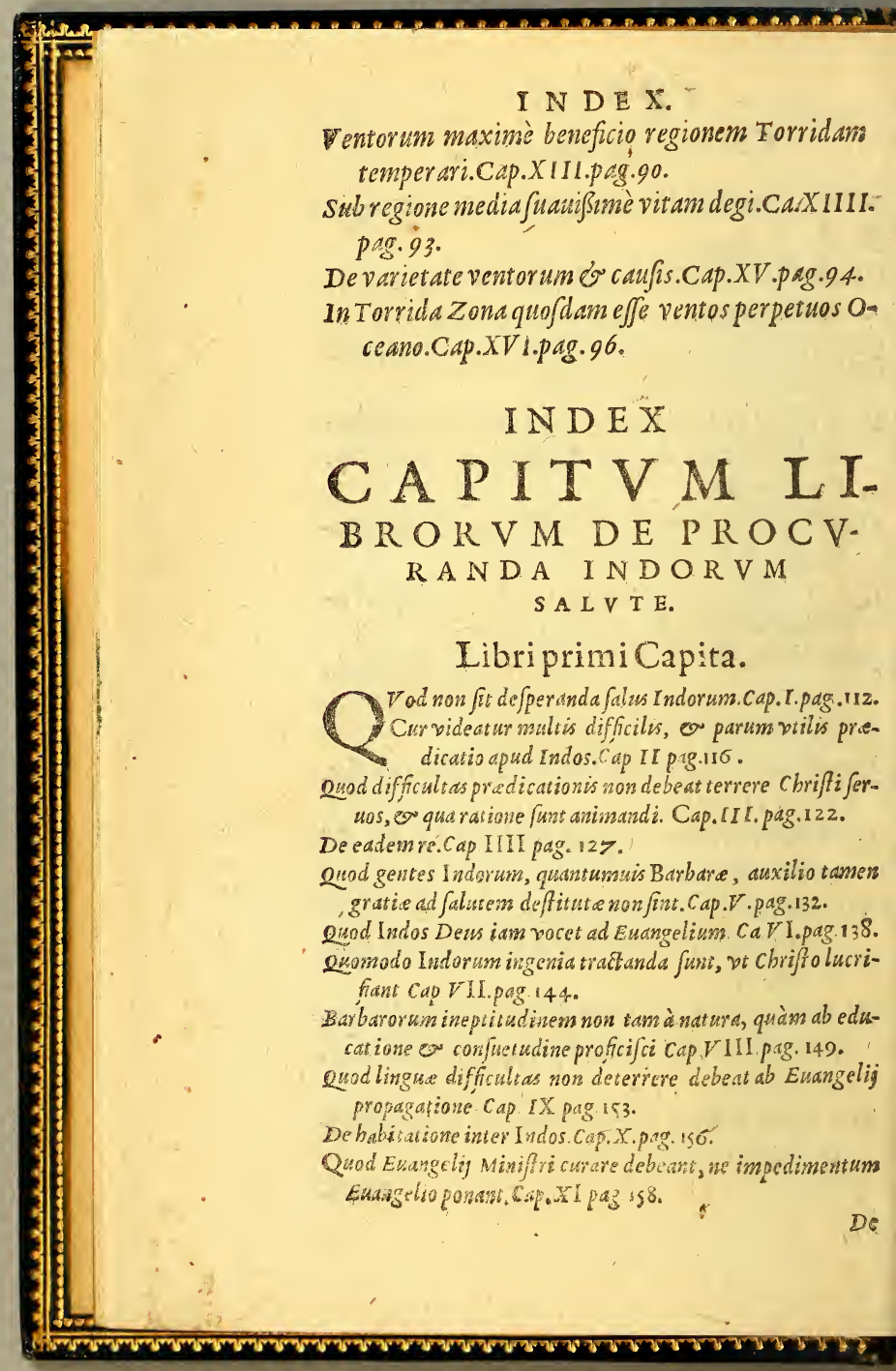




\section{N D E X.}

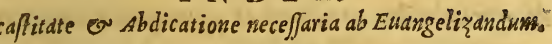
Cap XII.pag. 162.

ntum officiat Fidei violentia. Cap.XIII.prg.165.

lis in religione Chrifiana magna ex parte fit natio Indarum. Cap.XIIII.pag.167.

ilominus vere Fidei ac falut is apud Indos fperm effe monum, alienum'́; efje à Dei $\int$ piritu contra fentire. Cap. XI. gg. 168.

od etiam in prefentia labore miniftrorum fructurs animarum fit longè maior. Cap.XV t.pag. 17 l.

tientia, $\sigma$ labore effici, pt copiofi fructus ex boc agro Do= minico colligantur. Cap XVII.pag. 176.

od son folim futuri fructus Jpesfit; fed prefentis etians fatis magni certa documëta teneantur. Ca,XVIII.pa.18\%

\section{Libri fecundi Capita.}

ifficile effe rationem tradere predicandi barbaris Exangelium Cap I pag 188.

o)ter Infidelitatem etiam pertinacem non licere barbaros de bellaré. Cap. II pag ror.

yod quibufdam vifum fit propter crimina nature contraria licere noftris barbaros de bell are. Cap. III. pag 104. onfutatio fuperioris fententic. Cap. IIII.pag 199. efponfro ad abiettiones pro expugnatione Barbarorum $\mathrm{C}_{\text {ap. }}$. V.p.ja. 204.

e bello propter defenfronem innocentium, qui à barbaris trucidantur. Cap.VI. pag. 209.

urod ormia iam dicta de bello aduerfus Indos non folùn diuina, fed et iam regialege firmentur. Cap.VII.pag. 212. eterem ov Apoftolicam Evangelizandi rationem non pofje exactè fersari inter barbaros. Cap.VIII pag.213. Cur wiraculs in conuerfrone gentiuss non fiant nunc, ot olim,à Chrifi i predicatoribus. Cap. IX.pag.218.

auod etian exiguo merito predicatorum, fignoram parcitas aliqua exparte attribuenda.frt. Cap.X. pag.224.

De Pradicatione inter cos qui Fidem iam receperunt. Capo XI.pag.227. 


\section{N D E X.}

De expeditionibus neceffarijs ad predicandum barbaris $E_{0}$ uangelium Cap.XII.pag. 230.

Doso iure Chriftiani expeditiones facere poßint in regna barbarorum.cap XIII.pag. 332.

ouid in terris barbarorum Chriftianis liceat. Cap. XIIII. pag 235 .

ouando liceat barbaris infidel libss bellum inferre. Cap. XY. pag. 238.

De officio predicatoris Euangelici erga focios itineris. Cap. XVl.pag. 239.

Dualem se praffare debeat Cbriffi ferum in conuerfione infi. deliuts Cap $\mathrm{X} V I I$.pag. 242.

De sribus impediment is, que conuer fioni gentium maxims obftant.cap.XVIII. pag.246.

Epilggus diEforum Cap,XIX.pag. 250.

\section{Libri tertij Capita.}

Non effe queftiones ammes tractandas, ac deinceps de ciuili dimivifratione digferendum. Cap. I pag. 252.

Barbaros Fidem fufcipientes ad curam, ditionemq́que Princi. punc briffianoruss pertinere. Cap.II.pag.254.

Non oportere faljos titulos comminifci dominationis Indorum.Cap.III.pag. 259.

Quales adminifiratores res Indica poftulent. Cap. II I I.pag. 261.

Quam ob caufam difficile inueniantur idonei rebus Indicis prafe Ii.CAp.V.pag. 267.

Non effe iniquum tributa Indos pendere adminiftratoribus fuis.cap. VI pag.z7r.

Improbantur tria genera tributa taxandi.C ap.VIII.pag. 274. Vulgaris ratio tributa imperandi expenditur. Cap.VIII.pag. $27^{8}$.

An propter reuscandos ab otio barbaros tributa grauiora im. peranda fint. Cap. IX pag. 280. Quis modus in tributis taxandis tenendus. Cap.X.pag.284. caufe, ob quas Hijpanis Indi cummendati funt, Cap. XI.pag. $2 \delta 8$. 


\section{N D E X.}

od doctrinam fidei, ov moribus jufficientem Patroni In dis fufceptis prabere teneantur Cap. XII.pag. 293.

id erga nondum baptizatos Indos Patronis liceat. Caps. $X$ III pag 298.

temporalipronidentia Patronorum in fuos. Cap. XIIII. pag.302.

ùn circum [pectè onerofoleges fortunis Indorum indicen. de.Cap.XV.pag. 303.

d in confeßionibus Patronorum audiendis facerdotiproiddendum.Cá XVI Pag.305.

feruitio perfonali Indorum. Cap XVII pag. 309.

metallorum operatione. Cap.XVIII.pag.3'9.

bus modis jalus Indorum per feculares miniftros prockari poßit. Cap.XIX.pag.324.

ebrietatis malo Barbaris familiari. Cap. $X X$.pag. 326.

e mala ex ebrietate oriantur. Cap.XXI.Pag. 330.

bus modis ab ebrietate Isdicompefci queant. Cap.XXII. pag. 336 .

Pretoribus Indorum Cap. XXIII pag.343.

es Indorum Cbriffo non repugnantes permittendos effe, o de concordia Pratoris cum facerdote. Cap. XXIIII. ag: 346 .

\section{Libri quarti Capita.}

excellentia facerdotalis officij. Cap.i.pag.3so。

indos maximè facerdocies preftare oportere. Cap. II. ag. 355 .

tra eos, qqui Indorum tarditatem accufant ca. VII pag. $35 \%$. itra eos, qui peruerfitatem morum Indorum fidei non reepte caufam afferunt. Cap.IIII.pag. 361.

Tem effe copiofam, modò operarij idonei non defint. Cap. pag. 360.

peritia Indicelingue neceffaria.Cap VI.pag. 369.

arochis Indicifermonis ignaris. Cap. VII.pag.372.

dquidam non recte infcitise fermonis Indici confulane. Cap.VIII. pag. 377.

oporteat ad Indos venientes predicatores Indicum :ioma diligenter difcere, Cap.IX. pag. $38 \mathrm{I}_{2}$

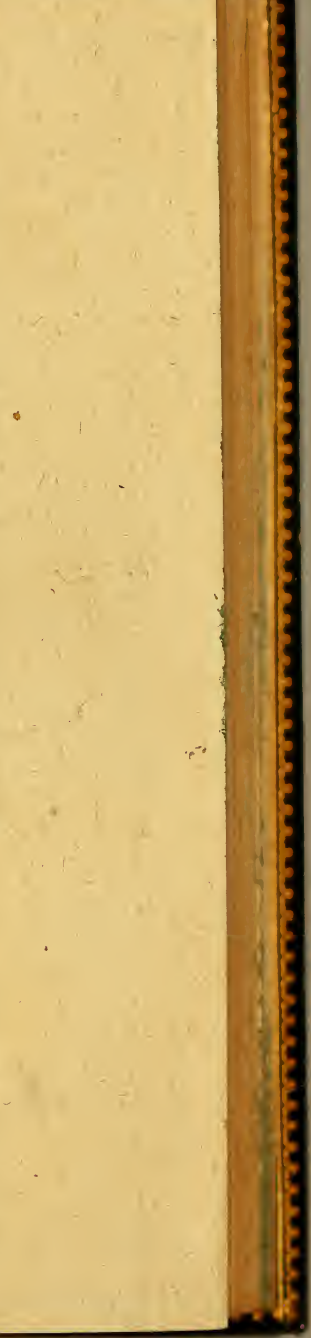




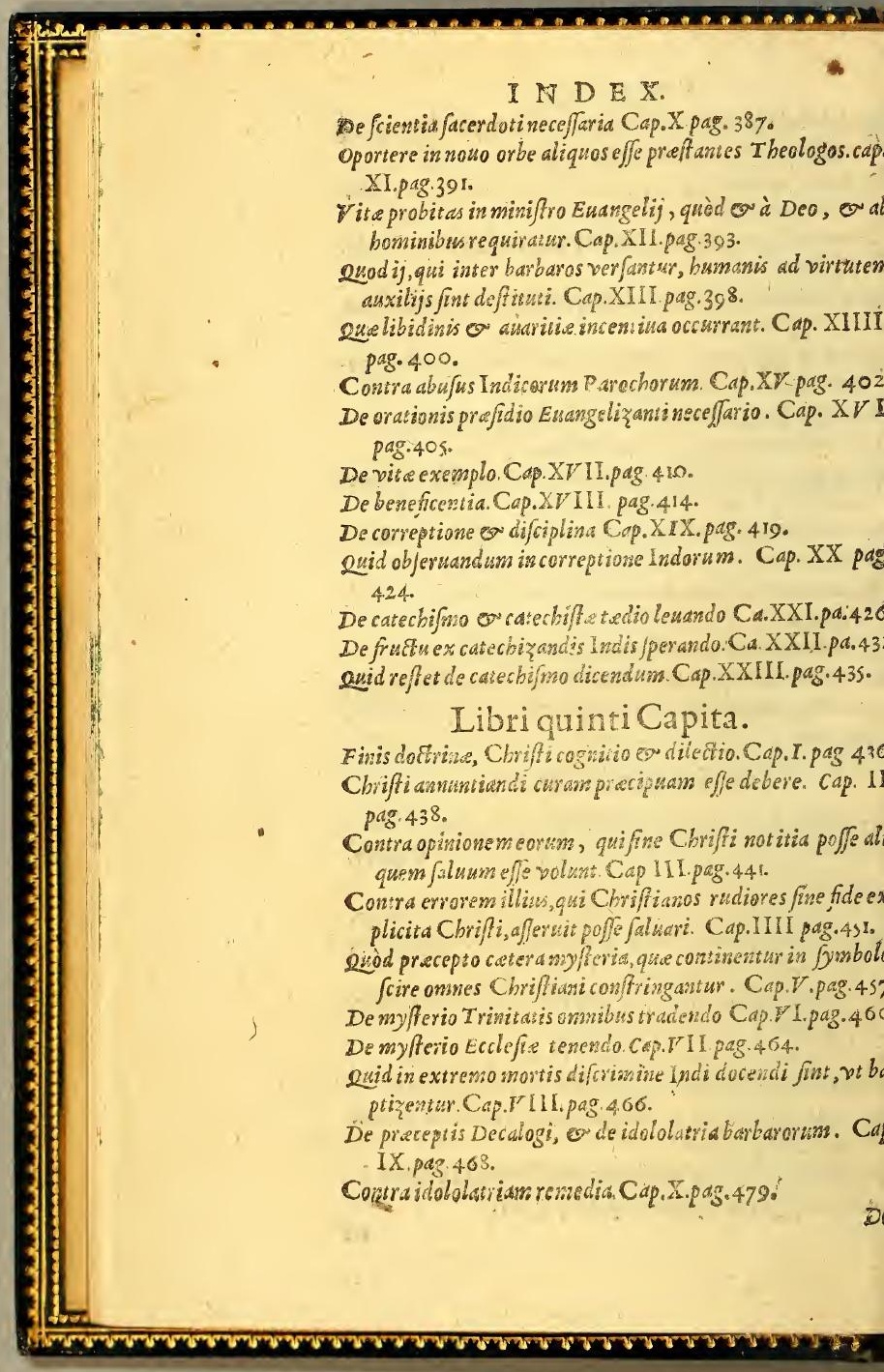




\section{N D E X.}

De enertendis idolorsm fignis e templis. Cap. XI. pag. 48I. De recta dilectione fui.Cap.XII pag. 4.83 .

De dilectione proximi.Cap.XIII.pag. 487 .

De Cairchifmo vulgo Indorum neceffario. Ca.XIIII.pa 490. sinfructione Indorum diu effe perjenerandum Ca.XV.pag. 491.

An expediat $P$ arochias Indorsm regularibus commititi. Cap. $\mathrm{XVI}$ pag 494.

Salutem Indorum focietati Iefu proviribus effe procuraso dasin Cap.XVII.pag 497.

Cur mult is videat ur fociet tus Parocbias Indorum debere JuJcipere. Cap.XV III.pag.4 99.

iu a rationes a fufcipiendis Parachijs Indorwm focietatess deterreant, Cap.XIX.pag.5or.

造e in fufcipiendis Parochijs moderatio adhibenda fit. Capo XX.pag.jo3.

Ai Sionum rfus in Ecclefia antiquns of fre quens, Cap.XXI. pag. so6.

Mißionum vt ilitates inter Indos. Cap. XXII.pag.sog.

2uod Parachi Mijiones vtiliter or liberaer accipiant. Cap. XXIII.pag.sil.

uid cavere oporteat in Mißsionibus.Cap.XXIIII.pגg.5Iz。

\section{Libri fexti Capita.}

uatenus modò de Sacramentis agendum Cap.I.pag. jiś. Aulta in bis regionibus contra Ecclefse confuetudinem geri. cap.HI.pag.5ito.

Ce voluntate Baptifmo neceffaria. Cap III pog.521.

De Fide ov Poenitentia ad baptifmi gratiam necefaria Cas. IIII.pag.s26.

De ijs, qui fe baptizatos vel negăt, vel mêt iuntur. Ca.Y.p $52 \%$ De Sacramento Confrimationis 0 illius materia. Cap. $Y$ I. pag. 529.

De Euchariff ia percipienda diuinum effe praceptum. Cap. VIr pag. 530.

Luod quamuis diuinum preceptū fit de communicando, poßßis tamen Eccle fia pro iudicio fúo sammnunionem kegcre. Capo. VILI.pag.534.

Qunos? 


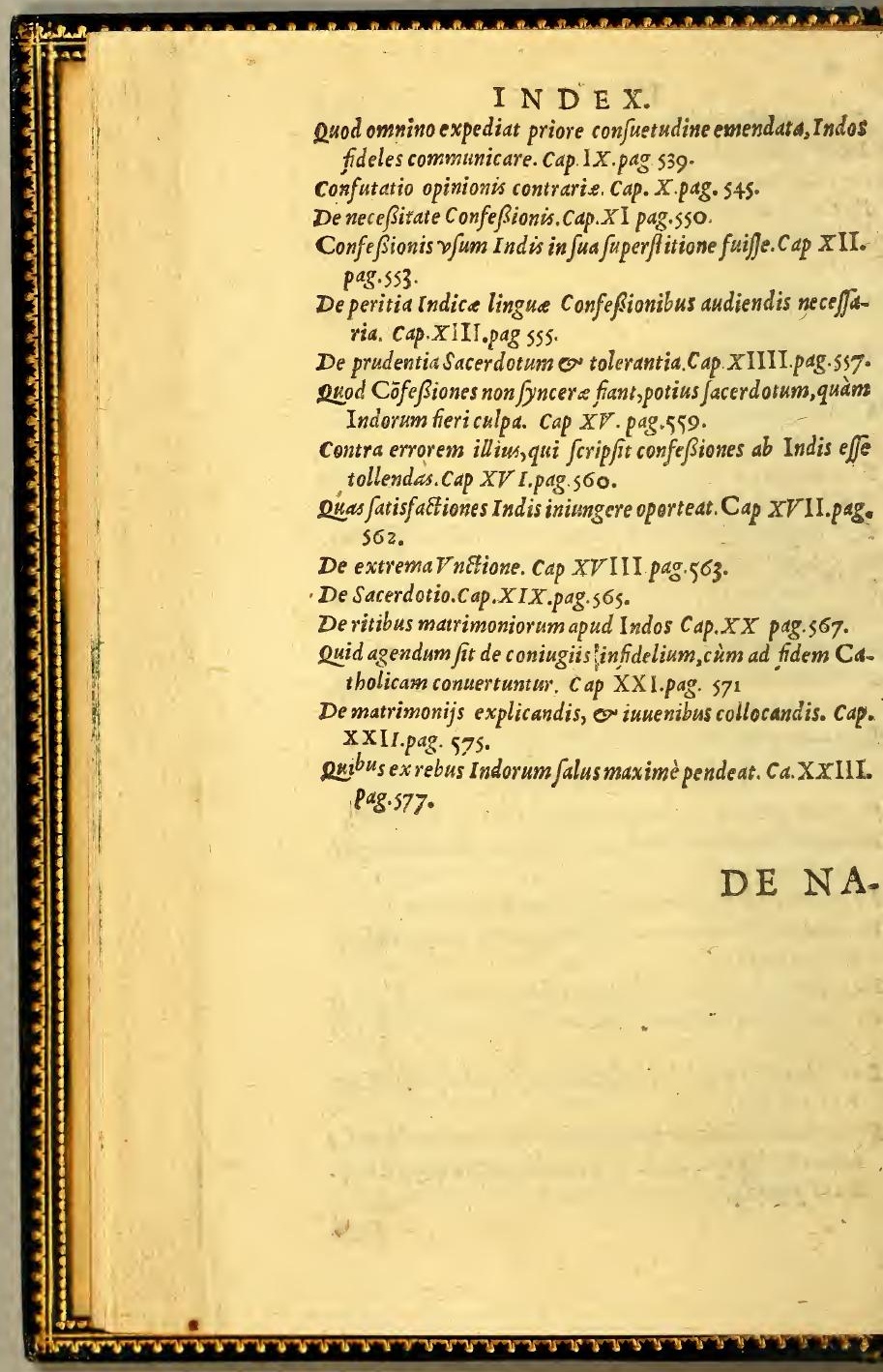




\section{E N A T V R A NOVI ORBIS, L I B E R I.}

C OELVM LOVI ORBIS quofdam de rerum natura abftuliffe. Cap. 1.

O V I huius Orbis gentes vfque 6. (20) adeò ab opinione veterum abfu1). 1 iffe videntur, vt pleriq; ne terram (c) (1. Is) quidem hac parte effe putarent, x.: nónulli ( quod amplius eft) ipfur hoc cxlum, fub quo nunc agimus, etiam de rebus auferrent.Et fi enim plurimi atque optimi philofophorum cxlum (vteft) totum fphæricü \& terram vndique ambiens tradiderunt, tamen ex noftris auctoribus neque pauci,neque obfcuri contra fenferunt mundum hunc vniuerfum domui potius fimilem fabricantes, cui tectum ex vna tantùm parte non quaqua verfus immineat. Neque enim terra molem grauem in medio aëre fufpendi rationem pati. Atq; alium effe cxmenti, alium culminis locum. Ac Ioãnes qui- chry yof hodemChryfoftomus in commentarijs Epiffolgad mi.14.et 27. Hebraos nonfemel eos provocat ac laceffit, qui in Epiff. ad cxlum fpharicum ponunt, cùm fcriptura potius Hebr. tabernaculum à Deo fixum commemoret, quo loco motum quoque omnem cxlo adimit, folem verò \& af ra cxtera ferri, vit vólucres, cum per aërem fefe mouent, non ficut radij voluuntur in rota. B. Chryfoftomo etiam Theodoritus $\mathrm{Cy}$ Hebr. 8. Id em hom.6. 13. in $\mathrm{Ge}$ nef. 12. ad pop. A. renfis Antiocks. 


\section{- DENATVRA NOVIORIS}

Theodorit. renfis in hac parte affentitur, vt Theophylactis ortheophil. vbique. His omnibus antiquior Lactantius in incommê. ad libris diuinarum inftitutionum Philofophos Hebr.8. Iactan. 3. li. Peripateticos, \& Academicos de cæli figura \&\& diuin. inftit. $2 \mathrm{mbitu}$ irridet ratione iam dicta, magilq́á $\mathrm{E}-$ 64.24. picuri probat fententiam, qui terram ad chaos quoddam immane definit; quod attingere Hieran.li.z. quoque videtur Hierony mus, vbifcribic, Phyin Epiftad ficus perfcrutator oculos trans calum leuat \& ephe.inc. 4 vltra profundum terrarum $2 z$ abyfí quoddam inane demergit . Porrò Ariftotelis fententiam Sixtus Se- de cæli \& figura \& motione circulari facræ Scri nen.lib.s. Biblio. ansot.3. pturæ contrariam Procopius in Commentarijs Genefeos pro certò affirmare narratur. Nam ego eius fcripta non legi. Sed quicquid auctotes bi fenferint, equidem non magnoperè admiror, quos video grauioribus fudijs intentos, demonftraciones Philo fophicas non admodum perfpexife. Diuum Auguftinum fortafsè quis miretur, qui cùm frcularis literaturæ periciffimus fuerit, \& Phyficen atque Aftronomicam non mediocriter nouerit, tamen vtrum Augustlib. terra cælo vndique contineatur, vbique dubi2.de Gen.ad us hret. Quid ad me pertinet, inquit, vtrum ba.6a. 9. calum ficut f phæra vndique concludatterram in media mundi mole libratam, an eam ex vna parte defuper velut difeus operiat? Quo in loco coniecturis potius, quàm vlla folida demonftratione teneri cali figuram fphricam vult

Anguft in Ejal. i3. quemadmodum de calefti quoque circuitione, \& ibi \& aliâs tanquam de re dubia videtur soribere. 


\section{I B E R}

caleste corpus omn ex parte effe rotundum, bo in feipsum volui.

C A P. II.

$S E D$ facilè condonandum eft patribus, fi cùm cognofcendo colendoque creatori toti vacarent, de creatura minus aptè aliqua ex parte opinati funt.Sxculi verò fapientes, qui tantum valuerunt, vt poffent féculum seftimarc, ve fcriptu Sap.to ra loquitur, id éf vniuerfi huius ordinem certa ratione deprehendere, eo profectò infeliciores habendi funt, quod operibus attêdertes, aut nö cognowerunt, quis effet artifex horum, aut certè cognitum non perinde atque oportuit, glorifi- Rom. to cauerunt, fed euanuerút in cogitationibus fuis. Certè Ariftoteles, \& cateri Peripatetici Stoicis plutar. de hac parte confertientes ea de creli figura \& con Placitis Pbi- de uerfione tradiderunt, qua nos hic terrarum po- lof.lib.2.6.26 fiti apertius oculis intuemur, quã Philofophica vlla argumentatione didicimus. Spharicum effe cęlum; \&z terram vindequaquie concludere, dubitare nổ finimur, qui portionem illius veteribus nunquam vifam ex obuerfa hac orbis parte fpectamus, qui vtrumque cardinem, id eft, polum ArCicum \& A uftralem, de quo dubitataugufti- Ang $2.7 \mathrm{ib}$.d nus, nauigatione vltra aquihodtialem circulum Gen.adlit. to $_{0}$ procedente, fubinde notamus, qui gradus deni- 10. que fexaginta vltra citraq́; mediam lineam com meauimus, vt omittam interim; quæalij certius explorare pozuerunt $v$ fq; ad fepeuagefinum ad Antarcticum gradum imméfa nauigatione progreffi. Vna nauis victoria prorfus incly ta de toto terrarü orbe, fimul de veterum immęfo inani triumphauit, Oceani magnitudinem curfu fuo emenła, minoremq́'; terrę quantamcunq̧; molem

A a rel 


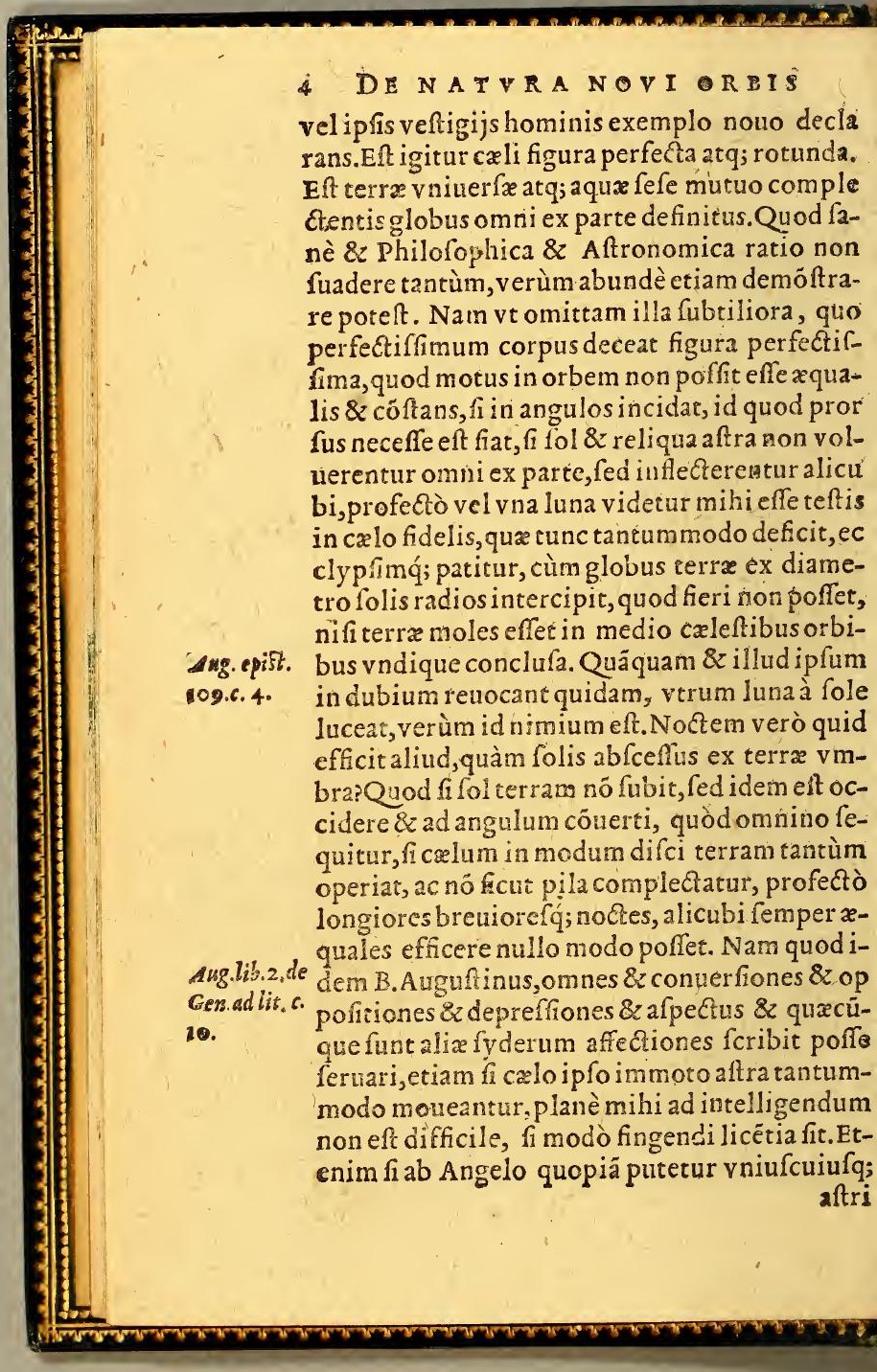


Atri corpus ferri, quis non videt omnes eiufmoli varietates prodiuerfo mouentis arbitrio pofe contingere? Sed ratio non patitur, fi regio illa xleft is elementaris fit \& corruptioni obnoxia, er quam aftra feruntur.neq; enim per inane feuntur, quin 8 ip fa aftra fint natura corruptioi obnoxia \& tempore ipfo tranfmutentur atq; fficiantur, quod illorum xternitati, qux vt $P$ fal $p \int_{a l} l_{4} \%$. nus habet, ftatuit Dominus in æternum, \& vnierfi huius ordini \& conferuationi contrarium It.Sed rationi oculos quoque teftes adhibere li et, cùm cernamus nó folùm manifefta aftra vol ii, fed partes etiam integras cali non folùm luidas illas, qualis eft lactea via, verùm etiã quaflam alias obfcuras atque atras. Sunt enim infigles prorfus maculæ in cęlo, quas, in Europa cùm ffem;nufquam ita notaffe me memini, ex lunx aborantis atrorem prorfus referunt, quas perpe wo tenore cum ipfifmet aftris, quibus funt intermixtx volui manifeltiffima experientia deprehendimus.Vnde autem illa veluti maculatio cęli contingat, ego aliud cogitare non poffum, quàm vt denfiora cęli luce accepta galaxiam effi ciunt, ita contra rariora magifq́; diaphana, quia nihil lucis reddunt, atriora apparere. Quacunq; autem ea ex caufa fint, certè effe \& cum itellis ipfis immobiliter ferri attentiffima frepè obferuatione perfpeximus. Cęleftes ergo orbes, \&z ter ram perfectè omni ex parte concludere, \& perpetuò in feipfos revolui non oportet amplius controuertere.

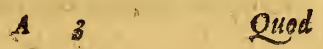




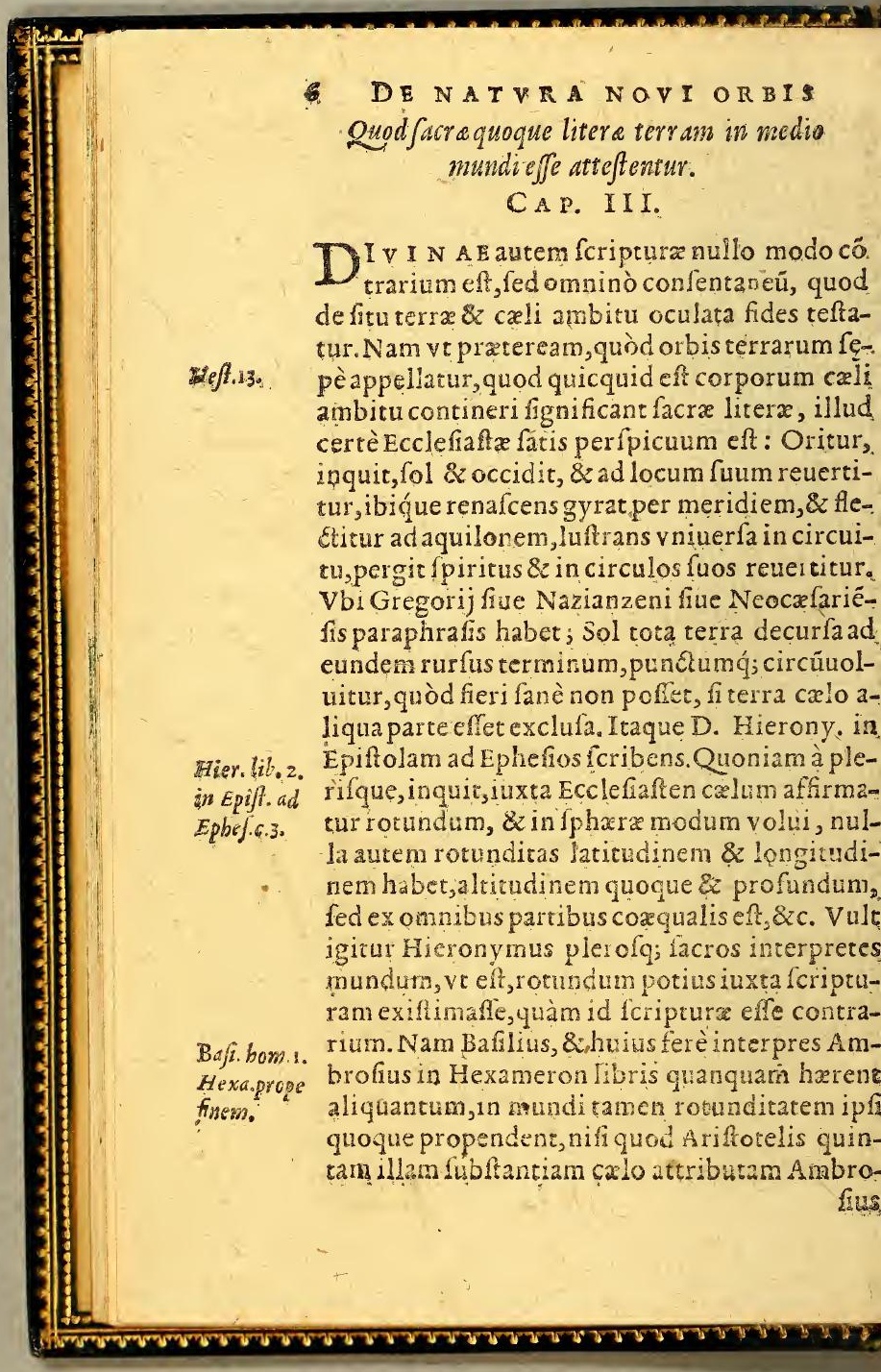




\section{I E E R .}

Sus infectatur. De terræa autem fitu, \& firmitudi- Amb.lib.r. ne mirabile eft quàm eleganter, quàm iucundè Hexa.c.6. criptura loquantur, vt ineffabilem conditoris otentiam atq; fapientiá noft $\& z$ admirationi $x$ voluptati excellenter exponant. Iam enim co lumnas fe terrę confirmaffe Dominus narrat, vt Pfal.74. antę molis pondus diuinæ potentiç manibus fu Itentari intelligatur, quemadmodum commodè exponit Ambrofius. Nã \& cęlo \& terrę fcriptu- Lib.1. Hexas ra columnas quafdam fupponit, non illas Athlä- c.6. icas poëtarum; fed has verbi Dei omnia fua vir- $10 b .9$. O 26, zute portantis. Iam verò vt terram elemento a- Heb.l. qux hęrere, \&z plurima ex parte ab illo contine- P falm.13s. ri, fapientiffimè in finuet. Frmauit, inquit, terrä Pfalm.23. fuper aquas, \& rurfus orbem terrarum fuper ma ria fundauit. Ac licet B. Auguftinus ne ex facris Auguft. in literis certum dogma reputetur terrã aquis im- $P$ falm.135. mixtam in medio mundo pendere, illud fuper aquas aliter conetur exponere, tamé planiffimus fenfus eft, quem fonat $P$ falmus, vt nulla alia terræ fundamenta cogitentur quàm aqua ipfa, fluens alioqui $\&$ facilè cedens, qux per fapientiam fummi opificis tam vaftam terræ machinam im mobiliter continet. Super aquas autem \& maria terra fundata defcribitur, cum re vera potius fit fubter aquis, quòd more cogitationis noftra, id quod ex altera parte terrę à nobis habitatæ refpondet, non nifi fubtus terram effe videatur, atq; ita aquas \& mare immenfum terre oppofita veluti infra iacere omninò imaginamur, cùm ta men ipfúm infra vbiq; nihil fit aliud quàm orbis medium. Ira ergo loquitur fcriptura, vt noś vulgo cogitare folemus. Quod fi vltra quxras, cui nam fundamento innitatur tã vafła $8 z$ terrę,
A. 4
\& aqqua- 


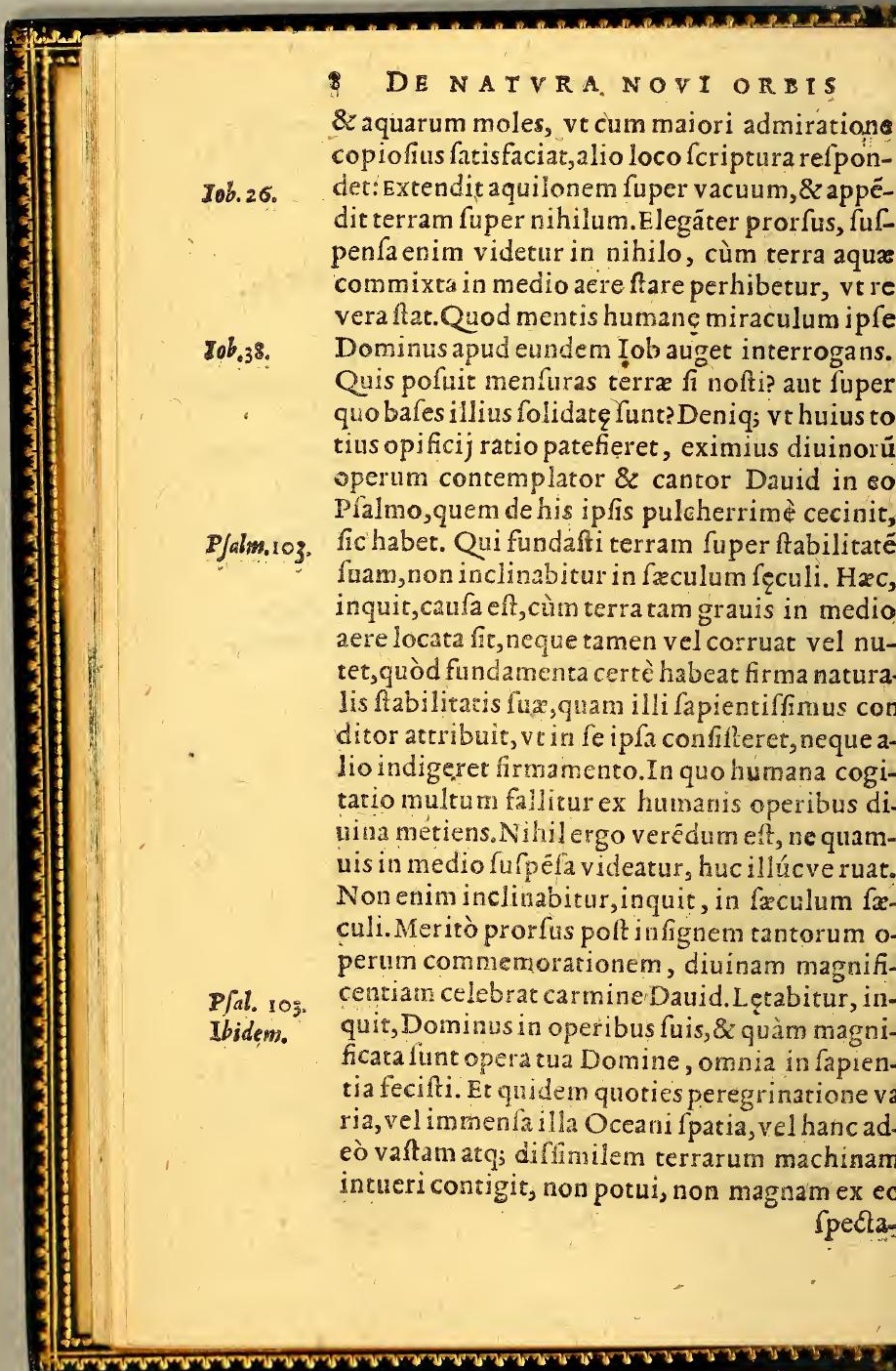


ectaculo iucundiffimo voluptatem capere, $v t$ r $x$ diuinæ fapientię $\&$ amplitudinis argumenis humana omnia quamuis regia, quamuis exuifita vilefcerent.Sæpè dicere venit in menté; Delectafti me Domine in factura tua, \& in ope- $\boldsymbol{P}$ fal. $9 x$. ibus manuum tuarum exultabo. Ac re vera necio, quid habent intus latent is \& arcanæ elegan ię,artis diuine opera, ve fępius fpectata nouam emper voluptatem pariant. Contra humana onnia quouis artificio compofita, facilè fpectanli affiduitate vilefcunt, \& faftidio funt. Hortos moniffimos, templa auguftiffima, arces fuperè conftructas, ftatuas ingeniofiffimè effictas, $v$ $\mathrm{i}$ bis aut ter contemplatus fum, vix poffum ocu os pręterea tenere, veluti faftidium refpuentes: dem mare quoties intueor, aut prẹcelfam aliquam ac prom inentem rupé, aut campos haturai copia floribu fq́; virentes, aut fluuij rapidum 2 inexorabilem vorticem cum faxis perpetuò concertantem,atq; frementem, cæteraq́; naturæ fpedacula, noua fem per reperio, nouam qu; fine faftidio voluptatem capio: vt occultæ profectò cuiufdam fapientięatq̣; inexhauftę fplendidum. quoddam conuiuium effe videatur.

\section{Reponfio ad ea que contra celirotunditatem ex facris literis afferuntur. \\ C A P. IV.}

$S E D$ redeoad mundi faciem, quem non effe omni ex parte rotundum, neq; in feipfum conuertinefcio ex quibus fanctarum frripturarum verbis fufpicari nonnulli potuerint. Nam quòd Paulus tabernaculum vocat cælum, quod fixit Hebr. \&. Deus, \& non homo, quid eo percineat, nó video.
A 5
Neque 


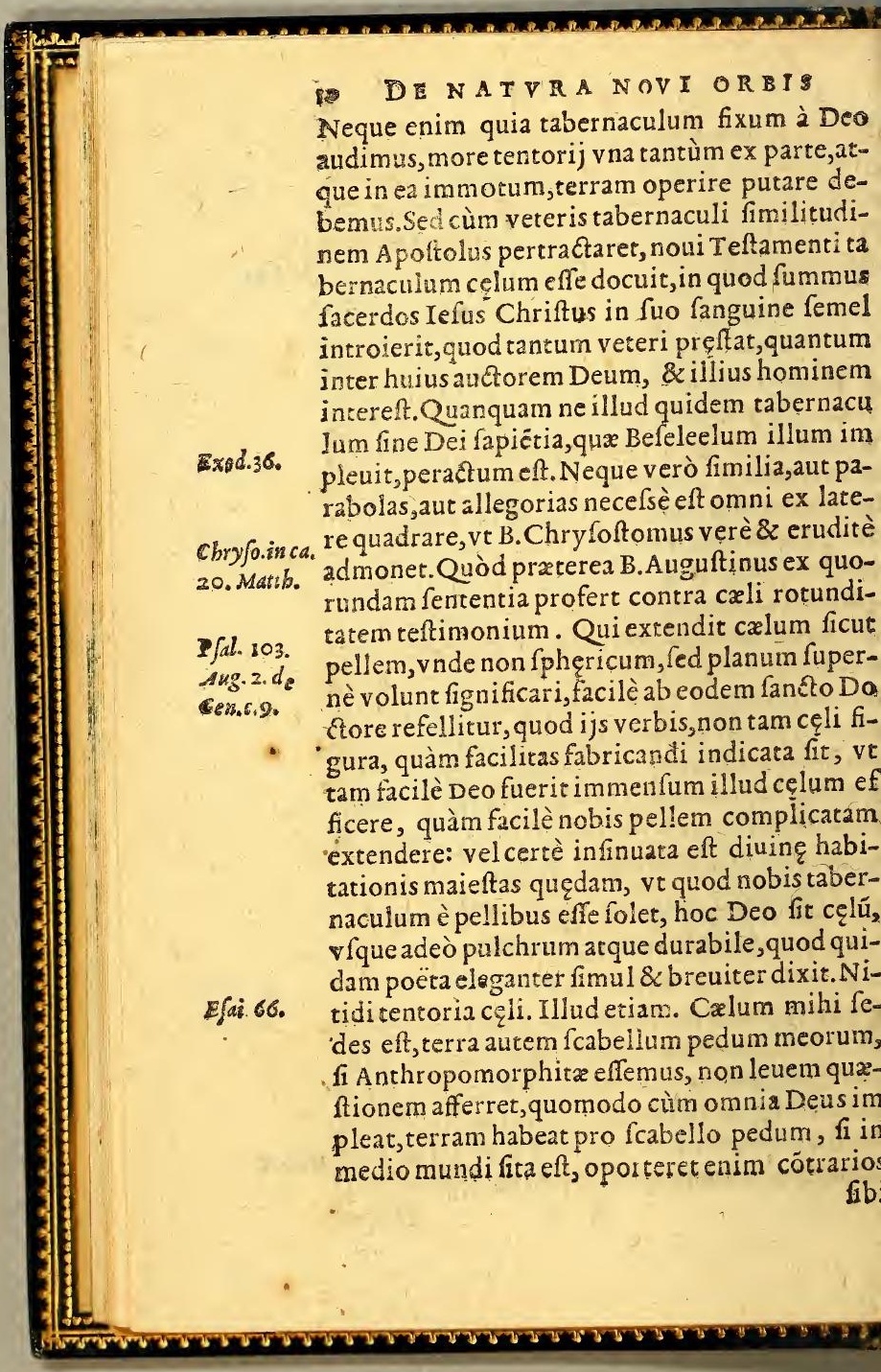




\section{B E R, I.}

i effe Dei pedes, \& caput non v num, fed pluma cogitare, qua quoniam ad nugas potius $\&$ fum pertinêt, quàm ad feriam difputationem, tis fit in feripturis non occidentem literam $2 . \mathrm{Cor}$. uxrendam effe, fed fpiritum.

Defacie cali Antarctici. .

$$
\text { C A P. V. }
$$

V. A I I s autem facies fit cæli huius Auftra2 lis, multi quærunt in Europa, quod apud eteres Aftrologos nihil legere poffint, qui \& fi fe certò deprehenderüt, cuiufmodi tamen efet, affequi minimè potuerunt. Quanquam \& fyus Canopum ingens $\&$ clarú illi celebrăt apud os, \& fi qui peritiores huc nauigarunt, magnta uradam de hoc calo fcribere folent, quod aftris plendeat crebris \& grandibus. Solent enim renota facilè amplificarị. Ego verò \& maiora \& itidiora circum Polum alterú fpectari opinor, eque feptentrionibus atq; Vergili js noftra hæc ræaferenda exiftimo. Illa tamen eft praclariffi nafpecies in hoc calo, quam Cruciferum appel lamus, hoc eft fydus quatuor clarioribus ftellis ex equo ferè diftantibus Crucis formã pulcherrimé effingens. Hunc Polum offe Antarcticum imperiti reputare folent, quòd videant Naucleros ad illum rationem nauigationis expendere, ficut vltra xquinoctialem ad Polum Arcticum faciunt.Sed hoc proptereà fit, quod nulla ftella fixa Polus hic Antareticus demonfiretur, atque ita coguntur natura proximam quęrere, quam Cruciferi pedem vocant, quętamen à vero Polo, vt à viris peritis accepimus, gradu trigefimo diftat.Itaq; difficilior eft menfurę in hoc Hem if phęrio 


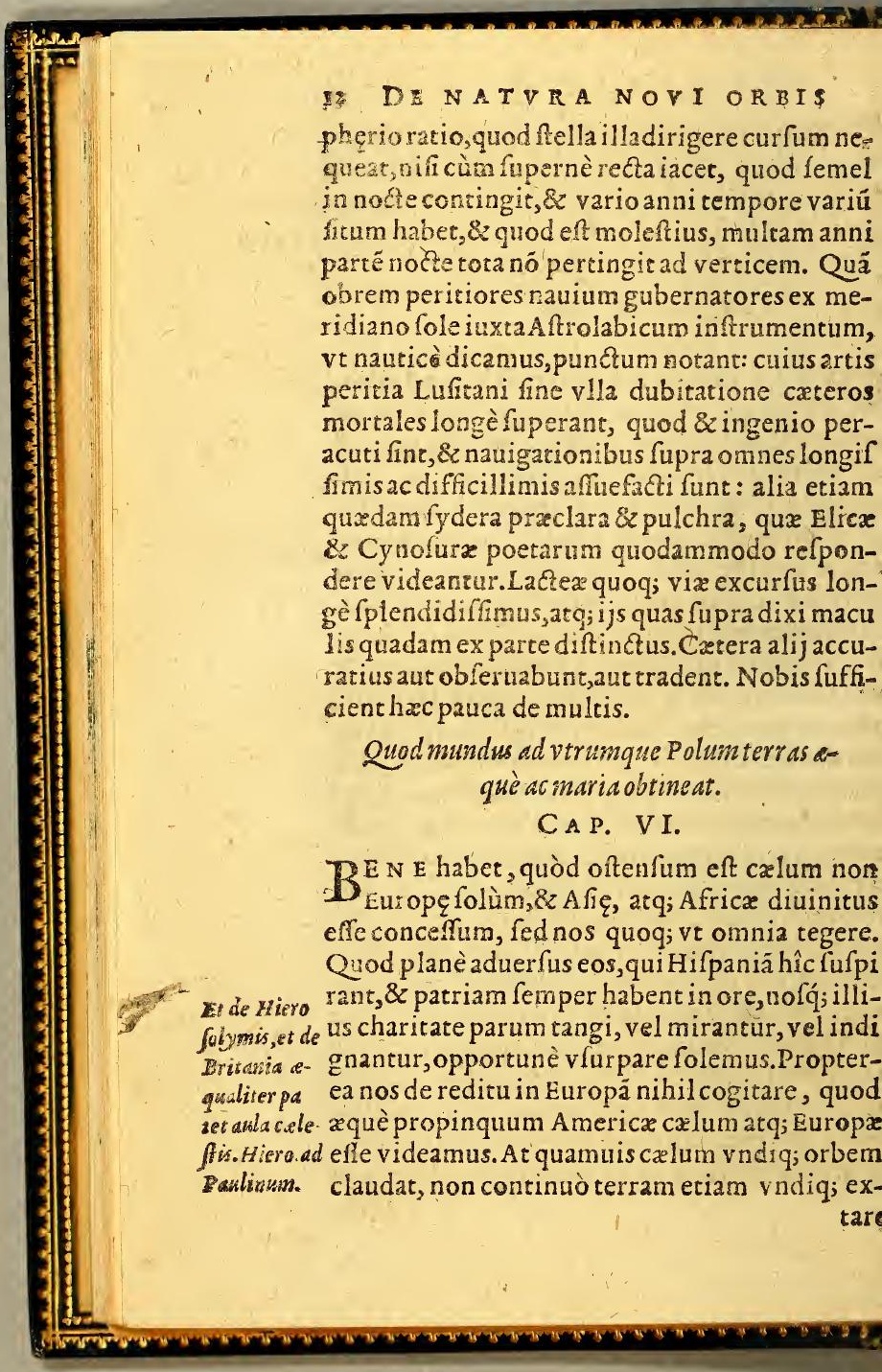




\section{- I I B E R $\mathbf{r}$.}

ré confequitur. Nam cùm ex duobus elemenszerra \& 2qua vnus efficiatur globus, quod $\&$ eterum doctiffimi cenfuerüt, \& a pertis demon plut.lib.3.t rationibus conftat, intelligi fanè poteft ad Po- placitis $P h$ Im Antarcticum mare quaqua verfum effe dif- $l_{0}$.c. $.9 \cdot 10.8$ fum, neq; vfpiam terræ locum reliquiffe, quê- II. Imodum B.Auguftinus contra Antipodum af- augufflib. rtores argumęntatur. Non attendunt, inquit, 16. de ciuizt. iam fi figura conglobata \& rotunda mundus sa 9 . le credatur, fine aliqua ratione monftretur, nó men effe confequens, vt etiam exilla parte ab juarum congerie nuda fitterra.Redè prorfus: on enim iliud neceffariò ex mundi rotunditate onfequitur.Sed tamen neq; contrarium demóratur ratione, \& hoc iam tandem experientia fa patefecit. E; fi enim multò maximam eius lobi partenr agux obtinent, tamen ita terræ viiffim cedunt, vt non tota huius congeries hinc, ota illa rum inde fe teneat, fed mutuis excurfioibus fefe per omnia complectantur. Qua in re oirabilis conditoris ars obferuantibus apparee folet. Sacris quidem literis tradentibus didiimus aquas initio congregatas effe in locum v- Gem. um, \& terram protinus apparuifie: exdem todnen æquè nos docent congregationes aquarum ocata effe maria, quæ fine dubio plura funt. Neue mediterranea folùm maria multa funt, vt Eu inum, Cafpium, Erythræum, Perficum, Hefpeium, \& reliqua tot penè nominibus diftineta quot patijs. Verùm etiam Oceanus ipfe in diuia feriptura Abyffi vocabulo appellari folitus, quanuis re vera vnus fit, multiplex tamen eft, vt in hac America. Alter eft Oceanus Borealis, aler Auftralis, alius etiamn in Oriête eft Indicus, alius 


\section{i4 DE NATVRA ITOVI ORPTS}

alius Synenfis.llludautem ego in ijs, qua hacte: nus partim nauigatione, partim aliorum narrarione habeo explorata, notare potui, quod vix v fquam terra diftat à mari amplius auã viginti quatuor millia fadiorü, id eft, leucas Hifpanicas mille, fed vbi vis maxima Oceani f pacia eã men furam haudquaquam fuperant. Nó equidem nego latius longè Oceanum nauigari, cùm probè fciam Lufitanicam claffem quadruplo plus itineris maritimi folere conficere, quin potius $O$. ceanum ipfum in orbem cingi poffe, noftra ipfis rebusagnouit. Sed illud affirmo hadenus reça linea continentem à cótinente aut infulis, terram deniquè terra qua parte fe fe proxime refpiciubt aut nufquam, aut vix amplius quàm ijs fpatijs diftare effe compertum. Nam ab extrema Europa, \& Africa Infulx forcunatz cxteræć; innumerçillo fitu protenfx tercentum leu cis propemodum abfunt: $\mathrm{ab}$ ijs ad Occidentale Indiam venientibus, polt nógentas plus minus occurrunt Infula illa, quas Dominicam, \& Virgines, \& Beatam cæreralqúue vocamus, hæ longo ordine excurrunt $v$ fquc ad eas, quas Barlouenti nautre appellant. Ab his continens bis centum, aut paulò amplius abeft. Vbi Florida regna viq ad Patagonum regiones infinitis fpatijs vifunEur.Hoc autem altero Oceano Auftrali à freto Magallanico vfq; ad Promontorium Mendocinum eodem modo terra longiffimè tenditur, fed nufquam latior quam hoc iplo Peruano loco, in quo nunc agimus, cui ex altera parte refpondes regio Brafiliz quater \& vicies mille fadijs à no bis diffita. At in hoc Oceano Auftrali Sur vulgò appellato, quamuis Occidentem verfus nullus 
rrus finis habeatur : tamen non ita pridem Irliæ quædam \& multæ \& magnæ, quas Salomois vocant, noula nauigatione explorata funt, oingentas leucas ab America remotæ. Et quoiam totius orbis obferuatione compertum eff. ifulastum frequentes, tum magnas nufquam lere occurrere, quin continens in propinquo $t, \&$ multis aliis $8 z$ mihi ipfi perfuafum proris eft, ab illis Infulis Salomonijs non procul ab Teterram continentem latiffmam, qua huic mericę ex Occidentali parte refpondeat, $\&$ ad [agallanicum fortaffis fretum conuertatur. Na : nouam Guinzam terram effe continentem adunt, quam peritiores quidam Infulis illis a $\$$ ngunt.Itaq; magnam orbis partem reftare aduc nobis incognitam ratio ipfa perfuadet.Iam erò hoc ipfo mari Auftrali ad Synarum celeber mam latiffimamq́; regionem nauigant noftri, eque maiora eius nauigation is f patia reforunt, uàm qux $\mathrm{ab}$ Europa ad Indiam Occidentalem nenfi fumus.Vtriufq, autem Oceani continuz 0 , Borealis inquam illius \& huius Auftralis, in $r$ quos intercepta eft America noftra, ad Poim quidem Antaréicum certo explorata ef uinquagefimogradu elata, vbi fretum infigne lagallanicum redditur. Sed vtrum ad Polum doque Areticum fimiliter vterque Ocearius mmittatur afque concurrat, multi quęrunt, \& uod equidem lciam,inuenit hactenus nemo. antum indicia quædam 8 coniecturas probailes afferunt fupra Floridam effe alterum quo ue fretum Magallanico fimile. Nobis qua haenus certa fide comperta funt, fatis effe debẽt, orbisterrarum portionem; vniuerfa Europa atques 


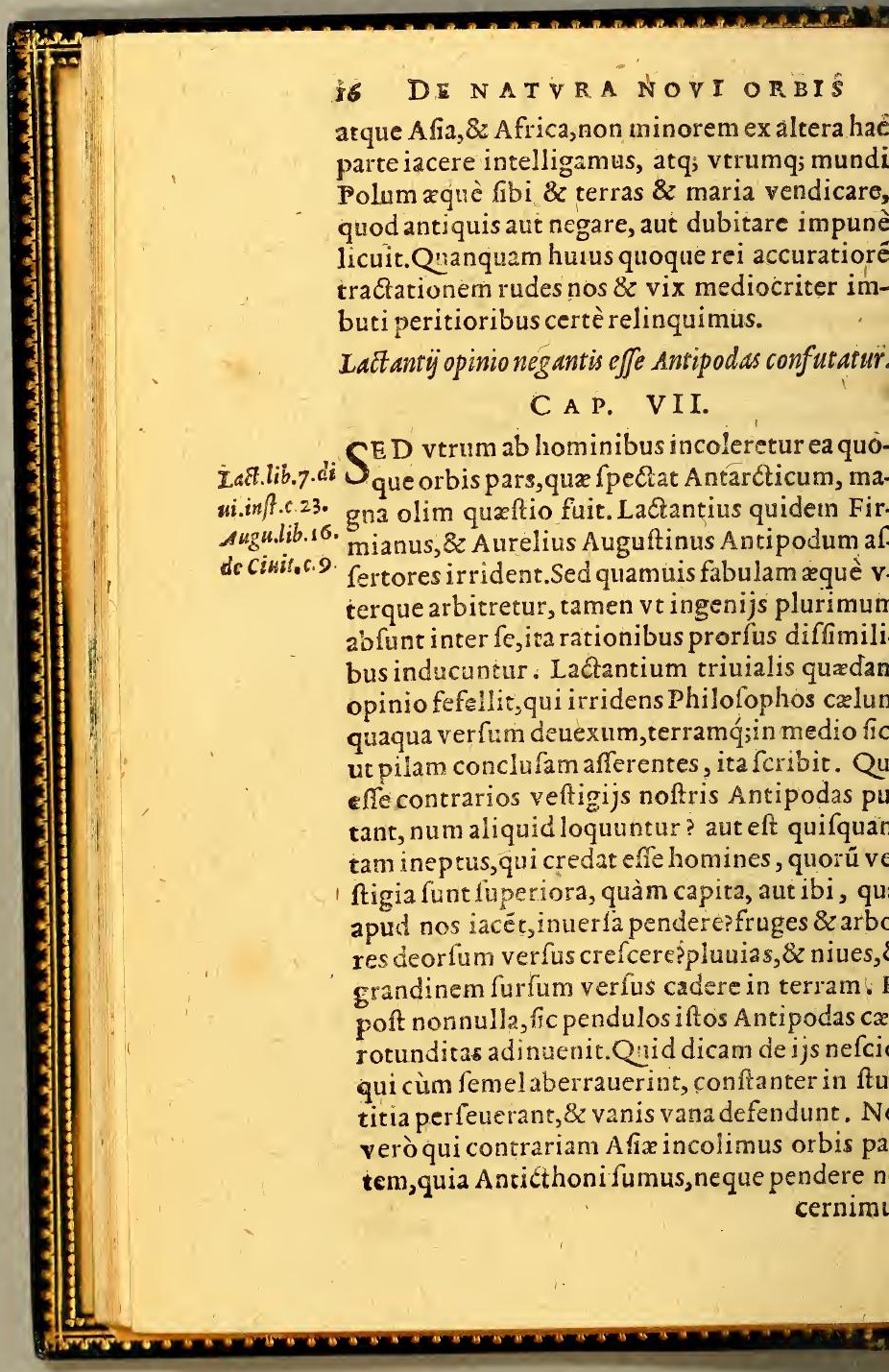


I I B E R $\mathbf{r}$.

rnimus, neq; veftigia nobis effe fuperiora, quả pita. Neq; fruges noltras \& arbores aliorfum efcere, neque niues, aut imbres aliter cadere uàm in Europa videmus. Omninò eft admirale dictu, rationem humanam, $\&$ verum fine ilaginatione percipere non poffe, $\&$ tamen $f i$ iağinationi obfequatur, nó errare nó poffe. Ca im rotundum,vt eit, \& terram in medio pofitá ifi imaginemur, non poffumus intelligere: At andem imaginationem fi mens fequacur,ac nó otius caftiget, \& corrigat'omninò fallimur, \& perramus à vero. Ita in nobis efle cęlefte quodam lumen, quo ipfas etiam rerum formasadin elligëdum oblatas, dijudicemus, \& probemus, q; improbemus, a pertilfino viu deprehendius. Quare \& animú omni corporea natura fueriorem, ' $\&$ xternú veritatis vigorê in fumma ominis fede præfidenté, qui immortalę lumen lum ex illo primo, \& fummo lumine accenfum onteftetur, qui ignorat, aut dubitat, is profectò fe etiam effe homınem ignorat, aut dubitat. Iaque forma omnis fenfu percepta, vifque ipfa maginandi fi de cali rotunditate interrogetur, ihil aliud dictura êt, quàm quod docuit Lactäius. Si cælum rotundum fit, folem, \& aftra cadeead occafum, furgere ad meridiem, terram effe, ufpentam in aëre, homines, qui ex aitera parte. ncolunt, veftigiafuperiora ferrequàm capita, iuem $\&$ imbres illic non cadere deorlum, fed nfernè afcendere, \& catera portenta etiam ditu ridicula: $A$ r fifiprema rationis vis confulaur, nugaś has omnes facilè irridebir, arque imaginacionê fanquam anum delirantem refpuet. fum illa fua deueritate incorrupea relpódebit, 


\section{DE NATVRA NOVI OREIS}

eos decipi, qui perinde mundum fabricantur, domum quandam, cuius fundameto nil nifi te ra, tecto non nifi cælum fuperius fit. Quin po us $v t$ in animantibus, quamuis alijs aliter fitu fit caput, alijs quidem fupernè, vt hominib alijs obuerfum, vt quadrupedibus; alijs med vt Polypo, \&zaraneo; in omnibus tamen cap effe fupremum, ita etiam cxlum vbicunque 1 fupernum effe, terram femper infernam. Na quia imaginatio no:tra addicta eft loco, \& te pori, tempus autem 8 locum non percipit v1 uersè, fed definitè, iccirco cùm ad ea affurg quæ tempus excedunt, aut locum fibi notu protinus corruit, \& nifi ratione erigatur, momento quidem ftare poteft. Itaque ante mi dum condirum tempus quarit, \& illi quoque bricando locum parat, neque aliter fieri po fatis videt, cùn ratio tamen neque ante motu fuife tempus, neq; vniuerfo ipfo locum vllu priorem fuiffe perfpicuè oftendat. Hanc igit ex vana imaginatione conceptam contra ter fitum argumentationem philofophus, \& dilu arift.1. de dèrefellit, \& breuiter eundem effe in mun loçum $\&$ medium, \& infimum verè omni pronuntians.

Queratio impulerit B. Augustinum, vt negaret effe Antipodas.

C A P. VII I.

D $\mathrm{v} \vee \mathrm{M}$ verò Auguftinum acerrimo ing nio virum longè alia ratio, vt de medio a Auguft.libr. ferret Antipodas, côpulit. Nam illam de incef Categor.c. contrario ipfe diffoluit in libro Categoriarur co.ini. tom. Veteres,inquit, vndequaque verfum afferent 


\section{I B E K I:}

rram effe fubter, cælú fuper. Nam \& Antipos noftri, qui nobis dicuntur figere aduerfa vegia,cxlum fuper fe habent. Hoc igitur cùm alolophicè prorfus intellexerit Auguftinus; iid quxlo potuit hominem vfque adeò doum in eam opinionem perducere? Nempè ex edia Theologia fumpto argumento, quodones homines ex vno Adx femine propagatos $A \mathbb{C}_{0}$ i uinæ liter $x$ tradunt, vt autem infinito Oceano aiecto homines ad obuerfas terra partes comearent, nulla ratio pati poffe videbatur. Ac nivfus ip fe rerum oculata fide fecus effe oftenfet,profectò hodiè quoque inuicta ratio illa erftaret. Quam cùm nullo modo effe veram, Iiidò conitet, quomodo tainen foluenda fit, id. t, quemadmodum genus Indorum potuerit ad inc Americam penetrare, operis \& difficultas plurimum habet. In cuius explicatione diu= us nobis eritin confequenti difputatione larandum. Nunc ipfum B. Patrem audiamus in bris de Ciuitaté Dei differétem. Qúod verò 8 ntipodas effe fabulantur, id eft, à contraria par terra, vbi fol oritur quado occidit nobis, aderfa pedibus noftris calcaréveftigia, nulla raone credendum eft. Neq, hoc vlla hiftorix conitione didicife fe affirmant, fed quafi ratiociando coniectant,eo quod intra cóuexa cẹli terfufpenfa fit, cundemq́; locum mundus habeat in fimum, \& medium. \& poft pauca. Nullo mo o fcriptura facra mentitur, quæ narratis præritis fidé facit, eo quod eius prædicta complen ur. Nimıfó; abfurdum eft vt dicatur, aliquos ho ines ex hac in illam partem Oceani inmenfiate trasecta nauigare \& peruenire potuiffe, vé 


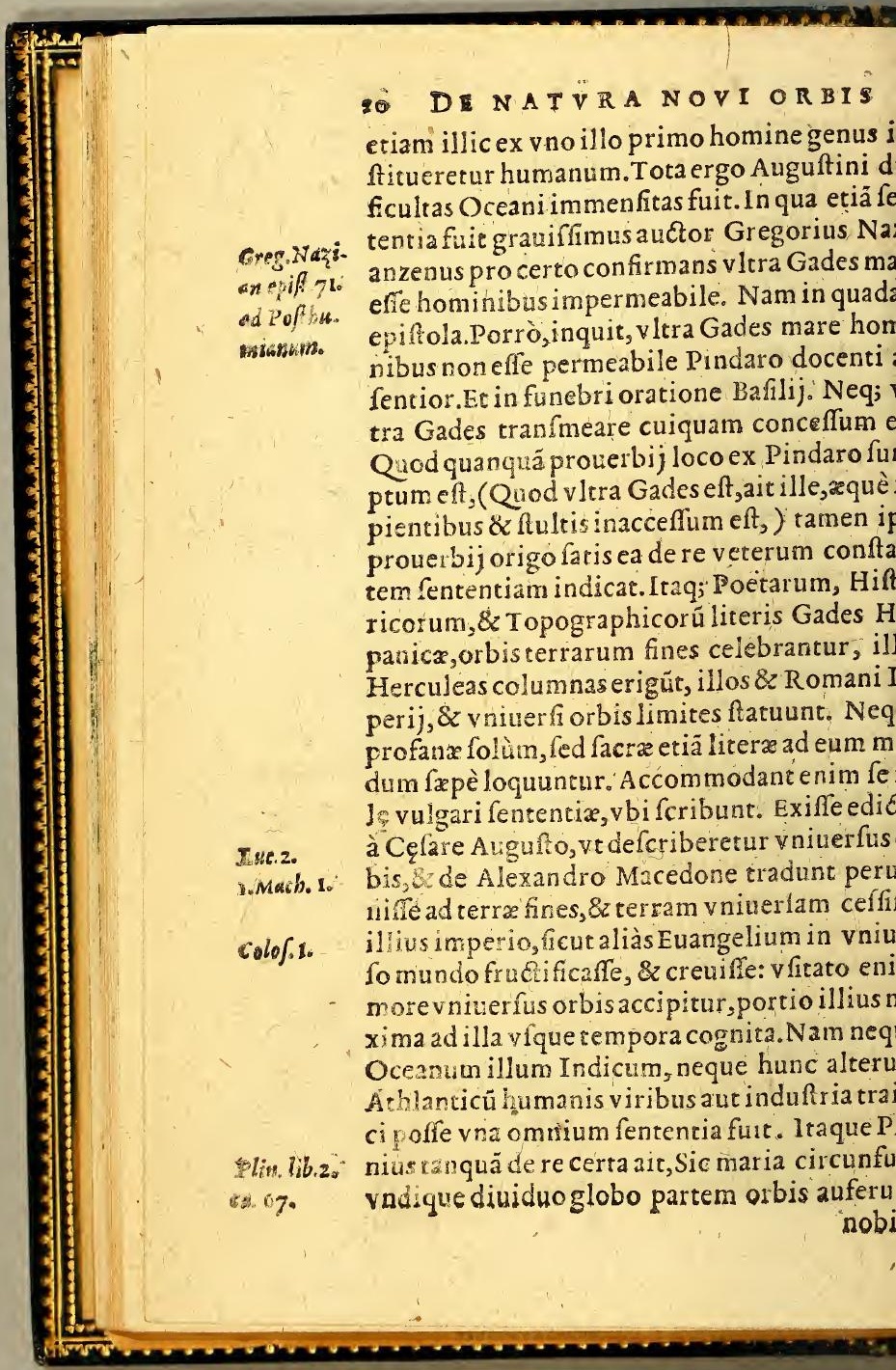


L

bis, neque inde huc, neq; hinc illo peruio tra,id quod Cicero, Macrobius, Mela,cæterique rique fripferunt.

ariftotelis fententia de babitatione alterius or bis, G quainre aberrauerit.

CA P. IX.

V I T quoque altera caufa, cur veterum opinione ad hunc alterum orbem mortalibus $n$ pateret acceffus, quod prater Oceani vaftiem,cælum ipfum obltaret folaris Zonæ imcabili 2 ftu, quo ab eo itinere, vel mari, vel ra conficiendo audaciffimum quem que comceret.Namque ij, etiam, qui terram, vtcf, fee rotundam, $\&$ ad vtrüque Polum habitabineffe cenfuêre, negarunt tamen incoli poffe hominibus mediam hanc eandemque maxiim \& longiffimam Zonam duobus folltitialis circulis comprehéfam, properer æfiuos percuof́́; ardores ex Solis propinquitate dam oem regionem adurentes, $\&$ pabuli aquarume imporentem efficientes. Huius fententix au r eft Ariftoteles, magnusille quidem natura plorator, fed in hac relongè aberrans à vero. lid autem philofophatus rectè fit de fitu or, quid fecus, breuiter expediam. Is de Auftro putás an ab ipfo meridie exoriatur, an potius vltimo vertice. Poli Antarctici, ad hunc modú ibit. Ratio docet terræ, quæ habitatur latitunem quidem determinatam efie, eam tamen atinentiorbe cóiungi non poffe propter tem rationem. Non enim ardore nimio, \& frigopremitur in longitudinem fuam, fed in latitu nem, ita ve ficubi maris valtitas minimè pro-

B. 3 hiberét, 


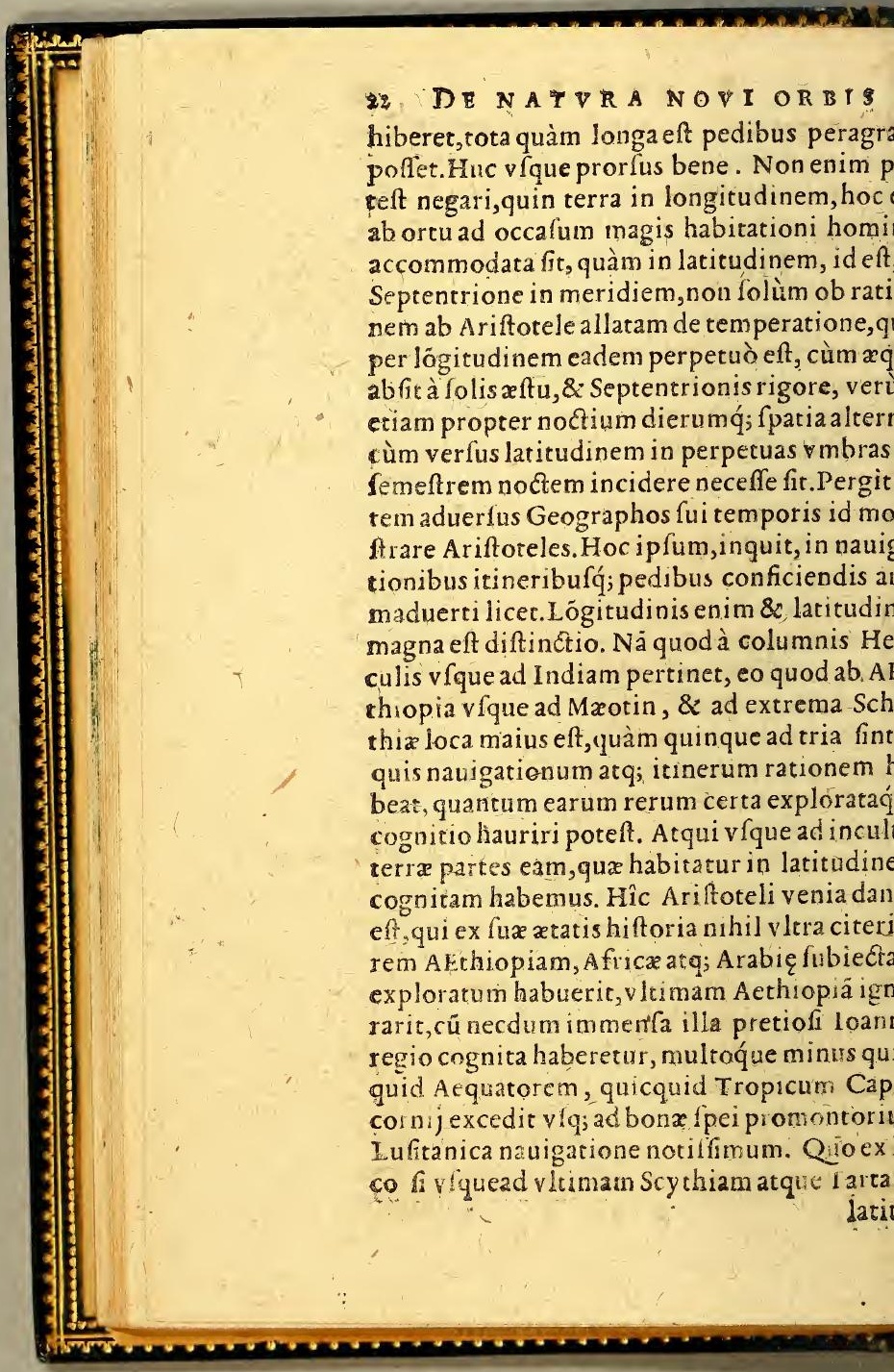




\section{I E R I.}

itudo capiatur, non dubium eft, quin æquara fit totam à columnis. Herculis vique ad Inam longitudinem. Sed \& Nili fontes, \& infita propemodum interioris Aethiopiz fpatia norauit antiquitas. Ob hanc rem Lucanus $\mathrm{C} x-$ rem ab ea inquifitione coërcet. Qux tibi, init, nofcendi Nilum Romane cupido? \& Nilü fum aliâs alloquens idem poëta. Et te terra$m$ nefcit cui debeat orbis: Scripturæ autem oftrx, id eft, facra auctoritas eam quoque ter$\mathrm{m}$ habitari facilè obtinet. Neque enim in So- Sophen. onia legeremus. Vltra flumina AEthiopix fidifperforum meorum deferent munus mihi, im de illarum gentium vocatione vaticinareIr, fed, vt dixi, veniä oportet dare philofopho is hiftoricis \& topographis fidem habenti. Ilid quod fequitur, expendamus. Altera, inquit, ars, hoc eft Septentrionalis, vltra inculta eft, nod frigore rigeat,altera, id eft, vltra Solftitiü, uod vratur calore. Qux autem vltra Indiam, olumnafq́; Herculis fitx funt, ex propter mare oniungi minimè ita videntur, vt tota fit contiens terra, qua habitatur. Hoc verú eft prorfus $r$ indubitatum. Adiungit verò. Quoniä neceffe It aliquem locum eandem habere rationem ad lterum verticê, quàm is, quem nos incolimus, d eurn, qui fupra nos eft, habet, non eft id quilem dubium, quin eadem ratione cætera alia, un ventorum fitus refpondeat. Et interpofitis uibuldam de Auftro \& Aquilone. Neceffe eft rofectò Auftrum effe ventum eum, qui flat à lo co qui calore vritur. Is autem locus, quod folem oroximum habet, aquis \& pabulis caret. Hæc Ariffoteles, nec potuit fortaffis certius aliquid

B. 4 affequi 


\section{DE NATVRA NOVI ORBIS}

affequi humana fuf́picio. Qua etiä ex re (vthoc religiosè dicam ) foleo fxpè perpendere, quã in rebus diuinis infirma fit philofophia fapiêtium huius fxculi, quando in ipfa terrena, \& infima materia, vbi fibi videcur maximè fapere, vfque adeò defipit. Habitationem terræ ad hunc alterú Polum Auftrinum, ve vocat Plinius, collocatz fecundùm longitudinem ab Occidente in Orjëtem effe maximam, fecundùm Jatitudinem veròà vertice Auftrali vfq; ad æquinodialem,aut nullam, aut perexiguam Ariftoteles vult. Sed adeò falfum eft, vt totius noui orbis tota propemo dum habitatio fit fecundùm latitudinem, id $\in \mathbb{f}$, à Polo in Polum: ab Oriente autem in Occafum breuis admodum menfura fit, tantumique latitu. do noui orbis longitudinem fuperat, quantum denarius ternarium, \& eò amplius. lam verò, quod mediam regionem, quã torridam $Z$ onam vulgò appellamus, afferit prorfus inhabitabile, quòd calore exuratur propter folis vicinitatem, quodque pabulis, 8 aqua careat, omninò eft fecus. Nam \& noui huius orbis lógè maxima pars ac frequentiffmè habitata, intra vtrumque Tro picum continetur,eadem, \& pabul s, \& aqua fupra omnes orbis terrarum regiones abundat, atque plurima ex partetemperatilfina eft, vt hic eriam $D$ E v s ftultam huius mundi fapientiam feciffe videatur. Eft ergo habicabilis, habitaturq́ue coprosè, quicquid reclamet antiquitas, Zona torrida. l'orrò regio illa, inter hac corridam, \& illam Polarem pofita, quamuis fitu ipfocommodiffima fit habitationi humanx, tamen raiò admodum habiratur, quod hactenus fola regio Chylenfis occurrat, qux non fit Occano inter-

cepta. 
pta.Multi tamen, quorum me etiam in numeeffe profiteor, terram huic Chylenfi oppofitá tra Tropicum Capricornij porrigi opinan$r$, fed eandem nobis nondum effe exploratam. eque dubium eft, quin ea regio, vt optimum, temperatiffimum fitum tenens, medium inter rridam, \& Polarem, ita etiam omnibus rebus xftet, vtpotè Europę optimæ parti ęqua ratiorefpondens. Et hoc fatis confentaneè Ariftoles fufpicatus eft. Sed tamen, ve dixi, \&z illa antum hactenus compertum eft, breuiffima t, \& ipfa torrida longè maxima.

\section{Quod eadem Plinij o complurium veterum}

Sententiafuerit.

C A P. X.

A Riftotelis fententiam fecutus eft Plinius.

Lux, inquit, media terrarum, qua folis orbicft, exufta flammis, \& cremata cominus vapoplin.lib. 2 . ca.68. torretur. Circa quam duæ tantúm inter exufta rigentes temperantur, hæó́; ipfę inter fe non eruix propter incendium fideris. Hæc eadem dit vulgaris fententia veterun, quam etiâ Poëfuo carmine celebrat.

Quinque tenent calum Zone, quarum vna corufco Verg.in Ge: Semper fole rubens, \& torrida emper ab igne. orgic. demq́; aliâs, Et fi quem extenta plagarum Qua- Et 7. Aenei. uor in medio dirimit plaga folis iniqui. Et alius oëta apertius.

Totidemós plage tellure premuntur: Quarum qua media est, non est babitabilis astu. tamor. verò veterum fententia, perfpicua atque inicta, vt ip fis videbatur, ratione nitebatur. Nam quæa; regio ad meridiem propius accedit, ita B 5 folis

Ouid.1. Me. 


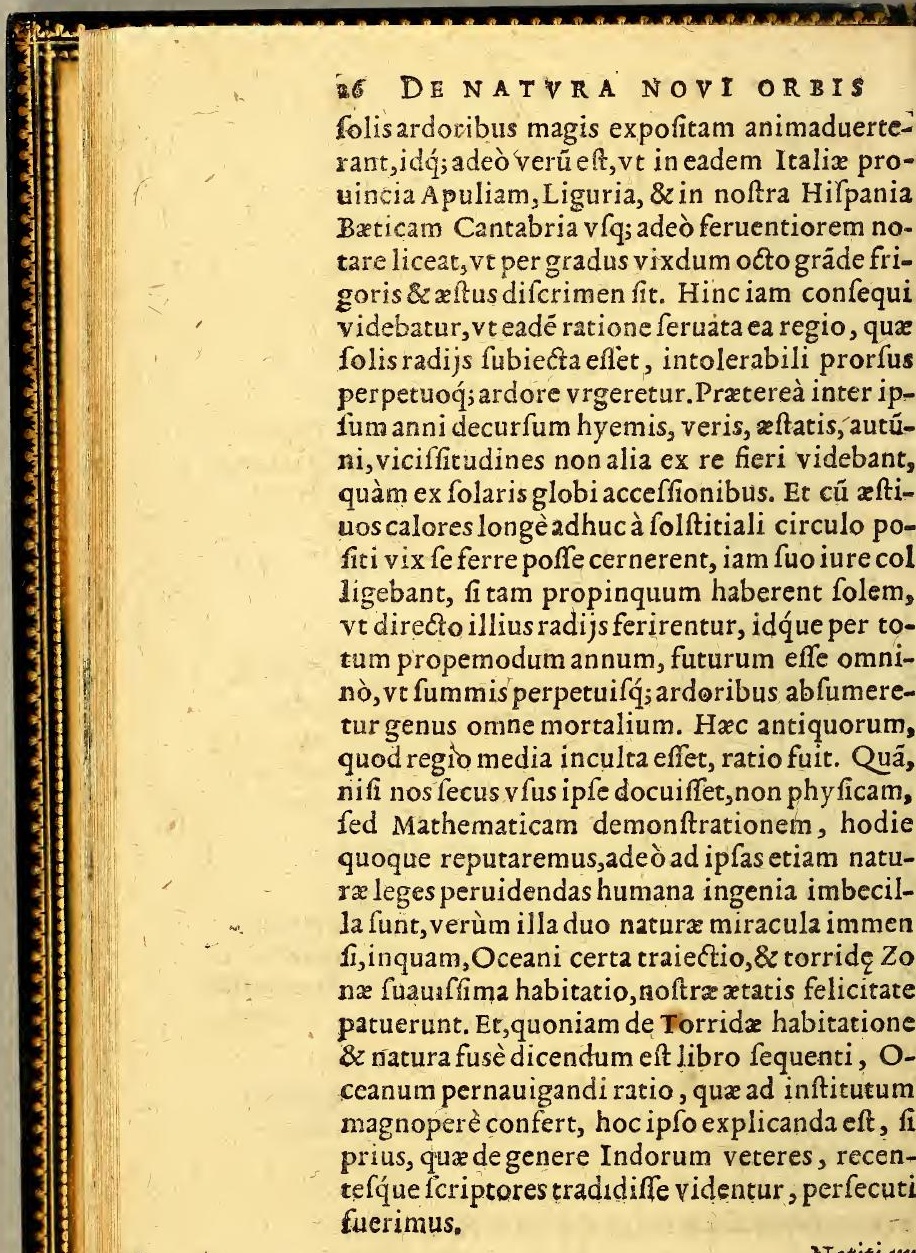


Notitiam alterius orbis apud veteres inueniri.

$$
\text { C A P. XI. }
$$

G I T V R hominum genus vltra Cancri circulum habitare veteres aut omninò negarút, Lactantius \&z Auguftinus, aut certè, fi qui efent, intra mediæ regionis terminos non poffe onfiftere affirmarunt, vt Ariforeles \& Plinius, $z$ v troque antiquior Parmenides, vtrumque au em fecus effe fatis conftat. Sed vtrum ante no- Plut lih. 3 tram xtatem eius rei notitia extiterit, accuratè placitós $P b$ permulti quærunt. A pparet enim monftri fimi- lof.c.u. $e, \&$ alterum orbem effe tantum, quantum hüc cernunus, \& antiquos to facula latuffe. It aque nonnulli tanquam eam gloriam noftro \& fæcuo \& generi inuideant, conantur huius quoq; orois notitiam antiquitati tribuere. Atq; effe certè nonnulla eius veftigia negare non poffumus. Scribit Hieronymus in epiftolam ad Ephefios: Quærimus quoque quid fit. In quibus aliquan2ur ad E. do ambulaftis fecundùm freculum mundi huius. plees.

Vtrumnam $\&$ aliud freculum fit, quod non pertineat ad mundum iftum, fed ad mundos alios, de quibus \&z Clemens in epiftola fua frribit. Oceanus \& mundi, qui tranfipfum funt. Quænam hxc fuerit Clementis epiftola ignora: fed illud fcripfiffe Clementem Hieronymo fidem no habere non poffum. Perfpicuè verò Oceano traicClemens Ra
manas epist.
ad Corint. Clemens Ra
manas epist:
ad Corint. Clemens Ra
manns epist.
ad Corint. cto alterü effe mundum, imò etiam mundos Cle mens do:et, atq; ita re vera eft:longiffinè enim vterą; nouus orbis, id eft, America, ab India Oriêtali dıftat. Caius quoq; Plinius, accuratiffim ${ }^{9}$ rerum mirabiliü ind gator, memorix prodidit: Plinlib.2. Hannoné ucé Carthaginếlem à Gadib ad finé cap.67. vquae

Hier. inc. 2:pift.ad E. phef. 


\section{DE NATVRA NOVIOREIS}

$\checkmark$ fque Arabize circumiectum, eamq́; nauigationem literis commendaffe. Quod fi verú eft, quic quid hodie Lufitani immenfa fua nauigatione bis aquinoctiali fuperata Oceani conficiunt, Hannoille emenfus fit neceffe eft. Eandem naui Jdem, lbidĕ. gationem contrario ordine confectam ab Euda- . xöquodam, quem, cú Latyrum Regem fugeret, Arabico finu egreffum Gades vique peruect um, idọ; fua ztate, Cornelius Nepos auctor eft. Traduntetiam auctoies non ignobiles nauem Carthaginenfum vi ventorum per Oceanum abiejram in nouam quandain regionem incurriffe, mox́c; ; d lios reuerfan cognofcéd $x$ eius regioris triúli m carthäginen hibus excitaffe, verùm nator un decreto eam inueftigationem effec cohibitam, ne nouarum rerum occafione Carthaglais gloria, \& celebritas fu caretur. Quibus ex rebus intelligere poffumus nonnullam noui orbis apud veteres notitiam extitiffe, tametfi de Occicentali hac India, deq́; hac America vix aliquid monumentis antiquorum confignatum inuenire licear. Nam de Orientali India etiam citeriori, qua antiquis erat vlterior, eo quod ex altera parte orbem peragrarent, non rara neque obfcura mentio eft. Nam de Aurea Cherfóneío, de Cori promontorio, de celebrata illa Taprobane, qua alijs hodie vocabulis frequentantur, quis ignorat vecerum foriptorum literas? Quid de vtraque Aethiopia, de Brachmanibus, de gen te Synarum? Nónne \& multa $\&$ perf́picua horú commemoratio extat in libris antiquorum? Por rò Occidenealis nauigations, quätum etiam faPlin.lit. 6. ma alfequi Plinius potuit, tantum ad fortunatas cap. 32. Iniulas curium protendit, earumó; præcipuam a mulci- 
multitudine canum Canariam vocatam refert. nde pelagusillud am pliffimum, quod meritò Iagnum nautæ appellant, vix vllis certis veftiijs antiquitatis notatum reperimus. Sed nonullos maximèillud Senecx carmen mouere fo$t$, cùm in fuis Anapęfticis noui orbis res præicere videatur.Ita enim illius Medæa habet;

Venient annis facula feris.

Quibus Oceanus vincula rerum;

Laxet, Gingens pateat tellus.

Typhisǵg nouos detegat orbes,

Nec fit terris, vltima Thule. ..

Seneca in Mo

dea actu 2.

in fine.

ta effe factum negare non poffumus. Nam feros nnos mille \& quadringentos àT ragico plufqua is mille à Medá meritò aecipimus. Oceanum uoque rervm laxaffe vincula, cùm alios terraum terminos oftendit \& patuiffe ingentem telurem, tota certè Afia atque Europa maiorem, eniq; nouos effe detectos orbes, omnes cerninus, ve Chorusille prædixit. Sed vtrum diuiarit Seneca, an fortuito ac temere cecinerit, uæri poteft. Mihi vero diuinaffe videtur, fed o genere diuinarionis, quod prudentes virifaniliare habent. Videbat namq; iam illo frculo laugationibus mare inufitatis folicitari, terıa ffe alteram Anitichthonam ex Philoiophia dilicerat. Potuit iure $\&$ meritò hominum indutriam, \& audaciam eò aliquando progreffuram exiftimare,vt magno Oceano enauigato rouos errarum orbes aperiret.cùm præfertim ea atae naufragia illà, qux Plinius narrat, longilfimi Oceani nota effent. Nam poft veterum quietem collaudatam,adiungit de audacia fuorum tem-

porum. 


\section{$3^{\circ}$ DE NATVRA NOVIORBIS}

porum. Nunc iam ceffit Pontus, $\&$ omnes patitur leges: \& mox. Qualibet altum cy mba pererrat.Terminus omnis notus, $\&$ vrbes muros ter. rapofuêrenouos. Nil qua fuerat fede reliquit peruius orbis. Indus gelidum potat Araxê, Albım Perf $æ$, Rhenumó; bibunt. Huius itaque au. dacix hominum quafí incrementa extrema con: nectit, Venient annis facula feris, \& cxtera, qua recitata funt.

Platonis fententia de India Ocidentali.

\section{A P. XII.}

Plato in Ti. DLA T o veràin Timæo expreffus hunc no. ma.

uum orbem Occidentalem, \& propius attigiffe videri potelt. I unc, inquit, pelagus tlluc nauigabile erar (loguitur aút de Oceano Athlan tico)infulam enim ante oftum habebat, quoc vos columnas Herculis appellatis. At Infula il. la \& Lybia, \& A fia fimul maior erat, ex qua alcê fus ad alizs infulas tunc proficifcentibus contin gebat,ex Infulis autem in omnem ex aduerlo cö tinentem circum verum illum Pontum firam. Hæc apud Platonem Critias. $Q$ i verò Platoné, 8 hiftoriam tradere, \& vera narrare fibi perfua dent,ij hac ita exponunt, vt Infula quidem illa, Achlantis dicta, tota A fia \& Africa mator plurimam Oceani Athlantici partem, quê modò Hifpani traijciút, occuparit: Infulas autem ad quas ex Athlantice alcen fus cótingebat, effe eas, quas noftri naute appellant Barlouenti, Cubam, Hif panicam,S. loannis Boriquen, lamaicam, \& rel quas eo ordine pofitas. $\mathrm{tx}$ his verò ad continen. tem adiri, hoceft,ad terram frmam à noltris di etam termino hoc Peruenle regnum \& totam

Amer 
mericam.Verùm autem Pótum, circum quem ofita fit Continens, interpretantur hoc mare uftrale, vulgò Sur appéllatum, ideò verò à $\mathrm{Pla}$ ne verum Pontum nominatum, quod præ vaitate illius Mediterraneum omne atq; Athlan cum ipfum tanquam ficta \& ludicra maria votri poffint. Acutè quidem atque concinnè ex- Zaratein fits gitata hęc à viris ingenio fis 2 antiquitatis ftu bifforida oinquiremus.

Quod quidam Ophir in facris literis effe no. Strum Peru opinatifont.

CA P. XIII.

$\mathrm{N}$ facris quoque literis, huius Occidentalis Indix métionem fieri fub Ophir nomine quilam volunt. Rupertus quidem Stephanus, vel otius Francilcus Vatablus vir Hebraicè doct if imus, ve ego à Præceptore difcipulo illius acce i in fcholijs ad caput nonum libri tertij Regú, Dphir, vinde Salomon afportaffe dicitur qua- In Biblijsk lingenta viginti, fiue quinquaginta auri talen-berti Stephas a, fcribit effe Infulam Hifpaniolam à Chrifto-ni.

horo columbo inuentam, vnde aurum optimú, x probatiffimum ex monte Cibaico noftri eruint. Neque defuêtre viri perdocti, qui Ophir in acris literis tantoperè celebratam exiftimarint effe hoc ipfum noftrum Peru, quod vocabuium In apparain pfum etiam Hebraicè extet, ficq́u appellatum BiblieRegie hoc regnum credant, cùm Paralipomenon fcri- in Phaleg. $c_{0}$ eretur hiftoria. Per Metathefim verò Ophire $9.0 \mathrm{in} \mathrm{Bi}$ fue Opire fit dictum Piru:Adduci etiam in eam blijs Robert fentëtiam vidétur, quòd fcriptura cómemoret Stephani. aurum optimú \& ligna thyina pulcherrima $\&$ 2.PAr.6. و pretiofis 


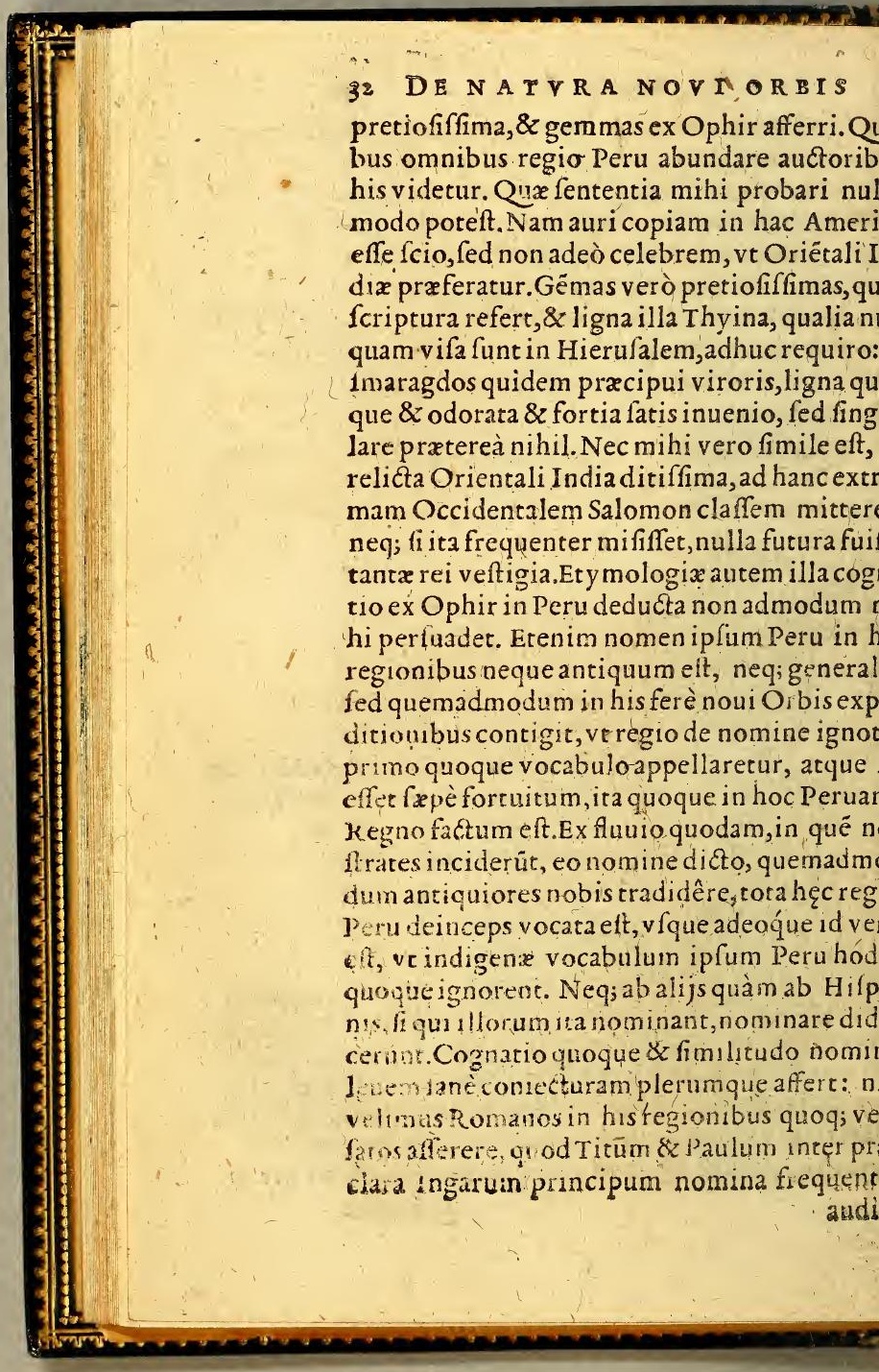


udiamus. Me verò fi quis interroget, quam re. 3. Reg. ionem aut prouincia arbitrer effe Ophir, quò 3 Reg. 22. laffis Salomonia Tyrijs \& Sidonijs nautis in- Iofeph. libr.' tructa vehebatur auri exportandi gratia, \& quo 8 antig. tutructa vo ùm eadem ex caufla claffis Iofaphat Regis perseret, in Afiongaber naufragium perpeffa eft, terram auquidem Flauio Io fepho potius affentior India ophir. Orientalis fedem afferenti, abO phir filio Iectá, Gene. 10. cuius in Genefi mentio eft, collocatam, eandem- Montanus in que primi auri ditilfimam. Ex quo in Sacris lite-alpha. is Aurum Ophir, fue Opham, fiue etiam obri-Hieron.ad um quafi Ophirizum celebratur, quod cùm 2- Principia. in oud Hebræos tefte Hieronymoauri feptem vel 3.tomo. senera vel vocabula fint, Ophir principem locum teneat, ficut apud nos Valdiuiz aut Caraaiæaurum celebratur.Curautem in Orientali potius India quàm in hac Occidentali Ophir fu fe exiftimem; illud caput elt, quod ad noftrum Peru non nifi infinito circuitu tota India Oriêali \& Sinarum regione enauigata Salomonia claffis peruenire poterat. Neque fir mihiverifimile per tot fpatiorum millia sidonios nauigaf fe auri quęrendi caufa, ad ea prafertim terram, cuius nullam habere nocitiam per continentem potuerint. Nant noftra naugationis artem, \& methodum veteribus fuife ignotam argumenis haud quaquam leuibus poftea of endemus.

Qwidnam Tharfis or opbir in facris literis 1 Sginficent.

C A P. XIIII.

VOD fufpicionibus \& coniecturis tantu concedi debes, ego lanc Ophir \& Tharfis in duinis litcris lapius non certum alıquem defiC nitumás

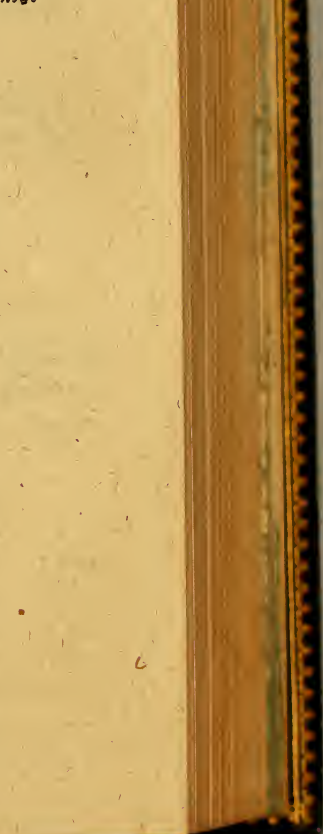




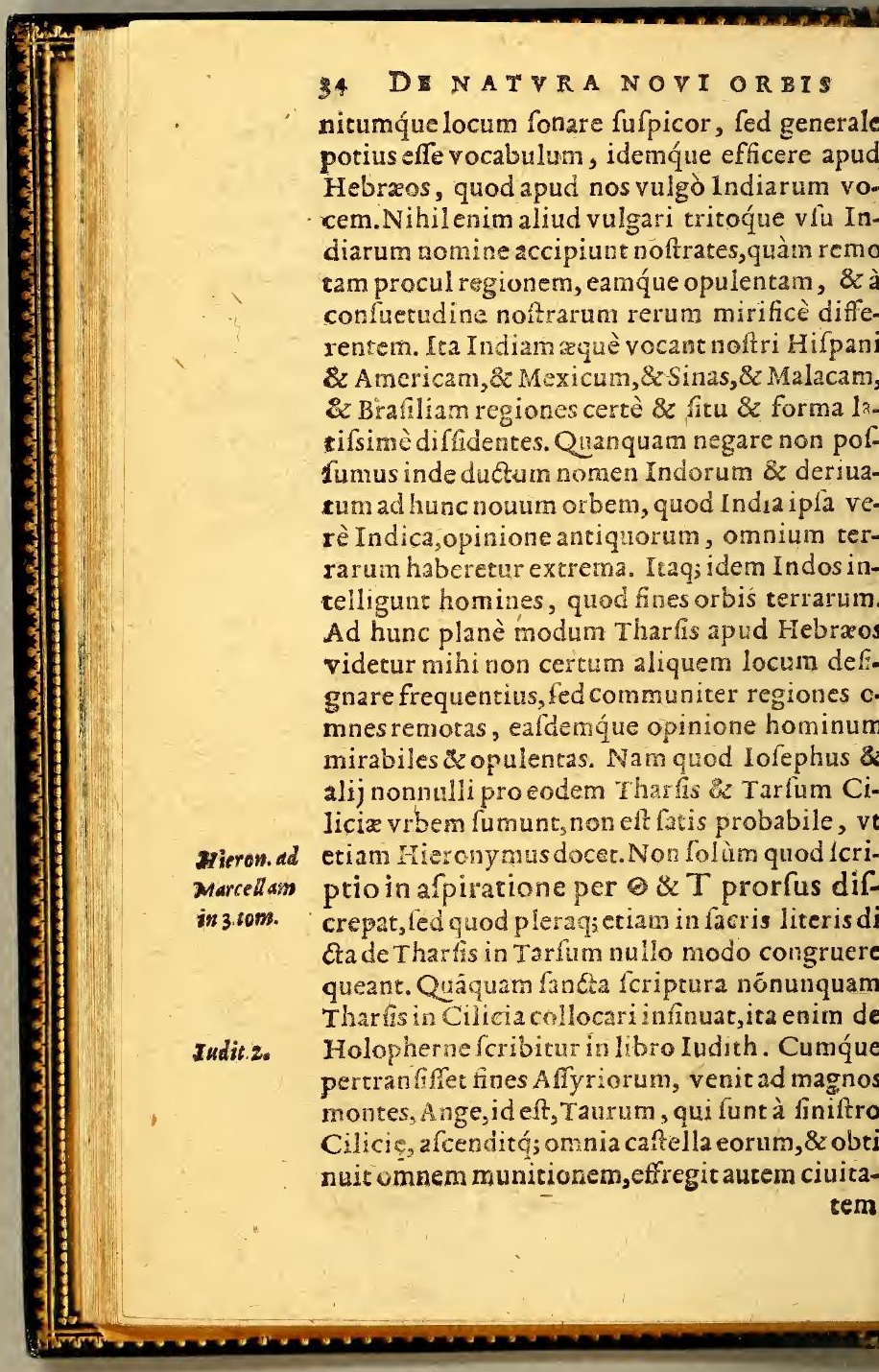




\section{I $\mathrm{I} R \quad \dot{\mathrm{I}}$.}

tem nominatiffimam Melithi,pradauitqúue omnes filios Tharfis \& filios Ifmael, yui erant contra faciem deferti \& ad Auftrum terr $x$ Cellon, \& tranfiuit Euphratem \& $є$. Verùm vt dixi, rarú eft, ve Tarfo conueniant, quz de That fis legimus aliâs. Iram verò Theodoretus $\& z$ quidam aliy, verfronem feptuaginta interpretum alicubi fecuti, Tharfis in Africa effe, eamúue à noftris Carthaginem dictá volunt. A iunt enim eo curfum intêdiffe Ionam, cum fcribitur fugere voluiffe à facie Domini in Tharfis. Quod praterea certa Indix regio 1 harfis vocetur in facris liceris, quod D. Hierony mus vult, non equidem repugno. At vnam eandemq́ue definitò regionem femper fiTheodor, is 1. Iore. Arias Mont d nusibiow in Aiphabcto op paratus. Hieronad Mairellam. gnificare,idcertè nego: Etenim reges Tharfis, quos munera Chrifto oblaturos Pfalmus canit, pfal.44: Magos fuiffe ab Oriente venientes, eofdemq́ue E/ai.co. Sabxos; \& Ephazos \& Madianitas fatis facra fcri ptura docet, quos \& Aerhiopes; \& Arabas, \& Per fas viri docti fuife tradunt, fed Tharfis vocabulum homonymum effe ac plura variaçue fignifi care in facrisliteris Hieronymo affencior, ita- Hieron lit, que interdum Chryfolitus aut Hyacinthus eft, in Efai c. 2 interdum India regio quadam, quinetiam mare ipfum quia caruleum eft, \& illorum lapidum co lores radijs percufum imitatur, sed bene idem Beatus Pater in Efaiam fcribens negat Tharfis, quo Ionas peterer, effe aliquam Indire regionem. Neq, enim,inquit ille, Ionas de Ioppe nauigans ad Indiam poterat peruenire, ad quam illo mari non poteft nauigari. Nam maris medicerranei, non rubri, vnde in Indiam nauigari potef, olim Ioppe nunc Iapha portus eft. Longè ergo alia fuit Claffis Salomonix nauigatio, fue in Ophir,

$$
c i \text { fiue }
$$




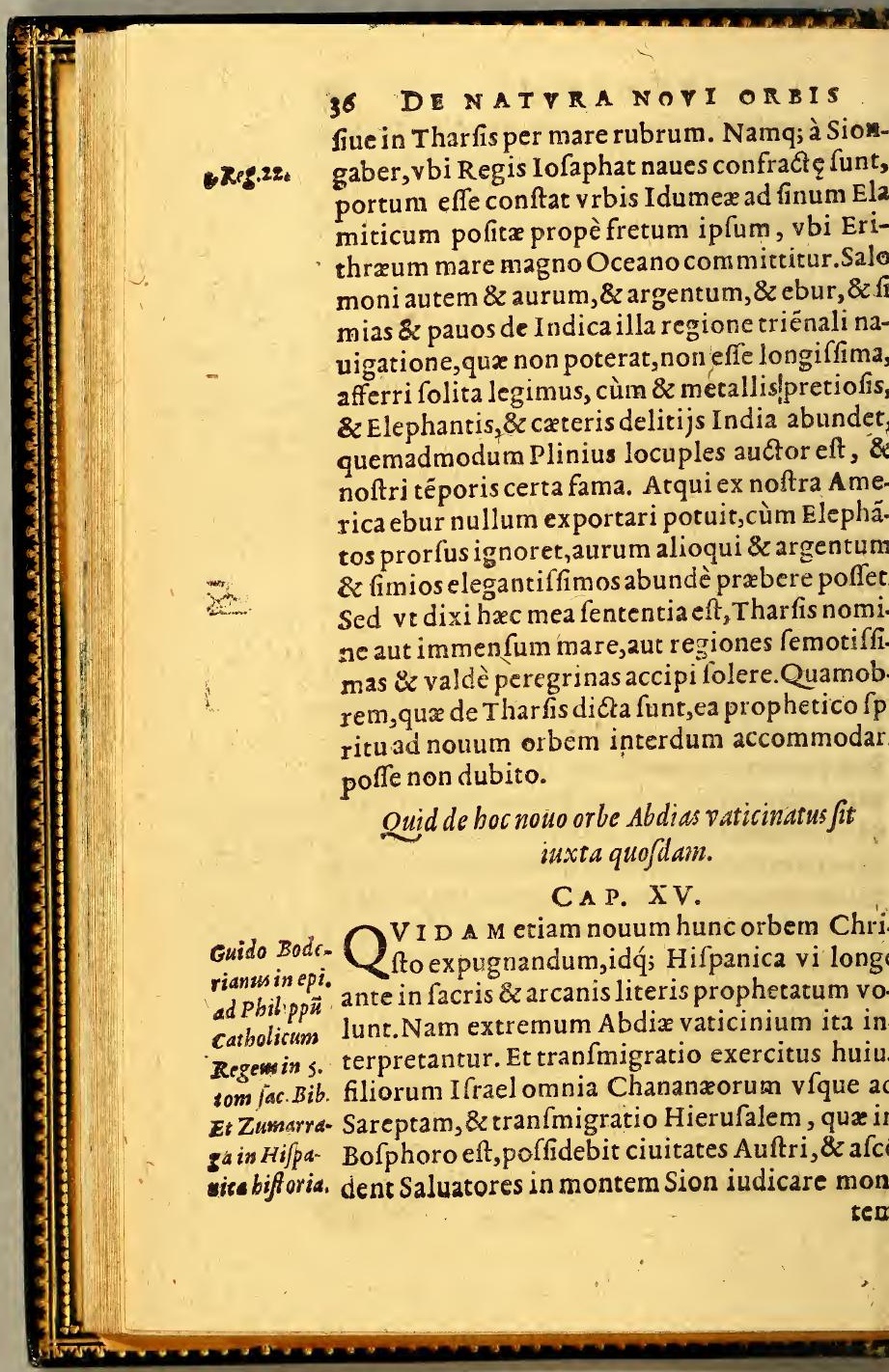


tem Efau, \& erit Domino regnum. Sic nos legimus iuxta vulgatam.Illi verò ex Hebræo, vt dicunt, hoc modo:Et trăfmigratio exercitus huius filiorum Ifraël, qui Chananzi funt vfque Sarphat, (id eft, Galliam)\&ztranfmigratio Hierufalem, qua eft in Sepharad(hoc eft Hifpania) hære ditate poffidebit ciuitates Auftri, $\&$ afcendent falutem procurantes in montem Sion ad iudicädum montem Efau, \& erit Domino regnum. Sed cur Sepharad, quodHieron ymus vertit Bofphorŭ, feptuaginta verò Euphrata,defignet Hifpaniam,nullum ex antiquis proferunt teftimoniú, nullam certam rationem, ficut etiam Sarphat, vbi vtraq; editio habet Sareptam, Galliam Guido parrix fauens interpretatur. Nos verò, qui de linguarum peritia certare non poffumus, illud iure requirimus, quidnam cogat ciuitates $\mathrm{Au}$ Ari fiue Nageb, vt habét feptuaginta noui orbis gentes accipere? Quid etiam tranfmigrationem Hierufalem in Sepharad gëtem Hifpanicam intelligere? Nifi Hierufalem fpiritualem cogitemus, hoc eft, Ecclefiam,vt per trăfmigrationem Hierufalem, qux eft in Sepharad Spiritus fanctus fignificet Ecclefix fanctx filios, qui verfantur in finibus terræ aut portibus, id enim Sepharad Syriacè notat, atque in Hifpanias fatis congruit, vbi \&z fines orbis terrarum à veteribus po fiti funt, \& mari cinctam regionem ferè omnem Hifpanicam conftat. Auftrum verò fiue Nageb hunc orbem accipi poffe inde fortaffis oftendêt, quod torus penè hic mundus inuentus fub meridie iaceat, \&z plurima ex parte Auftralem polum fpeftet. Nam quod fequitur. Et afcendent falutem procurantesin montem Sion ad iudicandú 


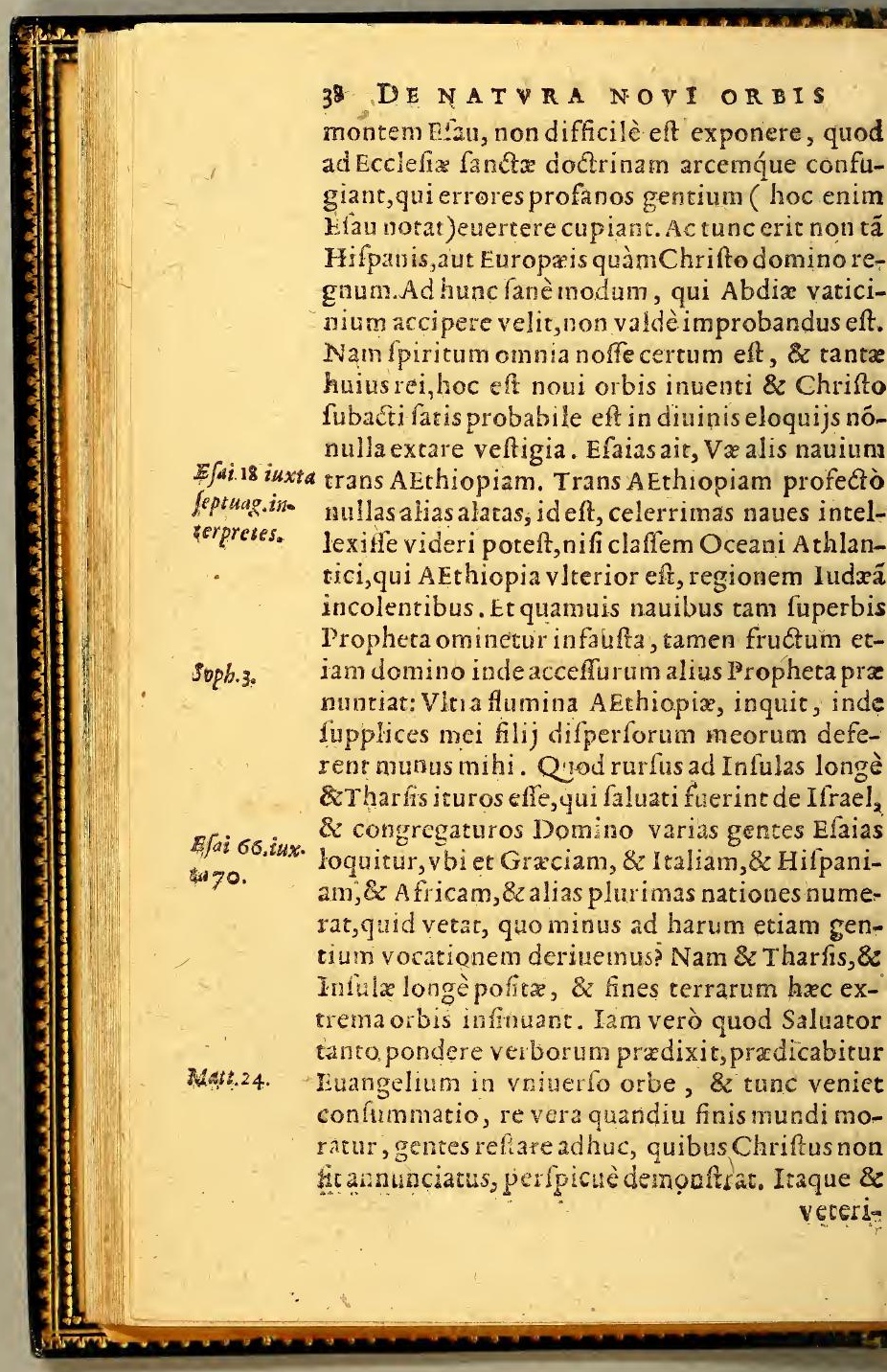




\section{I B E R I.}

veteribus plurima orbis pars reftabat incognita, \& nobis non minima hodie quoque reftat.

Qunodoprimi homines ad Indos venire potuerint: oquodnonvenerint certanauigatione.

\section{A P. XVI.}

T A verò illis fatisfaciendum eft, qui negant 1 effe Antipodas, aut hã c quam nos modò incolimusregionem poffe habitari. $D$. Auguftinum vehementer deterruit Oceani immenfitas, vt genus hominum ad huncalterum orbem traijcere potuiffe exiftimaretur. Nos verò, qui \& homines olim hic habitaffe fcimus, \& diuinis literis contra dicere nullo modo poffumus, ex vno factum effe $A$ it. $1 \%$. omne hominum genus, huc ex Afia, aut Europa veniffe homines affirmare certò poffumus, fed. quomodo, aut qua vía quóue duce gens İndorum innumerabilis huc penetrarit, meritò fanè hodie quoq; \& admiramur \& quxrimus. Nam neque alteram Noearcam huc appuliffe cogitare polfumus, neq; Angelum quempiam, vt olim Abacuch Prophetam ex Palartina in Babylonem, fufpenDan.14 fos per aëra tranfuexiffe Indicz gentis progenitores. Non enim quid Deus potuerit, quaritur, fed quid humanarum rerum ratio atque ordo patiatur. Meritò igitur vtrumq; inter admirabilia Dei opera atque occulta confilia referri debet, $8 z$ quod tã vafta pelagi ac terrarú fpatia genus mortaliū penetrâr it, \& quod longẹ lateq́; diffufum tă diu noftros latuerit. Quxfo enim te, quo confilio, qua ratione, qua vi tantum pelagus gens Indorum pernauigâuit? quo auctore ad infinitè diffitas regiones peruafit? Equidem diu de hac

$$
\text { C } 4 \quad \text { caufa }
$$




\section{DE NATVRA NOVI ORBIS}

caufa \& cogitaui ipfe mecum, $\&$ ex alijs quęfiui neq; certum argumentum rei tantæ inuenire $p$ tui.Dicam tamen, quod occurrit, \& quoniam te ftes non habeo idoneos, fequar certè rationis d Ctum, quamuis tenuiter deprehenfum, $v$ fq; dum illius veftigia ex oculis euanefcant. Vno igitu ex tribus modogenus Indorum ad hanc Ameri cam veniffe manifeftum eft, aut enim terreftr itinere, aut maritimo vẻtum eft, ac maritimum quidem vel fortuito peragi potuit, vel certo có filio \& ratione, hoc ef, aut vi tempertatis \& $\mathrm{O}$ ceani prater fpem ad hunc alterum orbem ap plicuerunt primi habitatores, aut ftudio nou quarendi nauigationem huc direxerunt. Alium præter hostres modos inuenire non poffum, quid res humanx habeant, cogitemus, neq; pro. digiola quadam atquePoëtica comminifcamur Neque enim vel Ganimedis aquilam, vel lerfe equum alatum, neque Syrenas $8 x$ Nicolaos ge nereIndorum accerfere oportet. Excutiamus er go fi placet atque libremus eorum quos dixi fin gulos modos, quod \& vtiliter $\&$ iucundè fieri $p$ teft. Ergo illa videtur planiffma $8 z$ expeditiffi. ma via,ve quemadmodum nunc noftrx Hifpanienfes naues, curfusaftrorum cælique conuerfionem notantibus magiftris, vim ventorum aquarumq́; fcientibus ad Indos certum iter inten dunt, ita olim antiquitas horum omnium perita has fedes inueftigauerit, inuentalqú tenuerit. Quidenim fola notra atas, foli noftri homine Oceanicæ natigationis induftriam fant confecuti? An non ficut non ita pridem Clasfis noftra Aluaro Mendano duce ex hoc Limano portu foluens, \& perimmenfum Oceanum, Occiden- 
I I B E R I. $m$ verfus delata,fudio nouam mundi plagam ic Americæ occiduæ oppofitam perueftiganpoft trimeftre tandem tempus Infulas illas, $8 z$ ultas $\&$ maximas inuenit, quas Salomonias vo re libuit, eafq́;; aut magnæx nouæ Guinxæ, aut icui ingenti continenti hærere conftans fama $t$, idque ve liquidò ex ploretur hoc tempore feIndam Regij fenatus auctoritate expeditioné rari, eodem duce, \& præfecto cernimus:fic et$m$ potuit quondam antiquitas, vt terram Anchehonam quareret, quam certa tatione effe inftabat, naualem quápiam profectionem inuere, inftructam hucufque dirigere?Profectò hil vetat, quò minus ita olim effe factum pumus, vt fieri modò cernimus. Adde quod hioria facra atteftatur à Tyrijs \& Sydonijs Saloonem accepiffe viros nauticos $\&$ gnaros mas, eundem triénalem nauigationem exercuif- Quorfum verò vel nautarum peritia celebre ir, vel tam diuturna nauigatio referatur, niff agnum Oceanum Claffis Salomonia traiectufuerit? Multi ergo ita opinantur, putantq́ue B. 3 Reg. 9. uguftinú immeritò Oceani immenfitate derritum, cùm potuerit ex triennali illa nauigaone Oceanum tandem, quantus ef, permeari, icilè deprehendere. Ego verò fecus fentio, neq; dducor, vt Indorum primos auctores certo cur 1, fixoq́; conflio exiftimem in hunc alterum or em commeaffe, neque verò peritiam nauticam oftra atatis, qua vna incredibili, \& celeritate, z certitudine Oceanum vndevis quouis enauiant noftri, veteribus.cócedere poflum, cùm rei laximæ, \& praclariffim $x$ ne tenuia quidem veigia in antiquitate reperiat. Etenim vfum ma-

C s gnetis

2. Para. 8. Reg 9. 


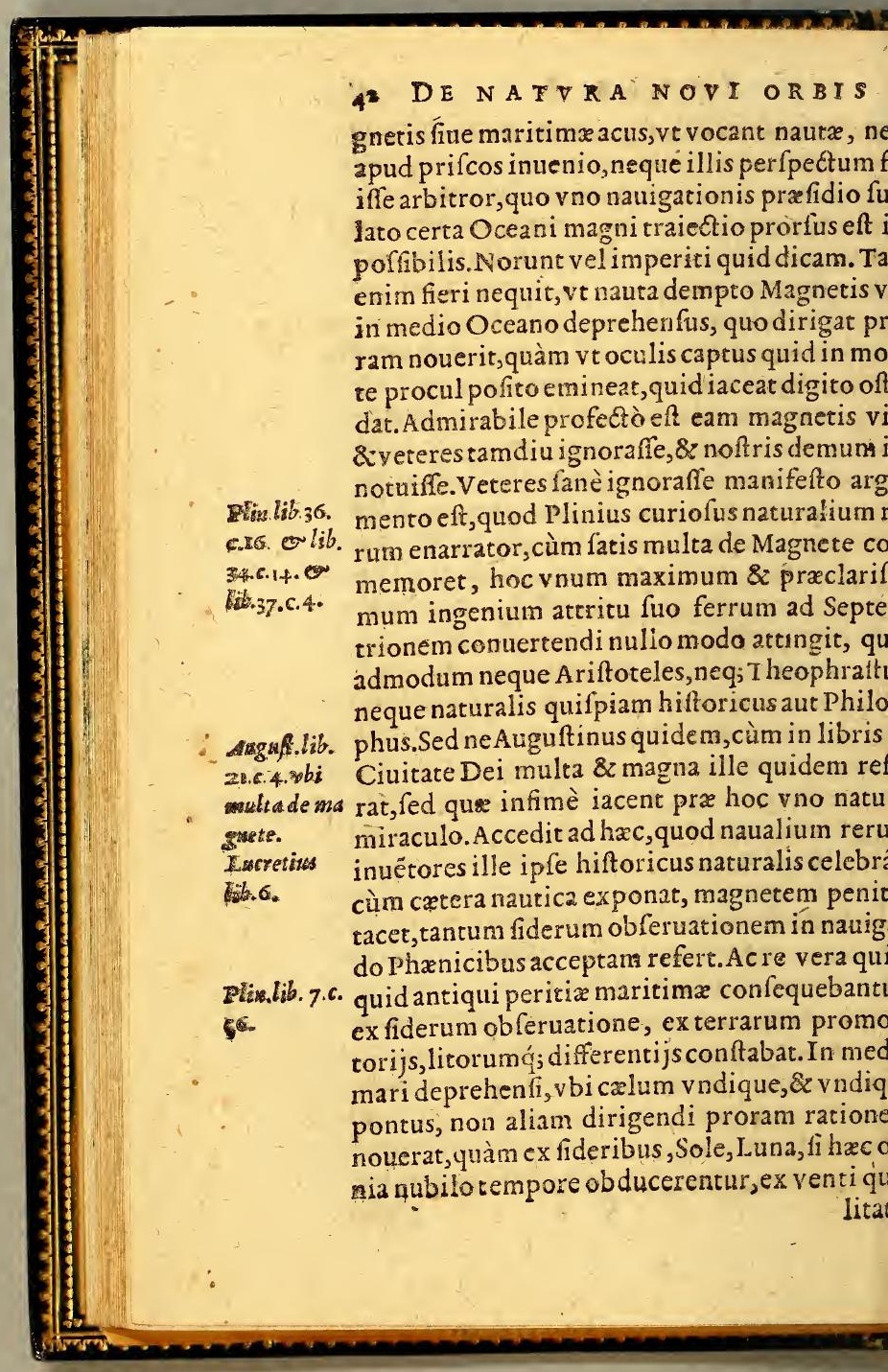


te, ex itineris peracti coniecturis, denique ex enij dexteritate \& deftinatione, ficut etiam d nos Indi nauigant plurima maris fpatia ea uftria conficientes. Quid quod Taprobanes ula, quam Samatram hoc tempore appellari ant, nautas nouam in nauigando induftriam ui Plinius fcribit.Septentrio, inquit, non cer- Plin.lib.đ. ur, fed volucres fecum vehunt emittentes $\mathfrak{x}_{-}-22$. $s$, meatumq́ue earum terras petentium comitur. Quod fi Magnetis vfus illis innotuiffet, il auium volatu ad terræ firum cognoficendü us effet. Deniq; velillud folum abundè indinautis veteribus eam magnetis vim penitus fe ignotam,quod nautici inftrumenti, quod trio vocabulo dicimus,[Aguja de marear,] ; a pud Latinos, neq; apud Græcos, neq; veró d Hebræos nomen extet, quod fi effet nota, nimè nomine res tam præclara caruiffet. Itaq; igationis Magiftri, ficut modò folùm fupra ppim fedent, affiduè fpectantes nauticum inumentum, vt tenenti clauum viam edicant, ita m etiam fedebant ad proram, ve obiectas termarifó; notas circunfpicerent, quamobrem ad Græcos Proretæ appellartur.

De magnetis admirabili efficacia o v v u ad naugandum veteribus ignoto. C A P. X V I I.

R G O Magneti accepta referenda eft Indica nauigatio tam cer ta, tam breuis, vt compluhodie homines viderimus, qui Vlyipone oam, Hifpali, Mexicum aut Panamá, \& in hoc fo Aufrali Oceano ad Sinas v fque \& fretú Mallanicurn nauigent,idǵj facilè \& crebrò. Nam qui 


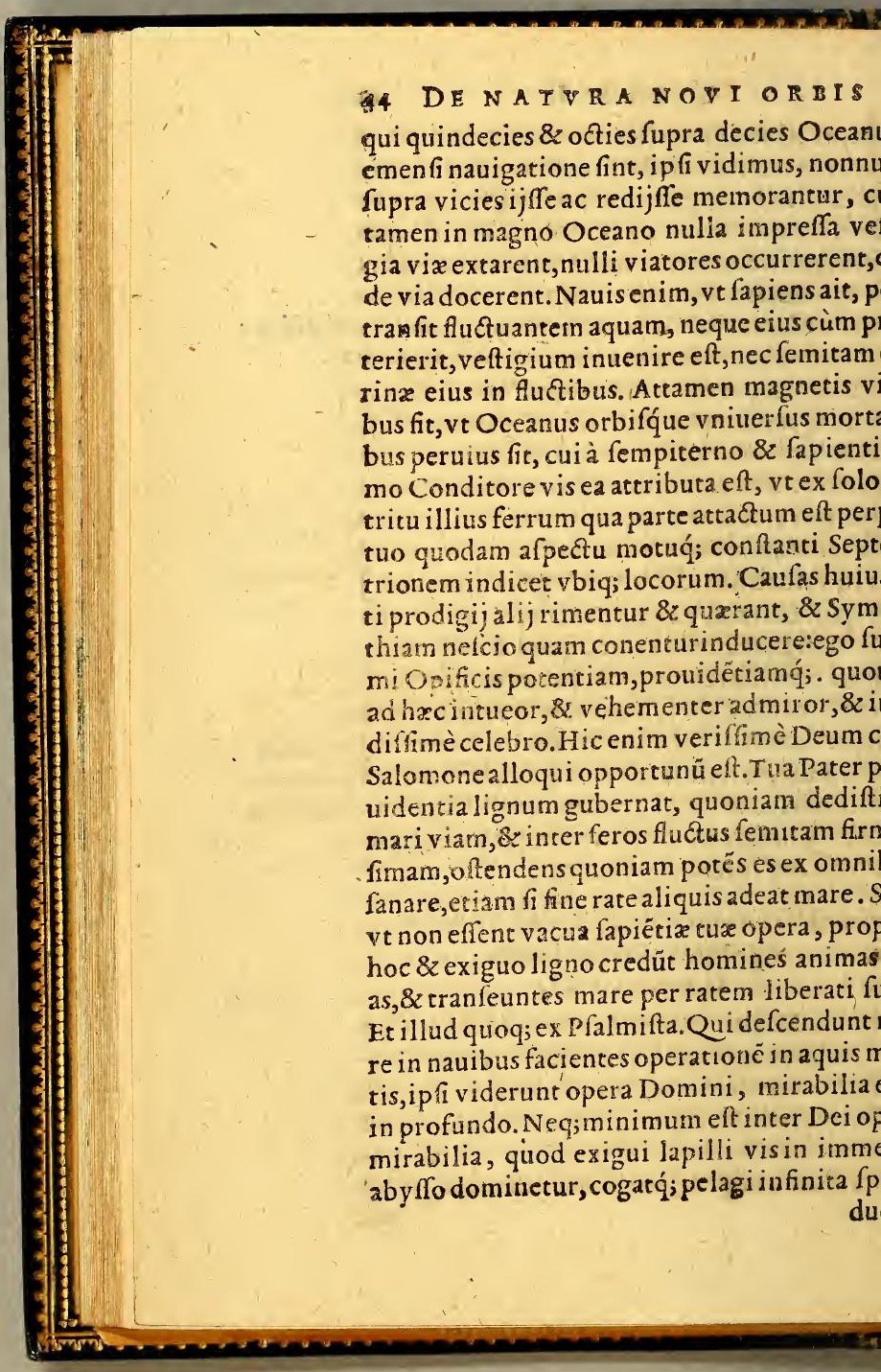


fui fuo promptiffimècedere. Hoc quia fxpè \& facillimè fit, neq; homines iam mirantur, q; verò curant, ipfać; liberalitas apud impruates quo effufior eft, minoris ducitur. At nos cet $\&$ fapientiam Dei venerari, \& pro ingeneneficio gratias agere. Cùm enim gentes Inrum tot faculis anteà ignotas adiri, atque freétari à noftris, vt jpfæ quog; falutem, qua eft Chrifto Iefu adipifcerentur, diuino confilio cretum effet,prof pectum eriä diuinitus eft, vt n longi \& inufitati itineris cux certus homious præberetur.Itaq; Magnetem ducem $\& z \mathrm{ma}$ trum accepimus. Quo autem tempore primú is nauticus vfus innctuerit, percrebueritq́ué re vix poffumus.Equidem non fuifle antiquü Lib.r de It niecturis idoneis teneo, non folum ex ijs qua lia illuftr. periore capice retuli, fed quod in Horof copis reg. 13. oq; veterum nullam magnetis mentionem le. Plin.lib.2.e. , cuius tamen eft pracipua immobilibus horo 72076.00 gijs ratio. Scribunt illuftres biftorici Lufitani ama primo Orientalis Indix inueftigatore oforius de uentos efie barbaros nautas citra Promontoum bonz fpei, qui Magnetis vfum edocti ma- lis. a illa circumquaq; percurrerent. Sed vide ijs titia ez parta,non tradunt. Quinetiam nónuleorum Icriptores veteribusignotam rem eam noftra opinioneconfirmant. Addā aliud eiufem Magnetis maius mea fententia miraculum, aod incredibile haberetur, nifi\& à peritiffimis ccepiffemus, \&zexplorata experientia confirIaffemus.Spectat fanè Acus maritima, hoc eft, erri illa acies magnete attacta, femperó; atque biq; gentium Arcticum polum, verùm non biģ; æquè directo.Sunt climata qua dam, vbi re cta 


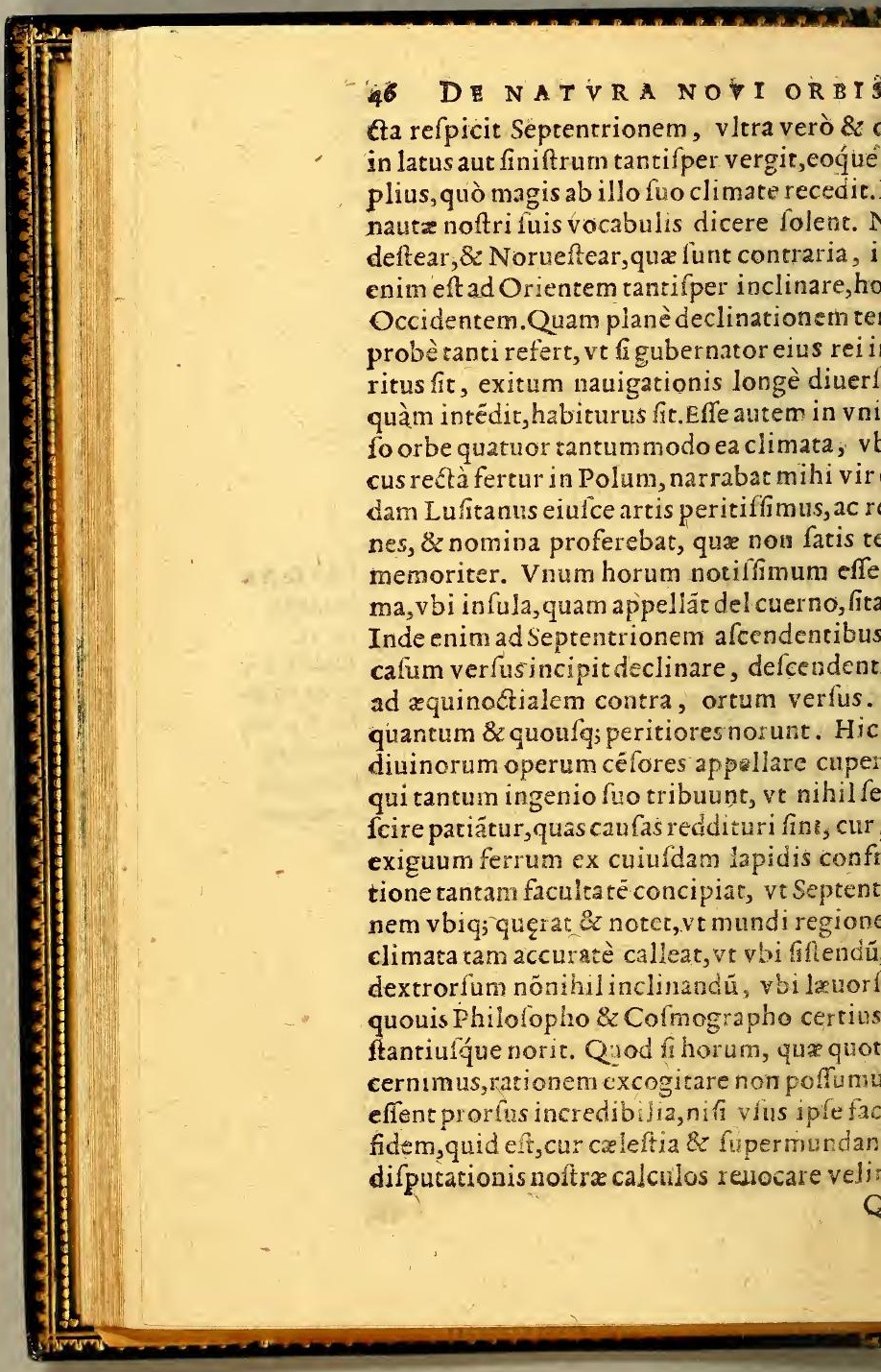


in potius, ve prxclarè Gregorius Theologus erit, Fidei concedat ratio, qua fuis etiam teris angufta imbecillifój;eft. Verùm hactenus lifperad philofophandum divertife fit fatis: nftitutum reuertamur, Magnetif́,; vrum nau Im antiquis ignotum probabiliter demöfrateneamus, ex quo fit confequens, vt nauigaOceani non fuerit olim ad hunc nouum orcerto confilio \& ratione fufcepta.

Refonfio ad eos, qui volunt olim narigatumoceanum, vt boctempore nawigatur.

C A P. XVIII.

A M quod de Salomonis claffe obijciebamus, parum me mouet, neq; enim facræ litelocent integrum triennium in ea nauigatioexpleri folitum, fed femel pertres annos, hoe quouis rriennio claffem mitti folitam. Quod iam trienvalem eam nauigationem fuife ponus, potuit certè, quod eft magis confentaneú Atimare, ad Indiam Orientalem fecundùm va sportus \& regiones terrarum nauigare, ficue dò totus hic Oceanus Auftrinus à Chyle vfq; Nouam Hifpaniä ferè nauigatur, quòd genus igationis, vt certius eft, quoniam terram ferề profpectu habet, ita longè prolixius, quod cour multo circuitu ferri, \&z moras fxpè trahere portubus. Equidem nauigationé altiff́mo 0 . no commiflam, neq; apud veteres lego, neque illisaliter Oceanum nauigatum puto, quàm oftris hodie Mediterraneum. Quocirca docti ifentiunt veteres fine rèmis nufquam nauire folitos, quod oras ferè terrarum legerent:id od diuina fcriptura infinuat in longa illa à 


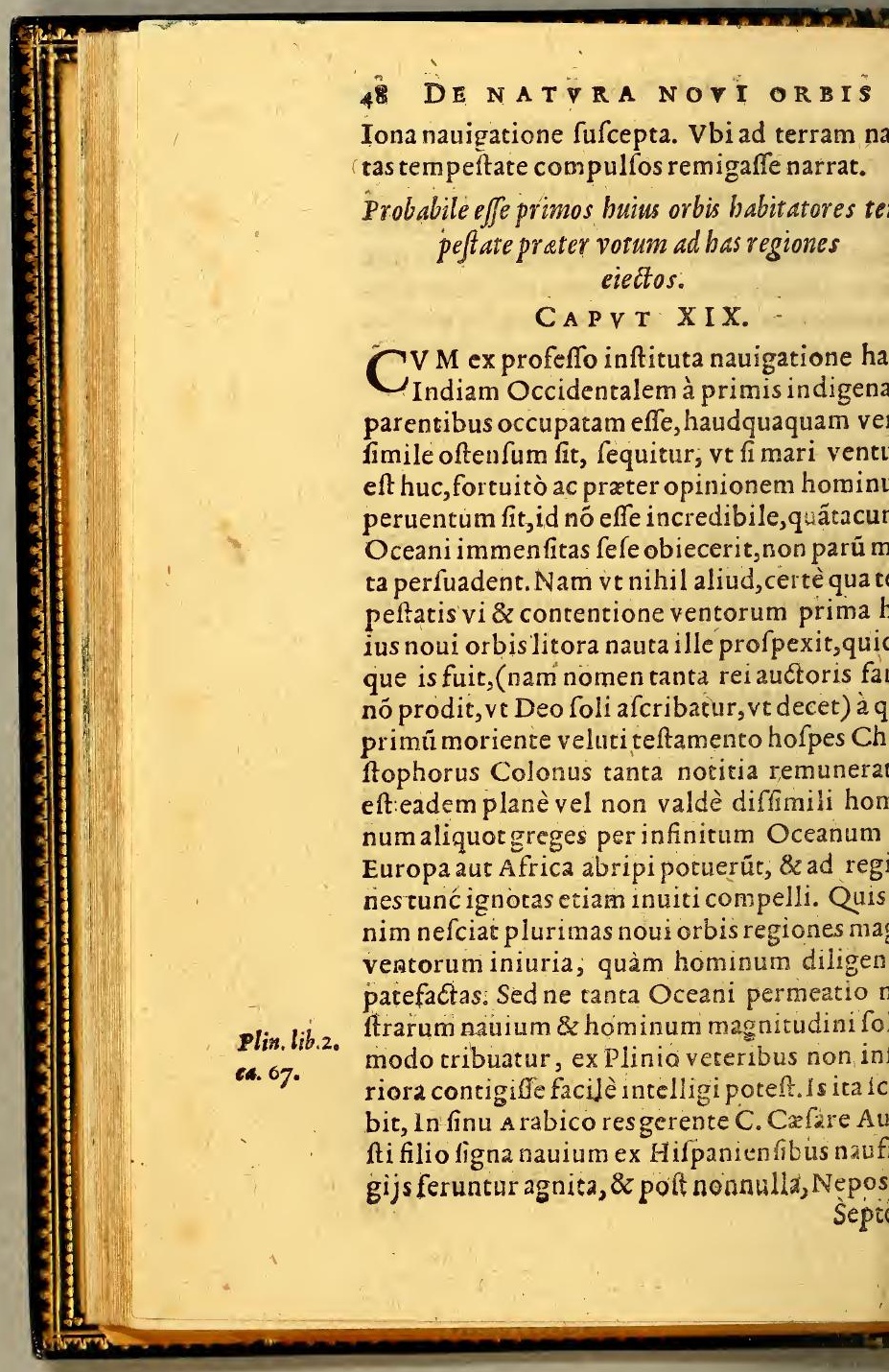




\section{I $\ddot{B}$ E R}

aptentrionali circuitu tradit, Q.Metello Celeri, Afranij in confulatu Collegre, fed tum Gallix roconfuli; Indos à rege Sueuorum dono datos; ui ex India commercijgratia nauigantes in Ger laniam effent tempeftatibus abrepti. Profectò vera Plinius narrát,non amplius modò à Lufinis pernauigatur, quàm illo vtroq; naufragio Indorum vfqg; ad Germaniam, \& Hifpanienfiú que ad finum Arabicum percurfum eft. Idem plin.lib. $6_{0}$ alio lib. fcribit, Annij Plocanij, qui maris ru- 6a.22, ri vectigalà fifco redemerat, libertus circa Araiam nauigans Aquilonibus raptus prater Caraniam decimo quinto die Hippuros portum aprobanes inuectus eft \& c. Referunt quoq; naem Africanam ex Mauritanico Oceano aquiloe raptam olim vfq; ad noui orbis confpectú pereniffe.Quantum enim fruiant in Oceano venti; uamq́ue pertinaces fint, vt plurimis diebus ne inimum quidem de vi remittant, omnes nouius. Ego certè intra decimum quintum diem noi orbis Infulas primas alpexi, afpecturus fine ubitatione longè citius, $f$ plena vela Euro Auilonibus panderentur. A deò perpetuò \&zani10 fo flatu vfifumus. Valde igitur mihi probaile apparet olim homines Oceanum nauiganes prater fententiam vi ventorum exillo ad unc orbem efle compulfos. Atque celobris fana eft in hacPeruenfiregione, vbi nunc Manta \& Porcus vetus oppidum perexiguum ab Hifpais ædificatum eft, reperiri ofla hominum gigan: rantæ magnitudinis, vt duplo aut certè femiuplo corpora proceriora teftentur, quàm fint có nunia hac Indorum. Illos autem gigantes olim riari ad hxc litora efle delatos, ibicum indigen is 


\section{DE N A T R R NOVI OR BI}

bella geffife, \& qurdé extruxiffe immania ope ra,cuius generis profundus puteus lapidibus im menfis adificatus hodie vifitur, ve ferut. Tanden homines illos fauos \& 2 portentolos, quod nefari \& impuriffma libidine abuterentur calicus eff confumptos. Ad infulas quoq; proculadmodun pofitas, pluteis corijfq́; inflatis pro nauigijs ve ctos veteres indigenas ijfife acredijfe, qui Icam \& qui Aricam incolunt pro certo narrare ferun tur.Itaq; ante Hifpanos huc appulfos Oceanun hunc Aufralem nauigatum quędam indicia pro dunt. Quamobrem exifimare facilè poffumus naufragio aliquo aut Oceani iniuria \& Aquilon contentione olim hunc orbem effe inhabitatum ficut nunctandem proditus eft. Nam \& illud mi rabile ent, in maximis clariffimifque nature mu neribus, quod cafu atque fortuito reperta fint, $n$ induftriz hominum conquifita.Plerafque herba rum vires hominum vitz falutares \& lapidum, 8 firpium vfum $\&$ fofflium, quz vocant, minera lia gëmas quoq; \& auri venas, proprietates quoc magnetis, fuccini,adamantis, 82 caterorum tali cafus potius oftendit mertalibus, quàm vlla ar autinduftria,vt in ijs non hominum ingenium fed Dei prouidentia commendetur. Quæ enin fortuitò apud nos fieri videntur, ea confilio dius no prorfus eueniunt.

Longè probabilius effe primos buius noui orbis babitacores terreftri itinere buc peruenife. C A P. XX.

Gitur vi tempeftatis eiectos primos homine 1 has regiones incolere cæpiffe probabile eft.Ve rùm illud me non bene habet ita opinãtem, quo vi de 


\section{I B E R $\mathrm{I}$.}

temus viros $\&$ foeminas, vade propagaretur genus hominum, mari delatos, belluas profeciò itque animantia multa \& magna $\&$ noua, qux nurit hic orbis, nô video quemadmodum naui imonere atque huc defcrre poffimus. Q od fi proter fcripturarum fanctarum feruádam fidem onnes huius orbis accolas ex altero huc veniffe có itcri cogimur, ne homir es vllos ex alio quàr ex rimo Adamo propagatos faciamus, profectò ealem diuina aucoritate tradente belluas omnes tque animantia terrena in magno mundi catalyfunc per vnam fancti Noëarcam côferuata, cæ era omnia fine vlla exceptione interijfe, oporebit nos iam etiā quarere horum animalium ex llis montis Araratreliquijs, vbi arca çóquieuit; ropagationem. Itaque ficuthominibus, ita betijs debemus ex veterio orbe in nouum hunc viă uærere.D.quidem Auguftin hanc quaftio.inci- Aug lib. 16: lens, quomodo quadam infula lupos habeant \& de ciu.c. s $^{\circ}$ antheras cæteraf'q́; feras, 'quæ non pertinent ad rocurationem fudiumó; hominum (nam de eephantis, equis, bobus, canibus reliquifque vitz umanx vilibus facilè eft intelligere induftria 1ominum nauibus efle delatas, vti hodie quoque ieri cernimus longiffma naugatione ab Oriene in Europam, atq̧; ab Europa in hanc Americā) llas igitur beftias, quz nulli vfui funt, ac potius serniciem afferunt, quales lupi funt, quomodo Infula habeant, fi vaiuerfum orbem inundauit; itq; deleuit dıluuium, quærés vir ille doêt iffrmus sx ijs anguftijs ita conatur euadere, vt eas feras vel natando perueniffe ad infulas, vel fudio venationis ab hominibus effe delatas, vel diuina procurations ex ip̧a terra éffe generatas, vt olim.

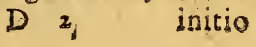




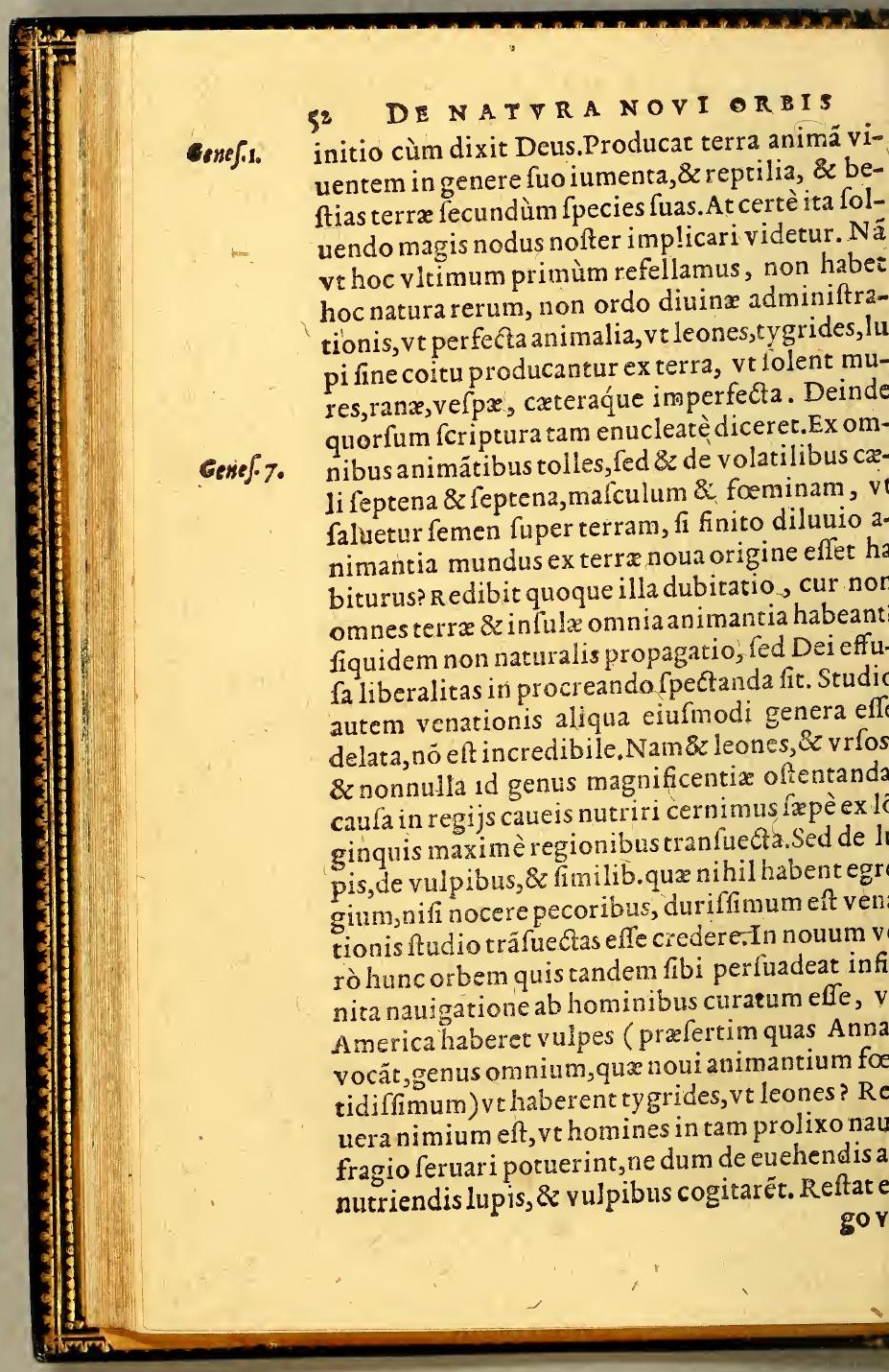




\section{I E R I.}

go vt hx beftix natando peruenerint. Ac planè de nonnullis infulis,qux vel ab alijs Infulis, vel à có tinente nón longiffimè abfunt, vt credibile fit, fa cit oculata experientia, qua feimus integros dies 8 noctes eiufmodi feras aliqua neceffitate perurgente natare, atq; enatare poftremò.Verùm Ocea nus hic nofter tales natatores rideret, cú volucres quoq; deficiant alæ in immenfa abyffo. Nã ad mil. le $\&$ quingáta ftadia volare certú eft, cùm in profundiffmo Oceano ad hanc Indiam nauigantes turtures ex Afric $x$ litoribus in puppi fedentes $f \varepsilon$ pè notauerimus.Sed volando aut natando fuperari Oceanus totus certè nequit. Quid ergo faciédum?quam viam aperimusad hanc noftram Ame ricam volucribus $\&$ feris? Non leuis mihi hinc coniectura fit, vt hunc nouum orbem non effe penitus, ab illo altero diuifum arbitrer, quin potius aliqua in parte vel hærere, vel certè nố longè difiungi iamdiu opinor.Neque verò hactenus certo documento patuit cótrarium. Nam ad Polum Ar cticum non eft omnis longitudo fatis explorata, multió; putant fupra Floridam latiffimam effe terram Septentrionalế,qux ad Germanicum,aut Scythicum mare pertingat. Quidã etiam nauem ea regione delatam teftem proferunt,aiuntq́; $\mathrm{Ba}$ callaos vfquead Europx extrema porrigi. Vltra promontorium quoq; Mendocinum non eft fatis cognita terræ amplitudo, fed effe oppidò ingenté omneś referunt. Iam verò ex noftro Auftrali vertice quoufq;procurrat continens vltra Patagones pofita, nemo hactenus exploranit. Terminum nul lum oculis occurriffe Caruajalis Epifcopi Placen tini nauis retulit, qux fupra Magallanicum fretú aliquot millia pernauigauit. Nihil ergo neq; ra-

D 3 tionis 


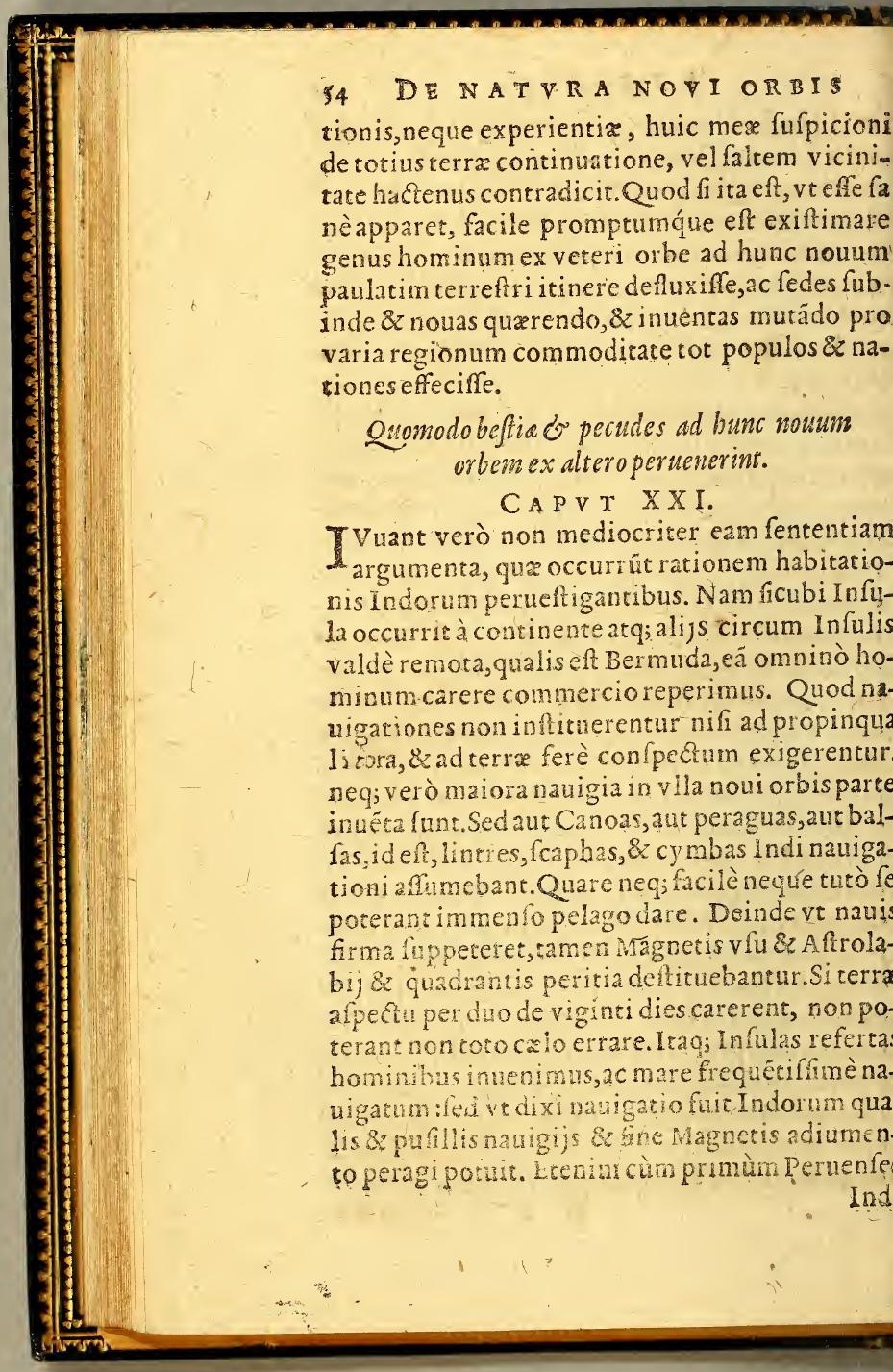


ndi Tumben accolx, noftras naues Hifpanienfes elis expanfis intuiti funt, rei nouitate territi, uod tam magnam molem nauem effe nullo moo cogitarent, feruntur ftatuiffe inter fe, fcopuos effe aut rupes mari euectas, quodq́; mouerenur neq; mergerentur, attonitos diuftupuiffe, doec viros quofdam barbatos per nauim difcurrées notarunt, eofq́ue effe aliquos creleftes Deos aritrati funt. Adeò maiorum nauiū v fus Indis inuditus erat. Maximè verò facit fidem, quod belux illæ, quas minimè eft probabile homines naibus impofitas aduexiffe, reperiuntur quidé per otam continentem, in Infulis verò à continente juatridui itinere diffitis nequaquam reperiútur. Id ego, quod magnum huic opinioni đ’ contiuatione vtriufq; orbis argumentum putarem, diligenter inquifiui. Sunt in hac noftra A merica iufmodi fera non paucx:funt leones, tametif, \& magnitudine $\&$ audacia \& colore ipfo haud ita chluo Africanis illis longè inferiores:funt tygres æuiffimæ ac plurimæ, fed in genus Indorú, quod mirum eft, prorfus truces: Hifpanis non ita infen $x$ :füt vrfi rariores, funt Apri, vulpes quoq; innumerabiles. Hęc genera \& his fimilia fi apud $\mathrm{Cu}$ bam Infulam, aut Hifpanicam, aú Iamaicam, aut Margaritam, aut Dominicá quaras, ne vnum quidem inuenias. Adde quod vtilium quog; animantium gregibus olim vacux erät, nunc poft $\mathrm{Hi}$ if $\mathrm{pa}-$ nos habitatores, boum, equorum, canum, fuú innumerabiles greges alunt, $\mathrm{v} f \mathrm{q} ;$ adeò $v t$ vaccarum armenta nullos certos dominos habeant, fed more venationis ab indigenis capiantur fine difcrimine, tantùm ve corijs detråtis \& ficcatis merca turam faciant. Canum verò breuiffimo tempore

D 4 eainfi- 


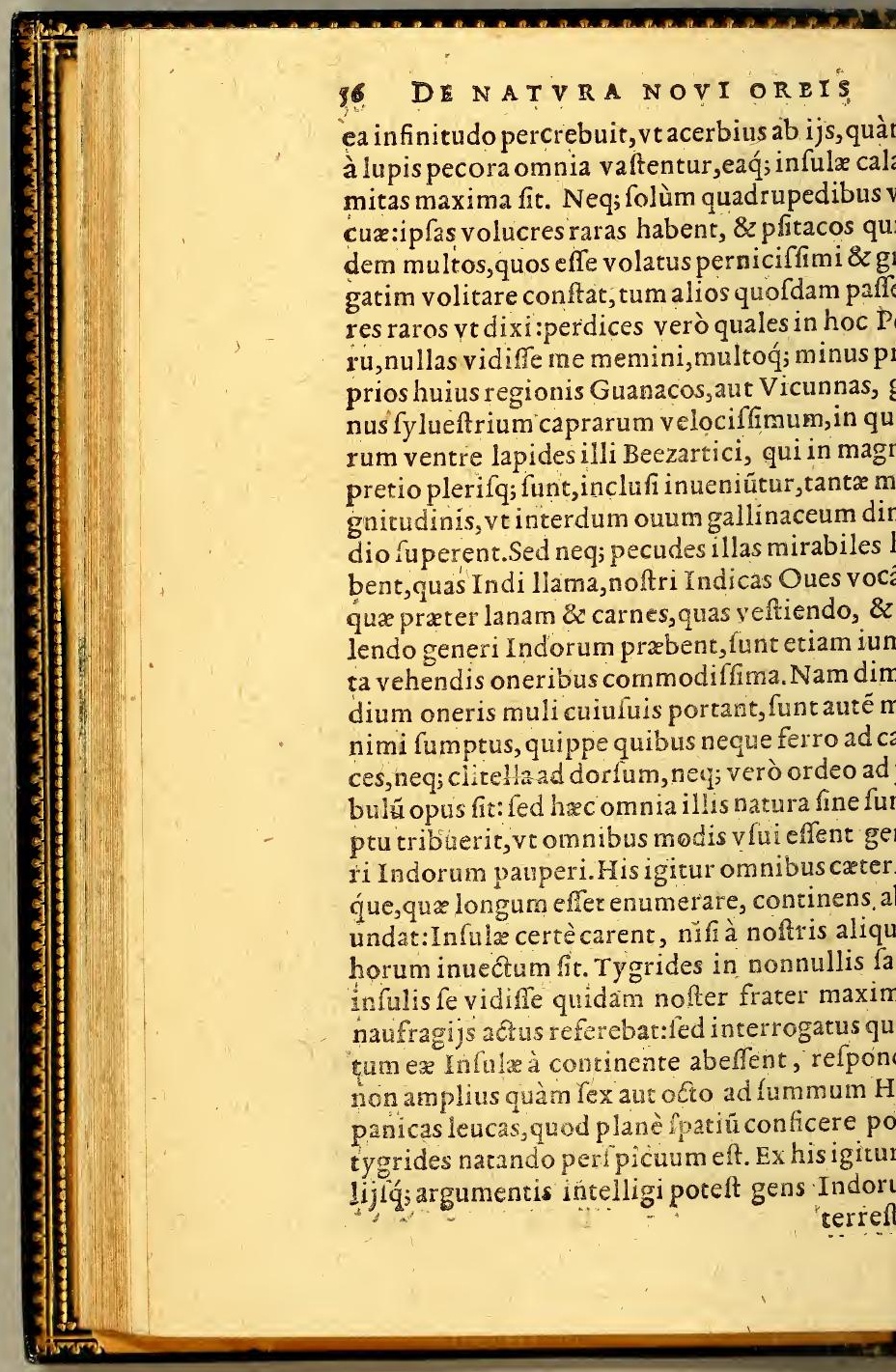




\section{I B ER I.}

reftri maximè itinere, aut nauigatione vicif$\mathrm{n}$ non difficili aut longa, ad hunc altertum orbé rmeaffe, quod reliquo orbi continens fit terra c, hoc eft aut aliquibus locis hærens, aut certè in valdè difúneta.

\section{Quod nonvenerit genus Indorum per Atlan-} tidem, vt quidam opinantur.

$$
\text { CA P. XXII. }
$$

JO N defunt autem, qui iuxta Platonis fenten tiam iam fupra memoratam putent has gen sveniffe ex Europa, aut Africa per Atlantidẹ lam tantoperè decantata $m$, deinde in alias at $q_{\text {s. }}$ ias infulas $\mathrm{vfq}$; ad magnam continenté, in qua inc fumus. Nam horum omnium Critias in Tixo mentionem facit. Si enim A tlantis illa toA fia, \& Libya fimul maior erat, vt ille vult non Cedubium, quin totum pene Atlanticú OceaIm vfq; ad Infulas noui orbis occupârit.Ingenautem diluuio Atlantidem fubuerfam olim elagus illud cæno \& fcopulis innauigabile relidiffe, tale enim fuiffe fua atate Plato refert.Mox erò tempore procedếte illius magnę Infulę ruias penitus confediffe, ac nauigabilem pontum ræbuiffe. Hæc homines ingeniofi feriò differút, uæ vel mediocriter animaduerfa nugæ merę derehenduntur, vt magis Ouidianas transformaones, quàm Philofophicam aliquam narraconem habere videantur. Ac plerique fanè $\mathrm{Pla}-$ onis interpretes omniailla à Critia narrata tam nufitata tam mirabilia de Atlantidis illius oriine, magnitudine, felicitate, deq́; bello ab Atlan icis cum Europxis gefto, cæteraq́; omnia veram fe hiftoriam volunt, quod Critias præfatus fit in.

D 5 Timæo, 


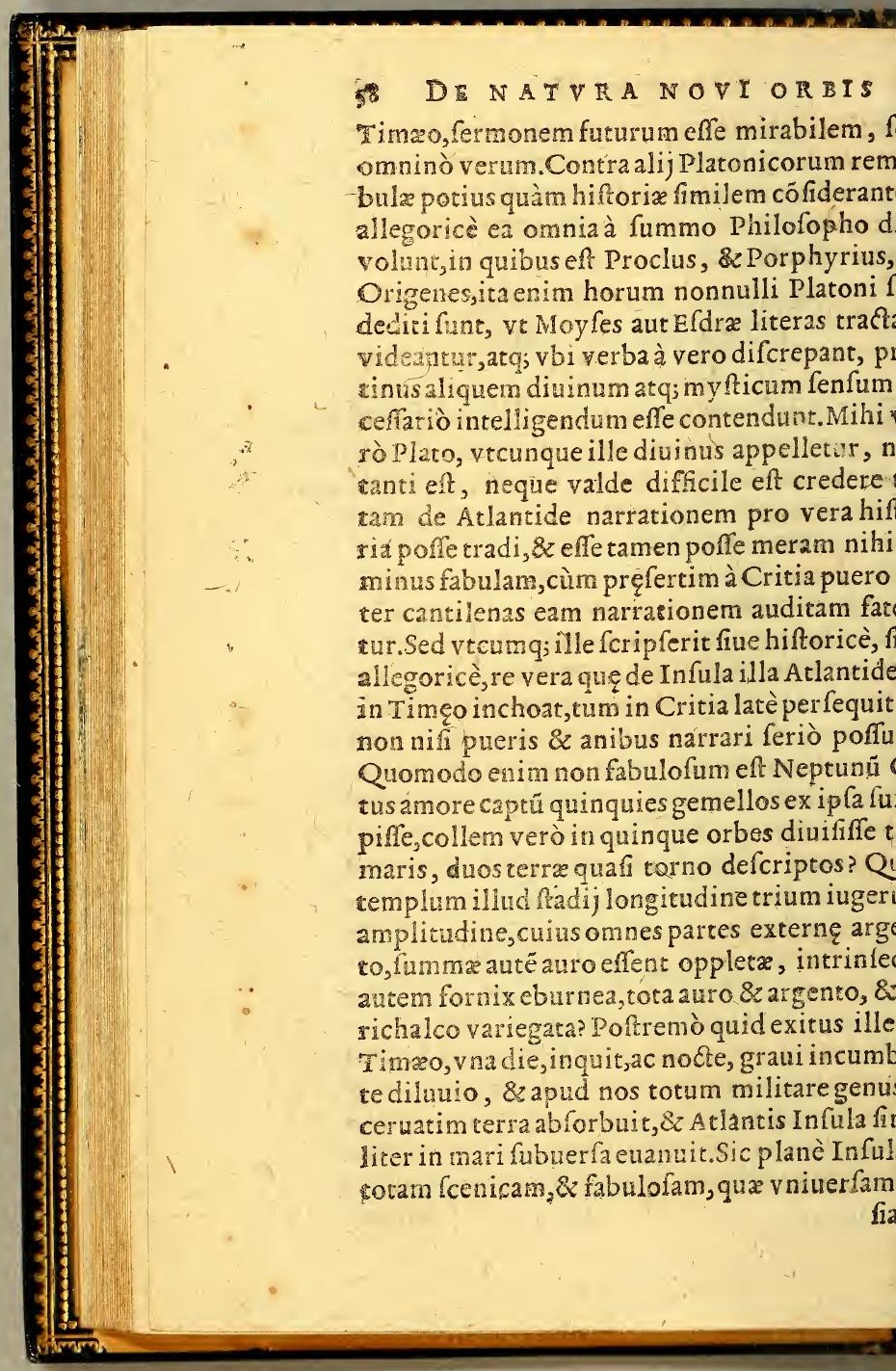


$n$, fimul $\& *$ Africam amplitudine fuperabat, $v-$ nocte oportuit euanefcere. Ruinas aute m illiub vndis ab ijs tantummodocerni, qui eo aclere nullo modo poffunt. Adiungit enim fcitè. apropter etiam nunc innauigabile \& intentan manet illud pelagus luto paulatim impedie, quod Infula fubmerfa inuexit. At ego liben quærerem, quodnam pelagus tantam terræ lem Afra, \& Africa maiorem, \& qux vfque ad ium hunc orbem pertingeret, abforbere parit, ita vt nulla extent veftigia, vt ne bolidis dem iactu nautæ in infinitum hodie fundum eniant aliquem?Sed imprudenter ea pergo relere, qua aut ridiculè fcripta funt, aut certè ne il Platonis grauitatem vereamur, per pictun \& parabolam ad ciuitatis, \& felicitatem \& tium oftendendum philofophicè introducta t. Nam quod validum argumêtum quidam pu t fuiffe Atlantidem Infulam, quod mare illud die quoq; Atlanticum nominetur, puerile eft. nim \& montem Atlantem in extrema Mauriia effe fcimus, ex quo Atlanticum Oceanun di im Plinius vult, \& idem auctor eft è regione set li.6.c.3! intis fitam effe Ațantidem infulam, fed par$m$ \& ignobilem.

ouod fallo multi Indos ex Indaorum genere. defcendere affirmant.

\section{CA P. XXIII.}

L I A ergo via Indis noftris, quàmilla Atlan tidis ad nouum orbem quarenda eft. Hanc nulli apud Efdram effe fulpicantur. In cuins roquarto ita feriptum legimus. Et guoniam diffi eum colligentem ad le aliam multitudi- 


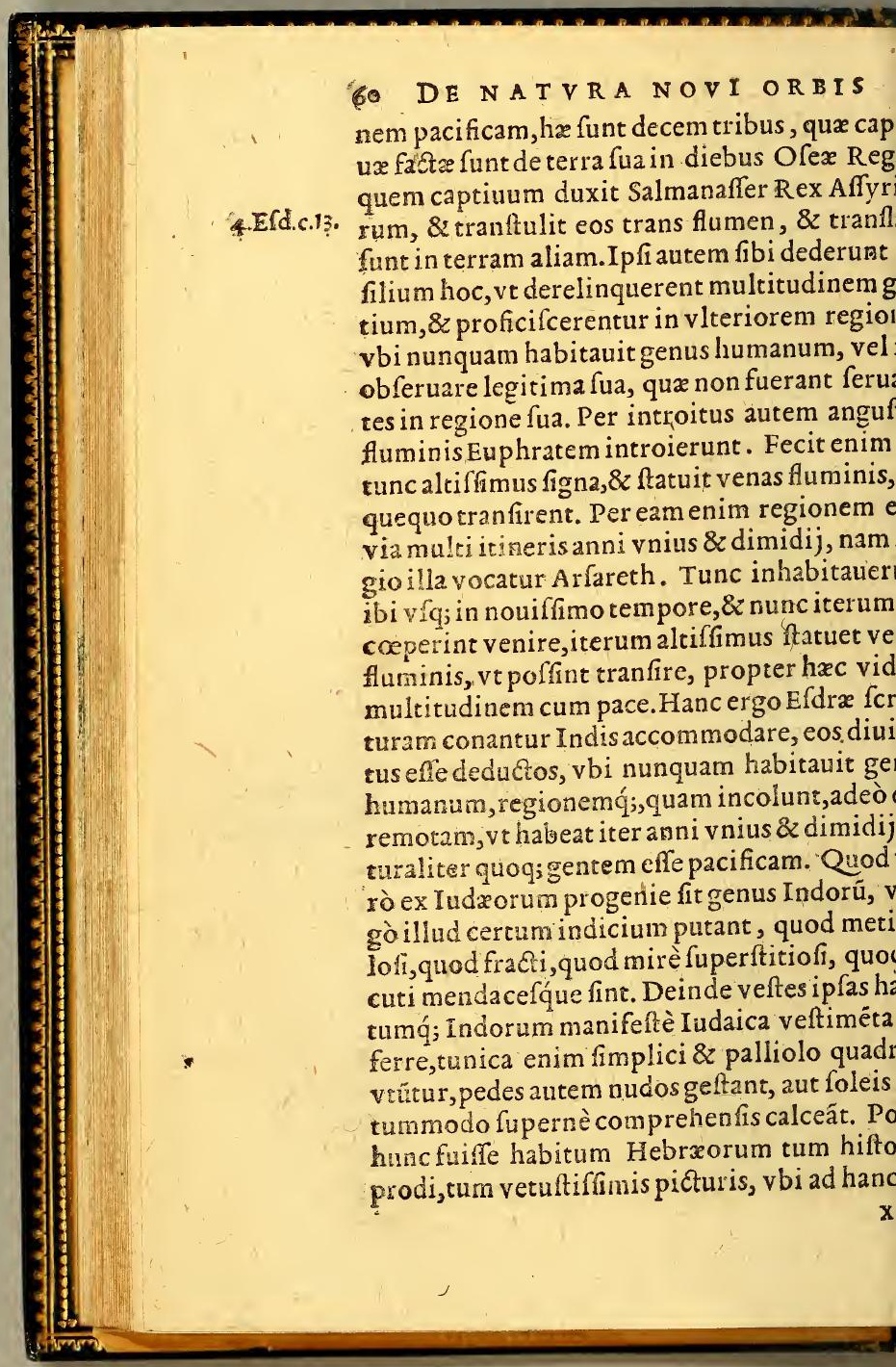


1. L I B E R I. 6 ? è fpeciem veftiri exprimuntur. Atq; hæc duo. is genera, quibus folis Indi vruntur, Sampfoolim depópofciffe, tunicä \& \{y ndoné, id eft, Iudic.1\%t. ulgus noftrū appellat [camiferay mants.] ùm hæc vniuerfa tufpicionis func leuiffima, entó́; contra fe quàm pro fe \& plura \& maioJebrxos literis vfos noumus: in natione Inam nullæ literæ: illi opibus fudebant, apud mirus omnium contemptus: Hebrei fi circísfe non vider ët, Hebrxos e\$c aut haberi poregabăt, apud noftros Indos praputia prorfus gra, neq, ve Aethiopes, aut Orientales eiufdi fuperftitionem vnquam nouerunt. Quale ò eft; vt cùm Hebręi tantoperè \&z genus \& an. itacem iactarët fuam, \& in cateris orbis terim partibus hodie quoq; fudiosè conferuent, olo nouo orbe, illis \& genus, \& ceremonize, \& ffias, \& Iudaifmus denique omnis exciderit? od verò meticulofi fint, \& fuperntitiofi, \& acu $x$ fallaces, primùm neque omnes barbari funt fmodi, fed plurimæ gentes ipforum ab ijs manè abhorrent, funt enim nationes Indorum au iffimæ, funt inertiffmę, fuperftitioni verò ois gentilitas femper dedita fuit. Veftium auté baratus ideo talis quia fimpliciffimus eft, nulla è arte aut induftria conftans, neque magis $\mathrm{He}$ eis quódam, quàm cæeteris mortalium v fitatus. inde hiftoria ex Efdra fumpta, fi quid curæ Acrypha merentur, potius oppugnat, quàm addat caufam fufceptam. Ideò enim multitudiné ntium fugiffe decem illæ tribus dicuntur, vt remonias fuas excolerent : hi verò idololatriæ inidediti funt . Euphratis autem aperta oftia derint quomodo ad hunc nouum orbem perdu cere 


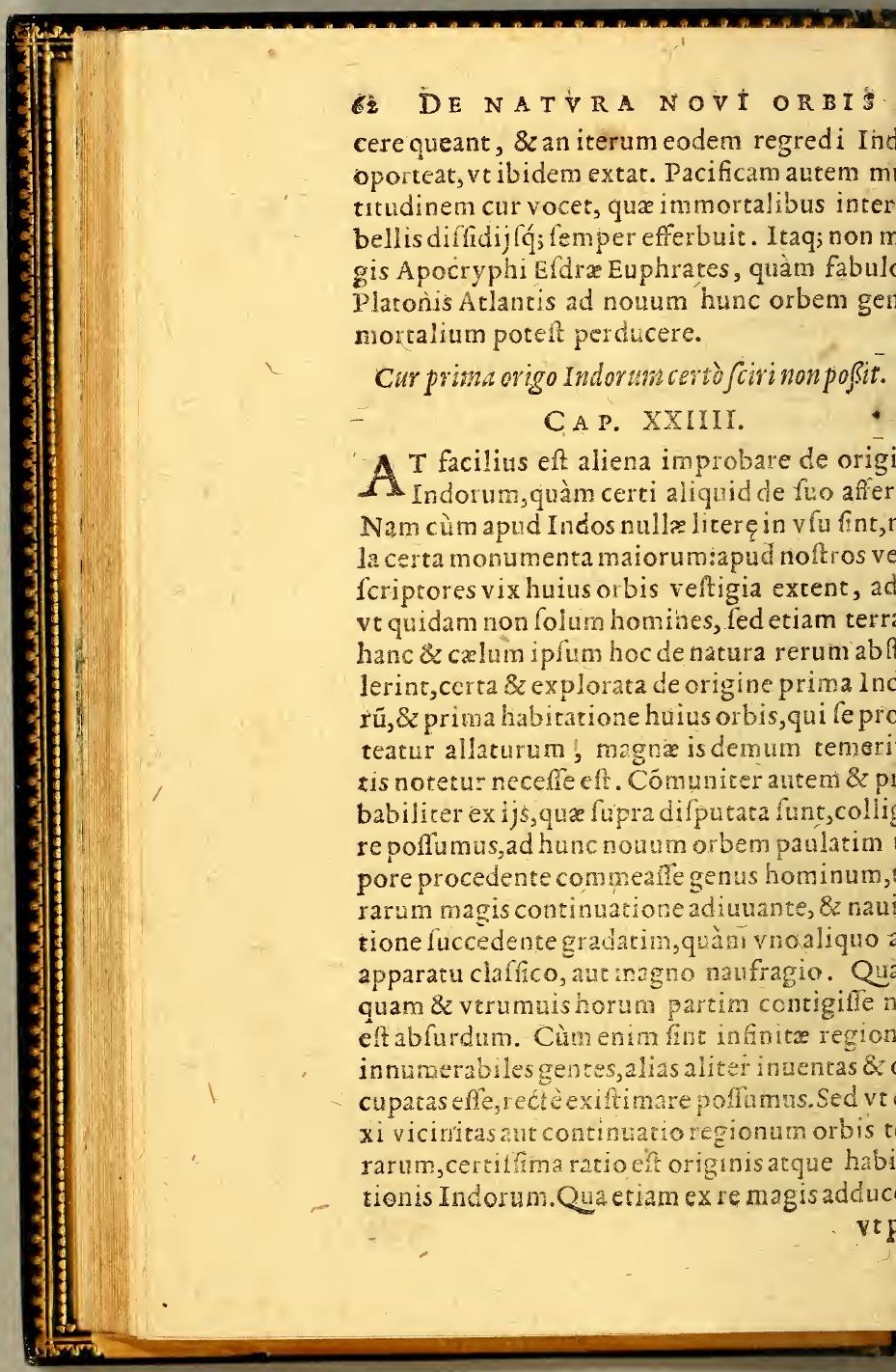




\section{I BER I.}

outem hunc nouum or bem occidentalem non It is abhinc annorum millibus habitacum, ma que ab hominibus fylueftribus \& 2 palantibus, In ab aliqua republica obitum, cùm errore po aut patrix angufijs nouas fedes paulatim ha. re copiffent, at tue his affueti nibil nifi nacuslucis cuctum, eumćue obfcuratum, ac pafortaffis gentilitix aliquas confuetudines nerent. Neque incredibile eft etiam fix excultbene morata republica profecti effent alindo, tamen ipfa diuturnitate $8 z$ defuetudine nana, pene omnia obliuione deleffe, cum taefe in ipfa Hifpania \& Italia hominum grepreter os \& figuram hominis habentes præa nihil, notius fit, quàm ve tefibus egear. Ita ctum eft, vt iqmmenfis quidam barbarifmus deret.

Quid de origine fua Indi rradan.

\section{A . XXV.}

V I D autem de primis exordijs gentis fure, ipfi Indi referant, nó eft alicuius pretij norùm fomnia potius fua, quàm hiforiam aliim narrare videantur.Ac magni quidem diluplurima in his regionibus mentio eft $\&$ fama ebris.Sed verum commune illud totius orbis, ddiuina literæ prædicant, an proprium alid harum regionum $\&$ gentium haberi debenon fatis conftat. Certè ingentis cuiufdam exdationis non obfcura monumenta à peritis notur. Ego magis in eorum fententiam eo, qui iquiffimi illius Noetici apud hos barbaros lla veftigia effe confirmant, peculiare aliod diluuium, quale Plato narxat, \& Poeta Deus
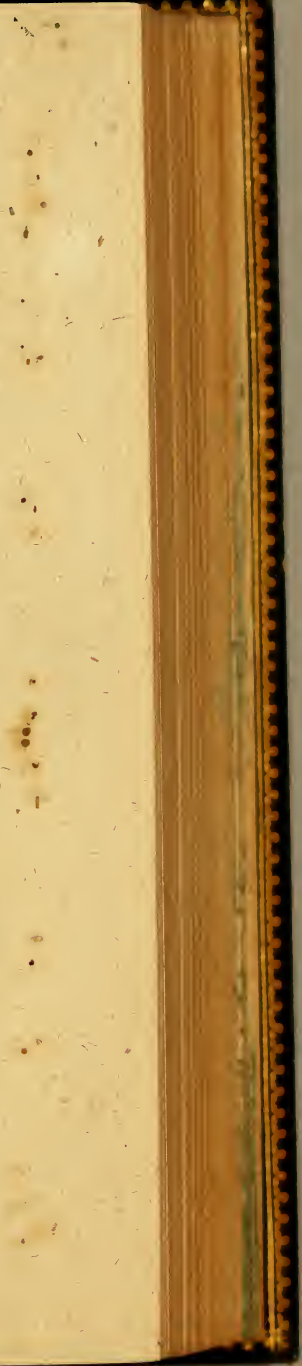


\section{DE NATVRA NOVI ORBIS}

Deucalionæum fabulantur, fuiffe non dubital Igitur illo magno diluuio hauftos effe omr mortales ifticonfentiunt. Quidam ex magno cu Inticaca emerfife Viracocham quédam, eu dem Tiaguanacum, vbi antiquorum $\& z$ admirab lium ædificiorum ruinæ vifuntur, fedem habu fe, inde ad Cuzquenfem regionem veniffe \& $\mathrm{p}$ pagaffe genus humanum. Namque in eodem la infulam oftendunt, vbi folem conditum efie $r$ gantur, eamq́ue ob caufam plurimo olim fa guine, non ouium modò, fed etiam hominum tatum effe perfpicuum eft. Alij ex fpecu quad: per feneftram fex aut nefcio quot homines p dijffe à fole videlicet factos, eofque generi me talium propagando operam dediffe, qua etiam re locum nomen acceptum retinere, hodieque caritambo vocari. Itaque $T a m b o s$ antiquiffim effe hominum vulgaris fententia eft. Ex ijs M: gocapaille, quem primurn fuæ gentis auctor gens Ingarum agnof cit, ab hoc dux familix ce bres Hanan Cuzquenfium, \& Brincuzquenfiu Feruntur Reges Ingæ, cùm cæteras huius or gentes debellarent, eam belli caufam potiffim pratexere foliti, quòd oporteretomnes morta ipfis fubdi,à quorum genere \& patria omnes pagati effent, \& quibus etiam vera religio di nitus innotuifet. Quid opus eft cætera hîc re tere, qua veritatis inania, vanitatis pleniff funt. Illud viri eruditi foriptis mandarunt, $c$ nem iftorum memoriam ad quadringencos $m$ mè annos porrigi, vltra id ętatis nihil aliud qu denfastenebras ignorationis occurrere. Ne mirandum eft fanè, cùm literarum imperitia niam hiftorix promereatur,pro quibus exact 


\section{I E R $\mathrm{T}$.}

Quipocamaiorú fupputatio admirationi maseffe debet, quod ad id vfq; æatatis tenax fit. Midiu inquirenti, an apud hofce barbaros notialiqua extaret, vnde huc commigrarent prii auctores ipforum, adeò nihil occurrit è re, ve tius fefe in hoc orbe natos 8 conditos ferè onentur, nifi fide Catholica reuocentur, ex vno nus mortalium omne fuxiffe.Tenêt verò conturis non mediocribus nobiles auctores, quä utiffimè hifce barbaris nullos fuiffe Reges, Aï.17. llam certam conftitutam Rempublicam, fed omifcuè turmatim habitaffe, vt modò Florivt Brafilienfes, vt Chiriguani, vt pleræq; gen Indorum, qui nullos habent certos Reges, provt belli pacifúe fortuna tulerit, fubitò temere duces creant, atq; eos mores probant, os libido furorque perfuaferit. Tempore veprocedente homines viribus \& induftria xitantes per tyrannidem copiffe dominari, olim Nemrot, paulatimq́ue crefcentes eam nftituiffe Remp.quam a pud Peruenles, \& Mecanos noftri inuenerunt, barbaram quoque fam, fed à cętera barbarie Indorum plurimum horrentem. Quare genus hoc hominum fylueftre ex barbaris, profugifque hominibus maximè propagatum ratio ipfa perfuadet.

E DE AER.17. 


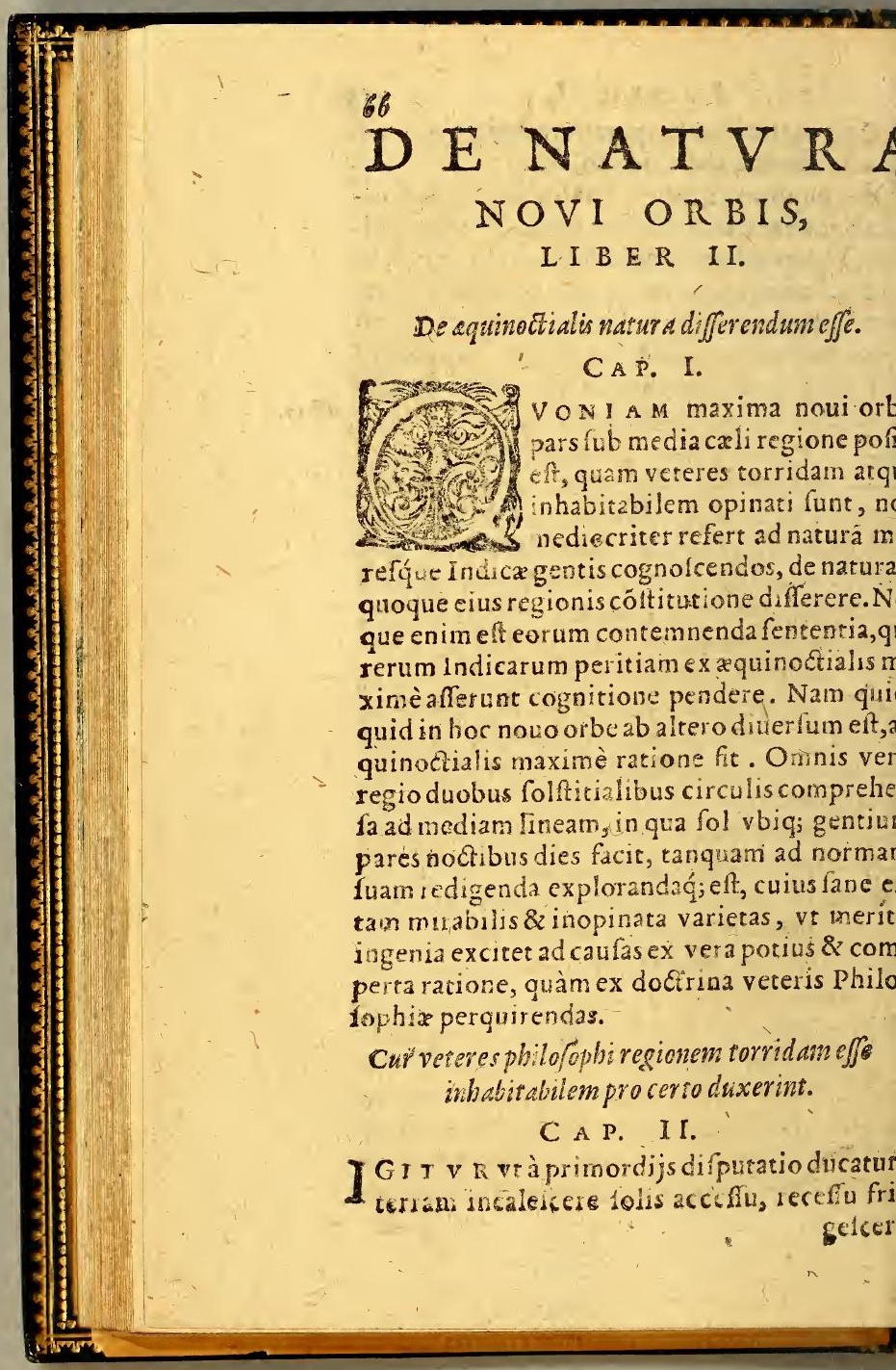


fcere cùm ister amnes conftat, tum verò hyeis atque $x$ ftatis, noctis ac diei variatione abun monftratur. Qu ì magis etiam fol appropintat, quò directius quiroq; radijs terram ferrt, eò hementius vrere, in i poodie meridies, in anxftas perfpicuum faciunt. Hinc fieri confiens neceffariò videtur, vt quanto regio qua = $s$ à folis conuerfionibus remotior $\mathrm{eft}$; tanto loque frigidior fit. Itaque qưx ad Septentrioes iacent, terras effe rigidilfinas experimur. am ordine eodem, qua Zodiaco viciniores $\mathrm{nt}$, calidiores. Ita AEthiopia Aropiamatg; Aican, Africa Bxticam, Bretca Cal ellam \& Agoniam, atque hæ Cantabriam \& Galliam ca ris copia certa prorfus ratione fuperant. Qua iam ratione feruata, cxter $x$ regiones, qua folis nuerfionibus expofita femper funt, atg; illius dijs rectius petuntur, reliquas fuperare xfus ruore neceffaria confecntione videntur. Adint nonnulliad folis radios etiam motionem li intra Tropicos velociff mam, qux propePo stardiffima fit. Quamobrem \& radijs folariis propinquiffmis ac direetifrmis; 8 cali con rfione conciatiffma regionem omnem $Z_{0}-$ aco fuppointam perpetuò ac vehementer exuHoc de calore \& frigore \& ienfus, \& ratio vintur confentienter docere. De ficcitate verò humore quid? Eadem profus. Nam ficcitatem lis acceffus videtur inducere, humorem rece?s. Itaque tempora ipfa cognata \& amica efe dentur, humida frigidis, calida ficcis. Nox vt igidior die, ita etiâ humidior; dies \& calidiors ficcior:hyems cùm plurimum fol abeft, \& fri diffima \& pluuiofiffima; æetas, cü ille propius:

$$
\text { E } 2 \text { ade } \ell_{\text {? }}
$$




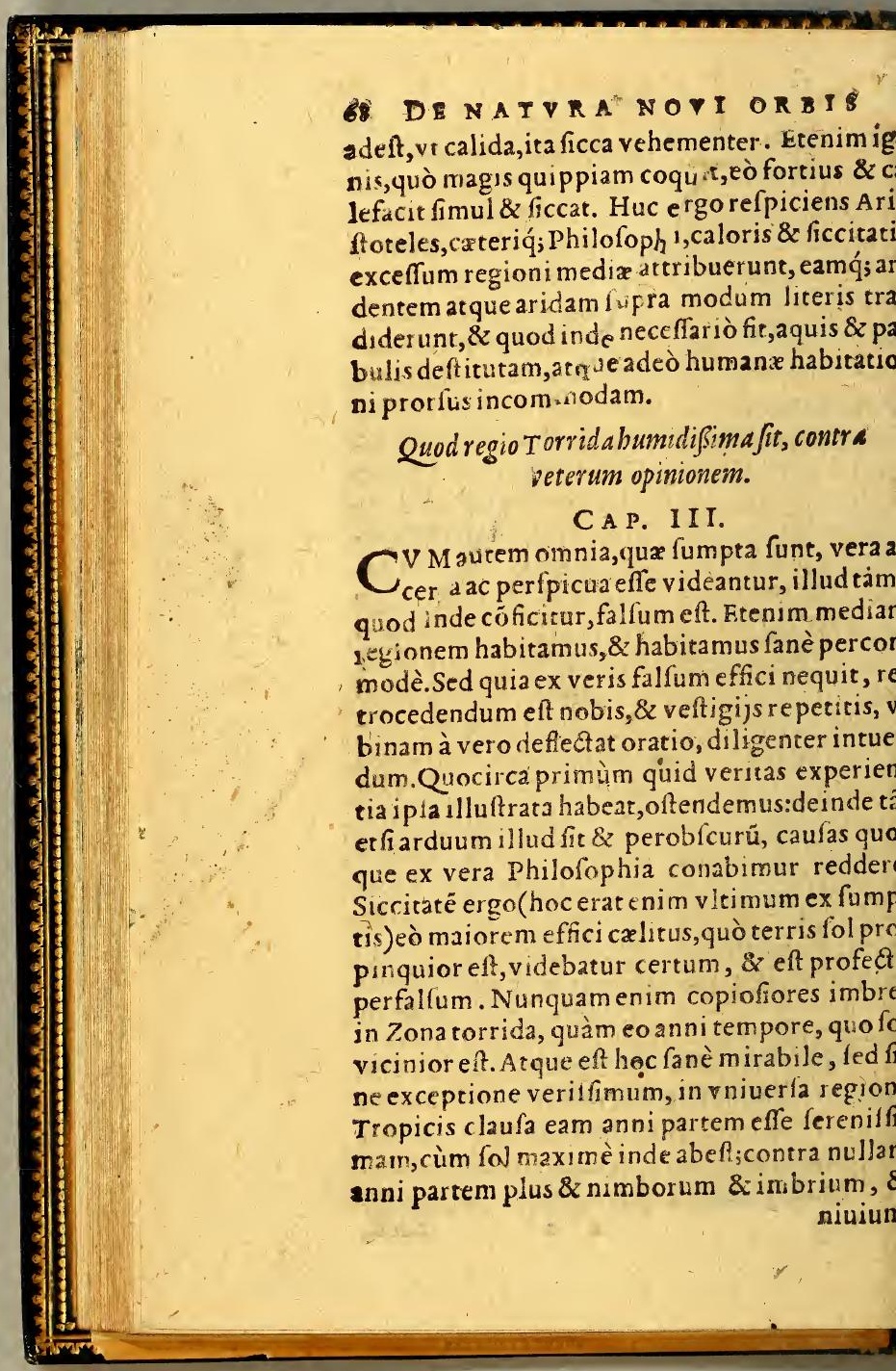




\section{I'I E $\mathrm{R}$ II.}

iuium (vbi illæ funt) effundere, quàm vbi fol ropinquiffimus eft. Hoc ijs, qui nou um orbem on adierunt, incredibile fortal fis appareat: ijs uoque qui adfunt, fed non attëdunt, nouum acdet, led vtrique experimento notiffimo facilè dent. Ab hac Peruenfi prouincia, qux Antaricum Polum fpectat, tüc remotiffimus fol eit, im Europx propinquiffimus, hoceft, Maio, Iuio, Iulio, Auguftu, in quibụs, Tropico Cancri icinus eft: at per eofdem menfes, mira call leritas apud nos, nulli imbres, nulla niues, fluij onines pertenues, multi etiam exarefcunt. $10 x$ vero procedente anno, \& fole huc ad Capri ornij circulum commeante, incipiunt niues 82 luuix, \& fluuiorum magnx acceltiones, id eft, o ineunte Octoöri vfque ad Decembrem. Tum erò copiofifimi imbres, \& niujam copia, \& flu iorum furores, cùm fupernè acdireciò lol caita noftra ferit, rediens ex Capricornio, cim unt etiam $x$ ftus grauiffimi, népe à I a nuario v fq $_{\text {. }}$. $\mathrm{d}$ medium Martium. Hoc nemo eft qui perpeuum huic regioni ignoret. In ijs verò parcibus, ux vlera xquinoctialem Polum Areticum fpetant, contrariú omninò euenit, fed ratione pror us eadem. Nam fiue Panamam \& eum omnem rasturn confider es, fiue nouam Hifpaniam, fiue nlulas illas Cubam, Hifpanicã, Lamaicam, Santi Ioannis, liquidò inuenies, ab ineunte Nouéri vfq; ad Aprilem fereniore, \& clementiore : lo vti, quod fol ad hunc Tropicum veniens ab js locis maximè fe difiungat: contra terribiles imbos, 8 imbres vberrimos ibi fieri ab ineune lunio vfq; ad totum Septembrem, quod folis 2dij per id temporis minus obliquę̇, 32 magis

$$
\text { E } 3 \text { pro- }
$$




\section{DE NATVRA NOVI ORBIS}

propinquè feriant ea climata. Hoc idem obferuare licet in India Orientali, quantum ex literis inde allatis ego intelligere potui. Itaque quamuis peculiari aliqua ex caufa alicubi fecus fortafsè contingat, tamen pro generali lege tenendum eft id, quod dixi. In media regione, hoc eft. torrida Zona ficcitatem effe maiorem fole recedente, eodem appropinquante humoris copian gigni,idć; adeo vt pro ratione acceffus ac receffus illius, v naquæq; regio aut arefcat, aut imbribus abundet.

Ouod extra Tropicos humoris copia foli rece ffu mo xime fiat, contra quim in regione Torrida.

\section{CAP IIII.}

F Xtra Tropico vero fecus accidit: nam imbres \& frigora, $x$ ftus $\&$ ficcitas coniuncta furk. De Europa manifeftum eft, $\&$ de toto ille wu Chilenfis tota prouincia têt is eft, quę quoniã v tra Solfitium Capricornij pofita ferè gradibus cum Hifpania paribus alta elt, eafdem eriam leges hyemis \& 2 ftatis patitur, hoc vno dempeo, quod $x$ ftuum $\&$ hyemale tempus cócrarium ha ber, quippe cùm Polum contrarium fpectet. Itaque copiofifima plusia in illa prouincia fole quàm plurimum recedente, fimul cum frigore hyemem efficiunt, ex Aprili incunte $v f q$; ad Septembrem, eftus autem \& ficcitas pariter fole il luc commeanteredit.Prorfus vt in Europa. Qua ex re fit, vt frugibus ingenijfq́; hominum Europategio illa Chilenfis cxteris fimilior fit. Idem accidere traduntia terre portione, qua vltra in $\operatorname{timax}$ 


\section{I E R II.}

Iam AEthiopiam vfq; ad celeberrimum bon: i promontorium in formam culpidis tendi: Atque hancefie veriffimam Nıli redundanintempeftucè caufam, de quo tam multa infita, tam pauca à prifcis inuenta funt.Etenim egio à menfe A prili, fole Arietem deferente, ipit,ve par eft, hyemalibus imbribus fluere, partim ex niualibus, partim ex plutialibus ais paludes illas implentes, ex quibus verifliGeographıa Nili fontes deriuat, alueum ip$n$ paulatim turgefaciunt, \& longiffimo tractu It menfes aliquot A Egyptum xflivo maxime npore, vtpotead alterum Tropicum pofitam pinat is flumin is incrementis foecundant.Silis Nilo excurfio annua eft ingentis fluuij in nerica Paraguai dicti, cuius ex montanis imbus tanca copia côfluit, vt atnpliffimos cápos andet, cogató́; homines terrefti habitatione ferta in lintribus per id tempor is degere. Quod intra Tropicos imbres aflinifint, $b$ de. ratione hyemis \& aftatis.

\section{CA P. V.}

raque in duabus regionibus temperatis, ver ca lore \& ficcitate, hy ems frigore $\&$ humore con atiunt. At intra Zonam torridam vtraque illa fsident. Nam aftum potius imbres, frigus (iic im caloris moderationem voco) (ereniras coitatur. Q 112 ex re fit, vt cùm in Europa hyematempus plunijs fimul \& frigote definiatu r, $x-$ uum contra calore \& ficcitare noftri hamine hacregione difunda illa videntes, hyemem agis ex pluuijs, ver ex ferenitate nuacupent, quo re vera tälluntur. Nam ver ticunt fite in

$$
4 \text { MOR }
$$




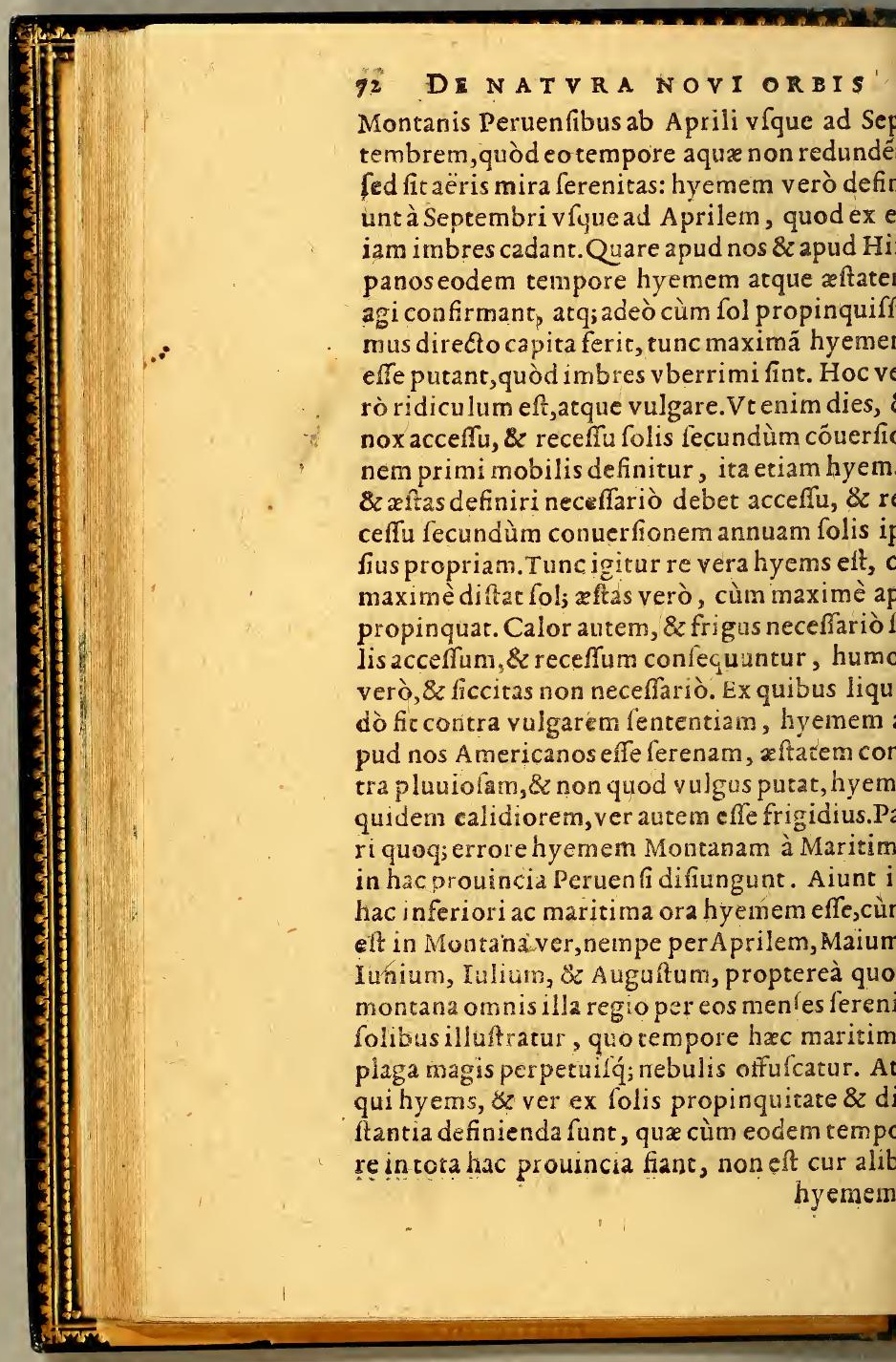




\section{I B E R II. .., 73}

emem, alibi ver effe arbitrentur.Sed de vocalis certandum non eft. Appellent, vt libet: $æ$ 12 \& hyemalia tëpora ferenitate potius quàm ore definiât, dum modò de rei veritate, quod cimus, conftet.

Quod torrida aquis pabulisǵg abundet, quicquid Ariftoteles contradicat.

\section{CA P. VI.}

Bundat ergo torrida regio humorc, idq́; adeò vt largitate perennitateq́; aquarum cæteomnes facilè vincat, excepto fi qua in parte oulo arenifá; oneratur, aut folo nimium defer vritur,quod in alijs quoq; mundi plagis freenseft. Caleftium quidem aquarum copiam is oftendimus, imbres, niues, pruinas, quibus aximè hæc Peruana prouincia frequentatur. eterrenis quales funt putei, fontes, fluuij, torntes, lacus, paludes, nihil hactenus dixi.Verùm $\mathrm{m}$ infernę aquæ fupernis ęqua ferè ratione reondeant, facilè eft id quoq ; intelligere.ERt auin ea aquarum fcatentium multitudo, vt nuf1am terrarum neq; plures, neq; latiores fluuij, Ifquam tanta paluftrium locorũ moleftia.Pluma huius A mericę,eademó; latiffima loca præe imia aquarú copia habitari nequeunt. Nam \& umina xftiuis imbribus in immenfum excurint, atque omnia euertunt, \& limof $x$ paludes Ifinitis Spatijs firma veftigia excludút. Quambrem immenfi illius, cuius fupra meminimus, araguay accolx, cùm iam fluuijannua incremëi prâfentiunt, longè lateqúue vagantem fcaphis nteuertunt, ibi larem fibi confituunt, $\&$ fe fuaue per trimefure ferè tempus lintribus natanE 5 docono 


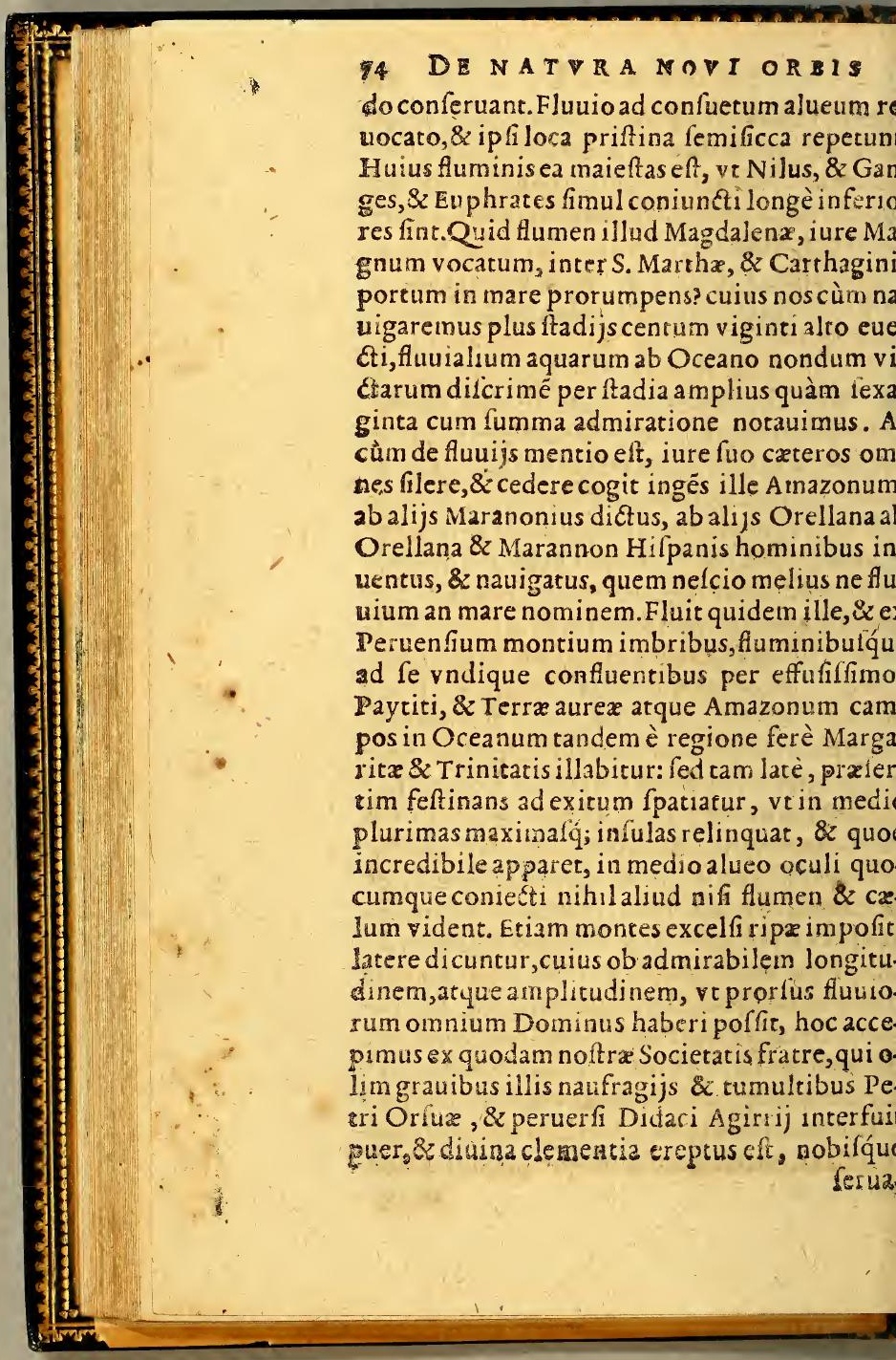


atus. Tales igitur fluuios habet torrida atque a Zona, quam inopem aquarum \& pabulorí toteles atque omnis putauit antiquitas. Et niam ad indicium aquarum Maranonij men é feci,iuuat de lacu Intiticaca, falfo vulgò caca dicto, aliquid etiam promere, qui in fu1a prouincia Peruana Collaa medius iacet. uúc flumina plus decem, eaq́ue fatis ampla có at, exitum iabet vnum, eumq́ue non valdè $\mathrm{m}$, fed, vt opinio eft, profundiffimum, quem ue ponte iungere profunditas \& latitudo fi$t$, neque tutò $\mathrm{fcaphis}$ traijci rapidi infernc̀ tices patiuntur.Traijcitur tamen, miro inge\& Indorum proprio: ponte prorfus iunceo aqua cómiffo, nullis fulcris nixo, fed in moa fuberis ponte fupernatante, ac pre leuitate erix nunquam merfo:eft verò trajectio facil 2 \& tutiffima. Occupat lacus ipfe circuitum mille quadringenta ftadia: longus eft ferè genta, latus vbi maximè ducenta \&z viginti. ulas habet olim habitatas \& fertiles, nüc deas, producit vberrimè iunci genus, quod Inenæ Totoram vocant, cuius plurimus ipfis veft. Nam \& cibus eft fuibus, iumentis, ipfif́ć, ninibus periucundus, \& domus, \& focus, \& tis, \& nauigium,\& omnia penè vitẹ humanæe fidia vna Totora Vris preftat, hoc enim acco um eft nomen. Ij adeò fe ab hominum cętero$n$ confortio \& opinione alienarunt, vt interzati aliquando, qui fint, feriò refpoaderint, fe n homines effe, fed vros, $\$$ genus ab humano terfum effe fentirent. Vrorum reperf̧i funt po li integri in medio lacu habitantium fcaphis ibufdam iunceis, quibuș inequitạıt, fimul cô-exis 


\section{DE NATPRA NOVIORBI}

nexis, \& ex vna aliqua rupe aut ftipite religat Vnde interdum foluentes totus populus fubi patriam mutat. Itaque aliquando conquifitus pulus Vrorum hefternis fedibus commutatis, ne veftigio quidem relicto, facilè veftigantiu fudium curamq́ue irrifit. Ex hoc lacu poft le cas quinquaginta alius longè minor efficitur, ria dictus, fed iple quoq; tantus, ve Infulas p! res reddat, huius vltra meatum nemo nouit. mare Auftrale influere per occultos terrę can les multi iactant, atq; argumento proferunt, $f$ uium quendam magnum in mare pene fubito rumpentem, cuius fons nullus appareat, ego n gis lacus aquas folis rádijs exhalari puto. Verù huc efle digreffum fit fatis, cùm abundè his do mentis conftare polfit, falsò regionem hanc $m$ diam deaquarum penuria damnatam, cùm $\&$ cxlo «è terra præ cateris humedtetur.

Redditur caufa, cur intra Tropicos folis pra fentiabsimorem efficiat, extratropicos ficsitatem.
C A P $\mathrm{T}$ VII.

Aufa autem, cur equinoctialis conera vet rum fententiarn humidiffima fit, diu mi atque acriter cogitanti, nulla alia certior occu rit,nifi quod vis ipla folis maxima, \& $\mathrm{amplif}$ fimè circunfulo Oceano plurimam vaporum piam exugat,eandemq́; citiffimè lique factā ve tat in pluuias. Nam quòd prxpotentis ardor caura imbies proueniât in regione torrida, $\mathrm{ml}$ ta, $\&$ perfpicua documenta funt. In primis eft lud, quod iatis fupra commemoraui, quòd eoa - $\quad$ i tempore, quò fol fupernè maximè ac direct 


\section{I R IY.}

incumbit,jimbres fiant:cùm verd lógius reerit, fieri definant.Solis igitur vis valida plu ciet. Deinde obferuatum eft in hac Ameri$b$ ipfo meridie, cùm radij folis potentiffim? , imbres folere cadere, manè verò toto nihil nobisab imbribus timemus. Q Qamobrem cùm facimus, diuerforio egredi maturè feamus, \& ad medium diem tuti iter carpimus. c norunt Peruenfes omnes. Quid quod viri fa ntes deprehendiffe fe per hibent in his regiou's poft fumma lunx incrementa pluere maè̃ foler èqquod nos quoque eriam experti fus. Iraq; \& znnus, \& menfis, \& dies hoc idem ftari videntur, intra Tropicos fumma calovi imbres generari. Poltremò in arrificijs que, vbi ex herbis aqua in medicinx vfum lantur, idem accidere cernimus: ignis namq. nemens $\&$ exęftuans plurimam humoris eiufdi copiam furfum effert, eandemó ; calore ipcircunclulam exudantem in aquam vertit, em vbı argenti viui admirabili potentia aurú argentum puriffimum reddirur. Nam fi deis ignis fit, nihil ferè exudar: fi validos, pluriin eliquarur, \& in fumum quidem materia primùm refoluitur, deinde in priorem argéviui liquorem vertitur, ac lupernè defluit. Iur vis ipfa ignei caloris, cùm materiam eft $\mathbf{n a}$ idoneam, fimul rapit furfum, fimul vi quipa obftat, ne extraclủ vapos em ablumat, fta$\mathrm{n}$ liquat in pluuiam. Iam verò quod in regiotorrida tol calor is copia generet pluuias, quas tra regionem torridam iolis potius ablentia caloris inopia facie, \& fi videtur prima fronte ntrarium, fed re vera non eft. Plus 1 mi natura- 


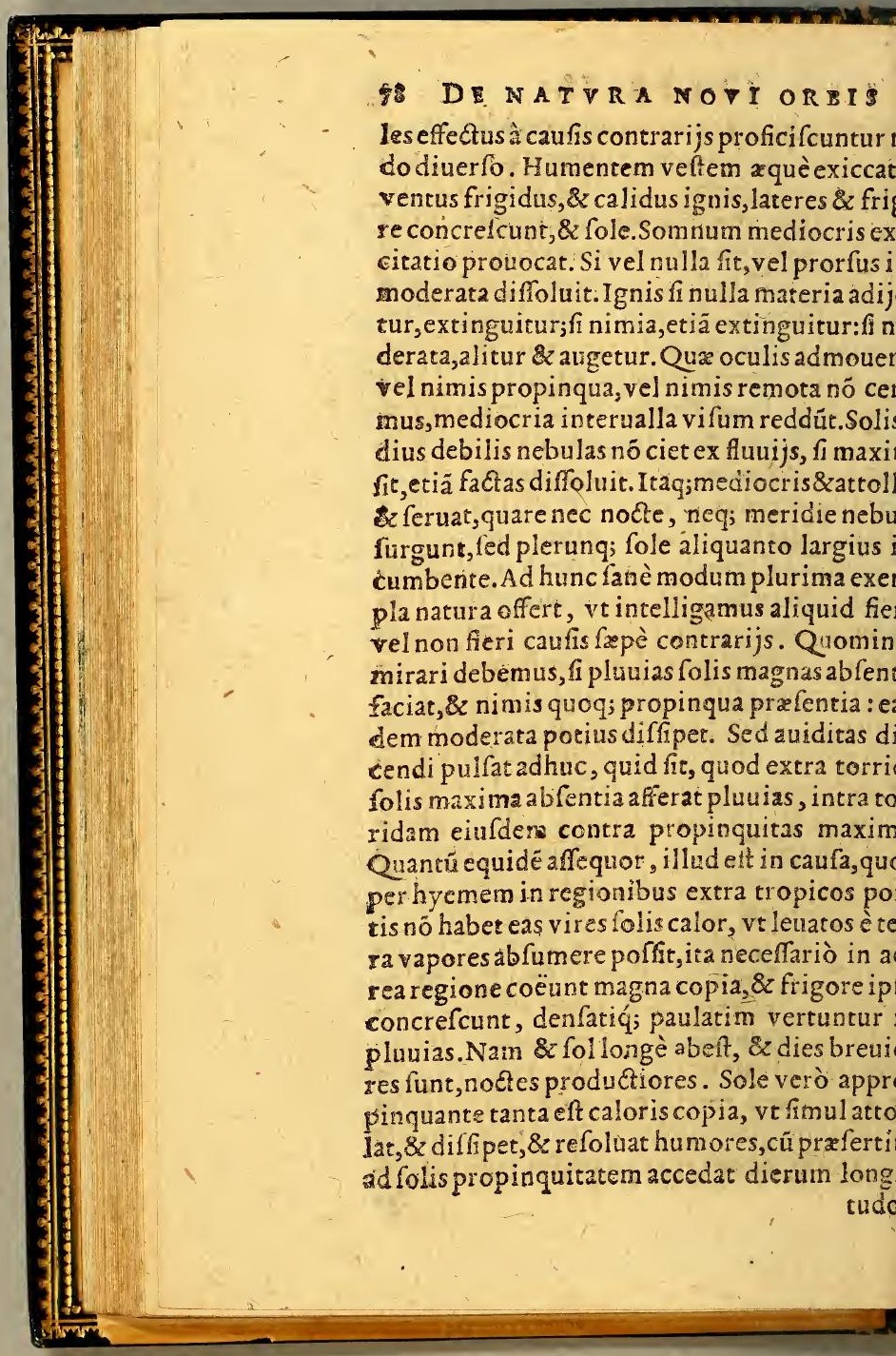




\section{B R R IT.}

o. At verò intra Tropicos, hoc elt, in Torrida na folis quidem abfentia tanta eft, vt prafen$n$ aliarum regionum $æ$ quet. Vnde etia $m$ tune em ratıone ficcitas accidit. Maximè verò ac ectiffimè incumbente fole, ideò non magna itas, ve videbatur confequens, fed magni \& repentini imbres funt, quia imnoderata ilda vi fubitò copiam plurimam humoris èter 8* Oceanotrahit, qua cùm non difpergitur ipaturó́; vento, facillimè coalefcit, ac veluti naturas pluuias facit. Nam vis magna caloris noris cópiam fubitò attrahere poteft, eãdena in multa elt, fubitò refoluere non poteft. I taq? t attracta prę multitudine ipfa concrefcat in uiam: Quôd tanè fubdito exemplo intelligi eft.Etenıin cùm fuillæx, ant vitulinæ, aut aliopingues carnes fubiecto igne torrentur:fi isquidem exiguus fit, fillant, eò quod calor norem attra here poteft, fed abfumere non po præ inopia. Qnod fi ignis contra maximus 82 pinquiffimus fit, ftillant nihilominus, fed r $\mathbf{2}$ ne contraria, quia vis ipfa immodica caloris tam fúbito humoris copiam excitat, vt fimul uata prorumpat. At verö fi ignis moderatus ijciatur,\&interuallo idoneo diftet, videmus è elixari carnes, $\&$ vix quicquam defluere hu ris. Quare coquorum ars pracipit ignem, nenimum, neq; perexiguum, fed mediocrem poni, eumq́; maximè vnotenore perfeueran:ita enim $\&$ humor paulatim extrahitur, $\&$ umieur. In cereis quoc; lucernis idem eft cere.fi enim flamma maxima fit, reram prorfus גefacit, quia excitare liquorem poieft, abfure non potef. Flatama verò pro jatione ma- 


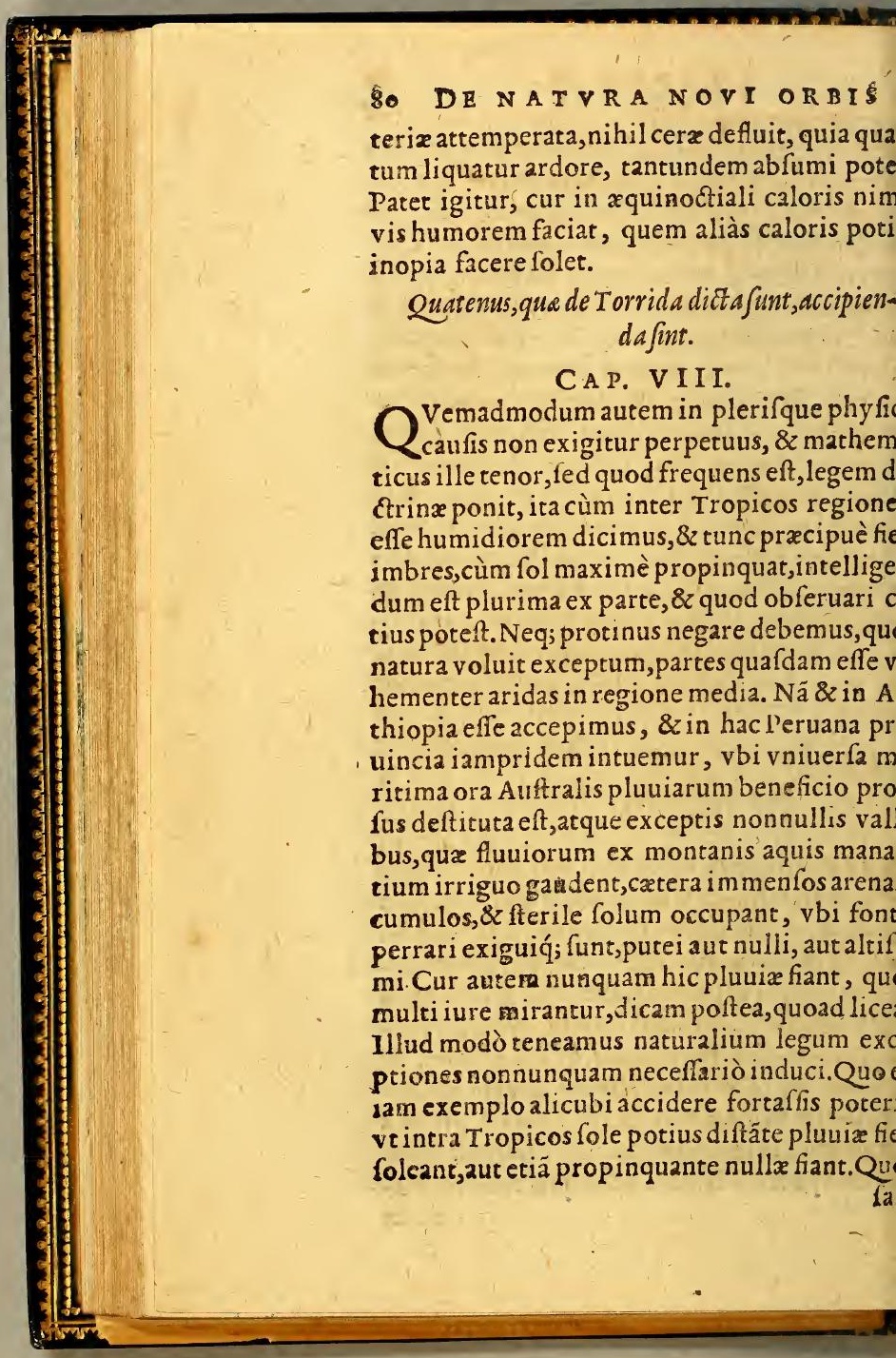


fi perpetuum eft,terræ ipfius atq; fubiectx erix qualitati peculiar: afcribendum eft : fin $\mathrm{m}$ interdum fic; interdum fecus eueniat, faeft intelligere naturales caufas alijs contra ectis fxpè impediri.Quamuis enim fol pluciear, ventus tamen poteft obfiftere, quod brò videmus, \&copiofiores etiẩ pręter more eft ventus inducere. Sunt varix \& origines torum \& vires, qux fxpè annuum \& ftatum inem interturbant. Quod cùm vbique terracertum fit, incertos inde fieri anni curfus pter variantem fapè figniferi ftellarumque antium fitum atque confpectum, nemo iure pare nos poterit, fi in noftris de æquinoctiali itudine obferuationibus, fimilem quoque ra nem excufemus: Illud certè quod dixi, multo quentiffimum elt atq́; certiffimum, intra Tro os, \& regionem effe humidiorem $\&$ humor is c maximam copiam effe, cùm fol viciniffiseft.

\section{Quod Torrida regionon fit vebementer ca:} lida,fed mediocricer calida.

\section{CA P. I X:}

E ficcitate \& humore regionis medix diximus hactenus. De calore \& frigore dicendú nceps eft.Siccam \& calidam definita m effe ab iquis initio huius difputation is commemoimus, atque verumque extremo quodam graEft verò æquinoctialis humida quidem \& caa, calorem autem maxima ex jarte habet atnperatum, quiod incredibile haberetur, nifi efnus experti. Equidem ex phivofophica illa raine, cuím ad Indos traijcerem, mihi perfuadeF bam 


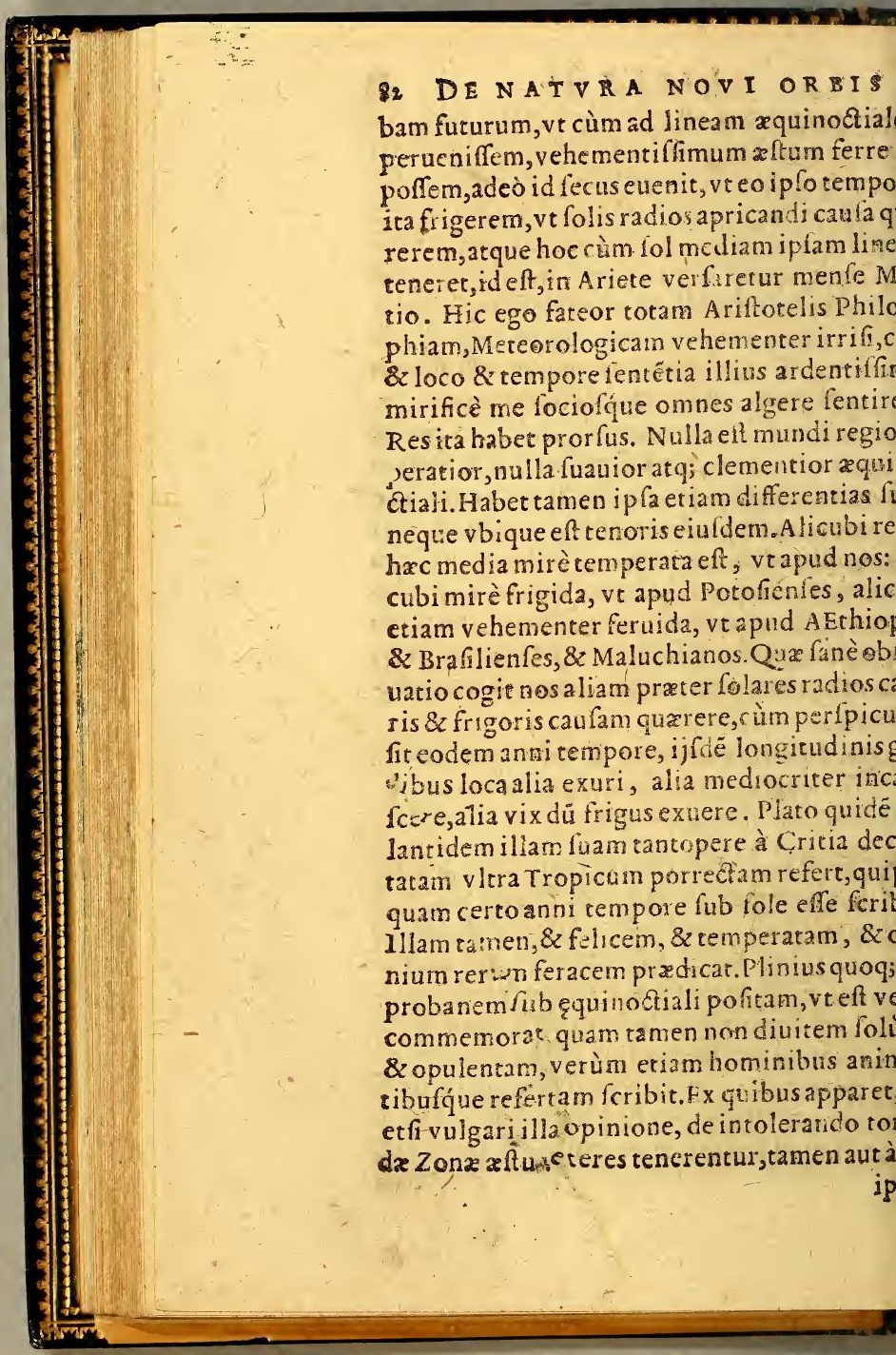


saliquando diffenfiffe, aut habitationi homi $n$ eam regionem non effe incommodam poTe facilè deprehédere. Ea res clariffimo Cofgrapho Ptolomxo, atq; infigni Philofopho, ledico egregio Auicennæa alıquo certè modo it in mentem, qui fub Aequatore habitatioa effe placidiffimam tradiderunt.

ionis Torride af um temperari tum multitudine imbrumitum aft iuorum diersom bre-

uitate.

\section{A P. X.}

EM ita habere nemo iam dubitat poft nouum orbem inuentum : fed natura compaim eft, vt quanto quippiam incredibilius oreter hominum opinionem experientia paacit, tanto caufas perquirendi ardentior iditas excitetur. Itaque fcire auemus, cur, - folem propius incumbentem regio pati, ea non folùm fxpe temperata, verùm indum etiam frigida fit. Communiter Zonæ rida habitudo caufas habet duas, ob quas $x-$ sillius vehementiffimus mitigatur. Prior eft , quamdiximus, quod eadem pluuola addum fit, imber autem omnis refrigerat, quip cùm aqua nàtura frigida fit, qux quamuis aclente extrinfecus vi ignea incalelcat, tamen lem remittir fine dubio immenfum illum ar$\mathrm{rem}$, qui ex puris radijs folaribus efficeretur. cumento eft regio omais arida, vt Arabia inior, quę eadé ardentiffimo fole torretur, quod Ilis imbribus vis illa ignea remittatur. Et nuergo vrentis folis furore intercipiunt, \& ex is inftillati imbres aërê ipfum terramớ; fimul 


\section{DE NATVRA NOVI ORBIS}

Madefaciunt atque refrigerant. Quantumuis nim calidi fluant, bibuntur tamen, $8 x$ fitim ard remq́ue reftinguunt, quod noftrì homines exp ti perfxpè funt in graui aqux penuria . Itaque Iatio, \& experientia fibi fatis congruunt, vt dandi caloris efficax pluuia fit. Et quoniam to ridam oftédimus omnium effe pluuiofiffma fit profectò, vt inde non leuem tem perandi ris caufam opinemur. Iam alteram ratione fl ijcio, atque eam eiufmodi, vt cum ad hanc, qu modò tractamus quæeftionem, turm ad alias co plures nobis nó mediocriter vfui futurà fit. $B$ uiffimè ergo,vt dicam, æquinodialis foles pa tur ardentiores quidem, fed tamen omnino $b$ uiores. Ex quo fic, vt cùm diurni calor is $\mathrm{fpa}$ minora fint, non ita vehementer inflamme Verùm explicanda, \& latius producenda fen tia eft.Tradunt fphxræ tractatores prorfus ve quando eft obliquior Zodiaciafcenfus, tanto es noctef́́; magis inaquales exir e: contrà, $\int \mathrm{pl}$ ræ rectæ tempora effe æqualia. Itaq; tota Tro cis claufa regio minoris diei ac noctis diffim tudines patitur, tantoq́; id certius; quantơ $æ q$ tori vicinior êt. Hoc nos hîc abüdè experim Nam Quitenfes linex proximi nullum dier noctiumq́ue toto anno difcrimen agnof cunt. menfes duodecimo pene gradu pofiti notát $q$ dem dies longiores per Decembrem,atq; Ian rium, fed vnius hor 2 vix fprtio exceffus om abfoluitur. Porrò Cufquenfes, multoq́ue ma Potofienfes perfpicuè hyemalium, \& ęftiuor dierum longitudinem breuitatemá; difcern Qui verò extra Tropicos pofiti funt, \& $z$ maì manifeltus interuallum dierum notant, \& 
I I B E R I I.

meridionali ad cali cardines abfunt, $e$ uctioribus per æeftatē diebus fruuntur. Quä m Germania \& Anglia lógiores dies quàm a, \& Hifpania æeftiuos habent. Hæc cùm \&z nenta fphxræ tradant, $\&$ resipfa obferuanfacillimè deprehenfa confirmet, iam illud perfpicuum addendum eft, plurimum ad ta omnia naturalia pollere cauf efficientis euerantiam. Cùm ergo regio æquinoctialis os dies habeat breuiores quacumq; alia, cứ10x ipfa fuapte natura, \& humida, \& frigida idemq́; diei æqualis, fi quæratur ex me, cur orrida Zona non tanti xeftus fiant, quantos ca,exempli gratia, per Sextilem, \& Quintitolerat, equidem breuiter \& probabiliter onfurus fum, quod Bxtica foles habeat eo tê longiores, noctes breuiores: noftra autem enfis regio contra ipfa xftate media, \& dies cis breuiores, 8 noetes noctibus longiores, e adeò vt maxima dies vix trẹdecim horas as habeat apud nos, apud illos etia integras decim. Et fi ergo ad xitum, nos folis vicinipræftamus, tamen nos illi folis diuturnitaingè fuperant. Ac certè mediocris aliquis samplius vrit, fi longo tempore perfeueret, $\mathrm{n}$ alius maior breuius admotus, præfertim fi ida, \& contraria vi diutius interpoletur. Has ar duas obferuationes veriffimas fi quis $x-$ lance cópenfet, hoc eft regionis torrid $x$ pluitatem, \& xftiuorum dierum breuitatem, affis exiftimabit, rectitudini, \& propinquiati folarium radiorum in ratione caloris ciendi, fedandiqúu non magnopere cedere. 
86 DE N T TRA NOVI ORBIS Aluas quoque effe peculiares caufas temperama torrida, atgue in ijs oceani propin. quitatem.

\section{A P. X I.}

Von I a M veròea, qux dixiad region mediam remperâdam commun nequetamen omnis ea plaga folftitialibus culis comprehenla aquè temperata eft, fed bufdam in locis vehementiffimè exaftuat, burdam etiam friger, \& quod mirari polfis, id prorfús clima alibi calidum, alibi frigidum, bi temperatum eft, idque vno, codemq́ue t pore,omạninò compellimur præter allatas co muniter alias qualdam peculiares caulas qua re, cur Zona torrida tot vicififtudines capiat currunt autem accuratius cogitanti tres nota quarta quædam alia ignota. Notas numero ceanum, terræ fitum, ventorum vim:præter latere fufpicor occultam aliquam terræ ful ctx qualitatem \& cxli fupernè dominantis caciam. Nam qui contemplacus fuerit fub rida Zona non folum Manomotapam, \& pre fi loannis regna fole exuri, \& atri coloris indigenas omnes, verum etiam in Infulis dique maricircunlitis idem prorfus accid quatiseft Infula Sancti Thom in mediali \& Infula Caboverde : contra fub eadem $\&$ infulas, \& continentem huius regni Pery fis à Granatenfr, \& Popaiana prouincia vfqu hanc Limenfem adeò effe temperatas, $v c$ in dum frigidiores fint, homines autem prorfu bi nafantur : tum vero Brafilienfeñ om prouinciam Oceano Boreali expoficam effe 


\section{I B E R II.}

fimam, hanc nofram Peruenfem eodem pe$s$ climate Oceano Auftrali incumbenrem emperatiffimam, atque huius generis miradifferentias mille perfpexerit, non poterit ofectò generalibus illis documentis effe centus, fed vltra inueftiget, neceffe eft, vt fitanta diuerfitate fatisfaciat. Maris igitur Ira quamuis falla fit, eadem tamen frigida nequealtius caufam petere oportet, quàm p fus aquæ natiua qualitate, qux fine dubio ida eft. Radij quoque folares ex aqua, quòd luit \& facilior eft, minus vehementer quàm erræ materia repercutiuntur, quod ad æltus contentionem, vel remiffonem plurimum rt. Accedit ad hoc, quod Oceani immenfa tudo prohiber aquam feruote folis affici, ve ialesaquz ferè lolent. Arque omninò ficut ro quod falfum eft, aqua frigelcit, ita mari$n$ aquam refrigerandi vim continere experir. Q aqux potabilis fcyphos marinæ aquæ frigeiendos committere. Quibus ex omnibus percuum fit Oceani ad fedandum $x$ ftum refriandumque vim effe permagnam. Itaque main terra quàm in mari $æ$ Ptuamus, fi cærtera pafint, \& regiones omnes maritimæ Mediterheis temperatiores fuauiorefque habentur. Ioniam autem maxima noui orbis portio quáfúb torrida Zona iaceat, tamen vel Oceano propinqua eft, vel eriam alluitur,aquarum beneficio temperari non abfurdè exiftimari poteft. 


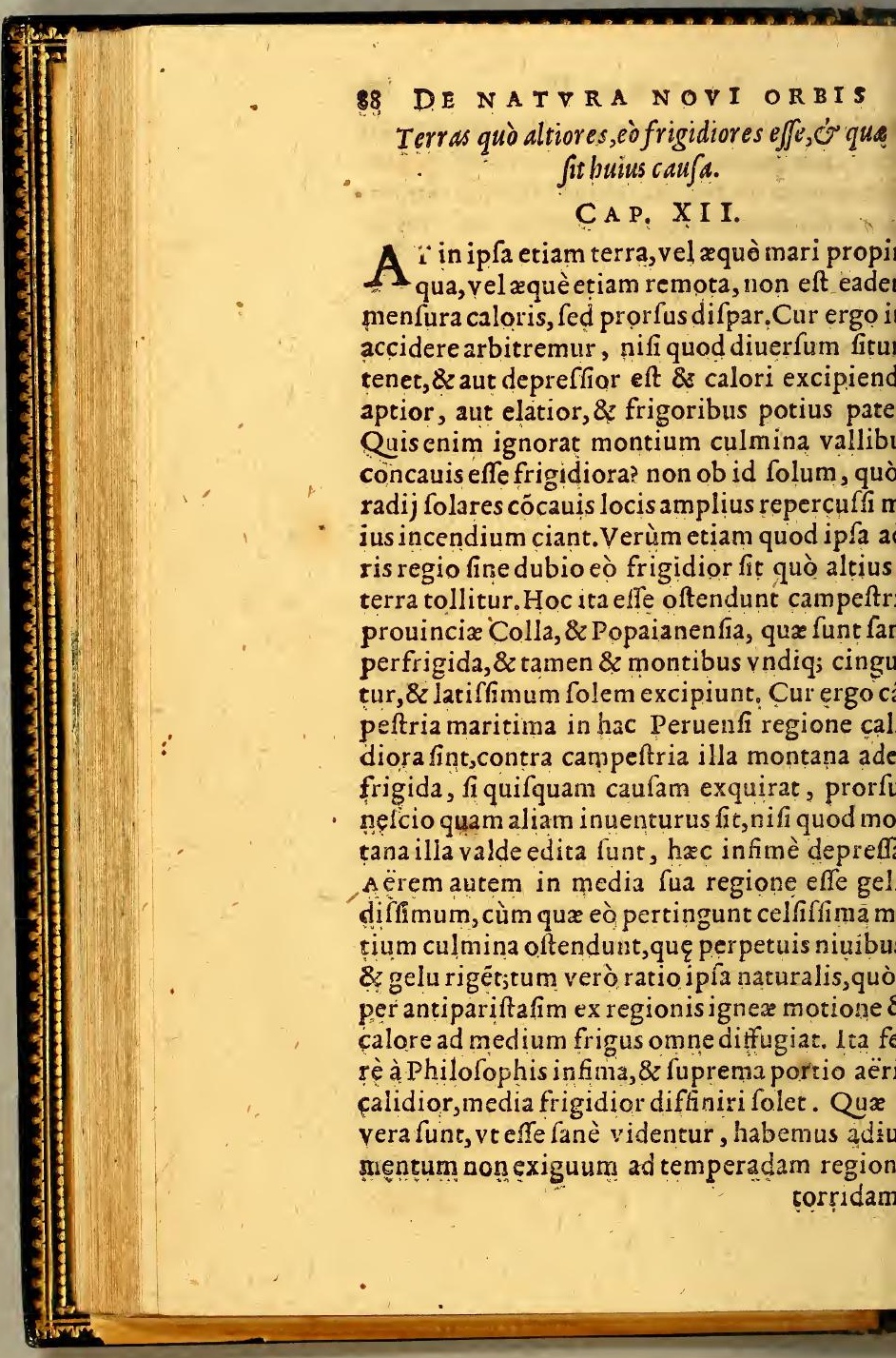




\section{I B E R I I.}

idam, montana illa atque edita terræ faftiqux in his locis frequentiffima funt, qux fa2 natura fua frigida funt, \& reliqua circunina magnoperè frigefaciunt. Hic niues perpe aquæ gelu maximo cócretæ, pruinæ crèbræ, ris denique tanta vis, vt ex niuali illo horroampos latè cernamus exuftos, herbamq́ue oem decoctam, ipfi homines atque equi pra ore fapè corruant. Atque hoc, vt dixi, in metorrida regione accidit, \& accidit maximè -propinquiffrimè incedente. Cur autem frigi ra fint montana campeftribus dixi atque itea repeto, quod aëris regio media, ad quam po imum pertinent, frigidiffima fit. Cur illa fice eat, dixi fupremum aëris orbem ignex exhaoni vicinum, vt Ariftoteles vult, quicquid frigoris à fe depellere, atque ad medium per teorol.c.4. tipariftafim ferri. Hîc fi pergat aliquis quze,cùm aër calidus atque humidus fit fuaptè ura, vnde nam frigus illud ipfius media regio ccipit?nufquarn enim apparet, nifi \&zaër cali8 igni proximus, itaque infimam aëris renem aqua \&z terrræ contigua m, magis frigidä oportebat. Equidem non mediocriter harene fateor, parumque abeft, $v t$ in eorum fentê. $\mathrm{m}$ eam, qui Ariftotelis iftas fymbolas ac difnbolas qualitates contemnunt, magifá; arte jictas, quam vlla experientia allatas aiunt. Iue aèrem frigidum natura fua contendunt, ue multis, \& magnis experimentis probant. am vt alia prætermittam, certè in æftatis mama vifolemus aërem flabello ciere, atque ita frigeramur. Nulli ergo eleméto qualitatem ca dam natiuam effe volunt prater ignem, cuius

$$
\text { F. commi- }
$$




\section{go DE NATVRA NOVI OREIS}

Diamy).cais. commixtione plena funt omnia, vt ait magnu de calef. Hie Diony fius. Sed fiue hoc ita fir, frue non fit, (neo sat. enim facilè nifi in re certa Ariftotelicæauctori. tati refifto)illud omnes confentiunt, \& eft expe simento ipfo abund è compertum, aëris region hac ima celfiorem effe perfrigidam, vnde $\&$ ni ues, \& grandines, \& pruinas, \& cætera omnia m gni frigoris arguméta depromimus. Igitur cùn longè maxima torridx portio inde Oceano in genti, hinc pracelfis montibus cincta fit, fatis ea duæ cauf $x$ ad folis ardorem temperandum for taffe videri queant.

\section{Ientorum maxime beneficio regionem Tor - ridam temperari. \\ CA P. XIII.}

TErùm Torrid $\mathfrak{x}$ regionis temperatio praci

puo ac propemodum fingulari aura leniff ma beneficio accepta referenda eft, ita fummu Conditor huic tam magn $x$ orbis portioni con fuluit, vt vbieffet folis omnia fubiecta vaftanti potentiffimus ardor, ibi plerunq; fpirarent ven ti frigidiores,quorú fuauitate grauior æitus ini ria depelleretur.Videri certè poterant aliquid dixiffe, qui paradifum Edé fub eqquinoctiali col locarunt, nifi eos caufa defeciffet, qui proptere hanc regionem temperatiffimam efle voluerü quod dierum $8 z$ noctium æqualitas minimè pa - teretur calorem effe immoderatum. At probabi lịs alij contradixerunt, poëtaq́; in primis.

Vergil. in Gerg.

\section{Quod Zona corufco}

semper fole rubet, or torrida femper ab igne.

Neq; enim noftis tanta frigiditas eft, vtimmen Los diei ętus vfq; adeò moderaretur. Igitur auı 
erpetuò fpirantis proprio ac peculiari benefiio fit, vt Zona veteribus torrida nobis ver quoammodo perperuum fit. Hoc ita habere, certifma documenta demonftrant. Namq; in eodem. limate videmus vrbes ac regiones alias alijs cadiores, quod minore venti refrigerant is copia otiantur, quædam etiam, vbi ventus flat nulus, aut terrenus certè eft, $\&$ xftuofus, vulturo Hifpanico fimilis, vque adeò exuri fcimus, accenfas formaces putes. Tales in magna Ethiopia, in Brafilia, in Paytiti, \& Paraguaij ampis effe notiffimum eft. Neque terra foum, fed maria ipfa idem difcrimen fubeunt. unt maria $x$ fu grauia, quale Mozambiquene perhibent, quale Ormuzianum, apud Oriritales; Panamaenfe, \& Brafilienfe, apud Ocidentales, quibus fanè refpondent eodem fiIs maria alia mirètemperata, vt hoc noftrum eruenfe, in quo nos algere, cùm primùm naigaremus, meminimus, idq́ue eo tempore, quo ol rectiffimè incumbebat, id eft, prope æquinotialem menfe Martio. Nihil hic aliud cogitaelpoffumus, vbi \& calum \&z pontus eodem modo refpondent, nifi venti fpirantis naturam, qua vel refrigerat, vel inftammat. Atque vna hac de venti ratione demonftratione cóprehenfa multa foluuntur, quæ in hifce regionibus folene non immeritò mirabilia cenferi. Cur cùm fol ardentiffimus fit apud nos ac longè immitius feriat, quàm canicularis Hifpaniæ, idem tamen leuiffimo v mbraculo pellitur, adeò $v t$ fub ftoria aut framéto tutiores fimus, quàm in noftra Hifpania fub teftudine lateritia? Cur apud nos noctes aftiue nequaquam calidx funt? Cur in ipfis 


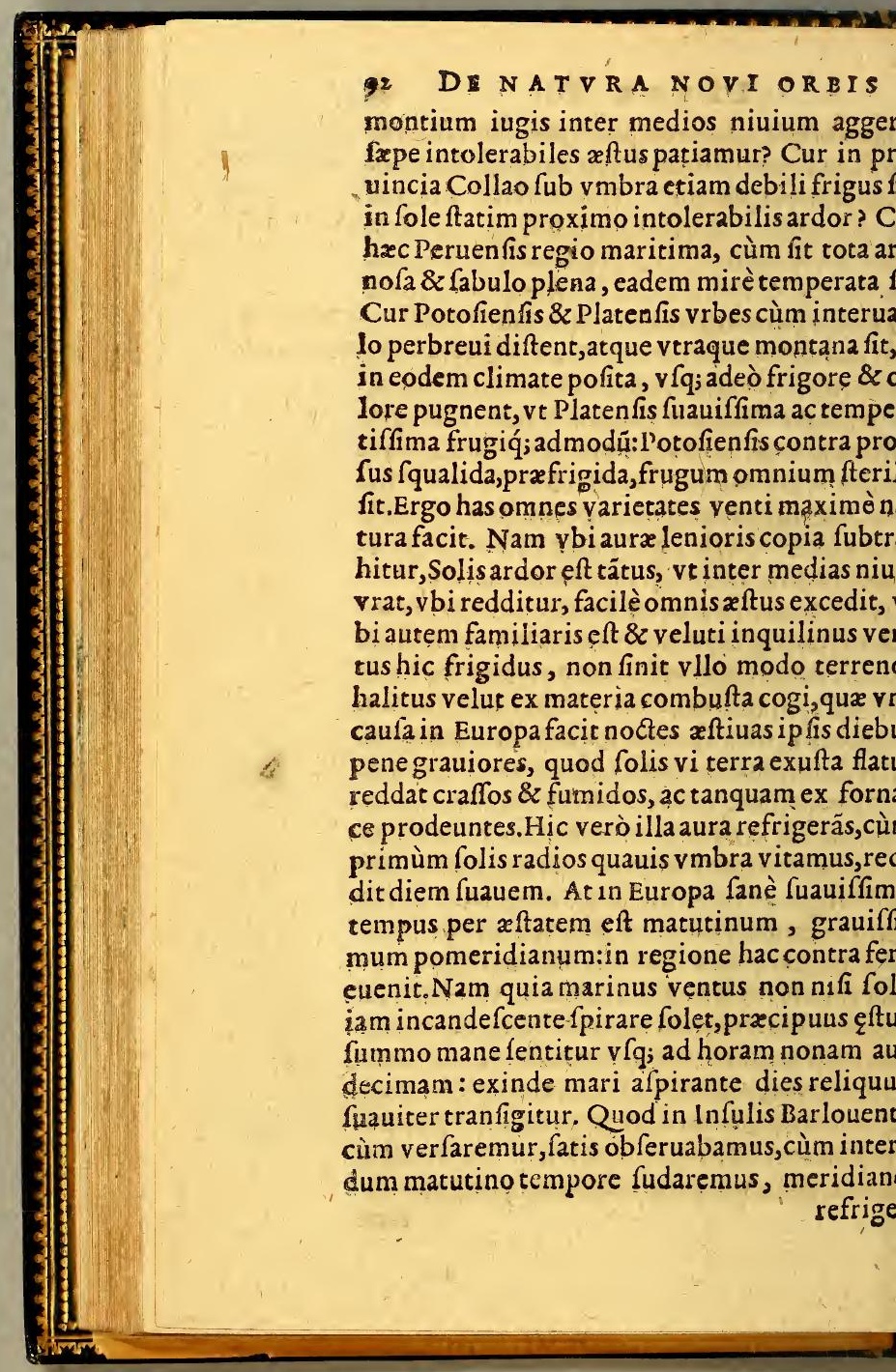




\section{I İ E E R İ}

frigeraremur, quo tempore farniliaris illis reonibus Euro aquilo à noftris Briffa dictus, coofrus fpirare inicipit.

Subregione media fuariß̌mè vitam degi. C A P. XIIII.

JOC igitur argumento, qui fub AEquino- Via.li. 13. de

1 tiali Paradifum collocant, fi adducerétur ciuit.c.26 edibile aliquid afferrent, non quod in hac me a regione hortus ille voluptatis laceat, neque im id pro certo nifi temere affirmare poffuus, fed regio hac, vbi temperies eft maxima, tiquam voluptatis hortus atque altera tempe eritò haberi poffit. Nihileft enim humanx vi - moleftius aëris cæliq́; inclementià,nihil illisbenignitate iucundius. Ex omnibus elemens riullum neq ; frpius; neq; interius accipimus re, hic \& continens eit humani corporis, \& viera ipfa atque intimum cor quouis momento uadit $t_{j} \&$ pro fui qualitate afficit. Si corruptus t, facilime perimit:fin falubris, vires cófirmat: enique hic vnus vita mortalium eft. Itaq; quan curque copia fit rerum omnium, vbi calum It infalubre atque infuaue, humana vita mifera $z$ afflicta fit, neceffe eft. Contra cxli clementis ërifqúe fuauitas omnium rerum inopem abun è locupletat $\&$ beat. Mihi in hanc tanquam veis perpetui benignitatem intuenti, cùm neque yems premat frigore, neque $æ$ it as caloribus co juat,adeò vt paruo cefpite iniuria omnes fatis ropulfentur, veftumq́; viciffitadine vix opus it, profectò fxpè venit in mentem, fi homines upiditatis prauarumque opinionum vinculis xpedirentur, facilè hîc iucundam ac beatam vi-

tam 


\section{DE NATVRA NOVI ORBI}

tam fuiffe victuros. Nam quod poetæ de Ely fijs, quod de Tempe, quod Plato de fua illa $\mathrm{A}$ lantide, vel fingit, vel narrat, id certè in h regionibus reperturi fuiffent, $f$ ingenua libe tate dominari potius, quàm feruire pecunia do creuiffent.

\section{De varietate ventorum or caufis.}

\section{A P. XV.}

$7 \mathrm{Nde}$ in vento ea tanta vis fit ad refrigerar dum,ve folis vehementiffm is flammis no cedat, fapè adeò fit fuperior, ve in media regic neTorrida Scythicum frigus efficiat, alij natur valentiores indagatores facilius fortaffis inue PJalm. 134. nient. Ego in hac admirabili ventorum $\&$ origi Iean. 3 . ne \& efficacia illud cogitare frè foleo.Qui pr fert ventos de thefauris fuis. Et illud, Vocẽ eiu audis, \&rnefcis vnderenit, aut quò vadit, ita pro fus eft, vt veritas dixit, effecta lentimus, primor dia, finefó; nefcimus. Et quanquã apud AEolun fub fpecu ventos cohiberi non opinamur : tam in præpotenti illa efficientia, qua natutã a fecó ditam latè moderacur \& regit, non dubitamu veluti quofdam thefauros delirefcere, originef que vêtorum,vnde varietate mirabili prodeut alij frigidi, alij calidi, alij nimbofi, ferenialij falubres \& morbidi, feriles \& foecundi. Quid etiam quibufdam regionibus dominantur, neq riualem paciuntur, quidam \& contrarios ferunt \& cedunt, aut vincunt viciffim, interdum quoc his fepè vidimus, regiones ita partiütur, vt aliu infernam, fupernam alius fimul perflent, neque inter fefe concurrät. Ac multa quidem cum alij, tum maximè Ariftoteles cómentatur de natura viribufq́; ventorum, fed nefcio, an qux occulta 
t, dicendo obfcuriora feceriut. Ego verò libềquęram exillis, Cur in tota hac maritima oper longiffima fparia vnus tantú ventusafpiCur idem Aufer, qui apud nos fuauiffimus , tranfita xquinoctiali prorfus grauis $\$$ calinofus fic? Cur Aquilo nubes congreget, \& in uuias exprimat in his locis, idemq́; veternos habeatur, yui aliâs femper \& frigidus \& nuum diffipator eft.Cur Inful $x$, quas Barlonenti pellant, perpetuis Aquilonibus refrigerétur, tamen pluuias habent copiofas, $\&$ vix vllus il Aufro aut Africo aditus patet? Cur Brafilien regio ante promontorium S. Augufini perpe os terrenos ventos obtineat, hac noftraPeruéfub eodem climate perpetuos cótra marinos? $x$ catq; huius generis multa difficilè efteciấ vi svaldè rerum Phy îcarú peritis adiperfótum o dignitate differere. Nenihil tamen fudijs minum demus, illudef promptum cernere locis editis atq; fublimibus, rete niualibus pruinofis \& a fole minus affect is, ventos gigfrigidos \& fubtiles:contra è vallibus \& torrébus, locif́que paluftribus craffos, \& inflamma$s$, fi abundet calor. Ad hoc accedit non minus rtum, è mari flatum fpirare folere fuauiorem falubriorem; è terra afperiorem minulá; fabrem, quod marini vapores fine dubio fubtioresminufque concreti fint, ipfaq́lie falfedo on permittat tantùm fterilicatis dominari, ve erilefcat, itaque \& fuauiorem \& foecundiorem omninò falubriorem effe auram è mari fuiran m perfpicuum eft. Cim ergo Torrida hac re- montibusaltiffimis pléna fit, cùm Oceano doque maxima ex par te anbiatur, confequens 


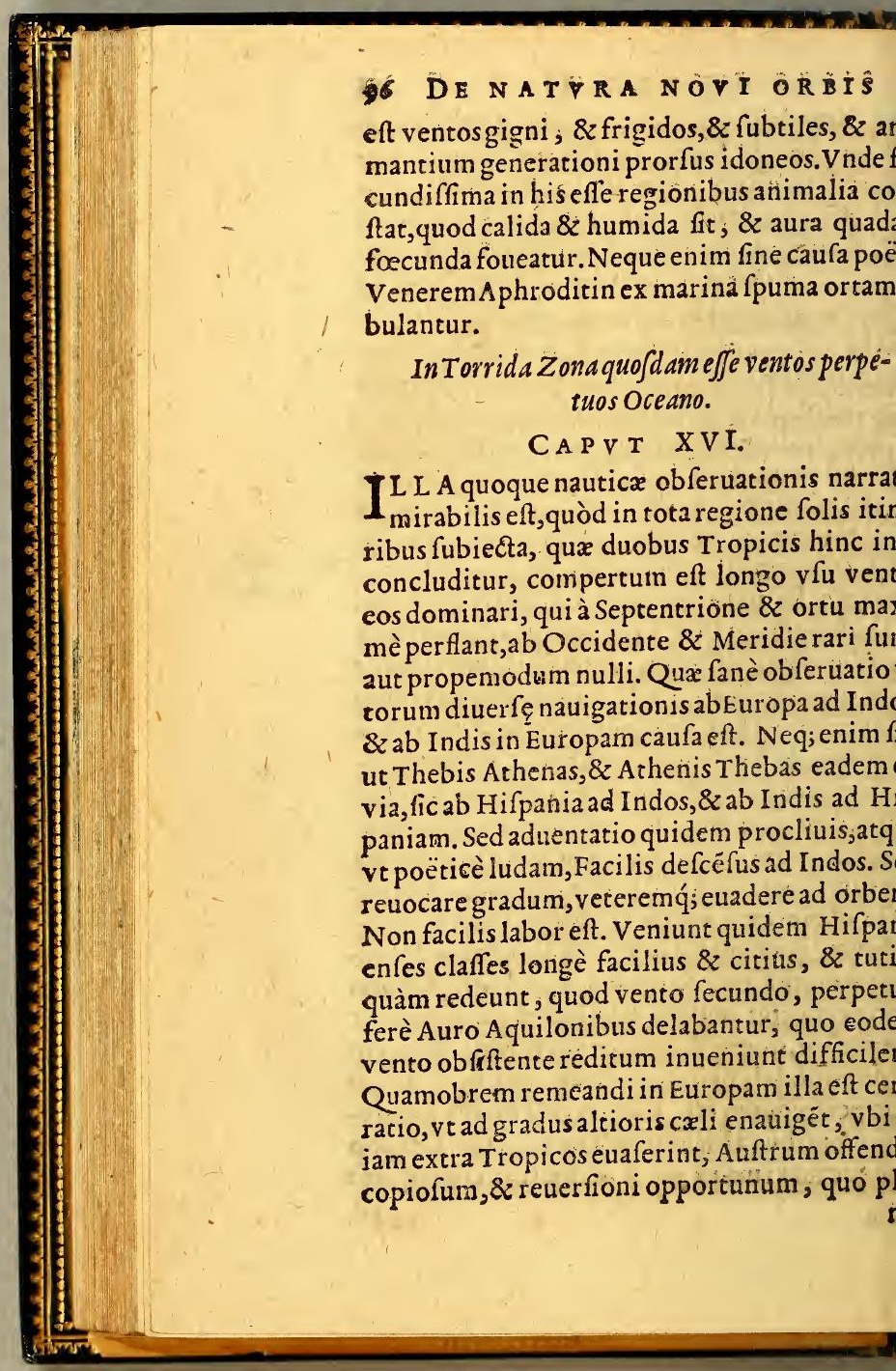


velis ferütur ad fuos. Itaq; ab Hifpali aut Gaous foluentibus occurrit primum pelagus ilprocellofum, varijfq́ue ventis agitatü, quod aarum vocant, vfq; ad Infulas fortunatas. Invaftiffimo Occano fefe committút, perper uis è Septentrionibus vfque ad noui huius orbis afpectura delati. At in Hifpaniam reuertétes noftra Carthagine ad Infulæ Cubx notiffimú rtum Habanam contendunt, vude vtraq; claf\& Mexicana, \& Peruen fis cóiundta, paulation rione Torrida enasigata extra Tropicos ad ridx ferè confpecium Auftrum puppi caint, eumq́ue nacti perualidum, inmenfum lagus \& Bermudx infortunia præteruecti ad rceras Infulas adlabuntur, atq; inde ad façrí Vincentij Promontorium Patrix optatum nfpectum tenent. Ad huncetiam modum in hoc altero immenfo Oceano cum ad Salomois Infulas ex noftra America iter fit haud difile, reditus tamen ton eft faciliş, fed aut vltra uinoctialem \& Cancrum quxrendus eft $\bar{Z} \mathrm{e}$ yrus, 8 in noux Hifpanix litora procumben $\mathrm{m}$, aut contra fuperato Capricornio ad $\mathrm{Chi}=$ fis'regni regionem cómeandum. Eadem proreft obferuatio nauigationis ad Sinas atque ad fulas Philippinas Sinis propinquas, ad aquas Mexicanis portubus neque diuturna, neq; $\mathrm{pe}-$ culofa nauigatio narratur. At ex ijs Infulis retus prolixior propter circuitü, atq; periculor propter ventorú viciffitudines. Itaq; magna ceani fpatia contêplâti certû̉ \& velut lege fix currit,intra Tropicos Septentrione \& Ortum minari, exclu fis ferè Auftro \&z Occafu. Quod më quemadmodü catera phyfica penè omnias $G$ 田辚 


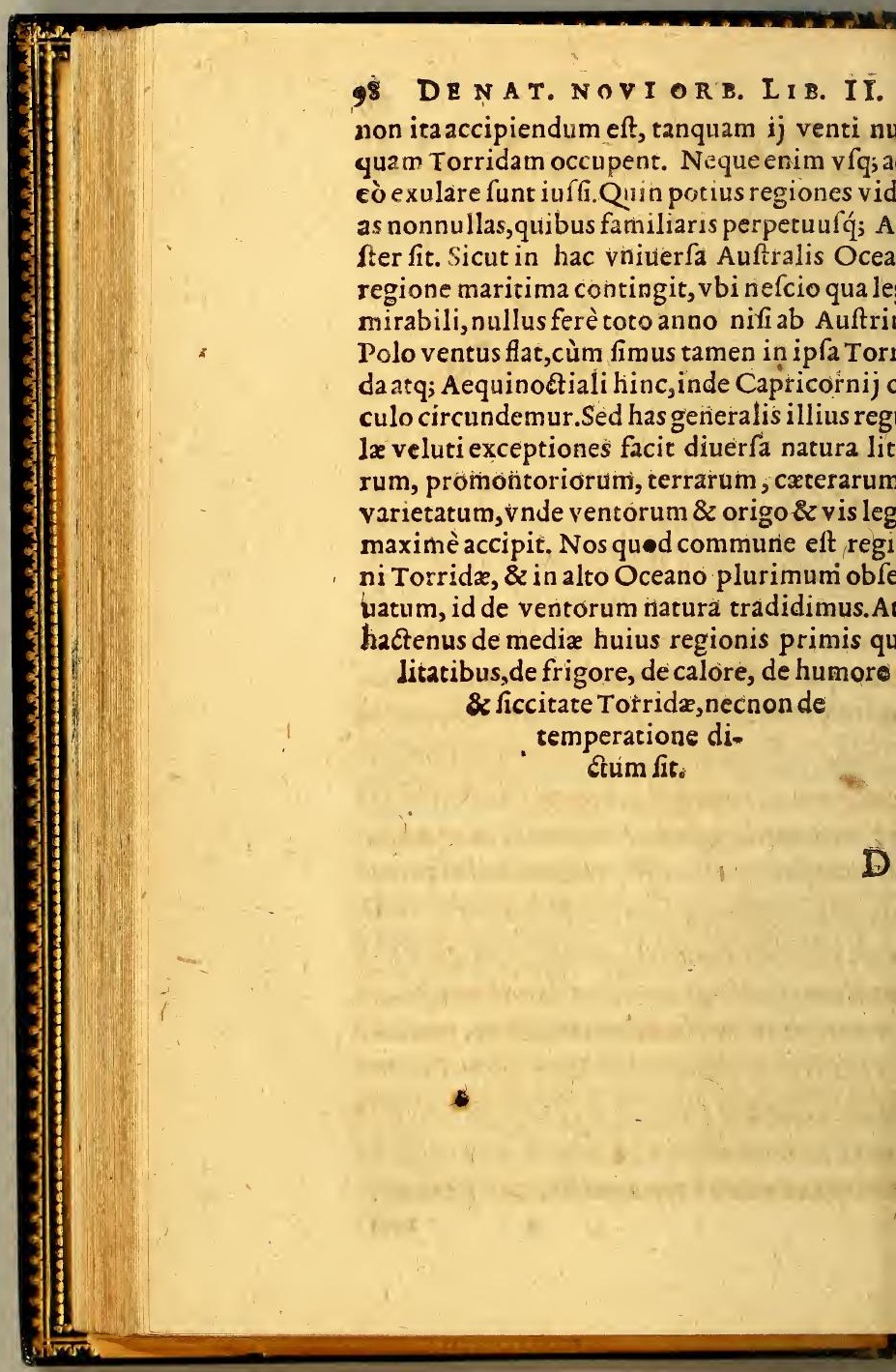




\section{E \\ 99 \\ ROCVRA NDA}

$S A L V T$ E I N.

D O R V M,

L I B R I S E X.

\section{P R O OE M I V M.}

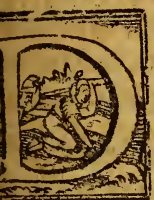

E prociuranda falute Indo: rum, recte atque aptè dicere,perdifficile est. Primium, quòd Barbarorum gentes inmumerabiles fint, vt celo, los, babitu, it angensio, morabus, inftitutis tijsime dißsdentes : quibris omnibus Eungelio conciliandis, inft ituedis, regendif $g_{\text {s. }}$ liquid commune pracapere, at que in tanto ominum rerumg, difcrimune, accomodatè c certò quid expediat definire, magnecuudamfacultatis est, quam profecto nos inimè confecuti fumius. Deinde res India vix firma ftabile góconfistunt, dr nou notidie, fuig. difirmilem babitum prefe erunt, vi innprobandum modo fit, quod no ta pridenz valde probabatur, or rebus inu at is vtili a ante confilia etiam pernicio/a iant. Quamobrem wt frina acperpetua irecepta ea de re tradantur, vix fieri pro-

(4) fecto 


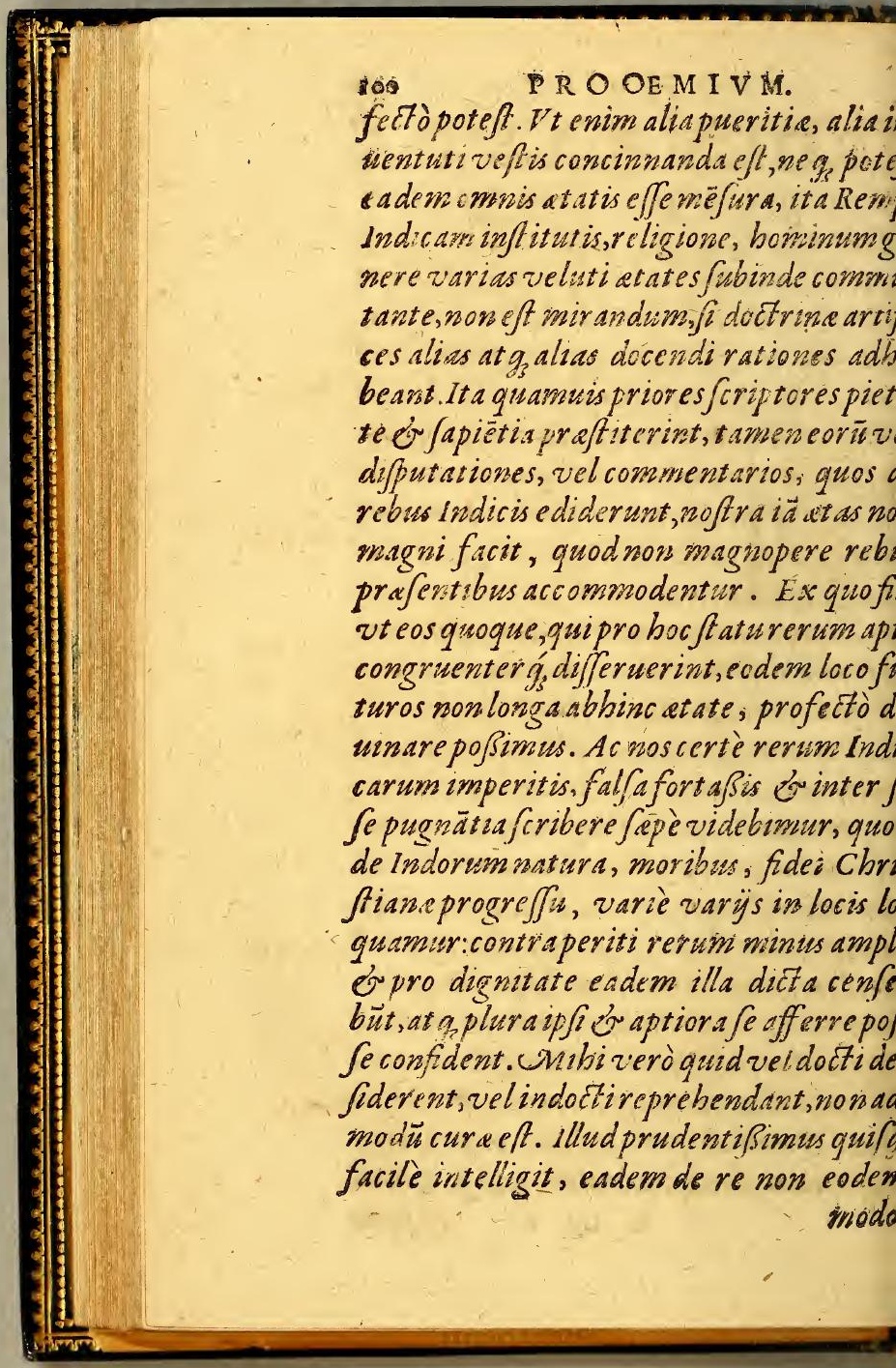


P R O OEM I V M. odo omniex parte dicendum effe. fi veriti ac non libidini abfequerdism eft. Negs Hit is, qui in argumiento multiplici pro bus dinerfis diwerfa pronuritiat. idem orfus borno fui a ape disimitis est, eadem os, \& domus eadem varÿs locis of lauri fovituperarinon falso poteft Licuit rtè Apoftolo Paulo ins eademepiftola CQ- I.Cor.to ntbios furm is ornare lawdibus, [pirituds, aprentes, quibresnibil deeffet in omni atia or dono dicere:eof demita deprime,vi carmales effe, inflatos, piritualibus bus ineptos exprobraret. Neg fibicötraus eft, aut fui iwnmemor: fed qua per par- chryf. bow? sinerant, potuit falua veritate, wt Chry- 2.in i.Corina tomus commentatur, vniuerfis afcribe- Ifaie s. , 1 raclem, Co iudiam ÿdè prophetajape itupesant, femennequarm, filios Jceleras, populum Gomorrbe, erridgenus infiniconuitia iact antes: quems tamen vel eaem interdü pagina fummis laudibus eueunt, populüiufturn, fllios Dei, buereditatēe Ifaie $6.5 \%$ ilectam,gevitem fanctam, at qalua mult o onoris cauf appellantes. imo verò eadew eriodo Paulus, fecurdü Euangelium quie, inquit, inimici propter vos, fecundü ele-Rom, nto Fone autē charißimi propter patres. Quo ag is nobis falua veritate hoce put and G 3 eft gern. 
102

P R O OE M I V M.

est gentes Indorum, quarum est tantad uerfitas, modo Euangelio aptıßimas pr. dicare, vt verè funt maxima ex parte, $m$ dòvalde alienas accufare, quódhominu fcelcre, oo perwerfa educatione conting Vuigaris error est, res Indicas täquam r aliquod aut oppidum anguste definienti of icut vno verbo dicuntur, itavnius ef nature rationif'g putantum. Sedquih. nostra legerit, inueniet profectọ nos nu. partium Jtudio ductos er proba, of prav depromere, er iucunda do triftia aque a ferre. Nibil enim teste Domino IES aliud optamus, atque agimus, quàm vt $p$ compert a nobis rerum fide, quic quid eft. eft, slÿs tradamus, quippe quifciamus $D$ Rom. 3. $\quad$ um nequaquam noftro egere médacio. $N$ queverò gentes bas vans aut falfa conc pta opinione rectè adiri or queri ad Jal tem. Sed tum demum vnicuique consta animum, cium quale és quàn magnum pus Dornini aggrediatur, non inani rum re duct us, (ed frrmo diuine vocationis co flio nitens, fecum prudenter expenderit Quamuis autem Indorum nationesi numerabiles fint, quarum fongulis fuice ti ritus dir mores funt, quas alio atque al modo infitwere oporteat, tamen cum 
P R O OE M I V M.

103 o prestare non poffem, cui plurime gensignot a funt, \& vt maxime effent cogite, immenfum opus existeret figilla $m$ de omnibus diputare, opere pretium uxi, vt barbaris omnibus accommodatius riberem, Peruenfium maximie babere ationem. Idquie feci duabus excausis, vna wod be Prowincia mibinotiores effent, vt liquidccrtius afferrem: altera, quìd hoc idorum genus velutimedium mibi inter atera femper est vifum, ex quo facilius elutiextrema indicariqueant. Et flenim ndi vocantur barbariomnes, quos noftra ongifima Oceano traiecto inuenerunt, nö olim ab Euangelica luce alieni, fed ab bu nanis quoque institutis abborrentes, $t a-$ men non omnes einfdem ordinis funt, red Indus Indo, vt Comicè dicam, multum interest, barbarus barbaro longè pr.estat. Barbaros autem probatz auctores D.Thom.in cos effe definiunt, qui à recta ratione epil. ad Ro.

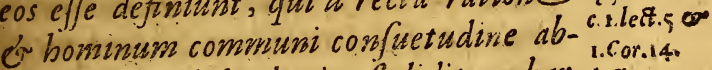
borrent. Vnde barbarica ftoliditas, bar- lect.z. baricaferitas, barbarica quoque opes ir opera apud nobiliores foriptores celebrare folent, qua o ab vfubominum caterorum valde recedunt, \& fapientia certe$G^{4}$ quíe 
\$o4 P O OE M I V M. quie rationis vix quicquam babent. Hos tem ommes noui orbis barbaros, inde Ina appellatos existimo, quòdapud veteres: motifsimaregio, qua fines orbis terraru claudere putaretur India effet, quò $A_{1}$ xandrun chiacedonem or Traianum $C$ farem penetrafje, \& facri é profa foriptores, tanquam terminos terrá ad rint, cum magna laude commemor ant. $z$ quorurs imitatione nosininowen ad nou a fe inuentas gentes deriuaffe mibivide tur. Qusiguam untio non indi, fed Sulani aut Antiliani, Occidentales ba baridicebantur. Cium igitur borum pr uzwcic, wationes, genera plurima fint, $t$ men mibi diurem diligenter peruefiga ti tres veluti clafjes effe barbarorum $v$ dentur, que magnopere inter fe difor perat, ad quas fere wationes be Iridica rea gipojint.

Prima clajis corum est, qui aे recta $r$. tione, or confuetudine geveris buman non it a multum recedunt. Hi funt potis mum, quibus dor Repsublica constans, do gespublica, Crowitates munita, or mag stratus infegrais, docerta, atque opulen comariercia funt, es quod omnium cape est, literaru celebris vous. Nufquari enis

liters 
P R O OE M I V M. rarum, et librorum monumenta extät, neagentes bumaniores, \&o miaxime po cefint. In boc gevere primi videntur sinenses, quorum egocharacteres vi. syriacis perfimiles, qui librorum copia, ademiarum plendore, leguxn, of $\mathrm{Ma}$ tratuum auctoritate, publicorum oum magnificentia plurimani florere untur. Secundium bos funt lapponentum plereque Indic Orientalis prouin, ad quas Usfiatica, atque Europea fituta alim perueniffe ego non dubiHa gentes, quamwis barbare re vera t, ơ à rect a do naturali lege plerifque rebus difcrepent; tamen ad falutem Eugelÿ sson aluter ferè vocarsda funt, quä mab Apastalis Greci, \& Romani,creriǵsu Afia, atque Europe populi. Nam potentiaprest ant, ¿ir nonnulla buma/apientia, atque aे fua ipfir ratione poSimury, DE O intus agente, vincendi nt, of Eusngelio fubigendi, quos $f i$ per ó potentiam Cbristo fü̈̈̈cere peras, nibil aliud agas, quam vt à lege Chri isna alienißimos reddas. In fecunda ego ajfe cos barbaros numero, qui quamuis eque literarum vfum norint, neque leos foriptas, neque Philesophica, aut ci $G S$ wiliu 
ro6

P R O OE M I V M.

silia ftudia habent; tamen Magistrat fuos certos, babent Rempublicam, bent frequentes, $\dot{\sigma}$ cert as $\int e d e s, v b i$ litiam fuam feruant, habent militia duces or ordinem, or religionis fua ce britatem quarsdam. Denique ration quadam burnana reguntur. In boc ger re erant Mexicani, do Peruen es $^{2}$. stri, quorum imperia of Republic. leges, or instituta merito admirari $q$ sis po/Sit. Et quod incre dibile pene vid. tur, liter arum inopiam, tant ingen $\ddot{y}$ xteritate fuppleuêre, vt \&o bistorias, vitas, \&leges, \& quod est amplius, te porum curfus, \&o rationes numeror ita teneant quibu (dam à $\int e$ excogitatis gnis, or monimentis, quos ipfi $Q u i$ vocant, vt nostricum liter is fuis pleru. que corum peritic cedant. Nefcio eq dem an certiores Aritbmeticos, ch quiduis est numerandum, aut partic dum, litere nostr a faciant, quàm bos gnailla fua . CHemoriam verò omninò dmirabile quàm fidelem etiam rer minutißimarum per 2uppos fus diut fimè coisferwent. CMultum tamen etic hi \&े à recta ratione, ô à con/uet $u$ me generis. bumani ablunt. Hac aut 
P R O OE M I V M.

$10 \%$ Sis latè patet, \&o primùm imperia conot, quale itigarum fuit, deinde regna. nora \& principatus, quales Caciqui rique babent, tum creagistratus pucos ab ipSa Republica creatos, guales Aucani, Tucapeleness, cuteriquie Chilenferè funt. His onnibus illud commuest, vt oppidatim viuant, ac non pates more ferarum, vtcertum iudicem efectumquie habeant, \& iura fua cuie ferwentur. Sed quia morum \&o ritu\& legum monstra tot tantáque apud ce furot, \&s tanta in fubditos feviendilintia, vt nifi potentia fuperiore of alsoritate regantur, vix aut Euangely lu$m$, aut homine ingenuovitam dignam cepturi videantur, aut fy femel accepent, nonfacile in ea perfeueraturi intelgantur, meritò his preffici, qui inter ta's ad vitam Christianam tranferint, bristianos Principes of cMagistratus, im res ipfa depoficit, tum Ecclefia auctoit as pracipit: Jed ita tamen vt facultaibus fortunifque fuis of legibus nons naure aut Euangelio contrarys vti liberè ermittendi fint. Lam verò tertia atque xtrema claßis barbarorum, quot bomiwam rationes, quot buins nowi orbis regiones

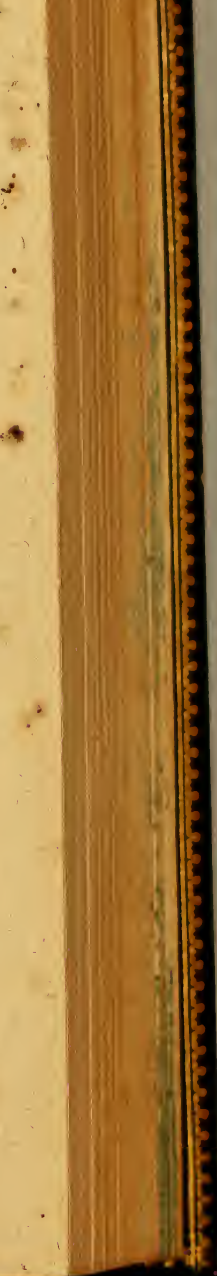




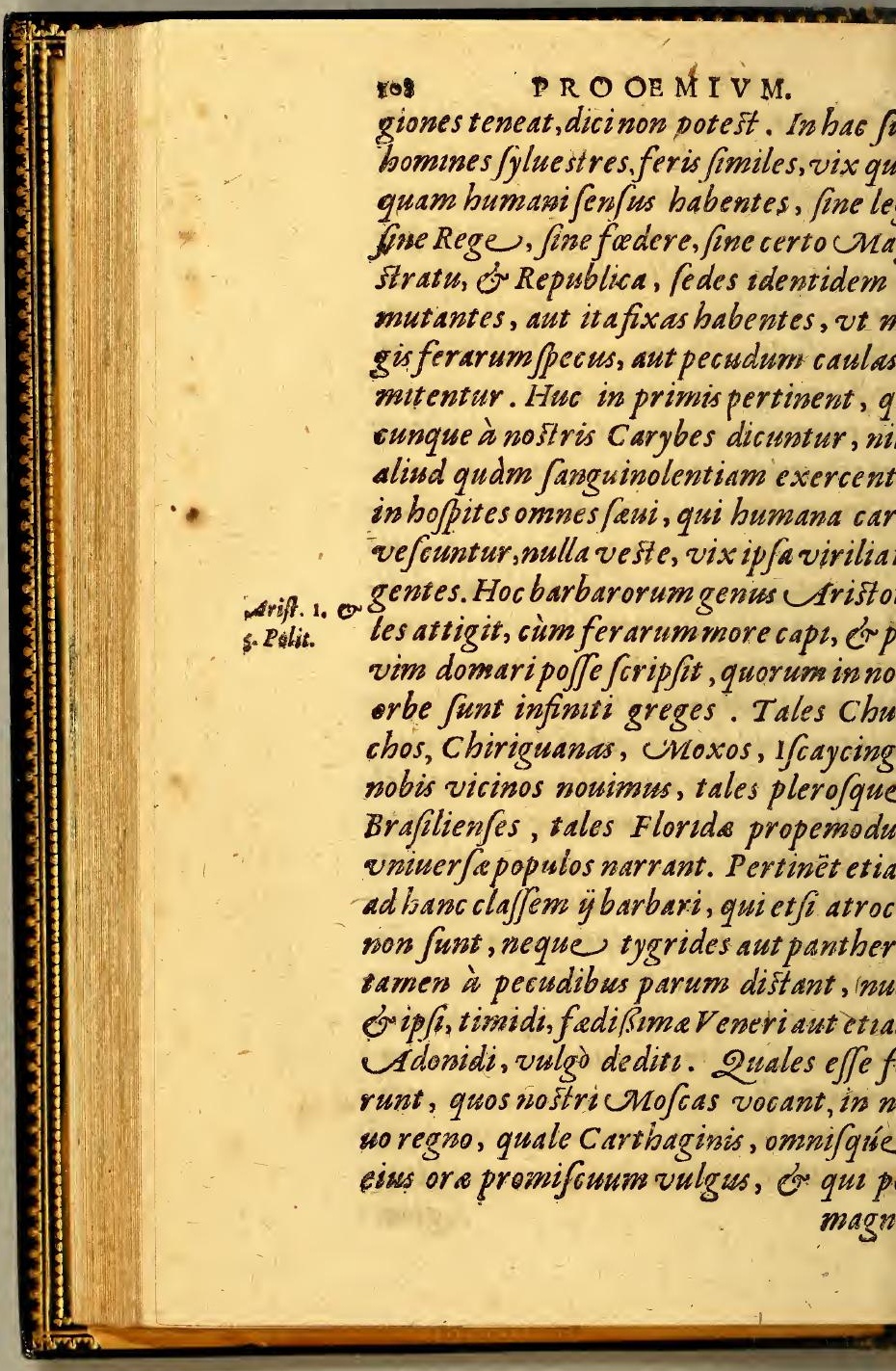


P R OOE M I V M:

10)

Tros $P$ araguay flumï maximi carsipos olunt, tumetian plusrims gentes, qua nitum viriufque ocean medium te$t$, nondum nobis $\int_{\text {at is explorat }}, \int e d f_{\Delta}$ cerce. In orientali guoque India injuspermulti eius generis effe videntur, Maluquiani. Huc etiam pect at aliud barorum genusmanfuetum, /ed Jenfis de exiguo, auinonmbil fuperiores ex. ere videntur,quandam Reipub.imagin refe ferentes, (ednugarum perfimis on leges, dr cultiug gerentes : cuing modz̀ feruntur, que apud Inf iulas Salornonias as innumerabiles babităt, ơ maxime inenti herere dicuntur. Hos omnes bo nes, aut vix bomines, bumana docere otet, vt bomines effe difcant, tum pueromore inst ituere, of fiquidern blandiSonie ad meliora ducantur, bene: fin nus deferendi non funt, fed fi aduerfus utem fuam proteruant, et in Magiftros dico $\int_{2}^{\prime} \int$ uos ing asniant,per potentiam ó neftam vis quandam ne Euägelium ins diant, coercendi funt, of in officio contindi, quos de jyluis transferri ad urbes, et. manam vitam, \& quodarnmodó inuitos Lue. Is regnum introire compellere expediet. egenim de omnsbus Indorum gentibus codem: 


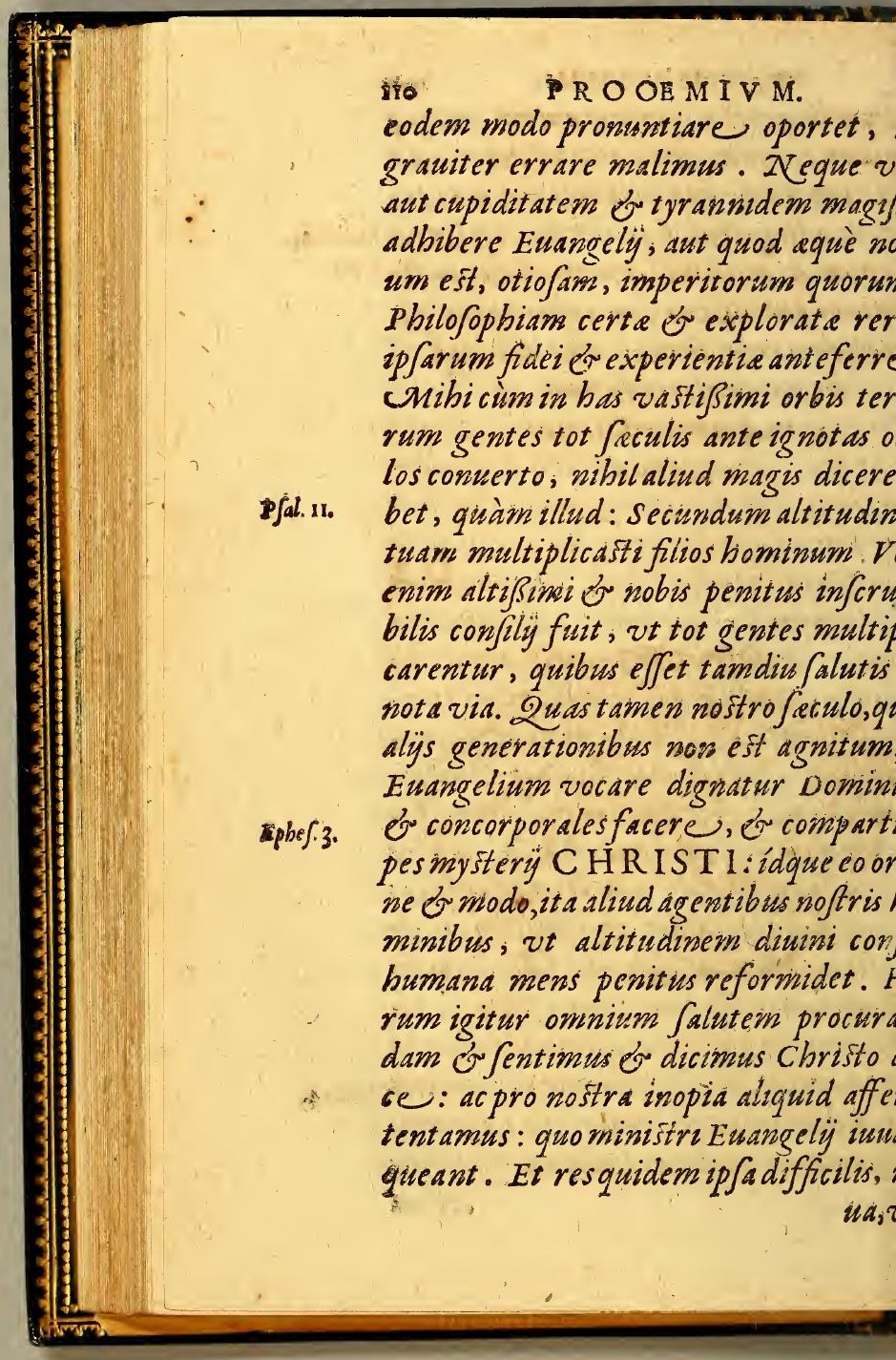


P R O OE M I V M.

ixt: varia existit: vires autem nostre wam exigux. 2ui autem docere didé potest, \& que docuerit, animo perdere, ille certe est, qui unus eft CMa- Matth. $2 j_{0}$

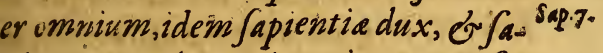
stium cmendator, in cuius manu $\int u$ nus or nos \&o fermones nostri, ip $\sqrt{i}$ bonor ơ gloria \& nunc \& in diem at ernitatis.

Ameri.

D

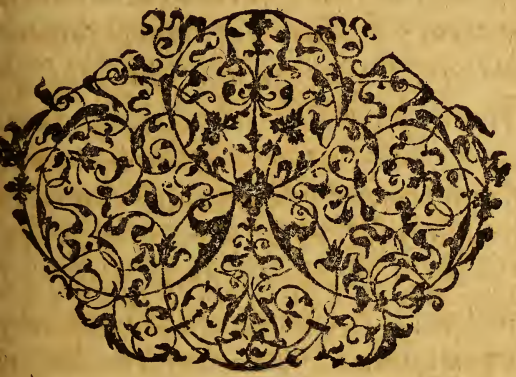




\section{2 \\ D E \\ PROCVRAND \\ I $N$ D O $R$ $V$ M \\ S A L V T E, \\ I I E R PRIM $\vee$.}

Quodnon for deßperanda falus Indoruns:

CAPYT $I_{\text {. }}$

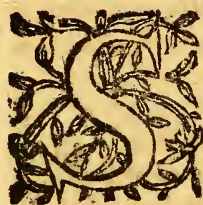

A L V T i M barbarorum, deiq̣́; propagationem, quilo gè pofiti funt, ac rem voto fi meriuntur, facilem ac fpeci fam prouinciam arbitrátur, cú innumerabiles populos $h$ altero orbe diffufos breui tempore adChrift i men tranfijffe audiunt, vberèm copiofamq́; m fem non multo negocio ex hoc agro fibi perfu dent. Itá fapè accidit, vt qui ad opus accedun tune de manipulis $\&$ horreis cogitent, cùm de ratro \& femente deberent. Contra qui perica faeto propius rem viderunt,atq; trastarunt, $t$ talefć; difficultates offendunt, vt pleriq; labo victi penè defperatione frangantur: \& fudor quidem magnos \& diuturnos, frugem verò nullam,vel perexiguã effe contendunt. Mihi v rò fi quid melius \& $\&$ vilius fapere donatum fi vtraq; fentétia corrigenda, ac moderanda vid tur.Nã quemadmodum præclara omnia nequ quä cuiuis peruia effe folent, ita profectò quse r ceffaria homini Deus effe ftatuit, in ijs qui diff dit, fummę prouidentię facit iniuriä. Neq; eni genus aliquod hominü exclufum eft in Euägel fideic 
iớ; communicatione, vbi à Chrifto DomiApoftoli audiunt, Euntes in mundum vniuer Marc.16. ,prædicate Euangelium omni creaturæ. Et Cus, Prædicari in nomine eius pónitentiam Luc.24. mnesgentes incipientibus ab Hierofolyma. pertius, Eritis mihi teftes in Hierufalem $8 \mathbf{z}$ At. . mni Iudæa, \& Samaria, \& v fque ad vltimum x. Et alibi,Docete omnes gentes. Quis igitur Matth.28. illuftris precepti toties commendati auctotem contemnat? Aut quam hominum natioadeò feram \& ab omni humano fenfu remo beneficio Prædicationis, Fidei, Poenitentiæ iuinæ doctrinz deftitutam putet, cùm audiat ninum de vniuerfo mundo obeundo, de omus docendis difcipulos conteitantem? Quod on omnium effe Fidem Paulus docet, tamen on conditioni hominum aut natalibus tri2.The $\int .3$ , fed peruer fitati \& importunę cuidam obcę oni.Certè enim vt non folùm prædicationê ngelij in toto orbe cogitaremus, verùm etiä gnem vbique fructificationem, Ioannes in calyp fi in turba illa magna \& beata Agnum Apor.7. uente,omnem populum, omnem tribum, om n linguã, qux fub cælo elt, cómemorat. Quin ius fiattétius diuinas fcripturas legamus, apebit $\mathrm{f}$ urtafís non fine magna ratione, ac diuiquodan myfterio extremum \& abiectiffmú us hominum, vel pracipuêad fortem Euanij vocari. AEthiopia, inquit, præuenietma- P $\int a l .67$. eius Deo. Quæ verò gens defpicatior his, qui ipfo tetrore $\&$ putore horrori pene habenDe his Sophonias quog; Propheta: Attenua- Soph. 2. omnes Deos terræ, \& adorabunt eum viri de o fuo, omnes infula gentium. Sed \& vos AEH thiopes 
II4 DE PROCVRANDA INDOR V I thiopes interfectigladio meo eritis, illo nim Watth.10. rum gladio, quem Dominus venit mittere int Heb.4- ram,quod eft verbum Dei, pertingens vfque divifionem anim $x$ f piritus. in codem quoq Soph 3. Propheta legimus. Qia tunc reddam populis bium eledu, vt inuocentomnes in nomine $D$ mini, \& feruiant ei humerovno: vltra fumi Aethiopix, inde fupplices mei filij difperfort meorum deferent munus mihi. Quosnam difp 2fal.126. fosfues Deus nofter intelligat, nifi quos al Ieq́; vident vocat filios excufforun?quod cęlefti virtute $\epsilon$ primi, que- cuff, vt electx fagittx, ac toto or be difperfi vust tamen pulos innumerabiles falutariter feriant, \& $\mathrm{v}$ biquoque se ctos, ac fupplices Deo fuo fpolijs gloriofi poft oes, Acthiopumg;feris alienogurgite cispos. Et teterrarum nejcit sui debert or diuinis literis terras has omnes magno Ocea bis Lucan. circunfulas defignari, tametfi continentes plt so Ebarf.de maex parte fint, fortaffis, quod ea antiquorú $f$ ivilo. In oratione notalitora, vel nullä habitari regionem, vel tétia fuerit,vltra Afix, Europaq́;,atq; Africęf funebri $B a$ fi qua eflet infularem effe tantummodo. Nam fili, $\infty$ ad à Pindaro poếta decantatum eft, vitra Gac Pofibumia- mare effe hominibus impermeabile, $\phi$ prou num epif. zi. bij loco non femel fanctus Nazianzenus ce brat.Itaq; cũ vel Sophonias omnes Infulasge Efaside 66. tiû́adoraturas dicit, vel Efaias ad Infulas lon ituros,qui faluati fuerint, vltra Africam, \& L diam,\& Italiam, \& Græciam, \& annunciatur Dei gloriam gentibus, deq́; ijs omnibus adduc sos fratres fuos donum Domino:fue etiam cù hort 


\section{SA I V TE. LIBER I. - IIT}

tatur ad decantandam Domino laudem eos, Efaie 4r" in extremisterra habitant infularum inco- D. Fitero ain Rz máris:non abfurdè profectò torius huius Epz at $\mathrm{L}_{-}$ miorb homines ad Chrifti nomen \& glo pheji.z. clemens in nagnofcenda conuocandos, conducendolć; Epif fos i ificare intelliguntur. Cur enim contemptos, sis, Poft Oes empiternç obliuioni datos homines arbitre- nups muxi $i$ r apud pium Conditoré, \& benigniffmü k e- fentalii. nptorem? Nunquid nó vnus eft Pater omniú? Loqui $; b_{i}, \forall$ alio fanguine Graci \& Romani, al io barbari videtur, de ndi redempti funt? Ipfos certè Iefu Chrifti gentibus nooftolos fcimus ad remotiffimas, ac ferocilfi- uiorbis. s nationes penetraffe, neq; earú belluinis mo us deterritos, neq; fenfus ituporé pertx $x$ os 8 . dicaffe Euangelium \& baptizaffe, \& munus e Domino iuxta propheticum vaticiniü ob- Malach.z. iffe.Agnofcebant fe debirores crediti talen-Rom. jręcis pariter $2 c$ Barbaris, fapientibus atq̧; inientibus. Intelligebant in Chrifto Iefunon Iudæum \& Græcum, barbarum \& Scycham, colef.3。 nouam creaturẩ, qux lecundùm agnitionem i renouatur in imaginé eius, qui creauit illá. nim quos paterfamilias licet debiles, licet rac.14. udos, licer pannofos \& horridos ad praclazas eftis conuiuij epulas pro fua magnificentia ditari iubet;cuius obfecro temeritat is, cuius puderizerit, hos ve ferui conuiuas dedignen,auerfentur, faftidiant? Nifi putamus melius e perfpesam miniftris vel conuiuarum ratio$\mathrm{m}$, vel conuiuij dignitatem, quàm ip fi omniü. nditori \& largitori?ln illo certè linteo, quod tro efurienti cęlitus oblatum eft,omne genus n folùm volucrum $\&$ animantium; verùm etm ferpentium ac reptiliŭ expofitú,ac præxara H 3 tủ 


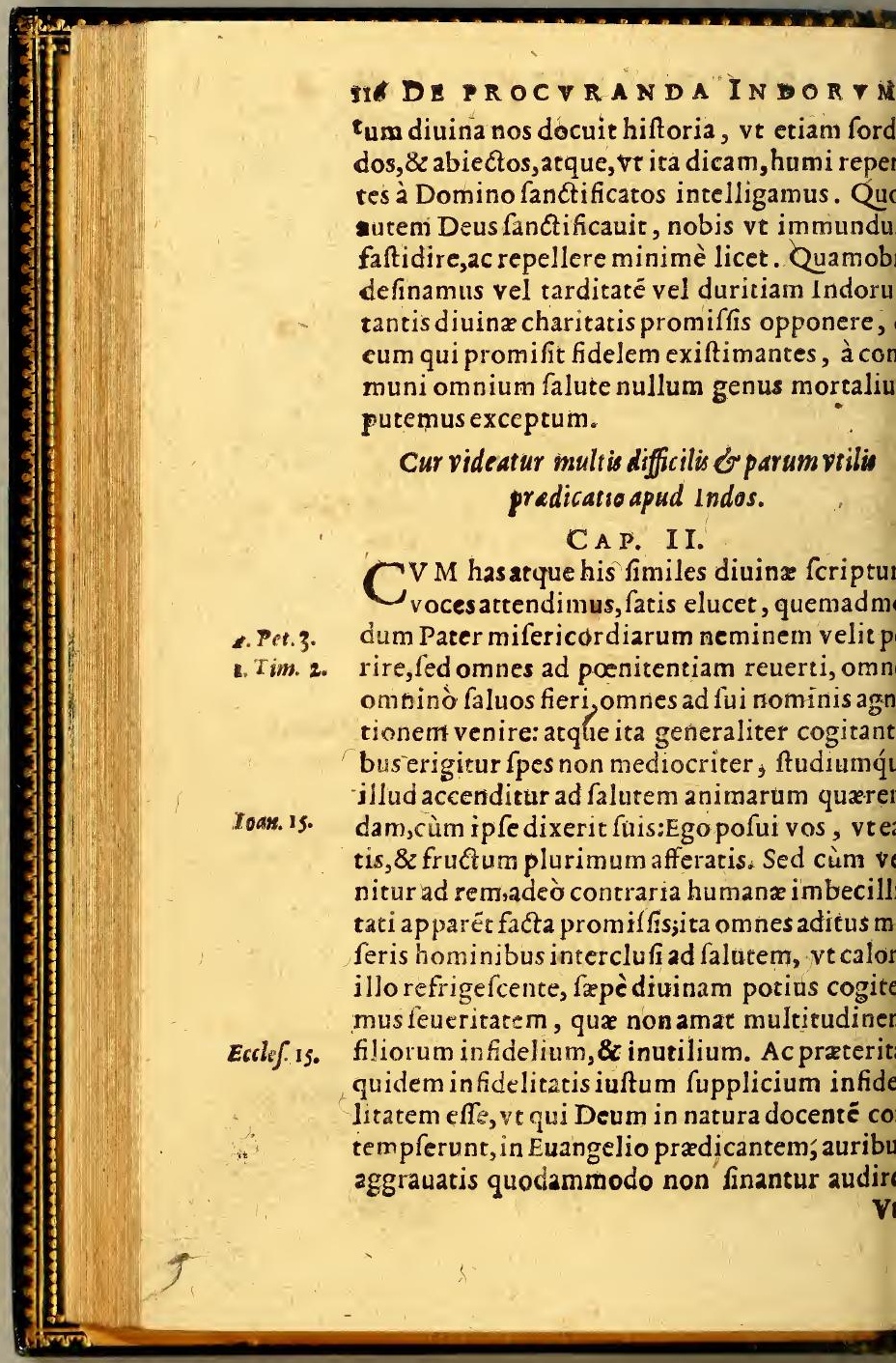



enim arcani cuiufdam ac diuini iudicij fuit innumerabiles populos tot annorum milliDei notitia caruiffe, ita quoq; eidem tribuen n effe, quod notitia quadam tenuis offeratur, ita offeratur,ve facilè repudietur, vel ita dem recipiatur oblata, vt mox perniciofius deatur. Quis enim cognouit fenfum Domini? c̀ iudicra illius abyffus multa. Itaq; videtur Eja.40 erientia ipfa docere infinitam hanc Indorú bariem, fuis ita exigentibus malis cùm à luuangelica per mille quadringêtos annos abaffe;um verò diunna vltione acrius perurgé oftquä, vt Pfalmus habet, corufcauerunt or- P folm. 76. erræ fulgurationes eius, atque his locis illuveritatis radius,-occxcatas effe mentes infiium, ne fulgeat illis lumen Euangelij pacis. $m$ quòd quidam Apoftolicam tubam ethis regionibus olim in fonuife arbitranhuc vocantes I'rophetre teftimonium à Panronunciatum : In omnem terram exíuit foeorum, \& in fines orbis terræ verba eorum, Rom.10. mihividentur tantam rem fatis conficere, n etiam Auguftinus fua xtate in Africæ qui- Epif.So.ad daa partibus ignotum adhuc fuiffe Chrifti no Hefyshiumo naffirmet, quo ne Romani quidem imperij a peruaferat. Me verò yt illud fecus intelliadum putem, mouet maior auctoritas Chrifti mini, qui perfpicuè docuit tunc venturam mundi confummationem, cùm Euangelium it toto orbe vulgatum. Quamobrem illud, pleraq; alia, ita de A poftolis accipiendum eft, Auguff epif. A poftolici viri fimul cogitentur: quorum fo- 80.78 . s in ornnem quidem terram exit, led grada, fuif́q́; temporibus fecundùm xterni confilij H. 3 decre- 


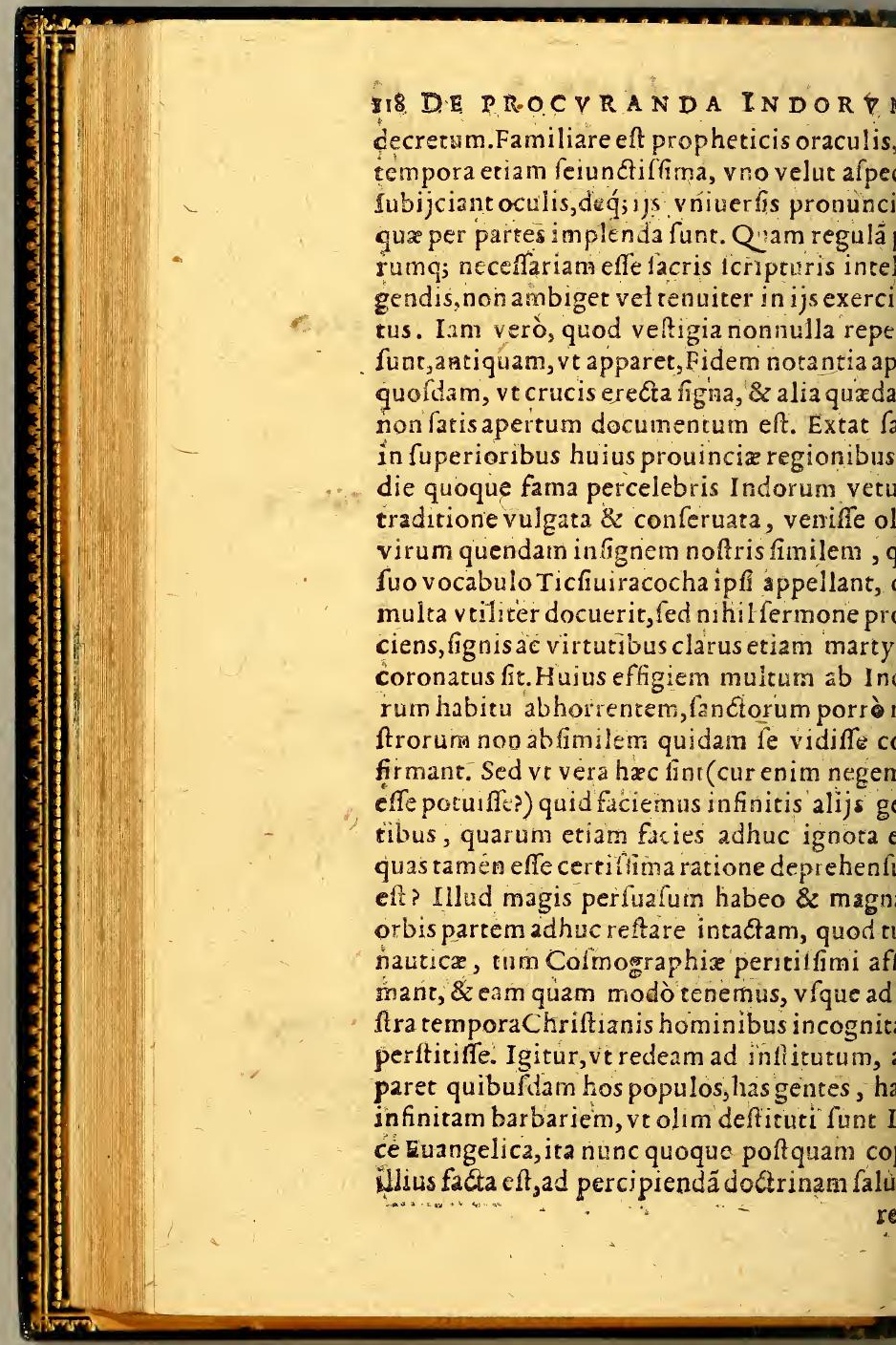


S A I TE. I I BER Y. $n$, neceffaria intelligentia \& capacitate defti- Vtrumque enim aquè infcrutabilis iudicij equod vt penetrare non polfumus, ita neque culare debemus. Re vera, quod in libro Sapiria de antiquo Chananzorum populo legis, id aptiffimè in Indos quoldam conuenire ilè annuerit, qui eorum ingenium morefque rfpexeric. Non ignorans, inquit, quoniąm ne-sap. $1 \mathbf{2}_{\mathrm{q}}$ am elt natio eorum, \& naturalis malitia ipfo$\mathrm{m}, 8 \mathrm{q}$ quoniam non poterat mutari cogitatio rum in per petuum. Semen enimerat $a b$ inimaledictum. Sunt ergo quidam ingenita ac lut hæreditaria malitia imbuti, quorum adeò rtinax \& peruerfo hærens cogitatio eft, vt nè auelli nó poffit.Si mutare poteft Aethiops Hiere. 19 llem fuam, aut pareus varietates fuas, \& vos teritis benefacere, cùm didiceritis malè. Tam ofundè humana mens nequitiæ gurgite $a b-$ rberi folet interdum, vt pene miraculo tribui beat, fi quis eam inde polfit eruere. $\mathrm{N}_{8}$ verò nditorem fuum audeat vile figmentum accure, diuinus fermo continuò præuertit dicens, is enim tibi dicet, quid fecifti? aut quis Rabit Sapient. $1 \%$ ontra iudicium tuum? a quis in con pectu tuo eniet vindex iniquorum hom inum?aut quis tiimputabit, fi perierint nationes, quas tu fecii? Hæc ergo prima, ac præcipua caula fe offert,

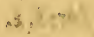
ur multo labore in his regionibus parum emométi fperandum fit,quod femen maledictum, c diuinisauxilijs propemodum deftitutum in erditionem deftinatum fit. Sed ve altiora conlia inueftigare defina mus, certè doctrina Chritifublimiseit, vira Euangelijplufquam humaa. Homines integrosatque ingenuos poltulat 


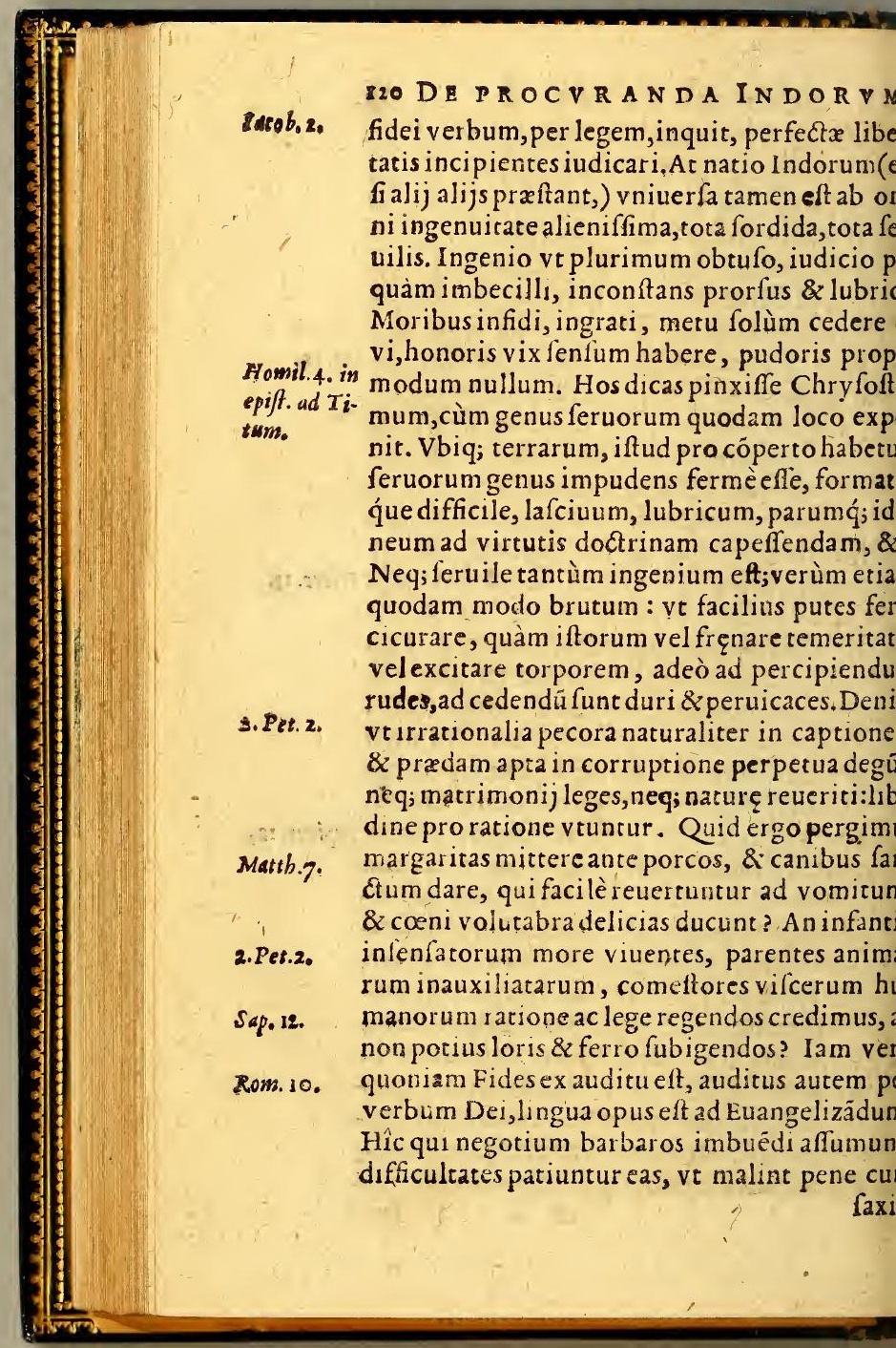


SAIVTE. IIBER I. I2I is, \& marmoribus agere, quàm de rebus in fe dem arduis \& fublimibus, \& elingues dice$\&$ à furdis audiri. Ferunt olim feptuaginta bus linguis confufum effe genus mortalium: i feptingentis, \& eo amplius inter fe difcre$t, v t$ vix vallis habitetur paulò latior, quæ nó materna lingua gaudeat. Et fi enim in vniuer ngarú imperio, quod ab xquinoćtiali Quíto ; ad longiffimam Chilæ prouinciam per graferè quadraginta diftenditur, lingua generaRege Guainacapa introducta viget, tamen ndorum gentes innumerabiles lunt his telnis excluił, \& eæ ipfæ nó ita illa familıariter ntur, vt apud vulgus promifcuum in viu fit. cedit quod my fterijs Fidei præcipuis vocabu xpè defunt, vt Indicæ lingux periti tradunt. interpretem verò rem tantam agere, $\& \mathrm{cu}$ que plebeij ac vulgaris hominis fidei, \& ferni comittere documenta falutis, tametfi nefitate impelléte factitatur, tamen res ipfa do$t$, quàm non folùm incommodum fit; led etperniciofum interdum, dú alia proalijs inpretatur, aut quia non affequitur, aut etiam ia fequi docentem piget. Quid igitur faciet, i linguarum donum non habet, neque interetationem fermonum, qui cum barbaris cogi;\& ip f barbarus effe, vt cùm loqui nefciat, ta cenon poffit ? Lingux difficultates, locorum n minores fortaffis excipiunt. Nam, vt onit$\mathrm{n}$ nauigationem longilfimam, moleit ijs perilifq́ue pleniffrmam, ipf $x$ habitationes Indo$\mathrm{m}$ ferè inacceff $x$ fpem falutis videntur exclure.Videas plerofq; ferarum inftar non vrbes, oppida, fed rupes, atque antra incolere, neque 


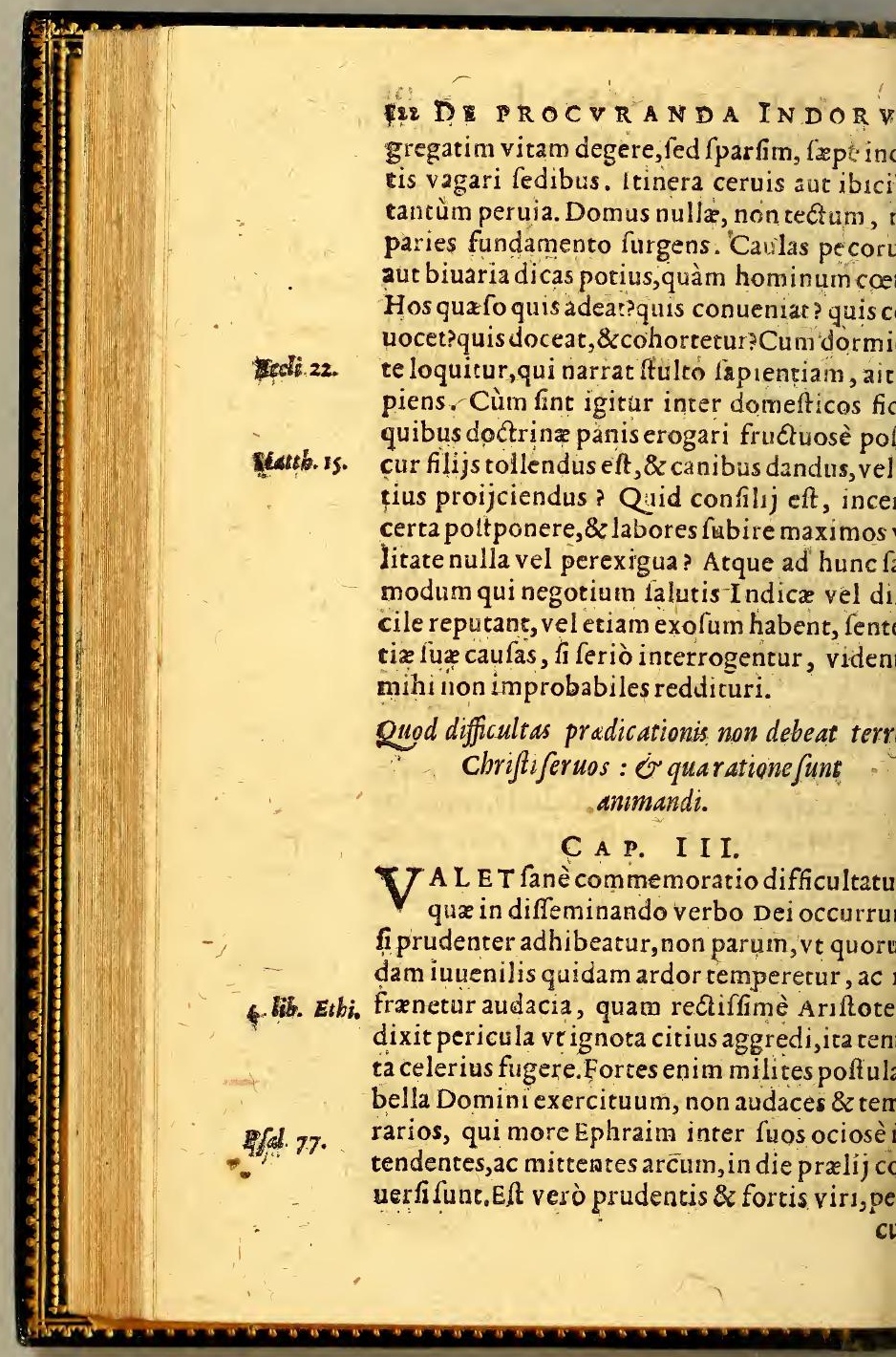


2, difficultates omnes, rerumq́; incertos exilecum ante roditari, non vt magnitudine laris territus, fpem abijciat victorix, fed quò $\& z$ atier, inf ructioró; accedat ad rem, \& dubiam tem, fi fecus cedat, minus iniquè ferat. Ita ceridemus Mofem fuas metientem vires, detrefie cum Pharaone congreffum, Hieremiam ophetandi prouin ciam deprecatum effe, Sau- I Reg 10 $n$ cú adhuc Dei f piritu regeretur, ob regnum latum latitaffe: quos tamen omnes cxterofq́; mines Dei \& fi rei magnitudo probè perfpeterrebat;tamen Dei omnipotentis amplius re auit, \& confirmauit autoritas. Illud enim vesimè à quodam noftro fratre, diu multumoq́; in c negotio Indorum exercitato dictum etiam experiri iam mihi videor; Inter omnes virces ad functionë eam neceffarias caput effe hulitatem. Hæc neq; magna fa pit, neq; fibi pollicur illuftria, neque labore vnquam frangitur, q; verò fructus etiam tenues dedignatur : fed iduis per eam efficiatDominus, id gratum pro gno habet. Verè humilibus dat gratiam Deus, 7; his adminiftris, fortia frculi \& præclara cóExod.3:
Hierem. T: $^{-}$
I Reg. 10 ndit. Ac mihi quidem humilitatis maximè inia in caufa efle videtur, penuriam vt fructuú deamus, $\&$ cùm multum fortafsis feminauerius, metamus perparum, quia iuxta Prophefermonem, Vnufquifq; in donum noftram fe- Agge. inamus, $\&$ domum Domini non curamus, id $I$ scob.4: 1.Pet.5. $t$, auidius noftram quàm Dei gloriam quærius. Sed venio ad rem. Indorum veram conueronem ad Fidem perdifficilem effe dicunt. Eft nè. At illud non of citanter cogitare oporter, m e: Fidei predicationem fuifle difficilii$\mathrm{mam}_{2} 8$ 


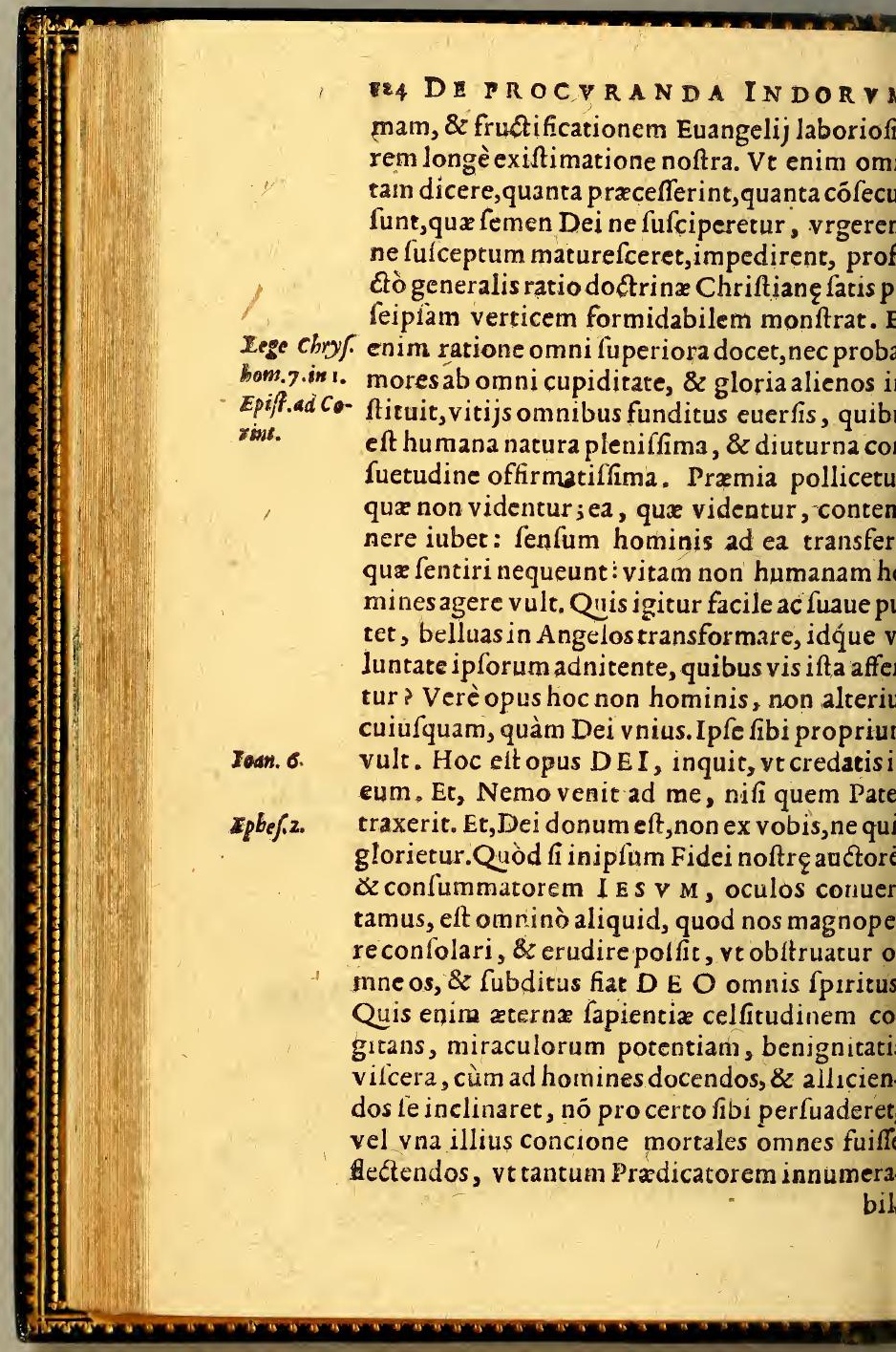


SA LVTE. I I BE R I. 125 multitudine certatim orbis vniuerfus feretur? At vide, quàm resenenerit fecus. Diu ngelizauit, fummoconatu, magna diligenadhibitis fignis ingentibus, qua nemo aliàs it, vita innocentiffima, conuerfatione fuauifa, auct oritate diuina, quid egit q quid confeus eft? Si confilia xterna fufpicias, plufquam elligi poffit. At fi hominum gratitudinem $\&$ equium confideres, horror eft dicere. In exipopulo, eoque per plus mille annos infrulegis, \& Prophetarum oraculis, vix paucos cipulos habuit, eolque neque præcipuos, neconftantes: plufimos aduerfarios, innumeiles obtrectatores, quide malis verterentur elfimos. Et indignetur homuncio non fibi s fegetes furgere ad primum feminis ia$m$ ? fruftratum fe conqueratur, fi ad prædionem fuam non cernat hominum millia da manibus fterni? Ioannes Baprifta ipfa homi$n$,qui Chrifum fequerentur, paucitate com tus, dixit ad fuos.Qui de calo venit fuper o- Ioan. z. es eft: \& quod vidit, \& audiuit, hoc teftatur, eftimonium eius nemo accipit. Nam prodoris dignitate, tam exiguus difcipulorum nurus quafi nemo Ioanni meritò videbatur.Aumus verò ipfum ducem $\&$ A poltolum confeljis noftre piè cum Patre fuo zterno expoftutê. Et ego dixi, In vacuum laboraui, fine cau- Efa. 49. vanè fortitudinem meam confumpfi. Nón labores tot \& tantos prædicandi, pernoctanvicos \& caftella circumeundi,clamãdi, nauidi,curädi grotos, diuina $\&$ mirabilia patrãvacuos \& infructuofos penè dicas, fi paucitaChrifti difcipulorú fpectes, cateruas inimicorum, 


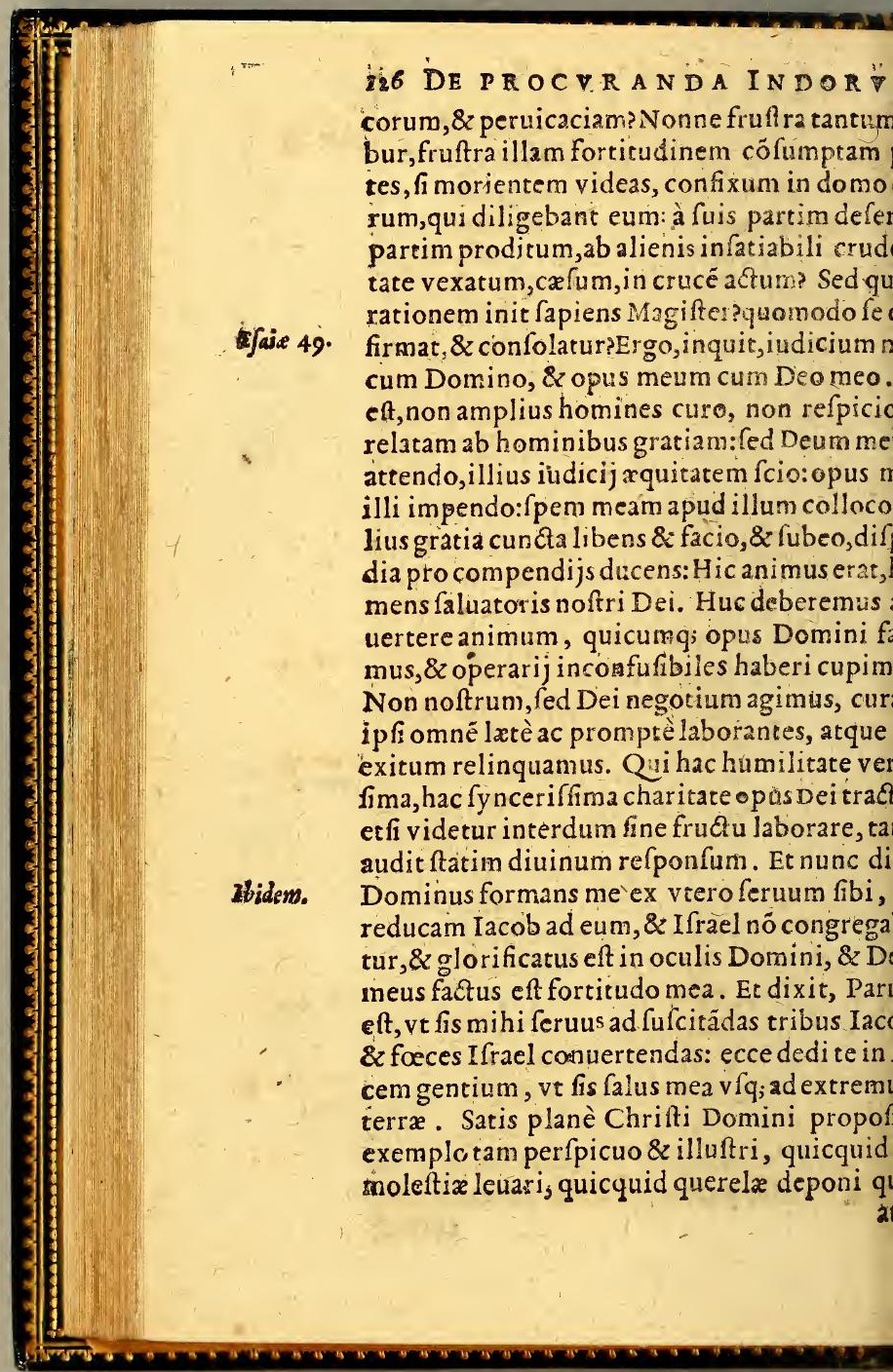


i cordis aliquid ac frontis fuperfit homini. que cnim dif́cipulus fupra Magiftrum eft, neferuus maior Downino fuo.

\section{Deeademrie. CAP. IIII.}

fficiebat quidem Chrifti feruatoris exemlum:fed redarguendaeft adhuc noftra defi\& compungenda per cætera exempla Patrú. oflolorum lanè trophá cernimus, \& totius is victores figna crucis vitra Romanas aquiextulife miramur, magnæ felicitatiscurfum imus, \&z fi caretur, tantam gloriam iuuarec tari.Sed cohibeamus tantifper animum, $8 z$ rum fudores, pericula, certamina, tempor is ticultares, hofium magnitudiné cogitemus: elligemus profectò longè carius illis ftetiffe toriam, quâ quifquam facilè credat. Arma, in$t$, militize noftra non carnalia funt, fed poten 2.cor. Deo ad defructionem munitionum, confilia truentes, \&omnem altitudinem extollenté Iduerfus fcientiam Dei.Quid igitur?Comme Rom. 1s, rat fealibi ab Hietofolymis vfq; ad lllyricú pagaffe Euangeliú Chrifti, \& longè latè per cumpofitas regiones, quas, fi quis confidere menfa terrarum fparia, mirabitur potuiffe $v$ is hominis peregrinatione cognofi, nedum etrina Apoftolima impleri : quoetiam in loco Hifpaniam profectionem fuam prędicit,eame prædictionem poft priorem eins catenä Ro e re ipfa completam, non defunt, qui affirmét, quibus effe videntur Hieronymus \& Chryfomus. Sed quibus periculis \& r rumnis tanta regerit, nemo melius polfit narrare, quàm ipin pofteriore ad Corinthios Epiftola. Pelagus
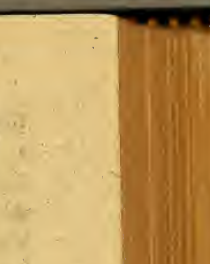
128 DE PROC VRA N DA IN DOR V Cbryfoft. ho. illud laborum, actempeftatem fi quis intue to. in 2. ad videt omnino nullo modo nifi per crucem Timoth. $\sigma$ cisprædicatores viciffe, eorum quoque $x \mathrm{~m}$ de Landibus tores non aliter effe victuros. Verùm cùm $\mathrm{C}$ Pauli bo. 7 .

1. Cor. 11.0 dz. non diffinilis fit,nefcio tamen quomodo $\mathrm{d}$ cultates patimur nunc omnino contrarias, quis attentius confideret, diuini confilijalt dinem admiretur. Nobis nihileft perinde ue, ac uimius fupor \& infipientia barbaror contra A poftolos nihil ita exercuit, atq; inf illa præpotenf'́; fapientia,tum Iudæorum, t ,

; Gracorum,tum maximè Romanorum:vt fe luti ridiculos exhibere viderentur fynago: Academijs, curix. Nos prædicamis, inqi y.cor.j. Chriftum crucifixum, Iudæis quidem fcanda gentibus autem ftultitiam: ita vt in magna 1 zom. r. de fua Paulus ponat, Non enim erubefćo Eu 2.Tim. 2. gelium, \& ad Timotheum fcribat, Noli erub cere teftimonium Chrifti. Illos vrgebat po ftas freculi, cùm imminerent imperij fafces. $N$ poteftares quidem ac Magiftratus Gentilium rum timemus, cùm fit lumma penes Chrift nos:fed abeadem poteftate non parum fuft it mus nonnunquám moleftię, \&incommodi, ci cernamus non rarò euerti prauis exemplis at ritiaq́ue quorundam, quicquid ab alijs ædifi rur ad fidem. Illi ingenia hominum nacti ft elata, \& peruicacia, ipfáque faculi pruden fimplicitatem Fidei inflexibiliter relpuent Nobis mobilitas conerà imbecillitafque nat ralis Indorum ingenij moleltize plurimum fert: vt illos quidem laxis mandare Euangeli femina diceres, nos arenç. Maiores noftros Jab indefeffus, inopia, ignominia, cruciatus neci 
tidianum quodammododifcrimen: nostæ$\mathrm{m}$, fermonis inopia,ipfa hominum ignobilifolitudo quadam, ac defperatio maximè opnant.I taq; Fidei predicatio ficuti res eft ma, ac maior omniexiftimatione hominum, ita quam fine ingenti labore \& conftantia peraotuit. Quis credidit auditui nofro, \& bra- $1 \int a i . \$ 33$ : um Domini cui reuelatum eft? Sed in Deo po da fpes, qui dat verbú Euangelizantibus vir-p pal.6\%. e multa: vt quamuis euntes fleant mittentes P Pal.1zs. nina fua, venientes certè gaudeant portantes nipulos fuos. Ipfe dicit, Ecce ego mitto vos: Mattb.10. e eft, qui operatur Fidem, $\&$ dat incrementú, Pbil.z. suangelium crefcat, \& fructificet in viniuerfo colos.r. do. Verú nos tyrones terrent militiz labores; rangunt.Et dicimus, Quid putas quia præte-Eccle. $\%_{0}$ tempora meliora fuerunt? fulta fine dubio itatio. Nam fi in illa fuperiora incidiffemus? tam afperitatem nequaquam ferre poffemus: I quia prærerita funt, felicia; \& fuauia putan:S igitur antiquorum temporum allicit nos, ue tenet mirabilis in Chriftianitate prouen, 2 noftra nos egeftatis tadet, cogitemus laes illorum noftris fine vlla comparatione fe maiores; \& Dei fapientix ac bonitati gras agamus, quæ pro magnitudine operis idoos operarios parat. At funt multi, qui tametfi magna atque A poftolica abeffe xquo animo iuntur; tamen pro modulo etiam diligentire leftixçue fur non refpondere fructus vehenter dolent. Qua in re vt id quăm maximè ve$n$ fit, quod exiltimant, illa certè eft firmifsima folatio A poftoli monentis. Vnufquifq; pro- 1. Cor.3\% am metcedem accipiet fecurdùn fuumla1 borem:

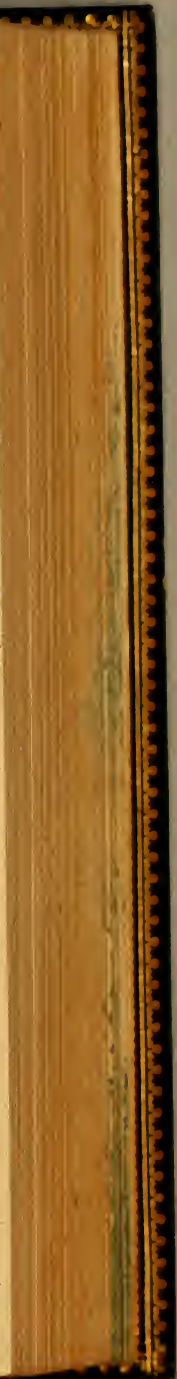




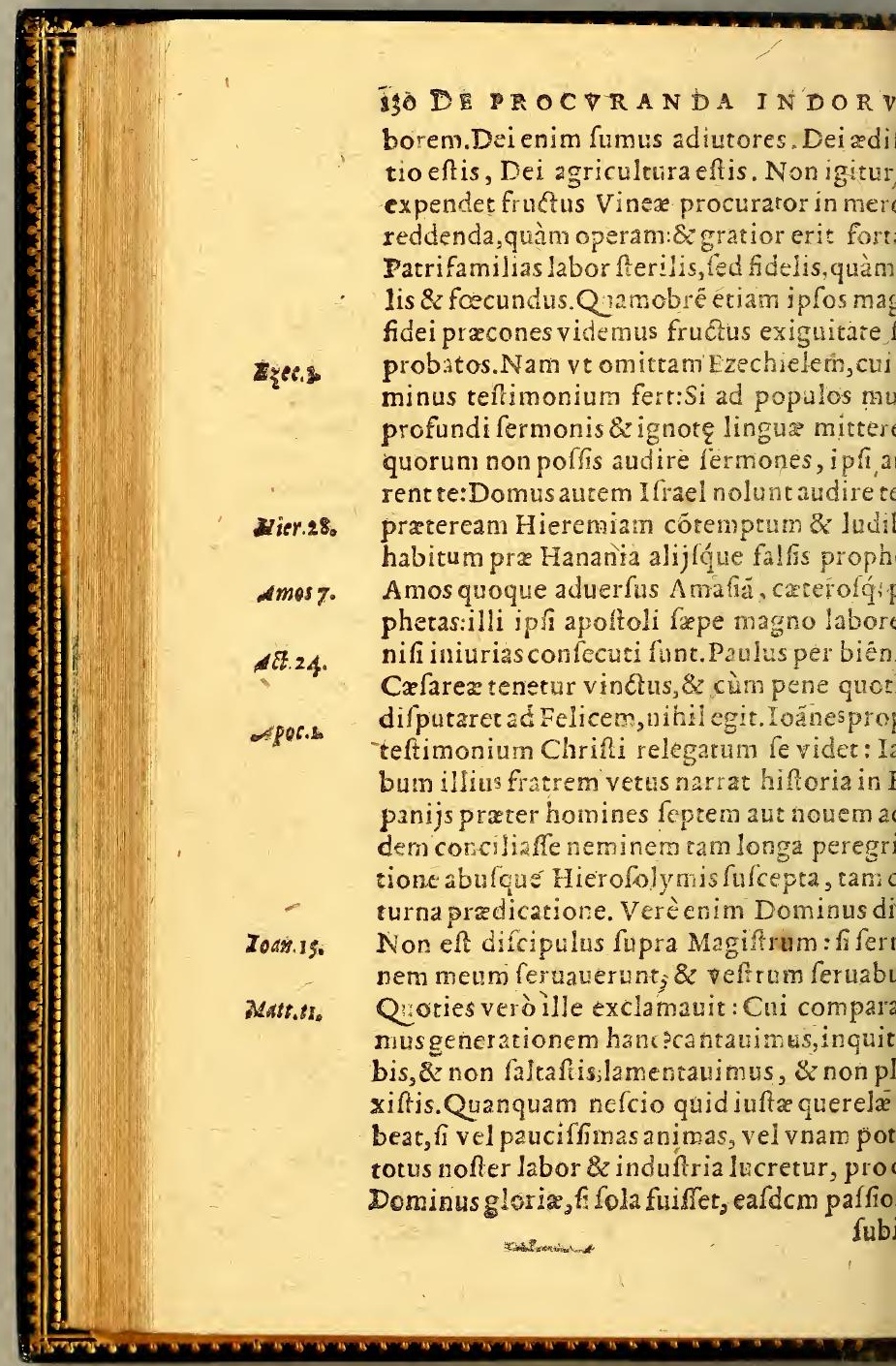


SALVTE. LIBER I. - 13\% bire minimè recufaflet, vt fanctus Chryfoftous quodam loco praclarè docet. Cuius auum os audire libet tantifper đe hac ipfa re, qua In 2. cap at imus. Nihil eft qúod animx poffit æ cuiparari, Gal.inillc vniuerfusquiden mundus. Itaq; \& fi immeh verba:Dil pecunias pauperibus eroges, plus tamen effe- xit me, is, fi vnam conuerteris a nimá. Et poft pauca: tradilit feuod fi hodie nemini perfuaferis, perfuadebis metipfum fridiè, etfi nunquam perfuaferis nercedé ta- propterme. en integram habes. Et fi non omnibus, paucis Hom. z. in nen ex multis perfuadere poter $\mathbf{i}$ :Nam neque ${ }^{\text {ep }}$ if.ad ofoli vniuerfo orbi perfuafer unt, licer cum nibus difputarint, \& mercedem in omnibus ecuti finc. Siquidem Deus non fecundùm borum operum euétiam, fed iuxta façorum pro.fitum coronas elargiri folet, etiâfi duos obosconferas, \& quod vidua fecit, idem in docenus operabitur. Noli igitur, cum orbem terrx uum facere non poffis, etiam parua contemne neque maiorum defiderio à paruis te abftras. Si centum nequis, decem curam fufcipias: fi cem non poffis, noli quinq, defpicere:fi quinvires tuas excedunt, vnum ne contemnas. hod fi ne hoc quoque poffis, noli defperare, li labori cedere. Nam fi parua non contempre nus, afequemur \& magna. Quæ beati Patris hortatio ad recreandos confrimandofque anishrift operariorum, vel fola eft fatis, modò rationi quituis obfequentem prabeat. Deniq; communibus non vtamur, habet fanè Indorü fa propria ac peculiaria emoluméta, eademe magni a pud Chrifum pretij.Primum hum atis, quod labor omnis ift is impenfus tanto ferior, quanto ab omni humana gloria remo 1 t. tior: corint. 


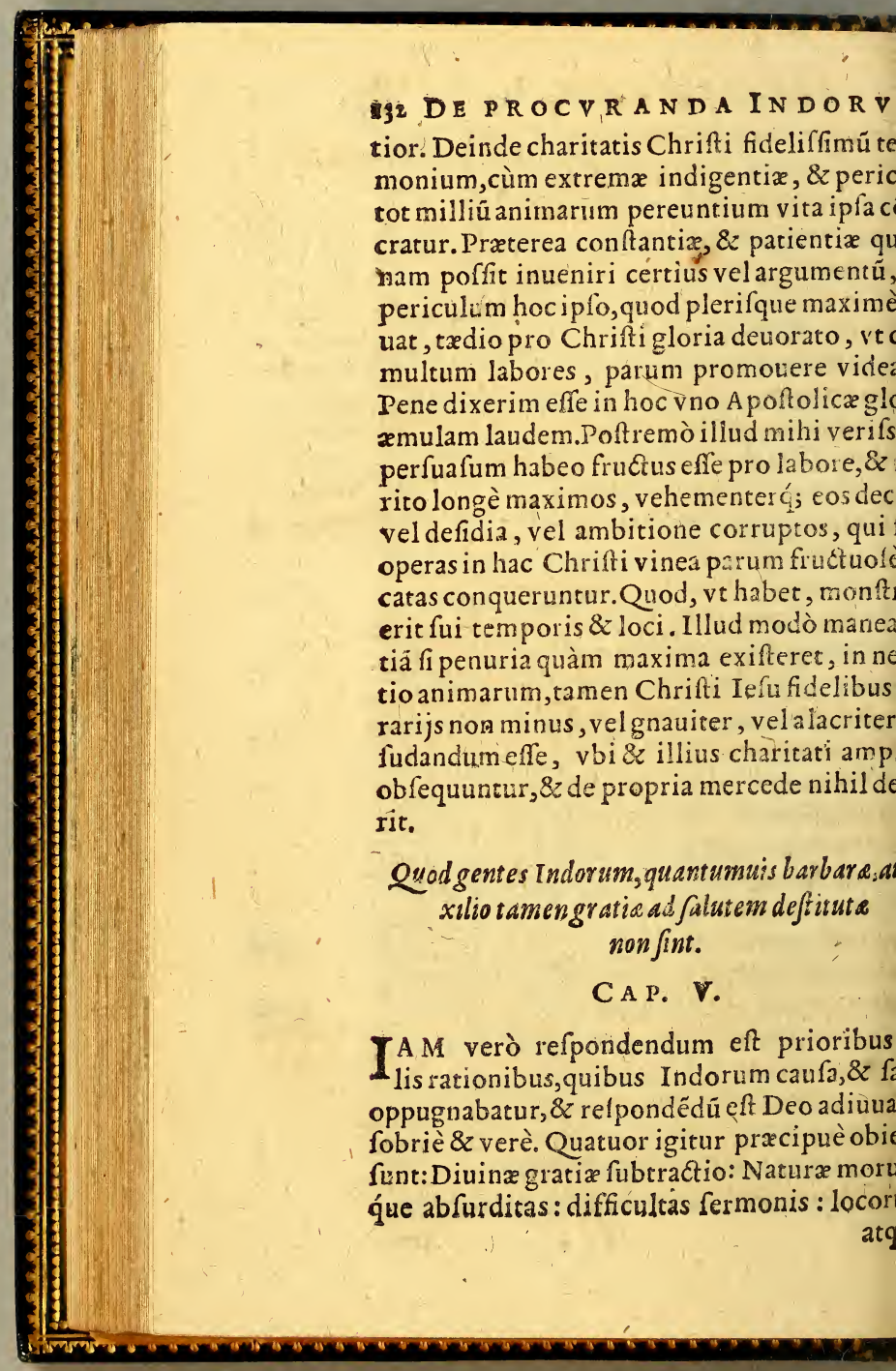


e habitationis incommoda. Principio mulffe homines fuis tenebris relictos occulto Ephre...? veroque iudicio, negare non poflumus, nehomines modò, fed \& familias, \& vrbes, \& gras fxpe prouincias \& $z$ gentes. Qui \& olim e, \& nunc vque funt fine Chrifto, alienati uerfatione Ifrael,\&z holpites tefta métorum, milsionis fpem non habentes, denique fine in hoc mundo. Cur autem tamdiu eos diuiratia atque electio præterierit, tot animarú libusinterin pereuntibus, humana ratione us arcanum eft, quod temerare velle impieta it. Hoc loco Paulus Apoftolus curfum cohi- Rom.tis $\&$ inquifitionem fuam ad infcrutabilis fatix excelfa fufpendit. Cùm enim narraffet tes Ifraele obcæcato vocatas ad Euägelium, ne autem etiam ipfum faluum futurum, cú auerit plenitudo gentium, perpendens, qux funditas fefe obijceret perueftiganti vlera, Deus incredulitatem Ifrael diuitias gentiú. voluerit, \& cur eo vfque falutem earum dierit, eaq́ue oblata repulfam tulerit Ifrael, fivtrumque populum diuina gratia capere uiret, hæc \& fimilia ex fua narratione conui cernens, fiftit gradum, \& exclamatione ilhirabili mauult hominem in ignorantix fux hærere, quàm per obfructifsimæ quxftioabrupta præcipitem dari:nihil omittens, vt egiè dixit Ambrofius, fue quifquis is autor Lib.r.devoc: de vocatione gencium (nam 1ty lus magis re-gent.cap.5. . videtur Profperum Aquitanicum) de ijs enon oportet ignorari, nihil contrectans de qux nölicet fciri.Multa enim funt, inquit, in penfatione operum diuinorum, quorum cau- 
134 DE PROCYRANDÀ INDOR I I fis latentibus foli monfrantur effectus, vt $c$ pateat, quod geritur;non pateat cur geratur, gotio in medium dêducto, $\&$ in occultum rat ne fubducta: vt in eadem re $\&$ de infcrutab bus prafumptio comprimatur, $\&$ de manife Iibr. 2. de vor gent. cap.l. falfitas refutetur. Idemọ́ue rurfus libro fequ te. Et quisinter hæc querulis aut curiofis not faciet, cur adhuc fol iuftitia quibufdam g tibus non oriatur, \& à tenebrofis cordi etiain nunc radios fuas veritas reuelanda co neat?Sarius ergo effet in re tanta, ta mque abıt fainfirmitatem noftrx fcientia confiteri, $t$ negotiun integrum Dei æquo veroque ind: Ecsli.3. committentes, quam dum nitimur, qua tun oculis not ris abfondita videre contra prxc tum, fortaffis immentalucis fulgore cacari.: quia creberrima eft quafio intér infideles qua acrius animos pulfare folet \& pungere, : idendum eft aliquid, quod etfi clatan ment non faris premat; tamen obedientem arque $f$ iectam non parum confuletur. Id verò nemo Lius explicet, quàm beatus Auguftinus, qu bancquafionem diu ac frepe à fe verfatam in Epift.ry densinepifola ad Optatum Epifcopum ital bit, Curautem cteentur etiam illi, quos crea prafciuit ad damnationem, non ad gratiamp tinerebeatus Apofolus tanto fuccinctiore $b$ Rom n. Dicate, quanto maiore autoritate commemon demenfuare potentiam fuam attulife in an Rarienciavala iregux perfecta funt in perdit nem, \&ut notas faceret diuitias gloria fua vafumifericotelte. It mox:Merito autem dece iniuftum quodfiunt vafa ira ad $p$ 
SALVTE IIBER I. I3\% onem, fi non effet ipfa vniuerfa in Adam, a dannata. Quòd ergo fiunt nafcenda? 1rx, pertinet ad debitam poenart : quèd, $m$ fiunt renafcendo vafa mifericordix, per-? $t$ ad indebitam gratiam. Oltendit ergo Dets, fuam, id eft iuftam fixamque vindictam. deftirpe inobedientix ducitur propagopec atque fupplicij:oftendit \& potentiamfuam, bene vtitur etiam malis, multa illis narura\&z temporalia bona largiens, eórumq́ue maam ad exercendos, 8 comparatione admo dosbonos accommodans, vt in eis difcant regratias Deo, quàd ab eis non fuis meritis, in eadem maffa pares fuerant, fedillius miatione difcretifunt. Et infra. Notas etiam fediuitias mifericordiæ fua in vafa mifericor, ita enim quid praftetur fibi difcit,gratis ificatus, dum non fuo merito, fed gloria larimæ Dei mifericordix difcernitur à damnacùn quo eadem iuftitia fuerat $\&$ ipfe damdus. Tam multos autem narci voluit, quos uam gratiam non perti ere pręficiuit, ve mul adine incomparabili plures fint illis, quos ui regnigloriam filios promiffonis prędelti edignatus eft;vt atiäip\{a reiectorum multiline oftenderetur, quàm nullus momenti fie d Deum iufum quantalibet numerofitas iufimè damnatorum. Atq; ve hinc eriam intelant, qui ex ipfa damnatione redimuntur, hoc fle debitum maffa illi vniuer a , quod tam gnæeius parti redditum cernerent. $\mathrm{H} c \mathrm{c}$ Auitinus, quibus generaliter quantum facra lira infinuant, rationes attingit, cur tam innuerabilis hominum ac populorum multitudo 


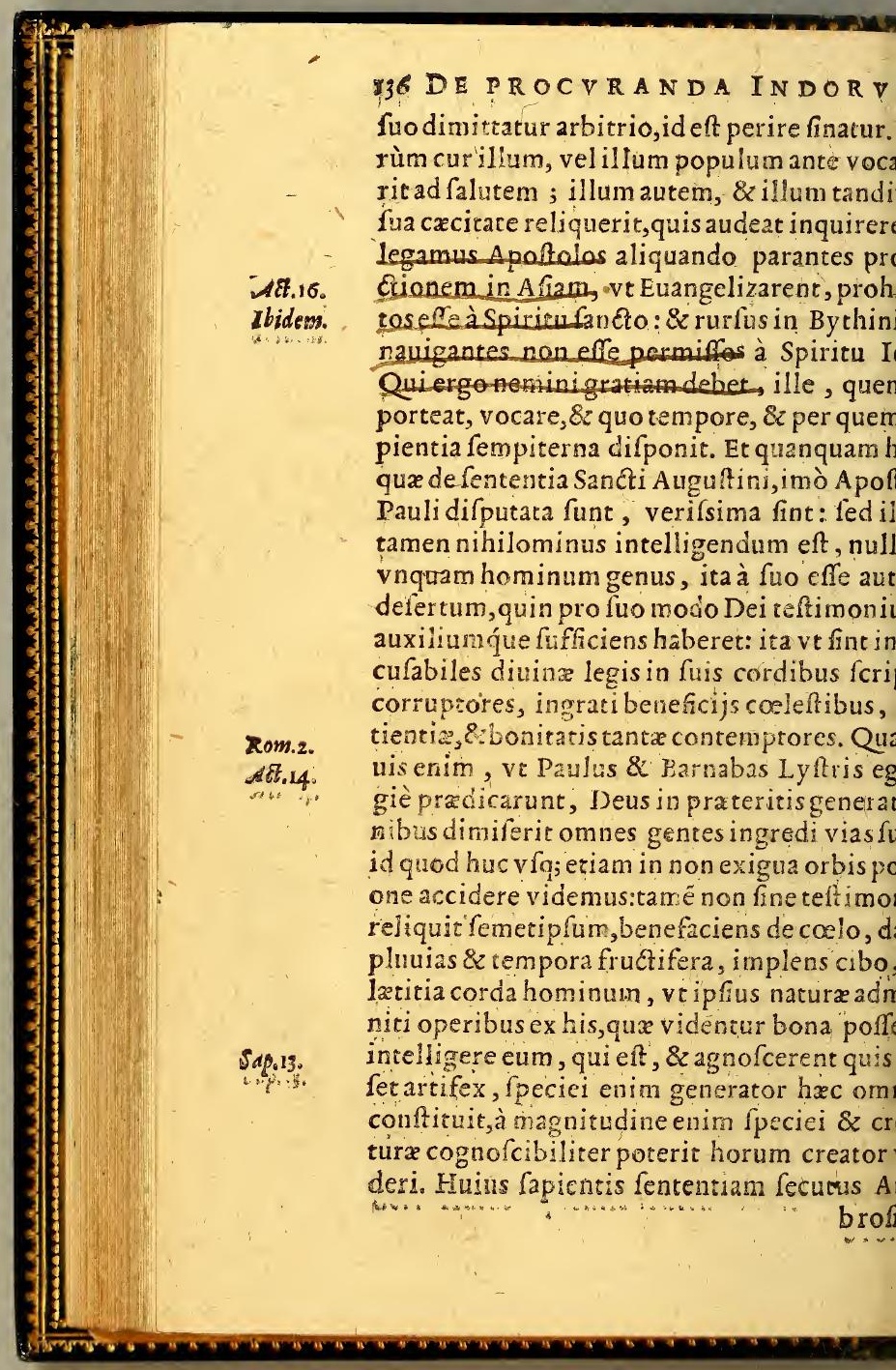


S A I V T E. LI B ER I.

fus libr.2.de Vocatione gentium : Adhibit2.2. de $V_{i,}$ per eft,inquit, vniuerfis hominibus quadã gent.c.5. ernæ menfura doctrin $x$, qux et fi parcioris oc iorifque gratiæ fuit, fufficit tamen ficut Dous iudicauit, quibufdam ad remedium,omus ad reftinonium . Non quod fine Chrifti falutem cuiquam, quod abfit, permittat Am fius:led quòd gratia in naturz doctrina lu\& \& lequentem, ad fpiritum fidei 8 charitanducat. At dicet aliquis hoc loco. Quomodo Rom. io. dent, fi non audiunt? quomodo veróaudient prædicante ? Prædicabit fanè Philippus Eu- A\&.8. ho, \& Petrus ad Centurionem mittetur, mo- $A d t .10$. lli praftent,quod per fe poffunt. Neq; enim per naturam inuitat, deerit per gratiam, fi rum non reluctetur arbitrium. Quamobrem $n$ autor in eodem opere.Quod fi fortè etiam c in extremis mundi partibus funt aliquę na es, quibus nondum gratiaSaluatoris illuxit: ${ }^{\text {gen.cap. } \sigma_{\text {. }}}$ mbigimus etiam circa illas occulto iudicio tem pus vocationis effe difpofitum, quo Euá um quod nondum viderant, alidiant, atq; fuf ant. Quibus tamen illa menfura generalis au j, qux defuper omnibus fensper hominibus rabita,non negatur: quamuis tam acerbo nere humana natura fauciata fit, vt ad cogniem Dei neminem contemplatio fpontanea nè valeat erudire, nifi obumbrationem corlux vera difcufferit. Quibus profecto verbis uerfam Indorum caufam præclarè actam ef-' b Ambrofio nemo non videat. Interim verò, itia \& crimina omnia iftorum, quamuis vemeque mereantur, neque impetrent apud imum Iudicem Deum, leuius tamen omnino

$$
\text { I } 5 \text { puniun- }
$$




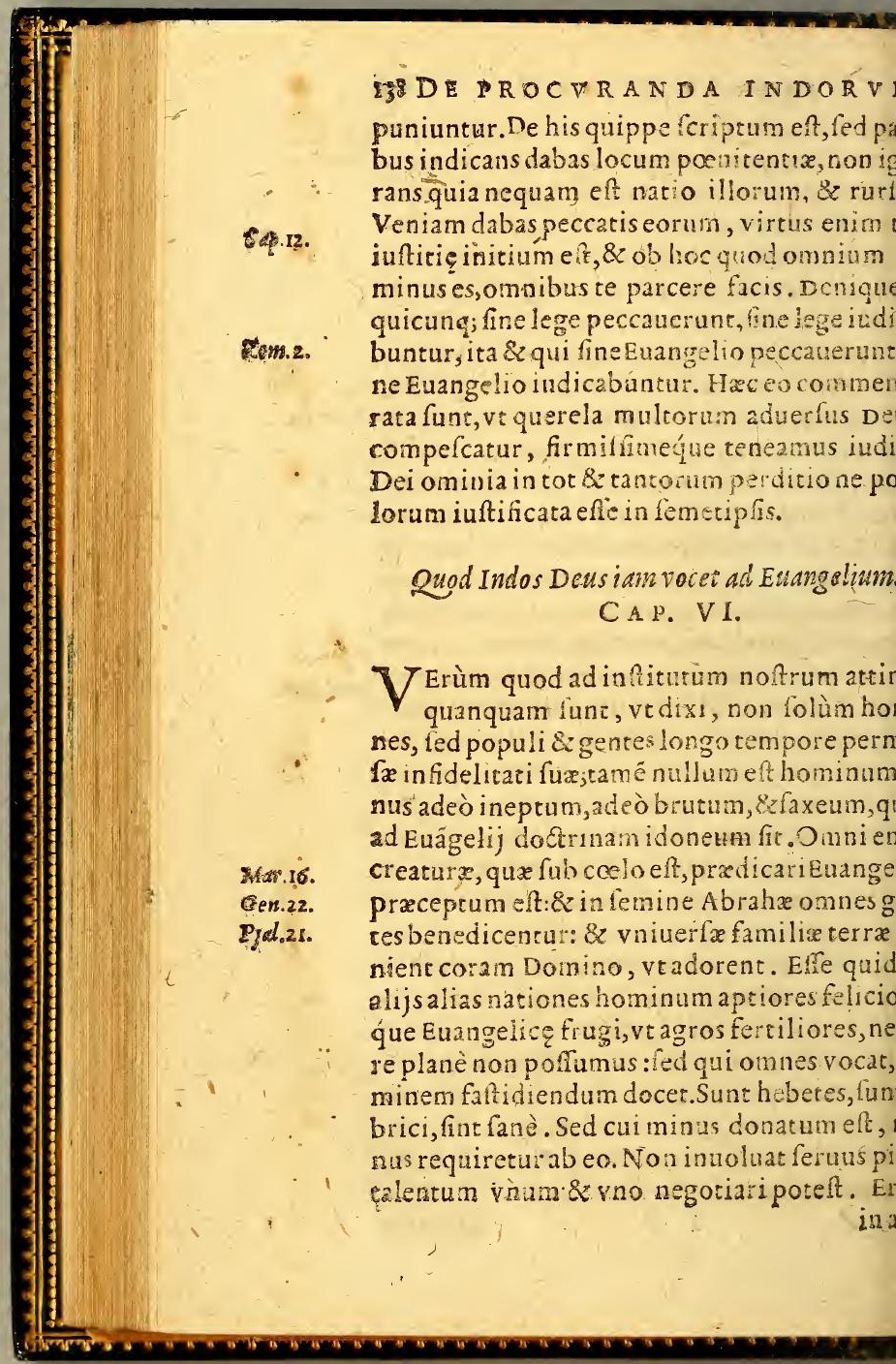


ca Noëtrifega fue tabulata in fima, \& me- Gen..$_{0}$ R-iupremd, om ne genus animantium'eoilIr induci, vt ceteris pereuntibus, ipfa feruen. Non excludicur coruus pra aquila, non leulus pra leone. Petrus quoque occidere iuir audacter, \& manducare de omnibus, non in volucribus, fedetiam reptilibus, $\&$ nimundum, \&zalienum cenfere, quod à Do- Lanctificatum fit. Habet coleftis ciuitas Ioan.r4: fiones plurimas non minus genere, 8 graquam ipfa numerofitate mirabiles. Neque Exod.25. m folùm \& gemma, fed pili quoque carum taber naculoDei oblati recipiuntur. Dee qui abiectos iftos ac miferos Euangelio tos putant, \& patrix coeleft is beneficio exiunt, qui contemnunt, atque peffundant, ant tandem Dominum, \& fuum, \& iplopariter,feuer èadmonentem.Videte ne con natus vnum ex his pufillis: dico enim vobis, Angeli eorum in cxlis femper' vident fa$n$ Patris mei,qui incolis eft. Opinor non inos humano fuffragio, \& patrocinio, quibus ulatus exhibetur Angelicus. Omnes enim ACt.10: aniftratorij fpiritus funt propter eos, qui hę itatem capiunt falutis. Nullum ergo eriam f̂m, \& belluinumgenus hominumà falute ngelica alienum cenfendum eft, cum Deus irié vocet, cui non ad id confequendum què at, intelligentiam, \& gratiam idoneam confe Etfi enim vocanturmutri, eliguntur pauci, $A$ Et is. ien nemo vocatus negligitur, nifi qui vocan, cùn liceret, audire contempfit. Notum culo eft Domino opus fuum: noftrum ent, niam ad omnes ire iuffi fumus, nemi-

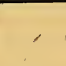




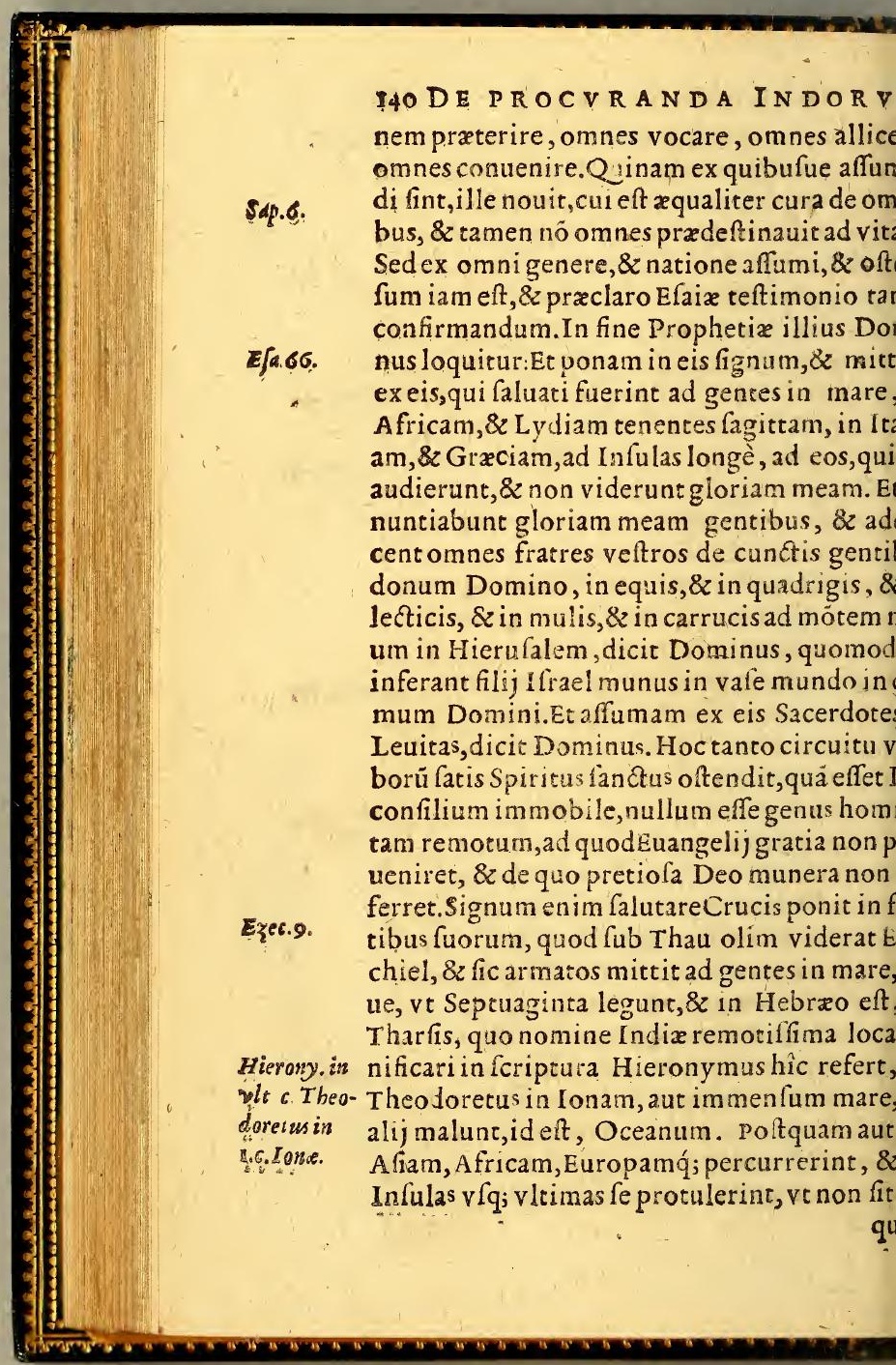


S A L T TE, I I B ER I. la \& fermo gentium adeò barbararú,vbi non iantur, \&r refonent verba eorum,túc munus nino egregıum afferent, id eft, fratres fuos; num \& gloriofum prędx apparatum agétes quis, in curribus, in quadrigis, in mulis, \& ucis, quod quid eft aliud quàm pro diuerfita enientium ad Fidem diuerfa effe aptata vehi ?Alijequis vehi poffunt, v tpete celeri \& per ingenio, alij quadrigis gloriofi \& curribus potentes.Sed qui tardiores fuerint \& ignobi es, habebut etiam ipfifua vehicula. Si equis us funt apti,at mulis infidere poterüt fi qua$x$ non erunt, ăt non deerunt vel carrucæ, qui imponantur.Vt non folú Græci \& fapientes; un etiam barbari $8 z$ rudes in domum Domi uæe eft in Hierufalé, id eft, in Ecclefiam Chri gregencur.Atq; vt intelligant omnes, etiam tis beneplacitum efie Deo noftro, eliget de fis Sacerdotes fibi \& Leuitas. Diftribuet, inm, ipiritum fuum, \& charifmata non folùm folis, \& Ifrael, verum etiam gentibus, vt Petrus, qui eft coeli ianitor, viderit Dei dodiffufum in eas pariter, nõ prohibeat aquã, introituseft Ecclefix:fratres quoque fi forlatius difceptét, ipfo exemplo ac teftimonio ino edocti conticefcant. Nihil enim magis firmat animos fidelium Chrifti prædicatoquàm teftimonium Spiritus fancti perdona \& charifmata, quæ partitur, vt vult. Et quilona Spiritus, figna \& miracula, qux in Fidei dicatione innotuerunt, his etiam tempori, quädo charitas $v f q$; adeò refrixit, enumeraongú effet tum in Orientali illa India,tum in Occidentali. Res Iapponenfilim notæ iam ACt.10. AEt.11. funt: 
ז\$2 DE PROCVRANDA INDOK funt.Synarum regio ingens diutentata, ia trimq́; aperta nauigatione Lufitanorû, 8 ftrorum ex noua Hifpania. De Mexicanis n narrantur. De Infularibus ipfe quoq; aliq parte nonnulla confpexi. Hiftoriæ inuent orbis loquütur multa, \& mir̀anda, \& vera, hodie quoque teftes faris fide dignos habe Duo, quarecëtia funt exempligratia nó $\mathrm{n}$ bor apponere. Fcemina in fua infidelitatis re obîtinata, \& fuperftitioni cuidä venefic dictirsima, quæ cæer is omnibus in illa far baptizatis fola repugnauerat: morboiá $\mathrm{v}$ ! laborãs mifit ad facerdoté, vt ad fe feftinare enim le poffe exire de vita, nifi aqua prius ri perfunderetur.Semel atq̧; iterúaccerfus dê venit, inuenitanum in extremis agente baptifmú magno affectu pofcentem:rogat tá diu diffuleritrefpóder illa, frbi nihil n fuiffe femper in animo, quá fieri Chriftian deratenin, vel ipfum nomé, fed tamé mort propinquâti aftitiffe fibi iuueré cảdidú, $q$ reaclä vitä acriter reprehéderit, \& Chrifi gioné quätocy ${ }^{9}$ fuícipere perfuaderet:cótr rò tetrü quendä Aethiopé alcera ex parte p fuperfticione diu inculcafe: \& cú anxia di reret, tandê vicifie iuuené Chrifti: ftarim t fibibaptifmi defideriun accéfum, ve nihil a lamëtaretur, q̃ feà prima ẹtate nó fuife $\mathrm{Chr}$ nā. Quid multa? Interrogata de fide pro mo poentétiã ante actę vitæ magnodolore fig cảs, ba ptizatur, 8:ba ptizata protin ${ }^{9}$ animá ê ipfo facerdote cúcęteris, $q$ aderät, admirát hementer; huius ego factu narratione cogno etiam legitimo teftimonio probatú ad Epif 

ntrăfmittendú curauit. Fuit vir quoq; apud qui hodre etiá viuit. cóniugatus in valle $\mathrm{Hu}$ vocat s, olim baptizat ${ }^{2}$, Rzteltimonium habés ü in fimplicitate 1 ua 8 fobrierate. Hic graui xgrotan, cú wortuusomnino crederetur ab ie, qua fola cadaues viri feruabat opertum, eça: ad tepulnuam alicuius adiutorı́n(erã n foli in loco latis remoto) triduum integr â it, vt putabatur, exanimis, patno coopertus: tcpere monere le cospit, \& vxorem admira ac patentem vocans, vera effe dixit, quę a $\mathrm{P}_{3}$ us cicerentur de vita futura.Nã $\&$ fe perdunà quodaın multa ac fupenda vidiffe. Cùm acerdori innotuifer, qui hominis ruditatem mè noffet, \& miraretur tanta de rebus fpiriibus, \& occultis ex ordine referentem, iam bo leuatum ad Archiopifcopum examinantranlmifit:cuius confilio, $\&$ à noftris fratri \& à multis alijs diligêter interrogatus, apen refponfionem ordine, \& fenfu, \& ipfa vnionfancia, \& lacrymis ac profundo quodam in declarauit illa omnia non aliter fibi poe innotefcere quàm facta fuper eủ manuDñi nirabilé extâtim. Id quod vitę de mú innocế atis pofea cófin maut:atq; hodie quoq; Do. icui (hoc hominis nomeneft) dicitur multa are de faculo futuro ijs, quos audituros vtiindicat. Ferè eiufdem exépli eft cú illo Cur uriali, de quoAugu.fcribit in libro de Cura Áng. de ch mortuis agenda, \& cum illoaltero Steelfio, ra pramotuo narrat in hilforia Angelica Beda. Non du $n$ eft quin Deuscharam habeat falutem In$\mathrm{m}$, atque ex his numer ofifimis populis $\mathrm{mul}$ inis.c.12. Bed lib. Anbli. biffe in regnum Chrifi adoptarit, perducendos atriam co ordine, \& modo \& timfore, quod ipro 
I44 DE PROCVRANDA INDOR V ipfe conftituit. Firmum enim fundamen

2.Tim.2. Dei ftat, habens fignaculum hoc: Cognouit minus, qui funt eius.

Quomodo Indor um ingenia tract anda funt, vtC folucrifiant.

\section{A P. VII.}

CED ingenium barbarorum, morefque bel $S_{\text {ni nobis ftomachum mouent. Primùm }}$ dem debemus non effe nobifmetip fis fapier

Rom.12. fed humilibus, vt monet Apoftolus, confent tes. Deinde repetendum eft fedulò Chrif

2.Cor.5. proomnibuseffe mortuum, ve qui viuunt $n$ bi viuät, fed ei, qui pro ipfismortuus eft, fed non hoc,vt par eit, aftimamus, iccircò cha: Chrifti non vrget nos. Quòd fi probarbar coli3. Scythamortuus eft Chriftus, profectò à fa tionales, quod oportet etiam atq; etiam adu re, $\&$ animo altius infculpere. Non enim ex amplius à qquoquam Deus, quã illius natura adiuuante prattare queat. Barbaros præ Gra atque Indos nonnullos prænoftris fi quis di ciat, nihilaliud ferè cenfeat, quàm pra hom bus rarionalibus irrationalia iuméta. At vt Dei bonitas locum parat, vtraq; ad domum $\cap$ Hierem. 21. congregat.Seminabo, ait in Hieremia, don Iuda, \& domum Ifrael femine hominum, 8 mine iumentorum. Vna eft Ecclefia, quæ n lùm propagatur humano femine, fed etiam luino. Cuius magnificentiæ amplitudinè ad (al 3s. ratus Propheta exclamat: Quemadmodú mi plicafti mifericordiã tuam Deus?Quid ita? I 
S A L V T E. LI B ER I. empe, Homines \& iumenta faluabis DomiQux verba edifferens fanctus Ambrofius, Ambrof. in lelt homines \& iumentá? Rationabiles vti- P Pal.3s. irrationabiles. Rationabilibus iuftitia:irnabilibus mifericordia. Alijreguntur, alij untur.Quam interpretädi rationem ve per nta diuinæ literæ intelligant hominesiuis fimiles fenfu, etiam Hierony mus fequitque alij patres, vt Gregorius in illa verba; alia tua habitabunt in ea. Reuera in Ecclehrifti etiam iumenta faluantur, quia Dei ricordia multiplicata eft. Vides hominem aifenfus; ingenio tardum, iudicij inopem; Hieron in Hier.cap 31. ovion ca. 3 . Greg.lib 16. mor.sap. 2. PJal. 67. ntemnas, ne regno cxlorum ineptum put mon percipit quæ Dei funt; \& fultitia eft I.Cor. 2. uicquid fpiritualiter dicitur, nec poteft ingere. Adhuc noli repellere, \& iftum poteft It faluare, qui neminem vult perire. My fte- 1.Pet.3. dei pronunciat, neq; intelligit, imò vix etià untiat:frpe dicendo, fxpe inculcando nihil in buitur, femper hebes, \& truncus perinque iumentum canere doceas: Rurfus aio; efperes irrationaliseft, iumentum denique iops aut Indus. Audi A mbrofrum iftos effe ndos verbi capiftroad Fidem. Neq; enim fi ratione non poteft capere, que docetur, non n poterit quantum fufficit Fide apprehend faluus fiar. Alioqui fi non poreft credere, lum oporter, quomodo qui non crediderit, lemnabitur? Nifi pradicatione Euangelij Marc.16́. endas damnari poffe, faluum efie non poffe. dimpium nefas auertat Deus à chriftiano. iffimè igitur retinendum eft nullam barba, fenfu carere ad Fidé necelfario.Indi porr ò K omni= 


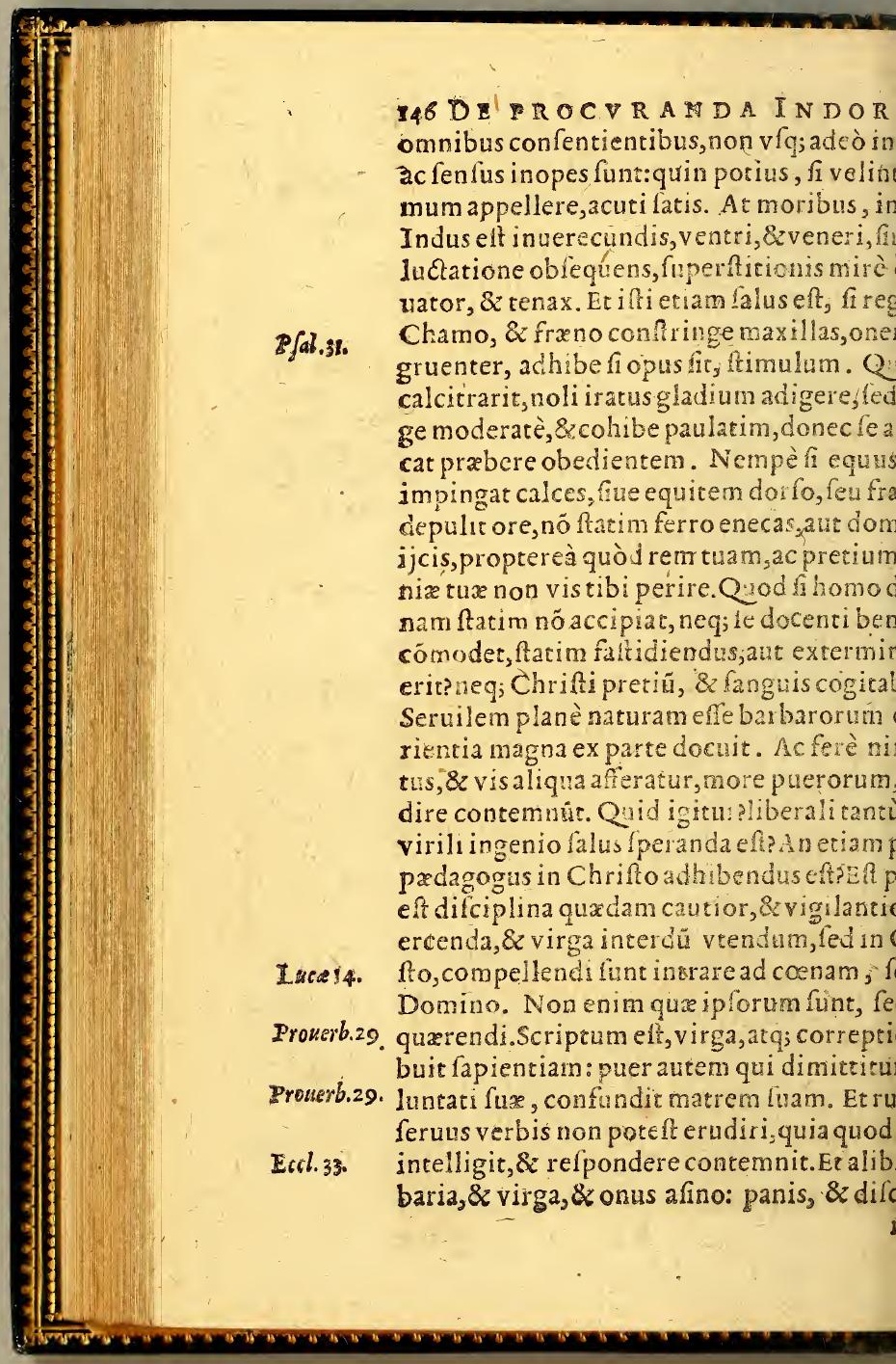


S A LVTE. LIBER T. 147 opus feruo, operatur in difciplina, \&z quxquiefcere:laxa manus illi, \& quaret liber, id eft, cum adhuc premitur opere, cogitat 1 am, quid erit, fi fe folutum, \&zvacantem vi- Fugam fanè cogitabit, atq; ideò adiungiugum, \& lorum curuant collum durum, \& Im inclinant operationes affidux. Et mox, illum in operationem, ne vacet: multam malitiam dociut otiofitas. Ac licet pracexcte moribus data à fapientibus de admiundo \& regendo conuenienter vniuerfo cipiorum genere perfpicuè loquantur, \&z quod experientia quotidiana fatis indicat regionibus, vbi nulla domeftica obfequia? externa opera nifi à feruis Aethiopibus quorum re vera mores difciplinam feue$\mathrm{m}$, \& afficuos labores exigunt: tamen de ijs laccipiendafunt,qui, \& fi conditione feri) fint, ingenuos tamen mores non pra fe t. Etenim ijfdem teftimonijs feueritatem iorem aduerfus contumaces homines adhiam, effiolim fecus fenfifet, tamen aperta rientia rei fe commotum Augufinus pro$r$ fcribens contra Donatiftas \& circumcelsgènus hominû improbilfimum ac fauifEpif?. so. ad Boinifo n. Lllud autem ab eodem gloriofo Patre faturpatum, magnoperead rem pertinere ar$r$ : quemadmodum olim fub veteri teitao fuiffe multos, qui ad gratiam noui teftai pertinerent, id eft, qui non fpiritu feruiin timore, fed firitu dilectionis, ve Dei lucerentur: ita nunc quoque fub EuangeIEcclefia plurimos effe, quibus veteris teenti ftatus \& inftitutio quodammodo conIs 2 gruat 


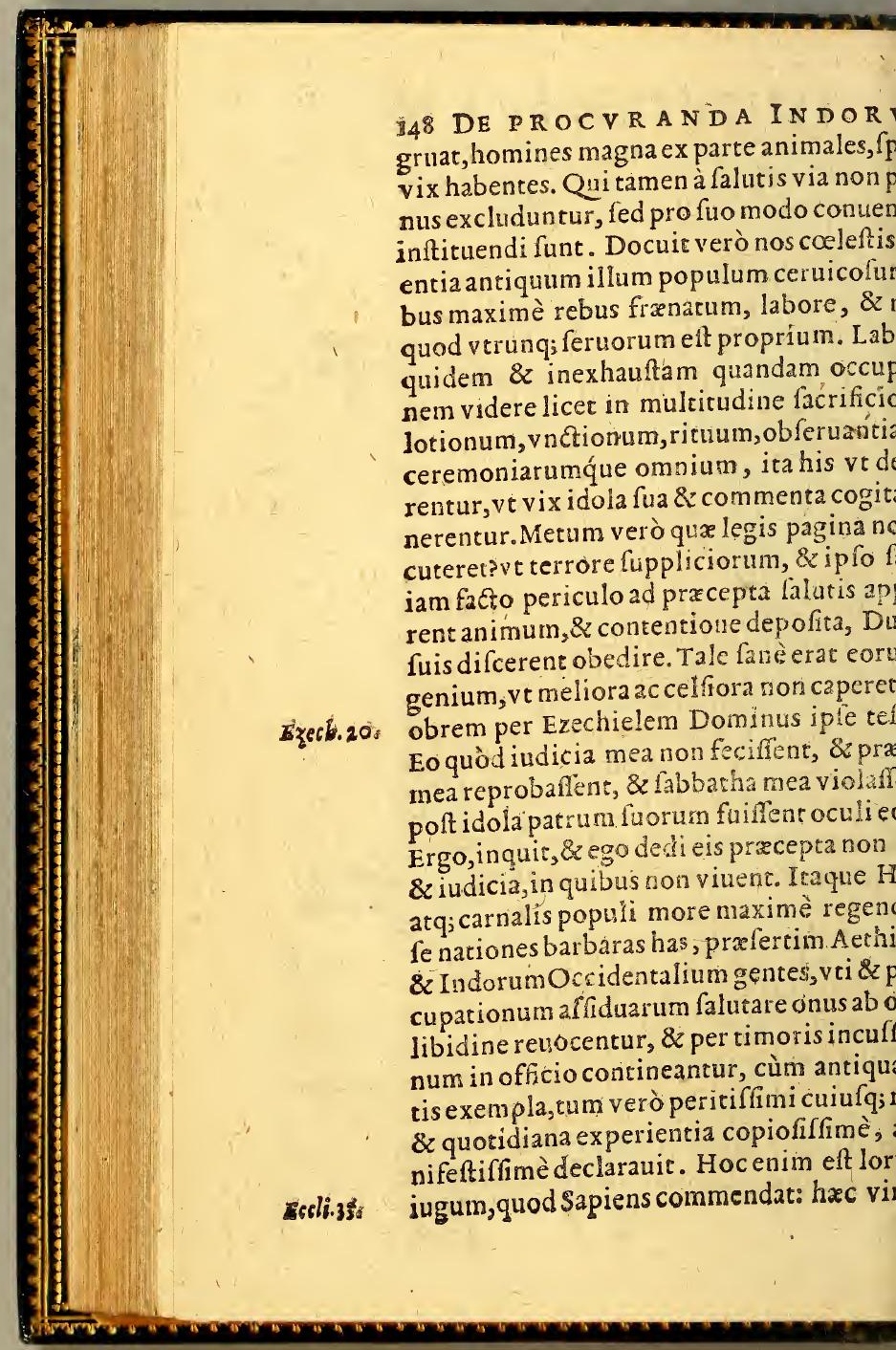


S A L V T E. LI BER I.

Hoc modoad falutem vel inuiti compelIr intrare. Quæ non eo commemorata funt a, quo vim \&z fxuitiam à Chrifti vifceribus iffimam in Indorum nationes vllo modo em, aut tanquam in feruos dominandum $\mathrm{n}$, fed vt oftendä etiam illiberali \& $z$ difficili jio non effe falutem defperandam, fi \& $\mathrm{pa}$ er feratur, \& fapienter regatur. Charitas 4.Cor.15. fuffert, omnia fuftinet, omnia fperat : paeft, benigna eft. Seueritas ergo quxcunque enda eft, à charitate aliena effe non debet. itatis porrò nihil eft ita proprium, quàm ve uxrat, qux fua funt. Hanc fi \& animo intiruet, \& re ip fa declaret, qui infirmorum, \& ientium morbis curandis aufteriorem fe fe dum exhibet medicum, non elt timendum; minum animos fubditorum, ita offendat, là fe, velab Euangelica fimplicitate alieacilè enim recuperat charitas, quos difcicommouerit. Imò verò per vtilem timoim ad libertatem filiorum paulatim homiiuinitus inducuntur:

barorum ineptitudinem non tam à natura, quàm ab educatione, ¿o confuetudine

$$
\text { proficifci. }
$$

\section{A P V T VIII.}

Ddam verò $\mathrm{id}$, quod plurimum intereffe arbitror, omnino ad iftam ineptitudinem ani corumq́ue Indicorum feritatem non ita fanatalium, ftirpifue, aut aêris natiui caufas, nadmodum diuturnam educationem, \& cóadinem beftiarum vitæ non valde diffimiEquidem \& olim ita mihi perfuaferam, \& K 3 sebus 


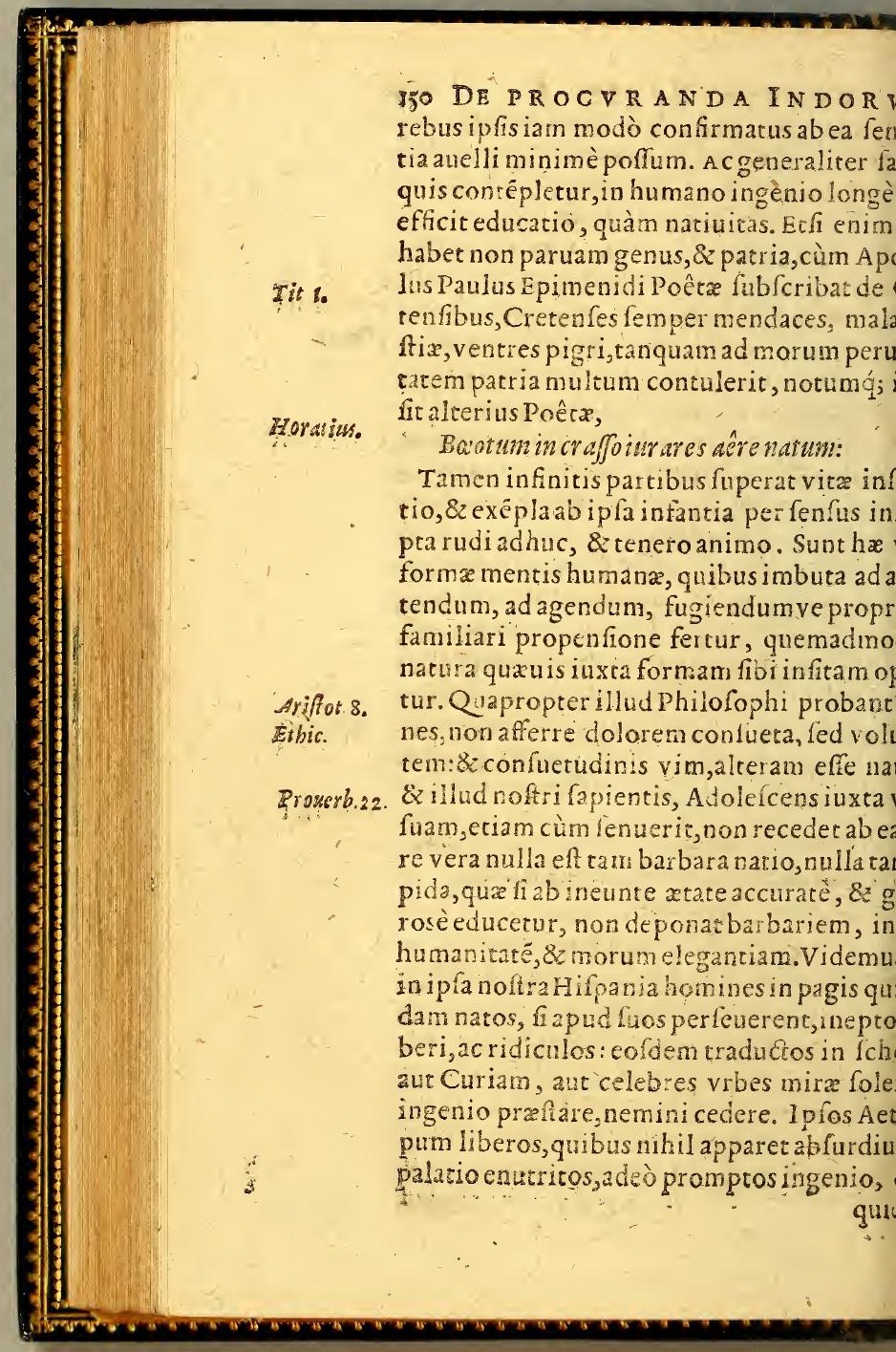


S A I V T E. I I B ER T. ISI is paratos videas, vt fi colorem detrahas, os putes.l'lurimú poteft confuetudo in om. 1ere morum in veramp; partem, \& boni, \&2 Quamobrem D.Chryfoft.vbi mores perdi ruorü expofuit, parumq́; idoneos dixir ad tis doctrinam capeffendam, fapientiffimè Hom. 4 in axit: Non id quidem natura caufa, ab fit:ve- epiff. ad Ti: oropter conuerfationis vitxq́; negligentiä, tum. t enim huiufmodi in ijs, quæ mores tangüt, gi a Dominis. Nihil enim fermè aliud $\mathrm{cu}-$ , in quorum poteltate funt, quàm miniftefuum. Quod fi mores illorum componere ando ftudeant, \& hoc fui gracia tantùm fa, ne iftis negotia exhibeant, moleftiq́; fint. B.Patris fententia noftrorum hominum va atio mihi videtur. Accufant naturam, mobarbarorum, ipfi nihil adhibent curæ, nifi uis vtantur ad fuas priuatas commoditates. igitur ratione homines pecudú inftar enuad fidei doctrinam ineptos effe caufarisesi ta effes informatus, inter iftos \& $z$ te quid o difcriminis incereffet? Audi cundē latré ufa adhuc feruorum immorantem: Cùm i- In eddens. fic negligantur, inquit, neminemq́; habe- Homil. ui componendi illos, ac formandi ftudium eritò ad ipfa nequiciæ prærupra ac præcipi euoluuntur. Si enim vbi Pater inftat, $\& \mathrm{Ma-}$ Pædagogus, 8z Nutritius, \& Magifter, \& es,ipfaq́; libertatis opinio, \&alia plurima, lifficilè quifpiam malorü contubernia conaq́; deuitat, quid putas his omnibus deftitu: ui quotidie iceleftis commifcentur homiis, $8 z$ cii quibus volunt licenter congrediunùn fit nemo, qui ipforum conuertationem I 4 amicie 


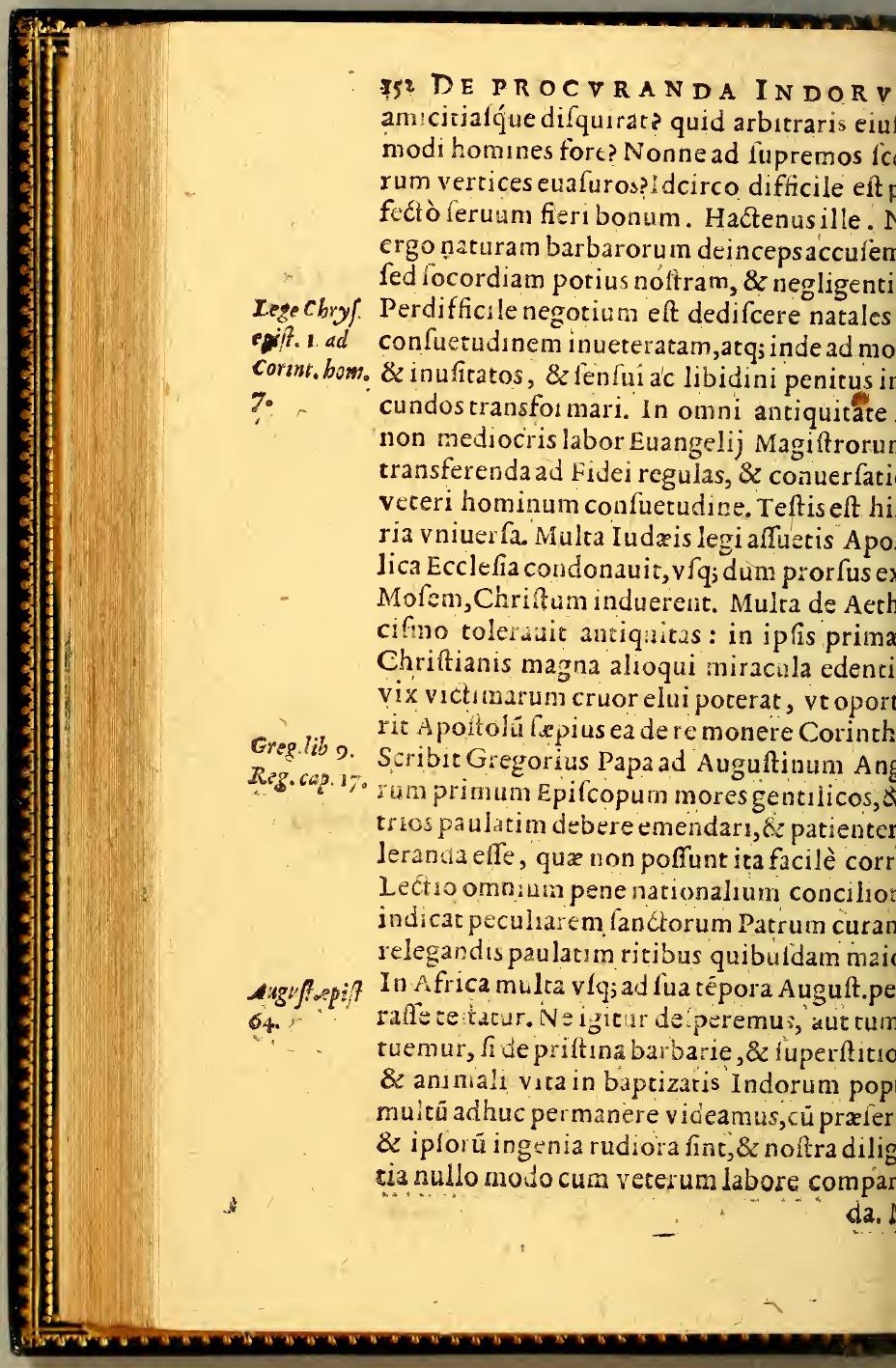


S A L V T E. L I BER I. 153 ores fenfim mutätur in melius. Fides Chrignam totius humani fenfus, 8 affect us hanegationem. Prolucro non mediocri comdum eft, quicquid ex tam horrida, tamq́ue ta barbarie humanitatis, aut etiam Chriitatis eluceat. Exemploac folatio fit Domimnium, qui populi ceruicofiffimi mores ingratos, \& infuaues fuftinuit per annos nò plufquam quadringentos: quem tamen, lere facilè poterat, \& magnis potius beneinustabat:vt hominis improbitaté Dei paia benignitafque fuperaret.

dolingue difficultas non deterrere debeat ab

Euangelïpropagatione.

$$
\text { CAP. IX. }
$$

monis autem, 8 locorum difficultates non igux ill $x$ quidem funt:fed ve charitaté exer thominis Dei, non ve extinguant. Apoltouidem datum fcimus donum effe linguarü, terea quod pauci Chrifti Præcones toto orfalutis nuncium breui inlonare debebant. mobrem Paulus gratias agit Deo, quòd om- r. Cor.r4t $m$ lingua loqueretur. Quamdiu verò generalud munus fpiritus in Ecclefia perdurarit, ue apud veteres compertum lego, neque ego lè dixerim.Illud procóperto habemus præationem Euangelij pofterioribus fecculis profiffe, cùm linguarum dona ceffaffent, fed chas omnium donorum maximum ftudiosè aet, vt quod deerat in dono, augeretur ad meum. Profectò enim potteriores hac in re, \& fi us alijs fortaffe videbitur, non ita infeliciofuêre maioribus.Etenim ve Chriftusad Tho-

$$
\text { K } 5, \text { mam }
$$

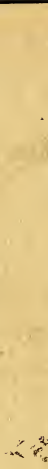




\section{8\$4 DE PROCVRAN DA INDORV}

Corti 20. mam dixit, Fidem ex oculis, \& tactu collig tem, Beati qui non viderunt, $\&$ crediderunt eriam dicere quifpiam queat, beatos eos, qu zeceperunt fermonem, \& tamen pradicauer Hîc enim vtrumque mercedis eft loco, \& nare, \& ipfa fibi arma expenfis proprijs par \& prædicare, inquam, \& fermonem neceff um pradicationidifcere. Vt ergo in prima xum conditione, ita naturas inftituit fum opifex, vt vnumquodque perfictum edere iuxta genus fuum, nullo terræ labore, nullo li circuitu:at mox iufsit temen proferre, $v$ cerralaborata genus vinumquodyue repara ita lanè oportustin regeneratione mundi verbum idem omnipotens primas firpesd nitus perfectas furgere, deinceps harum fem. bus accedente humani ftudij labore genus E gelicum propagari,cua iam, \& numero mult. ient, \& temporum non premerentur anguit Zac 10. Beari quidem oculi, qui viderút Dom inum: beati quoque qui non viderunt, $\$$ credider

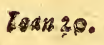

Felices quibus Spirstis 1anctus dedit don linguarum, interpretationem fermonum: at infelices, qui per chartatem fpiritus de fuo nunt in opere. Domini, quod non acceperu Quanquam, \&hocipfum pofuifie, accepifie Iam illud mulcum moueve nos debet, quod demus ad gentes profundi fermonis, $\approx$ ig tæ lingux homines penetrare lucri fpe, nec terrembarbarie immenfa, fed vniuerfa mer umgratia luftrare, non Aethiopum innumera les linguas, non Synarum, nou Tartarorúm, $n$ Brafilienfium, non extremi Oceani litora re fare, \& quicquid inter Mendocinum promo toriu 
SAIVTE. I I BER T. TYS m, \& fretum Magallanicum fitum eftinisterr $x$, acmarisfpatijs, idque vtroque ex e,\& Boreali,\&z Auitrali, magno ftudio obidenique, $\&$ fi quem tellus extrema refulo. mouet Oceano, velfi quem extenta plaga- Verg $\%$ Quatuor in medio dirimit plaga folis ini- deneid: hunc perfcrutantur, huius lingux vel balbu tes fe accommodant, vt aurum, argentum, a pretiofa, mercefq́ue exquifitas ad fuos, lant, quxitum vndique augeant: tam lon, \& periculolam peregrinationem auidif, fufcipiunt, vt profecto admirabile fit ompene portus veriufque Oceani, omnes finus is ter rarum ftationibus nauium Hifpanien. teneri, omnes Indorum farrapas cum nosmercatoribus, \& nautis commercium habe t qui pretiofiffmas merces quærimusaniDei imagine in fignes, qui lucra non incerut breuia;fed aterna in colis fperamus, lindifficultatem, locorum afperitatem caurar:vt appareat verè prudentiores efle filios hu iaculi in generatione fua filijs lucis. Et fer- I uc.16。 nis quidem difficultas in hoc fpatioforegna u magna ex parte leuata efr, cùm generalis ilngarum lingua, quam Quicham vocant, vbie in viufit, \& ea ipfa non ardua fcitu, præferad artem iam redacta diligentia, \& fudio ide Indotum natione optimè meriti. Quod $n$ fuperioribus prouincijs ea potiffimum vi, qux appellatur Aimara, neque ip fa eft valde fficilis, neq; mulcum ab illa altera abhorrens. Mexicano Regno aiunt effe linguam quoque neralem, vt facilior fit communicatio inter fe m multorum populorum, \& gentium, Quod fi

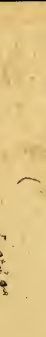

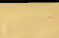




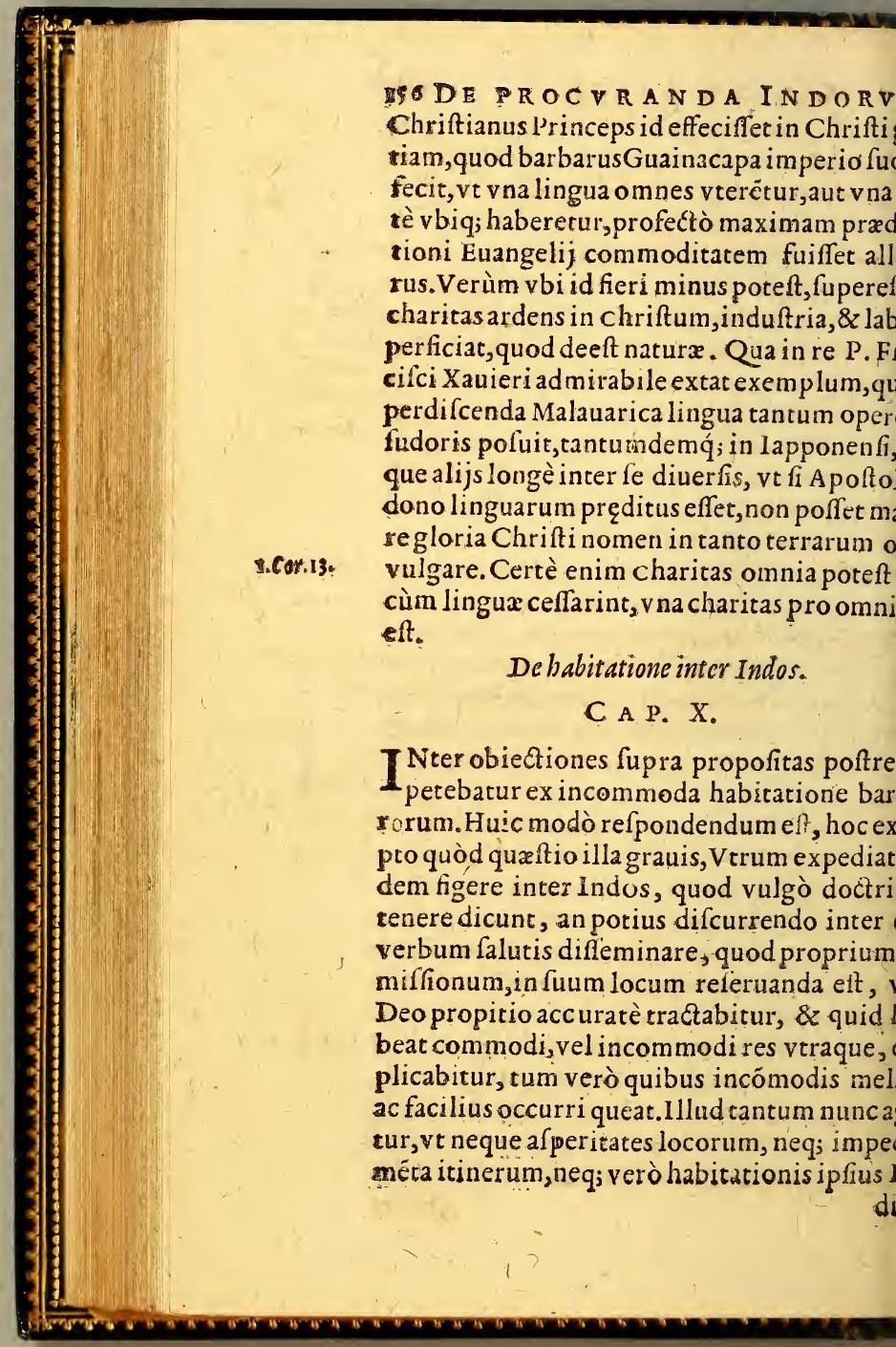


SA I VTE. LIBER I. ISP ratio præpoltera Chrifti feruum ab inftiretardent. Et quidem labores ærumnæq́ue. mari terraq́ue facientium, $\&$ mult $x$, \& graunt.Verùm quis aliter fibi perfualerit, nifi ens fit, cùm patria, atque amicis, \& charis ibusrelictis velut alter Abraham peregr:Ir, \& exit nefciens, quò eat? Ego, inquit, ero Genef $\mathbf{1 z}_{0}$ ces tua magna nimis. Hoc A poftolicum o- $\mathrm{Heb}_{\mathrm{u}}$. hæc gloria propria. Ettamen qui mifit fuos pera, \& facculo, \& argento, quarit ab ipfis, Matth.10, mquid aliquid defuit vobis? Nufquam diuirouidentia, neque certius, neque dulcius fui erimentum prabet, quàm cùm illius ope us incertas fedes, 82 humana prefidia inceronitituit experiri.Paulus A pofolus clamat, $\mathrm{Heb} .13$. mores fine auaritia, contenti prafentibus. Deut $3^{\text {lo }}$ enim dixit, Non te deferam, neque derelin- Io fue t. im, ita ve fidenter dicamus, Dominus mihi P Pal.ss. $\sigma^{\circ}$ utor, non timebo quid faciat mihi homo.Iam 117. ò quod de hábitatione rara, \& incommoda barorum multi caufantur, l'rimùm funt plafrequentiffim li numerofiffimi , vbi commodè $\&$ fructuosè rifti doctrina tradi poffit. Id quoq; quod diu lagitatum, \& non ita dudum inftitutum eft de ductione Indorum ad certos populos, $v t$ non iffim more ferarum, fed communiter oppida habitent, dici non poteft quantæ fit vtilitatis turum ad oin nem vita barbarorum informanem. Deinde ficut Saluator fuos admonuit, fi Mattb. se. in receperine vos in hac ciuitate, fugite in aim; A men dico vobis non confummabitis oms ciuitates Ifraêl, donec veniat regnum Dei:inobis quoq; dictum arbitremur; vt difperfos fratres 


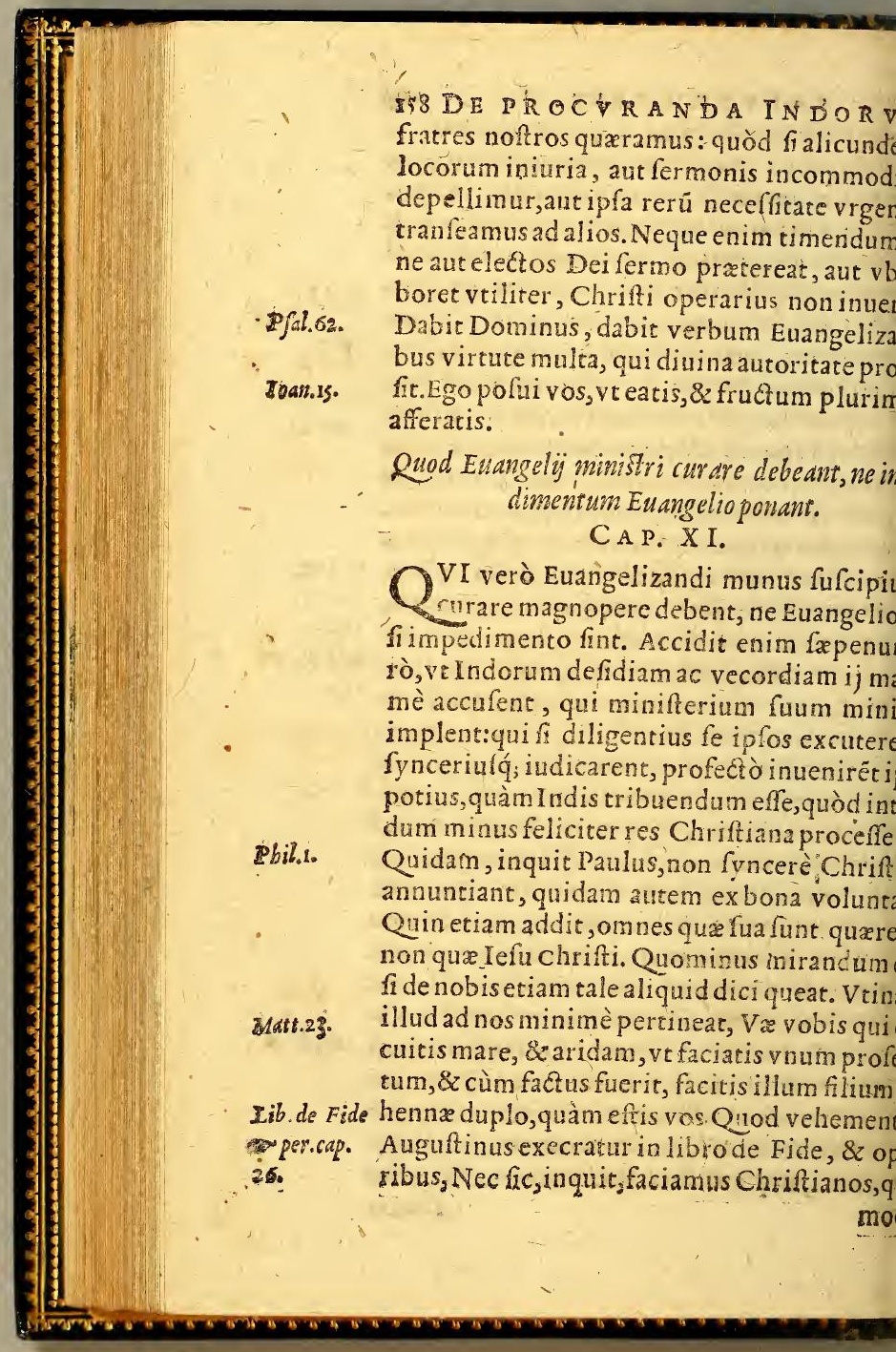




\section{SA L VT T: L I BER I.}

lo Iudxi profelytos, quibus Dominus ait, robis \& cærera. Sxpè enim quos pafores ,beneficentia, fide fentire oportuit, hos pofruos lupos miferi greges experiuncur.Cöantur certè diuinæ literæ nobis, Quivioer, ait Michęas tollitis pelles eorum defuper. Mish. 3. \& carnem defuper offibus eorum. Atque squogue Propheta. Odio habuerunt corri- Amess tem in porta, \& loquersem recta fiue perèabominati funt . Iccircò proeo quod diriatis patiperem, \& pradam electam tollebabeo, domos quadro lapide $x$ dificabitis, $\&$ habitabitis in eis; vineas'plantabitis amanmas, \& non kibetis vinum earum.Quod pro ò vat c nium vereor ne Indicæ opes nimiexperiantur, cum infar fomnij nimium peratæ fortuna, \& oriantur, \& occidant, \& de meretricibus congregata funt, ita Deo Mich.r. minante, vique ad meretricis mercedem reautur. Feftinara quippe fubftantia minuedeficiencefque ficut fumus deficient, quoni- $P / a l, 3 \sigma_{0}$ on profperabitur poffeffolcelerata. Igitur Eccli.ga porales Domini lndorum, né cupiditate $\& z$ lentra talutem eorum impediant, timendum De nobisautem, ideft, de minifris Ecclefi. cis fortaffis non fit minor querela, arque vtiminimè ad nos pertineantilla prophetica, acipeseius in medio eins, quafitupi rapien- Eqcelb.23. prxdam, ad effundendum fanguinem, \&zad dendas animas, \&z auarè fectanda lucra. phetæ autem eius liniebant eos abfque temamento, videntes vana, diuinantes eis menium, populi terræ calumniabantur calum$\mathrm{m}, \&$ rapiebant violenter egenum, $\&$ patiperem 


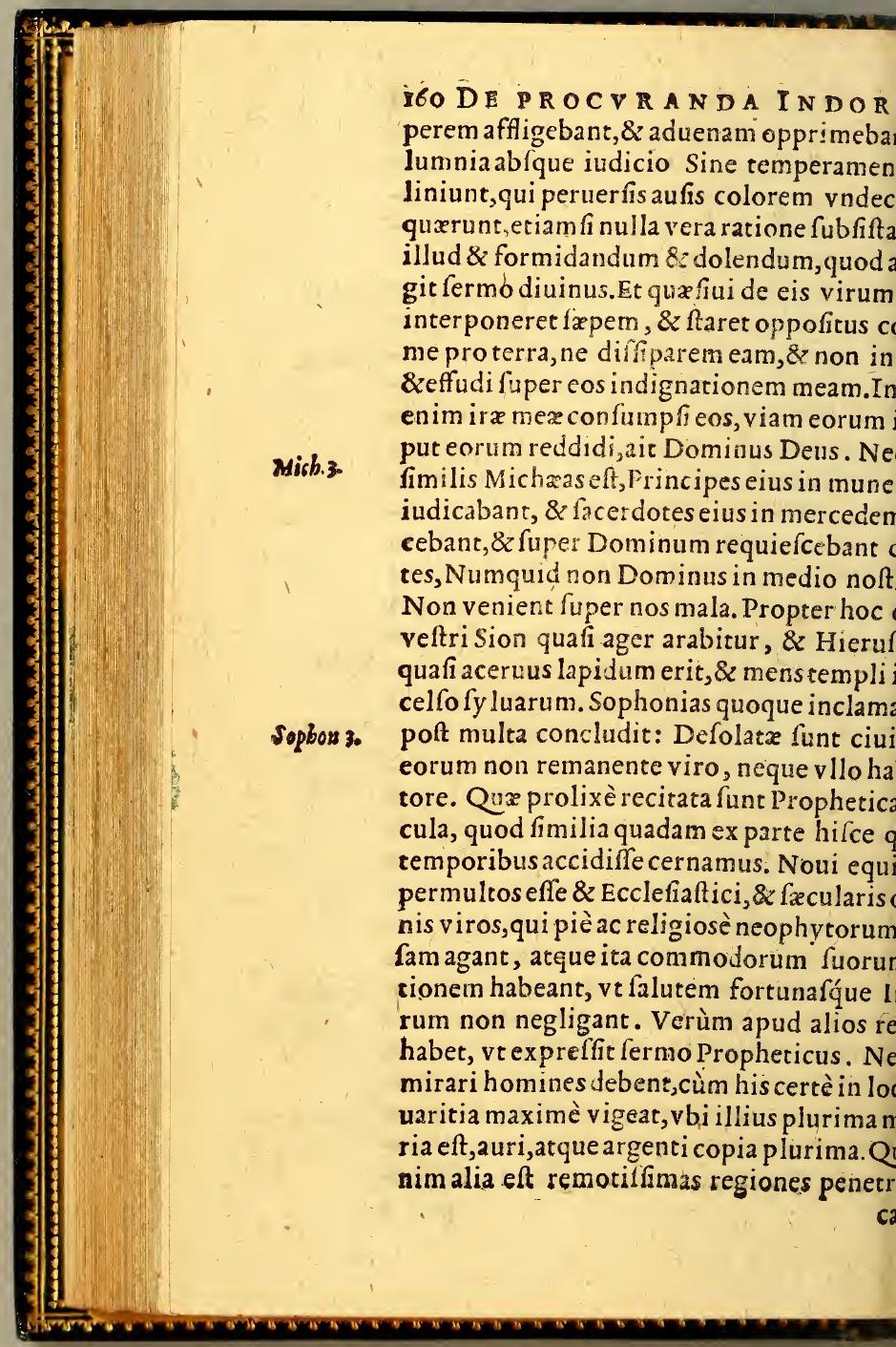


S A L T TE. LIBER I.

16 a? Cur immenfos Oceani circuitus, \& Jaboromines fubeunt? Nempe vt modeftifsime m, proprijs fortunis confulere fe arbitrancùm aut fuam, aut fuorum inopiam argen$x$ India collecto fe depulfuros conficút.Neid ego reprehendo modò, fed illud ago, vt omnem in Indos culpam reijciamus, fi procus Euangelici in hoc agro non ita læti atque res extiterint. Exiftent profectò quales vous, fi nos ijoperarij fimus, quos ager domiis poftulat, fi Chriftium non'noftra quæraNam qux fidei propagario qua mo:úintio fperanda fit, fi iuxta prophetam facer- Mich.3os es non folú mercede doceamus, fed merceetiam potilsimú requiramus? Reveraveré eft, ne vænale putent barbarieffe Euange$n$, vęnalia facramenta, neq;animas nobis cufre, fed tummú. At dignus eft operarius mer fua. Dignus planè.sed manducandú eft, vt ngelizes, non Euangelizădum, ve manduces: verò Euangelizádum, vt diteris? vt cógeras? pıbus plenus renertaris in patriâ? Iam ves ò $m$ fanciè,quàm integrè,quàm innocêter vius omnes qui Chrifti fanctirsimam legem aris promulgamus, nos nos ip los inter roge s. Certèbarbarifidem noftram de moribus icant. Procliuius quippe eft, quod videas, dere quàm quod audias: Rarò perfuadet fafermo contrarius. Illud autem magnopere uidendum eft ijs qui inter fidei tyrones vertur, ne priuaro fuo malo publicam Chriftiafamiliæ exiftimationem lędant, atq; corrum$t$, neve dum ex quibufdam cateros conici. $\quad$ tant?

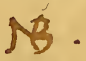




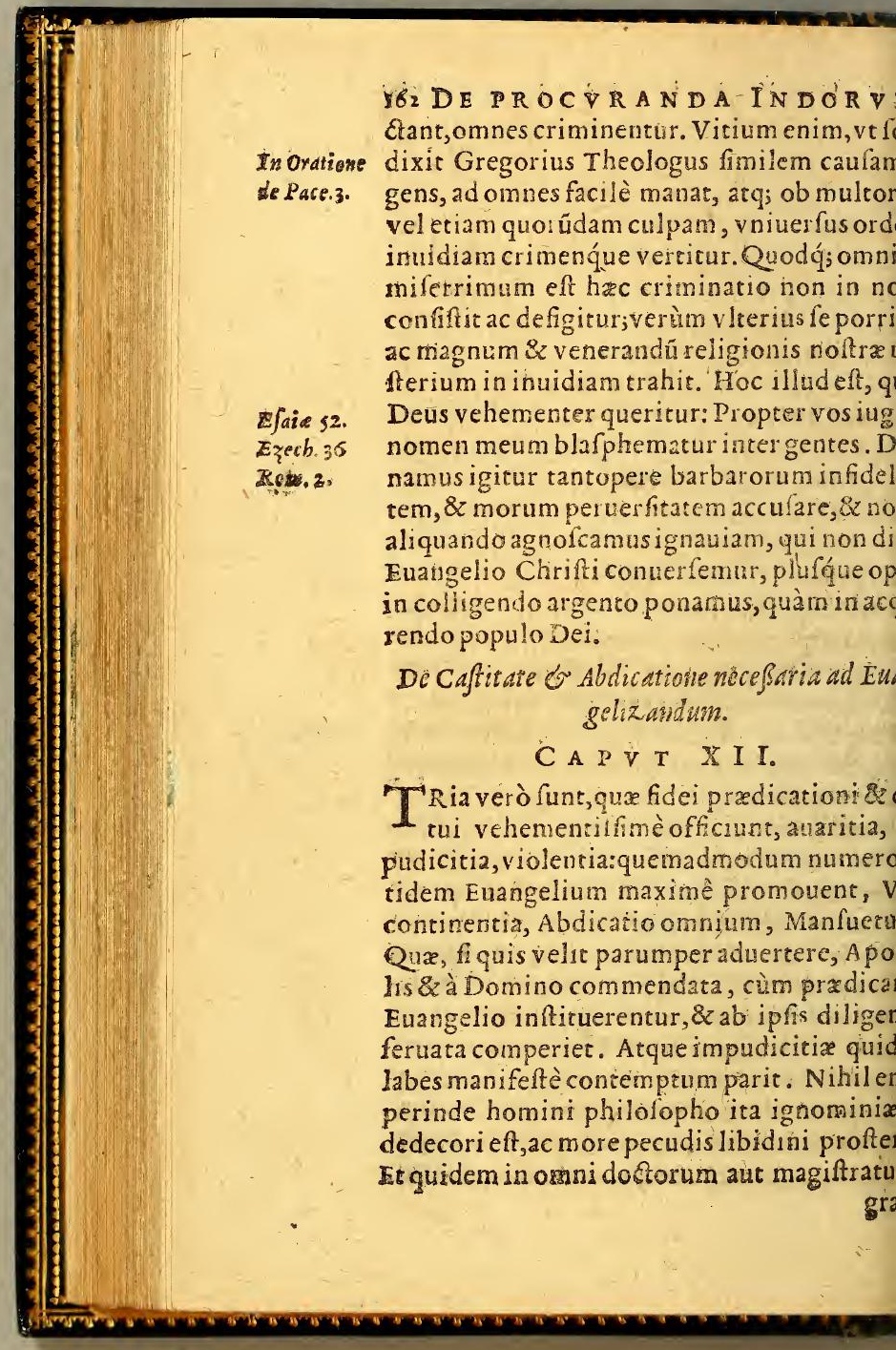


SALVTE. I I B ER T. u ita res habet:at in Euangelic o viro, qui vitotam lupra humanam ac penitus coeleftem tuit, id dedecor is dici non poteft, quantum dat oculos, quàm teddat abiectum, \& afperlem. Quam ob cautam,vt ego fanè opinor, unt alia grauiora crimina, nulla tamen $a b$ uis parribus grauius a nimaduerfa in homicclefiafico, ve qui prifcos caniones legerit, tò miretur ob femel admifium ftuprum, irperabiliter de omin facerdotali gradu \& mi rio Ecclefiaftico depelli conuictum. Idcirpoftolus Paulus \& toties \& tantopere Dilos Timotheum \& Titum, in quibus Eccle1agiftros informat, caftitatis cuiufdam peradmonet.In omni cafitate, inquit, \& rur- i.Tim. e ipfum caftum cuftodi. Et alibi, Te ipfum exemplum bonorum operum, in doctrina, Ibidem. tegritate, in grauitate. Vt enim nihil contê- Tit 2. ita ingenerat præceptoris vt turpitudo ifordes, ita nihil eft quod magis admirabireddat,atq; per fecta quadam \& omni etiam cione libera pudicitia.Admirantur, inquit, I.Pet 4" concurrentibus vobis in eandem luxurix ufonem. Virtutis cuiufdam coleftis id effe ines opinantur, quod nofts i barbari, vbi for tuentur, adeò fulpiciunt, ve vix credant. Cü lam in vrbe in foro clericum concionantem cxteros audiffet Curaca quifipiam Indorü, rmonis ardorem ac vim admiratusefiet, con us ad Hifpanos, quafiuit Quænam ratı hois, \& quod inftitutum effet? Cùm refpondifuifpiam, Hominem effe fanctum, qui faluiplorum tantummodo quareret. Perrexit a quærere;vtrum delicijs,opibufue vacaret,

I. 2 cùm 


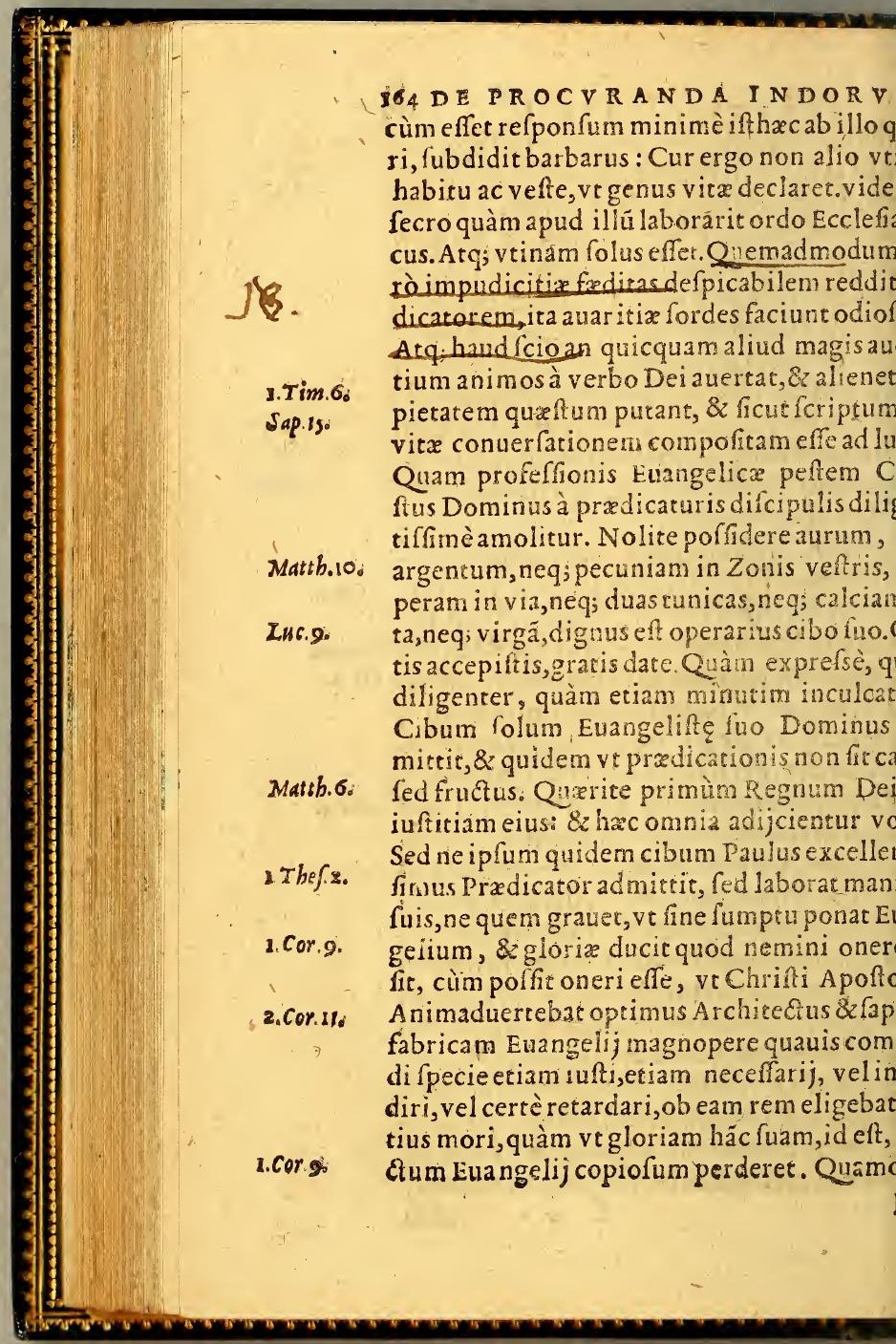


S A L V TE. IIBER I. omnibus Apoftolis non folùm amplius labo t.Cor.15" t, fed multò etiam vberius frućtificauit. Inerat re vera expoliatio hæc Euangelica anihominum admirabilem quandam vim amovt quem tuis commodis infudantemvideas, tum fui, rem propriam negligentem, hunc vifceribus complectaris, tanquam fyncerè aternè tua curantem.Quare cupiditatem om ,\& turpe lucrum principes A poftolorum Pe 1.Pet.5. \& Paulus, in Ecclefiæ miniftris fapè \& gra- Tit.lo mè deteftantur:Si qua ergo plaga dolenda eft c caufa, auaritia $e f$. Quid enim non agat aurifacra fames?

Quantum officiat Fidei violentia.

C A P. XIII.

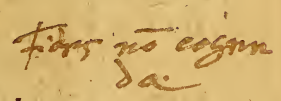

præter hæc incommoda, ipfa Fidei primor a ex multa nocendi licentia non mediocre num accepêre. Arque vr ftirps primis initijs. peruersè, \& inflexè non facilè mox vitium nit, cùm creuerit, fed aut perfringi, aut nafuo errori permitti debet, ita prorfus cùm rum natio bellici apparatus potius authoe, quam germana prædicatione magna ex e initio Chrifum acceperit, dubitare non amus, quin animo conceptum metum, \& fer m conditionem non ingenuè in filios Dei llata per regenerationem, adhuc retineat,ac s ipfis, vbi fibi impunè licere putat, oftenNihil enim ira fidei fufceprioniaduerfatur, e vis orn nis, \& violentia Nonenim eft fides volentium, vt prouerbij loco fitillud-Atini, catera poffe hominem etiam nolentem, Aug traש. ere nonnifi volentem. Quamobrem man-16.in Ioan.

$$
\text { L } 3 \text { Iuetudo? }
$$

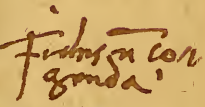


r

Tit.3.

Q.Tim.2.

Iacob.1.

Eacob. 2.

Yatsb. 70 .

I66 DE PROCVRANDA INDORV. fuetudo, \& fuauitas vel præcıpuè commenda Euangelicis viris. Omnem, inquit, oftender manfuetudinem ad omnes homines. Et alibi, modentià corripientem eos, qui refifune ver ii, nequando Deus det illis ponitentiam, \& fipifcant. Et Iacobus A poltolus monet, in $\mathrm{m}$ fuetudine fufcipere infitum verbum, quod teft faluare animas noftras. Quoniam ergo' Juntarium eft ac liberum curque obedire Eu gelio credendo, neque fides per vim extort liorum poreft effe, quàm dxmonum, fuauite beneuolè ducendus elt, non protrudendus at tor. Hinc diuinus præceptor miffurus fuos à uangelizandum exorditur, Ecce ego mitto ficut agnos in mẹdio luporum. Ac vide Don magnificentiam, ab agnis lupi fuperati funt depofita feritate in eundem fe gregem adi xerunt. Quando obfecro ferocia potentium nis cederet? Quando orbis domaretur vi? Tac do, tolerando, benemerendo de inimicis, $v$ runt Chrifti mitites, non cxdend̦o, non ter do non minitando. Quod fi non receperin uangelium,quid pracipis Domine? ubebun ignem de ccelo defcendere? ruinæ tradent $c$

Lues 9. tatem? Nefcitis, inquit, cuius fpiritus eftis. Fi hominis non venit perdere, fed faluare. Qui go?fi non receperint vos in ilta ciuitate, ite liam Q àm benigne?quam dulciter? Itaque fponte Euangelio cedunt, verè cedunt, fidé de concipiunt, $\&$ ore confitentur, $\&$ fixi man \& toti Deifunt, non partim in Deo, partin Baal claudicantes, fpecie \& voce Chriftian wimo, 8 re infideles. Id en im confequatur ceffe eft, vbi contra naturam fuam, co

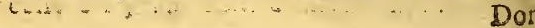


SALVTE. LTBER I. $\quad 16 \%$ mini voluntatem, Fides extorquetur inui-

unalis in religione Cbriftiana Whana exparte fit natio Indorum.

C A P V T XIIIT.

$C$ mihi quidem videtur res Indorum perfi-milis antiqux Samaritanorum hiftoriæ, quá 4.lib. Regnorum legimus, vbi terrore ac meferarum incurfantiũ perculfi habitatores pe- 4 .Reg. ruit Dei facerdotem, qui Dei legern doceret. Im veniffer igitor, ait, vnus de facerdotibus his i captiui ducti fuevant de Samaria, habitauic Bethel, \&dacebat eos, quomodo colerent Donum. Et mox poft enumeratas fuperftitiones rias illorum adiungit. Et cùm Dominum coent, Dijsquoq; fuis feruiebant, iuxta confuetinem gentium, de quibus tranflati fuerane nariam, vfque in prætentem diem morem feuntur antiquum. Non timent Dominum, nee cuftodiunt ceremonias eius, atque iudicia \&: yem, \& mandatum \& cętera.Poftremò conclu: Fuerunt igitur gentes ifta timentes Domi$\mathrm{m}$, fed nikilominus \& 2 idolis fuis feruientes. am $8 z$ filij eorum, $8 z$ nepotes ficut fecerunt $\mathrm{pa}-$ es fui, ita faciunt $v$ fq ; in prafentem diem. Non to totumnoftrorum Indorum habitum, \& reriofitatem defcribi potuiffe, vel plenius, vel eJantius. Et Chriftum colunt, 8 a dijs fuis feruiit:\& timent Dñm, \& non timent:virumq; enim. infmat fcriptura diuina. Timent ore tenus, tient dú inftat Iudex, aut presbyter, timêt deniq; mu latoriam Clrriftianitaris fpeciē pręferentes: on timent animo, non colunt feriò, neq; corde L 4. crejune: 
368 DE PROCVRANDA IN DOR V credunt ad uffitiam. Quid plura?Filij, \& $\mathrm{n}$ tes eorum, ficut fecerunt patres fui, fic fac $v$ fque in præfentem diem.

Nibilominusvera Fidei, ac falutis apud Indos, effe magnam, alienumqúe efse à Deifpirit contrafentive.

C A P V T X V.

F N noftrorum temporum Samaria: vbi ftus habitat cum Socot Benot Babylonio 4.Reg. 17. Nergel cuthro, cum Afima, cum Nebahihaz Thartac, \& Adramelech, \& Anamelech; \& bufcunque alijs portentis Deorum.Vbi non colitur cum alijs, quàm iniuriam fuam, $8 z \mathrm{co}$ meliam ferre quodammodo cogitur, Damo bus confociatus, \&z eorum honores confo fuo cumulans. Sed non funt ideo Samaritani ftriauerandi,non natim defperandi. Et Sa riæguoqs recordabicur Dominus: \& erit,

Atar.8. accipiat verbum Dei, \&y Simone relicto Phi pumaudiat, Petrumac Ioannen prædicat Ioan 4. mereatur. Eritcum dicat, et nos credimus, hiceftverè Saluator mundi. Omnino Sán? tanis quoque fui ipfus copiam facit Chrif Ibidem. \&oftendit fuis regiones iam albas ad meft \& laborem foelicem pronuntiat, \& fructum piofum pollicecur in vitam æternam. Cure 1pem abijciemus? cur Iudzorum fupercilio maritanos procul abire iubebimus? ac non

colofj 1. gis Dominum lliulq́; A poltolos imitantes Ev gelium proferemus? $x^{2}$ quod in toto mundo 1 Eificat, \& crefcit, \& hic in terra arida, 8 in Efaic 35 aliquando tandem fructificaturum creden Eaia35. Nam qua erat fitiens, erit in fontes aquar 
SA LV T E. L I B ER T. 169 fciff $x$ funt in deferto rupes, $8 z$ in flumina erunt. Veniet, veniet prorfus tempus fuum arix:\& qui prius in mandatis acceperant, In Matt. 16. ngentium ne abieritis, \& in ciuitates Samanorum ne intraueritis, audient polteaDomi pracipientem : Accipietis virtutem Spiriancti fuperuenientis in vos; 8 zeritis mihi teAttor.t. non folùm in Iudæa, fed in omni etiam Saia, \& vfq; ad vltimum terræ. Ac mihi fanè fuafum eft,neq; inde poffum reuocare fenten" a, \& fi aliquanto ferius, \& laboriofius, \& par- = fortaffe pro initijs, tamen aliquando Spixi= andi benignitate, Indorum gentes fore, yt', ungelij gratia multum locupletentur, $8 \mathrm{z}=$ ? es corá Domino Sabaoth fiuctus ferant. Neq; a alias ego difficultates perpendo aurt timeo, "f m operariorum fidelium, \& prudentiumin's rifto magnam inopiam cum magna profectò $2 . T$ im. I. A ia mercenariorum, \& eorũ qui fua quarunt, Philip z. quæ Iefu Chrifi. Igitur if Dominus ve- r, operarios miferit in meffem fuam, opeios inquam inconfufibiles, rectè tractantes." bum veritatis, quos hrc natio hominum, non? quarere, fed fe perfpiciat, qui libenter filijs? faurizent, infuper \& feipfos impendere pro ${ }_{2}$ Cor.12. imarum falute promptilfmi fint, quibusao chari fint filij fpirituales, vt non folum Eui-? lium Chrifti, fed ipfa quoque vifcera yaderes Theff.z. ent, qui probati à Deo ita Joquantur, ve non? xrant hominibus placere, fedDeo, quiprobat" rda, quorum fermo non fit in fpecie adulatio-? $s$, neque in occafione auaritia, deniq; qui non a m, fed Deigloriam fynceriffimè quarant:tíc anè manipuli pleni in area Chrificolligécus,

$$
15 \text { tuac }
$$




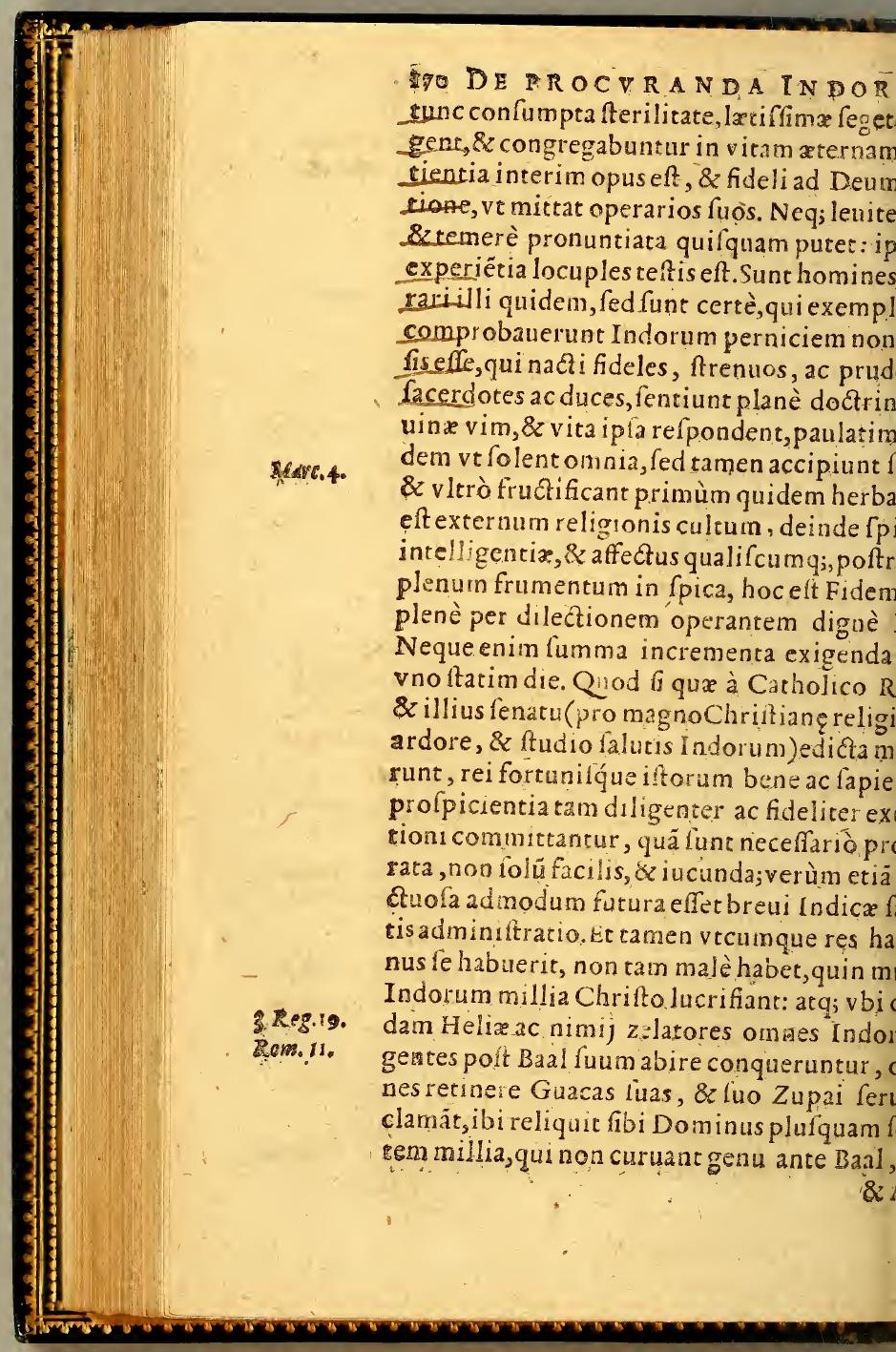


S A L V T E. L T B E R T. 877 bdias interdum eft, etiam Prophetise dono ulatus. Nouit Dominus qui func eius, omnes 2 Tim 2 tes feruient ei. Quæ cùm ita fint, nó eft Chri Pfal.s. si pectoris, fed à Chrifti fpiritualıe niffimi, nines inde auocare, \& à negotio gerendo detari:cü' difficultates oinnes quantxcúq; fint, pracepto, \& gratia fuperiores effe non pof, fructufq́ue animarum, vi parciffimè fucat in tam infinita multitudine non poffitnon copiofus, \& merces a pud Deum mulròmax-

d etian in prafentia labore miniftrorum frus-

ctus animarum fit longè maior. .

\section{A P. XVI.}

C fruatum Euangelica predicationis nos quidem animarum multitudine metimur, ut fcriptum eft, In vnum colligam reliquias aël,pariter ponam illum quafi gregem in oui- Mich.2; qua fi pecus in medio caularú, tumultuabúteur nultitudine hominum. Ipfetamen Dominus Mart.ara cit multos effe vocatos, paucos verò electos, ultos ad Euangelium, \& nuptias inuitatos, pau Lue.14. s dignos fe conuiuio præbuiffe. Quod fapiêter putans Paulus fibi quoq; ipfi timet, 82 non con 1 , cor.g. ntus tam raræ vocationis fux gratia, corpus ad c caltigat, \& domat, ne predicans alijs reprous ipfe efficiatur, neq; nos hoc confilij vilo mo. o ignorare patitur. Vt cum antiquos patres tot 1 .Cor.ro tantis beneficijs cumulatos videamus, \& bapfmo figuratiuo lotos, 8 menfaDomini fpiritua communicatos, \& tamen ex tot millibus homi Heb.4. um vix vnum, aut alterum bene placuiffe corä omino, quibus iratus iurauit, fi introibü in re $P \int a l .94$. quiem. 


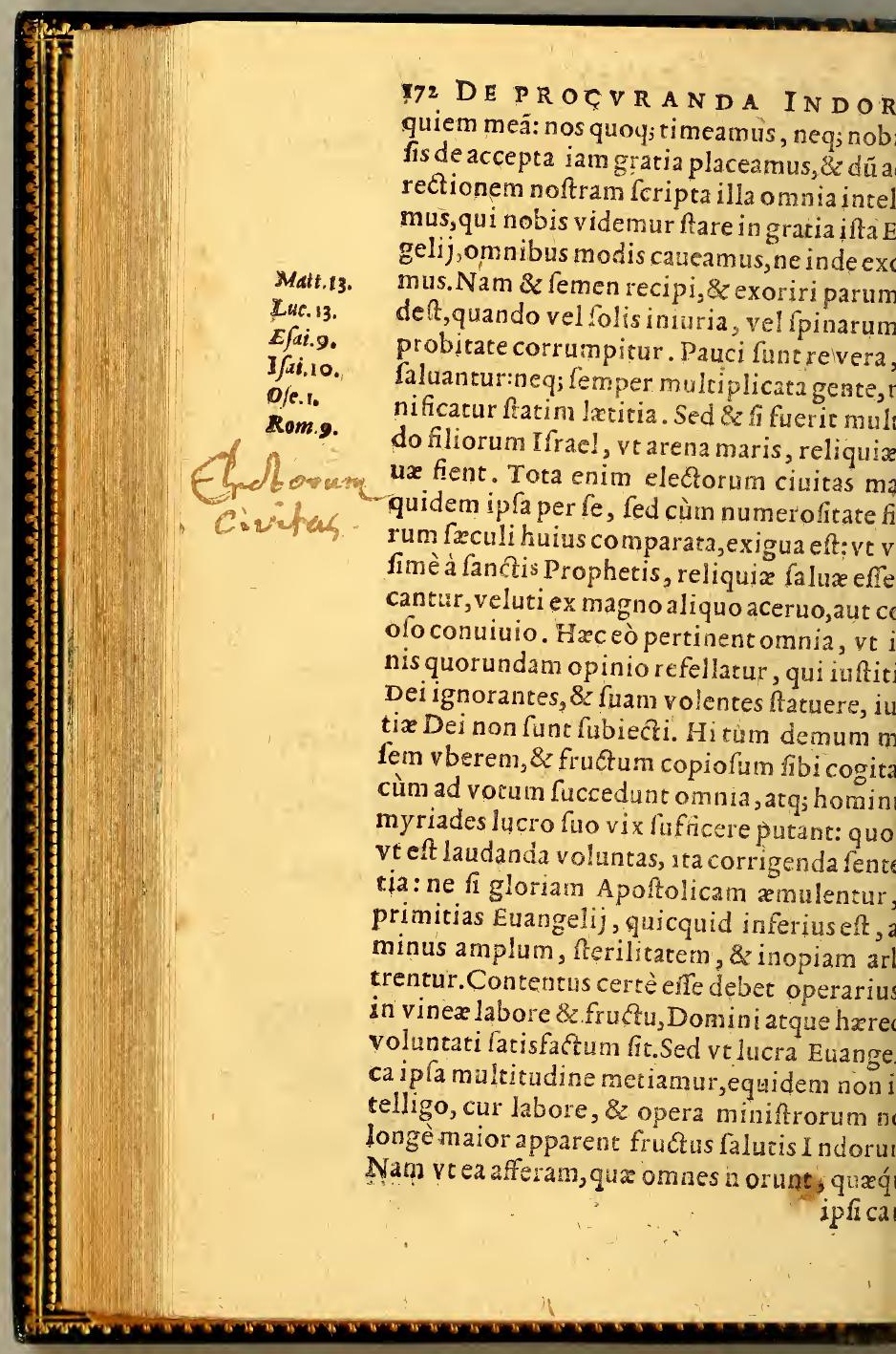


S A L V T E. LI B ER I. auf $x$ Indorum infeftiffimi confitêtur, pro, \&renalcentium, \& in Chrifto morientiarba non poteft non effe plurima. Quoteinfantium millia quotidie de interitu ateripiuntur falutati lauacro?qui emptiftatim ra teneri Chrift i languinis foetus Deo imlati off eruntur. Et fienim frequens eft vbiinfantulos recentes ab vtero extingui, ob $I n l_{i b}$.de caufam Ariftoteles fcribit gentium fuiffe biff. Anims. cietudinem, non ante nomen imponere qquả us dies veluti iam victurum puerum reiaret, quod primo dierum feptenario vix nomine dignus haberi poffit, propter natuconfantiam: tamen, vt quorundam opinio nefcio quo coeli, aërisve occulto tactu in prope regione duobus circulis Tropicis pretienla, multò frequentiffimum elt; ns ortos pueros ante paucos dies interire, ve ufim dicere, vtra portio fit maior abeuntian permanentium. Quos omnes cùm fibi iftus amator paruplorum facro fui fanguionte purgatos lucrifaciat, quis nó vel inte$\mathrm{n}$ hoc vniuer fi laboris Indic: operępretium t? Ip fos grandiores intueamur. Ulud firmú iuinz legis oraculum, in vltimaagone vite, ota caufa pronuntiari: xequem morsiuftifi$m$ inueniat, huic non adonodumabfir vira erioris iniquitas. Atque de Indorum gente plurimorum fententia eft, eorumǵtue maxiqui diutius cum ijs verfantur, vrgente metu tis, plerofque facerdotem protinus fibi vo,Patrem adeffe obnixè petere, peccata fua enter, \& feriò confiteri, magna Fidei, \& poentiæ indicia præbere, idq́ue cùm liceret illis $_{2}$

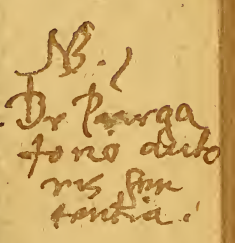




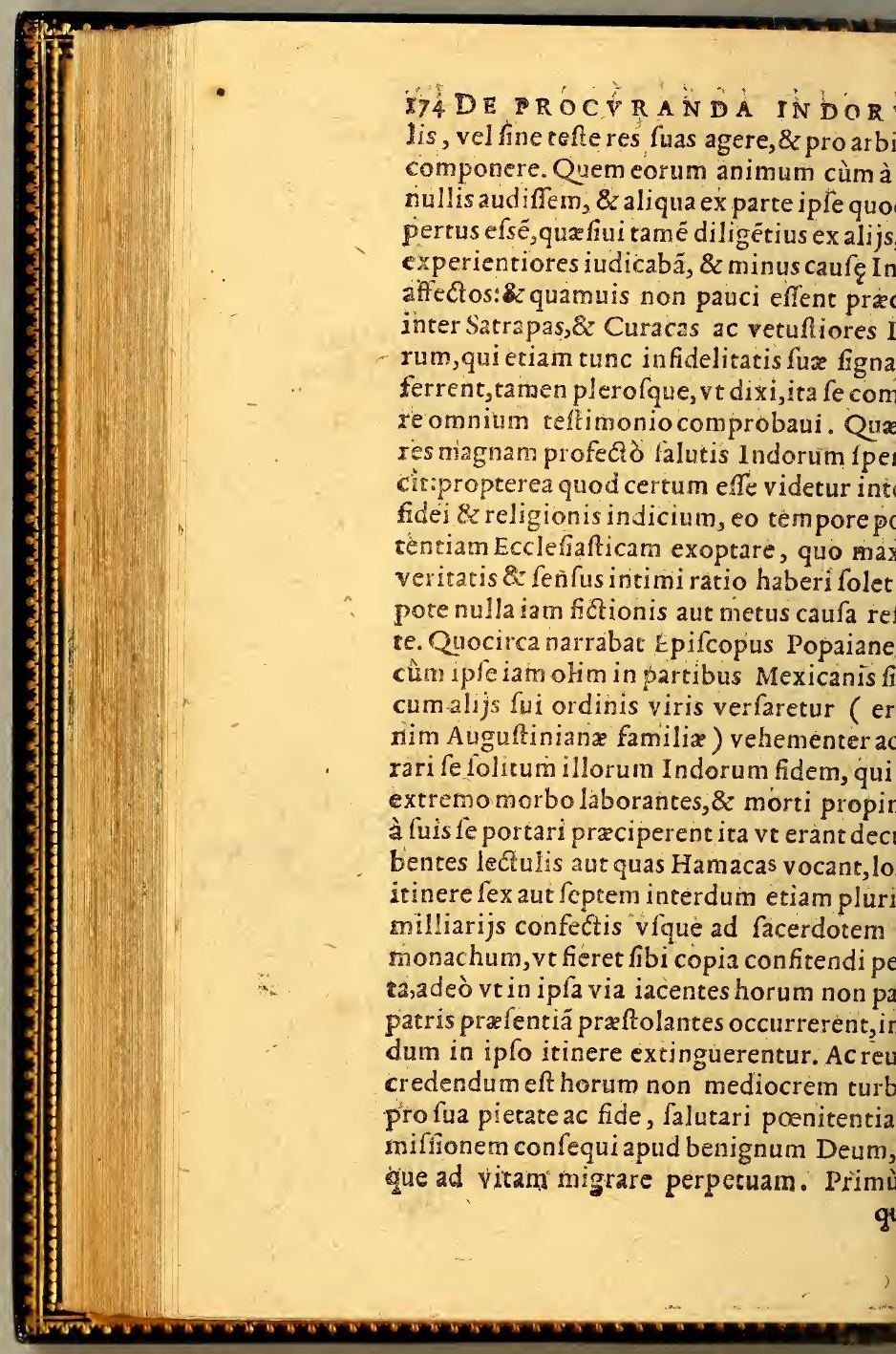


SA I T E. LIBER I. 175 quibus minus naturalis talenti donatum Luc.p ijs iuxta Saluatorss fententiam, minus rendum fit, exiguo quippe conceditur mife- sap. dia. Deinde iftorum crimina ve plurimü, ius genęris funt, ve inexorabilem fibi redDeum, atque in ipfo inreritu vetera vicifm,cuiulmodi fcripturæ prædicát maxime ta in Spiritum fanctú, ex certa malitia per-Prou ta. Peccant enim pleriq; vel ignorátia, vel Hier. s infirmitate incitati, quibus fi ebrietates, $E_{j} \sigma .6 \%$ rtationum flagitia adimas, vix quicquã re$\mathrm{m}$ fit. Pofremò,neq; reftitutionibus rei ali neq; iniurijs, autjinimicitijs impediuntur; bitinatione quadam fcelera perpetrandi, ix auaritia, aut violentix apudeos fenfus ibus omnibus rebus meritò adducimur, ve orum extrema falute nó parum fperemus; rafertim intuentes clementiam, qui pauatc; inopis oblationem licet exiguam non mnit. Mihi verò perfuadeo, vt de iftorum orum confelfione, \& ponitentia melius $\mathrm{m}$, quàm de multorum freculi huius poum ac fapientium in extremo vita fpirisenti apparatu, \& pompa, etiam fi facerin longo ordine cingantur, \& de male s diuitijs magna legata Ecclefijs relin t. Solus ille, qui nouit omnes, fcit vnde f faluifiant.Sępe $q$ altum eft hominibus, ab

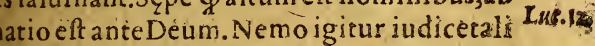
eruum, neq; fulta \& ignobilia mundi conItaq; vbi operariorum non cernimus $v$ fq; magnos fudores pro Chrifto, non poffumus fterilitatem accufare, fiquidem in tanta de miniftrorü hos certè fructus videmus, vio โมฉว 
$\$ 96$ D P OCVRANDA INDOR furi fine vlla dubitatione longè cunuatio modò dignitati Euangelij relponderit dig miniftrorum. Neque vero pro paruo ducer eft, quod expulfo Diabolo Chriftus regn: pronefarijs, \& impurisidolorum cultibı clefiafica facramenta celebrantur; quòd ficiorum, fiagiriorum, parricidiorum que decrefcat furor, neq; audeat fcelus impune fari.Tremit Satanas fe pulfum, \& quantisp viribus,agit, vt liceat rediread priftinam c Matt.12. iuxta Euangelium. Iccircò vacuam Chrift niftris optat, 8 dolens fe fpoliariantiqui hareditate, in omnefelatus vertit, cuino mille, mille nocendi artes, vt feruis Chrift fuadeat vanos, \& inutiles fuos effe labor torpore ac defperatione fuperati relinqua: fipatas Chrifti oues, ab immanilfimo lupo tinus trucidandas.Sed fat Dominus propo Matt 12. fuo, \& clamat: Qui non colligit mecum, di git, \& qui non eft mecum, contrà me eft. A moner, adhuc hortatur levare oculos, \& $v$ Joan.4. - regiones albas ád meffem: vt qui fe minat gaudear, \& qui metit.

Patientia, o labore effici, vicopiofifructus e agro Duminico colligantur.

\section{A P. XVII.}

Iodx.f.

Tla verò Dńi fententia comprobantis î 1 effe verbum verum, quia alius eft, qui fem \& alius eft, qui metit, fatis nos confirmare. 3 folari deberet fi pro diligentia feminandi tis verbum, nó apparet illicò fidei, \& chari fructus affurgere. Fieri enim potent, vt fem 
SALVTE. LIBER I. I7\% $n d x$ præfens tempus fit, futurum aliquando meffis colligend $x$. A poitoli in Prophetalabores introiffe dicuntur, neque tamen, vel lilli fibi fructificarunt, fed Deo, qui nouit rtuna temporaiuxta fapientis fententiam uiq; negotio. Hominis autem affictio mul- Eccl.8. propierea quod futura fcire non poteft.Sed in \& qui arat, in fpe debet arare fruetus per- 1 Cor. 9. ndi, \&zhuic fuæ fpei, etiam fi dilata affi- Prouerb.13. debet nihilominus patientiam \& longanitem adhibere. Ecce agricola; ait Iacobus A-Iacob.5. lus, expedat pretiofum fructum terrx, $\mathrm{pa-}$ erferens, donec accipiat temporaneum $8 z$ inum, patientes igitur eftote \& vos, \& conate corda veftra:Abraham longanimicer fe- Heb.6. adeprus eft repromilfionem. Ac ferè omnis ria, ómnis fermo dininus eò maximè tentper patientiam foripturarum fpem \& con. Rom. is. jonem habeant, qui laborant quidem, fed um fuorum ewolumenta noa vident. Nilagnum, nihilgloria dignum frue fatientia am peractum eit. Ip fos Romarios rerum do s patientia maximè \& tolerantia, orbis pc,non folum profanx, verum etiam facræli- 1.Mach. 8. commendarunt. Neque tam fuitadmirabiotentia in profpera, quàm in a dueria fortunftantia. Non videmus nos modò vafcentis efi: difficultates à Chrifianis orti, inter foChrifianos educati. Certè fides vbi nunc iores altiorefque radices egit, ibi initia halongè difficillima. Non igitur fementis Eelicx fruges ex prefentibus tantummodo enda funt. In lege fanè fcriptum legimus: ndo ingreffi fueritis terram, \& plantaueri- Lesit, 19. 
I9 DE PROCVRANDA INDOR eis in ea ligna pomifera, au feretis præputia poma, qua germinant, immunda erunt $v$ nec edetis ex eis. Quarto autem anno omni Etus eorum fanctificabitur laudabilis Don Quinto aurem anno comederis fructus, con gantes poma, qua proferunt. Fortafis in te nuper ingreffex plancatis lignis nondum matura atq; efui apta decerpimus fortaffis Indorum nondum fructus fatis fame prædi rum dignos edidit: adhuc p ratia aufer funt:adhuc mulcus priftin infidelitatis $g$ ef.Sed quid agimus? ita ne femper futurum Imò verò pofterorum faltem generacione dubitat frictus diuino confpećlu dignos, vetultaris fapore abolito, exorituros? Erunt parentibus feliciores, quod experientia fat cet,erunt fidei magis icionei paterna fua fu ftitione minus imbuti, religioni diligentit nutriti. Neq; video cur quilquam contra n ominetur infaufta. Natio nulla eft hominum fequentior, nulla fubiectior. Ingenio nequa duro \& obrulo, imitandi quicquid viderint, rè cupidi. In quibus potentiam \& regend thoritatem confpiciunt, nimium venerabu dicto citius obfecundantes. His moribus efle præditos, quicunque vel exiliter expe eft, non ignorat.Si ergo magifros nacti fint muos, Chrifti charitate feruentes, qui bono plo, ac fana doctrina greges fibi commiffos citè pafcant, quid aon fperandum eft, diuin primis, quæ non deeft fuis, gratia afpirante? quoniam omnia hic afpera, omnia aduerfa santur, vel certè exiftimantur à multis, often Jabore \& patiensia cuncta fuperari, \& de def 
SA L T IE. LIBER P. atque ærumnofis inirijs in latiffmos exilere conuerti. Oftendam verò non tam rabus, quàm exemplo patrum, quod efficacius adet. Ac placet pauló fufius referre, qux ncto Malachia Epifcopo coxtaneo fuo $B$. ardus fcribat, cùmprimùn creatus eft $\mathrm{Pa}$ Connereth, qua ciuitas eft in Hibernia. Cư fiet, inquit, pro officio fuo agere, tunc inIn rica $\hat{N}_{d}$. latchie 6 is: 6 . xit homo Dei, non ad homines $f e$, fed ad be deftinatum. Nufquam tales expertus erat in tacumque barbarie, nufquam repererat fic eruos ad mores, fic feralesad ritus, fic ad Fiimpios, ad leges barbaros, ceruicofos ad plinam, f purcos ad vitam.Chriftiani nomipagani. non decimas dare, non primitias, egitima inire coniugia, non facere confefs,pcenitentias nec qui peteret, necqui daenitus inueniri: Miniftrialraris pauci admerant, fed quid opus pluriû, vbi ip fa paú inter laicos propenodum oriofa vacaret? erat quod de fuis fruetificarent officijs in lo nequam. Neqg, cnim in foclefijs, aut praris vox, aut cantácis audiebarur. Hoc ftatu, oribus nemo opinor caufa Indic tam inifit, qui nó foliciorem, vel potius minus inem prouinciä iftam noftram agnolcat. Sed mus atdire, quod optimi Chrifti minifri oerdito populo officia fuerit. Quid faceret? it, athleta Domina aut cedendum turpiter, ericulosè certandum. Sed qui fe paftorem, nercenarium arnofcebat, elegit frare quàm e, paratus $8 \mathrm{z}$ animam dare pro ouibus, $\mathrm{fi}$ oret. Ft quanquam omnes lupi; oues nulla, intrepidus in medio luporu, omnimodis at

$$
\text { it is gumetion }
$$




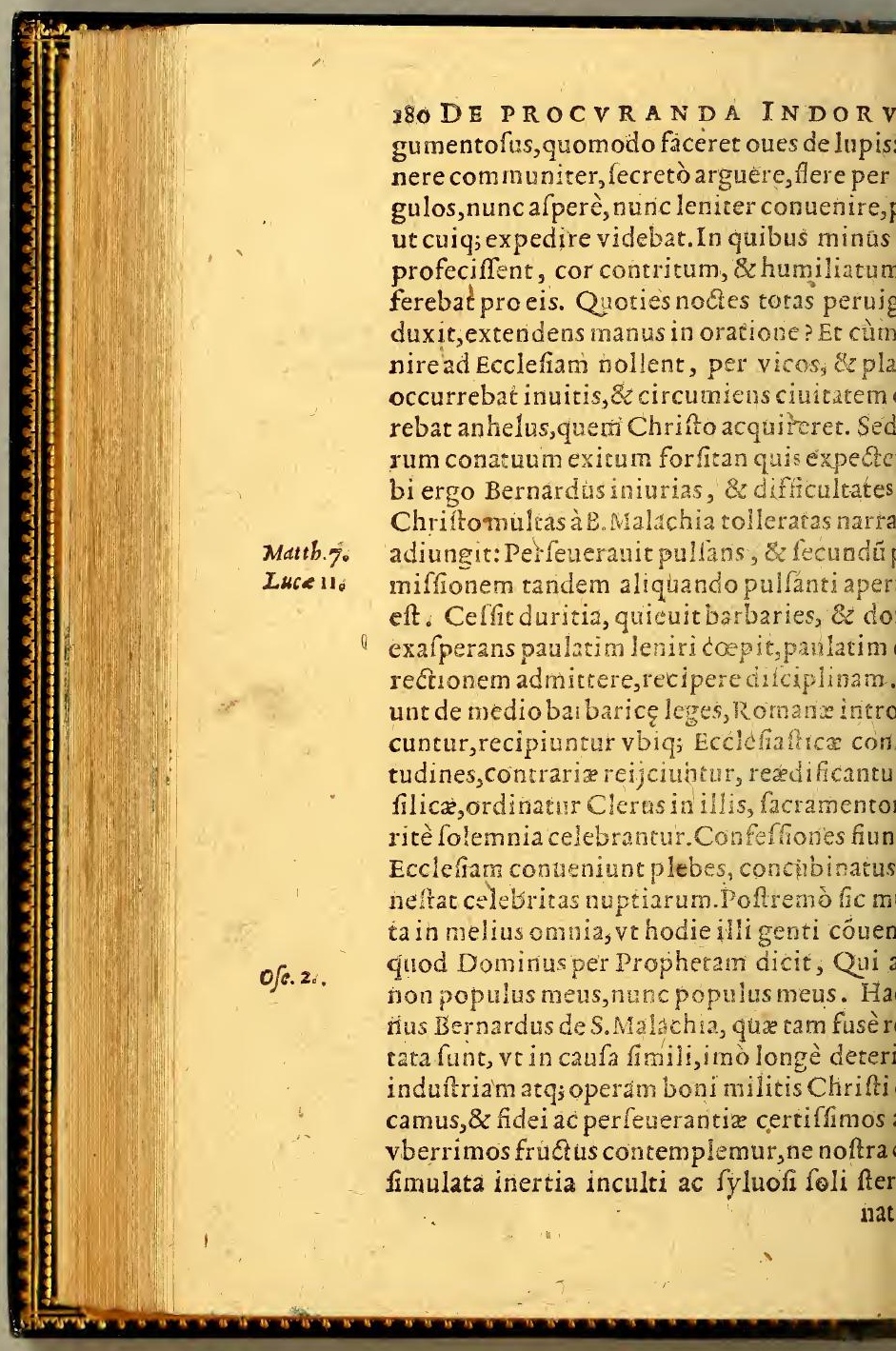


S A I V T E. LIBER I. 18E ira culpetur. Alterum quoq; exemplum eopertinens quamuisalia ratione ex hiftoria probata afferamus. Is lib.2. Anglicarum rerefert Mellitum olim à magno Gregorio $L_{i}$. 2. cap. 5 . Auguftino miffum, propter fruientis regis os 6. rias $2 z$ plebis exiguum numerum pulfum ria fede Cantuam veniffe, yt cum LaurenIufto coêpifcopis fuis traetaret, quid facto effet. Decretumq́ue communi confilio fueffe, vt omnes in patriam redeuntes libera nente Domino deferuirent, quàm inter rees fidei barbaros fine fructu refiderent. Itaq; litus \& Iuftus in partes Galliæ receffere .Cü Laurentius eos iä fecuturus, ac Britanniam furus effet, iuffit ipfa sbi nocte in Ecclefia ponolorum Petri \& Pauli ftratum parari: in cùm poft multas preces, 8 lachrymas adDeú ftatu Ecclefia fufas, obdormiffer, apparuit eatiffimus A portolorum princeps, \& multo $\mathrm{m}$ tempore fecretæ not is flagellis arctioricadens, fcifcitabatur A poftolica diftrictioquare gregem, quem fibi ipfe crediderat, reueret?An mei, inquit, oblitus es expli, qui paruulis Chrifi, quos mihi in indicium fuæ ctionis commendauerat, vincula, verbera, ceres, afflictiones, ipfam poftremò mortem nortem crucis ab infidelibus etiam inimicis rifi ipfe cum Chrifto coronandus pertuli? B. Petri flagellis timul, \& exhortationibus matus, atq; eruditus Laurentius, manere denit, focios ex Gallia reuocat, Regem fibi hanus infeftum adit, often fis vulieribus flectit, o lucratur, gentis totius falutem ad finem viq; Ita cum alacritate procurat, \& perfeuerantiz M, 3 tandera 


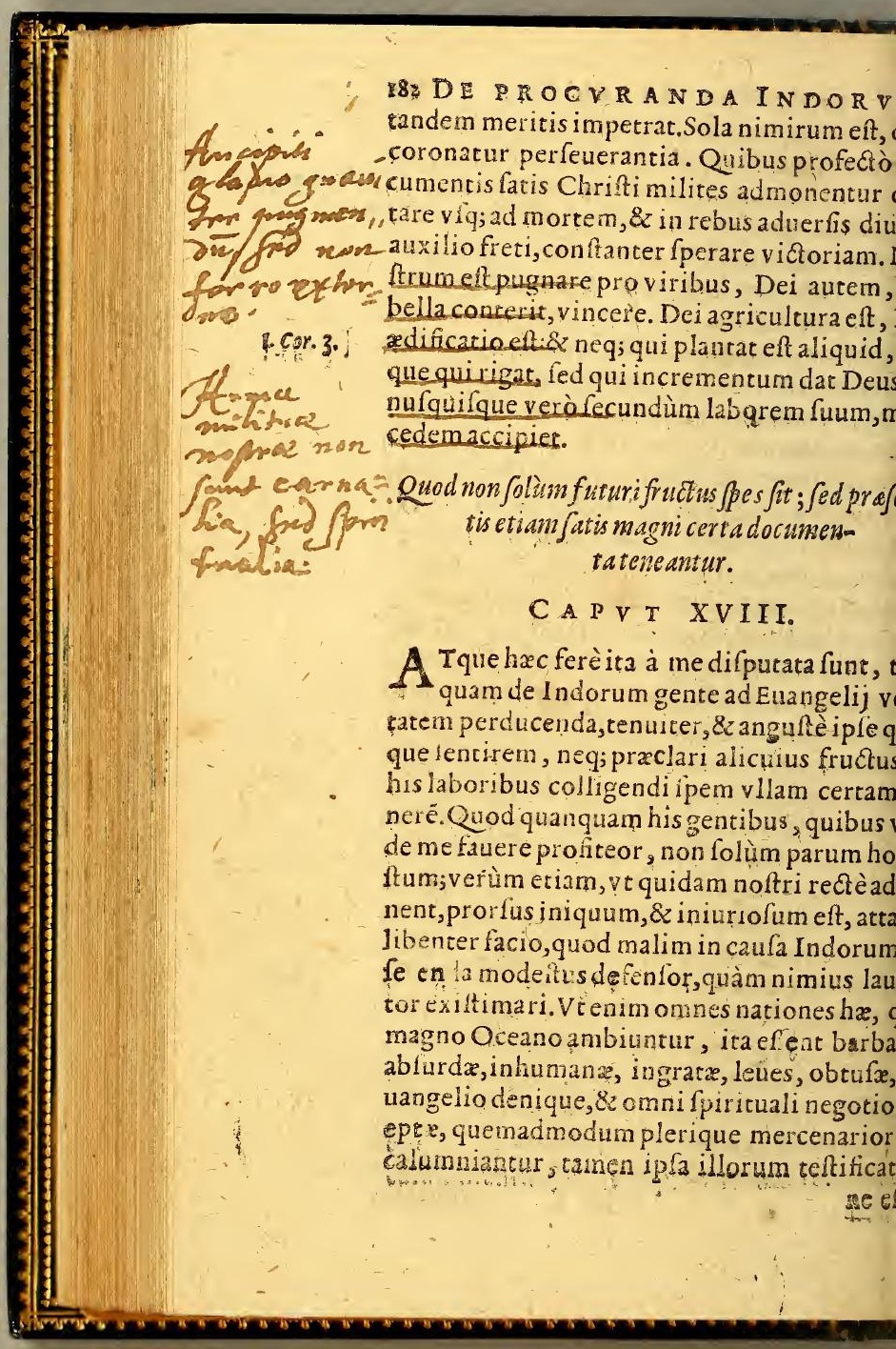


SA L $\nabla T$ E. IIBER I. I. ectum eft certè hactenus, vt tot gentium fas nullo modo defperare debeamus, neque falua rerum fide poffimus. Itaque quamuis neffet, quod fumunt falutis Indica oppures, tamen quod maximè volunt, minimè unt. Ego verò fi planè quod fentio dicturus immeritò prorfus in caufa Euangelij hagentum ingenium naturamq́ue accufari mo to dubito, atque equidem certus fum, ngelij introitus in has regiones is extitifquem Euangelij conditor maximè docuit, lios illius progreffus futuros fuife, quàn in pruma, \& A Apoltolica Ecclefia legimus. fi poft talem noltrorum hominum corruem, Ciriftum tamen colunt, \& fi quangittrum prafectumve paulo modeftiorem lunt,mirificè, \&z aufcultant, \& colunt, \&z s quauis cera molliores præbent, \& quicpræclari, atque honefti vident, imitari indunt, quid Deus bone, fururum fuiffe armur, fi ex ip fis pradicationis exordijs fpe$s$ Euangelizantium pacem pedes confpexifif fe folos Chrifto, non fua quari, \& $x$ verbis, us ipfis didiciffent? Nofræcertè minımæe tatis Patres, qui in his Peruenfibus regioninnos iam octo verfantur, $\&$ harum genmores experti funt, tum miffones diuturnultalq́ue obeundo, rum eorum Parochias riè fufcipiendo, tum verò fine Parochi muconcinencer cum his agendo, omnibus pror odis fe fe fructus opinione maiores inuetam leriò teftificantur, ve Deum inuocent imam fuam, fi non ita res fefe habeat. dam etiam in primis inter noftros grames, \&? M 4 maturi 
7̧84 DE PROCVRANDA INDOR maturiviri fe nufquam, neque faciliores que meliores Euangelij fegetes vidiffe, fcr literis cófrmarunt, qui tamen, cùm ex Hifp aduentarent, vulgari, id eft contraria opin tenebantur, quam facto abindè fatis peri penitus exuerunt. Nam \& ingeniofos effe Indos, $\&$ dociles, $8 z$ manfuetos, $\&$ bonorut cerdo:um amatores, $8 z$ obedientes, $\&$ fafu. pumq́ue contemptores, \&z quod multi minu dunt, fi femel feriò, atque ex animo, religic virtutemq́ue fufceperint, in fententia con tes. Quod ego ve fentiam, non difficilèadd cùm videamus Ingarum fidei deditos, aut carum fuperfticione aftrictos, pro accultan bi commiffa idolorum vanitate, aut gaza re dita, libentiffmè palfm occumbere, citi fortunas vitamćue ipfam fuam, quàm pat fuperftitionis arcana prodere. Quis enim n Indos flagr is fapè concifos, frepe flammis ftos, neq; verbum tamen in his cruciatibus tra fuam fententiam protulife? Cur ergo bolum Chrifto fortiorem in fe tuendo pute Aut ad falfa, 8 perniciofa, quàm ad vera, lutaria conferuanda confiantiores futura gentes à Deo, \& conditas, \& redemptas?Da certè apud Indos A poftolicos viros, reddar fe vicifim ex Indis Apoftolicos fructus. A fros, quod neficio quam vita honeftior is ciem, \& cupidiratis abiedionem fortè cor xerint, ita Indi accurrunt, ye paffim confelf faciendx caufa remotiffmi eria veniant, tr. ta, aut octoginta leucas emenfi: conciones ita frequentafe vidimus, vt infatiabili Dei bi fame ferri viderentur, v ná ex alia v foj; ad

buc 
SA LVTE. LI BER I. 185 3x quinque eodem die adeuntes, idque omdiebus Dominicis, \& feltis:poenitentia faentum perperua quadam frequentia ita , 8 Zreddi, qui cerneret, iubilæum, aut magnæ omadx tempus omnino crederet. Dari fibi s poenitentias pofulant, \& fi minus provo aues imponuntur, ip fiatripiunt, lachrymis rbo dolore fe cóficientes. Inuität alijalios enitentiam tanto ardóre, vt noftri non polnibus fatisfacere, \& illorum precibus imunis fe opprim conquerantur. In melior is propofico ita conftantes, vt nonnullas foeis, quifexus fragilior ef, conftet, neq; precineq; minis, neqi verò fricto cominus mue, \& iugulo oppofito peruinci potuifie, $v t$ ribus amatoribus obfequerentur, fua omnia ter dant: Chrifti corpus auidiffimè efuriüt, ibus conceditur, mundiffrmè accipiunt, \& jiosè conferuant, neque vltra fefemel conhicatos locum crimini dare poffe teftantur. $\mathrm{d}$ fecus cum erfer aliquando factum, tanta gnatione aduerfus fe ipfum Indum comum fcimus, vt à fe frangulando tanquam im \& facrilego Dominicorporis proditore vix us temperare potuerit. Quoldam ea deuotio liuinit impleri confat, vt de rebus diuinis, fa ater prorfus, \& excelsè fentiant, \& nonnun$m$ dono coelefti futura præuideant. Im modihac, \& per ex aggerationé diôta plerique ex mabunt, aut eriam velut ficta ridebunt. Ven egocerta, \& explorata loquor. Ac quicquid qui videntur fibi foli effe Chrifiani, contrà ceptent, in nationes quoque gratia Dei diffuft, \& nihil Deus difcernit inter iftos, \& nos, M 5 fide

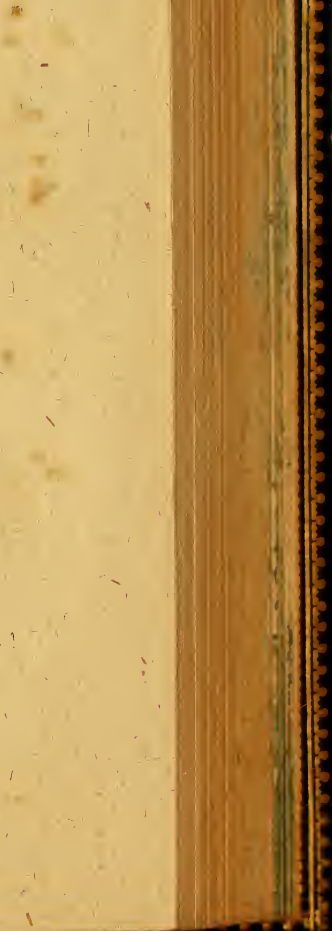




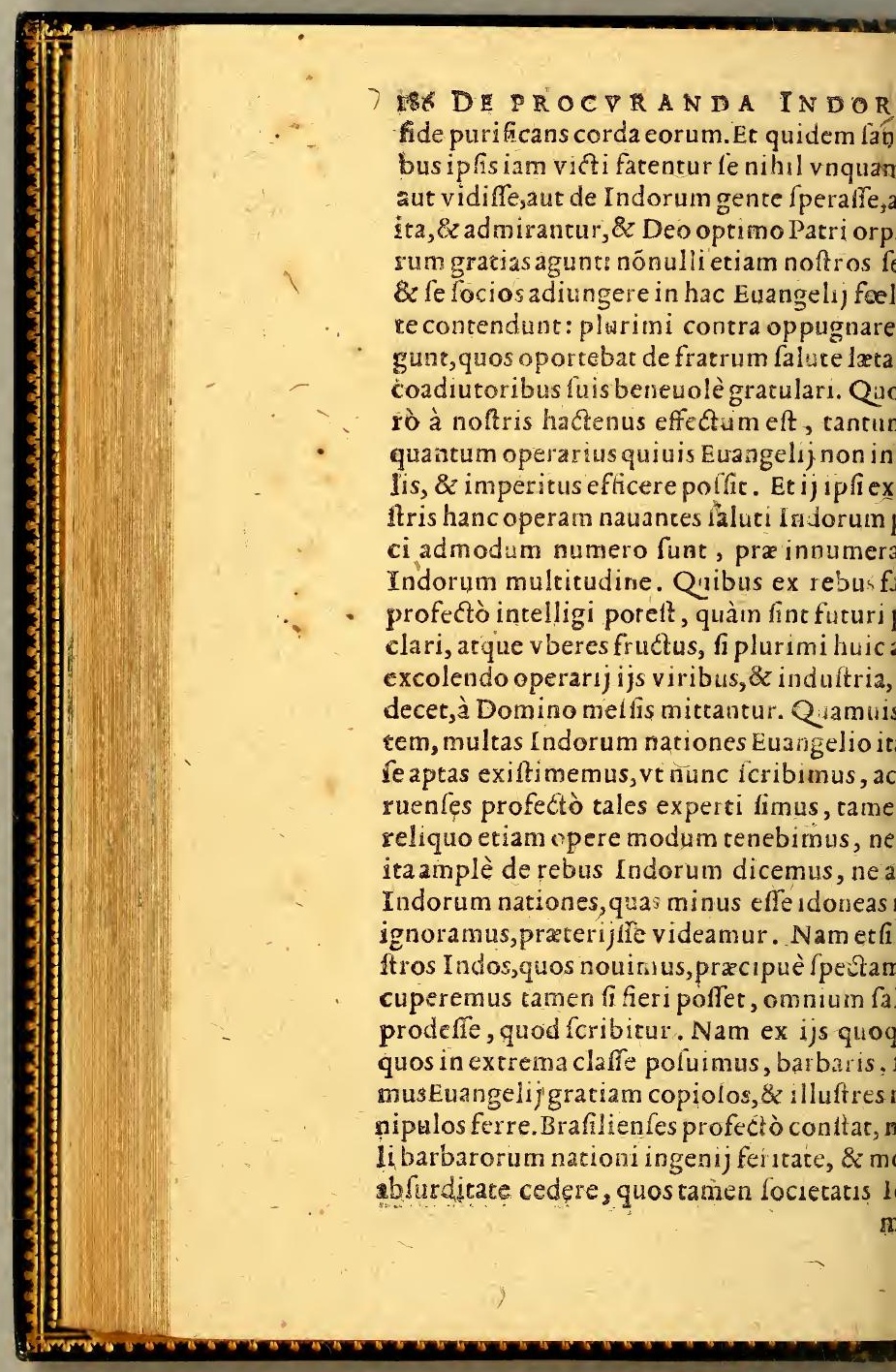


SALVTE, LIBER I. I8\% nè opera, ita effe domitos, $\&$ humanis diui elegibus affuefactos, noftrorum literis ac us, vt \& homines, \& Chriftiani boni fimul idicerint. Habet etiam nunc Fides gentiimitias fuas. Habet Euangelium inter nafructus omni opinione maiores. Illud foodo orandum eft, vt Chrifus Dominus s nos reddat noui teftamenti miniftros. ad hxc quistam idoneus? Atque hactenus icationem Euangelij apud barbaros, \& f $\mathrm{f}$ gna ex parte difficilem, tamen, \& neceffariam, \& fructu plenam oftendimus.

Iam quibus modis aggredienda fit, fequenti difputatione explicandum ęt.

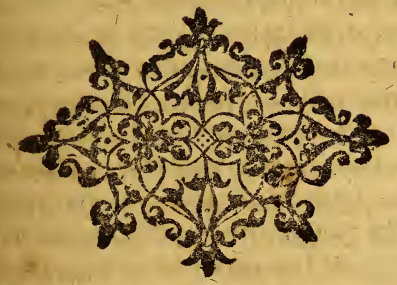

DE 


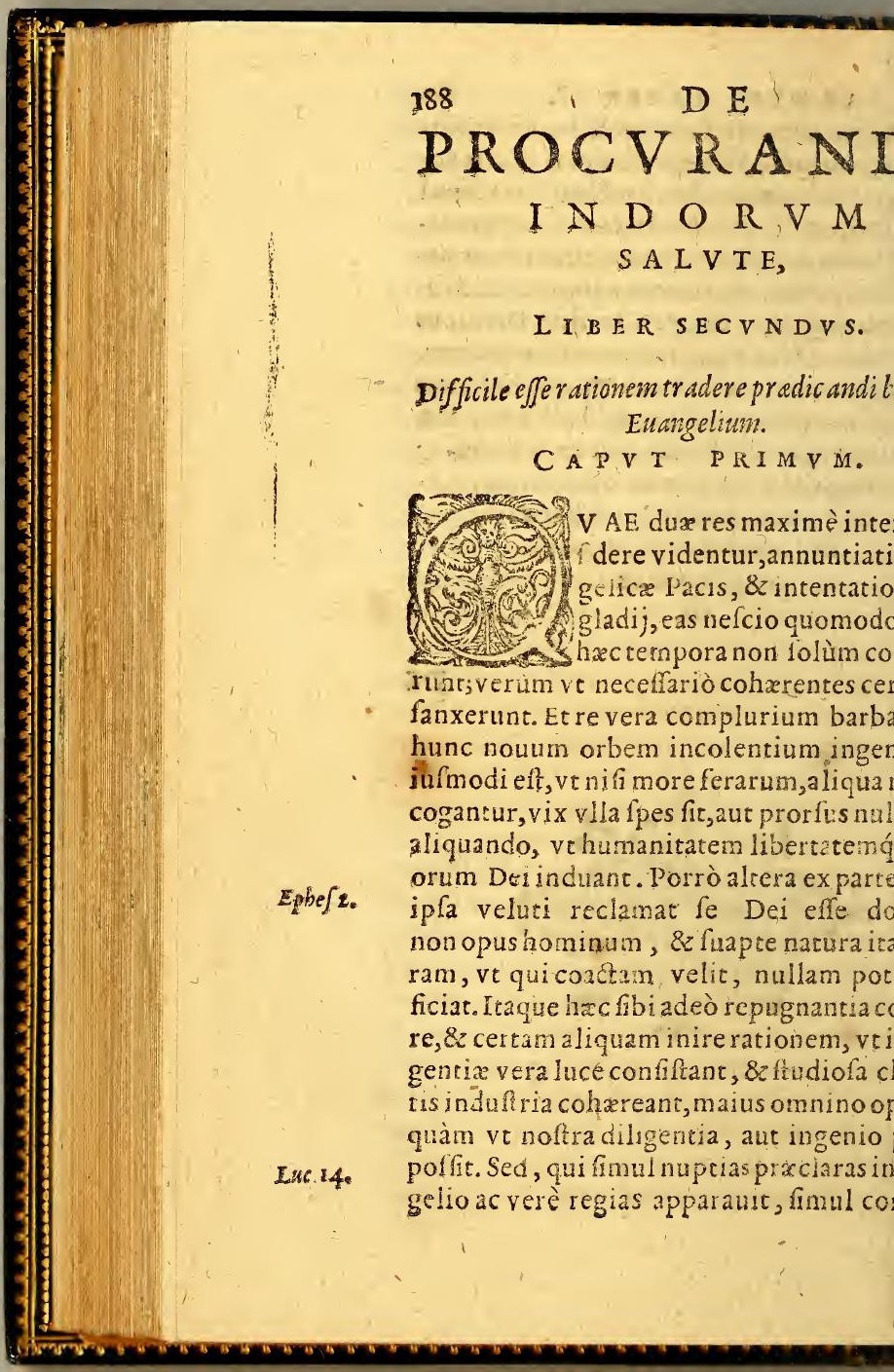



ifilaceros \& pannofos ac barbaros prorfus dit, docebit profua diuina fapientia feruos qua ratione neq; ad epulas admictant indig eq; quanttimuis tamen illiberales \& fordinta Domini liberalitate fruftrentur, etiam eita quadam v is ac voluntaria, vt ita dicá, ulfo afier enda fit. Huius tam difficilis nein conuer fione Barbarorum dux \& magiharitas eit, quz omnia fufiner, omnia fpe- 1. cor. 13 non agit perperam, neque inflatur, neogitat malum, \& ve femel omnia dicam, uxrit qua fua funt. Charitatis verò venefingulare cupiditas ent, pelfima fidei propa$x$ ac nutriendę nouerca, patrona mendacij, ritatis magiftra, comes violentıæ:qua mam $x$ feruos ipecie pietatis irterdum induit, irtuté eius funditus abnegat atque euertit. itusigitur extirpanda eft, fi in ouile Chrir oftumctipimus introire quàm plurimos, qui contra fecerint, Religionis Chriltianx ificanda pretextu Chrifti nomini infeftifsfe hoftes prębebunt, eruntćue de eorum ero, de quibus perfpicuè propheta prędixcosqui tranfibant fmpliciter, conuertilt is Hin, caulam paulò fuperius attulerat, Quo contra Deum eft manus eorum. Et concuunt agros, \& violenter tulerunt \& rapuerŭt os, \&z calumniabantur virum \& domumevirum \& hrreditatem eius. Hos alius quoq; heta mihi compellare videtur, cùm ita veienter inuehitur: Væ qui congregat auari- Habac.z. malam domui fur, $v t$ fit in excelfo nidus , \& liberari fe putat de manu mali. Cogiconfufionem domuitur, concidifti populos 


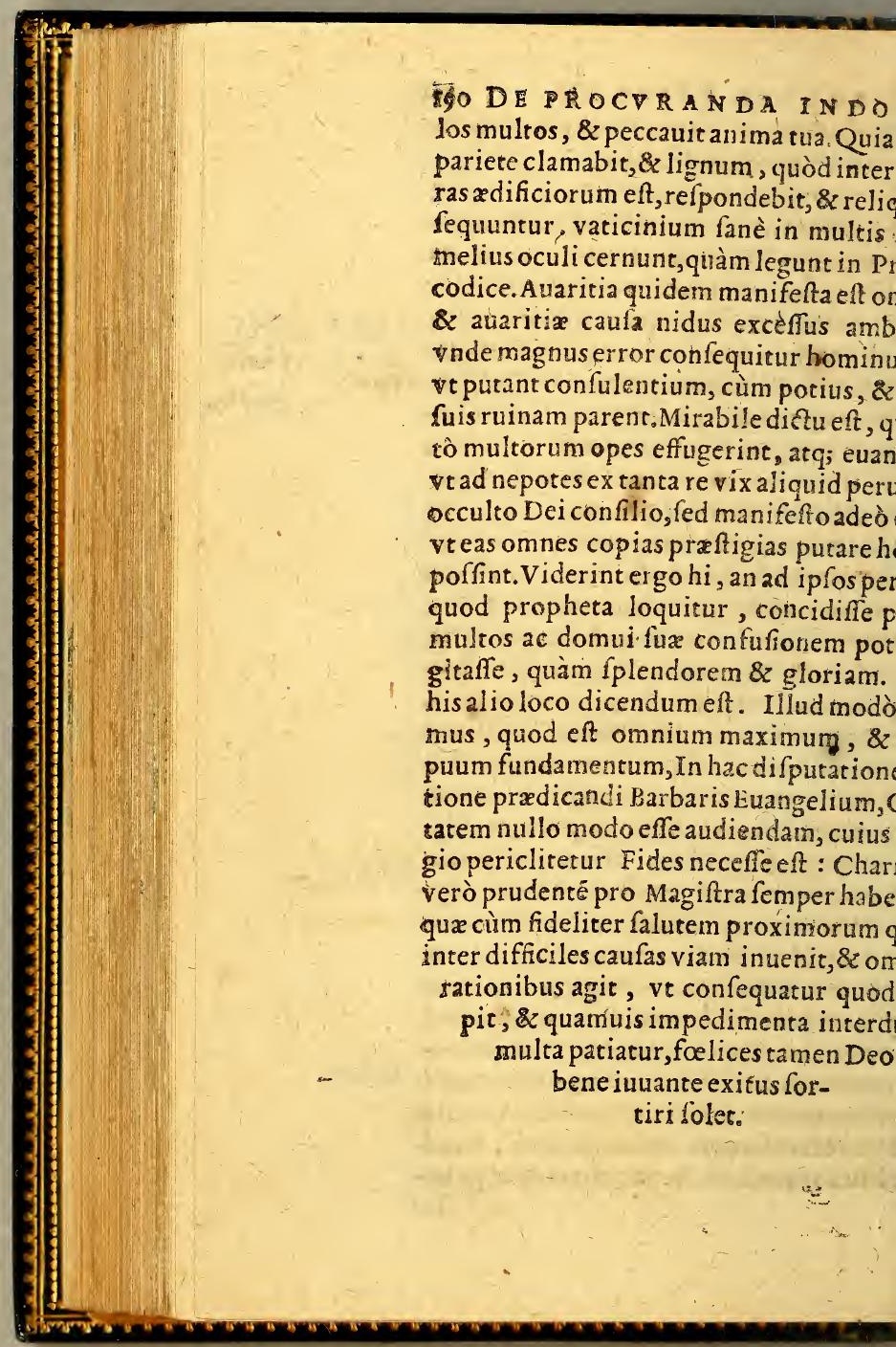


$\checkmark$

SA L V T E. L I B R IT:

I9) er Infidelitatem etiam pertinacem non licers barbaros dekellare.

C A P. II.

iftit verò hoc loco qualtio à multis qui- Nafa m copiosè grauiterq́ue 2 ractata, fed necef = nobis quoq; repetenda, An charitatis Chri fit baibarosbello domare, ve debellati pricdicationem recipiant. lllud autem pri fic in caufa barbarorum, Non effe facienda Rom t veniât bona, quod fentire blafphemix interpretatur A poftolus. Bella ergo fi ini. nt, fufcipienda non funt, etiam fi certam $\mathrm{m}$, vel dimidio orbis allatura videantur. obrem fi nullam aliam patere viam praoni inter Indos conftaret, guàm belli exone non iufta, claufam potius illis Euaniansam oportertet exiftimare, quàm vt lei perfracta ad eiufdem legis obfervand cationem irrumperetur.Si enim ea propo affione, vbi quifyuam baptızandus in poeft impiorum, atque infidelium conftad quem perueniri non poffit, vt lauacro erationis abluatur, nifi deceptis mentienftodibus, Auguftinus Ihealogize decus Auguft. lib. fpondendum exiftimat, ye claufum am contra vicrem reputandum fit, vbiad fubnenienduma-dacium,c.2\%? aternze faluti folüper mendacium aditus quis non videat, quanto facilius refponde oft ium fidei ferro iniufto aperiendum fit, um potius exiftimare oportere? Sedquani mentum hoc om ni dubi arione yacat qu manderse of confequentia videamus.Quzeritur, An iufti mimas. car fa in barbaros fit in fidelitas ipfa, quod gelium repudient. Sed breuiter $\&$ abfolurè,iufta

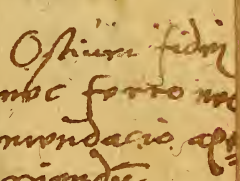




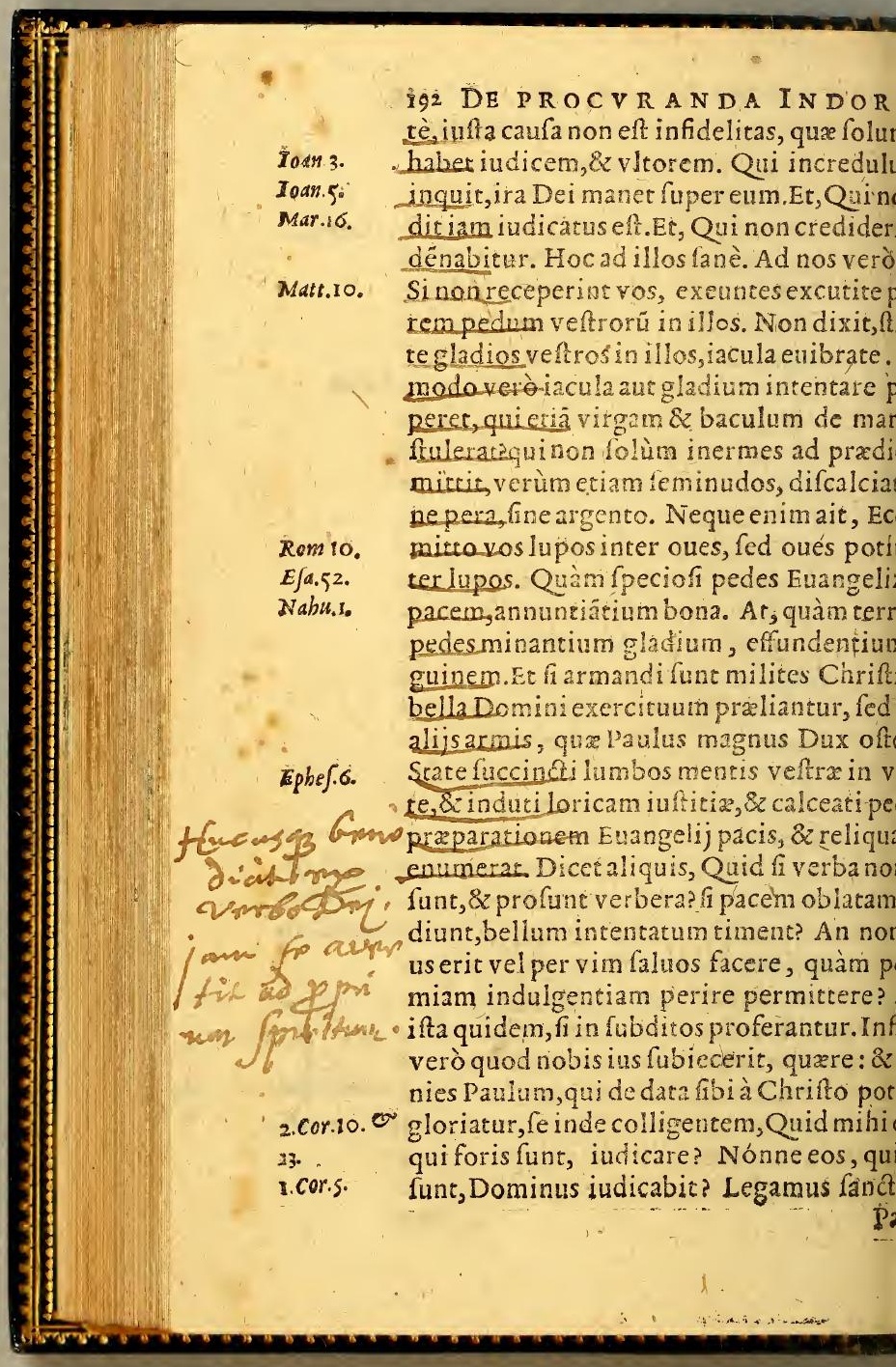



Im commentarios, certam fententiam Apoconfentienter docentium, Ecclefiæ ius $\$ z$ offe in infideles, fed in eos tantú, qui per m baptifmi ingreffifunt in ouile Chrifti. nobrem Auguftinus in quodam fermone uens quofdam Chriftianos, qui ethnicorum rificijs contaminauterant:De ijs, inquit, qui funt, nos non iudicanus, illis blandiendum Auguftro. tom. ferm. 6 . t credant, in vobis putredo hæc retecanda t mox, Nó tollo, inquit, idola illorum, quia habeo in illos potefarem, habebo autem fuerint faßti Chriftiani. Diuinè quoq; Ber- Bern 2 lib. us Eugenium admoner libro de conficera- de confid. fecundo, Vicario Chrifti non dominatum bem, fed a poftolatum conuenire. Nam prinsentum dominantur ecrum : at non sta eter vos. Neque ante paratum fe Paulus diIcifci inobedientiam fuorum, quàm illo- 2.corint ro. prior fuerit completa obedientia, id ent, Ang epift. bi A uguftinus interpretarur, non ante in so. ad $\mathrm{B}_{0-}$. quam agere lege fas eft Ecclefraftico viro, nifacium. per Fides obedientiam fe ipfe Ecclefę ponbmittat. Siue ergo infideles fint, \& Chriltum rent, fiue annuntiatum etiam reijciant, nonillos belli decernendi ius nullum eft, nulneftacaufa. Quam fententiam fatis authofua confirmaut $D$. Thomas, cum peripidocuit, ad Ecclefiam non pertinere in fideli. q.12. ar.2. $\mathrm{m}$ in illis punire, qui nunquam Fiden receint.Et quoniam nagna copia eft cort $\mathrm{m}$, qui accuratè expofuerunc, illud folum admoncn arbieror, veniam ijs dareoportere, fi qui qui zelo fortaffis potıus, quàin friécia ducttı. lummi Pontifis nunquam fatis commenN datam 


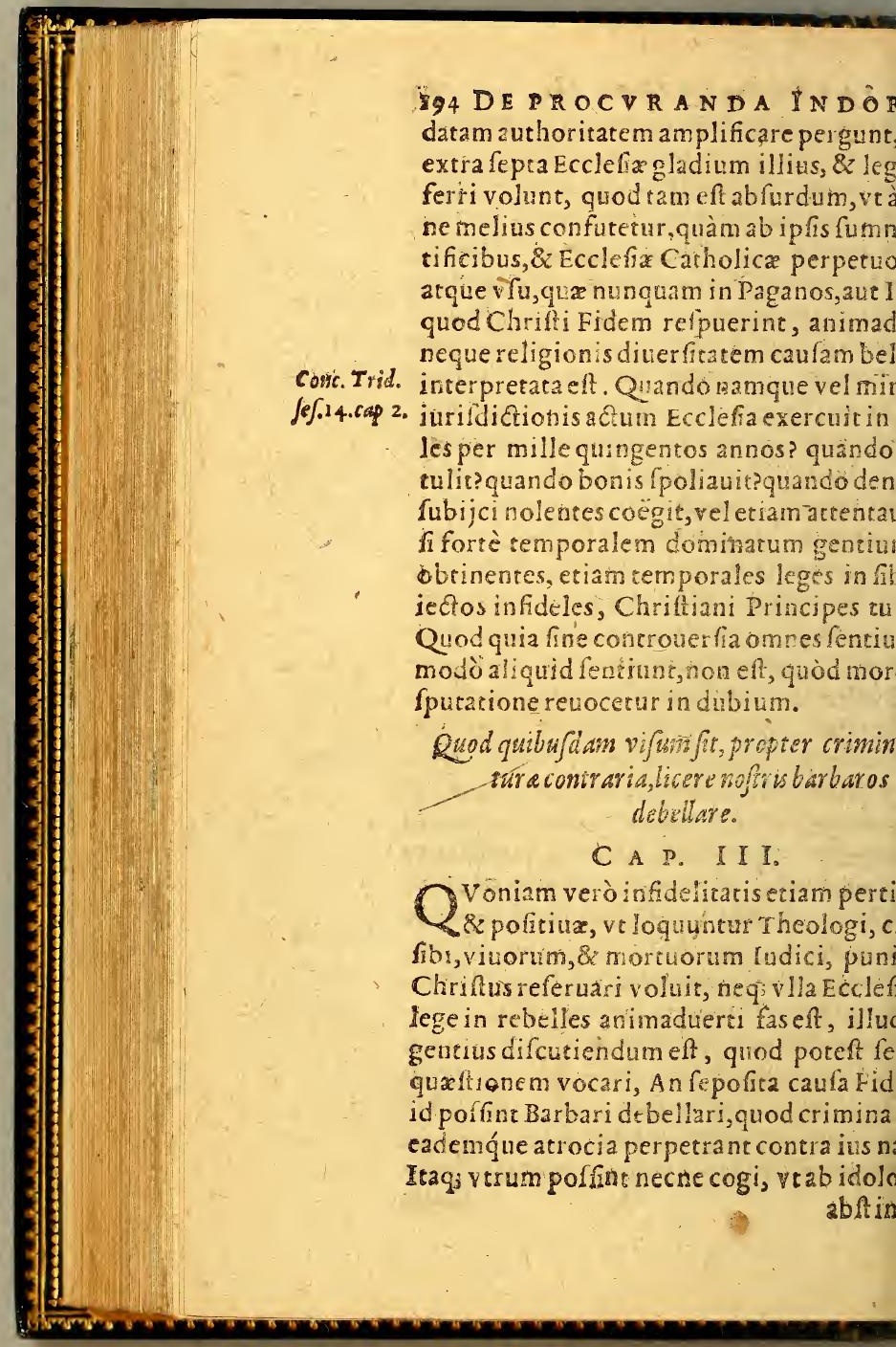


SA LVTE. ITBER II. Tو' neant, à nefarijs facris, \& collocutionibus, cum ipfo Diabolo per quàm frequentes haà concubitu mafclilorum, ab inceftuofa pol ne fororum ac matrum, \& reliquisid genus ijs? Nam facinora longum effet commemoquomodo alijalios indicra caufa enecent, otatiokes actemulentias fuas cruore mif, humanis multi carnibus pro fumm is deliefcancur, alij pueros innoxios fimulachris ent,alij fuorum inferias aliorum fanguine gant, pleriq; potenciam ad nihil aliud, quàm cendum, \& fauiendum, fibi datam arbitren erinde, atq; immanes feræ, qua naturaliter u inferiores ac viribus imbecilles pecudes, $x$ fur vendicant: ve idem fit apud if os dotri, \&z pradari : nihilaliud fubditum effe, potentioris libidini obnóxium effe.Q \& quàm latè patens hęc feritas barbarorum c vaftiffimo orbe, qui ritus portentofi, qux macdominorum tyrannis, referre exactè, voluminis opus effet. Hiftoria Indice quan multa narrantiexigua tamen ef portio pra qux res ip fa habet:verùm quod ad rem per, certum eft mores Indorum plurimorum erinos, vt quod fabula canunt de quibuffacie quidem homines effe, corpore verò ifces, aut fues, aut lupos, id verum effe noarbari fuis moribus probent. Fremit ergo rorum hominum turba ac tumultuacur, $c u ́$ udiunt, aut etiam intuentur: horum fe fcem vltores aquifimos, milites putant: quiccontra nefarios natur $x$ violatores ferr $\mathrm{O}_{2}$ ,incendijs fruierint, gloriæ ducunt, ac tum um excurfiones fuas in barbaros laude ac $\mathrm{N} 2$ pros

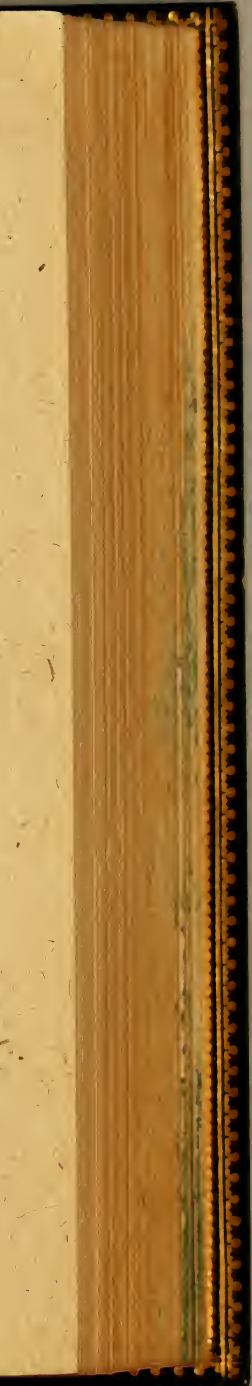




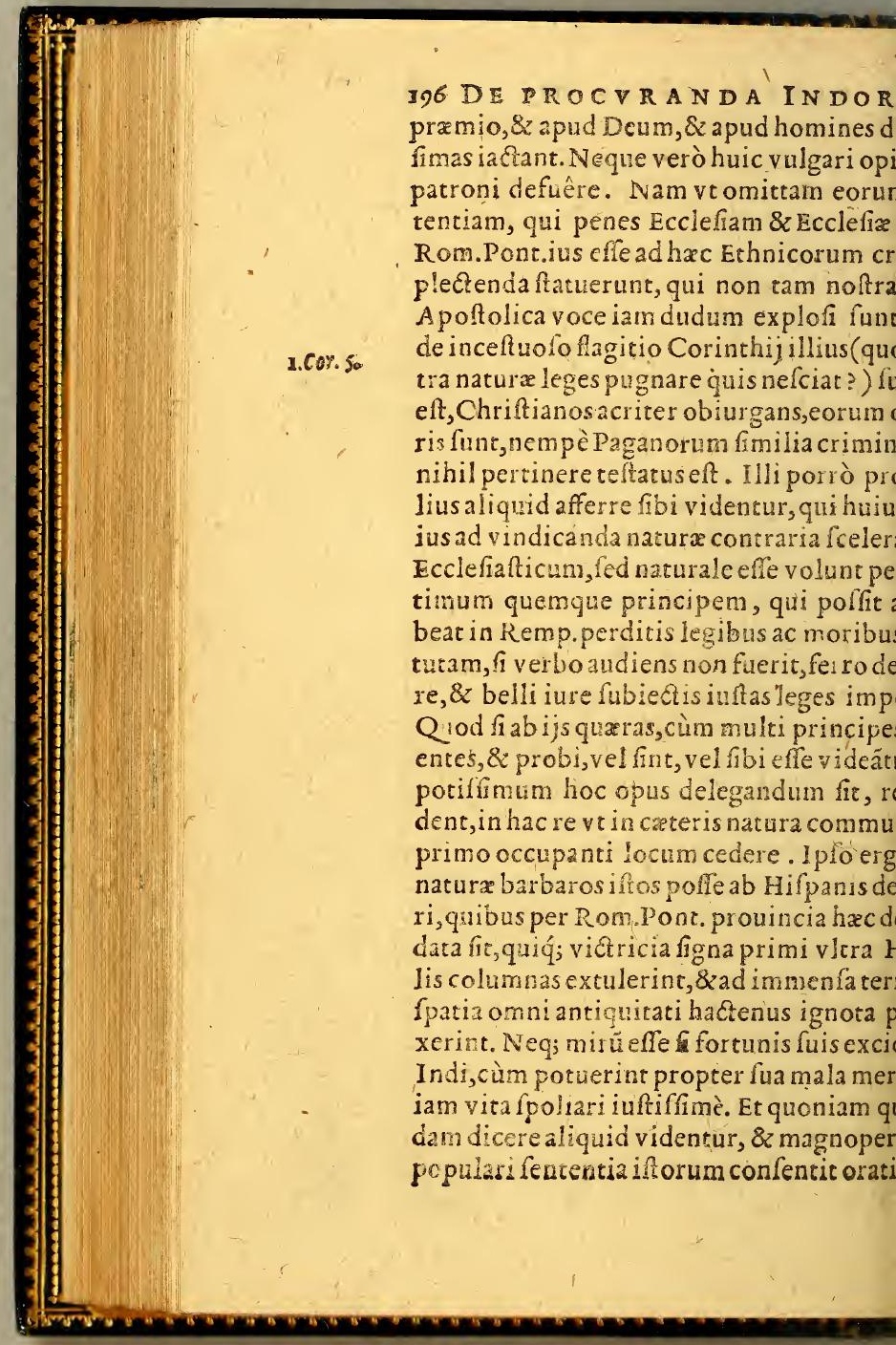


SA L TE. LIBER II. I97 aufa argumenta afferant, recitemus neceffe iftotelis, inquiunt, fententia eft, qui in li- Pri mus. olicicis ita fcripfit: Q lod poteft méte pro- Aitlo. I. e, natura imperat, \& dominatur: quod au- Pol.cap. so oteft corpore hoc facere, paret natura, \&z Et mox, Barbari quod natura dominetur, abent : quamobrem aiunt Poêtæ Grecos ris dominari oportere, quod idem natura rbarus, \& feruus. Cùm ergo barbari ifti nopra modum barbari ac ferini reperti fine, mentem habeant ad fe, \& fua regenda ido, natura ipfa comparatüeft, vit illis fubfint reant, qui dominari rectè poffunt, atq̧; eos dú naturę leges conuenienter regere. Q nod ugnent, debellari poffe iuftè idem autnor nat. Bsllica, inquit, vi vti oportet contrà be- 1.Poli.cap \&zcontra eos homines, qui ad parendum nat, nec volunt parere:quia natura id bellum mexiftat. Alibi quoque Philofophusfuam fententiam de iufto bello in barbaros amexplicat ita fcribens. Neg; exercitatio re- Lib.7.Pol.e bellicarum ob id ef meditanda, vt in Serui- 14. $n$ adigant immerentes. Sed primum ne ipfo feruire compellantur. Deinde v $r$ imperium ant gratia vtilitatis fubiectorum, non ante ia dominationem. Tertiò ve eis dominêtur, eruire fune digni.Hec ille. Atq; huc pertine detur aliqua ex parte Romanorum hiftoria, xqu, \& boni obleruantes forent, omnium t1 exiftimantur, diuino ita decernente confgrorum imperium à lanctis Patribus landa - Regenin.c. legimús; 8 quod eft ampliusin ip is diunis 4.5 .6 . is. At in finicis partibus preltant Chríkan a Mach.8. aris, quàm olim Ronini crectis, Secundutn Secundums

$$
\mathrm{N} 3 \text { Git, } \mathrm{Fi} \text { - }
$$

A:gafif. 9 de cisusap tz. S. Thom de 


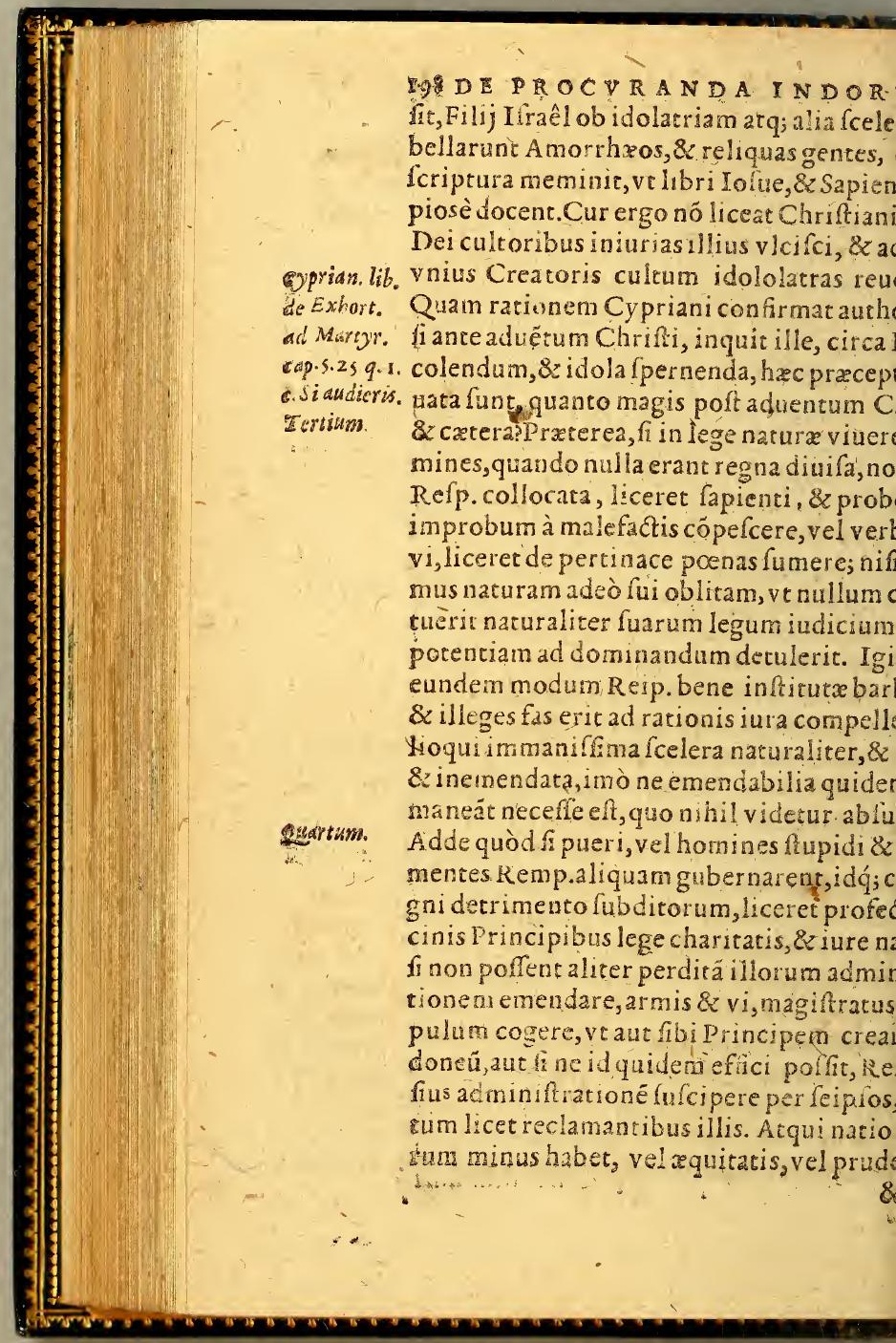


SA LV T F. LIBER II. icij, quàm pueri, \& femiinfani. Quid ergo ur fi vel ab inuitis pro ipforum lalute, \& ripitur principatus? Poftremò innocentem uria, \& cæde defendere quius potelt, atq; fit,aggrelforem mulctare fortunis, \& $z$ vita hanifeltum verò eft inter iftos innumerannocentium cædes perperrari, cùm \& obuof $;$ capiunt, \& trucidant, \& in fuos quoq niter fauiunt, pueros, foeminas, \& miferaenus neci dantes, adeò vt cruore humano li cuiufdam inftar permulta loca redundaoperta fint, quorum teftis locuples effe poexicana prouincia. Quamobrem non licei, fed etiam quàm maximè expedire barba. infanientes bello domare, rarioni confenm apparet. Hæc pótiffmum fune, qux pro belli Indici afferri à nonnullis folent.

nfutatio fuperioris fententia. C A P. IV. rùn fi partium fudijs fepofitis, qux tanuam nebulæ quædam crafix veritatis lubicondere folent, lex ipfa aterna confulaon dubium eft, quin puriffmis radijs omranc caliginem, juß nobis offundizur, dera fit, dilucidè oftendens, aquè effe iniquú, non iufa fiant, vel qua iufta tunt, non iuftè Iuftè quod iuftum eft exequeris, aic diuinus ator: quam rem praclarè explicat Dionylagnus, \& $z$ diuin $x, \&$ humanælapiencia póor.Infideles lanè, idololatras, mafculorum ubitores, inceltuolos, fine foedere, fine mife Detut. 16 Diony epift. $S$ ad Densophibum. Rom.2. dia, parentibus non obedientes, ingratos, tos, \& quibufuis alijs nominibus verè nocoerceri,mulctari fortunis, atq; ip fo capiecti,iuftiria, \& \&quirate plenum eft, quis hoc

$$
\text { i. } 4 \text {, neget? }
$$




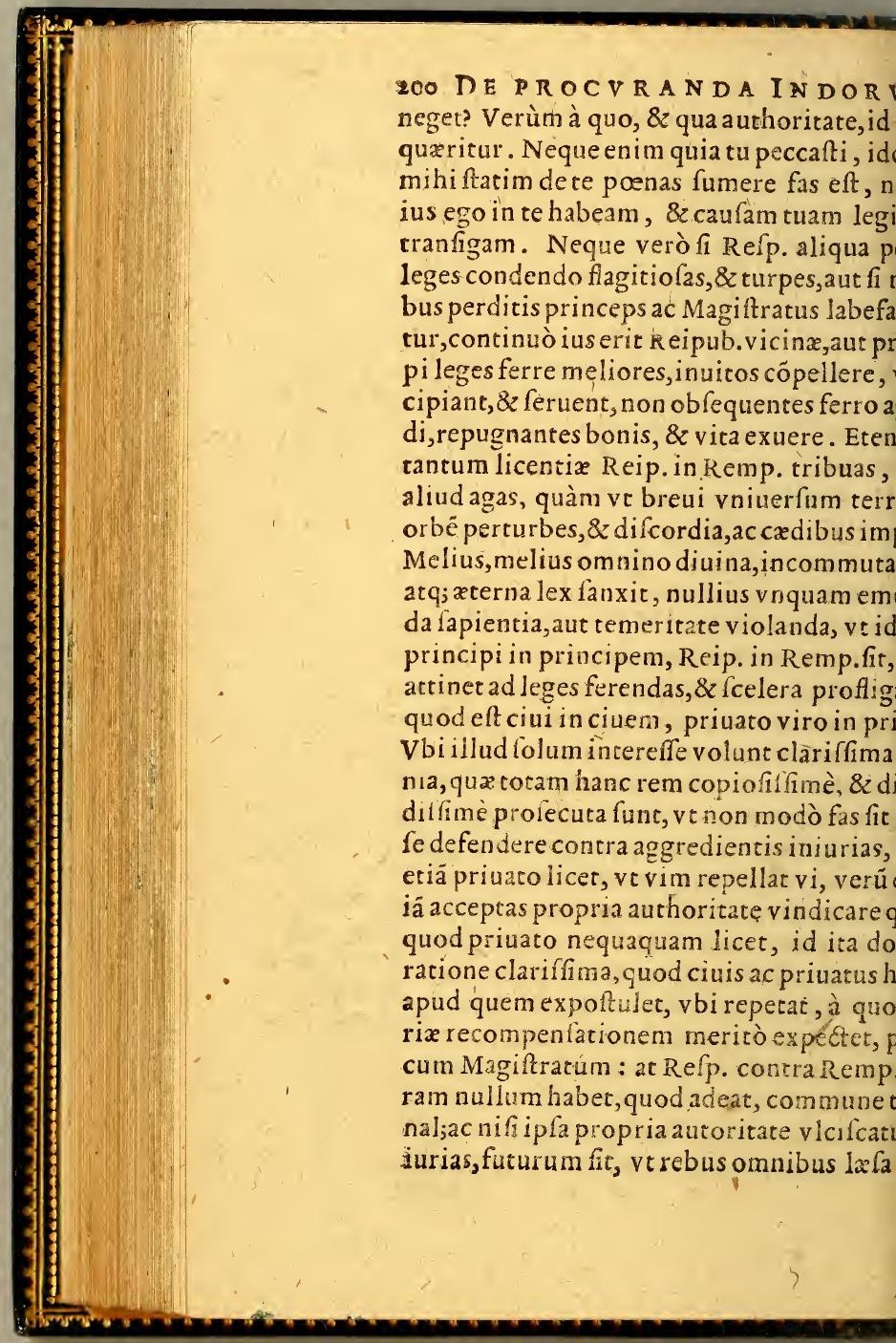


S A L V T E. I I B ER II. 20R ullo modo queat. $Q$ ı cùm ita fe habere tú a naturæ luce veluri in aperta legenotaftum perpetuo ab ipfo múdi exordio decuromnibus martalibus feruara, quotquot iuqualemcunque prætextum bello gerendo errent, animaduerterent, fapientes omnes fri, \& externi eam folam caufam belloagiend@æquam, \& iuftam Itaruerunt, ad refarda däna, \&ziniurias vindicandas, vel fuas, vel um, id eft ciuium, aut fociorum, aut eorum $n$, qui iniquè lafi ipforum opemi implorafPrater hác caufam accepta iniurix, aut viouris gentium, nullam notri maiores iuftam ouerunt, neq; gloria quxrend $x$, neq; cumaarum opum, neq; amplificandi dominatus, ue verö religionis propagandx. Quotquot non lefi arma fumplerüt, eos practones poquã milites vocitandos cenfuerunt. D.quidé uftinus fuo ipfe ingenio, acerrimus quaftio obfcurarum indagator, in hac vero etiam ichæorum calumnıjs, \& Ethnicorum contra emChriftianam opprobrijs excitatus, fæpeac genter totum hoc de bello gerendo negotiú tans, illud vbique conflituit, caufam iufam lifolam efle iniuria dépellêdre necelsitatem. quodam loco, bella, inçuit, iufta definir ifo, quæ vlcifcuntur iniurias. Ambrofus quoq; le fortitudine in lib. offic. difputaret, ita fcri Non fe ipfam commitrit fibi, alioquifortio. fine iufitia inlquitatis materia elt, quo en validior eft, eo própcioreft, vt inferiorem rimat, cum in ipfis rebus bellicis, iufa bella iniufa fint, lpectandum putetur. Nunquam Aug.lib. 6. Queft in tojue. s. 10. Aveblib.r. officap. 250 IN.5 Dauid 


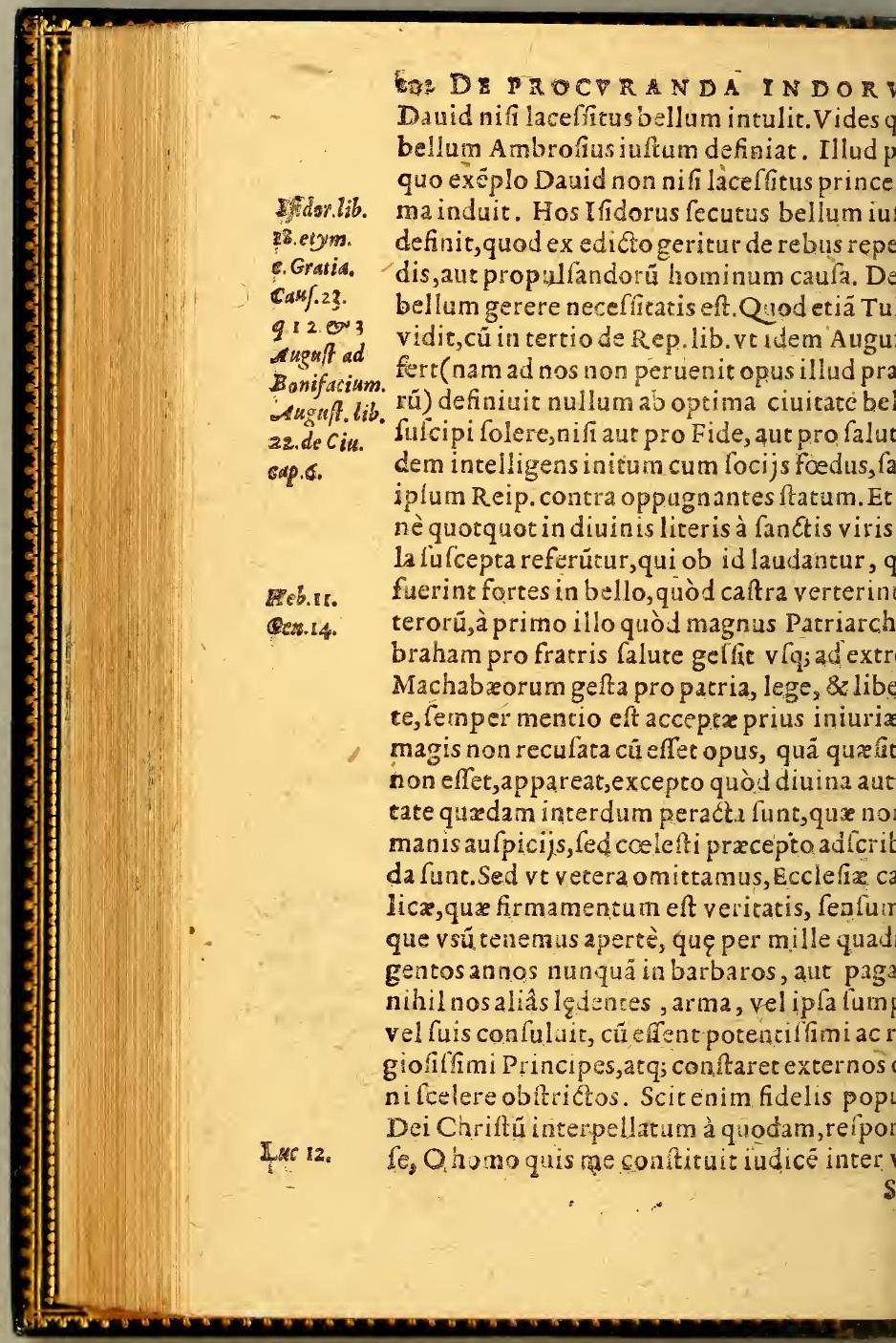


SA LVTE. IIBER II. 203 ati nationis Indorum rebus fuis compois vltro accerferent noftros, haberet fortafiquid rationis eiufmodi introdusta poteeges ferendi, emédandi,puniendi. A t numc ftiffimè ferüt caufx fuze nó vocatos iudices, neos difceptatores, qui nó folü leges, $8 x$ ius' t inuitis, verum iam olim admiffa ferociindicent. An fapimus nos plus quàm maiooftri? An Fidei zelo vehementius ardemus? Greg. lib. ino verum eft, quod fanctifimus Gregori- n. Regiff. hac re fcripfit, Qui Fidem afperitatibus cals.diff. agare volunt, fuas magis quàm Dei caufas 45 cap quz antur attendere. Interim quis illud non vi- fincers, ide quà implacabile ifto modo Chriftiani lib.1.epis. 49 i inis odium apud barbaros excicetur?quàm e, \& immedicabile fcandalum? Tota ifta res it in obftinatam quandam inuidiam, \& odi= idei, \&z certam perniciem hominum. Neq; fcandalum iftud feparabile eft vllo modo ac caufa, aut in ijs numerandum, qux non da d accepta dicuntur. Chriftus quod non detributum foluit, ne fcandalizet; nos nullo Math. 16 lo debitas terras, fi fpoliemus, vexemus, præur, nullum ne iufum timebimus fcandalú? ipfa fatis clamat per fe. Neque enim ea exla hastenus vidimus, quæ licentiæ, \& furori itari fræna laxanda perfuadeant. Et quod caeft, Catholicorum noftrorum Principum lelongè aliter faciendum effe edicune, quibus dire par eft. Quamobré pręclariffima $\& z$ fui inis \& noftri temporis lumina, qua in caufá orum propriè inciderunt, eiufmodi belli fuf 'caiet. 2.2. iendi confilium, idq́; iuris grauiffmè cùm $q 66$ ar $8_{0}$ outationibus fuis, tum etiam fcriptis de indu $V$ iftorio 
204 DE P R OCVRANDA INDOR Zel.de In ftrialibrisimprobarunt.Quorum fententia dis. 0 dudum apud omnes obtinurt, Salmantino 8 sello $\mathrm{nus}$. 2324.00 40

Solo in 4 . d.5.q.1.ar tic. 100 $l i b 4$ de inf oriug. $q .2$. ar. 2 . Anton Cor dubs Minevita ipa. qse.eftions rij $q 57$. canar. 2. prelec Re. plutenfi illuftribus gymnafijs damnätibu: audio, atque explodentibus fcriptum cuiuf librü contra caufam Indorum, atque ip $\mathfrak{l}_{0} \mathrm{C}$ lici Regis fenatu longèaliam rarionem in e ditionibus Indicis præcipiente, cuius æqu opportunè exponemus, fi prius obiection fupra propofitis refponderimus. Refponfin ad obiectiones pro expugnatione $B_{6}$

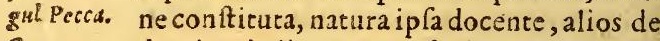
5. Io. dominari,alios parere, fapientes $\& z$ viros in Ad primim rare, impericos \& foeminas obedire, quod $p$ biect.

rorum.

$$
\text { C A P V T V. }
$$

A. Cprimùn quid fibi voluerit Philofo A. barbaros nacura feruosafferens, nonef fcurum cernere, fi paulo alcius illius difpu reperarur Sentic zz quide ctò veriffimum eft. Hinc colligit Gracos n: comparatos effe ad imperandum, quodefli pientiores, barbaros, vtpote rudes $\&$ impe ad feruiendum.Quid oblecro verius quàm \& maturos præelfenatura, adolefcentes ob perare, fominas virorum, pueros maioru bitrio naturaliter regir lam qui velit coll ex his, à barbaris imperiû quod iam habent pere liceie, eadé ratione conficier, à foemin adolefcente, vbi regaat, poffe per vim exto ridominatum, item q́; à rege imperito regn \&à przfule indóto pontificatum : quodo bus, $\&$ diuinis, oz humanis legibus, quàm re net, nemo non videar. Aliud eft enim quid 
SA L V TE. I I B ER II. $m$ fit ex ratione ac fecundùm naturam : aquid fi fiat,infectum fieri nequeat. Iure erpientiores, \& elegantiores regnant: fed re mperitus, \& barbarus fi regnet, non ius, fed ia eft, de regno hüc pellere. A lioqui rapina di res mortaliú omnes expofitas efie oporQuod ex codem Philolopho adiunktum iufto bello in barbaros, qui feruire recuobfcurius profectò eft, \& quod fufpicionon exiguam parit, illa non tam ex philoica ratione quam ex populari quadam opie proficta effe.Intelligi tamen potef, fi in quoque re Ariftotelis autoritas magnoper eruanda eft, in eos barbaros feruire nolenellum iuftim decernere, qui k emp.nullam ent propriä,neq; Magiftratus neq; leges, fed ferarü incertis, \& fedibus, \& legibus vagan quales $\&$ fuiffe olim, \& efle hodie quá plurinotiffinum eft. Bellum autẽ in hos non om lla cædis, \& feruitutis licétia cogitari debet, noderata quadam vis, quatenus humanè, \& beftialiter prorfus viuere perfuadeantur. di Alexandri, vt quidam ferunt, potenelectatus, figna Macedonica in orbem vnium proferri voluit, nobis non admodum cu ium eft, quid ille adulatoriè magis quàm ofophicè fcripferit.Quanquam non dicier Ia ftris fapiens, in Rhetorica ad Alexandrum, Ariftot in ipiendum bellum effe conftituit in eosqui Rhet.ad np. \& eius fiue amicos, fue focios iniuria Alex.c. vlto lare moliuntur. De Romanis parum ad rem tinent, qua afferuntur. Etfi enim laudari fo, neque fortaffis immeritò quod legibus $\boldsymbol{x}$ oribus fubdites gubernarint, foedera, \& focietates 


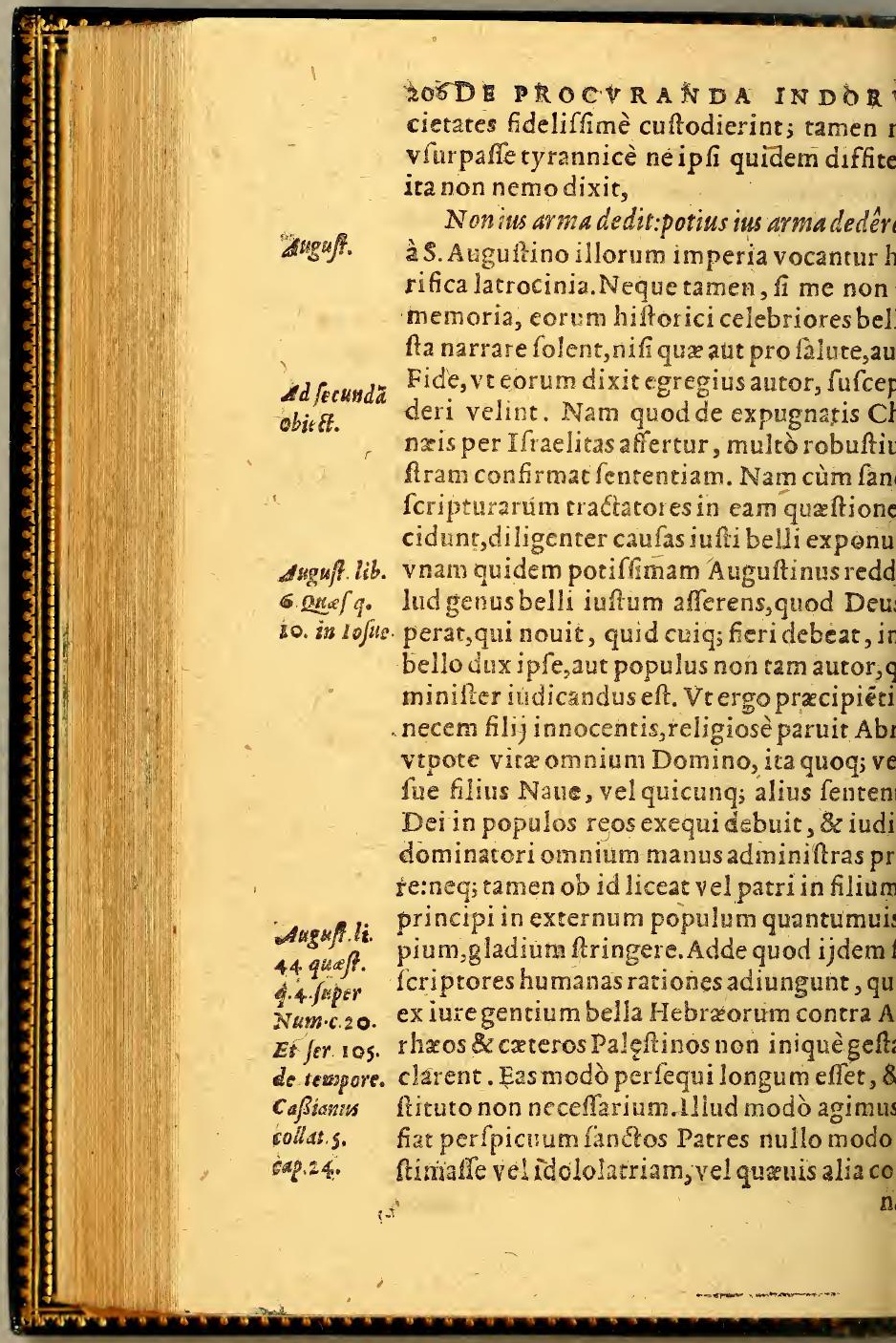


SALVTE. I IBER II. 2ब ram piacula caufam jdoneam extitife, vt co fuo pellerentur illa gentes, vaflarenturab Hebrais, fiquidem tam folicitè caufas aexquirunt. Et reuera eadem funt vel minus ia noftrorum barbarorum crimina, quàrn ilorum fcriptura commemorat. Ita enim is loquitur liber Sapientix. Illos enim anti- cos s inhabitatores terræ fanctæ tua, quos ex-Sapo uifti, quia odibilia tibi opera faciebant,per icanina \& facrificia iniufta, \& filiorum fio necatores fine mifericordia, \& comefores erum hominum, \& devoratores fanguinis à io facramentotuo, \& autores parentes anjum inauxiliatarum perdere voluifti per $m$ parétum nơftrorum, \& reliqua. Non opinor ibilior2 obijci Indis, ijs quoque, quos Cary ocant, qui func omnium trúculétiffimi.Ob tè paulo inferius diuinam autoritatem exillarum gentium interponens, fubdit per inogationem:Quis enim imputabit tibi, fi pe- sap. int nationes quas ru fecifti? Non enim alius eus quàmtu, cui cura eft de omnibus, ve ndas, quia non iniufiè iudicas iudiciú. Hoc on inuadis aliena, neq; vfurpas iniquéè iudi, figentes impias cogis commeritas poenas um fcelerú dare.Cypriani verò ineptè pro- cypris. e. ur autoritas, cuius longè alius fenfus eft. Sù- de Exbo\%, iens enim illo opere caufam Martyrijaggere, $A d M$ orum cultum vult adeò Chriftiano viro exe dum, vt quiduis potius perpetiatur, quã id ietatis admittat. Quod vt con firmet,admoquã fuerit quódã infeftus Deus Idololatrię, b id'cxde grafiari in exteros fuis iufferit, qu go tempore gratia reuelata amplius amare deber 
208 DE PROCVRANDA IN DOR debet fidelis ob fugiendum idolorú cultum guinem quoque proprium fundere? Ita er concludit, fi ante Chrifi aduentum circa I colëdum \& idola fpernenda hac pracepta fe ta funt, quanto magis poft aduentum Chrifti uanda funt, cùm ille veniens non verbis tant nos hortatus fit, fed \& factis, poft omnes ini as $\&$ contumelias paffus quoque $\&$ crucifi $v t$ nos pati $\&$ mori exemplo fuo doceret. Cyprianus. At verò quod de lege naturæ aff Ad tertiam batur, militat potius pro caufa Indorum. Ne biect. enim iure Natura priuatus de priuato pœna mere poffet,neq; vim aliquam coërcendi ha ret, cùm fint omnes homines natura pares. $Q$ niam verò mores inflitui rectè non poteran que Societas in officı contıneri, placuit on bus publicam potefatem creare, in quã ius quifque tranfferret, qua proinde \& leges co re, \& fupplicio afficere peccantes autoritar tius multitudinis in le tianifufa poffet. Qu Magiftratus, aut Refp. barbaror um fuo mu non facic latis, habet iudicem Deum, non Re aut principem aliquem externum. A lioqui grauilfima peccent incerdum Principes, au gifratus notri, licebit, vel Gallo, vel I ralo, Anglo, Hifpanienfis Reip. peccata caftigar ius dicere, vevicilfm inter lel'rincspes hab toritate fungantur. Hoc neque ineptus, ne rebus humanis exitialius dici quicquam po Neque verò vbi lubditorum conlentit vo tas, prafidentum holidiras, atque infipie poreft per viro compelci.lraque fi Principe barorum iniquè ac dy roni ècraçarét fuos, fent innocentes per vim (li iccus do effer lo) 
S A L TE. LIEER IT. rum fcelere, 8 iniuria eripi.Sin auté cormorum ea eft, quam ipfi quoque fubditi er fequuntur, non poffunt ab extraneis cóad virtutem. Neque eft eadem ratio in pue Ad quartam amentibus Remp.adminiftrantibus. Natu- obiet. t enim,vt pueri non cominentur in viros; uer etıam fi fit omnium heres, niliil à lerferat, tefte Paulo, acmulto minus infanis Gal.4. ntis compotes iurisaliquid effe poteft, quẻ dum, neque bellux in hominem. At barti, \& imperantes, \& feruientes æquè veil lä es, vel infipientes fiunt. Quare fr ligna fy $1-x_{t}$ dic.g. a, vt eft in antiqua parabola, $R$ hamnum fietermiffa oliua, ficu, \& vire Regem creant, mirum fi illius incendio concrementur? enim in funma intereft, quod barbarus atura, fed ftudio, \& moribus talis eft;puer; ens non ftudio, fed natura. Quamobrem arbari peccant, non eft cuiuluss animade.

bello propter defenfionem innocentium; qui ab brbaris trusidantur.

\section{A P. VI.}

ne huius de bello difputacion is non prabo fententiam illufrium Theologorum, fenfionem innocentium, iuftum ticulum Indico poffe pratendi fignificant. Aiunt, fi fint adeo tyrannici legefóf, vt innocentes trucicientur, quod Carybes faciunt, vt eis tur, dijló; fuis immolent, turic fanètépoere noftris, \& cuiuis Principi eiulmodi in homines à cade tyrannicaeripere, ac fi it, ferro decernere, \& barbaros ab ea imma d)

nitate 


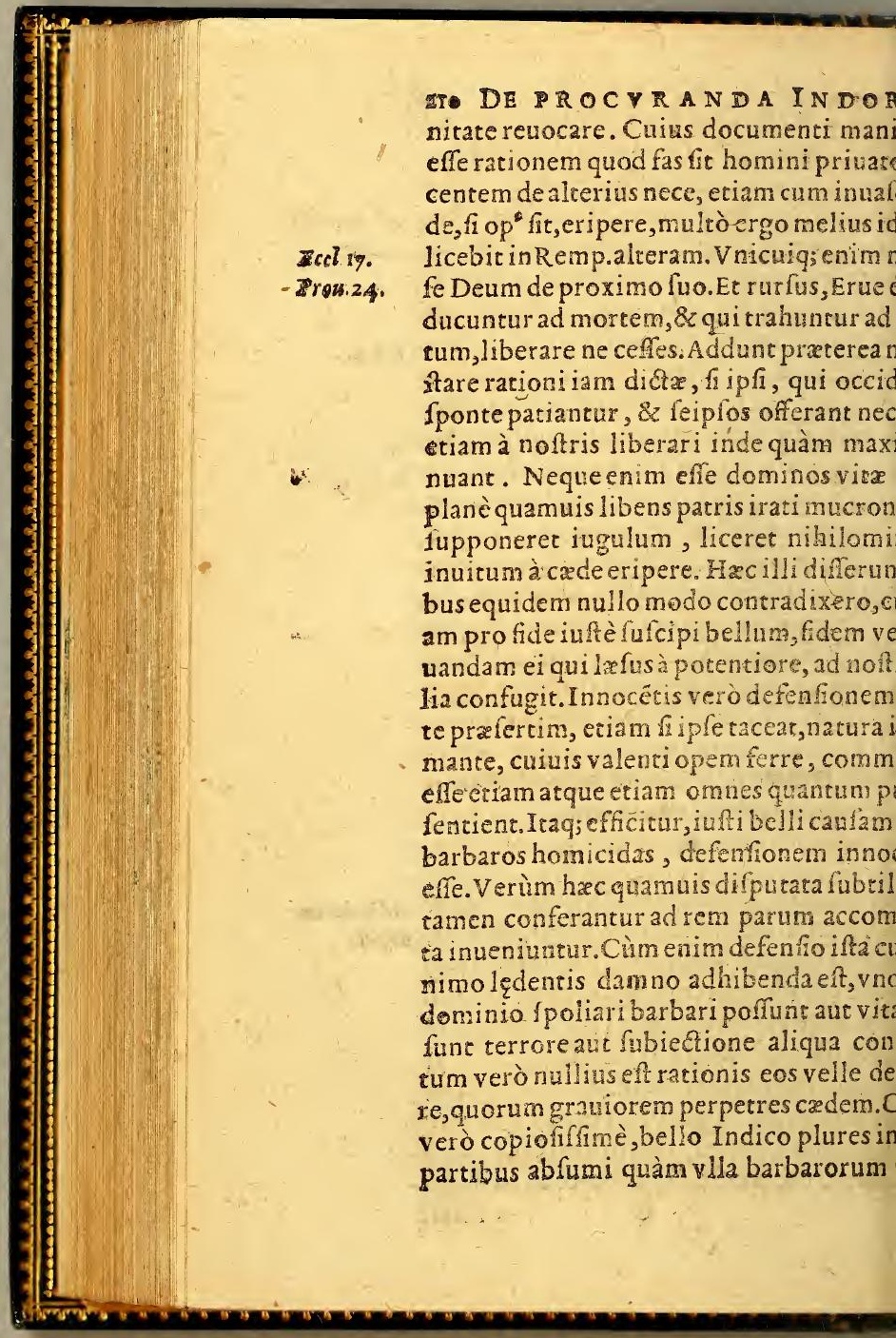


SALVTE. LIBER II. 2IS Zuare fi moraliter loquendum eft, vix pocl potius nunquam omnino poterit fufce li aduerfus Indos caufa infta in defenfioocentium collocari. Etenim quod \& filmonui, \& fape repetendum eft, valtatioananxorum \& terræ Palæefinæoccupatæ hanc commemorant fanctiPatres caufam, rofectò lacra literæ manifeftè doceant ies illas omni fcelere contaminatas, neque à plurimo innocentium fanguine teme. In libro Sapientix legimus ad hunc m:Aut enim filios fuos facrificantes, aut sap. of a facrificia facientes, autinfanix plenas is habentes, neque vitam, neque nuptias as iam cufodiunt, fed alius alium per inui ccidit, aut adulcerans contriftat, 8 omnia ixta funt, fanguis, homicidium, furtum, o, corruptio, \& infidelitas, turbatio, \& per 1,tumultus bonorum, Dei immemoratio, rum coinqquinatio, natiuitat is im mutatio; natio moechir, \& impudicitia. Infandoiim idolorum cultura, omnis mali caufa nitium, \& finis. Atque hæc quidem funt eragentium, qua Dei populum didicife im confortio Propheta dolenter memimmixti, inquit, funt inter gentes, $\&$ didi- 8 fal. 10 ; opera eorum, \&z feruierunt fculptilibus , \& factum eft eis in fcandalum. Et immo-. ne filios fuos; \&z fli ias fuas dxmonijs, \& efInt fanguinem innocentem, fanguinem fifuorum, ic filiarum fuarum, quas facrifiint fculptilibus Chanaan. Qua eò fufius cố rata funt, quò minus noftrorũ barbarorü foedos, \& fanguinarios miremur, cùm
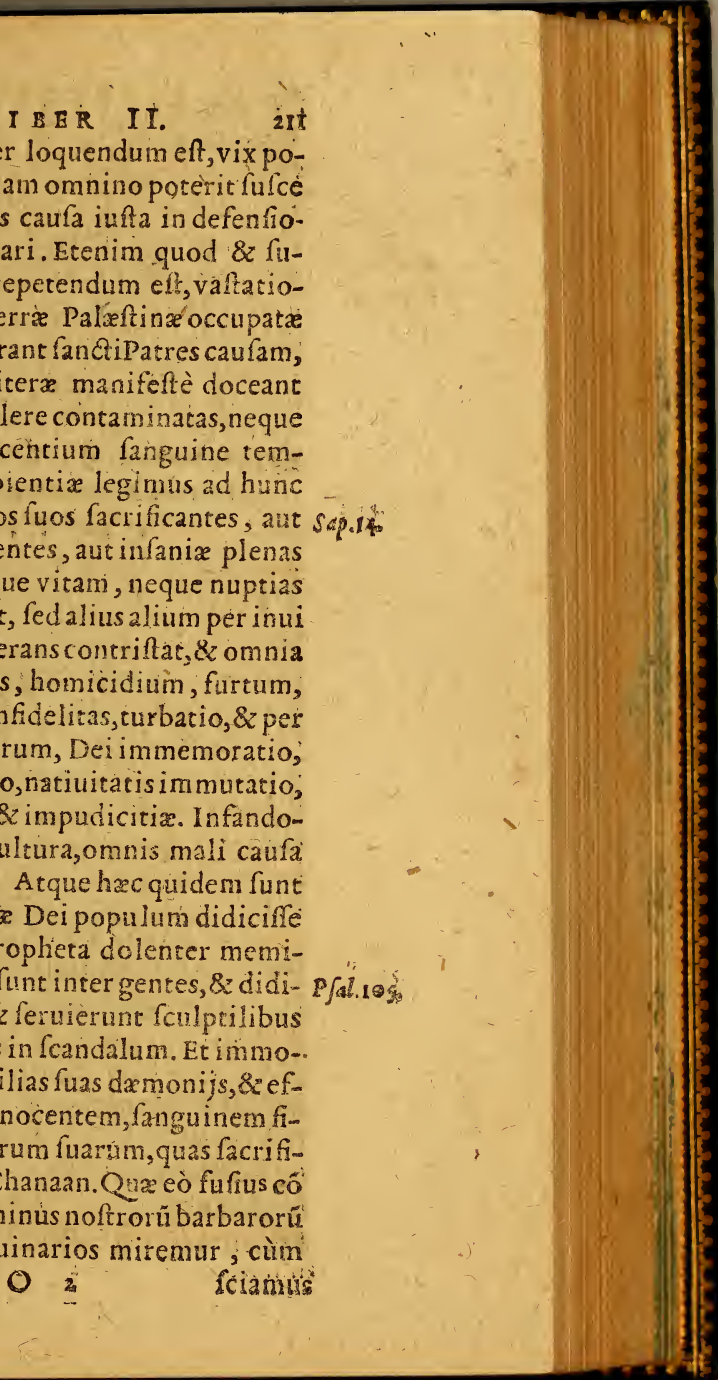
E18 DE PROCVRANDA INDOF fciamus familiare id fuiffe perpetuo $r$ idolorum cultura, quę, veSapiens dixit,, malorum caufa eft, \& initium, \& finis. It intelligemus eas omnes, qua à nonnullis fus Indos cauf $x$ pratexuntur, non defuifi quisiuft is fub lege aut etiam fub Euangel tibus, contra fui temporis infideles, \& b nationes: fed nequaquam tamen eas fatis e ftimafle, vt bello infeftandas arbitrarent

Quod omnia iam dict a de bello aduerfus In Solum diuina:jed etiamregia lege firmen

$$
\text { C A P T T V I. }
$$

TAud parum perfectum ef, quòd omn - caufas aduerfus barbaros, qua noltrur los ingreflum antecedune, remouimus, gari errore profligato putantiú beneficij nendum effe, quod barbaris pro agr is, $\& 1$ te prærepta, Fidem lefu Chrifi, \& vitam nibus dignam reddamus;quorundametia fapere volentium, quàm par fit, fententia cuè refellatur,qui noftris adillorum fcel compefcenda, vel etiam plectenda ius f: quad fummx potius iniuriętribuendum unidè, vtopinor, apparuit. Hinc iam conf effe videbatur, vr exponeremus, quid illis dum fit, qui eiulinodi expeditiones in In cuti, fortunis potiti, \& opera ac feruiture rorum iure belliabufifint, quorum fupe funt hodie quoq; non pauci. Aff potuerint fari ignorantia?an fint reftitutioni obnox ńsbus modis turn ip fi, tum res ipforum, ad cunq; tandem deuolutx fint? Et quid reme dem in tanta perturbatione afferri queat. 

qquam eft difficilis, \&periculofa cenfura, lio loco, fi Deus annuerit, dicetur opporunc vniuersè,ius, $8 z$ iniuriam indicendi actamus:atq; illud tanquá totius actre cauamentum adijcimus, quòd cùm in omninis Indiarum tam multa prælia cómiffa ot nationes fubact $x$;nullum tamen genus m feruituti fubiecit regia lex, quin potis omnes, \& liberos effe, \& fuis rebus libeeclarauit, grauiffmis ponis propofitis veluti iure belli captos, fibi manciparét. rò in omnibus expeditionibus, quæ fiüt, lixve funt, fiue ad nouas gentes quęrendas, iam quxfitas perueftigandas, inuiolabili citum eft, vt neq; noitri milites aggredion laceffici ad vexandos, cæedendóiue bar neq; illos vndecumque captos feruire coua vna lege pleniffimè demóltratur, nulIli ius noltris ex quantauis Indorum bar$z$ inhumanitate concedi.Supereft vt quodiuinis, \& humanis legibus bello laceffen s omnis caufa fublata eft, hac exclufa via andi Euangelium ijs, quos armorum vis flet, perfequamur, an alius aliquis aditus ad annuntiandum gentibus Chriftum.

$m$ do Apoftolicam Euangelizandi rationem con poffe exactè feruari inter barbaros.

\section{A P V T VIII.}

bus igitur modis, quantum mihi diligencogitanti occurrit,ad pradicationem Fiud barbaros infifti poteft : quorum nos tû́ tem, tum prudentiam expendere neceffo O 3 elt. 


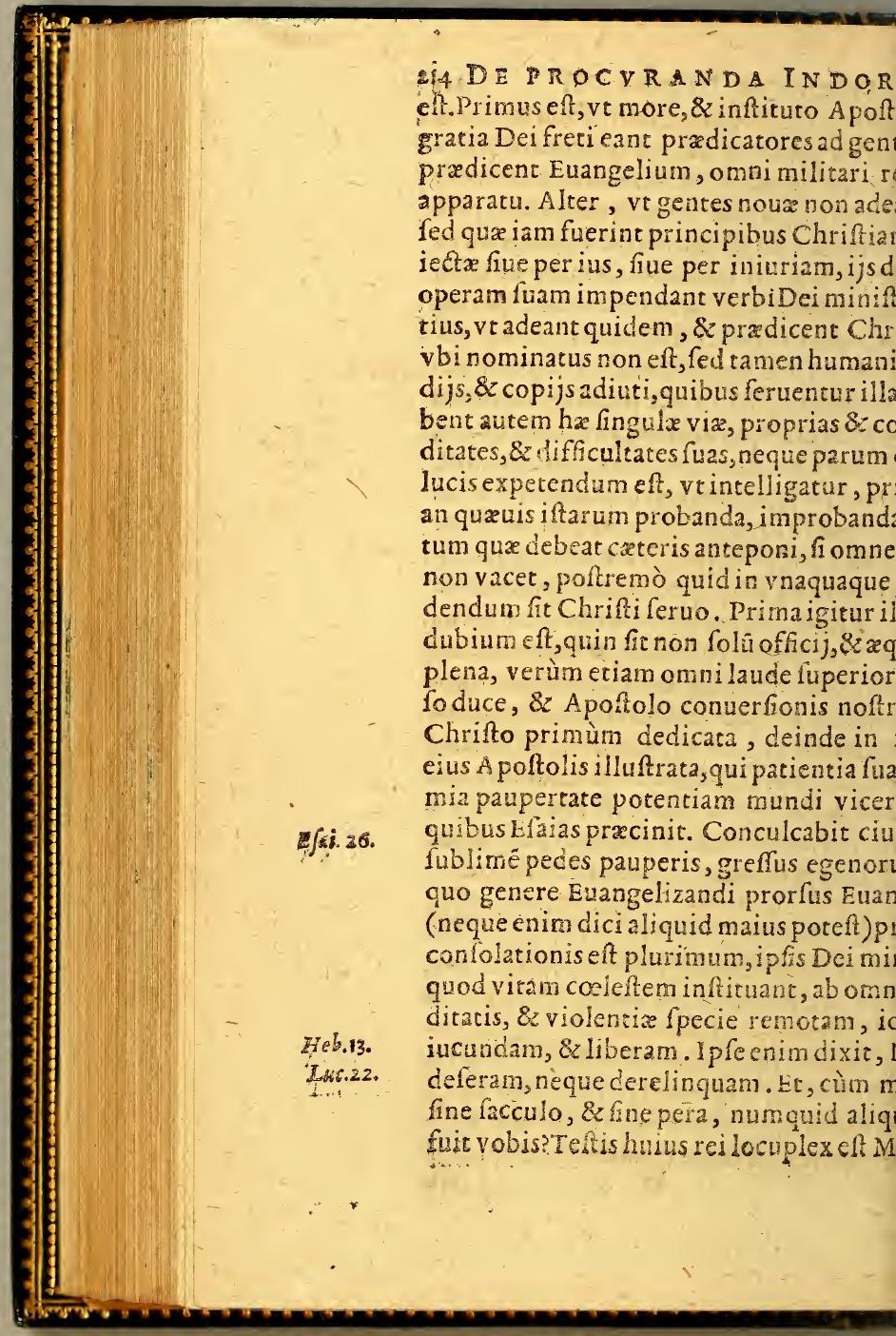



nofter, qui tańquam de alio loquatur,tanuinæ voluptatis, \&z confolationis flumen fua verè beata peregrinatione in animum. e folere affirmat, vt cogeretur à Deo pete ut imbecillitari fux parceret, aut fi ita de et, iuberet fe vitam commutare, quòd tan $\mathrm{m}$ coleftis dulcedinis ferre non poffet. affe minus facilè credét homines: fed exciunt, quid accipiant, \& nemo fcit, nifi qui 1 poc.2 t. Deinde fructus ipfe Euangelij meritò ur verior, vbi verbis facta nondiffident, emplo fuo, manfuetudine, paupertate, itate, Chrifti prædicator vehementius animos, quàm aures quibufuis vocibus. Paulus audebat loqui eorum, quxper il- Rom.19 n efficeret Chrifus. Admirabilis eft viagelica, \&z oculos ad fe omnium animof q́. ouitate conuertens; cumq́; intelligunt honon fua, fed le quari, tunc nef́cio quomofe \& fua libenter impertiunt. Poftrem uid moleftiæ accidit, quicquid difficultaericuli, mors deniq; ipla \& quiuis cruciaandem defignetw in Chrifti militem, viad illius gloriam cumulandam pertinere, in in fugam vertere, quàm palmam offerertaminum onnium fructum pretiofiffTriumphum Crucis. Quæ cùm ita fe haplerique eorum, qui ad munus dilatandi clij excitantur, eam fortem foeliciorem $t$, vbi poreft, $v t$ dixi, Euangelium Euangerædicari. Atq ; in ea re nó dubium eft, quin are cum noltris magna ex parte in India tali actum fic, in qua verè more A poftoliuit inter totgentes Chrifum annuntiare

- 4 Indis, 
216 DE PROCVRA N D IN DOR Indis, Perfis, Arabibus, Aethiopibus, Mala bus, Iapponenfibus, Sinenfibus, $\&$ infinit is Quam tamen Euangelizandi rationem fi it ritque huius Occidentalis orbis gentib amulfim tenere quis pergat, nihilaliud amentia extrema damnandus fit, neq; im tò. Experiétia ipfa omni exceptione fuperi ftis rem abundè monitrauit. Nam vi de al ceä, fola terra illa Florida lemel, atq; iterü, tiò pacificè ad fe venientes prædicatores, tos indicta caufa trucidauit, quòd \& Domi ni probarunt, \& noftri plus fatis experti Itaque infiturum illud Apoftolicum vbi ri commodè poselt, nihil prius, neque $m$ Vbiautem non potent, vt ferè in omai b rie res habet, non eft prudentix, Ipecie tix fanctioris committere, vt falutem ipfe cias, \& alienam nihilo amplius compares. yerò âtentius intuenti in hoc infituti g duæ occurrere caufa folent, ob quas Apolt illa Regula, \& forma inter has nationes ri exactè non polfe videatur. Vna eft fati זa , quòd hæ gentes ficut beftiarum mo vtuntur, ita humanitatis parum permittan ne fodere, fine mifericordia, prout quidui libitum ent, ita temerè agentes. In hofpites ternos nullum gentium ius obferuantes, inter fe quidem natura leges fciant. Quan qui horum fe rationi, \& arbitrio commifes terit is cú apris \& crocodilis amiciria inir que vero ab iftis Martyrium expectandu qua fortafis fpes tantum difcrimen le non enim pro Fide, pro Chrifto, pro Reli moriendum eft:fed vt vel fuauiores epulas sto 
S A L V T E. LT BER II. as, quod Brafilienfibus, \& toti Septentriohuius orbis vulgare eft, vel fpolium pręarbaris elegans, vel denique quia vifus es $\mathrm{m}, \&$ quid in te fibi liceat, experiri iuuat. oli predicabant Chrifum Iudæe is quidem 1 Cor. 20 lum, gentibus autem ftultitiam, alijs faam, alijs figna quarentibus : fed vtriq; taatione agebant:oderant verò illos propter Chrifti, atque ita beatos potius faciebat utio; per quam etiam miro modo Dei graplius dilatabatur. At barbari, excepto hoc homines fimus, nihil cogitant, imò illud diu addubitaffe non pauci comperti funt. caufa in nobis eft, cur A poftolica pradiinftitui omninò Apoftolicè non polfit, miraculorum nulla facultas fit, qua A polurima perpetrabant: quorum fplendore entia freti, authoritaté dicendi apud quoficquid placebat, facilè vendicabant. Habe- $A$ - io. $r$ homines Dijs fimiles, atque ita cætera eo- 14.028. aupertas,abiectio, ignobilitas, ineruditio aris, ornamento potius erant, quàm concui \& faftidio, diuinam eorum vim admious, \& prudenter iam inde colligentibus bus, quàm effent homines affectibus fupes, \& toti pene cœleftes.Quod de Sergio Pau 1 17.15 confule viro prudente diuinæ literæ comlandum memoriæ putarunt. At noftri, nunc oris, cùm talium operum maieftate fefe bar admirandos, \&z timendos non prabeant, reftat,nifi vereliqua vita inopia \& impoa penitus contemnatur, neque à gener olo celfo animo, fed à milera $\& z$ adueria fortuofecta intelligatur,atque a deò cùm fordidi
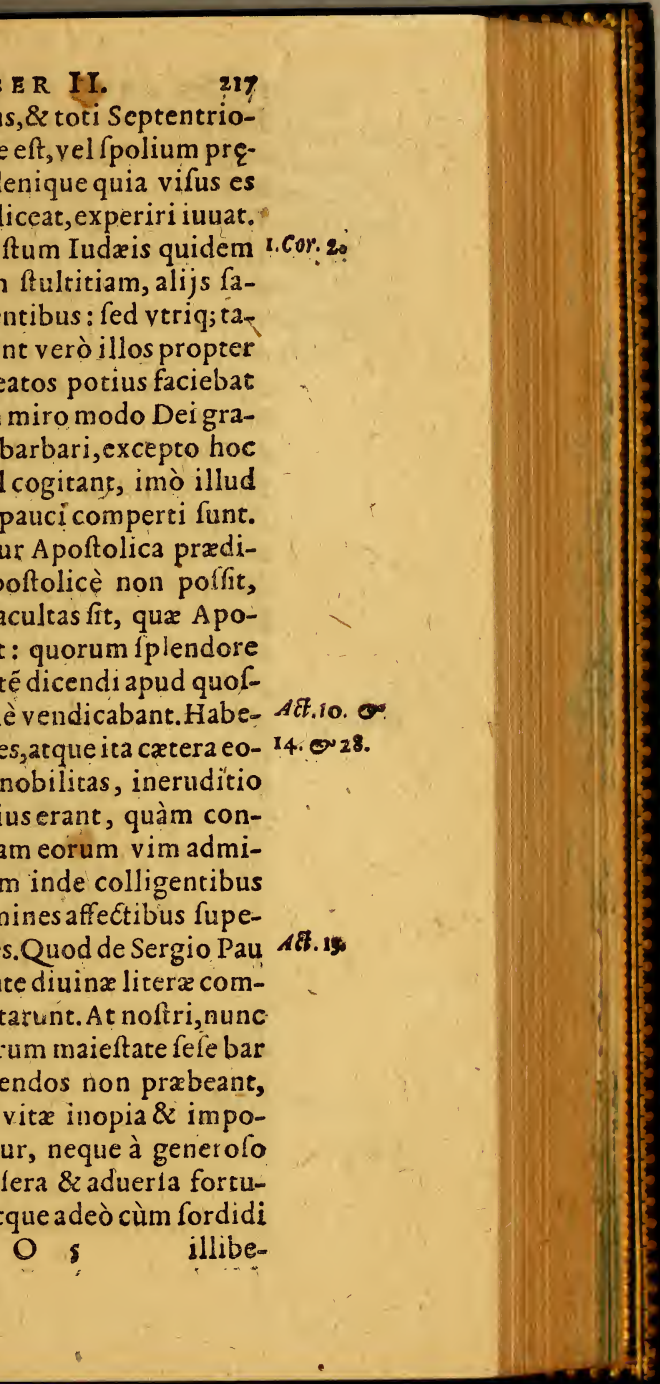


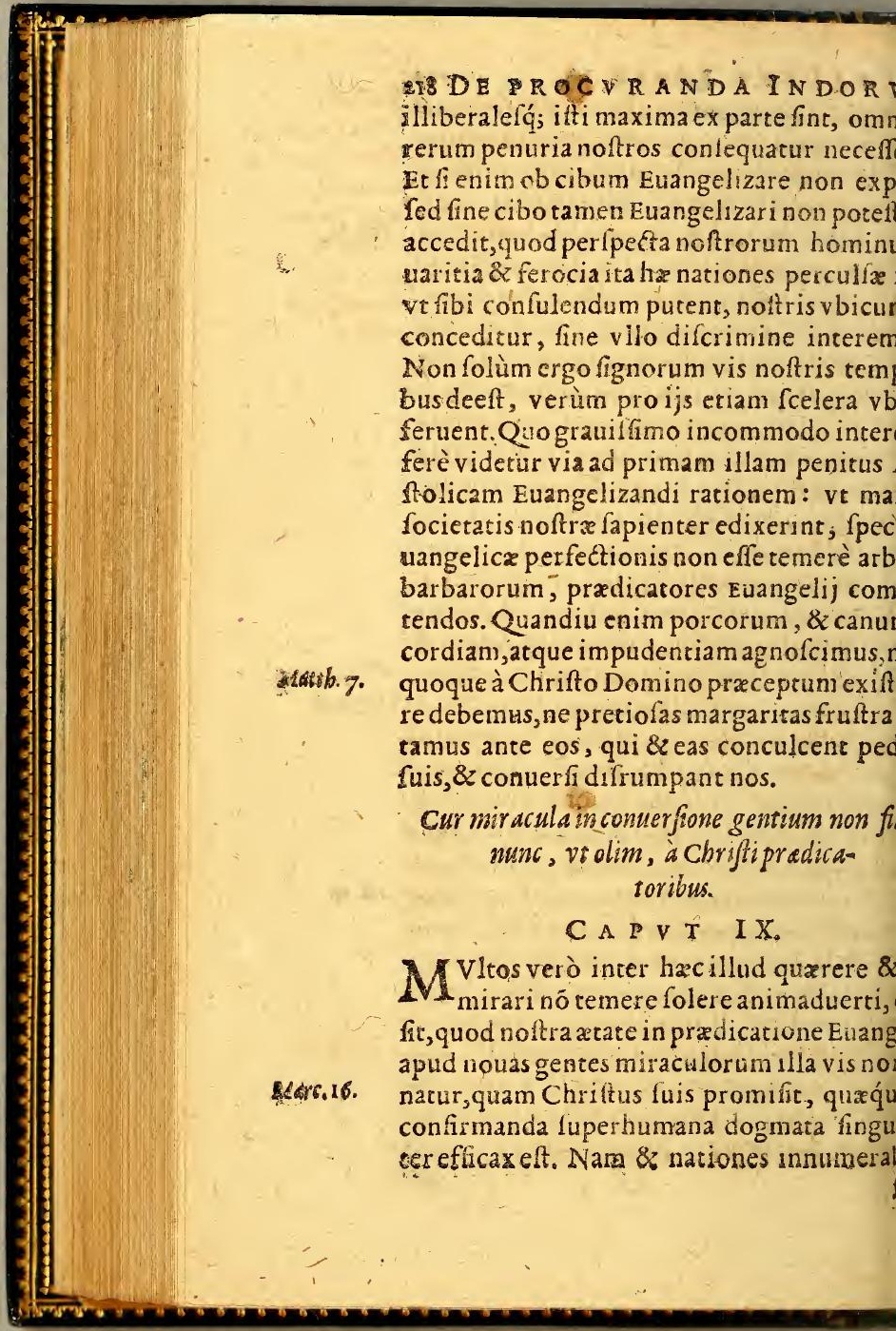


SAIVTE. IIBER II. 2IO quarum falutem Deo effe charam dubitare Barbar? offumus: $\&$ hæ, fi quæ vnquam aliæ, exter- $A \mathbb{E} 28$.pria znis \& operibusprodigiofis fidem commolufquam dici queat, facilè folent. Arguo eft mirabilis illa, \& inaudita noftrorum num peregrinatio in terra Florida, vbi ex enfo naufragio quatuor illi homines tanuperfites Cabeça de vaca, Dorantes, Ca- vipera. \& quidam alius, diuinitus gratia curatiodonati, \&opera Apoftolica perpetrátes, ho$s$ alioqui militares \& profani, inter immanos barbaros per totum decennium non foIlaff feruati funt, verùm infinitas populocateruas poit feagentes, itinera ad id teminaudita confecêreab Oceano Arctico vfd Antarcticum mare penetrantes. Qua in grinatione, quemadmodum eorum fide diommentarij habent, propter fanitatum otiones vitaç; innocentiam tantum admiras, \& gloriæ a pud barbaros funt confecuri,ve emodum adorarentur prodijs, \& quicquid irarent, non aliter quàm de ccelo profectum peretur. Quæres abundè monfrauit, vt eoetiam quidam literis prodidit, quàm effet $\mathrm{f}_{2}$ ac certa via ad conuerfionem gentium havitæ innocentia, præfertim fignorum fplen decorata. Quid ergo ? Cur putamus Excelf eram fe continere, neq; quod facillimè pogratia miraculorum tot pophlos ad Fidem ere? Iuuat interdum illa Prophetica oratioxclamare ad Dominú, Miferere noftri Deus Ecclef. $3 \sigma_{\text {e }}$ ium, \& refpice nos, \& oftende nobis lucem erationum tuarum, $\&$ immitte timorem tuú gentes, qua nó exquifierunt țe, vt cognolPaulum ha. micidam, mox Deune dicebant, quòd nibit lesuseffer meras. 


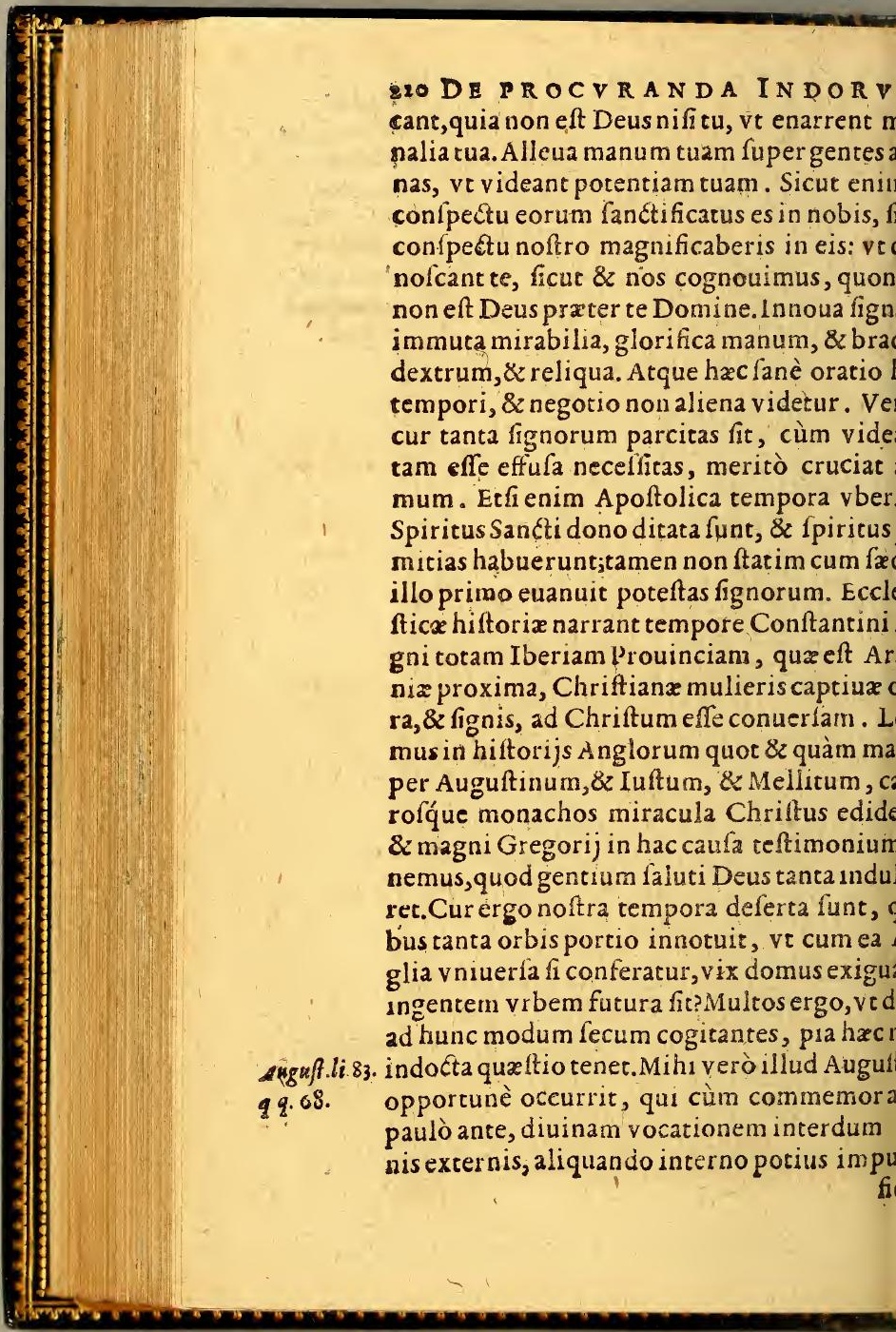


SAIVTE. LIBER IT. 22Ŕ , mox adiungit, $\mathrm{Hxc}$ autem vocatio qux frue gulis hominibus, fue in populis, atque in genere humano per temporum opportunioperatur alta \& profundęordinationis eft. senim cognouit fenfum Domini, aut cum Efaia 4⿳亠े冖. inijt confiliumá Populum Ifraêl fibi charü; o de feruitute Aegypti Pharaone toties proExod.14. to ingentibus prodigijs eripuit: eundem alum longè poft de Babylonica captiuitate reftituit,non ita magnis operibus perpes: illic quidem per Moyfem, \& Aaron, hic Zorobabel \&: Iefum: neque tamen minus fe bilem pradicari vult fecundo ifto reditu, a primo illo ingreffu in terram promiffioroinde Hieremias loquicur, Ecce dies vet, dicit Dominus, \& non dicetut vltra, Viuit Ag8.1. क्ष: inus, qui eduxit filios I frael de terra Aegyed viuit Dominus, qui eduxit flios Ifrael de Aquilonis; \& de vniuerfisterrisjad quaseram eos. Cui rei non diffimile mihi videtur, Ecclefiam fuam olim in ipfis Euangelij culis, multorum fignorum \& variorum chaatum copia congregauerit, eandem modò entibus non minus mirabiliter mirabilium itate colligit, diuerfa tempora fecundùm fimas fapientię fuę leges diuer fis rationibus iniftrans. Attamen in re obfcura, quantum redatur, nonnihiletiam rationis inuenire it hurnaria cogitatio, modò fobriè quarat, haritate primùm radicata $\&$ fundata, ve polomprehendere. Ac mihi quidem aliquoties Ephef.3. animo repetenti tam perfpicuæ diuer fitatis oteftate fignorum, illa occurrere caufa folet, d prifcis temporibus omnino neceffaria fue.

Zach.r. 3.Efd.s. Hier.16: rint, no- 


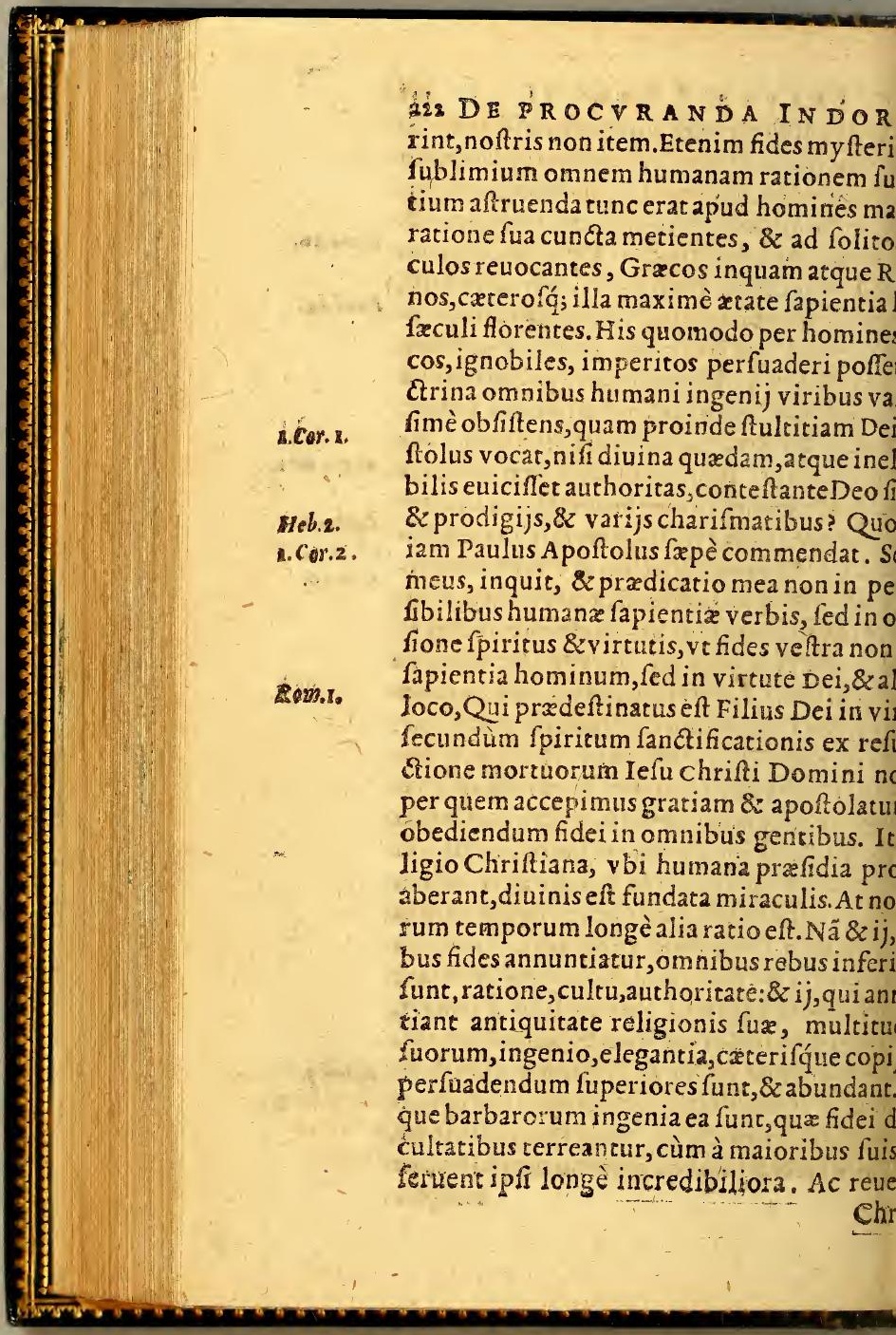




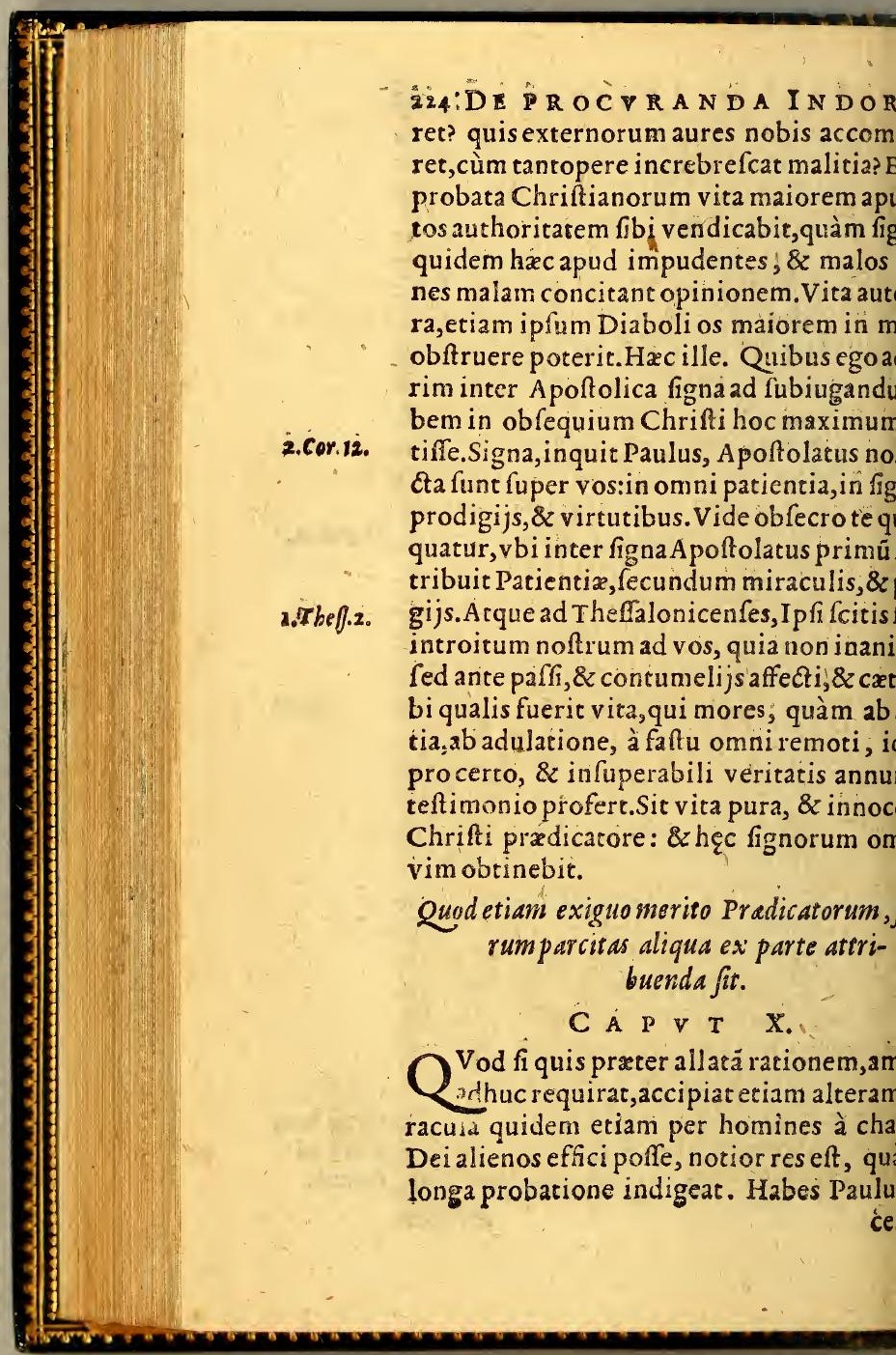


S A L VTE. LIBER İ́. $22 \hat{5}$ em, fi habuero omnem fidem, ita ve montes 1. cor.r. feram, charitatem autem non habuero, nim. Habes ipfum Dominum perfpiçù do$\mathrm{em}$ : Multi dicent mihi in illa die, Nonne in ine tuo prophetauimus, \& virtutes multas nus?quibus ipfe refporidebit. Amen dico vo Aug,li.8. efcio vos: Difcedite à me operarij iniquita q.q.79 fusè. uo in loco Bafilius Magnus, \&zautor de Ecalticis dogmatibus feriò monet vitx potius dum effe quàm fignis, quod hisinterdumepeccatores abundent. Nam \& ille in Euar. dxmones expellebar, qui Chrifum non fe-Luc.9. caly" atur. Hæc quanquam ita fe habent, tamen dubium eft; quin frequentiffimum fit, \& velege fixum,v quo quis fide $\&$ fanctitate maminuerst, eo aptius infrumentum fit, per Spiritus fanćtus tam præclara opera perpe Vix enim inter multos v nus occurret, qui ve znorum gloria claruerit, qui non idemeia fide opus Domini operatus fit. CùmeA poftoli etiam femicinctia ac fudaria magoppreffis peragerent, Scæuæ cuiufdam filij bus maiora conantes, etiamfi Chrifum inuo $n t, \&$ Paulum commemorarent, tamen iuftè erunt fibi à malignis fpiritibus refponderi, m nouimus, \& Paulunh fcimus: vos verò qui $A$ Et.19. Quo facto nos admonitos friptura voluit, mfichrifti nomen ad profligandas hoftes ex oribus humanis fatis potens effet, fed tamalorum meritis impediri fxpe rem tanQuid ergo mirum, fi rara illa, \& admiranda imonia aufugerint, fi figna noftra, vt eft in mo, non videamus, neque fit propheta in ter $P \int_{a l} l_{30}$ bi Fides exigua eft; vbi charitas refrigefcit; ṕ

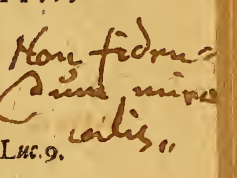




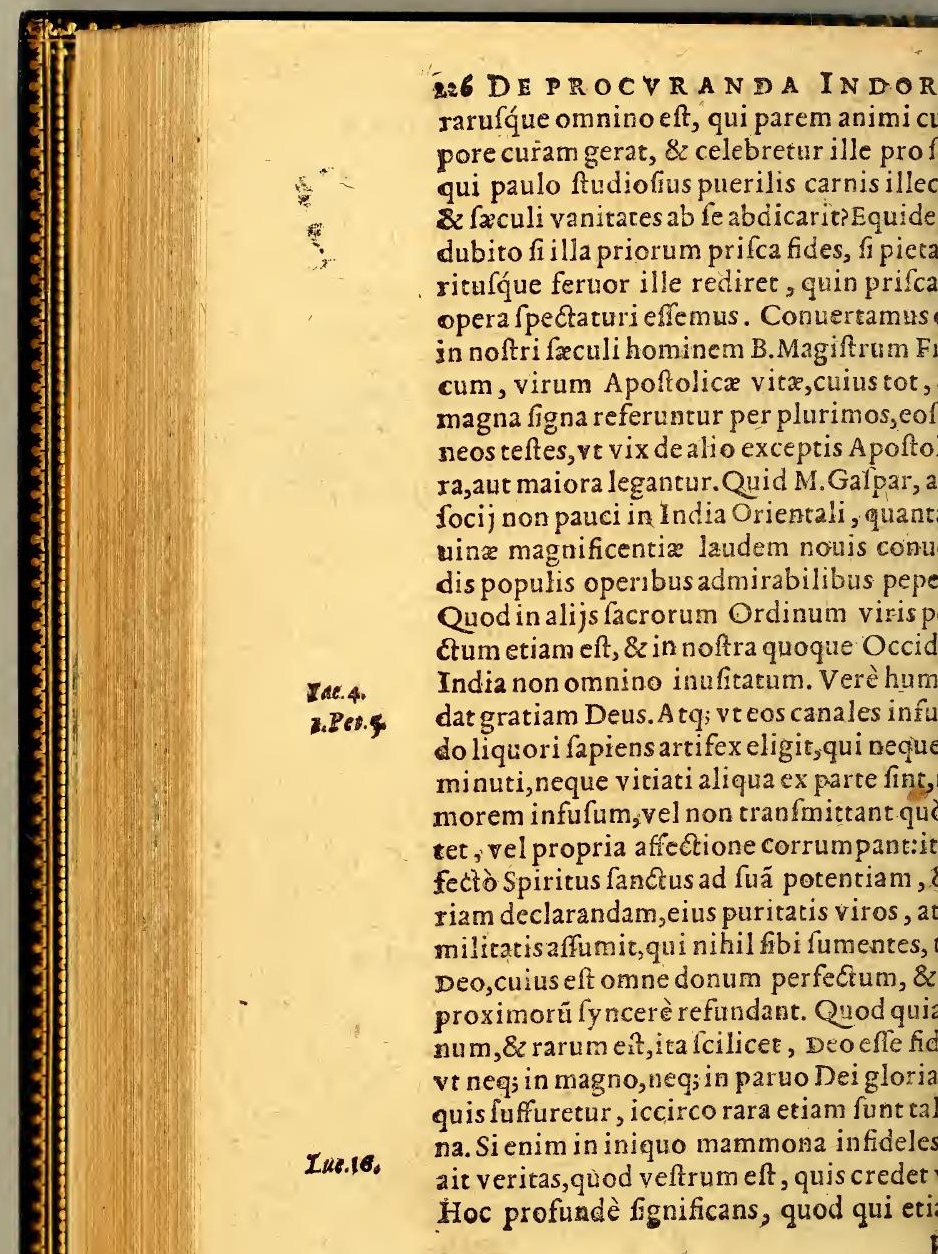


SALVTE: LIBER IT.

ilibus, \& frecularibus fuperbimus, de opide genere, de elegantia, quod vocat ini$n$ mammona; \&alienum, quia verè,neque rum eft, neque iufto dignum, quomodo non is intumefcemus, fi f piritus dona illa magi preclara noftræ fidei committantur? Atq; go duas præcipuas effe caulas reputare fon raritate fignorum: \& alteram diuinz effe tix, alteram fapientix, quibus fuprema il8 inexhaufta potentia quodammodo cohiir, atque libratur, ne fe fecundù diuitias effundat. In omnibus verò bonitatem fitxcedétem confiderare licet, qua etiam hoc m quod minus preftare, atque indulgere $v i=$ Ir, ad hominum certam falutem accommc atg; conuertit. Ipfigloria in facula, Amen.

radicatione inter eos qui Fidë iana receperunt. C A P. XI.

itur morem illum Apoftolicum Euangelindi vbi nominatus Chriftus non eft, vt omm beatiffmum, vbicumq; licet, retinendum vbi id verò minus conceditur propter maIm, vel regionum, vel hominú, faltem fufpitú, \& quoad eius fieri pozeft, imitandum, fait reor, monftratú eft. Sequitur vt de eo pręindigenere differamus, in quo auditores iam mq; Chriftianos offendimus, \& legibus nofubiectos. Id quod eft modò v fitatius, propa a quòd non tam nouis regionibus inueftis, quàm olim repêrtis excolendis, magis inilare hominum ftudià coepêre. Qua in re duo cipienda videntur.Vnum, vePrincipum ciiurifdietioni minimè refifatur.Alterúv vt in

$$
\text { p E Eccle }
$$




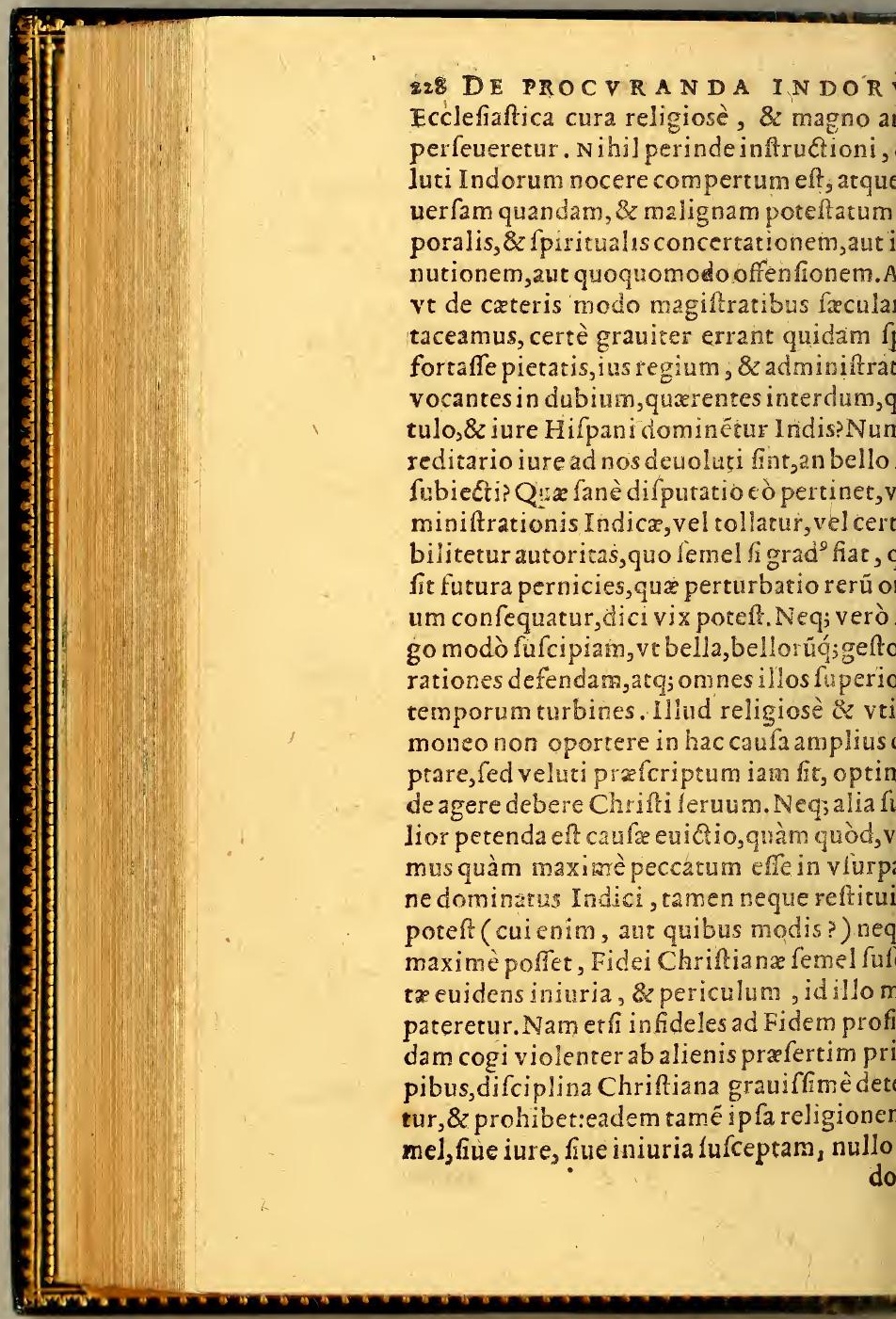


SA L V TE. I I BER II. ferendam effe, \&z defertores coërcendos eferè decernit.Qua de re extant Patrum anti ecreta in Concilio Toletano, Oportet, in- conc.Tol. t, vt Fidem etiam, quam vi, vel neceffitate 4.c.ss $d$. perunt, tenere cogantur, ne nomen Domi- 45. De Iu. fphemetur, \& Fides, quam fufceperunt, có da. tibilis habeatur. Plus enim habet iuris, vt ftinuscenfet, quod in eis Dominicus cha- Epir.so.ad agnof citur. Adde, quod fubditorum non Bonifa. a examinare, fed honorem potius omnem re principibus. Certè Cafarum dominatus em inuequs, fi quis exactius difcutiat, max $x$ parte tyrannicus fuit, neq; tamen Paulus, Rom.13. trus eoruin potentiæ refiftendum docuequin potius honorem, obediétiam actribu Tit. 3. 1.Pet.2. denda diligenter præcipiunt, idq́; non foropter iram, fed etiam propter confcienAc licet alijs gentibus iure aliquo imperaRomani, at in Iudxos iniuriosè profectò rant:tamen Chriftus Dominus, neq; censú, e tributa reprehendit, fed foluit ipfe quoq; Matt 22. Matt.17. te fua non vtens, cùm effet filius fummi Et cum multa in Herode loannes Bapti Luc.3. riter obiurgaret, potentiam tamen nunquá puit, imò verò milites ftipendia Romana, seft in ACtis Apoltolorum, ille Centurio, ACt.10. mereri fanxit.Deniq; \& magnarum opum gnorum maximè iura, cùm fæpe per iniuintroducta fint, tamen videmus in facris liprincipibus fua imperia confare, \& fubdiedientiam doceri. Igitur fue iniuria vfurfit dominatus Indicus, fruequod magis imandum, \& prędicandum eft, quantum atad Regum adminiftrationem, iure $\&$ ordi-

$$
\text { P } 3 \text { ne,ne- }
$$




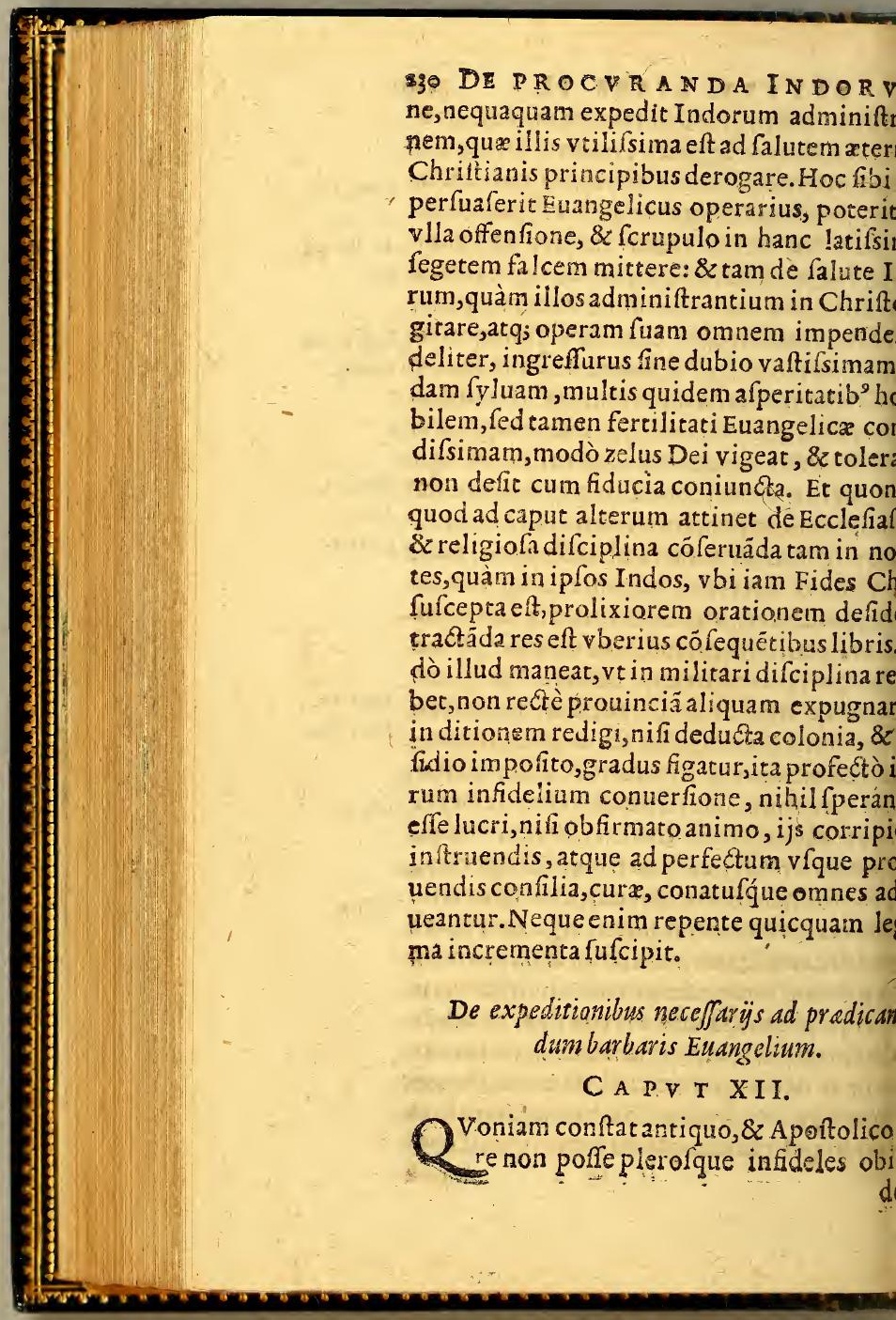


SA I VTE. LIBER IT: 23E ari barbaros prius, ve mox domiti religio hriftianam recipiant, multis, \& magnis busperuerfum effe monftrauimus, non occurrerevidentur anguftiæ, quoná moia verbú Dei ad nouas nationes perueniat.Sed quia omnibus gentibus prædicare lium oportet fecundùm Saluatoris præa, \& pradictionem, \& nulla eft hominum quam incurabilẻ réliquerit fummus cóolligitur, nouo aliquo Euangelizandigeendum effe, nouo quoq; hominú gener odato.Vtenim barbari, veluti mixta hux ferina natura conftant, vt moribus non mines, quàm hominum móftra videátur, cum illis inftituenda eft cöfuetudo, parmana \& liberalis, partim fubhorrida, \& it, neceffe eft, v fq; dú natiua illa fua ferita Jita,paulatim mã fuefcere incipiât , \& ad linam humanitatemq́; traduci. Nó igitur êda eft accuratior de expeditionibus traquibus, vel incognitz nationes exploranliam exploratæ adeuntur, idq́; fæpius naone prolixa, interdum terreftri itinere. a vtroq; genere in hoc Occidentali orbe, ceano Antarctico noux quotidie gentes, vfque inauditæ occurrút; quarú falus nulto contemni poteft.Simul ergo proficifci et viros militares, neceffaria humanze vite ia in tam longa,tamq́; periculofa peregrile ferétes, fimul vitæ æternæ præcones,cahriffi militătes, ve diabolica tyränide canimas Deo expugnent. Id ita cóiuncto ofportere fieri, non folü ratio docuit, verùm am longo vfu comparata experiêtia. QuaP 4 refis

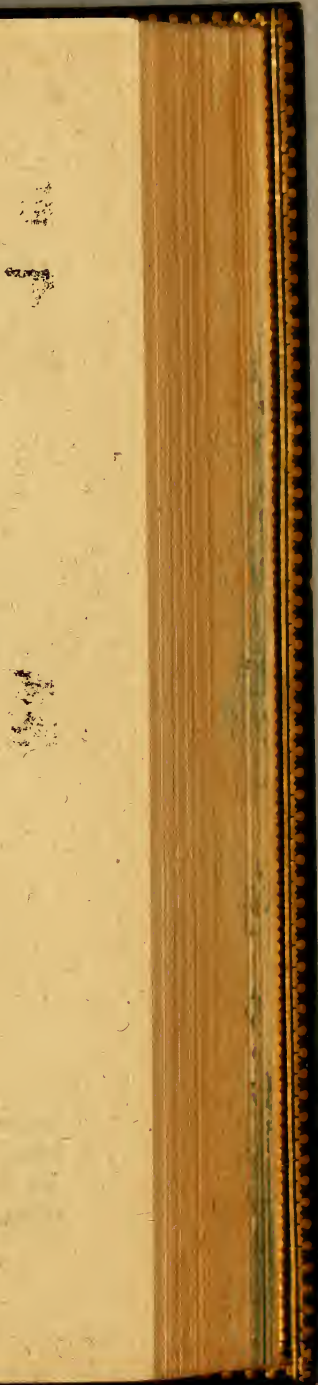




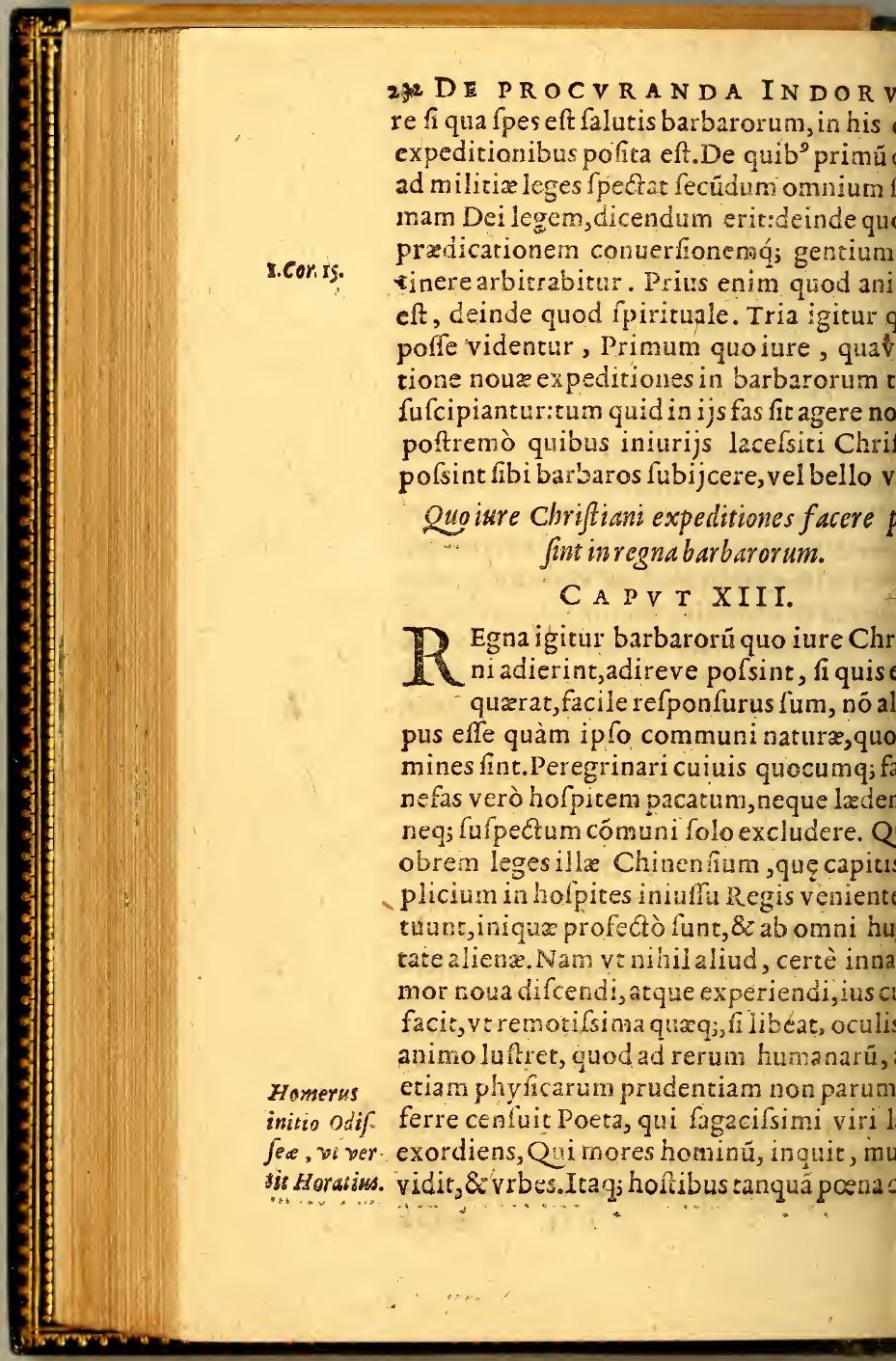


SA L T E. LIBER II. um ad nos præcludimus, cæteris non itë, nifî itò in fufpicionem veniant. Iam verò mer$x$ artis hoc proprium eft, vt qux apud fuos dant, deferantad externos, \& quibus vimilli circunfluunt, reportent fuis. Ita enim munis noftri generis author mortales omnterfefociandos, \& quadam communione ficio retinendos exiftimauit, fi fibi effent ffin opportuni, \& commodi. Atq; vt in houm ingenijs alios alia curare cernimus, vt alceos parer, ille contra domum ædificet, ifas orbis terrarum regiones fuo quoq; quofoedere coniunxit, dum rerum aliarum alijs alijs feracitatem attribuit, nec folicitatis anx effe cenfuit, quod ille cecinit, mnis feret omnia tellus.

Virgil. i atque argenti haud fcio an ditior vlla regio it concurrere hoc ipfo Piru, aliarum pene ium rerum olim fummopere indigente. Ametalla, alibi gemmæ abundant, a libi ligna, r, herba medicinales, lana, ferica,artificia, \& enus fexcenta. Qui ergo commoditates fuas, gantes aut peregrinantes apud exteros qux,illis viciffm vtiles futuri, operæ pretium re quis non videat? At in iftis, dicet aliquis, iditas potius regnat, \& immoderata rapacificut $\&$ in illis alijs perniciola fæpe curiofiut oftentatio potius, quàm vtile aliquid difdi communicandiuè ftudium. Neque humatris eft officium, fed auaritiæ fitis, qua ferunQuis hoc neget? At modò non quid vitiofitas ninum habeat, fed quid ipfa communis vtiliconcedat, expendimus. Licet ergo, licet fine dubitatione barbarorum fines penetrare,

$$
\text { P } 5 \text { idque } f
$$




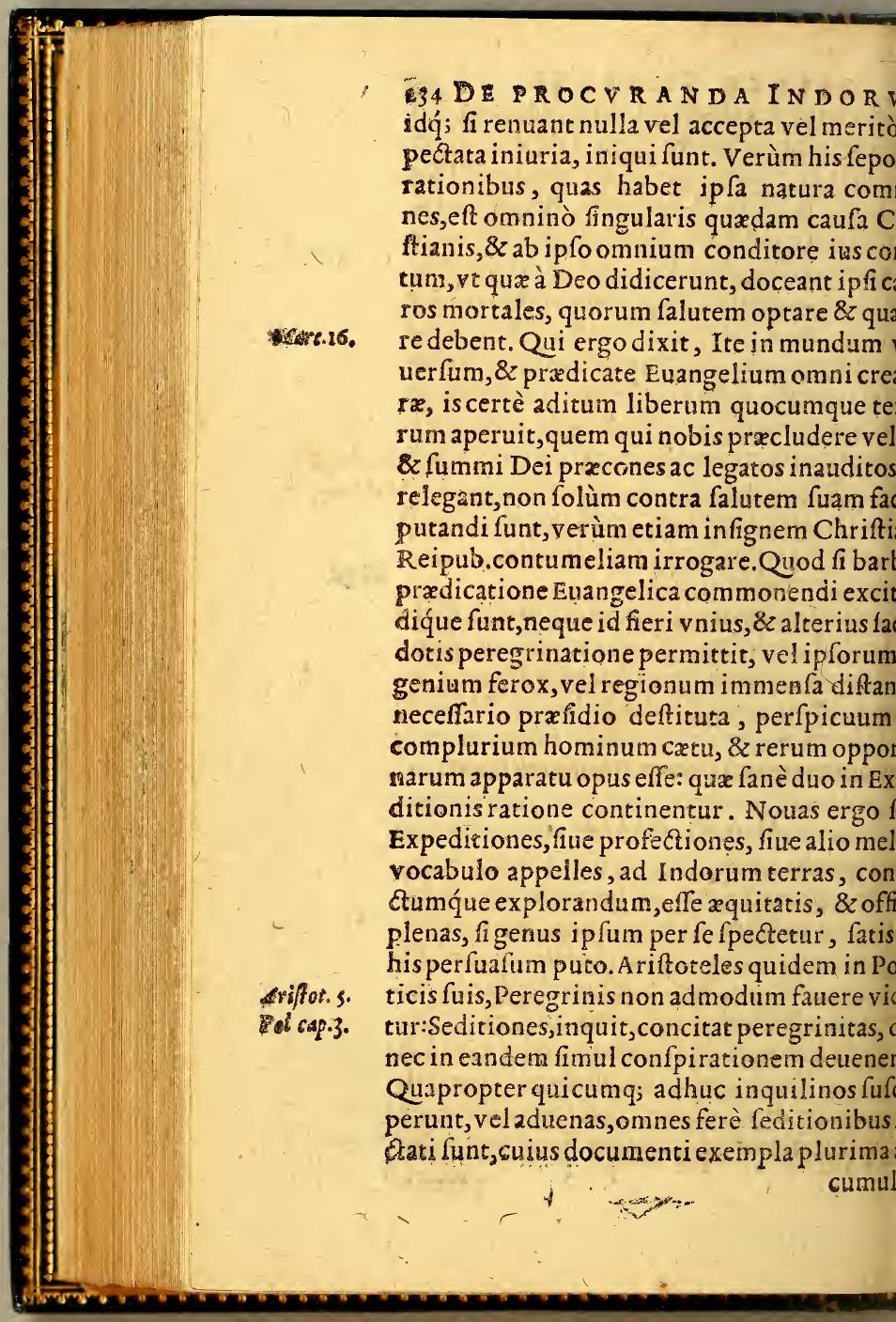


SA IVTE. I I B ER IY. at. Caterùm $\&$ fi rectè $a c$ perfectè inftituitatibus peregrinorũ turba méritò fufpe- debeat, ac proinde purgatio aliqua iufta hen barbarorũ alia longè ratio eft, qui vel cipfumexternis indigent, vt corum Reêtè conftituatuir, imò verò vt poffint co a dignam habere Remp. quip pe cùm femagis ritu vitam agant, quos ad focietate ue naturæ accommodatas attrahere, \& retes quodammodo compellere, feclufa taeruitute, \&zcrde, potius officio affignanit. Quod vique adeo certum habuit philo- Ariftok $s, \mathrm{vt}$ barbaros homines parere nolentes, Pol.6.5. etiam domare, iufum natura decernat, os ita temperàmus, vt capi quidem, aut aut profligari barbaros nequaquam finaropterea quòd naturalem feruitutem nulnofcimus, fed tamen melioribus, \& fapiibus pro fua falute docendos ac regendos, liberaliter committamus.

id in terris barbarorum chriftianis liceat.

\section{A P. XIIII.}

DE fit confequens ea omnia, quæ huic ni honeftè præf́cripto neceffaria funt, ipe natura, \& Chrift, noftris apud illos lice. ò verò etiam expedire, modò id quod vbiuidem, fed in hac maximè caufa feruaneft, modus adhibeatur: Vt ne quid nimis. niam ergo natura barbarorum eft maximè iftans, atque infida, opus eft, ve qui a pud ilerfantur, fecuritati fuæ confulant, 8 neque e çupiant, neque tamen fe fruftra ladi

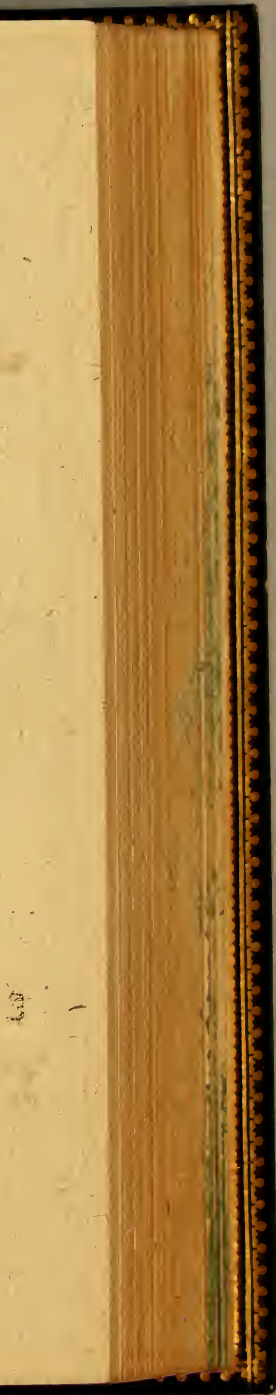




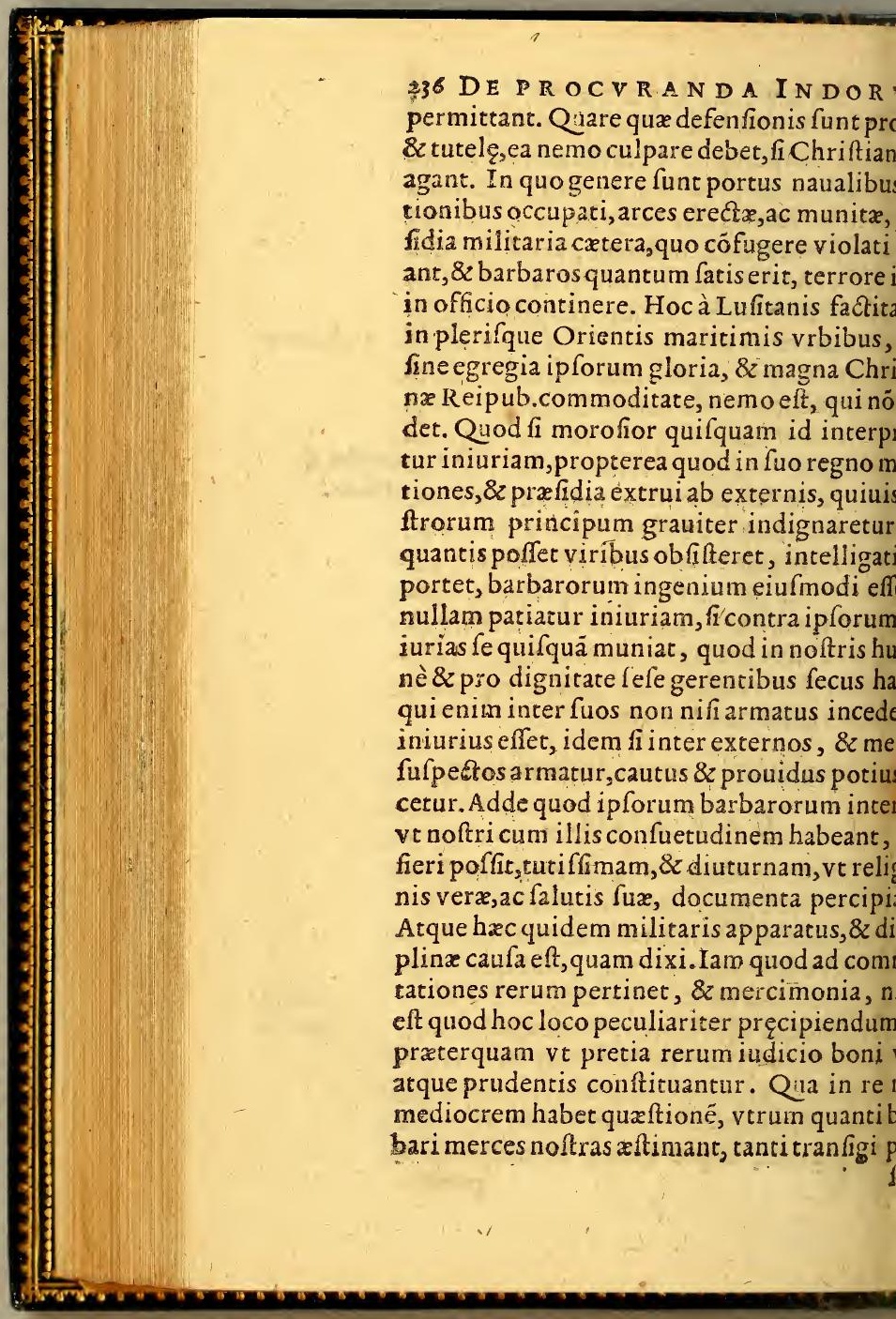


S A L V T E. LI B ER II. am bracteolas, \& calculos, \& gladiolos, \& vitrea, $\&$ id genus nugas ac fcrupea, tanretio apud ift os haberi compertum eft, vt at argenti non paruam vim, interdum exitiam fmaragdos cum his cómutare perliament. Verùm ifta difcutere enucleatè, dius negotijeft. "Illud exploratum teneamne genus mercimonij cum iftis exercere pretium verò neque lege, neque certa raconftare, fed iudicio fapientis, qui perfoiantum abundent ijs,qux ipfi reddunt, \& 8 faciant, vel ad vitæ prafidia, vel ad ornauendam ipfis charumea, qua accipiant ris, \& quanta horum copia inopiauè fit: vt us probè perfpectis atqué libratis qua reftimatio iufta cenfenda fir, ftatuere poffit. isverò colendis, $8 z$ fructibus faciendis, odo fundi ijs neceffarij aut culti non octur, non dubium eft quin beneficij etiam onendium fit, fi defertos $\&$ infoecundosaoftri exerceant, $\&$ fementem faciant, atq $x$ frugibus afluefaciant. Idem in gregibus siudicium eft, vbi pafcua vberrima nullis vacant, quod plerique barbarorum armen ecoris negligentes fint, venationibus deIIr. Denique quicquid vtilitatis noftris rum folo accedere poteft, fine vllo eorum nento, imò cum non exiguo emolumento, naturæ conceffum effe dubitare non pofQuamobrem quod ad auri \& argéti fodiercendas fpectat, quod præcipuè noftrates , pro conceffo reputandum eft, quicquid ri pro neglecto habent. Ita metalla fodiencipere,aut aurigrana ex fluuiorum obicibusco.

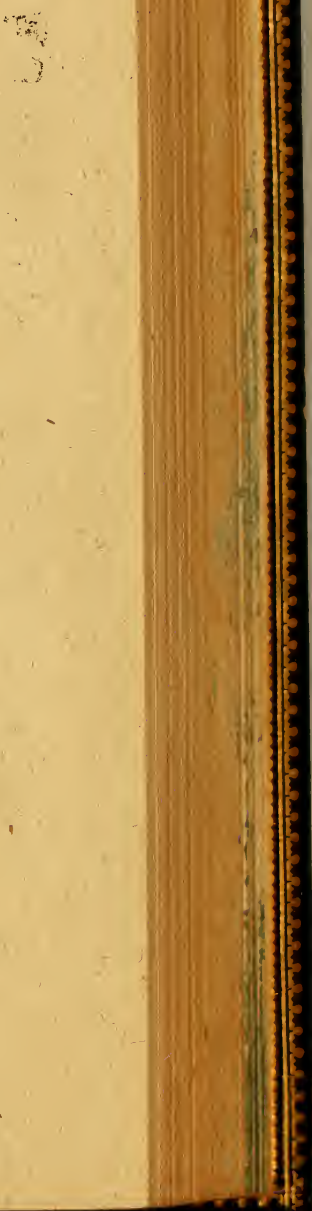




\section{DE PROCWRANDA INDOR}

bus cogere,aut argenti fundendi induftria qui, ant gemmas ex fundo expifcari, aut pr fos vniones eruere, aut quicquid denique $r$ eft, \& indigenis, vel ignotum, vel defpectu eft contra æquitatem, fi harum rerum ftu fua diligentia $\&$ indufria perfequantur. Se reruandum tamen, ve neque $1 \mathrm{am} a \mathrm{~b}$ incol cupata, \& habita in pretio, iniuriosè dolo, præripiantur, neque ipfimet noftris ad no non ipforum commoditates feruire coga quod v trumque periculi plenum e?t.

\section{Quando liceat barbaris infidelibus bellu?} inferre.

\section{A P V $\mathbf{T} \quad \mathrm{XV}$.}

Vod fi barbari, vt fæpe folent, nullis in læfi, fed humanè ac beneficè affecti, nc lædere pergant, aut fide violata cædem $r$ tentur, prafidia aggrediantur euertere, agr pulentur, fruges corrumpant, naues iniec ne cremareftudeant, dolo alimenta furrip aut denegent, cæterafq́j iniurias adoriantur folùm noftris fefe defendere, ac tueri liceb rùm etiam damna illata reparare, $\&$ acce contumeliam vlcifci, ac fi res exigat, feric re, \& bello profequirem. Nam belli sam in definiuimus caufam, vbi iniuria laceffitus ceps arma induit. Verum illud fummope uertendum, non eodem modo barbarorus iurias ac caterorum hominum perfequi tere. Cùm enim fint imbecilli, ac puerili nio Indi, magis puerorum ac foeminarum potius pecudum more trackandi funt, $v$ cam eos feriò vicifci velis, quàm neceffar 
SA LVTE. IIRER IT' 239 e, \& terrere, neque tam gladius in iftos alus eft, quàm intentandum flagellum,vt vel ulctati difcant timere $\&$ parere. Non enim a fęua ftatim veniendum eft, ad ædes incenonflagrantes, viros ferro trucidandos, ferem perpetuam, \& reliquas bellorum calaes.Sed quatenus progrediendum fit, \& vbi dugm, Ducis chrifiani charitas cum falurudentia coniuncta, \& melius dictabit, \& us, modò meminerit fe Chrifti religionem teri, \& verbo \&z exemplo debere, vt non uas curet, vel incommoditates, vel iniurias; vt pretiofa animarum lucra Domino aco t.

e officio pradicatoris Euangelici erga foo cios itinêris. •

\section{A P V $T \quad X V I$.}

sita explicatis, iã quod fit Euangelici prąa licatoris officium it nouarum vocatione um, intucdum eft.Atq; illud in primis prændum, ne quoniam nouo modo \& immutaione Chriltum barbaris annunciaturus fit, is militari præfidio \& multiplici apparatu, cò fe a poltolico officio minus fungi arbi$r$, animumq́; demittat, quafi Euangelium euangelicè annuntiet: Oportet Dei feruum ax per omnia voluntati promptiffimè fubfe æterna illius fapiétia regi, generosè perere. Non omnium eadem tempora, fed cunecit Deus bona in tempore fuo. Nouo gene- Eccle. minum, nouam Euangelizandi rationem ingratè fufcipiet, quifquis non fuam, fed gloriam meditatur. Sxpe aurea illa \& depicta 2 dis

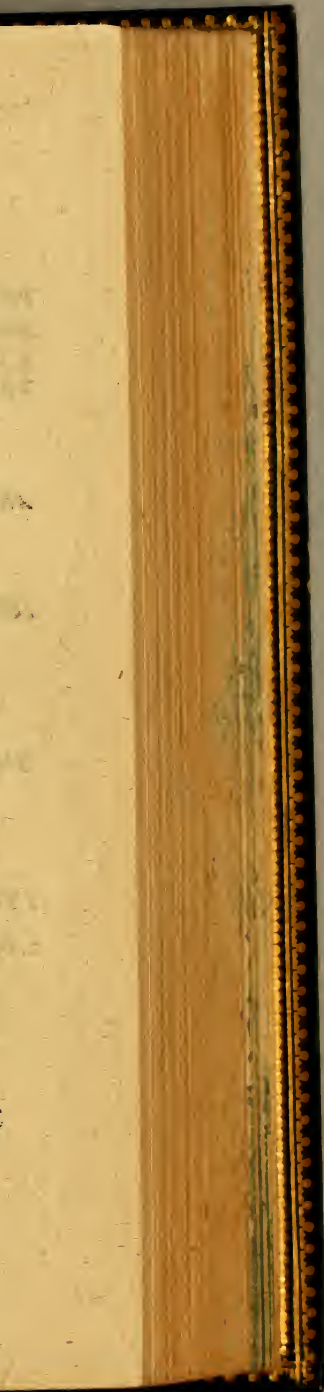


$24^{\circ}$ DE PROCVRANDA INDOR cta ante oculos antiquitatis laus, fi ad nos $r$ tur, nihilaliud, quàm vmbram quandam ctum \&z nominis appetentiam immoderat: pit. Etenim quid magis A poftolicum quàm que, $\&$ in omnibus inftitutum effe, vt fcia Philip. 4. feruus, in quibus eft, fufficienseffe, $\&$ abu Matth. 10. Ez penuriam pati.Aliquando Chrifidifcip 2. Tim. 4. ne facculo, fine duplici tunica Euangelizan Tit.3.

ACtor.27. quando verò etiam penulam poftulant, $\& 1$ tè præmitti iubentur, vt nequid illis defit. fi militum $\&$ fæcularium profana turba $n$ Chrifi feruum, meminerit laulum apud nauigantem cum cohorte Italica,eaque fup tionis Gentilicæ, eundem doctorem Ger AItor.28. récolat Romam caput mundi primùm ad gredientem fpectaffe vinctum, \& militari dia circundatum. Quis verò ita crederet? I mi predicatoris in maximam vrbem ingr quàm alienum, quàm incommodum putes, Ibilip 1. manas rationesconfulas?at fi diuinas, Qua me funt, inquit, magis ad profectum vener uangelij. Verbum enim Dei non eft lig: Quamobrem gloriosè prorfus nos hortatu.

2.Tim. 2. nuus militia coeleftis dux, Vt in omnibus beamus noś ficut Deiminiftros, non foli 2. Cor. 6. vigilijs, in ieiunijs, in caftitate, in fcientia, ganimitate, in fuauitate, in Spiritu Sancto, ritate non ficta, in verbo veritatis, quæ commemorat, verùm etiam in ijs, qua pri monenda putauit, in multa patientia, in tri tionibus, in neceffitatibus, in anguftijs, il gis, in carceribus, in feditionibus, in labo Denique, in virtute Dei,per arma iuftiria tris, \& à finiftr is, per gloriam, \& ignobilit 
SA I V TE. İ I B ER İ. famiä, \& bonam famam, ve feductores, 8 es, ficut ignoti \& cogniti, quafi morientes, viuimus, vt caftigati, \& non mortificati, riftes, femper autem gaudentes, ficut egen altos autem locupletantes, tanquam nihil tes, \& omnia poffidentes. His coeleft is tucibus generosè animatus Chrifti miles, cú induxerit animum, $8 z$ fe totum diuino iopermiferit, iam quid fibi præftandum a cateros, animaduertat oportet. Atq; hic cus focios itineris, vel maritimi, vel terreartes fuas diligenter intelligat, vt eos quãeri poffit, in difciplina Chriftiana conferrimùm beneuolentia in omnes, omnibus factus, vt omnes Chrifto lucrifaciat,affaCuauis, fermonem habens femper in gratia col 4. onditum, v t fciat quomodo vnicuiq; eum Ephef.s. eat refpondere, ac nihilominus tempus re- Rom.is. , vt fibi interdum vacet $\&$ Deo. Infirmita. orum portare, $\&$ non fibi placere, \& præatum in aliquo delicto fi fpiritualis eft, in Galat. 6. lenitatis inftruere, omnem hominem iux ftolum, corripere, $\&$ docere, $\approx$ conari, vt coloff.r. eat perfectum in Chrifo Iefu, Hoc ve effirequenter Verbum Dei proponet in fpiri- Hier. 23. virtute conterens petras. Neque valdè lotemporibus impedietur, fciens Paulum in oraffe, \&z prædicaffe in plateis, in tentonauigio, omnern locum Dei verbo non modum iudicabit. Ad pcenitentiam ma.. horiabitur omnes, confeffiones indefefsè ien \& f felerum,neq; multitudine, neq; madıne perter rebitur, fciens Chrifi fanguiropitiatione elle pro peccatis totius mun- i. Iodn. s. Q. di.In Aftor. $2 i_{\text {. }}$ 


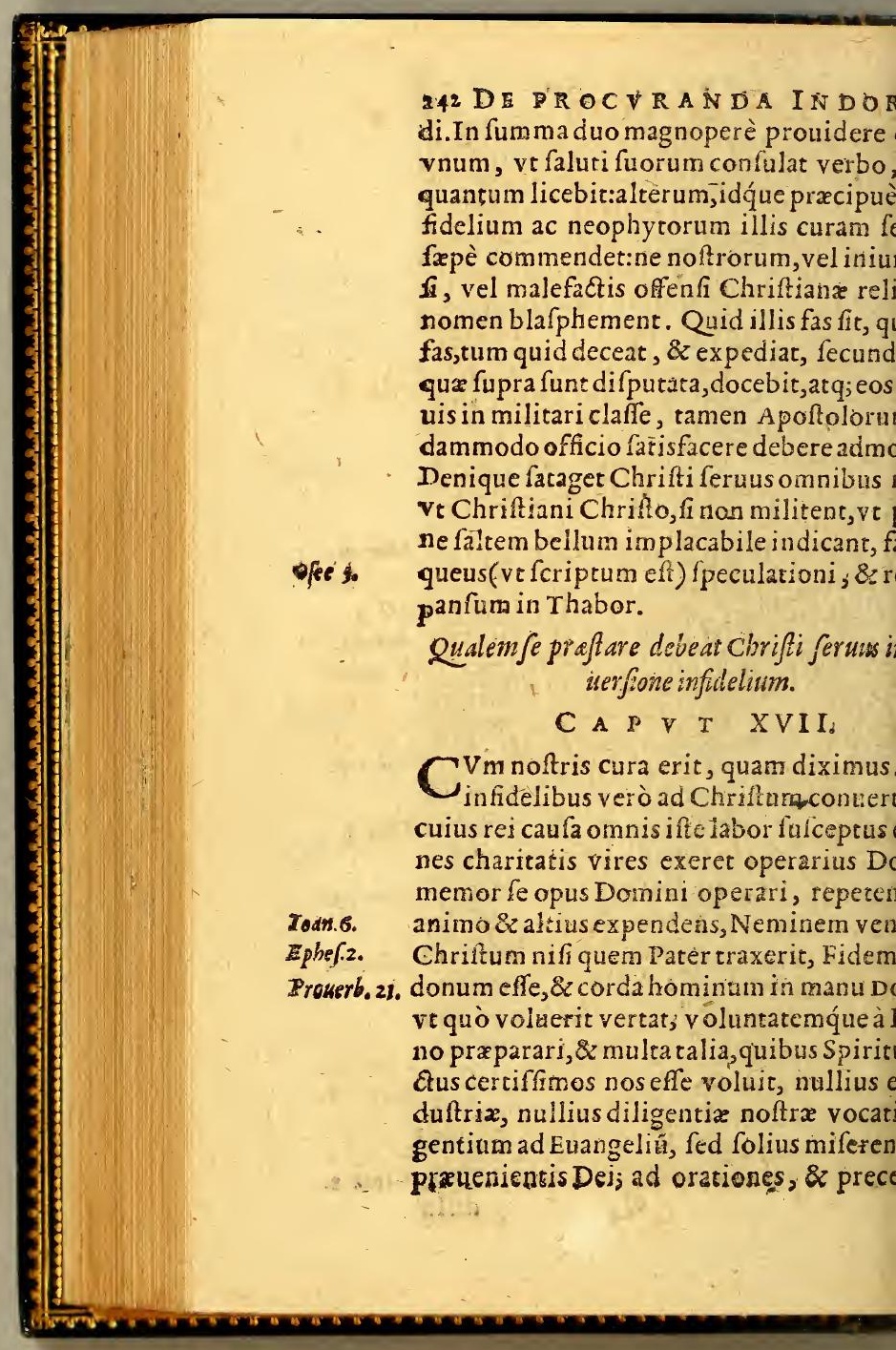




\section{S A L V T E. LI BER I T.}

tque feruentes totum fe conferat, fpem in coeleftigratia collocans, \& diuinæ mi diæ fores diutiffimè pulfans. Et quamuis i negotio orationis prefidio fidendum hac vna re nihil oratione magis necef, nihil omnino potentius: hrc vna impeatiam, cui acceptam oportet referre Fidé: li quidem cùm cætera beneficentix offieablegaffent, Nos, inquiunt, Orarioni, \& Actor, 6. erio Vcrbi inftantes erimus, adeò inter illa cohærere intelligebant. Nunquam \& Ioannes, nunquam Paulus ante precem im fufam, de Chrifto ad populum verba nt. Et reet è Diony fius moner antè omnem Dionyf. de Theologiæ prafertim, orationem praire Diu. nom. re. Auguftinus quoque cùm Ecclefiafiratorem informat, initio fermonis fe, mnia, \& fructum atque exitum oration is ommittere ingenuè admonet: In cuius fumus, \& nos, \& fermones nofri. Ipfe c. 3 . Ang. 4: lib. de Doctirix chrift.c. 1s. sap. 7 . tor Dei, \& hominum Chriftus lefus non pradicandum Apoftolos mittit, quàm tione peruigil pernoctarit. Neque enim tite 6 , ermonis, \& diligentix fux fructum, quàm num expectare debet fidelis Dei minifter. fuis tancùm facrificijs, \& precibus quamiduis, quamuis feruentibus, contentus ei: ebit, led aliorum etiam Chrifi feruouxilia ftudiofifimè effagitare, vi ex mulperfonis facierum gratiz agantur pro eo, 2 Cori. lenfus fratrum fuper omni re, quam petic- Mabib. 15 . in nomine Chrifti, obtineat apud Patrem cordiarum. Paulus tantorum apud Deum 2. Thef 3 . orun vir per onnes epiftolas profeorari
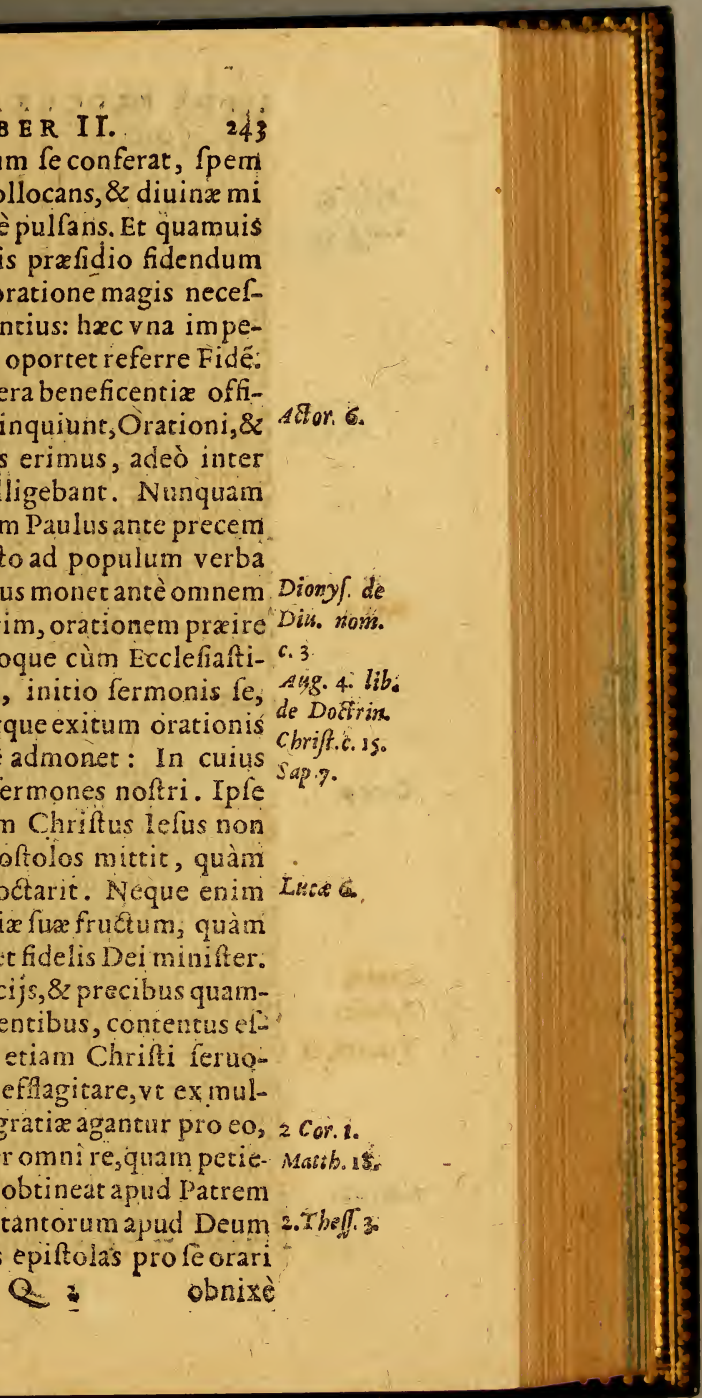


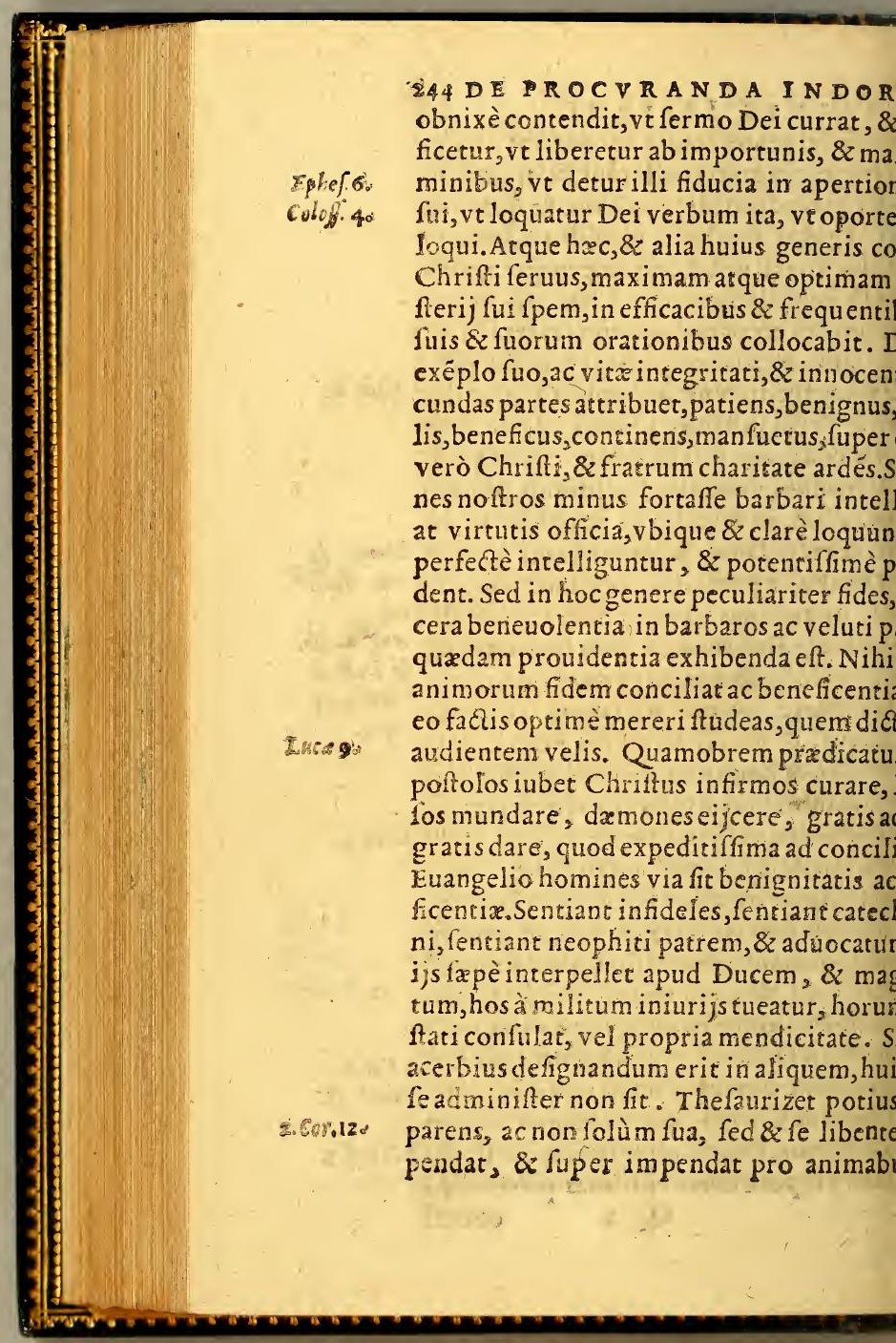


SA IVTE. I IBER II. 445 licet plus diligens minus ipfe diligatur., datum requirat, fed fructum. Dici non po àm fit ad perfuadendum efficàx charitas, era digna A poftolo.Vbi tamen (ne \& hoc philig. ' eamus) fic dilectionem impendere norit, tamen non improuidè committat alienis: d quibufdam contigit noftris, dum plus indulget infidis, temeritatis fuze poenas Tihil mutabilius barbarorŭ ingenio. Pauftolo naufraganti exhibent non modicam Ator.28. titatem pyra accenfa, eunden à vi pera ap$\mathrm{m}$, homicidam reputant, mox nihilà beum, pronuntiant Deum. Huiufmodi barun ingenium eft. Qui heri habebaris pro fummo, hodie indicta caufa interire iuquem paulò ante homicidam 2 extremo cio dignum ducebant, mox, fi ita restuleorabunt pro Deo. Itaque prudens ac fideSeruus, $8 z$ illis confulet quantum poterit, dihilominus non erit negligens. Iam terrtes in miniftro Euangelij, Verbum Dei ndicabit, qua vna in re vehementer, 8 inèlaborandum erit. Primùm, vt fermonis copia fit, vel per interpretem fidum, vel ipfum, fi confequi potuerit. Quocirca non neque ardua, fed pauca eademq́ue frpius :ndo elementa fermonum Dei tanquan. sedocebit: \& M. Francifci induftriam fe, fermone vernaculo atque ipfis familiaifteria fidei pracipua $8 z$ vitx Chriftianze as repetet: illorum fabulas ac nugas facifutabit: exemplis vetur atque fimilibus, fieri poffit, ipfis accommodatis: interronibus vrgebit non infuauiter. Si depreQ 3 hendat

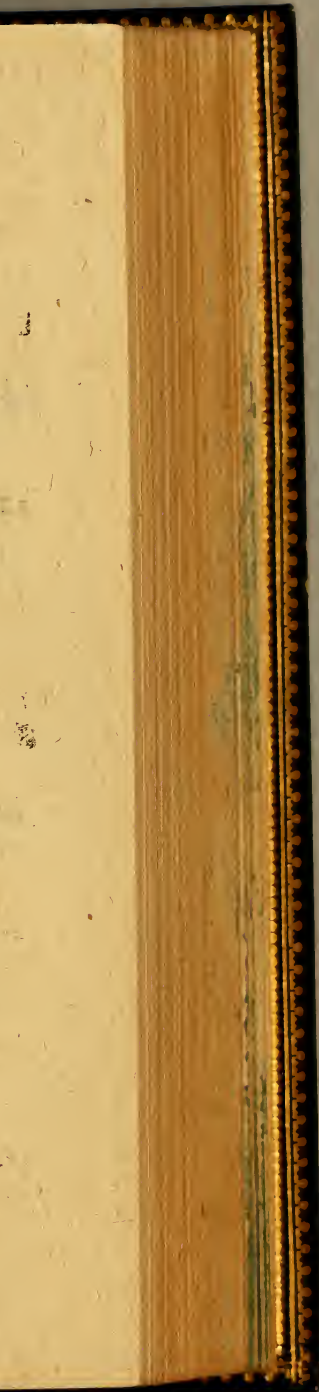




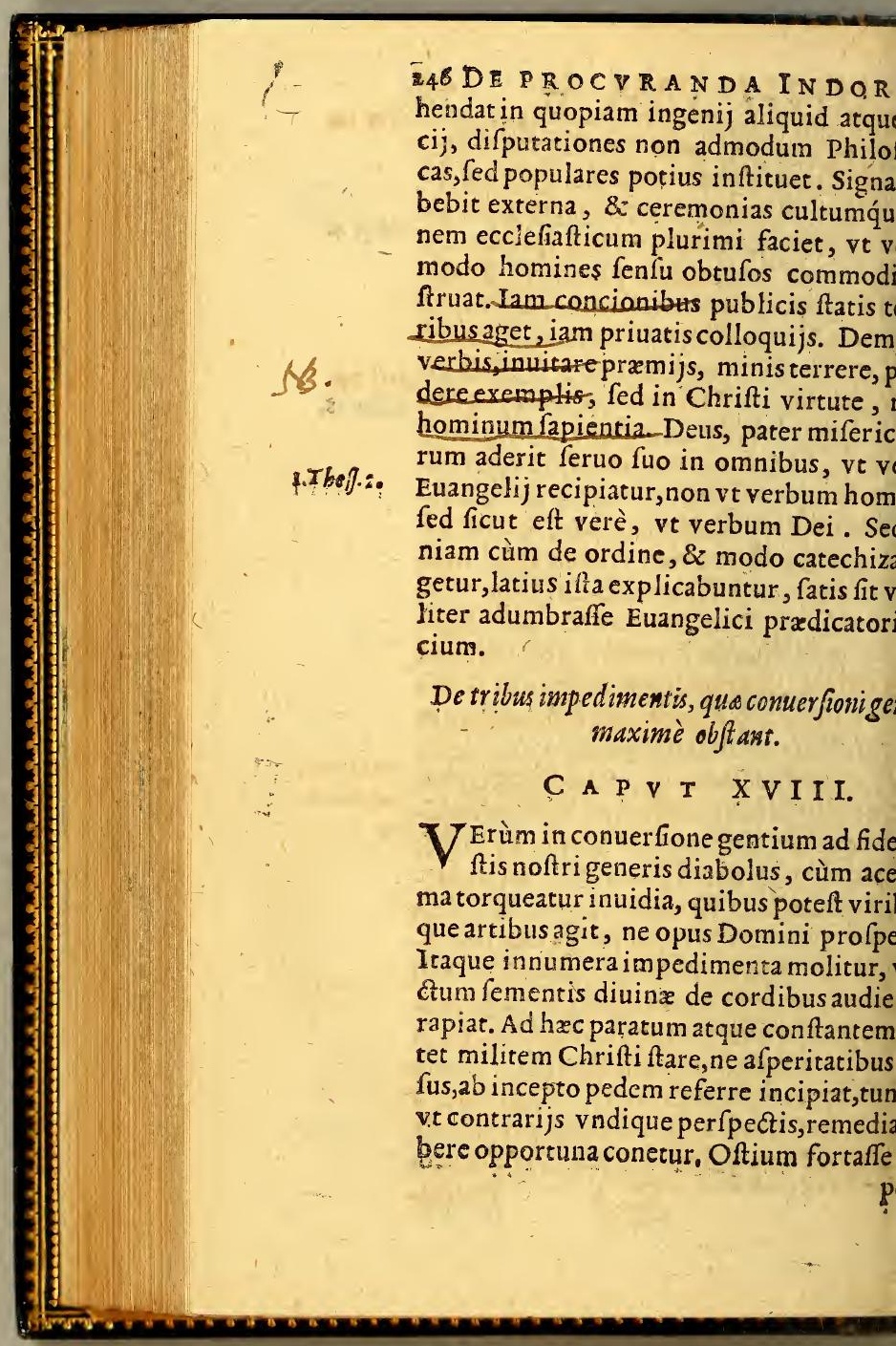


S A I T E. ITBER. IT.

in \& euidens, led tamen aduerfarij mul- s.Cor. 10 quanquam funt impedimenta verbi Dei a,tria tamen præcipua funt: quorum vnoftris, alterum ab externis, tertium ab et, quibus Fides annuntiatur, proficifcinoftris quidem, folent plurimum Indoeram conuerfionem retardare peffimi exmores. Vnus autem ædificans, \& alter de$s$, quid proficit eis nifi labor? Nullam re gograuiorem difficultatem fentio in hac propterea quòd cùm barbari religionis ignari fint,omnes nos fimiles ac veluti voloris reputant. Ita crimen huius atque ilomnium redundat infamiam, \& quod elt is ipfum Chriftianum nomen apud infiin odium venit. Huic malo quid poteft afemedij,nifi vt noftrorum hominum licenibus modis poffit, franerur, neq; vfque ad as infidelium animas fruire finatur? Deinud multum à $\mathrm{B}$.Auguitino commendatu $\mathrm{m}$ echizandis rudibus dacumentum accurat tur, vt admoneantur $i j$, quiFidem fufcipere $t$, ne religionem noftram ex noftris homimetiantur, fed ex ipfius potius aquitate, ctitate. In noftris fi quem viderint mode\& probum,eum fecundùm legem, \& Fidem erere, quos verò arrogantes, aularos, obfcrmmites notarint, hos nobis quoq; odio effe adeant, ac iuxta legem noftram multo granas fuorum fcelerum poenas daturos. In om nere hominum bonos effe \& malos : neque ftum cogere quemquam vi, fed in future vel prxmia, vel fupplicia cuiq; promeritis uare. Ad hæc quantum licebit, vt à talium

$$
\text { Q } 4 \text { confue- }
$$




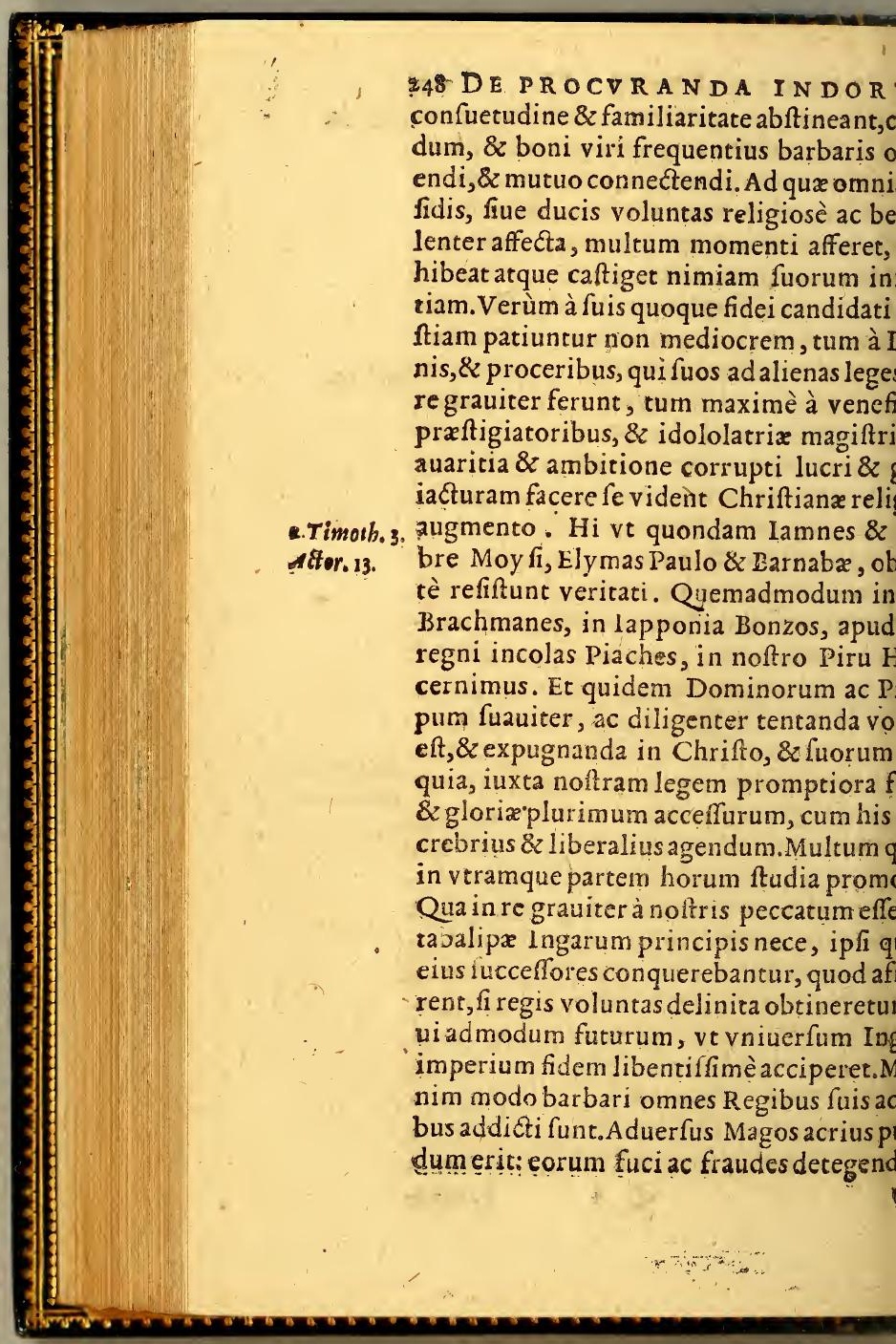


SA LV TE. LIBER II. : \$4 cenda infipientia, \& ridenda deliramenta, futandæ verfutiæ. Q ood fi refipifcere nuldo velint, \& facultas non defit, à cæteris andi, \& grauiter interdum mulctandi, moebem reliquam maior turbatio non fequaed his ambobus maius ac difficilius Fidei dimentum ex ipfa inueterata confuetudioficifcitur. Vbique fanè confuetudo magires habet, fed in barbaris longè maximas, e vbi rationis eft minimum, ibi confuetudices profundiffimas agit. In omni natuotio eò diuturnior ac vehementior, quo seft ad vnum determinata. Ita lapidem fur erri, impoffibile: deinde bruta animantia cere, difficile : mox hominem parum mengentem à confuetis retrahere, graue. Proin hac via palxftraomnes fuos fudores, 2s, conatus exercebit copiosè Chrifti difcis.Proderit autem quàm plurimum, ritus, na , \& omnem externum cultum diligenurare. His quippè, \& delectantur, \& detiur homines animales, donec paulatim abtur memoria, \& guftus præteritorum . Quæ fuit Moy fi, vt populum Aegyptijs ritıbus tú, multitudine facrificiorum, \& ceremoum diftineret. Neque enim prius quod fpi- 1 .Cor.ís. ale eft, fed quod animale. Poftea fuperftitiointiquæ monumenta cautè, \& gradatim exuenda curabit, ve idola fua Guacas adoratioque omnes penitus dedifcant, ac pro ijs pias $s$, atque Chriftianas frequentent. Deinde eriores animos puerorum nondum illa fufitione imbutos Chriftiana confuetudo, \&z iplina luauiter occupet, \& paternas nugas
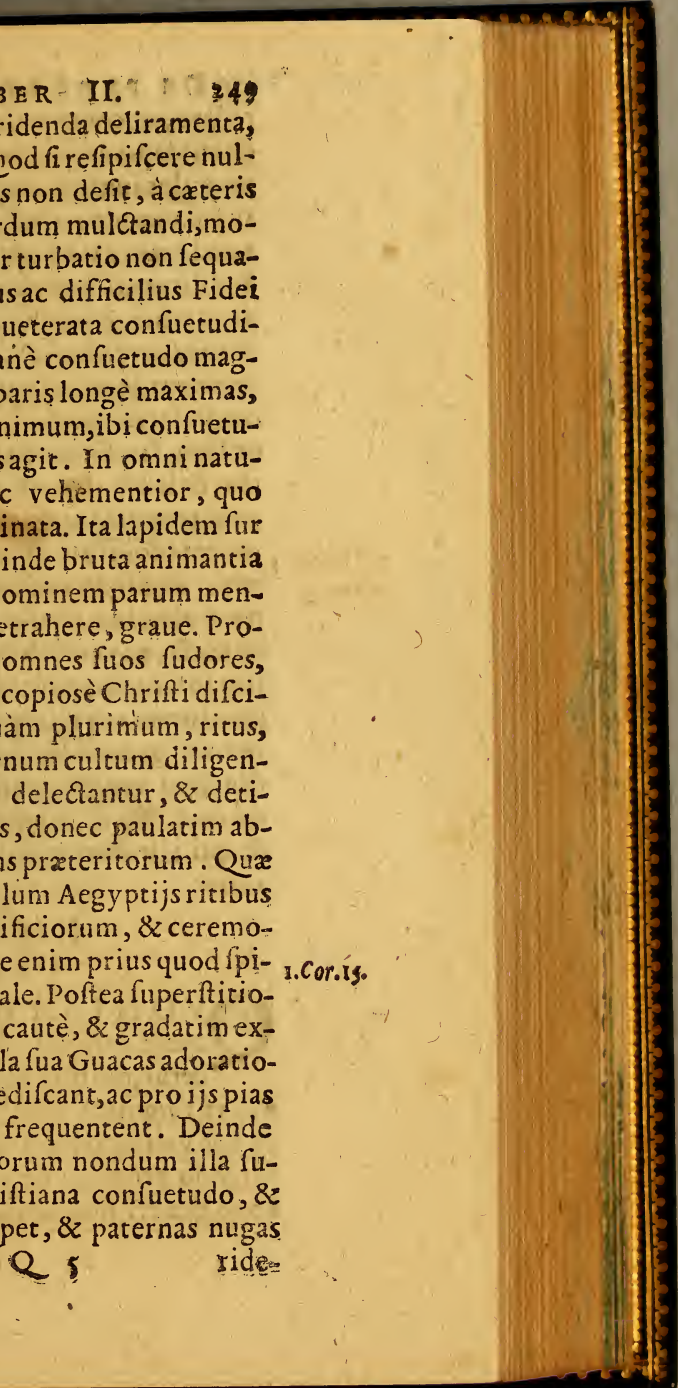


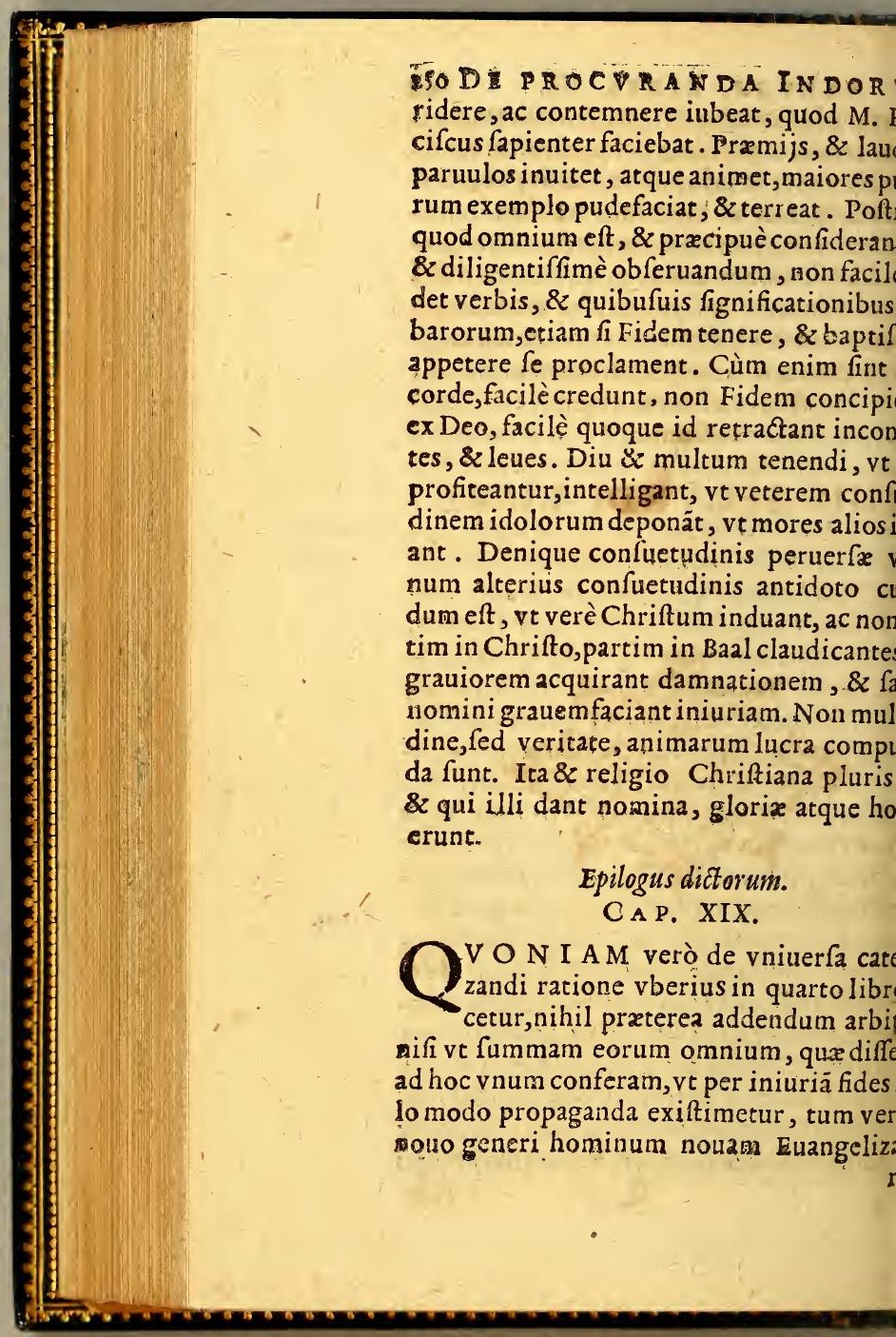


SAIVTE. IIBER II. lem non faftidiat Chrifti feruus: \& quaner rerum \& temporum opportunitates $\mathrm{li}$ inftitutum vetus atque Apoftolicum con$:$ vbi minus id exactè fieri patitur conhominum, intelligat, neque de merito, nelaude, neque verò de fructu aliquid fibi : fi fideliter Dei gloriam quarens atque imarum falutem, labores fuos, \& curas omnes in Euangelij dilatandi ftudio ad finem $v$ fque confumat.

\section{INIS SECVNDI LIBRI.}

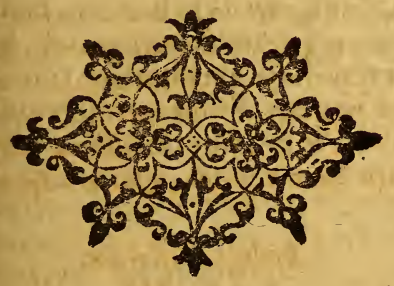




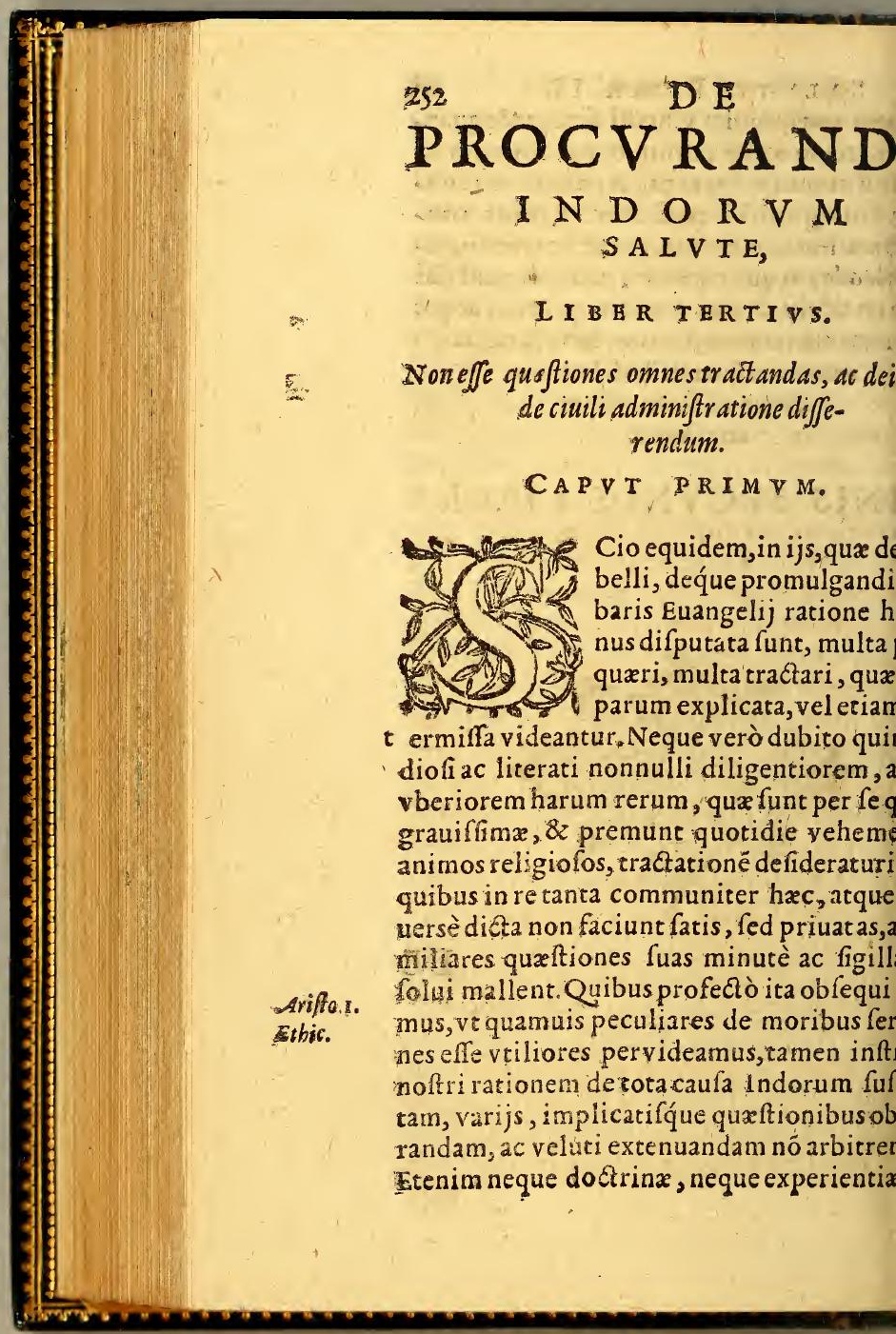


SAIVT I. I I BER III. 259 antü tribuimus, vt explorare liquidò omcerto definire poffimus, que præclariffitiä ingenijs negotiú faceflunt: neq; fi id ocriter praftare poffemus, ad propofitum finem accommodatum effet,quibus illud mè animo eft, ea afferre quæ \& intelligãomnibus, \& quantum fieri poterit, nemin probentur. Nam in tanta fylua,eaq́; ita fa, ac denfa,illud potius optandum effe vi, vt via aliqua ad barbarorum faluté certa, a muniatur:omnes verò latebras exquirênia abftrufa luftrandi, omnia deniq; im3,atq; implicata perpurgandi onus tantú nobis xquus imponet. Quamobrem \& in de rebus Indicis adminiftrandis dicta actenus, $\&$ in ijs, qux deinceps plura dir, præcipuas quidem res, ac veluti capita, um Chrifti Iefu dono licer, explicare, \& mare fatis putamus: tenuiora verò cętera, llarum veluti radicum, vel fibras, vel gervalde illa quidem alioqui neceffaria, perhoc loco minimè fufcipimus. Igitur Euãadbarbaros profectione, \& ingreffu fupebus libris declarato, quid illis pręftandum i diuinitus tacti verbo veritatis manus $\&$ in ouileChrifti intrare volunt, deinceps actandum reftat. $\mathrm{Hi}$ verò tánquam in Chri niti infantes multa cura, diligétiaq́); egent emadmodum Regij pueri tum pxdagogo di traduntur,tum magif ro erudiendijita ciuilium magiftratuum adminiftratione ti regédi sút, vt in officio difciplinaq́; tene, \& prẹceptorum I piritualiü, id eft Jacer$m$ doctrina accuratè imbuendi. Itaque de 


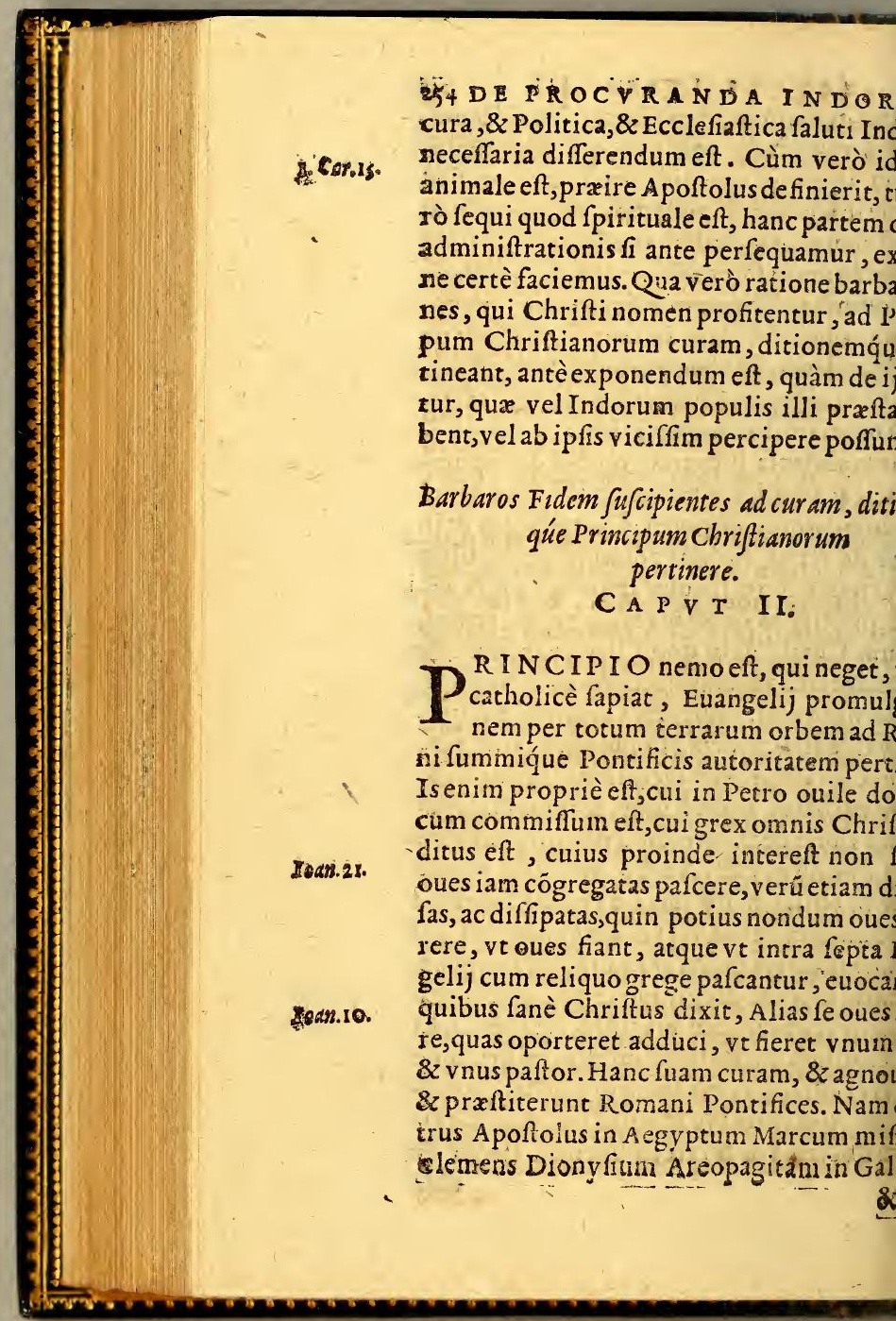


उALVTE. LIBER III. 25Y gorius Auguftinum fociofớ; eius in Angli jregorius item fecundus Bonifacium in aniám, Hifpaniam quoque, \& Africam :erdotes à Romana fedé deftinatos Chriecepiffe hiftoria veteres tradunt, atque etdi Euangelicis expeditionibusad expug$m$ Chriftoque fubijciendum terrarum I factis per fummos Reip. Chriftianæ imres, id eft A poftolicx fedis antiftites, pleomnis antiquitatis hiftoria.Et nomen ipsü olicum valde confentit. Neque enim ob id Apoftolicam Romanam fedem vocari quòd Apoftòlorum fuerit, nam fuit \& ina, \& H:erofolymitana, \& aliz non pauerùm etiam quia Apoftolorum munus hrifto legatione fungendi, \& vfque ad nos terre, illius Fidem immobili firmitaificandi propriè ac præcipuè in Romano fice perfeuerat. Hoc cùm ita fit, quis dubiin fanctiffimi Patres, cùm ipfis per fe orbire non liceat,eam curam alijs demanda offint, \& debeant ? neque vit eant folùm; deftinent ip fi ac mittant, quos idoneos iunt. Id ergo negotij in noui orbis gentibus dis, \& infinitis, \& difficillimis Romani fices Catholicis Hifpaniarum Regibus de ¿vt tanquam proprium, ac peculiare mu'nofcerêt, \& curarent. Cùm enim claffibus adeò crebris, \& magnis, apparatu quoque nptu ingenti opus fit propter immenfam ni nauigationem, 8 terrarum regiones ple ue incommodas, \& egentes, non potuit v 1 ido nifi Regiæ potentiæ res tãta committi. erò Hifpaniz Regibus potius aut folis, ff
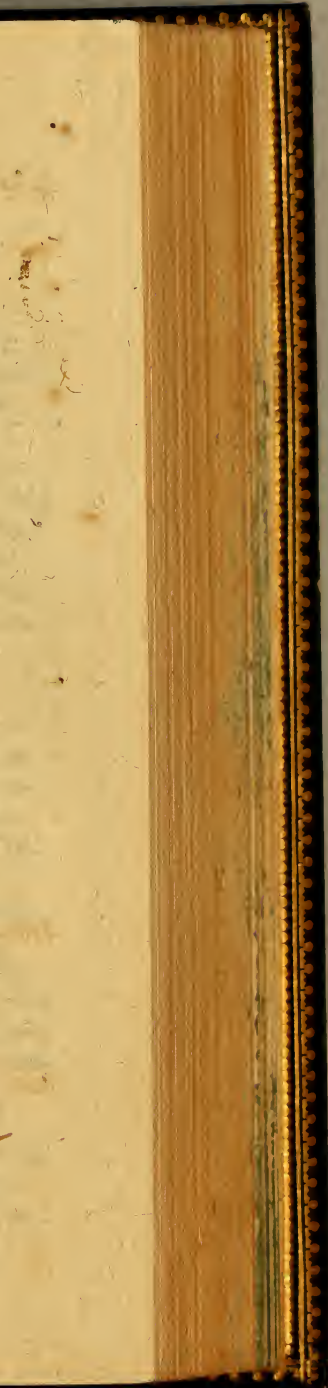


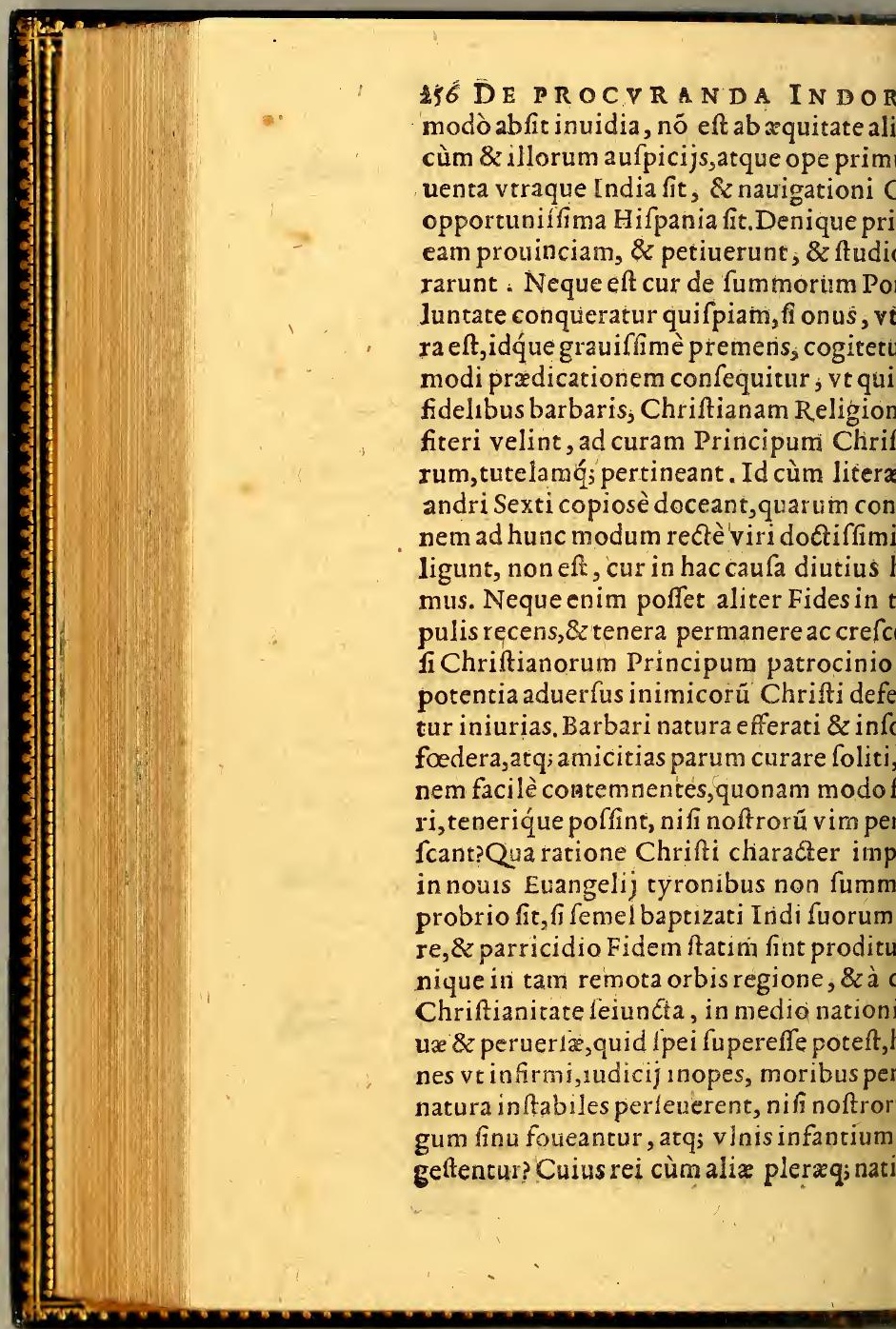


A I V T E. L I B ER III. $25 \%$ aximè Aethiopicx, Angolx , \& Maniconimonium abundè dant, in quibus lauacrú ti fufceptum maiorum perfidia \& temerinominiosè foedarum eft, curfus Euangeuptus, faluti hominum aditus omnis oc; quif fim noftrorum fentirent, non in onem léfu Chrifti tam perniciosè fauirēt. ffimè omnino fentiunt fummi Theologi Th.2.2.q. enes Ecclefiam integram, abfolutamq́ue ${ }^{\text {0.ar.8. ibs }}$ tem Fidem ab hottium iniurijs, \& 2 con- dem Caiet. Dur.2.d. lijs tuendi, eaque nifi grauiora exinde malequantur, aduerfus confilia \& vim peff $-44.9 .3 . a r$. $2 . \mathrm{Vict}$. Re-li m effe vtendum. Itaque fi expedire cenfe- ledt.de Inteft fine vlla dubitatione Ecclefia infide- dis. Sotus ges, aut Dominos de Fidelium dominatu, 4dift. sq. ione deijcere, eamq́ue ad Fidei defenfio- vmi ar.10. ommittere Chriftianis. Ac ne nouialiquid e videamur, prater concordem, vt dixi, ntiam; vetus fanè ef Apoftoli Pauli pra- i. cor 7. $\mathrm{m}$, in caufa matrimonij finfidelis coniux lnno.3.ca. fraudi \& impedinéto êre coperit, liberü ouanto o delem ab eiufmodi feruitute. Et certè con- c.Gaude retius ac magis naturale vinculum effe có- mus. de Di,quàm cuiufuis fubiectionis, \& feruitutis, norijs. f periculo Fidei etiam difroluto coninga- cóc.Tol.4. culo pro data fibi à Domino poteftate, ocndum putar Ecclefia, quid mirument, fi in $\sigma 2 . R e f e r-$ $n$ Fidei caufa fubditum, feruumuè Fidelem tur 28 q. 1.e. fidelis Domini feruitute liberet? Adde Iudai eor c. (dape malo. idem gentium Doctor caufas, difceptatio- rum. Fidelium non vult ad ethnicos magiftra- 1 cor. 6. eferri, fed ipfos fibilegere, qui ius dicant, Gelaf.d.54. terea quod Fidei iniuriam ab impijs perti- c. Generaebat. Quinetiam re ipfa Iudxos omnes a clis.D.Gre. R

Sarace-

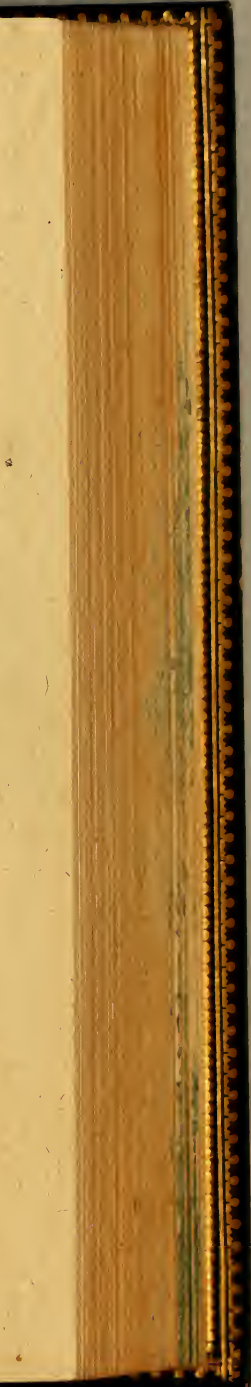




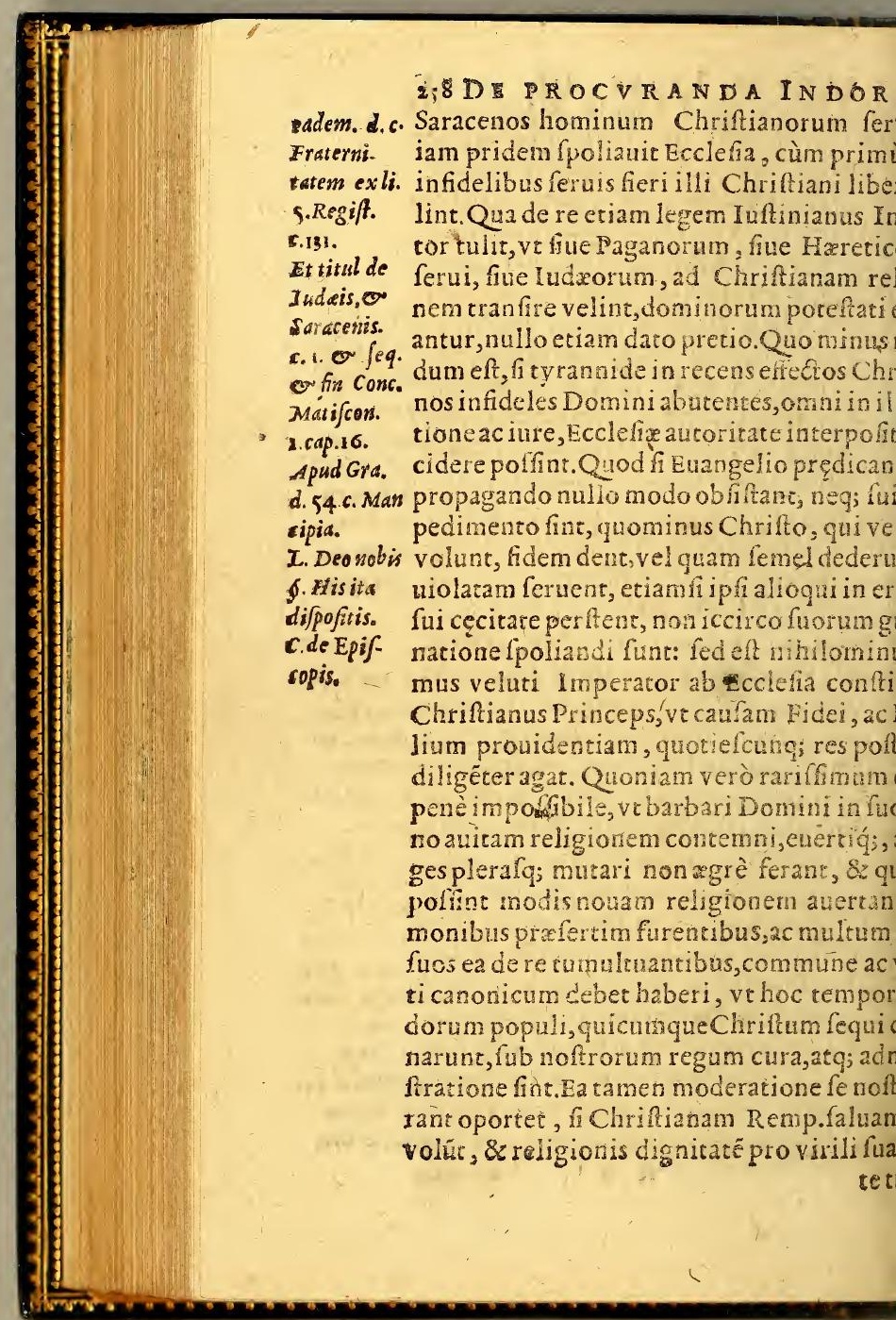


eri, ve ney; ferro, nifi extremum difcrimen ar,agatur in barbaros, neque de commodius ac dominatu fuo pellantur, nifi quatenus ij Fidei, \& fuis perniciofi deprehendantur, grauius quicquam defignetur, quo Chrifti gelium lædi, perturbariuè polfit. Denique nofcat religiofus Princeps poteftatem fibi rifto ad $x$ dificationem, non item ad deftrulem datam. Et quamuis Chriftiani prin2. cor.tis Domini fint, parentes fe tamen prabeant, tam qux Indorum funt fibi, quam Indos ipmnium Domino quarere videantur.

$n$ oporter e falfos titulos comminifci dominationis Indorum.

\section{CAP. III:}

$\mathrm{C}$ igitur ius adminiftrationis, ac fubie:tionis Indorum ex propria ac certa Eccle. ommiffone generale en , \& commune tum ui hactenus explorati funt, tum ijs,qui pro." nte tempore occurrent. Quod quidem nifi dè perturbetur iniuria, xquum ac falutare conftat. Alios verò titulos, quos afferre quinituncur,Regix porentix, vt mihi quidem ntur, affertores non neceffarij, ne affentato: icam, qui nimirum ex tyrannide Ingarú in regno, arq̧; vfurpato per vim imperio, itë Ģ; olycratia gentium plurimarum legitimo e carentium (has Hifpani Behtrias vocant) endunt chriftiano Principi regnandi ius faequidem neque fatis intelligere, neq; certè are poffum. Etenim fi à pradone alterius depradari, \& tibi védicare non potes, quæ$R$ roquid

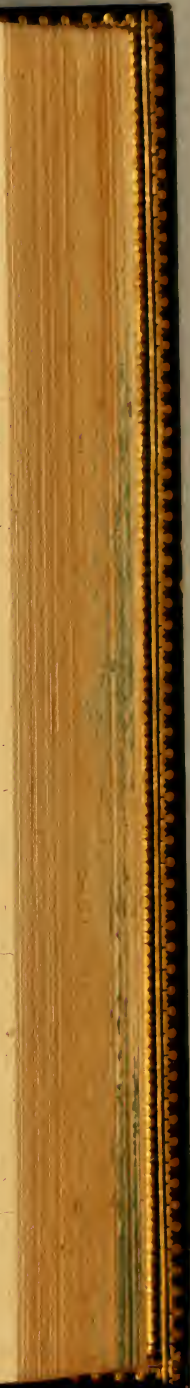




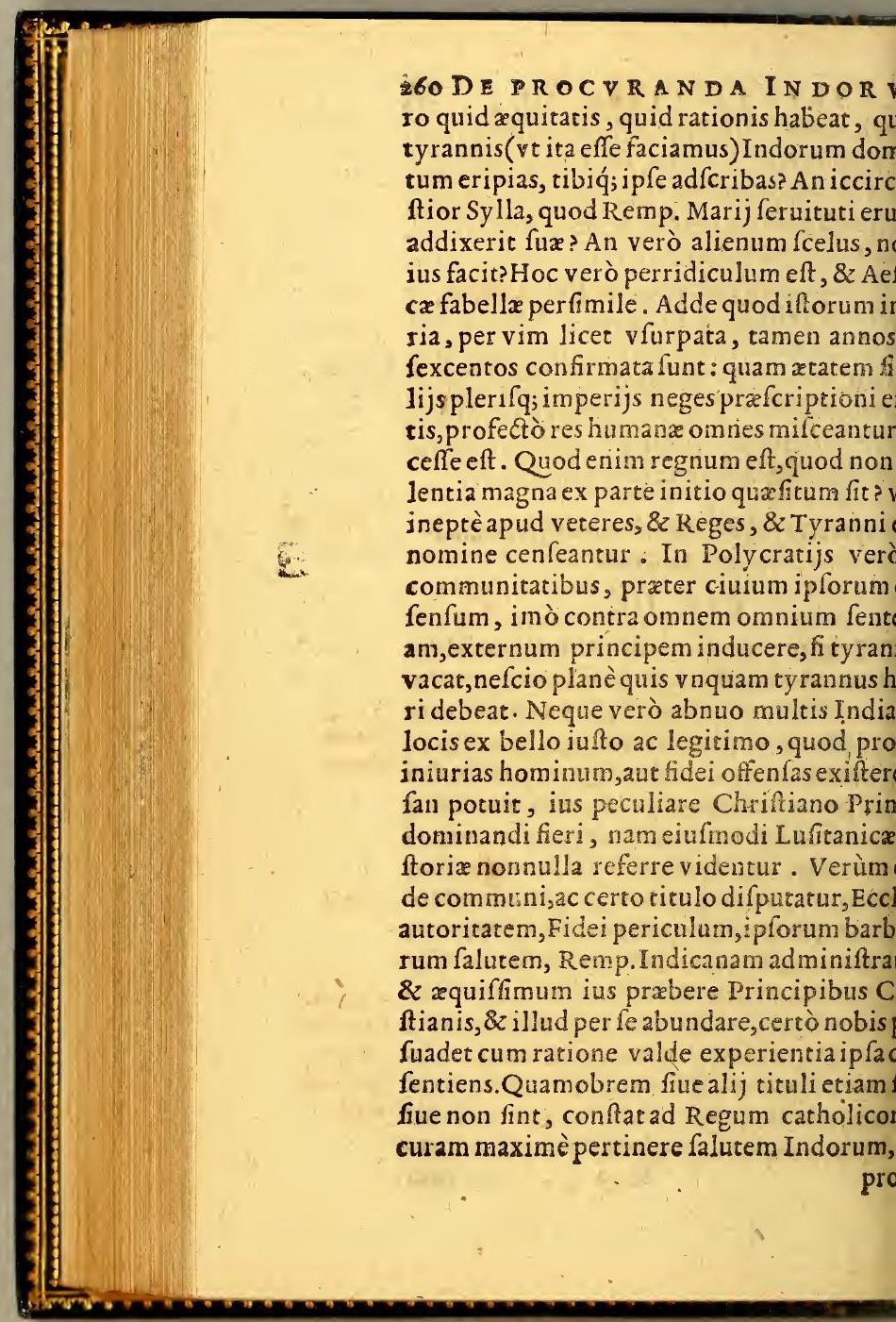


SA L T E. L I BER III. 268 urand $x, \&$ religionis præceptores, \& difciciuilis adminiftros lectiffimos mittant, ter, vt Deo atque Ecclefia iniunct o fibi muperfungentes, vt \& ipfos decet, \& cauґa tanigit, fatisfaciant.

uales adminiftratores res Indica poftulent.

$$
\text { CAP' T IIII. }
$$

tur quàm refert vniuerfitatis Indorum prętos, ac magiftratus optimos a pud chriftiaancifci, quantumue ponderis in vtramque in vel falutis, vel exiti) cuuilis adminiftraabeat, quouis etiä tacente, res per fe ipfa det.Nam cú in omni-Repub.Magiftratus perfit, atque prdagogus quidam, vt eft ab AmIn Epift. ad Rom.5.1. o prrclarè dictum, atque iufti \& æxqui cuimmortalis, facilè quisuis intelliget, ita ad efrafticam, ac fpiritualem infticutionem paratam effe ciuilem \& humanam, quemadum ad Chrifti Euangelicam legem,naturaris difciplina neceffaria eft, quippe nifi hac it obferuata, vt ait beatus ille, illa cuftodiri Rom.13. poffit. Quamobrem Paulus docet non effe ftatem nifi à Deo, eafque quotquot funt, à ordinatas effe adminiftras boni, mali vleriQuibus confentaneum eft illud Petri, qui \& 2 1.Pet.z. ibus, \& Regum ducibus obediédum monet; dbonis laudi, improbisterrori eorum offifit. Ergo fi funt hæc capita populorum, fi amos 6. ores, fi duces, gubernatores, aurigæ, tume- Hiere.23. lumina, fpecula, leges viua, \& quibufcum-1.Reg.9. alijs nominibus tum dinina tum philolo- Ezech.27. cx literæ ornandos ducunt, quis fatis dicere Arift. at,quantum in horum integritate, $\&$ fide prę

$$
R 3 \text { fidij, }
$$




\section{DE PROCVRANDA INDOR.}

qecl ro. fidijac falutis Reip. fitum fit? Qualis eni Etor eft ciuitatis, tales inhabitantes in ea, 8 dum iudicem populi, fic \& miniftri eius. $C$ totum locum ab omnibus penè Reip. legur tractatoribus externis copiosè grauiterq́ue fatum, à noftris Ecclefraficis, facris, \&ze: plis, \& documentis difertiffimè illuftra quanquam diucius proferre non opus eft, ta iuuat infignem Bafilij ea de re accumulare

Orat.20. tentiam. Neceffe elt, inquit, huiufcemodi mandare magiftratus, ac eosaliorum conft re duces, qui cxteros omnes prudentia, con tia, ac vitæ fanctimonia longè anteeant, vt tes, quibus praditi funt, communes fiant ec omnium, qui eos imitấtur. Nam ad mores qui gubernacula tenent, componere fe tot qui parent, folent, ita vt quales duces fuerin les efle necefre fir eos omnes, qui fequuntu quales fuerine in Republica principes, tal plurimum exiftere folent reliqui ciues. Arc quidem Magiftratum, atque potentiam op atq; apciffimo cuique demandandi cura in 0 Repub.in omni Principe debet effe vel max at in nou huius orbis adminiftratione, in $b$ rorum nationibus, \& fubigendis \& contine in Fide, quifquis rerum Indicarum vel ten experiens fit, nullo modo dubitabit eam, $n$ primam, neque maximam effe debere, fed o no ac penitus fingularem. Etenim à præfect ducibus, à iudicibus, à regize deniq; maie adminifris, perinde, atque à fonte fluuium res omnes Indicas, velperniciè, vel faluten fi quid alind certium eft, deriuari, ac perma perfpicuma cit. Neque dici poteft, eo font 

quàm latè lues influat, qua mq́ue omne reum refpuat. Ac ne cui fortè videar in fucaufa amplificäda ftudio magis, quàm raduci, afferam non nifi certa, Erexplorata menta, qua vtinam quantum habeant pon\& ipfe exponere pofsim, $8 \mathrm{ij}$, quorum int, velint attendere. Primû in alijs Rebufp. ditatibus ex multa antiquitate fundatis, $8 z$ itutis, habent moderatores adiumenta plu eademq́; maxima, quibus etiă volentes non tur errare.Sunt leges publica v tiles, eft paconfuetudo, funt exempla inaiorum, eft deequidam rerum veluticurfus ipfa antiquifirmatus, quo in otio \& negotio facilèac quillè ciuitatis fatus per fe pene confifit, ertè fi deffectat paululum, modica rectoris one dirigıtur, ficut in tráquillo ac tuto maaum tenenti viu venit. At in Indicanaguatione, cum prafertim noua regna adeuntque habitancur à noftris, omnino eft fecus. nia noua, nullx confuetudines certæ, leges q́ue omnia,naturali excepro, nihil propelum firma:auroritas exemplaq́ue fuperiorü porum vel nulla, vel non initanda, euentus ridie inopinati,repentinx plerunque ac peloræ mutationes, municipalia iura tum igata, tum non fatis firma ad iudicandú, Hifpaf́es, $R$ omanxque leges magna ex parte cum arorum diu retentis moribus re pugnantes, us iple Reip.adeò inconftans \& varius, fuiç; inilis, vt qux heri commodiffma rectiffi; habebantur, hodic rebus commutatis iniIfina, ac perniciofifima exifant. Hicquis videat qualem moderatorem eiufnodi $R$ ef-

$R$ \& pub: 


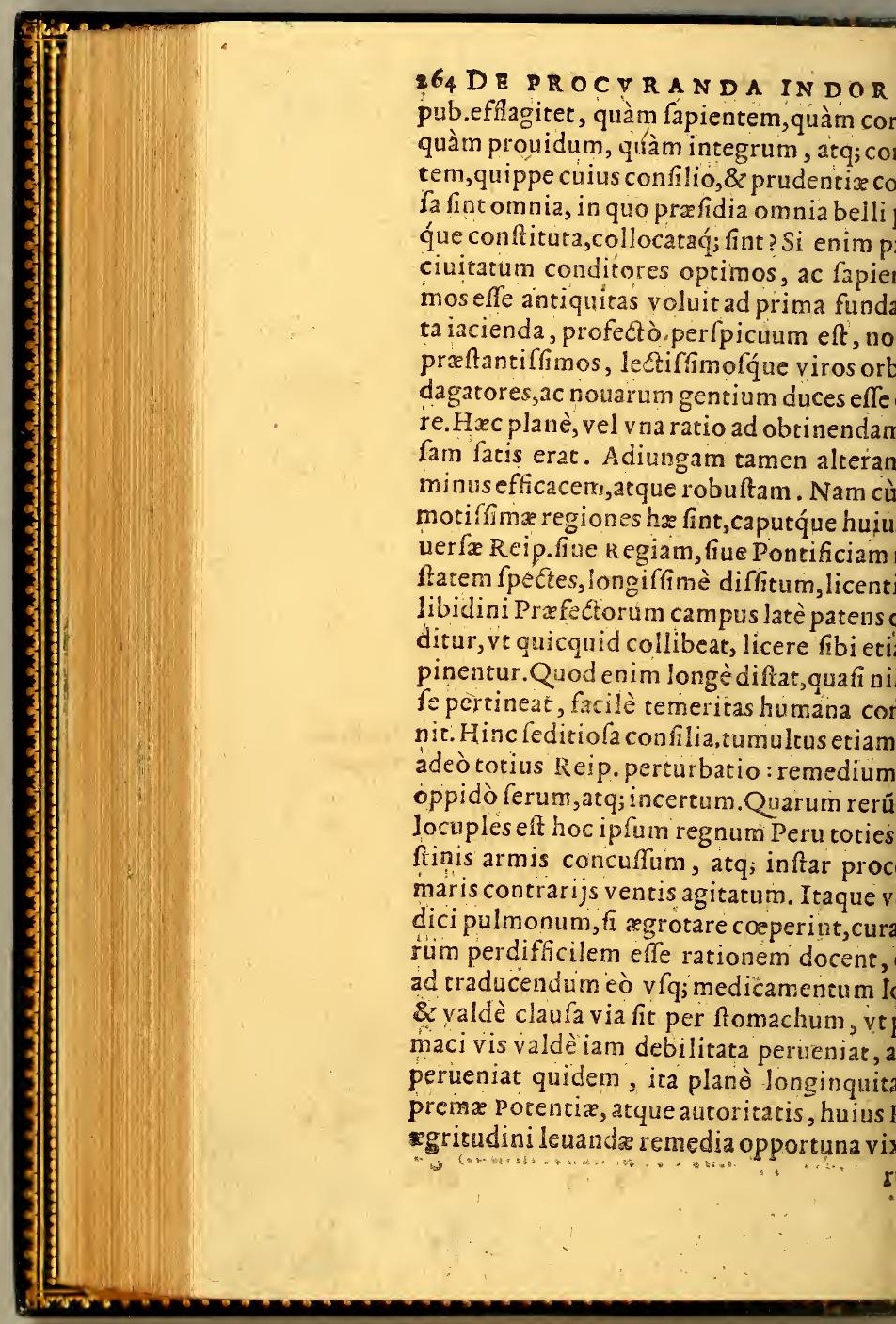


SA L T E. I I BER III. 268 le fperare permittit. Quamobrem quicin rebus Indicis à Præfectis peccabitur, modum dixerim fine emendatione peceaQuod equidem perfpexiffe Romanos mifuadeo, cùm ad remotiffimas quafque pro= as non nifi lectiffimos, atque integerrimos mittendos cenferent, aliquando quoque, $\boldsymbol{i}$ ftulare videretur, ipfi Confules Reip. lunon cunctanter proficifcerentur, quippe regiè noffent, quos animos faceret temedilata vindicta, vtq́; foleat à reliquo greunctus vel ipfe bos efferari.Poftremò fi hęe non effent, illud non paruum exiftimari quod vel leuia peccata gubernatorum, \&2 rum in rebus Indorum ingentia crimina i debent, propterea quod teneros adhuc im animos vehementer fauciant, \& à Chrireligione perniciofiffimè ăuocát. Etenim blicorum Magiftratuum culpæ abfcondi offunt, quia ve Tragicus dixit, ilucet omne Regia vitium domus: irmi adhuc, $8 z$ rudes Indorum fenfus nullo Thyefte. de Chriftiana gente, deque Chrifto ipfo aiudicare norunt, quàm ex his, qux perfpiin nofris fublimibus præfertim, atque autate eminentibus. Quæ res quanti fiat apud ffimum hominum conditorem, atque pa, inde facilè intelligres, quod cum lachryc dolori intimo fancti Regis Dauid flagiadmiffum condonaffet libenter, illud tafeueriffimè vindicauit, \& queftus eft, quod icos Domini nomen blafphemare feciffet, inter fe reputarent, Deum eius regis ami- 2. Reg. Ite habitum, qui tanta perpetraffet, quod ad di-

$$
\text { R. } 5 \text { uinx }
$$

\section{Sereca iv}




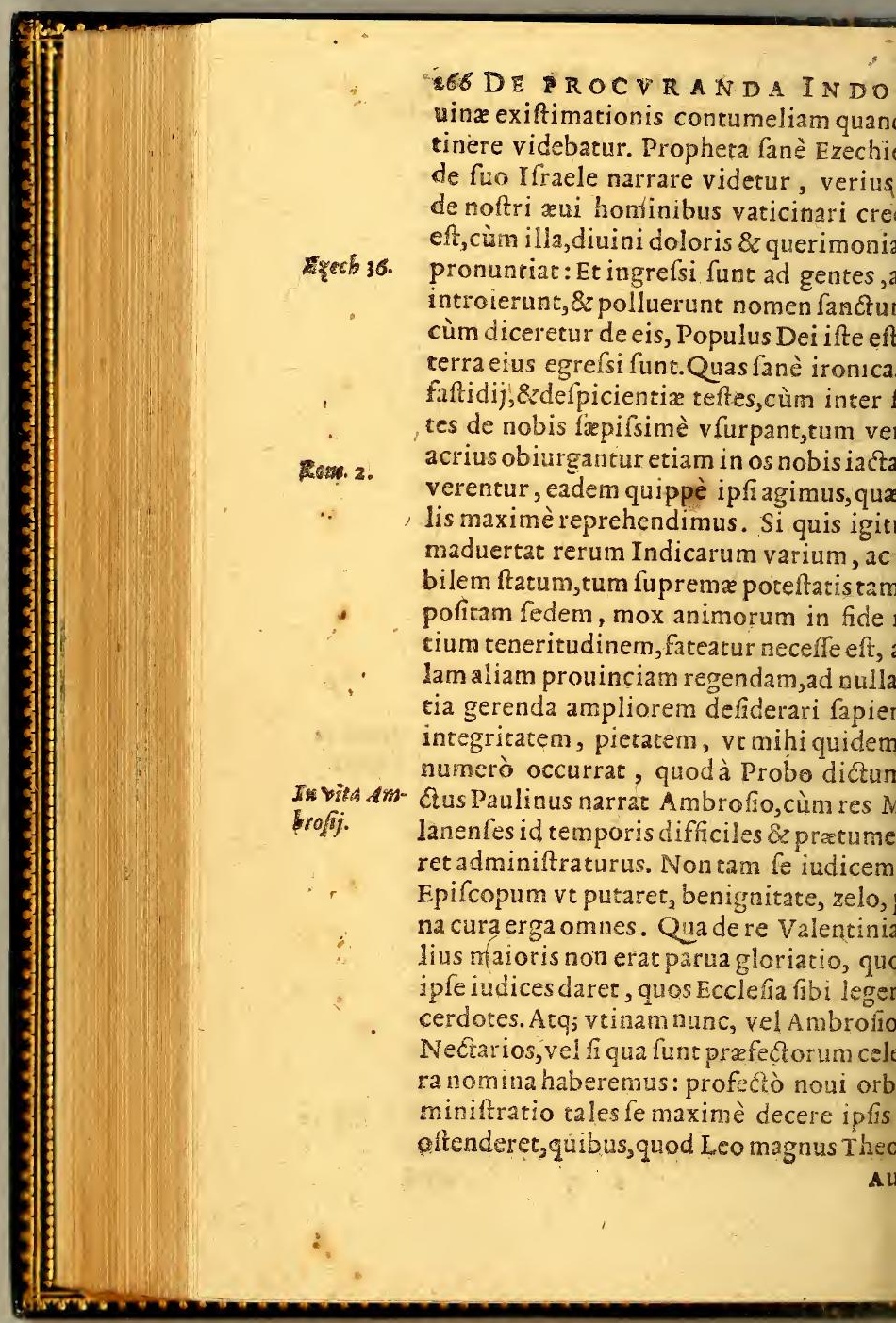




\section{SALVTE. IIEER IIT: - 267}

ogratulabatur, non folùm regius animus, Epiff. am facerdoralis ineffet. ob caufam difficile inueniantur idonei re: bus Indicis prafecti.

\section{A P. V.}

igitur duces, hos magiftratus res Indica fulant, neque vlla argumenta, quanquam illa quidé fatis, tanti facienda funt, quanlongi temporis experientia. Quam caum difertèageret vir quidam clariffimus, regios miniftros princeps, colligebat m fidem, prudentiam, animi magnitudiagis requiri, tum verò adiungebat aptifcùm tales miniftros efflagitent res, qui es ad hæc venimus? vt potius exonerand $x$ niæ caufa quàm huius reipublicę capeffenffi effe videamur. Quotum enim quemque ies, cui fi in Hifpania magiftratu potiri, $\mathbf{f i}$ tura licuiffet, Oceanum traiecturus fuifque hæc in extremo orbe quxfiturus? Ita ribus rebus exclufi ad hæc veluti extrema rtimur. Mihi verò hæc prudentiffimi vitio, non tam effe iniuriofa videtur in mulos prouinciæ hæ, \& habuerunt, \& habent intiffimos, Chriftianaqueac fapientisadtrationis laude florentes, quàm commopotius, \& conqueri Indicarum rerum naipa comparatam difficultatem. Etenim penetrandi ad Indos plerifque, vt modecamus, familiaris rei anguftix in caufa ac relictam patriam, liberos, charos ombores quoque immen $60 s, \&$ pericula nauinum, irinerum, noui coeli, ea vna cogitatione

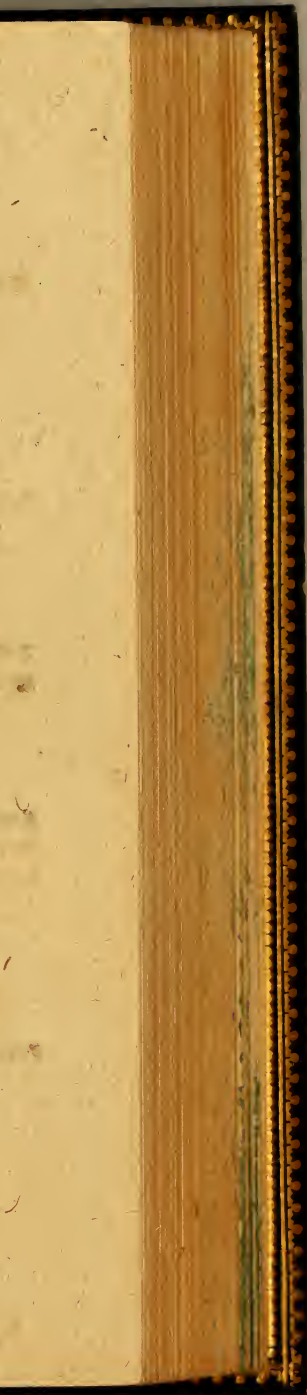




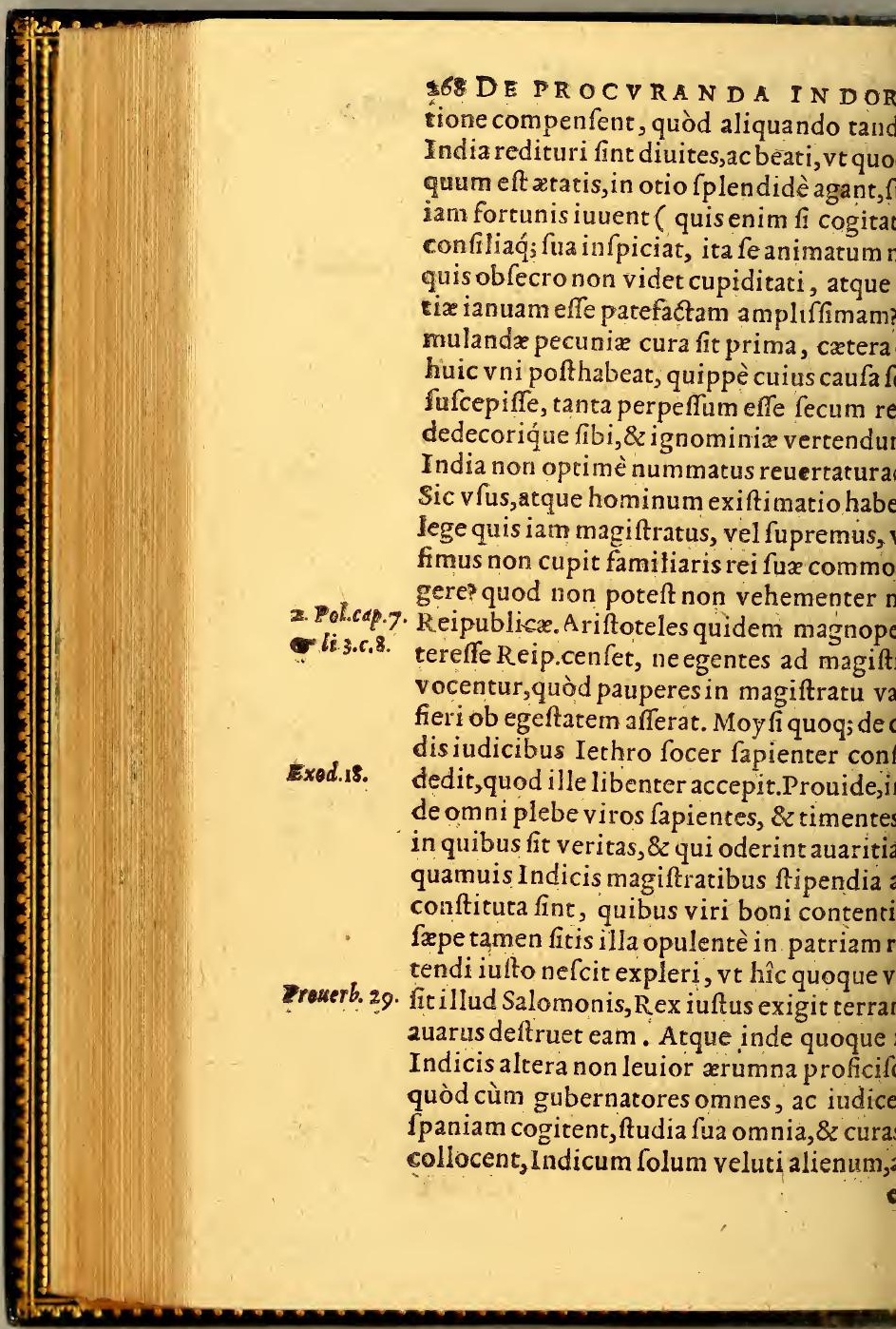




\section{SAIVTE. LIBER III. 2AO}

um habent, ita parum curant, quod nihil quod quantum itatui, atque incrementis - obfiftat, dici non poteft. Inter laudes qui ciuitatem aliquarm adminiftrant, 82 rias dotes, illam primam $P$ hilofophus na ve ftatum prefentem Reipub. ament. At s.Pols.s.n b. hanc ita plerique $a b$ animo fuo alieexilij loco habere videantur : aut certè rècum rebus Indicis agatur, fi quemada militares prefecti vbi caftra ponunt, in oris, quod eo in loco fe acturos intelliommeatum, cæteraq́; opportuna curant: leuntes diffipata omnia, atque exufta rent, ita noftri homines ad id faltem xtatis, îc exacturi funt, vtcumque res Indicas re velint. Hær func adminiftrationis Indises difficultates. Ad quas accedit quoque igè quidem maior, verùm non ita com, led propria eorum, qui nouas Indorum ideunt, fedibus ibi collocandis intenti, ùm ad barbaros eant, non nifi armorum ijs fulti rebus fe incertis committant, vbi : neri oportebit, vel ferro etiam aperire Itaque totus ifte primus ingreffus militaQuamobrem ei demandari prouincia foi peritia militari excellit, neque ad copias das tam Ducis probitas, quàm militaris I pectari folet. Hic quid occurrat incomfacilè quiuis cogitare poteft. Cùm enim singreffus fidei, prima exordia Euangelij, Chrifti annuntiatio pro ductu ac volunminis, vt parciffimè dicá, militaris tranfifit, illius fententia in omnibus princeps nǵue dux ipfe profanus fit, manus verò $f_{2}$ tellitum

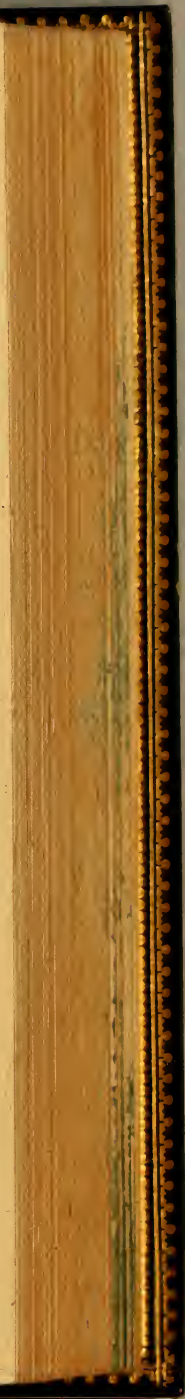




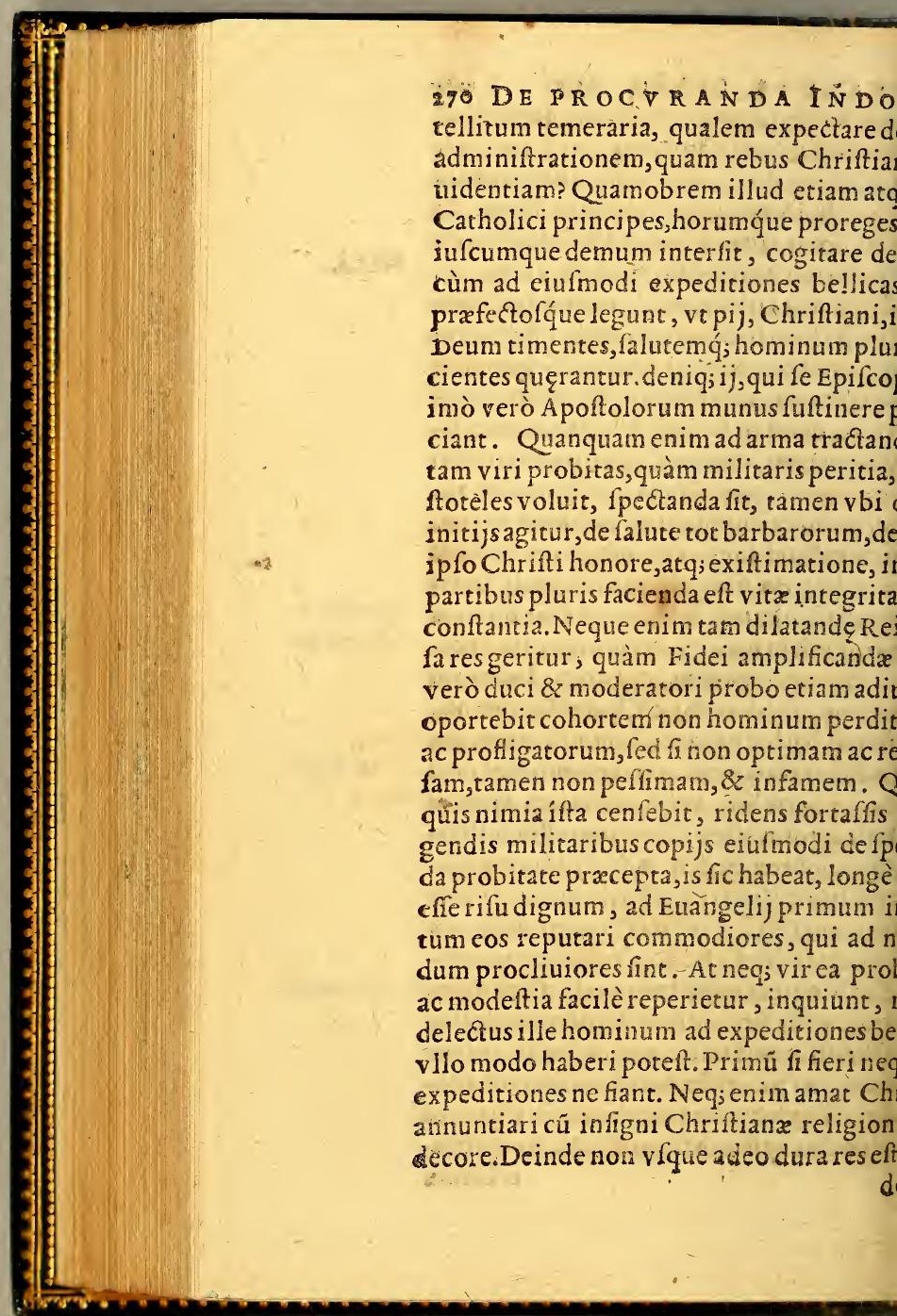



untas ne defit, vt præfectus quifpiam quæon folùm militari laude clarus, verùm, ians pietate commendatus: vtớ; ad illius tum fi non deligantur pij homines, tamen mittantur nefarij. Si enim homines infafordidos imperatoribus militareR omaes non iniuria vetuerút, quid eft cur chriprimo illius ad infideles ingreffu perdiis quifque nomen dare fit permittendus? obrem cùm in omni Magiftratu Indico, rò maximè in prima ad barbaros profeviros idoneos fapientia, \& pietate preftáeficere oportet, magna adhibita diligenales omnino quxrantur, inuentiqúue præ:q; honoribus ad rem pro dignitate gerenernoueantur. Quanquam magna apud gloria copiofaq́; pro meritis res tantæ reatione nihil poteft amplius, ac preftangitari. Affidux autem noftrum omnium ninum preces effe deberent, fi modò tor: um millia amamus, aut alicuius facimus, ofee is. ue det reges in ir a fua, neque propter pecipuli regnare faciat hypocritas, fed mittat. $10 b .34$ Hiser. 3. paftores inxta cor fuum.

effe iniquam triluta Indos pendere adminiflratoribus fisis.

\section{$\begin{array}{lllllll}C & \text { A P } & \text { T } & \mathrm{T} & \mathrm{V} \text { I。 }\end{array}$}

o N I A M adminiftrationem noux Chrianitatis penes noftros princıpes effe iạm us, \& his ex Dei, Ecclefiæq́ue præceptঞ bere, vt faluti Indorum miniftros idoum ad fpiritualia, tum ad ciuilia prabeinde dicendum eft, vtrum ad horum ip- 


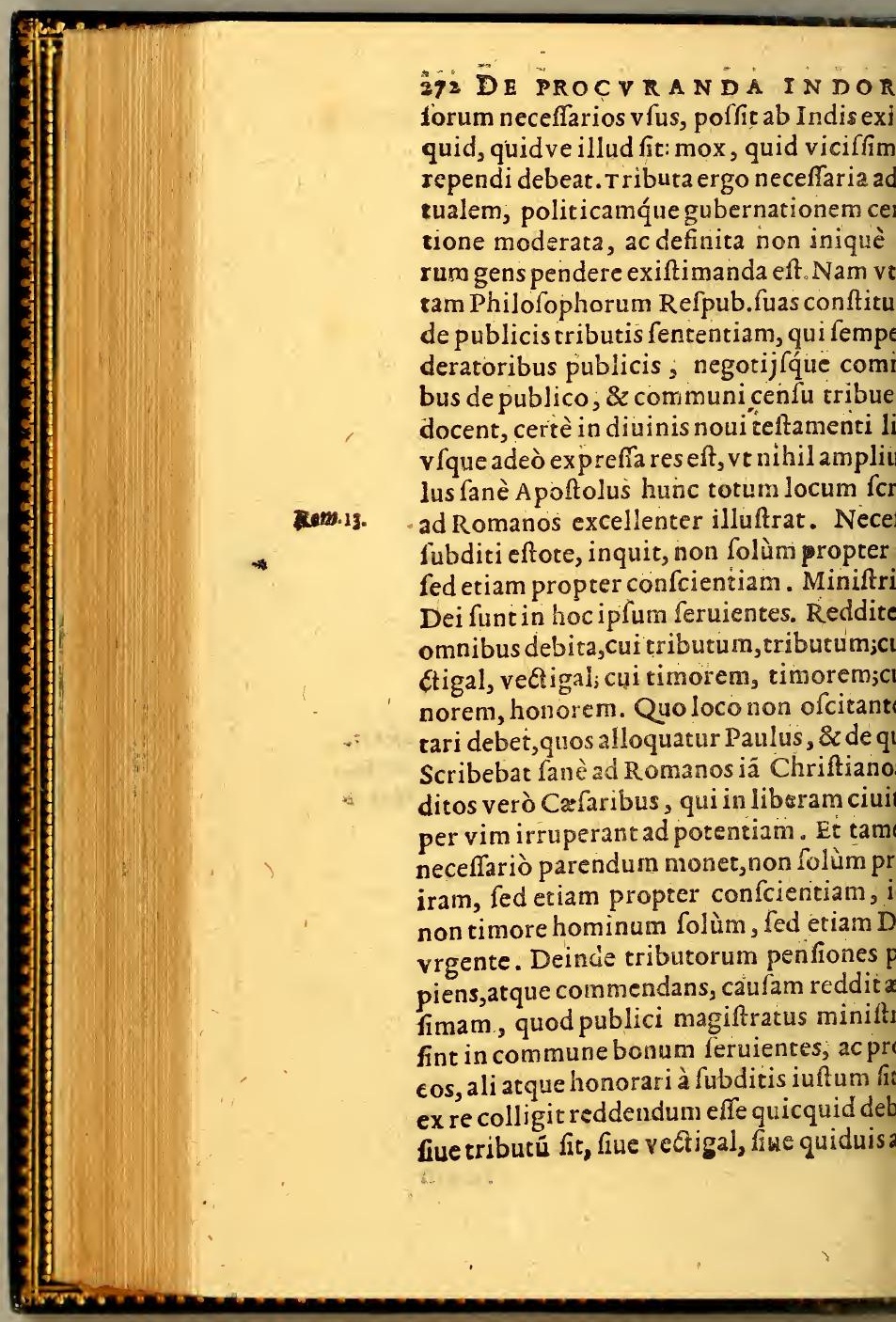




\section{SA L V TE. LIBER IIY. 299}

hoc loco commentetur Chryfoftomus, Homil,22, tiam afcribere. Innumera bona, a it ille, bus per magiftratus obueniunt, quæ fi fu,omnia fimul peffum ibunt, ita ve neque neque agri, neque domus, neque forum, yuid aliud confiftere queat, fed omnia fiouertantur, potentioribus imbecilliores è detiorantibus. Propterea $a b$ antiquis ibuscommuni omnium fententia prinnobis fuftentari debere vifum eft, ob id ua ipforum, negligentes, communes res Et mox, Quòd fi Paulus tunc cùm gentiuc effent Princıpes, ifta præcepit, multô. portet ea fidelibus exhibere. Eam A po-. . i doctrinam Chrifus Dominus non foxcepto ante conftstuit, verùm etiam excommendauit fuo. Nam de Cafari redcenfu rogatus, Cæfari, quæ Cæfaris funt; Matth. 22. da efferefpondit,magifterio obedientia, nctus A mbrofius, \& nos inhęremus, dum In orationè us, quæ funt Cæfaris, Crfari, \& qux funt contra $A$ uo, tributum Cafariseft, non negamus. l p-xentium. recens natus Saluator in Berhleem etiam Luce 2. useft, ac defcriptus, \& A Asgufto Cæfari n tunc cum catero orbe obtinenti cenfoluit, quemadmodum vult D. Nazian- In oratione Quam rem cùm $8 z$ diuinorum lisbrorum fiue epiffold itas, \& ratio ip fa fatis muniat, atque conneque noftrorum Theologorum eorum , qui caufre Indica fudiofiores funt, aliab ijs tributa exigi poffe quifquam nead Tuliañu. Et Auguf. de catorud. c. 21. ail eft cur in loco plano, \& expedito amamoremur:

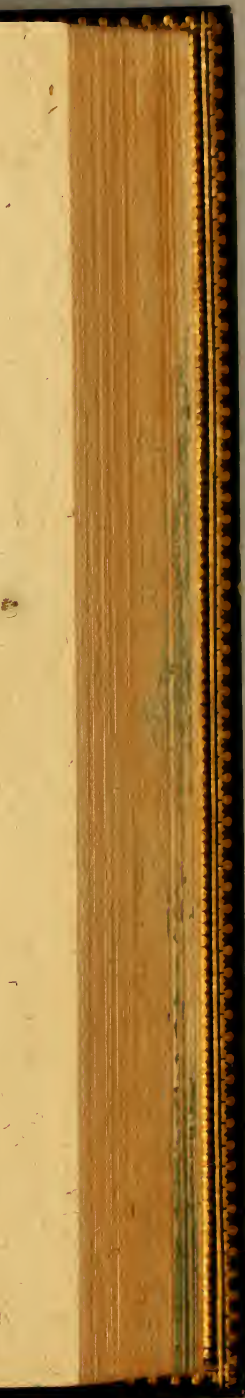




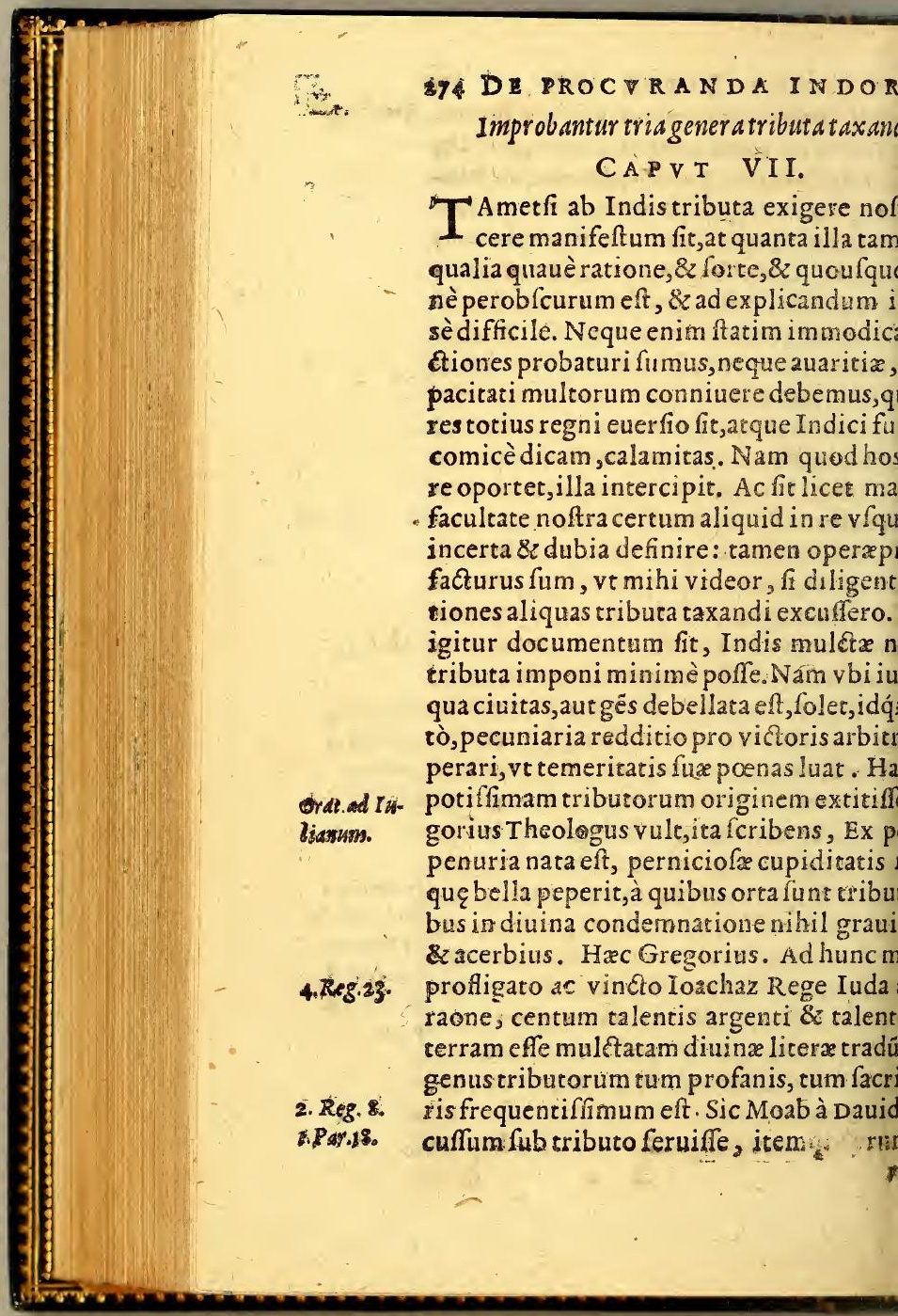




\section{SALVTE. LIBER IIT. $27 \%$}

um, fic Chananæum tributarium factum Iofue i6. đos $m$ authore Iofue, nec non reliquas illas 17. es lebufxorum, A morrhæorum, atque 2- 3.Reg. 9. Salomonis opera perpetuo tributo foladdictas effe populo Ifrael facra hiftoria morat. Quod fanè nullo modo iniurioe, non folùm fanctorum virorum exemconftrant, fed etiam aperta ratio, qux iuvißtos viktoribus fubdit, neq; fortunis fo 1 libertate quoq; vitaq́; i p fa reddit obnoIndorum populi, ve fupra iatis difputatú. riftianis debellari non poffunt, ac proin: libertate, neq; argenti penfione mulctadenim noftros laferunt, quorum ne no- " idë audierăt? Dei verò offenfas, naturæá; s vlcifci, noftra nihil intereffe, opinor aseffe monftratum. Itaq; grauiterprofectò ent, qui eo iure debellatos barbaros inftar hrorum, \&z Chananzorum, vel porius, ve ia loquamur, Maurorum,atq; Turcarum te, atq; multa penfione onerarent, exiftietiam beneficium fe collocare, quod non. lecterêt. Neq; enim tam ftolida ratio nifí eritia, \& inlolentia militari proficifci po od fi id genus quippiam hastenus perpeeft, confulant certè confcientijs fuis, qui wr pararunt. Atq; hoc fanè documentum mú eft:fequens verò multò certius, $\mathrm{Nefas}$ exigendo cenfu rationem habere Euangecömunicati, quafi retributio expectetur, Fide, \&̇ Baptifmo, Chriftiq́; notitia imper iffim repetatur argentú. Hæc tota fordicogitatio hominum tum imprudentium, proborum Euangelium veluti licitantiû́

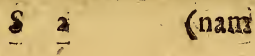




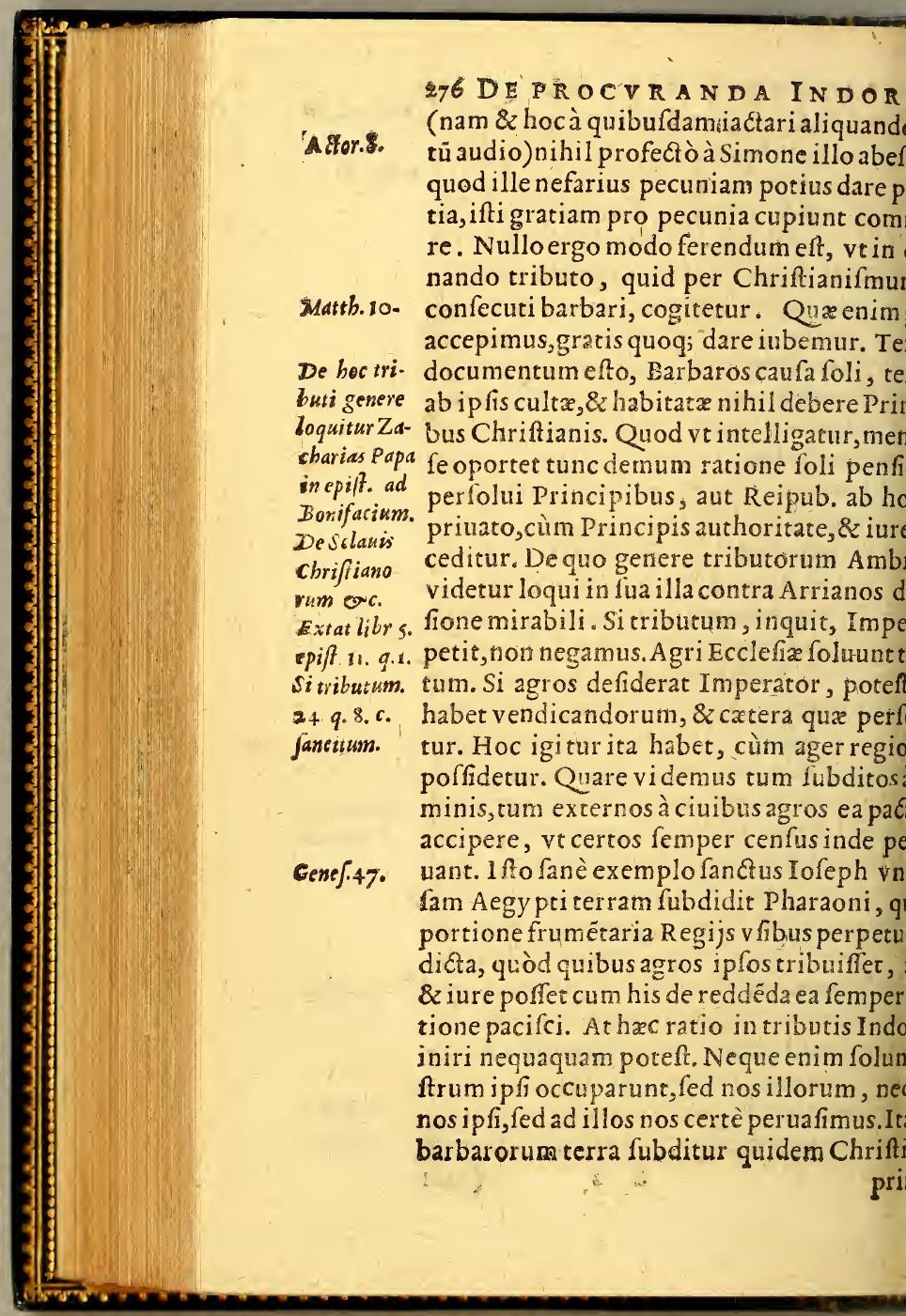




\section{SA I V TE. L I B ER IIT. - 277}

ibus, cùm primũ populi ipfífubduntur, il, illius ratione barbari debent, quam à utuati non funt, fed nobifcum potius córunt.Plurimum verò intereft, vtrum hoatione loci fubdantur, an potius homiafa locus ipfe, Hîc enim res nullo modo tur, fed integrum ius penes dominos $\mathrm{ma}$ amobrem Indis ( huc enim noftra iam tendit oratio)pro modo ac magnitudine onum, agrorum, gregum, pafcuorum, triam exaggerare, $\&$ cumulare, vt pro tanm certa ratione perfoluant, iniquiffimú uidem rebus nihil per fe debentibus cen oneretur. Quod fanè,neq; factitatum haiffe fcio, fed elt fortaffe improborum cutentatum. Neque tamen illud modò diin Rex, quemadmodum Ingarum impeelfit apud nos,\& Moteçumæ apud Mexita quoque in omnia illorum iura concefagros,greges, pafcua, mineralia, caterancipum, fuo ipfe iure adeat. Namfi rectè neab illis ifta obtinebantur, \&z legitimè noftri illss fucceffiffe cenfentur, rectè ta omnia retineri confequens eft. V trum tillud ita habeat aut illud, examinare $a c$ are, noftrum non eft. Habent Catholici onfilia, fenatufq́ue fuos, habent confcien,iftros. Subditis, dum iniuria non eft epro iure fuorum principum fentiendum tiandúmq́ue eft, vt A poftoli Petri præceategrè conferuetur, regem honorificare. 1.Pet. za oc loco folum agimus, quod \&z fatentur \& eft per fe fatis certum, etiàm fí barbari tantur ad Chriftum, non tamen rerum

fuarum 
978 DE PROCVRANDA INDOR fuarum iure excidere, neque verò noftris, uis fubdantur ad fider fufceptæ tutelam, v uitute vel fortunis fuis obnoxios effe, id Paulus quoque Pont.max.apertè decreuit.

$V$ ulgaris ratio tributaimperandi expendit

$$
\text { C A P V T VIII. }
$$

PLerifque autem illa ratio tributa impe videtur æquiffima, vt perfpiciatur pri quibus rebus vnaquxque prouincia abund trum frugibus, vefte, gregibus, mineralib gento: tum verò numero Indorum oppi tributimq́; inito, ea fumma quotannis im tur, qux poffit commodè conferri, ita vt $f$ certa portione tantum attribuant, quantu ex hifce rebus, vel ex operis fuis locandis tata familiola, præbere queant. Quæ fanèc tudo obtinuit, vt viritim tributa pendant tant regia edicta grauiter cauentia, ne ab ea exigantur, quæ \& ad fe fuftentandos, at ægra valetudine, fi acciderit, recreandos, liberoseducandos, ac matrimonio colloc neceffaria habent. Quam Chriftiano pecto gnam legem laudare par eft. $Q$ ra in re tot que illam prouincias luftrandi diligentian uentus, ac commoditates perfpiciendi, tum iniungantur, quæ commodiffimè poffunt $p$ re Indi, vt nihil fupra vires, nimis graue fu ant, caterafque inftructiones eodem pert tes, comprobare profectò decet: quin ne quidem improbandum eft, vt fínguli, qui yel atatis imbecillitate, vel corporis affec letudine, vel officio publico non impediu aliquid in commune conferat, vnde tribut
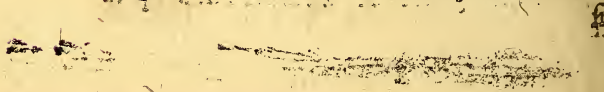
SA IVTE. IIBER IIP. - Bene hxc fanè omnia. At quod viros in s doctos non bene habet, quo etiam me mo ehementer fateor, illud eft, quod folùm co $r$, quid Indi foluere poffint, quid verò folebeant, non item. Qux fanè confideratio, exigantur,quæ non poffunt reddere, neia eft:fed nullo modo fufficiens, nifi prætedatur, vt neq; ipfi ab Indis capiamus, qua non funt, iuftitię fempiterna lex docer,ad ndum ab aliquo quippiam, tametfi neceft poffit ille prabere, tamen nullo modo id ffe, nifi \& poffit foluere, 8 infuper debeat. fiue non poffit foluere, fiue non debeat, $\boldsymbol{x}$ It iniqua exactio. Er fi enim fupra fatis mon im eft Indos noftris aliquid debere reddedorumin adminiftratione funt; non tamen inuò efficitur, vi quantum poffint, tantum ant, etiam fi rem temperes verbo leniore, ve im tribuant, quantum conmodè queant. ue ratio hæc peruulgata ad tributa barbanperanda,qua folùm fpectatur, quid quande vnufquif́; foluere queat, licet plerifque, $x i$, fancta ac legitima appareat, tamen peninfpecta, non fatis idonea, imò verò exitiofa ehendatur neceffe eft.Quæro enim, cur Hiis, \& Gallis caterifque per Europam, fi ifta ditio offeratur, ve finguli tantum pendant, atum poffunt commodè,iniquiffima, \& inofffima fit, Indis werò iufta \& 2 qua? An ifto imperitia, imbecillitas, tenuitas fecit obno? Deinde quid hoc à feruorum condicione It, à quibus iuftè exigitur quicquid reddere cunt, quia quicquid feruus acquirit, Domiacquirit?Præterea fi bello iufto domiti, muke

$$
5 \text { Stan } 8 \text {. }
$$




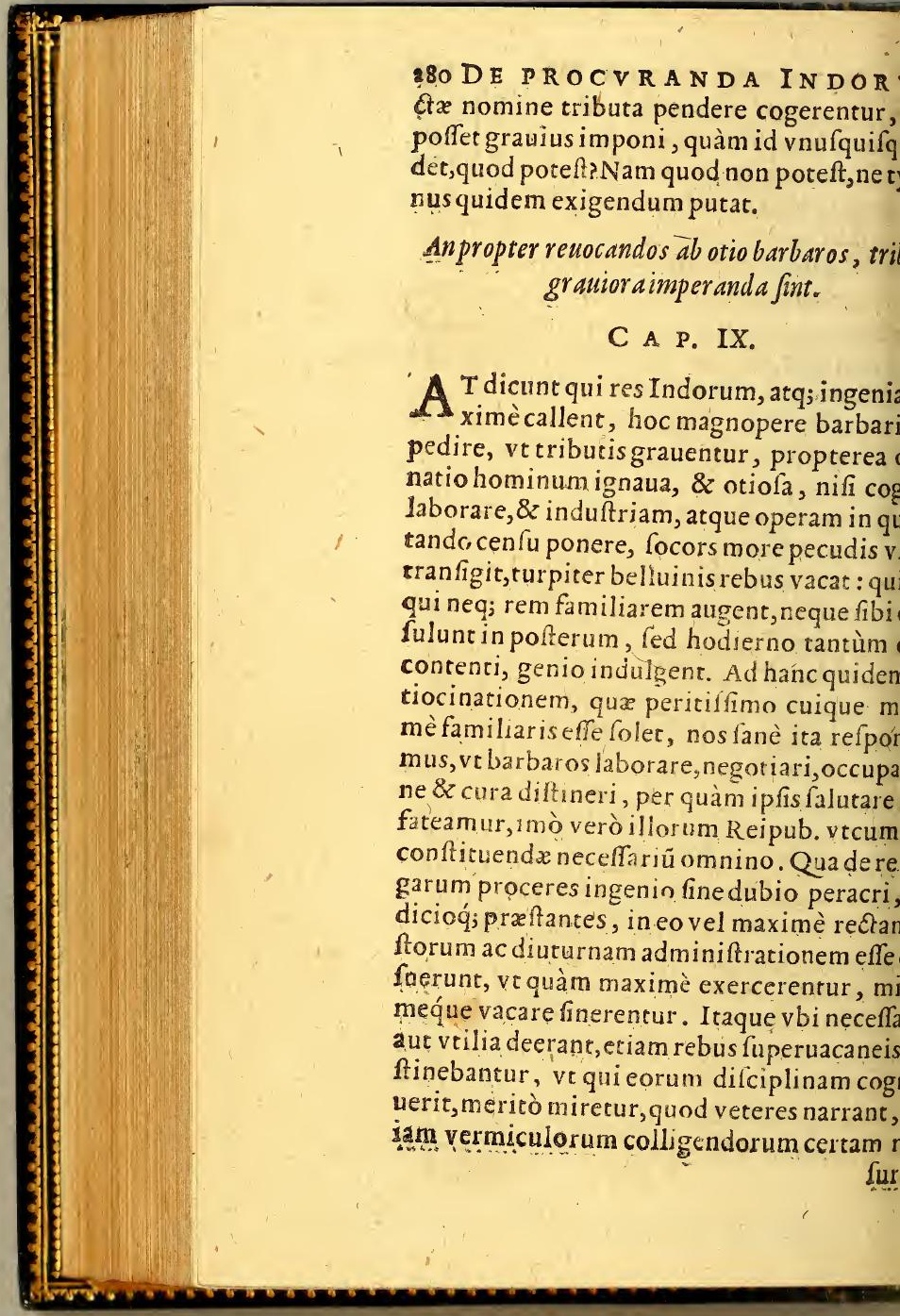


SA L V TE. ITBER III. $28 \varepsilon$ quibufdam imperatam, alios faxis vlerò ue voluendis feriò occupatos. Neque vefa aut oblcura eft, aut lógè pofita, cur Ingotio vrgeri maximè expediar. Etearbari omnes ingenio funt feruili, feruis ullú otium effe debere, etiam in prouerbi jffe Ariftoteles dicit, quòd otiü petulan-7.Pol.c.153 at, id quod nofter Sapiens pręclarè monute, inquit, feruum in operationé, ne vaEccle.33. ultam enim malitiam docuir otiofitas. exerceri Indi debent, non negamus, fed ifsimè amplectimur. At cui exerceri, cui ari, cuius inferuire cómodis debeant, hoc uæritur. Cùm enim illud à tyrannico douregalis abfit, quod hic in fubditis molis non fuam, fed ipforum magis vtilitate -profectò non eft obfcurum lyncerè cerus, operas atque negotia Indorum in ipmet emolumenta debere conuerti. Noneftar apiarij id tantum mellis in aluearilinquendum eft, quantum apibus alendis $t$, ne intereãt, reliquum omne auferendú: greges detondédi sút, quibus vellera ita mus, vt radices folùm denuo procreãd luaseffe finamus. Excepto igitur eo, quod itualibus \& ciuilibus præpofitis neceffari e prudens charitas fanxerit, quicquid vlutis Indorum prætextu nobis v furpamus, pina ducendum eft. Atque equidem verevife quidam Catones Mutiofue profiten. orefque barbarorú cenfura fua feuéra notq; emendare pergunt, Pharaones potius Exod. 5 . nt, depofitaq́; cenforia larua, qua tam rigirepitant:Vacatis otio,alteros fe Nabucho Hiere.sz.

s $s$ donolo-

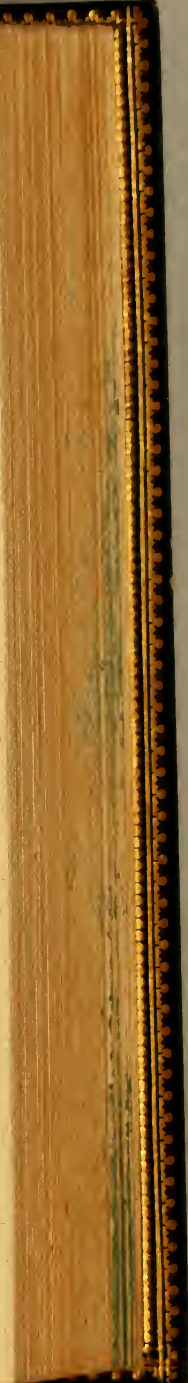




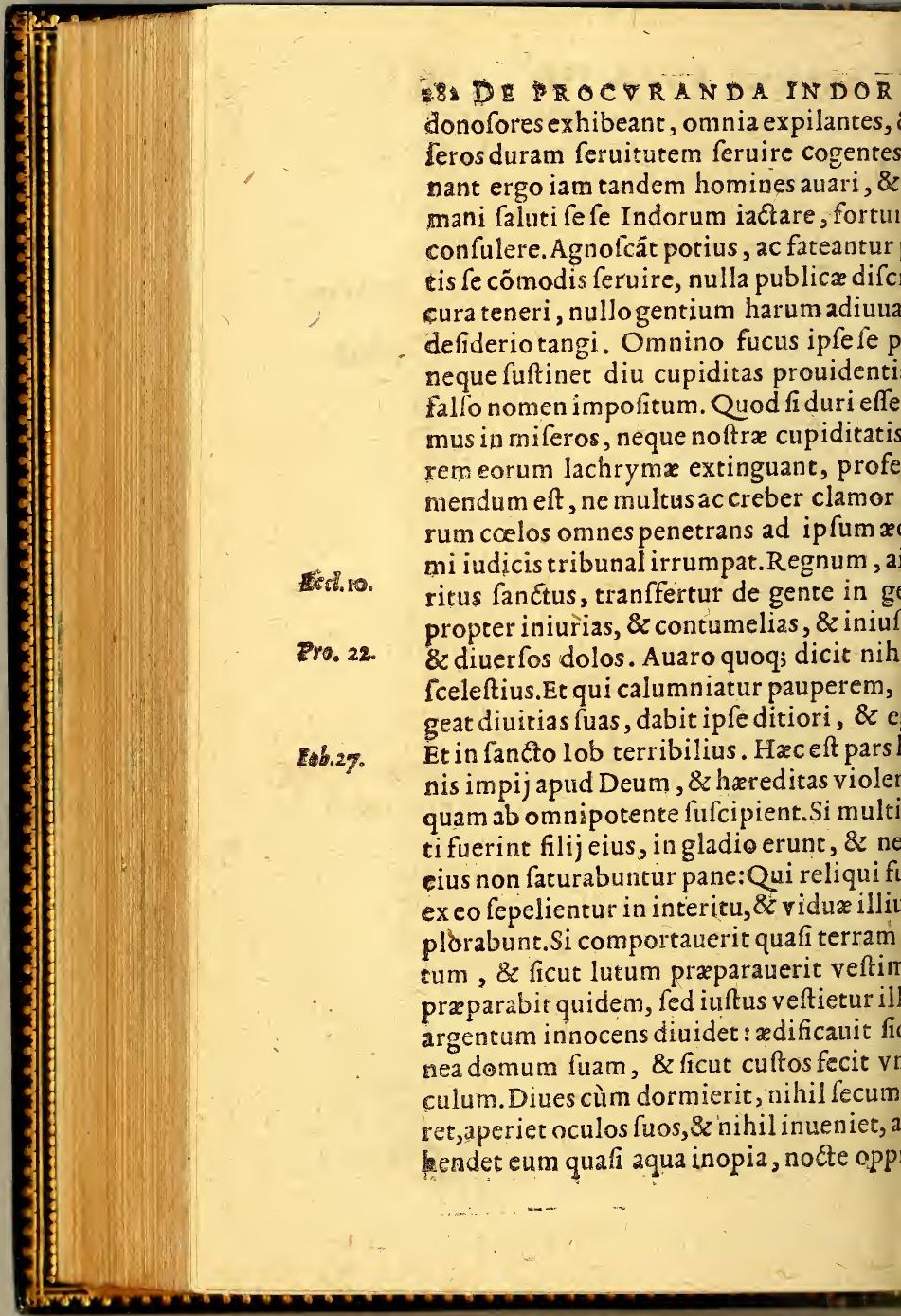


SAIVTE. LIBER IIT. empeftas.Quas fanè diuınæ feueritatis mipauperum oppreffores, violentofớue alie oris exactores, videant qui volunt, an de allis huius frculi hominibus res ipfa codeclarauerit. Filioscrfos, nepotes auita litate deiectos, vix pane faturatos, pofteriomnem extinctam, viduas etiam virorum latas, \& voti compotes, argentum terra emodum coxquatum ad pauperes deuoluacras domos pretiofis illorum fpolijs, \& coornatas,ac reliqua, quæ de violentorum ne diuina lob loquitur, promptum eft cerin plerifque noftræ xtatis hominibus, quæ imque meminerit, fateatur neceffe eft, etia $x$ Reipub.\& gentis referre plurimum, vt us teneatur diuinæ autoritatis lege præfcriquem fi exactiones excefferint, non folùm erunt adiumento, verùm etiam Deoiuftifvindicante, certi exitij, \& ruinæ caufa plemæ. Extat fanè epiftola grauiffima Gregoagni ad Conftantiäm Auguftam, in qua feuer è locutus adiungit, Idcirco fortafle lib. 4. Regla expen $\{x$ in hacterra minus ad vtilitatem epift.33. iciunt, quia cùm peccati aliqua admixtione iguntur.Præcipiant ergo fereniffimi Domihil cum peccato colligi. Nam fcio quia \& arum Reip. attribuitur vtilitatibus, ex co ultum Refpub.adiuuatur.Qua fapientiffimi Patris fanctiffima fententia cau-

fat totius Indicanæ nullum proferri potuit, vel plenius,

vel certius oraculum.

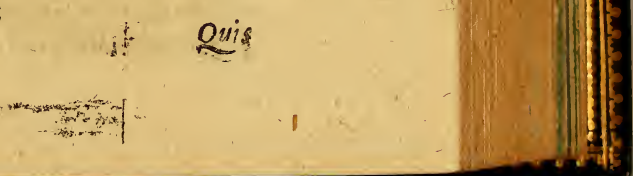




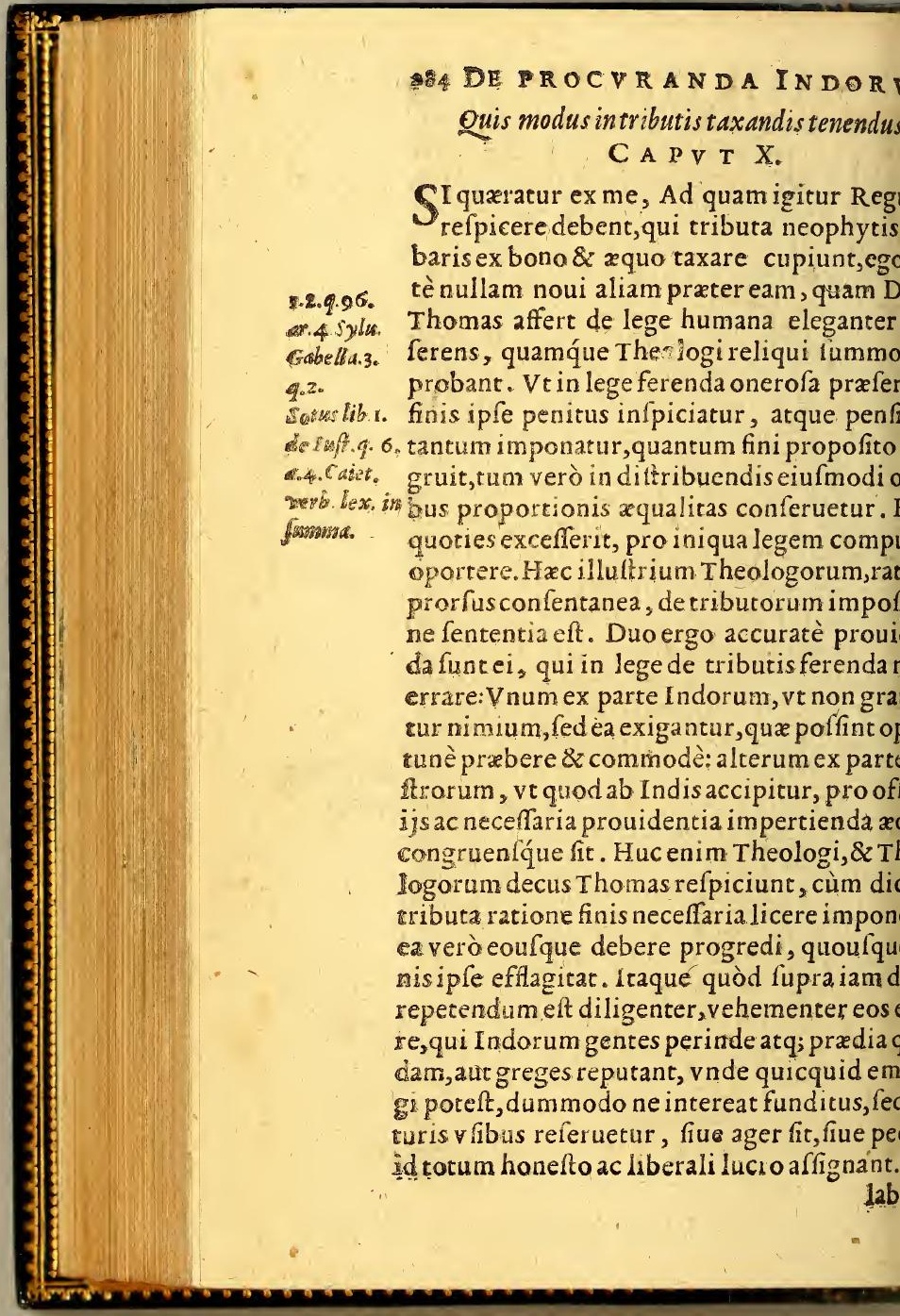


S A L V TE. LI B ER III. - profectò grauifsimè, quicunque ita fe irant. Neq; enim Indos tuos numerare po qua fi de tuo inde quiduis accipere. Quin fi quid accipis, ob id accipis, ve tu vicifquidaliud rependas, quod fi non dederis uicquid abftuleris, iniquú eft, \& iniuriot Medicus ab æroto, A duocatus à cliente retium capit, pro impenfa opera, \& offiPatronus ab Indo fi quidaccipit, pro ofccipit.Itaq; quemadmodú militib ${ }^{9}$ Reip. n fufcipientibus de publico, 82 annona, 82 dia præbentur, quæ fanè à cæteris pro colfe beneficio Reip.tuendx iure exigütur, tamen militiæ pratextu quantumuisexere, \&corradere fas eft, fed hactenus tantü, us militi, præfidijf̣́́; cóparandis ac tenëus eft:ita prors ${ }^{9}$ qux Chriftiani à barbaris capiüt, eo viq; folùm progredi oportes, q; fini propofito neceffariú eft. Eft verò ils ratione præf criptus, vt miniftri faluti, $\&$ iftrationi Indorü neceffarij nó defint, ho turq́; congruenter. Hi verò in duplicigeunt. Primi ac præcipui numerantur Paftoimarum, Miniftri falutis aternæ, quos eoargitionibus, $\&$ prouentibus ali, quos ip fi o verbi, \& facramenti pane nutriunt, non ifpofitionis humanæ, quàm diuini effe itutifsimum eft.Id omni lege definiri Paulus um doctor difertè oftendit. Nam de lege ü hoc argumentủ verfans, Quis militat, in-1.Cor-s. cuis ftipendijs vnquarn?quis plantat vineá, fructu eius non edit?quis pafcit gregem, \&z te eius non manducat? Ne verò fecundùm humanas tantùm agere videatur, producit Itatim 


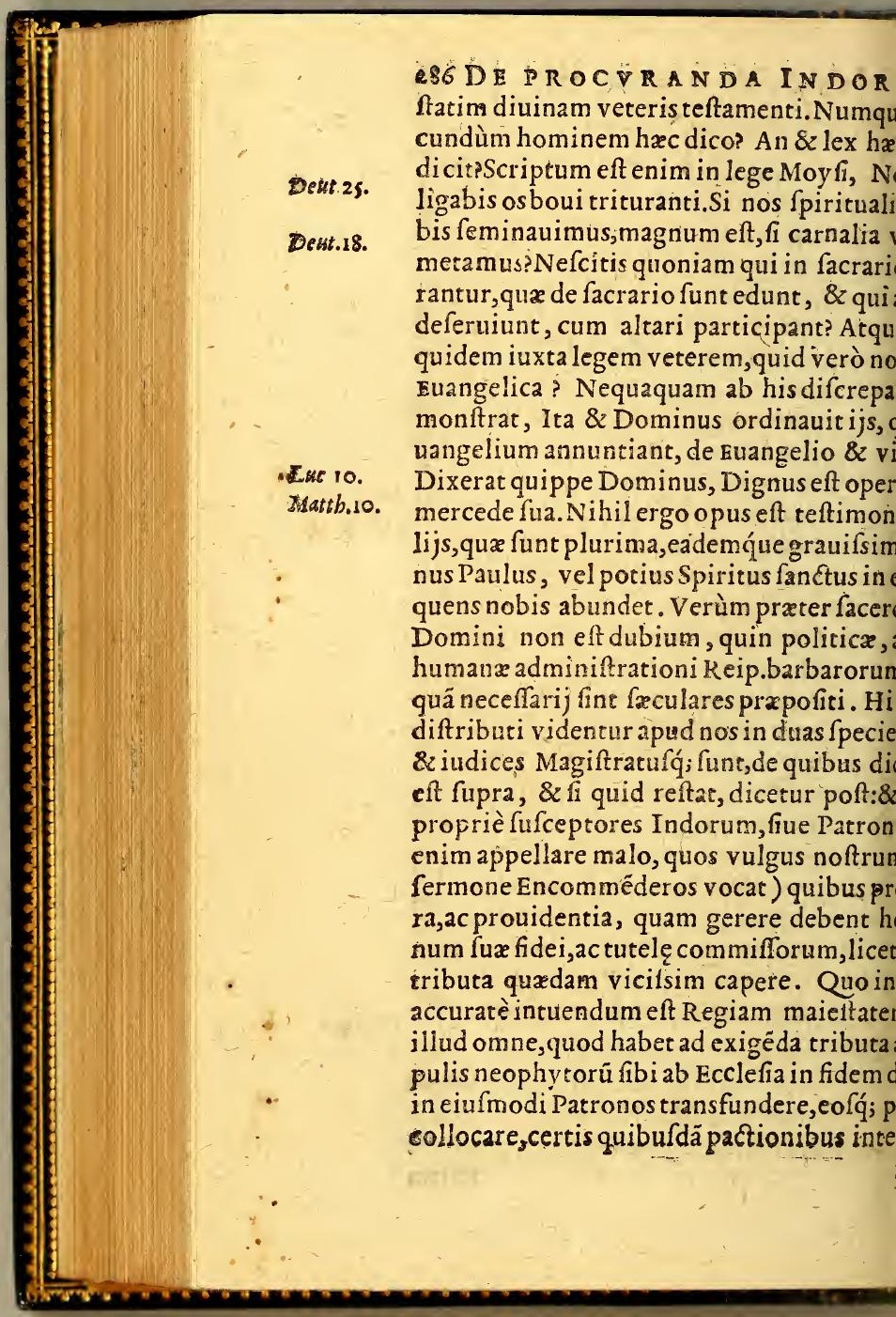


SAIVTE. II BER IIIT. quibus mox opportunè dicemus. His ersf fefe exhibeant, quos fide iurata profitributa rectè folui non eft, cur reuocetur um, cùm manifeftum fit licere Principi tribuere, qux percepturus ipfe effet. Qua noft rorum Theologorum, iurifq́ue pru$m$ cócors fententia eft, \&z accedit B. Greullo modo contēnenda autoritas, qui ad squofdam viros Sardiniz fcribens, cofquid debeant præftare fubditis fibi com\& quidem in fidelibus adhuc, \& quid ean percipere ab illis porsint, commodè adAd hoc quippe, inquit, illi vobis comunt, quatenus \& ipfi veftræ vtilitati valeterrenádeferuire, \& per veftram proui- - iff.epi.zgin im, corum animabus ea, quæ funt ærerna, icere. Vnde apparet rectè poffe nobilium num, ac bene de Rep. meritorum fidei cucömitti, vt faluti barbarorum confulant, $x$ caufa ab his fua ipfi emoluméta percipioniā verò cùm eft conuentio aliqua, v t ob lud detur, certa quædă ratio ac proportio cur neceffe eft, ne aut hinc excedat, aut inficiat, omnino perfpiciendum eft ad qux \& a Patroni Indorum obligentur, vt inde veè cognofcamus quando \& quoufque iufit talibus tributa perfolui. Sed ante confiidum erit, An ne expedierit Indorum poin Fide rudes eiufmodi patron is commitquibufuè ex caufis id excogitatum 2 effeqque.

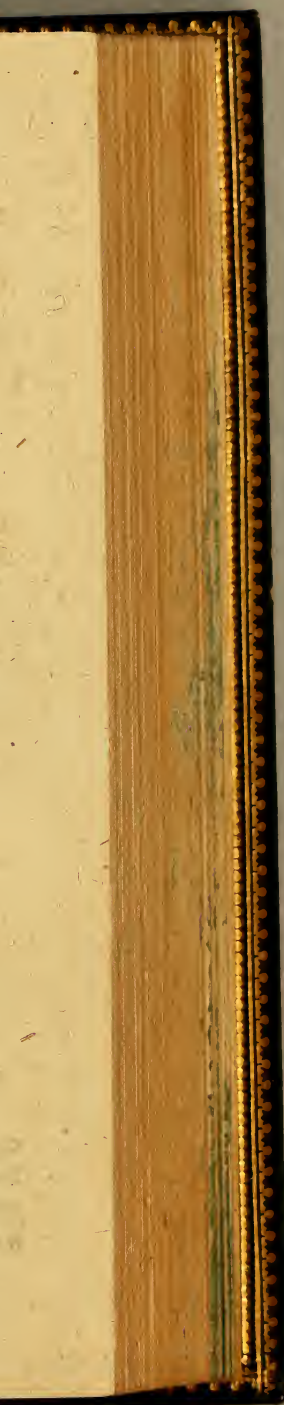




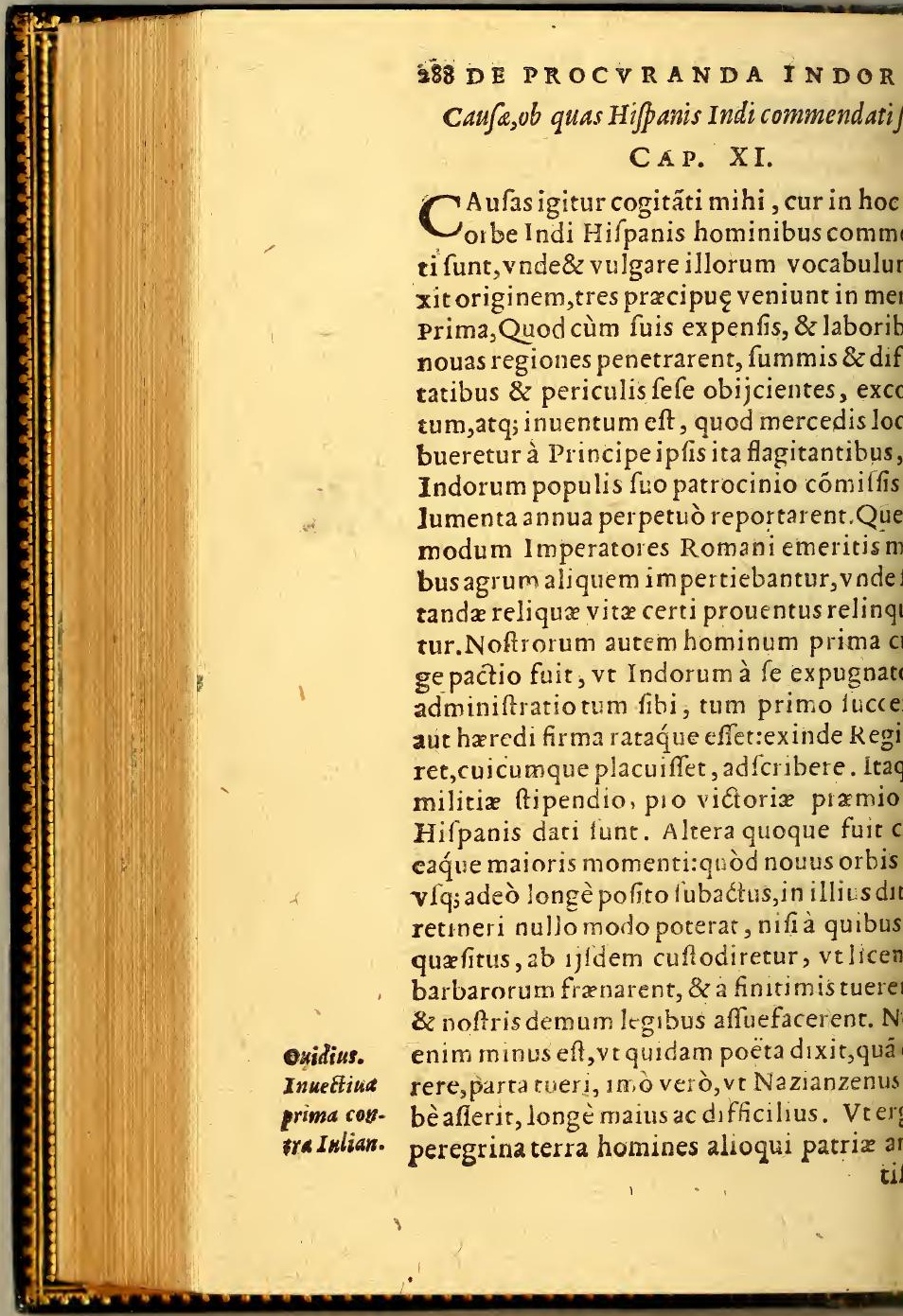


SALVTE. ITBER IIT. 28 \&े tenerentur, fierentáue nouæ Reip. culatque amplificatores ftudioti, fixas ibi felocantes, attributa fune certa oppida In, quorum, \&zdominatu \& commodis po11:Perinde atq; v mbra quædam Hifpaniæ um reprafentata fit, cum fubditis, fiue, ve vocant, bafallis imperitent. Tertia eadéima, ac reliquarum fundamentum cautit, vt noui Fidei tyrones, teneraq́ue ftirtrocinio curaq́; veterum protegerentur, erentur, religionis difciplina regerentur. ue falutis viam, veomnino munirent, atfirmos in Fide, ve monet Paulus, aflume- Rom.is? Arbitror me omnes infitutionis huius effe complexum. Iam fequitur, vt de vnae quid habeat aquitaris, quid difficultatis, fficij, differamus. Acprima illa de remulis laboribus fumptibufá; militarium ho, ex necelfitate quadam potius quàm ex tate, aut religione profecta fuifie videtur. enim poterat Princeps; aut per quàm 2 terat, tantos tot hominuti ficlores, imò ve n cruores dixerim, pramio pariafficere, nouo orbe illorum virtute par:o, potenuxftumq́; partiretur. Nam neque ifíaliontentieffent, $8 z$ cateris fimilia audengi, diendiq́; cupiditas omnis extinguererur. fitanica India, quod Regum Lufitanonum ijs, \& auroparta fit,poruit penes Regem lle dominatus fine iulta fiorum querela ri. Nofrorum velò hominum, quoniam edućtu \& re, tanta peregerunt, longè alia et. Itaq; necelfitaris, vt dixi, cuiud dáfuir, quodam iure, vt olim Ifraelitica tribus
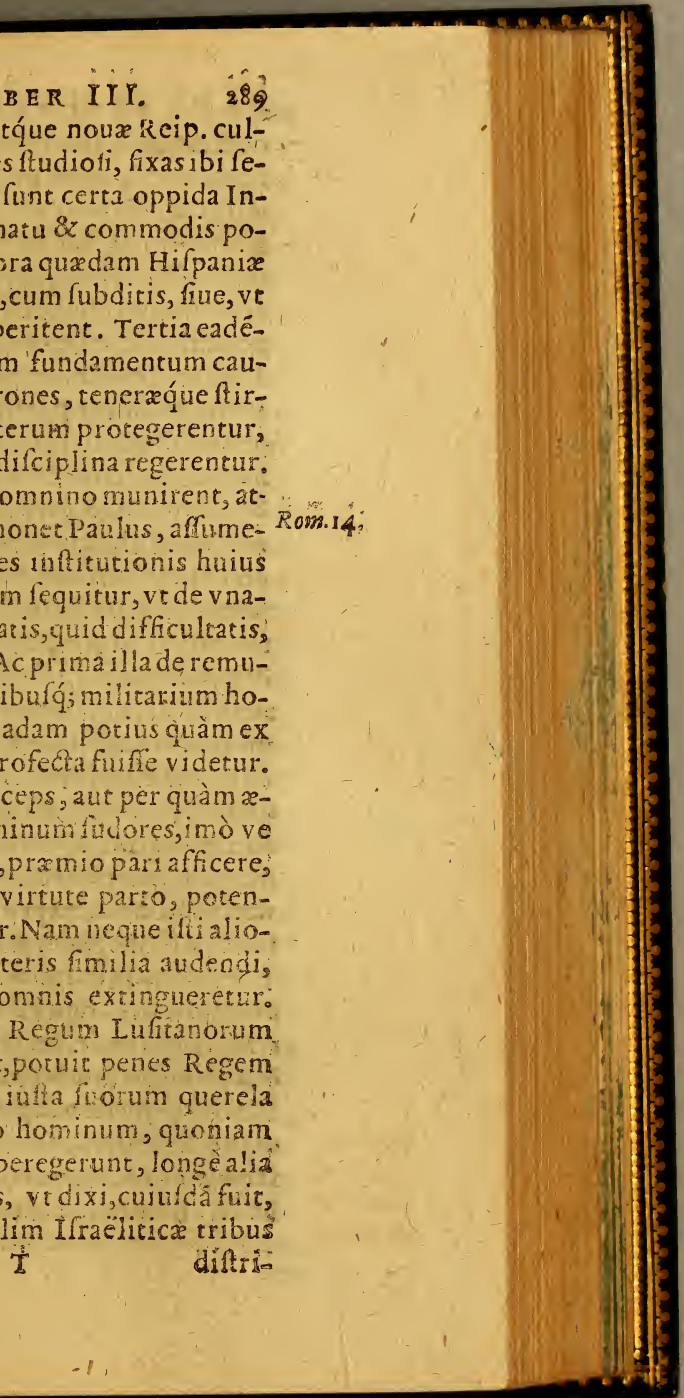


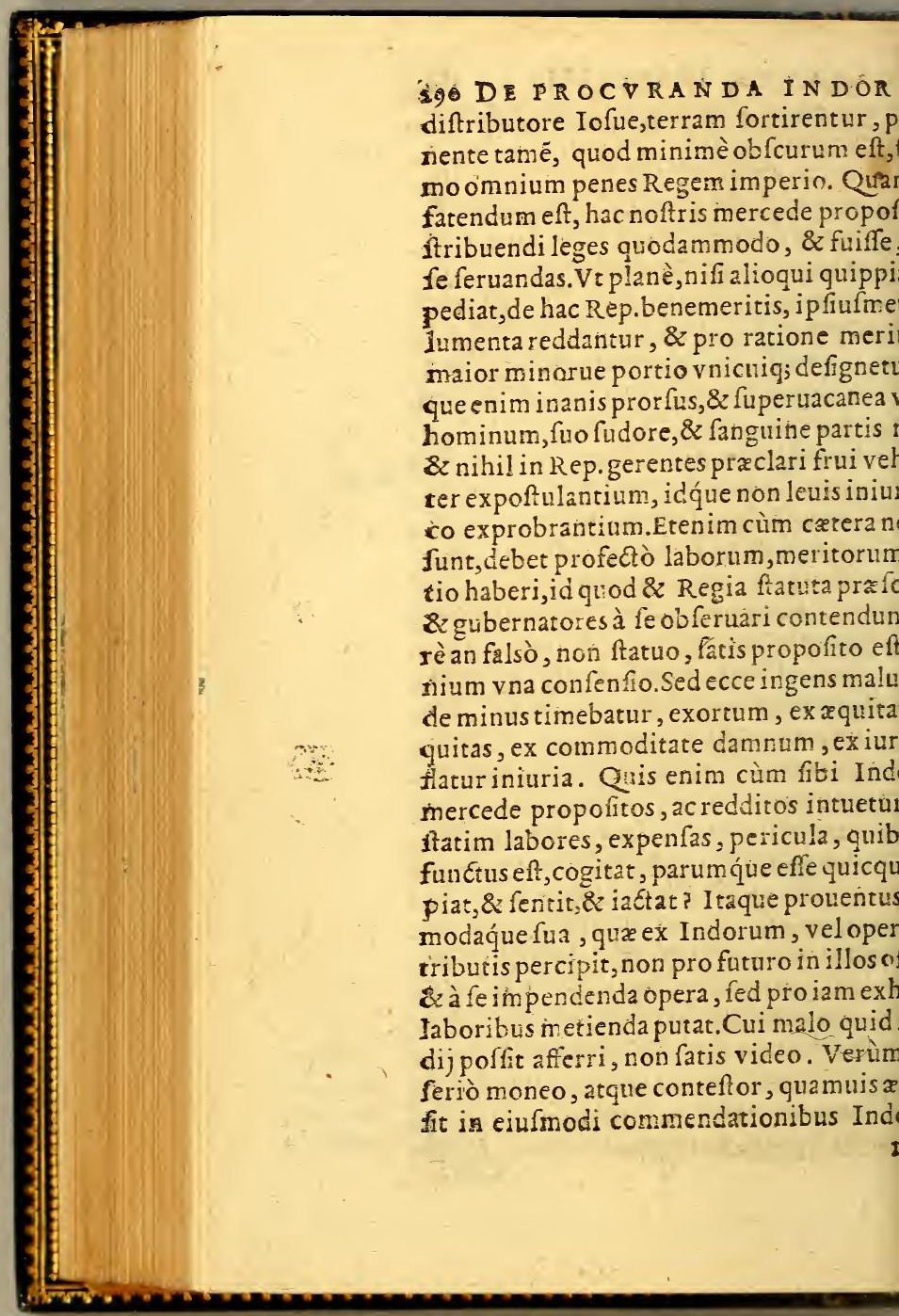


S A I $\checkmark T$ E. I I B ER III. n antea præclarè geftarum rationem habe: ainimè tamen tributa operasq́ue iftorum ius augeri poffe, quàm conferendi in illos ficij ratio poßtulet.Quemadmodum \& prær $x$ in $k$ ep. \& facerdotia in Ecclefiabenetis quidem conferenda funt, \& digniorioppidò ampliora:at cenfus, vel publicus; cclefiaficus pro futuro labore, atque ofdatur. Itaque huic percipiendo veteres lapratexere minimè licet. Sed fi profecto officio, atque impofiro munere non peraris, quantumcunque olimemeritus fis, pro us tutò non percipis. Secunda verò caufa eruand $x$, ac tuend $x$ Reipub.huius, non dueft, quin æquitatis vtilitatilque plurimum at, quin potius in eo falus Kegni tum temlistum fpiritualis fita fit, finon defint his ti deductis colonijs coloni fui. Nam idquoRomana Reipub. fapientiffma moris fuifonfar; vt nouos colonos, quo firmaret, deeretque coloniam fuam, domicilio donaarijs priuilegijs, commoditasibuig̣ue proeretur. Regis, regnique incereft maximè, int qui tanquam proprium domicilium ntur, \& quoad licet,amplificent. Quamobpropria quadam nuncupatione, eaćuc apud honorifica, hi propriè vicini, ciuefue nomir.ltaq; \& vxorati effeiubentur, \& certam vr incolere, vnde nifiannuence prorege, abeffquá liceat: fiabfuerit, abfentis expéfis aliu citur, quod fi diutius moras traxerit, ab In im moderatione remouetur, aliufóue fucce erinde,atg; demortuo . Quin etiam Princi iomues feudatarij habencur, fidem fuam la-
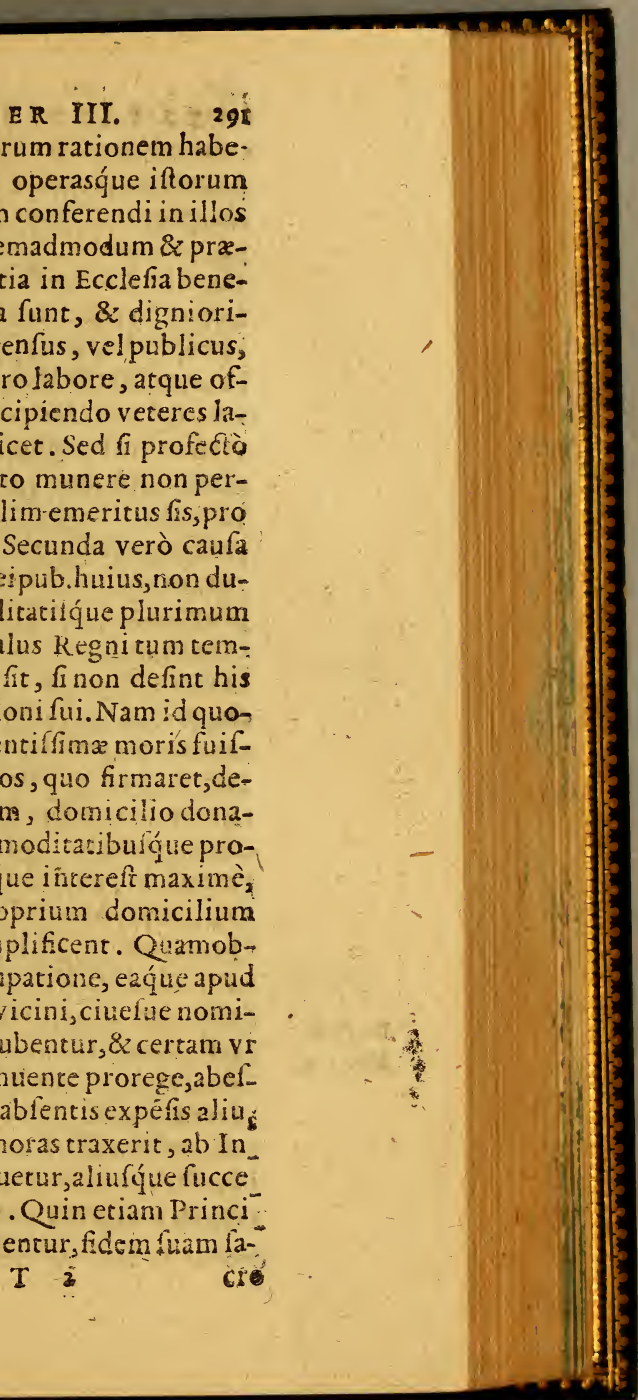
208 DE PROCVRANDA INDOR VI cro iureiurando Reip. Regifque iuffis aft gentes.Itaque bella fi qua exorianturin prou cia, proprijs fumpribus adire, \&z belligerari guntur, quod nuper in bello Ingarum Cuzqu des, $\&$ in Chiriguarienfum, Charquenfes, 1 'a felq́ue fecerunt:proinde equos, arma cætera in repentinum quernque tumultum parata bere, in otio, \& negotio Reip.adeffe prompt rùं. Qux quidem omnia, \& prudenter, \& tariter inftituta funt, neque parum confcien eiufmodi hom inum leuant, qui pto impofit bi onere houorem quoque, hoc ef, prouer referant. Neque enim, quod multi falio opin tur, fola eft caufa redditus Indicos percipiet propria ac peculiaris Indorum faluti adhi cura, licet ea pracipua fit, verum alia quoq; fa funt, funtaliz etiam publica, vilititis cia, quibus cum addicuneur nobiles homines re remunerandi funt. Eas ob res quod regem Indis capere oportebat, id in eiulimodi feud rios omne trantmitcit. Tertia quog; ac potiff caula fupra allata de cura, prouidentiaque $N$ phytorum, fi nuda ipla per fe fpectetur, fpec fa planè, \& honefta, arq; offici) plena videat Quidenim margis falutare dici porent, quan noui Chrifiani vererum diligentia comm

De Ecci. dentur?quodetiam in primaua Ecclefia in $\mathrm{m}$ Hier.6.2. fuifie Diony fus Arcopagita facis indicat, $c$ fidei candidati probatæ vitæ fufceptoribus! derentur, piè ac falubriter imbuendi, atque 0 ciosèadiuuandi. Hac vedixi, perpulchra, pe honefta caufa eft, fi nuda ipfa cernatur. Atv cogitatione venimusadré, Iefubone, qua $p$ urbatio, quanta foditas. Verùm vitio homi 
S A L $\checkmark T$ TE. LI B E R IIT. auf hoc fit. Neque verò prauorum peras bonis detrahere debet, fed Dei optimi, nigniffimi ope fiet, vt Patroni officium eferant, fed nomini fuo ipsi refpondeant. cum iam eft qux fint horum partes in Infe fufceptos exponere.

doctrinam fidei, os moribus fufficientem $P A^{m}$ troni Indis fusceptis prabere te-

neantur.

\section{A P V T XII.}

Rimum ac maximum onus fuftinent, Indos am Chriftianos effectos in fidei, morumq́; lof̂rina, cæterifq́; ad falutem opportunis, tum opus eft, adiuuandi. Rc enim vera Pa,Pædagogi, Nutricijq́ue in chriftoteneris c \& paruulis dati funt. Hoc omnes fine exone confentiunt, \& docti \& indocti, \& ex$\&$ imperiti.Hac lege, hac conditione Indi is à Principe commendantur, recepto vfi; more fe fe penes ipfos confcientiam fuam erare tefrante. Quod fanè onus ipfi, qui funt, rarò intelligunt. Ex hoc primo praci; documento efficitur in primis, vt quicüniundto fibi muneri non faciunt fatis, non $\mathrm{n}$ graue crimen admittant maledictionis \&rei, quod opus Domini fraudulenter faci- H.er. $\mathbf{4}^{\mathbf{s}}$, verú reftitutioni etiam obnoxij fint,quòd imè officio fundi, ob gq tributa inftituta sút, lominus illa perceperint. Neq; enim charita atùm Chrifianæ infenfi funt, fed etiam puam iuftitiam laciunt. Efficitur deinde, ve fi ligentes admodum fegnefó; fe praftiterint s Patroni, neq; emendare \& refarcire iactu- 


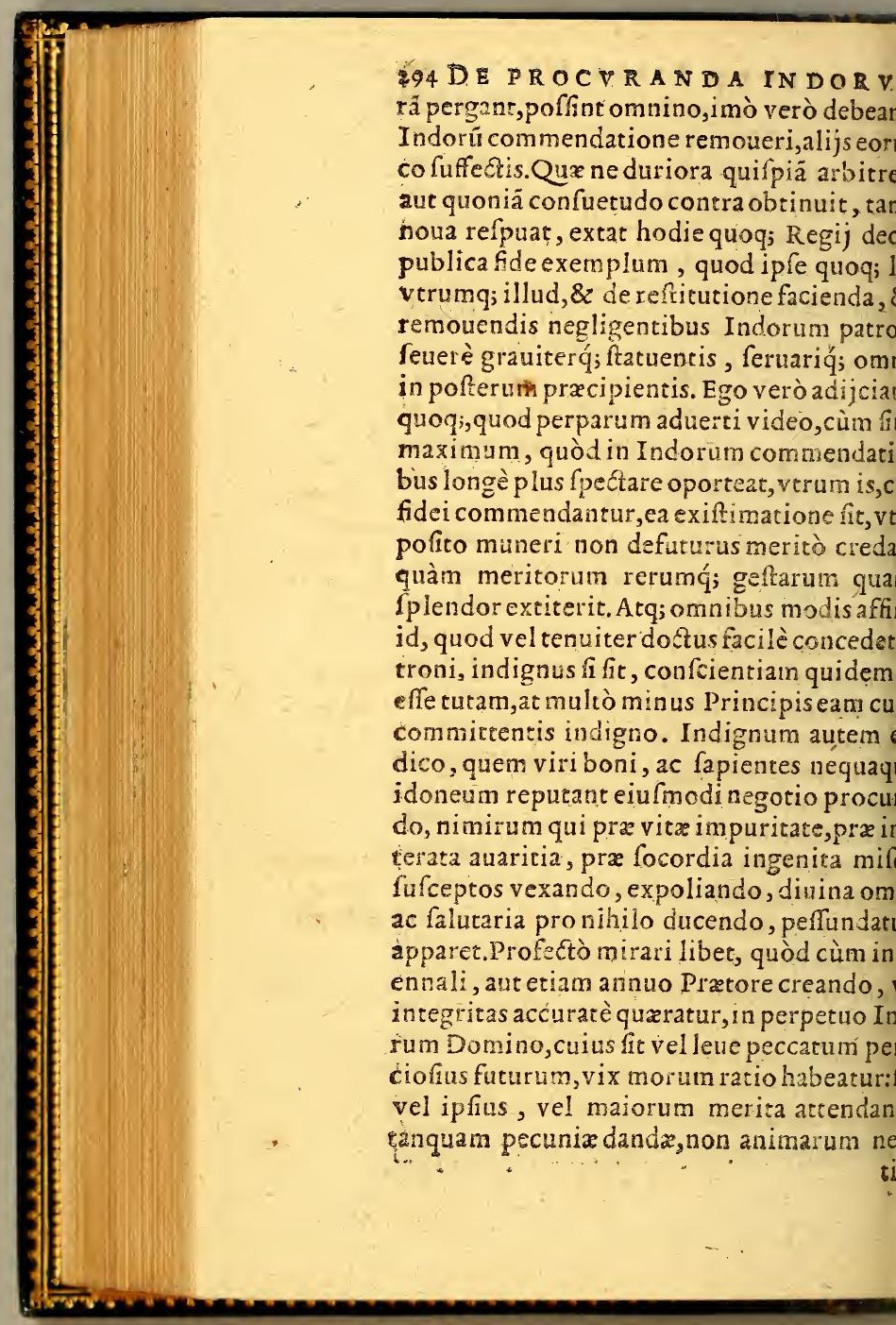


SALVTE. LIBER III. tractaretur. Quxret ex me aliquis, quam. inftitutionem, quam doctrinæ rationem ere intelliget Patronus, vt confcientix faiat fuæ? Refpondebo breuiter ac verè,nüc oris magna ex parte ea cura, \& moleftia lios effe patronos:fiquidem epifcopi fibi sûint, neque iniuria, vt facerdotes ipfi defigac deitinent: quibus patroni ftipendium à ribus præfcriptum optima fide perfoluant. $d$ fi hos, vel remiffos, \& negligentes notavel improbos, \& impuros, vel cupidos, ac ces, denique gregem Domini lædi grauiter lentia paftorum animaduerterint, pro fide, fuis debent, oportet ad epifcopos defe\&z quantú in ipfis ficum erit, ardenter agant, iniunex afceptis fuis quàm optime confultum fit. de Heret. fedulo protirerint, framen nihil pro- docet id ins int, fidem fuam hac in parte liberarunt: ${ }^{\text {nocent.3. }}$ quaretur de manibus illorum fanguis ef$s$, cuius antiftites Principi paftorum, cum Eyech.3. aruerit, rationem reddent. Quot verò facerin Indorum oppidis habere oporteat, brer quidem dici poteft, quot erunt neceflarij inftitutioni, facramentorum adminiftrai, cæterorumq́ue ecclefiafticorum functio- In coneilia Prouincialium verò fynodorum, vbi de pa- Limen/s ijs agitur, canonibus definitum eft, quoto confi.77. hero Indorum vnus facerdos fufficere exiftdus fit. Sequatur patronus Epifcopi fui iu um, fi fynodi decreta feruari vfquequaque poffunt. Quicquid verò parocho tribuennerat, fi abelfe contingat, fiue negligentia roniid fat, frue periurı minifrorum, frue

$$
\mathrm{T} 4 \text {, Epif }
$$




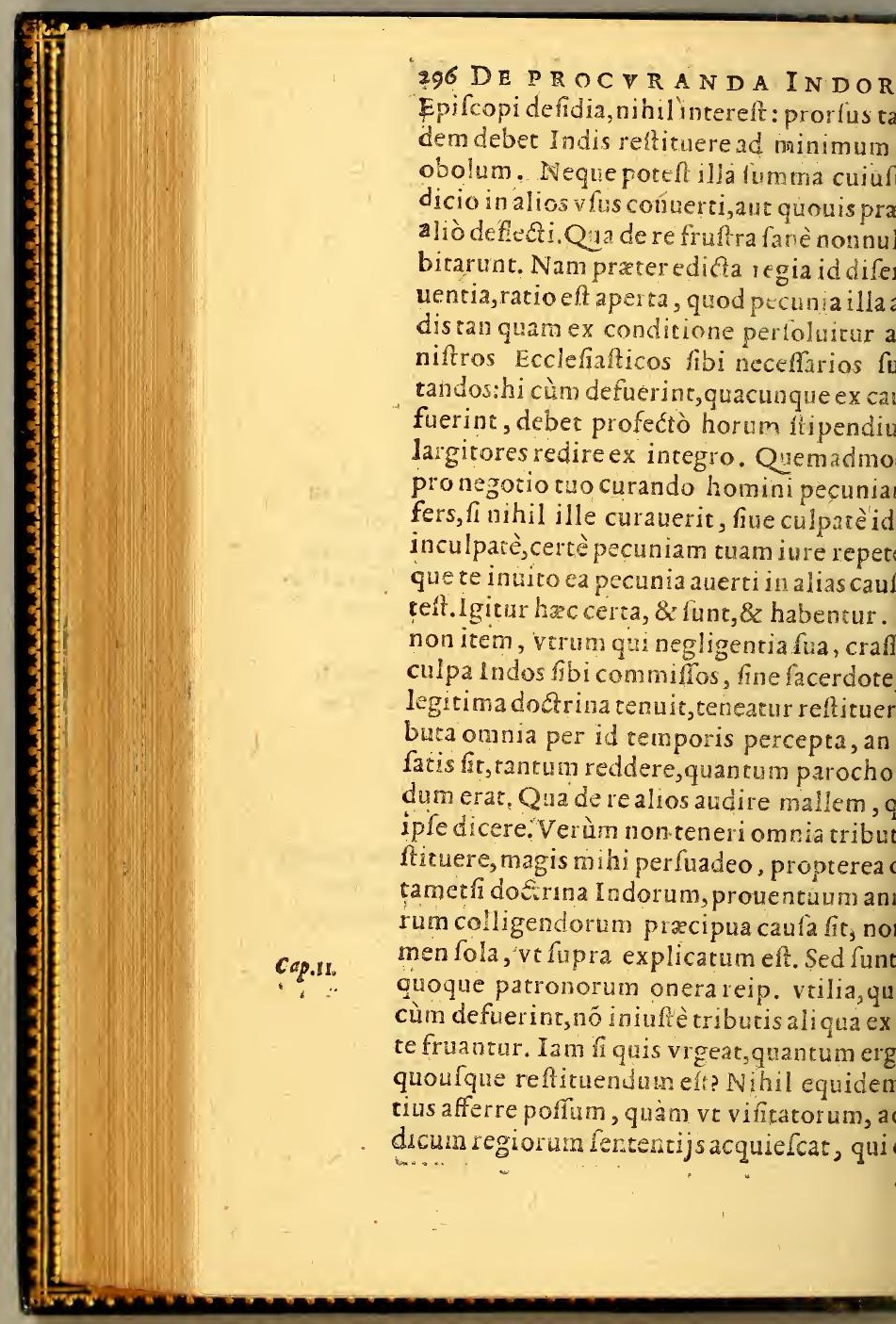


SALVTE. I I B ER III. oleant prater doctrina defectus, \& damna ui Indis data, aliud præterea iubere reftidq́ue mos habeat doctorum ac proborum num, aliquid infuper imperare, quamdiu aplius explorata non eft, minimè oportec. If Indorum tam populofa ac frequenstur$v t$ funt pleræque in prouincijs fuperiorianifeftum ve fit v num facerdotem tot hom curæ \& doctrinæ nullo modo effe facis: tamen antiftes admonitus plures mittat, dia non habet in promptu, vel quia fortaffe nulat, ita vt Patronus non fit in culpa, quæmerito, an oporteat reddere Indis id, quod facerdoti, fi adeffet,erat attribuédum. Hîc le varia res eft. Sed cùm iuxta retentum m, veliuxta fynodale decretum obferualures effent facerdotes adhibendi,non duquin redditurus fit Indis Patronus, quicle duorum ftipendio, vel plurium fuberafit, frue vitio id fuo acciderit, fiue fecus. Ná i, pactionis ea lex eft. Vbi verò neq; condo, neq; fynodidecretum, neq; præfulis viæceptum,etiam fi plures miniftros populi rofitas poftulet, poteft Epifcopi fui iudiciú fi vnum fatis effe ille refponderit. Deniq; dum ille ftatuat pluribus effe opus, poteft fibi miniftro effe contentus. Namque ve admonui hac parte folicitudo præcipua ad opos recidit, qui de Indorum rebus edocti nos moleftia antiqua idoneos miniftros itandi liberarunt. Hæc de præcipua cura norum, hoc eft de fpirituali minifterio ern Chriftianos Indos, attigiffe fit fatis.

I 5

Quid. 


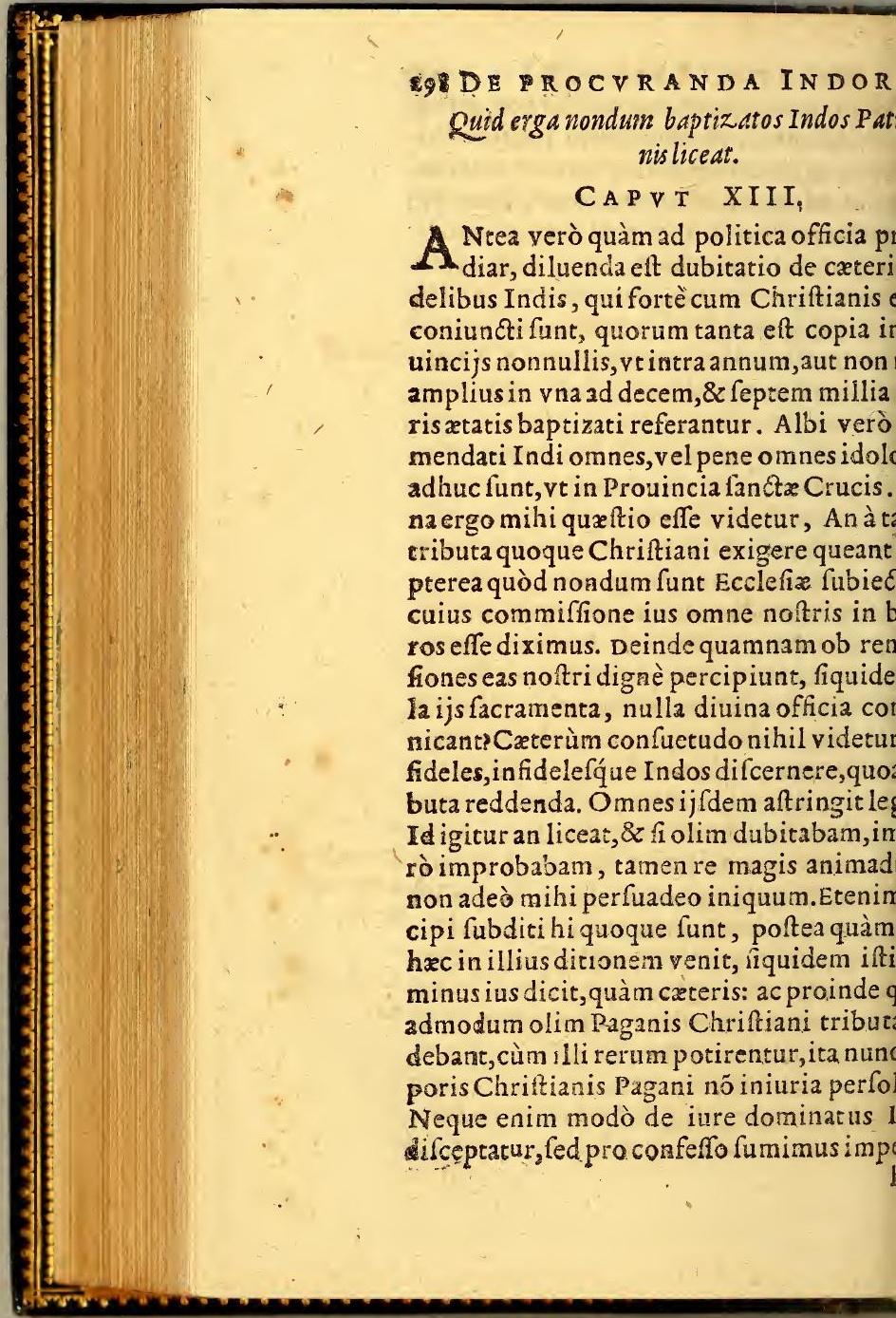


SA IVTE. L IBER IIT. iftare, qui imperat. Accedit ad hoc, quód es Indi nullo modo Chrifti baptifmum atur, quin \& cupiunt, \& petunt : verùm de in numero catechumenorum, fiue ipvitio, fue noftrorum negligentia tenenùm ergo in catechifmi cura, hi quoque teris communicent, non immeritò cum quoque miniftris neceffaria tribuunt. em Apoftoli Pauli praceptum eft, com-Galatiof et autem is, qui catechizatur ei, qui fe caat in omnibusbonis. Minimè verò ferenClet, vt Chriftiani Chrittianis, paganis pamperarent, cumq́ue vnum eundemq́ue um hi, \& illi conftituant, non poffet non iffimumeffe difcrimen eiufmodi. Quam præterquam quòd his quoque ius dicere, nostueri perinde ac cæeteros principis inpropriè ac peculiariter patronorum, parumque partes funt, cum iftis quoque de xterna feriò agere, ad Euangelij gratiam fedulò, de fide inftruere, inftructos moinformare, volentes $\&$ dignos vltrò adread Ecclefiæ gremium, fi grauiori perirgeantur, falutari lauacro fuccurrere, ctorum Patrum decreta habent. Denique prætermittere, quod ad illos Chrifto luiendos pertineat, quod non charitatis tanfed officij fui propriam obligationem agnt necelfe eft. Quod v fque adeò D. Gre- Lib.3. epij. $s$ fentit, ve ad Ianuarium Epifcopum fcri- 26.

De confec.d. 4 cap. Siquis. o jeq. $s$ verbis. Rufticos, quos habet Ecclefia tua, $v$ que in infidelitate remanere negligentia nitatis veftræ permifit. Et quid vos admovt extraneos ad Deum adducatis, qui ve- 


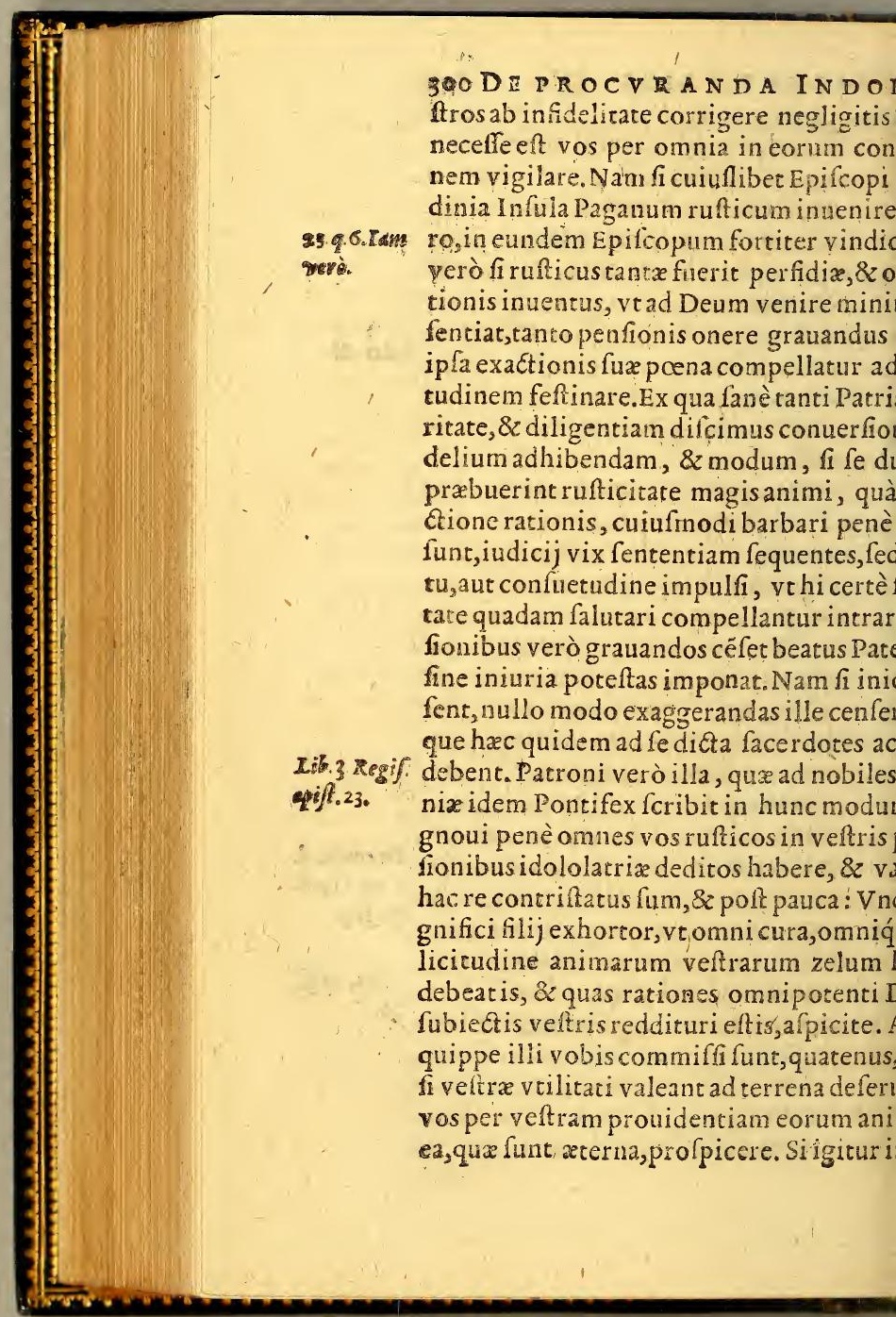


SA L VTE. LIBER IIŶ. jố li quod debent, vos eis cur non foluitis con. eliber: ebetis?id eft, vt affiduè illos magnitudo can.41 tuber commoneat, abidololatrix errore com- $t u r$ chriffirquatenus eis ad Fidem duct is omnipoten- ni infolelium minum erga fe placabilem faciat. Hac feruorumiius : quibus \& quid liceat accipere, \& dolacommiceat reddere infidelibus Indis fibi com- mere, iden Patroni fatis, quantum arbitror, edocen- infinuat AHdobiter aduerti deber, quamuis non li. guff. $\int e r$ de ud obiter aduerti debet, quamuis naptifmum Chriftianamó p pro- Puero Cesem compellere barbaros fubditos, licere De Paganis imò expedire ab idolis colendis etiam o templis s reuocare, hoc eft illorum fimulachra, $\&$ corum. lib. ro moliri, fuperftitiones diabolicas extru- ov l Nemo. tax non folùm Euangelij gratiam impedi Niceph. lib. rùm etiam naturæ legem infeftant, quam 7.ccp. 46. ent, compelli infideles fubditi fine vlla lege Ambro tione poffunt, id quod abundè declarant lib.sep 30 . onitantini, Valentiniani, Theodofij, cx- conirarela. mq́ue Principum Chriftianorum, quas tionem Sym è fancti Patres collaudarunt: neque lau- marhi. Amg. lib. 1. contra s modò, fed impulfores autorelq́s fe præ- epift. Pam nt. Et re vera quamuis officij minus ex- cop.7. 0 eppo ur infidelibus Indis, tamen non videtur $43,0050$. onfuli faluti eorum, fi tributorum minus tt, quàm Chriftiani, vel hac enim de caufa fmo percipiendo deterrebuntur, fi graunc fibi tributa imminere cognouerint, tius imminui fanctus Gregorius vult; ve Chrifti farcinam, \& ingum fuaue libenbeant.

Detem 


\section{SO2 DE PROCVRANDA INDO}

De temporaliprouidentia Patronorum juos.

\section{A P $\mathrm{V} T$ XIIII.}

F Adem quoq; Indorum commendatio 1 genter prafcribitur Patronis, vt not in Fidei, ac falutis aternę eruditione pop commiffi curam gerant, verùm temporal dio in vita huius ærumnis quotiefcumq; rum indigeant, benignè ad fint, intelligar Neophytis datos effe parentum loco.Hor tur rem politicam iuuare debent, $\&$ ab it vel hominum, vel temporum profua vir ri.Itaq; vt Hifpanix proceres fui munici minibus defenfonem, ac prouidentiam iure debent, quo nomine ab illis tributa unt, fic in his locis populis Indorum fibi a tis Patroni fingularis cuinfdam in otio $x$ negotio patrocinij tenentur obnoxij, 2 maius, quemadmodum familiæ fuæ pater milias confulere debet. Seriò ergo illud

Efais i. Cum cogitent de clientibus fuis, Difcite cere, quęrite iudicium, fubuenite opprefl

g.Reg.18. cate pupillo, defendite viduam. Abdiam dis famelicis, \& è periculo eripiendis inf́ reprafentent:autegregium bonorum $\mathrm{fib}$ nitus affluentium diftributorem fancium

- mitentur, qui fua illa fortunata tempora

58. 38. ria repetens, ait, Si negaui quod volcbant ribus, \& oculos vidux expectare feci, fic buccellam meam folus, \& non comedit $p$ ex ea,fi defpexi pereuntem, eo quòd nó ha indumentum, $8 \mathrm{abfq}$; operimento paupe beneficentia \& fide fi fufceptis fuis noftri 
SAL T TE: ITBER III: 303 , verè \& nomini, 8 officio refponderent Cetđ́; non voce tantùm, fed re ipfa horum atio nouisEuangelijcultoribus conferuanpromouendis quàm maximè accómodata. m circumfpectè oner ofa leges fortunis Indorum indicenda.

\section{A P. X V.}

umeraui hactenus omnes, vt reor, Patrerum functiones, inititutionif́ć; huius cauuas intuentes ijs, quas cernimus, legibus ipes hanc Indorum Remp.condiderunt. In rbistregicnibus, apud Orientales praferias effe rationes neophytorum inftituenn non ignoro:neq; verò difputo, an noiltrac longè illis inferiora fint, minufquead fa , quam quarimus, accommodata. Fuiffer fis alia Reip. forma commodior, \& ad Iefu trnotitiam confequendam nouis gentibus iucundior. Quanquam, vt dixi fupra, qua sbarbaris incommoda acciderunt, hominagis nequitiæ, quàm adminif rationis viferenda funt. Quamuis enim rectè \& fapiênftituta Refp.quamuis æquis legibus temi, facilè improborum temeritate violatur, it nihil, quod non humana peruerfitas, fi juatur fibi, cóuertat in peius.Viderint alij, cui præferendú fit. Nos ea omni collatione rmiffa, præfentia, \& nobis nota tractamus, fuperioribus adijcientes, caufas eas, quas $i$, noftris ve Indi cómiffi fint, oportere omivtriufq; fori,externi inquam, atq; interni ibus effe notiffimas. Quibus ex omnibus repiêteró́; a nimaduer fis poterūt profectò legiflatore

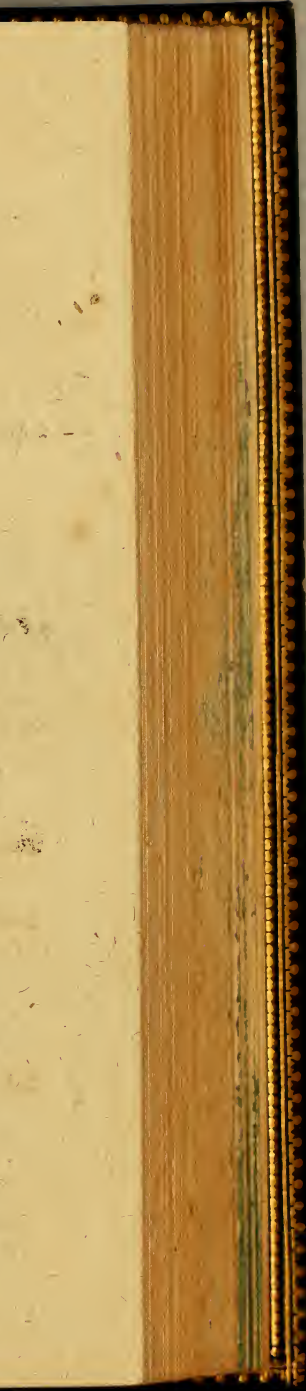


304 DE PROCVRANDA INDOR giflatores ftatuere, quid tributi gens quxq dorum Patronis fuis foluere debeat. Idque nevitio, \& errore decernant, perfpicient quantum, \& quibus è rebus prouétuum cor dè omnino poffit afferre, tum verò cum ra metientur, impofico oneri, ac functioni ex $d æ$ fuæ, quantum patronis affignare par eri ex $x$ quitate, \& prudentia moderabuntur, $v$ aliorum remiffio \& indulgentia, aliorum,

à.cor.8. poftolus ait, fit tribulatio. Et facultatem erg dorum, \& præpofitorum operam, atque of tiones intuebitur fapiens Reip. moderat tributa taxer, atque conftituat. Quram fanè cultatum, $8 z$ gubernationis rationem fimı eundam in cenfu imponendo, \& vel aug

3.P0 2.6.8. vel relaxando Arifoteles quoque ad Reip. feruandam incolumitatem valde commen quidem excedat, inquit, populus populiqu bernandi difficultas, (vt ego interpretor)al tur cenfus fecundùm multiplicationem: fi rò deficiat, relaxetur, ac minor fiat cenfus tio. Quo fanè fpectaffe videntur nonnulli g natores noftri. Iam verò vlterius progrec quantum ex vnoquoque viritim exigi opo \& vtrum hominestantum cenferi debean etiam fortuna, ve diriores plus tribuant, 8 ufque noftre confideration is fines egredit gum prudentix potius id vniuerfum relin dum. Nobis, qua caufa fit iufta tributorum corum, 22 ad quam regulam debeant tempe expofuiffe fatiseft. Illud taneummodo a nendum arbitror, tam grauem elie hanc nédi cributa prouinciä, ve nifi multa accur confultatione viroium prudentium; \& 5 
SALVTE. LIBER III. 3OI rum, atque, quod caput eft, ab omni cupifpecie alienorum res primùm agitetur, 2 que manifeftè conftet, quicquam decerneege fancire valde temerarium fit. Si enim uatas de fundo, de domo, de legato controsfiniendas; folent homines non contenti ribus, Regios etiam fenatus adire, $8 z$ è fafirmorum indicum fuffragijs fententiam are, quanto obfecro amplius, ac maius eft, totius gentis perpetuo cenfu agitur, vbi iiffma iufti, \& xqui ignoratio damnum ortunis innumerabilium hominum fem um? Quamobrem feueriffimè fimul atque fimè komani Pótificesinter atrociffrmos fedi Apoftolica referuatos illum femper andum putarunt, cùm domini Chriftiani orum fibi fubditorum ceruices, vel houis num oneribus premunt, velanctioribus ant. Quæ vel vnica res negotij magnitudi opiosé perfpicueq́ue declarat. Neq; enim teft Proregis, Prefidifve, leue, aut venia merratum, vbi velfudio partsum, vel rei fcendx negligentia, vel proprij fenfus fiin tanto negotio labitur. in confe Sionibus $P$ atronor um audiendis $\int \mathrm{an}$ cerdoti proutidendum.

C A P. XVI.

verðde Principú legibus magiftratuumue fententijs cenfere ron intereft caterouibus potius praceptum eft, ne contra iu- Ecil. 8. udicent, \& ve pareant fiue Regi quafi pro- s. Pet 2. ti, fue ducibus ab eo milfis. Certè Chri- Matt.22, ominus, neq; Cafaris centum, neq; facer-Mattb. 17\% Y dotuna

In 4. Cafu bullecend Domini 568. sylu. Excōo. $70.54 \mathrm{Ga}_{0}$ billa. $3.5 \%$ Nass C. =7: num. 58.

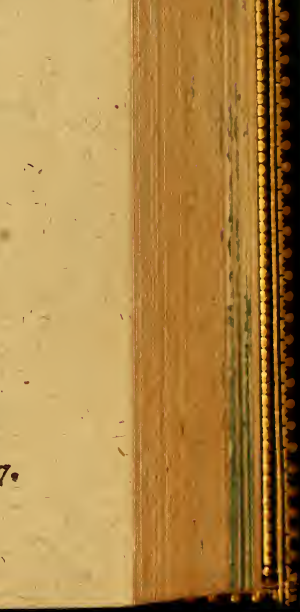




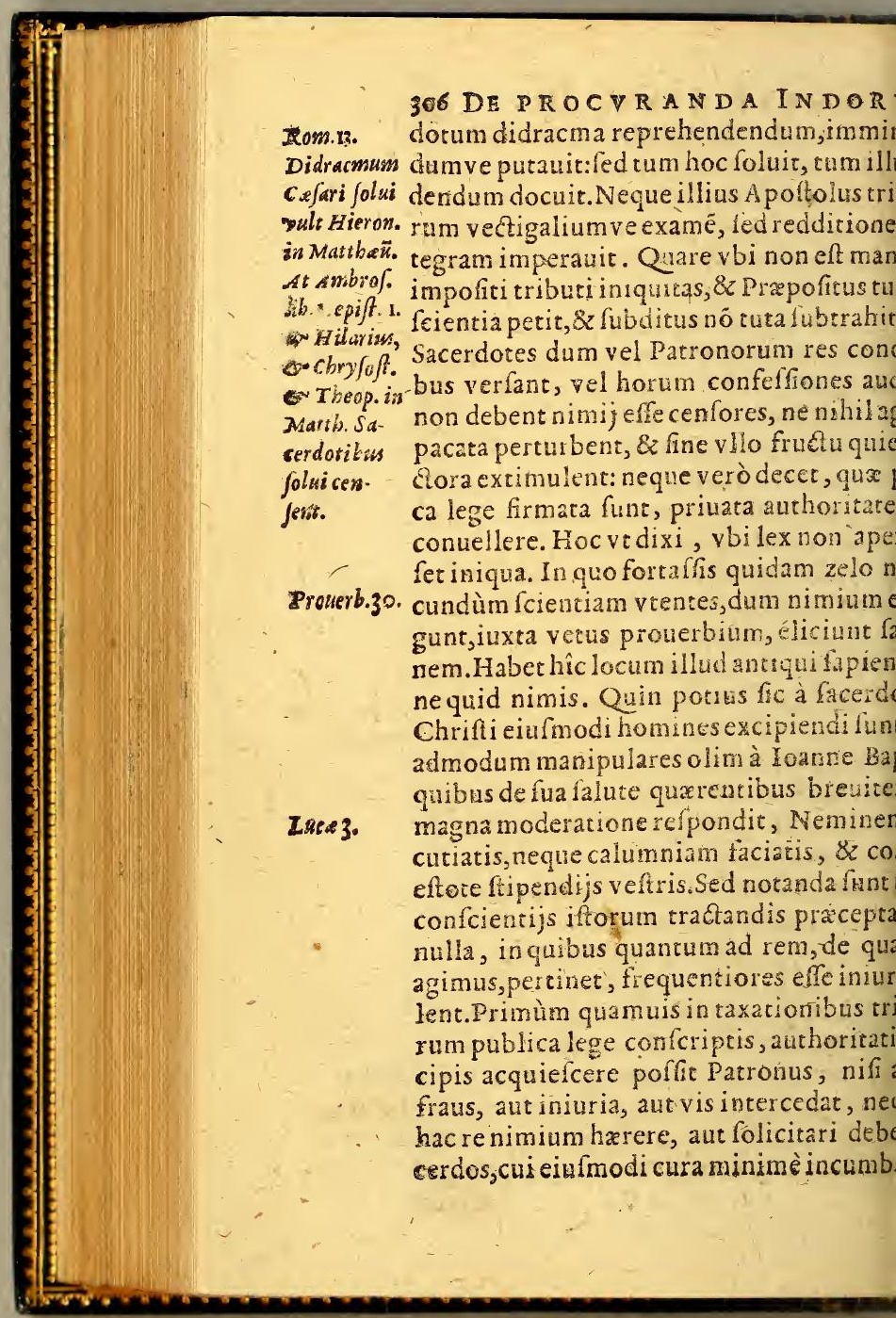


SATV TE, L I B ER III. 30? en, \& hüc \& illum oportet, fi Indus aliqua fa peculiari non fit nifi magno fuo detrifoluendo, non pofie tributun ab eo tutò Exemplis res fiet perfpicua. Fortè accidit, i inclementia agricola fi uges, vel vitiatas, rexiguas collegerit:accidir, ve agrotaret, tugurium ignis depaftus fit, velouicula interierint. Hîc fi Patronus rigidè tributü ron. cap. 49. $8 x$ infelicem Indum, cuiustenuifíma, 8 tantùm res eft, conijciat in vincila, aut nuletatum dimittat, magnam facere iniuutanduseft. Nam etiamfiex mutuo, aut tatione ifla ille deberer,tamen cú tã to fuo foluerenemoæquus cogeret, cum Proeuerè increper eiufmodi rigidos exactoens: Percutigis pugno impiè, $\&$ omnes deEjais s?. veftros repetitis.Praterea verò, vteft fufinitum, tributum nullo modo debet nifi qux habet, commodevehabere potelt, con ifibi familiać, fuftétatione feruata. $Q$ ux aliqu, lubtrahantur, neque premi moleet, neque in tequentes annos prafenti exonerari. in qua re nonnulli noltri liberaaberi volunt; quod ea remuttant, quae re renon poffunt. Alijinhumarla atrocique tione eruitutis genus edicunt, ve tamdiu re cogancur, quoad ipforum arbitrio fic ftum. Illi quidem non ad modum admiràid faciant, quod neceffett, fat: hive ò setiam deteftandi, quod ius 1uum inurıă m putent. Acque hoc ett, quodolim ian-

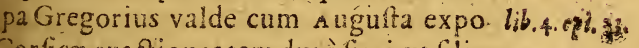
Corficæ exactiones tam durè fieri,ve filios nfulares vendere cogerentur, ve tributa $\mathrm{V}: \mathrm{z}$ perfols

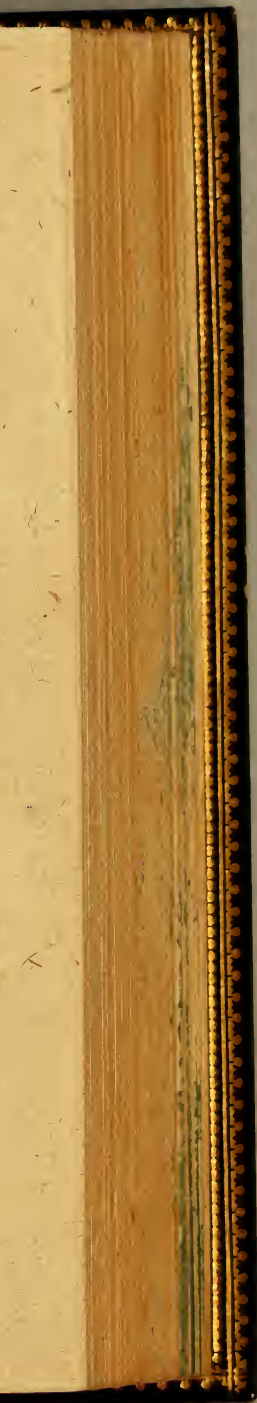




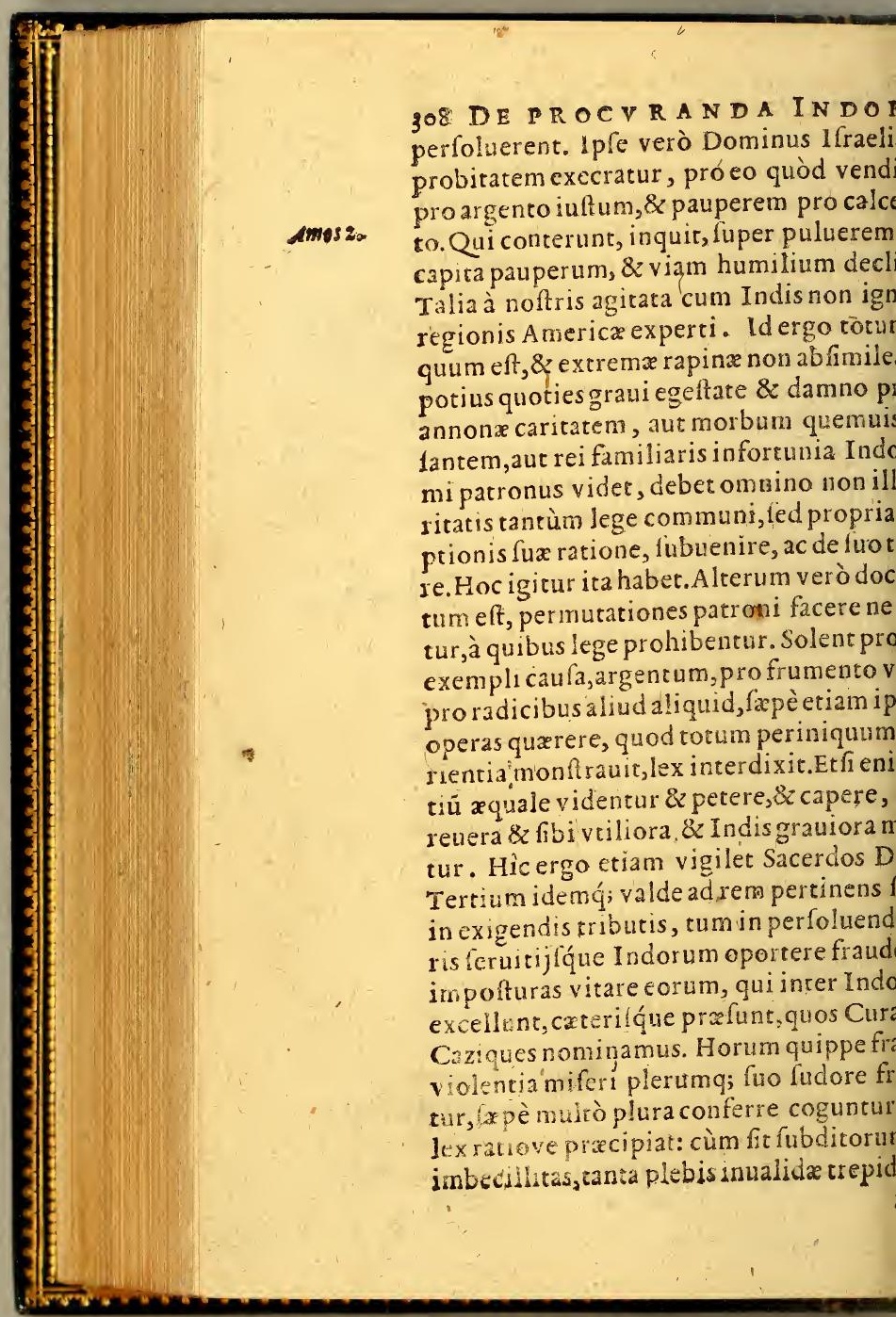


S A LVTE. IIBER III. Zं० utire quidem audeant contra fuos illos la$s$, fed viui ac videntes pereant potius, quả im imperijs minimum obloquantur. Hanc rxporentem tamque diu expertam tyran$\mathrm{n}$ noftrifufceptores compelcere certè det, atque eripere inopem de manu fortiorú, res habet: vtrique compoifitò fabulan aiftis illi fponte conniuent, illos iffi patienrunt:vt fimile quippiam paræmix lupi, atulpis agi videatur. Q ood malum quàm laeat, nemo non fentit qui res Indicas vel nis digitis attigit. Remedium vero quale Ire liceat, ignoro, cùm inde pernicies proatur, vnde falus maximè petebarur Sed pulege, vt eiufmodi fceleri, \&x dolo occurraaueriiam dicitur, häct enus certè caucum idemus nihil. Vecumque id habeat, peruefpiritualis medicus, an hoc quoque loco, let virus in fideat, aperiatq́ue diligenter, ac refecet, nec parcat igni, fiopus fit, quippe lethali profundoǵ; wlcere, feueriora medita tutiora fint, Ac neficio an hoc loco de maatibus, facerdotiburqúue vfurpen illud faneonis, inferioruth ordinum culpasad nulagis effereferendas, quàm ad defides negli- Epift.36. ad elque rectares, qui multam fxpè nutriunt Nicetem.dif. lentiam, dum auferiorem diffimulant ad- amo re medicinam:

De feruitio perfonali Indorum.

C A P. XVII.

uitur, vt de feruitio perfonali Indorum feramus, feruicium perfonale folemus ingere quicquid vrilitatis ex ipio haminum

$$
\mathrm{V}, 3 \text { dabore, }
$$




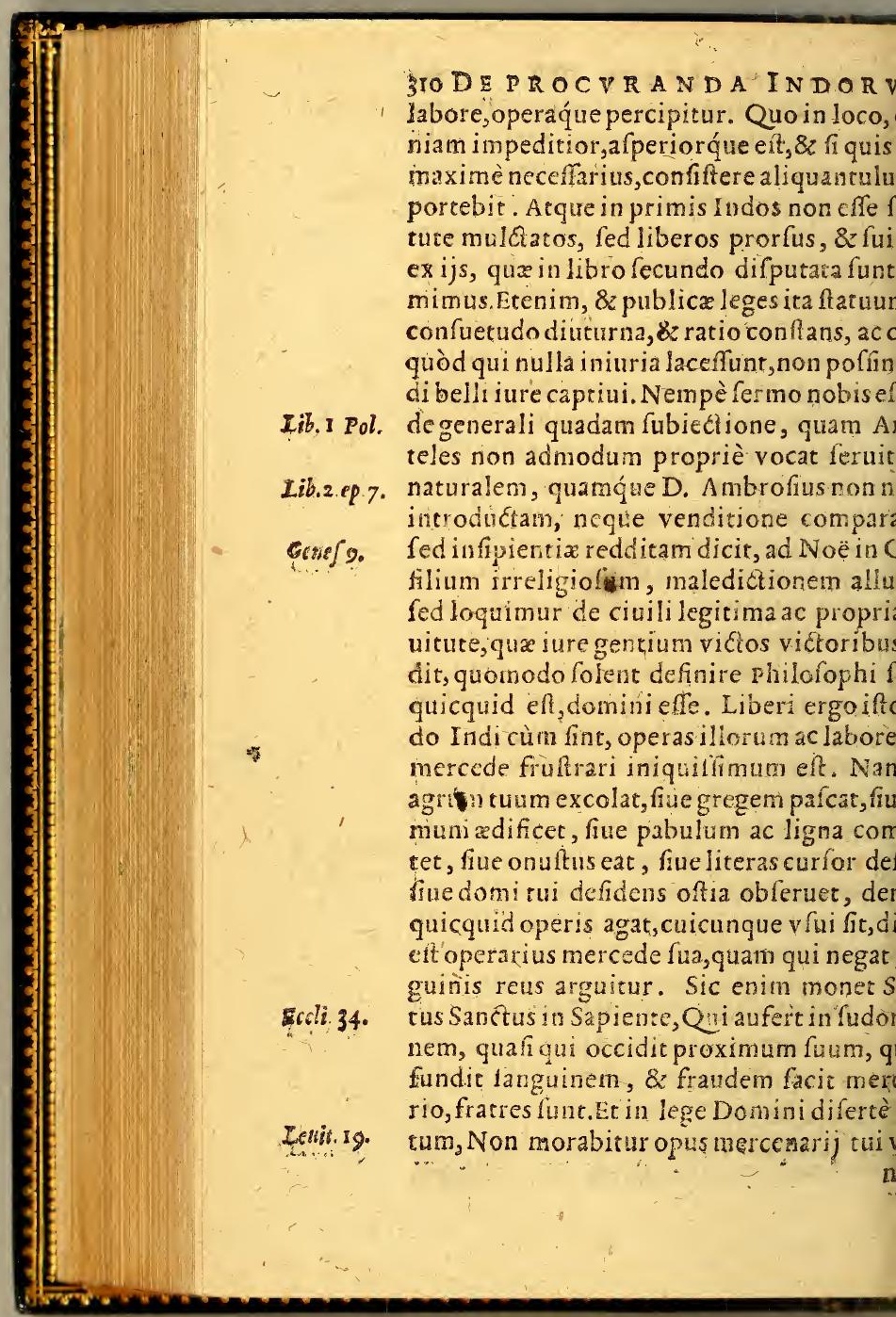


SA L V TE. IIBER IIT. รIT Per Malachiam quoque fe Dominus mi-Malach. $s$ ? teftem velocem in eos, qui calumniantur edem mercenariorum fuorum. Neque miIacobus A poftolus, Ecce, inquit, merces o- Iacob. 5 of $^{\prime}$ iorum veftrorum, qui meffuerunt regioeftras, quæ fraudata eft à vobis, clamat: \& or eorum in aures Domini iabbaoth introirerribilis fanè clamor, qui pro fubducta ede aures Dei aduerfus potentes, $\&$ diuites pellat. Quod fi in alieno iumento oneranel equo ferendo pretium domino iuftè reitur, cur non iniquum valde exiftimetur nis liberi corpus oneri laboriue addiceeque quicquam tamen foluere pro opera cata? Illud quoque vigilanter audiendum, fermo diuinus non eos culpat, qui mercepenitus abnuunt: immane enim id atque atum relinquendum putauit, fed cos notim perfringit, qui vel morantur vel imunt, vel quouis modo defraudant pretium is alienni. Ne mihi igitur obfoletum à te ciporrectum cómemores, ne veftem annuá, elli portiunculam illius $v$ fibus relictam as. Adelt iufus arbicer Deus, qui fe etiam n propaupere \&z quidem velocem pollice-Malack. 1uæres, quænam xiltimatio iufta fit, ve fcruomnis tibi eximatur. Si lege prafcriptum etium, vt in rebus plerifque eft, ne alium as interpretem, quicquid de legitimo detra. apina eft. Si nulla lex eft, communis aftimanorum, atque prudentium ponet modum, iam vtriufque locantis inquam $\&$ condus mutua pactio, dummodo dolus omnis, \& blit. Quototogensre mulțumac frẹ̀ pec.

$$
\text { V 4. } \operatorname{cant} 8 \text { \& }
$$




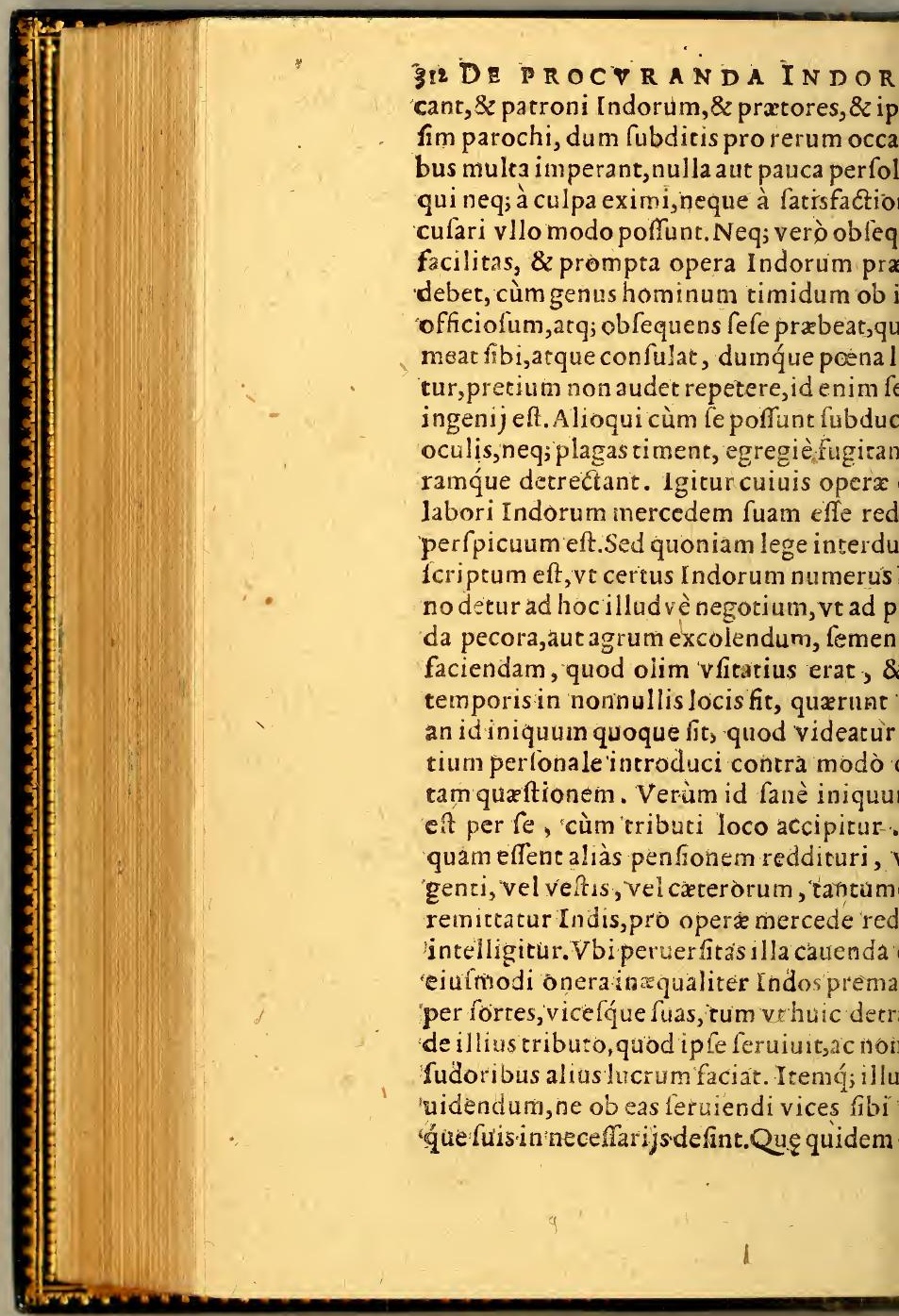


S A L V T E. L T BER III. 313 refacile eft, perficere verò, aut infecta elare per quàm difficile. Libero homini edem reddi oportere pro opera oftenfum rum verò liberam quoque effe oporteat ilperam, ac nullo modo cogi, à mu'tis mejuæritur. Mouet enim nó parum hinc, quod homo fi cogitur, liber-non eft, atque adde $\mathrm{d}$ opus inuitum trahit, non leuem facere ur iniuriam, feruile en im eft pati vim. Inrò non parum quoq; vrget, quod fi barba$m$ ingenio, \& voluntati indulgendum eft, operis vnquam fiet, nihil negorij confi$\mathrm{r}$, quippè qui otio defideant, ac fibi etram vix neceffaria laborêt:alios verò nifi vi aut perculfi, nihili faciant. Atq ; hocloco non atamus de ea coactione, qua affertur cùm um intereft, vt cùm fibi oppidum adefue care iubentur, aut templa extruere, aut os colere, cęreraq́ue rei, vel public $x$, vel faaris officia, eft enim in aperto res, cùm etia nui omnes ad ifta compellantur, cum miliacifue negotia ita fieri exigunt. Magıftraùm ifta \& indicit, \& vrget pro offirij fui ere facere non dubitatur. At Refpublic. hxc cana cuim partim Europxis, partim Indicis inibus conftet coagmentataq́ue fit, cumque multa, quæ nullo modo Hifpani ip his locis fe faciane, propterea quod vel laboriofa, vel ida ducunt, ¿r vt quàm maximè velint, non unt tamen canta perficere, quale eft, humum dere, rudera egerere, lateres cogere, onera lare, iumenta agere, caterá́; feruslia, qua fint, breui omnisciuitas deleatur, necere dalia igitur fi lponte fuabarbari minumè . 3 ducar

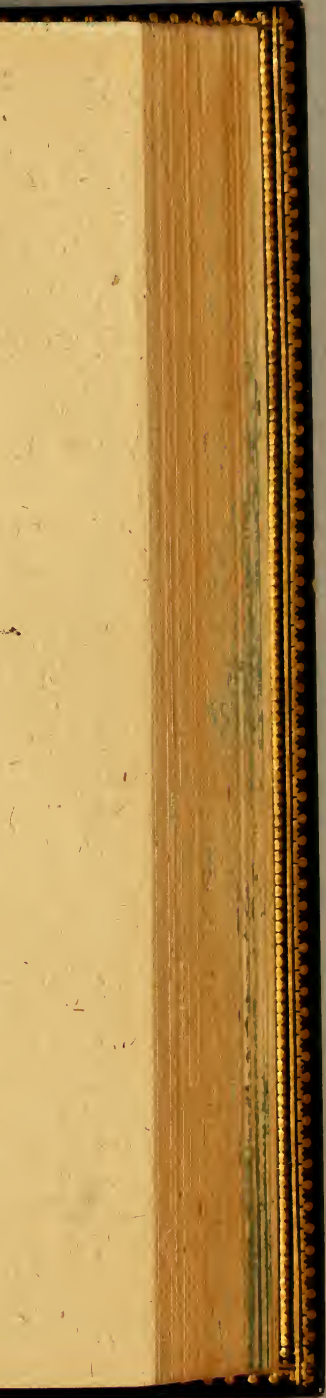




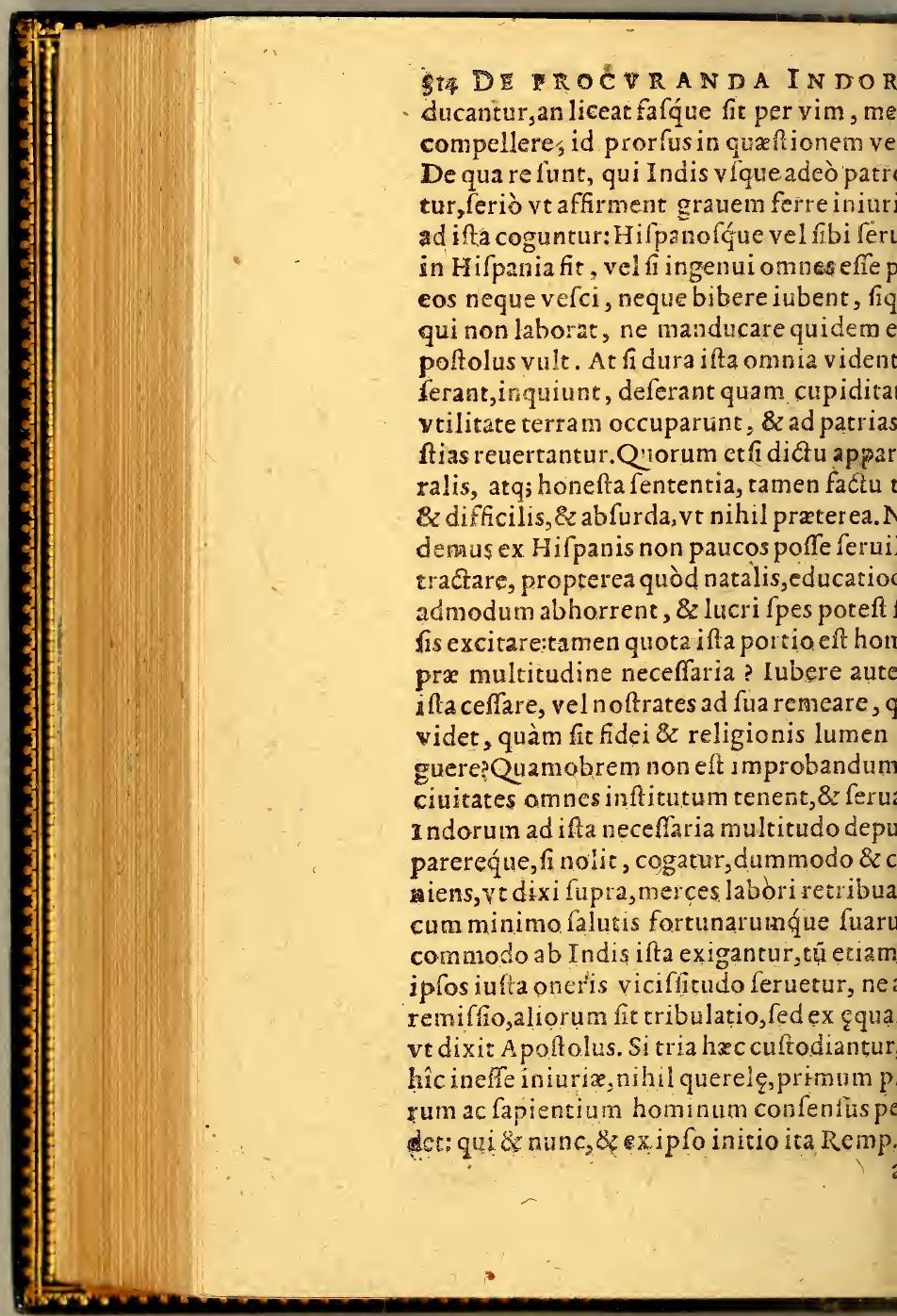


SAIVTE. LIBER III. उIT iftrandam intellexerunt. Deinde ip forum orú confuetudo perantiqua ab ipfis Ingaegum exordijsante Chriftianum nomen m multis frculis conferuata. Poftremò ur $x$ hoc habet, vt ad totius corporis, $\mathrm{fa}$ , ciuitatifue conferuationem neceffaria laborare iubeantur. Neque enim oculus cterram jubendus eft, vel culinariam pailias exercere. Vniuerfa porrò Indorum, Hifpanorum multitudo vna eademạ́ue b. habenda iam eft, non dua quadam inlifinetz: fiquidem, \& R ege, \& lege vtundem vtrique, \& vtrifque tribunal, \& ius iud, atque aliud, fedidem certè. Quare Indis nofris hominibus opera impen$r$, non exteris \& alienis collocari putan$t$, quod fortaffis fallit nonnullos, fed fuis ciuibus : quoniam \& fi tefta ferro malẹ et,iuxta Propheticum vaticinium, tamen in ftatux huius pedes ambo componunt. mirandum non eft, fi tefta ferro premaerdum, illud potius optandum, ne peniminuatur,ac diffipetur.Deniq; Ariftoteles as ciuitatis infrustor, toto fuo primo $\mathrm{PO}$. ,aut nihil agit,aut hoc certè obtinet, vt fe. m naturam in Rep. quidam feruiant, qui idonei funt, quidam imperêt, qui ratione præitant, dum modo alijs alij adiumento culofó; alter ad videndum, pedes alter ad landum mutuet. Qua fi vera funt, manifeff non effe ab aquitate a licnum, quòd pudiuerforia per vices fuas, quas mitas ipnt, Indi \& incolere, \& viatoribus neia prabere pretio dato iubentur, quod ex ve - 


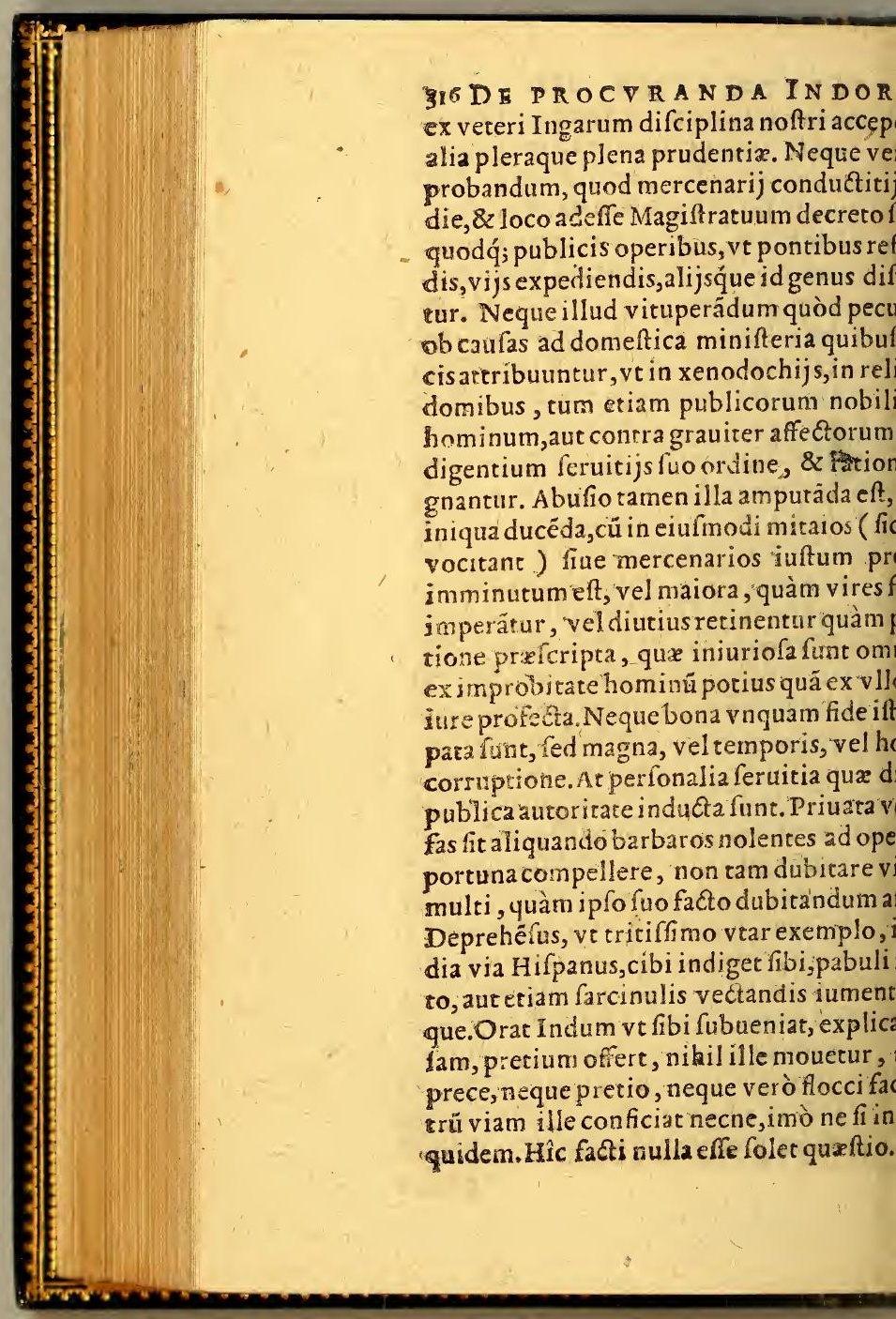


S ALVTE. LIBER III. cicius Indus capillis trahitur, calcib ${ }^{9}$ tüd idulò ftatim, atq; copiosè cúcta ad́miniadeo vt pleriq; iactent noftratiú, perfuaú effe à fuo Zupaio, id eft diabolo, nihil ve tianis fpontè impertiant, fed per vim om$\&$ iniuriam, Qux quanquam militum li, \& rapinæ fabula oppórtunè inducta eft, res ipla non adrodum abhorrere videvero. Etenim qui barbarorum confelfiones eteri fuperfticione idolorum facrifici ho uoque audiunt, feruntur grauiffimas poeinı̣ugere, qui fe fe aliquid chriftiano proconfeffus fit . Neque mirum eft eò vquie redi holtis antiqui in Chriftianos odiut, in quibus poteft modis transfufum. Sed redeo m. Cüm eiufmodi angufize incidunt aut niles, quod in his regionibus percrebrum uid Deum timenti viroagédum fit, dicam, ntio. Primùm fi poteft pactione tranfigi, id ò prius ac melius. Vbi non potef, fi comè conueniri poteft magiftratusaliquis, qui ica autoritate cogat,adeundus eft. Hic quoi defit,ve deeft perfæpè, ac negotijgrauitas $t$,nihil aliud pręcipi poteft;neque breuius, te planius, quàm vt leges neceffitatis obferqux tibi neceffaria funt quærens cum quàm imo proximi detrimento. Honefta certè ali vis, atque compulfo afferri poteft, \& terrouxdam fignificatio, tanquam pueroalicui a, \& commoda contemnenti. Qua in re mulplerumque iufti, \& æqui limites tran filiunQuorfum enim verbera, fi verba funt fatis? rfum plagæ, fi vel metus incuffus hominem igit? Iam yerò an onera baiulanda Indis imponere 


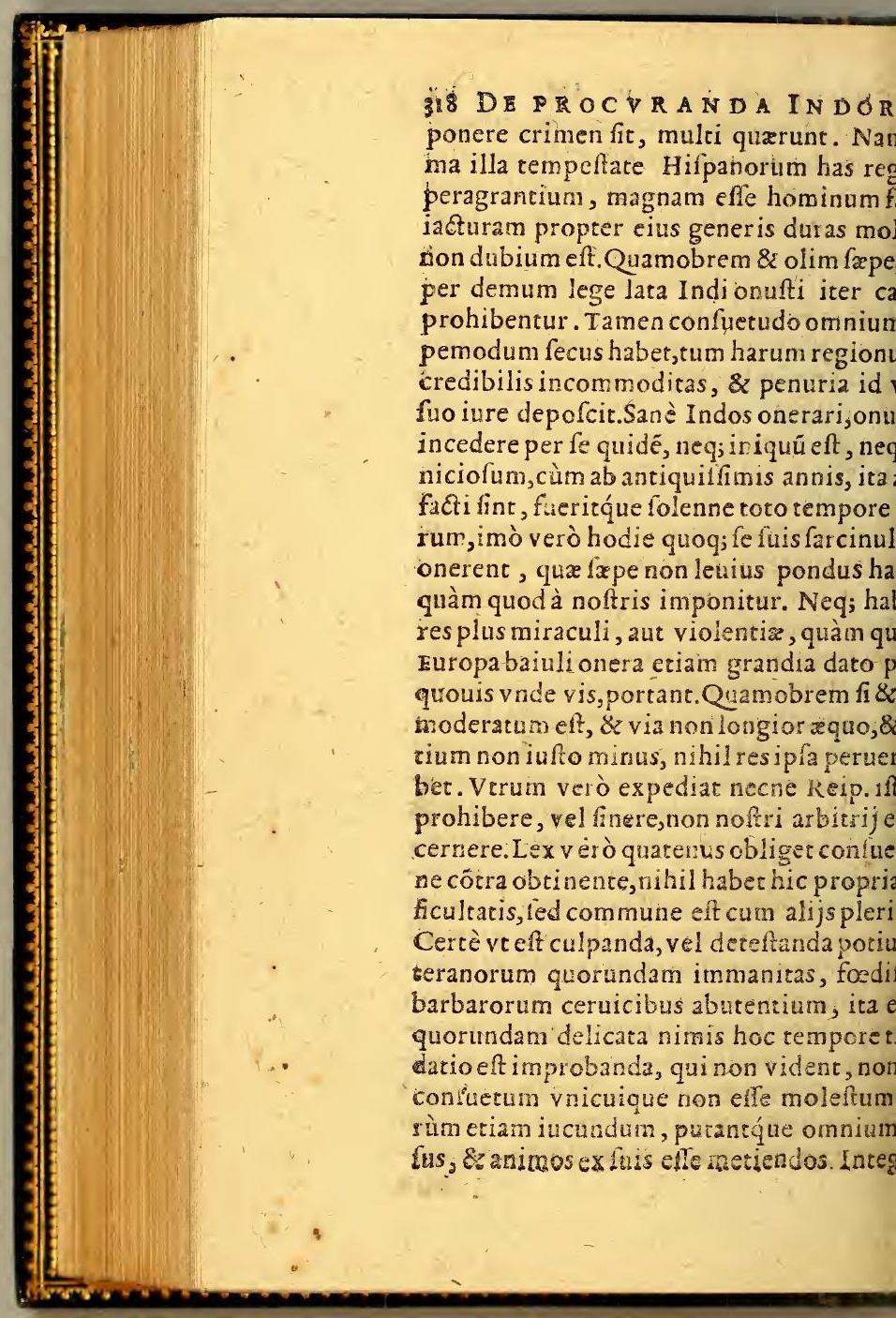


S A I V T E. II B ER III.' m diem meteridis frugibus infudabit ruus, aut aratro ducendo, qui fi quartạm hotem vtrumque genu humi figere iubeaecem fibi præangiet certam. Eft fuus vaiiucundus labor. Itaquegentes Indorum nos baiulandis oneribus peraffuetz, fi 2 us non vrgeantur, neque iniuria, neque modi quicquam !ubeunt,cxtera, vr dixj; ata fint, pondere, labore, pretio.

\section{De metallorum operatione.}

C. A. XVIII.

illud duriffimum videtur imperium, cum etallis effodiendis mancipantur, quod v $f$ eò ærünofum \& graue à prifcis eft iudicavt quemadmodum nunc ad triremes dampropter infolétia crimina homines faci, ita olimad fodienda metalla damnarenod capitali fupplicio proximum erat. Ad to homines liberos nihil mali cómmeriigere, inhumasum, atque iniquum vald te ar. Deinde compertum eft eo in labore sabfumi, vel fatigatione fractos, vel difne extinctos. Horror eft dicere, qua miium intra ipla abditiffima telluris vifcer fcentium facies fit, quavorago, vt ver us ipfe patere videatur, neque ineptè Poë$\mathrm{m}$ gazas apud Plutonem reconditas fabu nt. Chryfoftomus fui temporis laborem num in extrahendo metallo miratur, tq́ue eloquenter, verùm illa omnia pra is fumus, \& v mbra funt. Perpetua atque da nox, aër craffas \& fubterrancus, defcen 
320 DE PROCVRANDA IN DOR fus prolixus $\&$ perdifficilis, cum duriffim faua contentio, ftatio periculofa, fi veft nutet, actum eft, humeris vectatio perm per gradus obliquos, \& malè hærentes af cæteraq́; etiam cogitatu grauia. Achæc ci genti ven $x$ in præruptis plerumq; \& ina rupibus fitæ fint, terraq́; inhabitabili,vt tur,à patria extorres veniunt, folú aërem tanres, facillimè valetudine afficiuntur. verò vbi argenti viui effodiendi labor eft vel tenuiffimus halitus, cùm igne circu fum exhalatur, præfentem necem affert? de gemmis explicandis dicam? In oppi de la hacha, vocato cùm effem, comperi Indorum feruitutem extrahendis conc funmo mane in ratem imponebantur, gus defcendebant magnx fxpe profunc vbi integrum penè horæ dirnidium halit preffo vrinatorum more, conchilia, oftre quirerent immenfo labore, fummo per ic bus femper parciffimus:commercium on terdictum: cuftodia omnibus nocturna co nis:vitæ racio molefta, ac liberis hom prorfus aduerfa. Hxc diu actitata, ferò ta nimaduerfione digna emendata funt, fe tandem Rege catholico id femel, ac bis, ac inquirente, \& agente. Itaque Indi omnes declarati funt, \& ab eo labore ceffare iuf cunque fuperitites am diuturno labori ti lunt. Ad eundem ergo modum, \& metal effodiendorum non admodum diffimiles næe fiti debere non paucis videntur. Hal nim cùm iniuriam contra libertatem In quod leruire cogantur alieno lucro cum 
SALVTE. ITBER III. $3 A E$ ommodo, patria fxpe liberifque defertis: rò exitiale periculum, cùm cæli mutati,oris moleftia, rei ipfius difcrimine ime videatur interitus. At fi metalla curari $\mathrm{nt}$, fi argentum è venis non eruatur fubradicibus montibus, vt ett apud $S$. Iob, $I_{0 b}$. in ex fluuiorum obicibus non cogatur, liaq́ue cæetera negligantur,actum eft, Innegotium \& Refp.interijt. Neq; alios fru ifpani tanto Oceani circuitu quarunt, ne a ex caufa, vel mercatores negotiantur, lices prafident, vel ipfi quoq; facerdotes 1q; Euangelizant. Argentum aurumós; : fe fubducat ex oculis, omnis frequentia, commeatio, omnis ciuilis \& facerdocal is fus breui euanefcet. Infulx Hifpanica \& 3 fancti Ioannis, olim quidem frequentif um auri materia circumfluerent, nunc pe:rtæ \& horridx, poltquam indigenarum a pretiofilfima metalla, qux iliıc ábun-laborari non poffunt. In omni hoc nuuo as prouincias doctrina maximè florere us, quas opibus quoque præitare confiat, oc commune empor ium omnes vndique ere videantur.Equidem néfcio verum pociam, querarne noftrorum temporum caitem, $\&$ charitatem refrigefcentem, fidem. rò in quoquam inuentam iuxta Domini Lms.1 $\mathrm{m}$, tot animarum millia ve Chrifo lucrinon fat is merces videri dignas, que no$\mathrm{m}$ animos excitent, auri argentiónue cupi$m$ longè plus valere apud nos, vt ifta fi denimarum falus pro nithilo fiar?An verd onitatem, fummamq́ue prouidentiam ad-

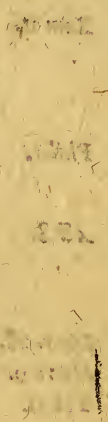




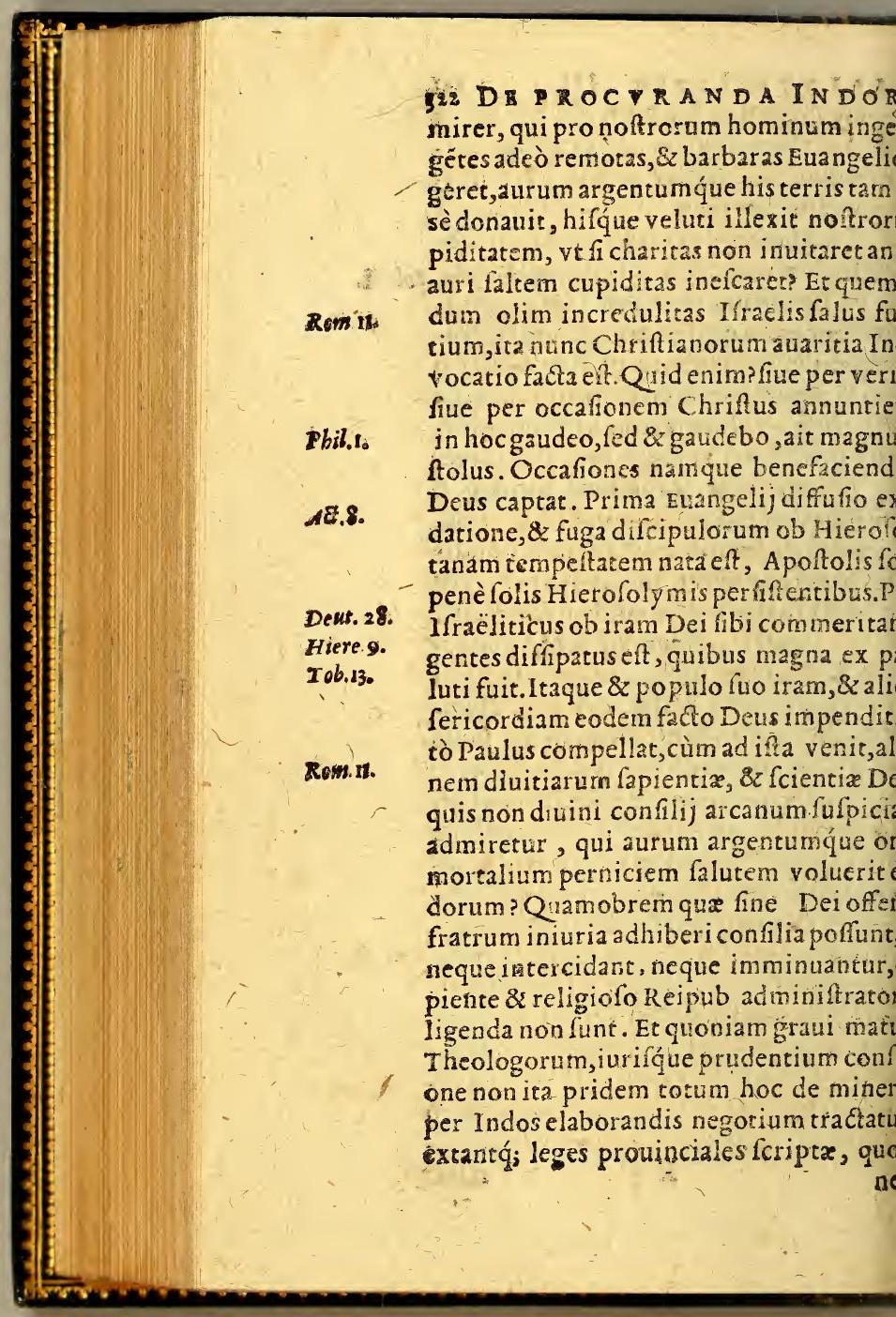


3A I VTT. LIBER III: 32\% uaue moderatione metalla eruantur, vt faommodiqúu Indorum profpecrum fit, non videor tantorum virorum fententiam imare, multoǵ̣ce minus leges alias debere pręere, quibus tam afpera Indorum conditio eretur.Tantùm capita repetenda funt, breque ponendâ, quibus eius rei facultas congatur. Primum igitur doctrına fpiritualis Ari in his, qui metalla operantur, ne defint, t qui miffas celebrent, qui in fidei rudimen udiant, qui morituros confeffione excipixteraq́ue neceffaria adminiftrent. Deinde letudini confulatur, ne aut contrario valdè vtentes traducantur, aut è longo valde tra. uocentur, aue laboribus immodicis sppriur.Mox, ve fortunis quoque fuis non peffonfuli fentiant, fed pretio iuf? tam inoleorú labor cópenfetur , finanturq́; lucella nterim quærere. Adhæc vt \&z valétibus opuna alimenta fuppeditentur, \& a grotantiolatia neceflaria non defint. Ad vlcimum ve riple diftribuatur commiodè per vices luas; utius contra voluntatem fuam à patria ab. ogantur, neue văa prouincia femper one, alia femper in otio degat. Quas conditioi, ve par eft, legitimè feruauerine noftri, que cdum à viris lapientibus enucleatè propo. unt, videntur tolerandi, ne commercio fi, cura quoque Euangelij concidat at fi neğtur hxc, \& acerbus cum Indis sanquam mancipijs agatur, viderint ipfi, quas Patri erum \& iudici orphanorum rationes redPfab. $8 \%$ ifint:
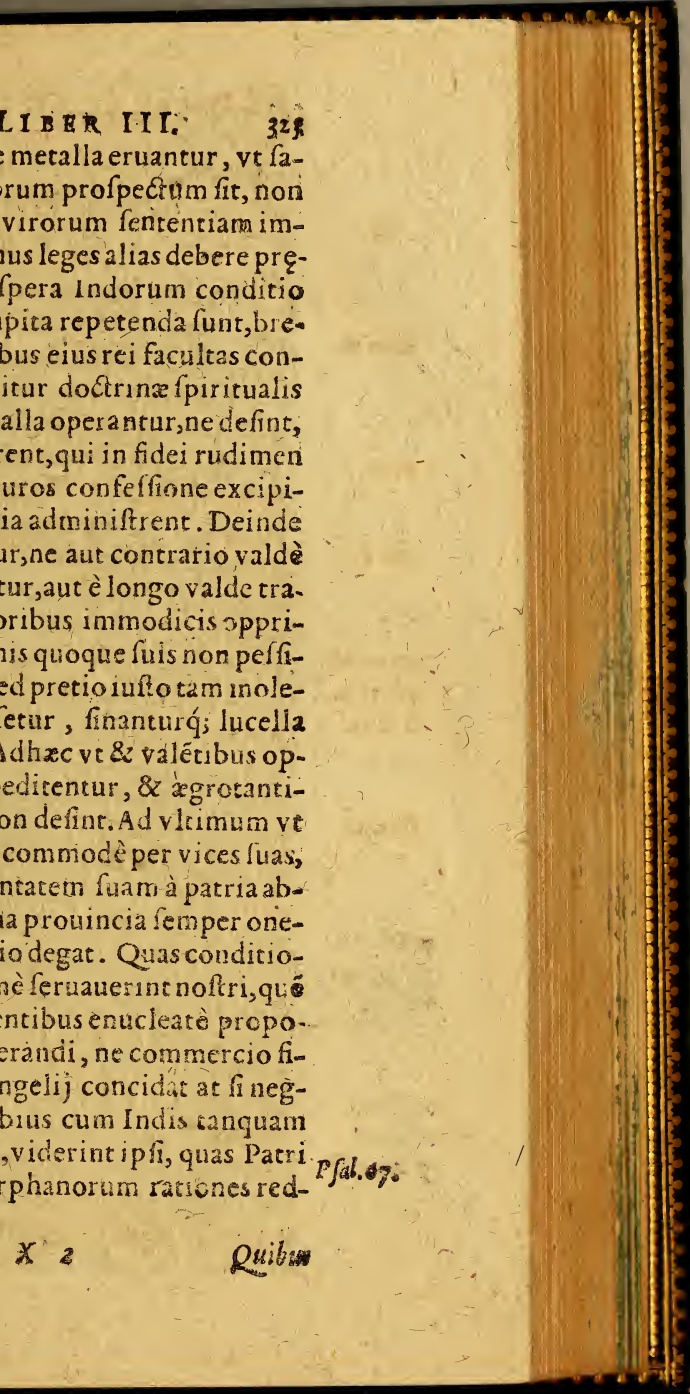


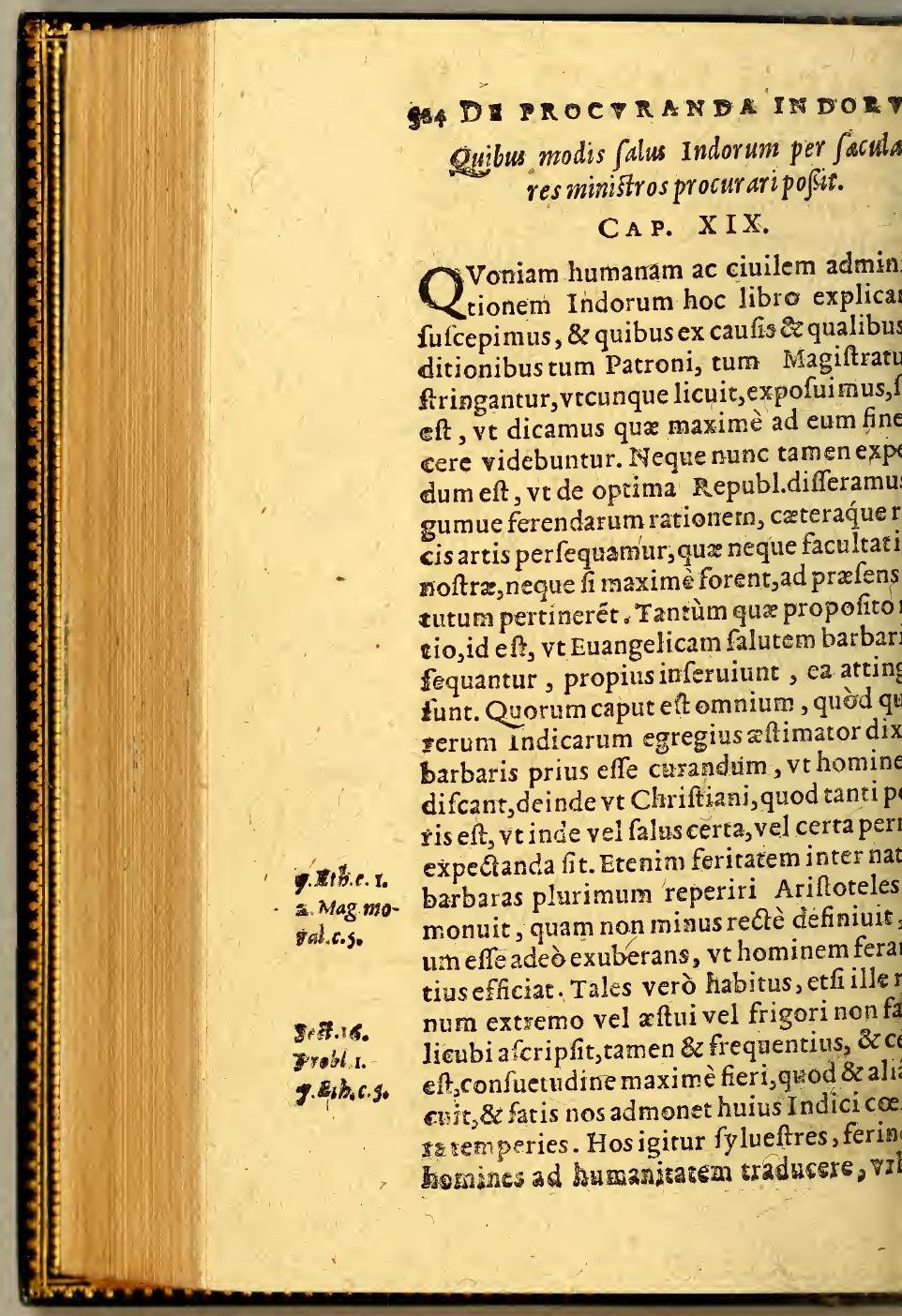


SA I $Y T$ E. II ER IIT. nftitutis accommodare prima debet effe noderatoris. Fruftra diuina \&zcoleftia do, quem ne humana quidem capere, aut cuerfpicias. Prodeft in ea re plurimum noim hominum confuetudo, prodeft cultus $s$ externus, atque obferuantia maiorum. int conuentus certis, \& diebus, \& locis, poe. e \& contumelix irrogatæ negligentix; hopramia rectè factis propofita:ex ipfis, qui ntiores funt, cæterorum magiftros, cenfoe conftituere. Ordo verò quidam tum opum,tum domiciliorum, vt non veluti cui fortuitas fedes eligant, tum verò vt in ectu eorum omnis actio fit, neque latebras finátur. Ad hxc permixta illa ac fine vllo tu fpurca habitatio, vbi fimul $8 z$ maritus, or, \& filius, \& filia, \& frater, \& holpes, \& ca fe atque fus cubat, accuratè auertenda eft cum licebit, qux caufa eft nullius pudoris, us paternæ reuerentix, generis quoque, 2 fexus contempti equinæ cuiufdam libiin obuia quxque fine vllo pudore graffanQuæ tamen neque breui omnia exigends neque defperanda vel ferò. Videmus certè parum effe perfectum, vbi nonnulla cura eratoris effulfit, qua fi confirmata, vigilanf fuerit, non dubium, quin alium hominum m efficiat.Vnus M.Francif́cus Xabier,if́que ciuili poteltate munitus, Infulam Mori ir ex immaniffima feritate ad miram mandinem traduxiffe, neque adeò longo temQuæ verò antiquorum inueterata confuene occalluiffe videntur, vt in meliorem for m uanferri nequeant, maioribus fua aman-

$$
\text { X } 3 \text { sibus, }
$$

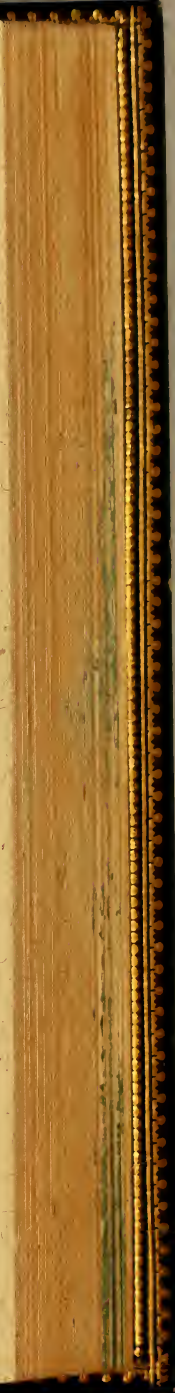




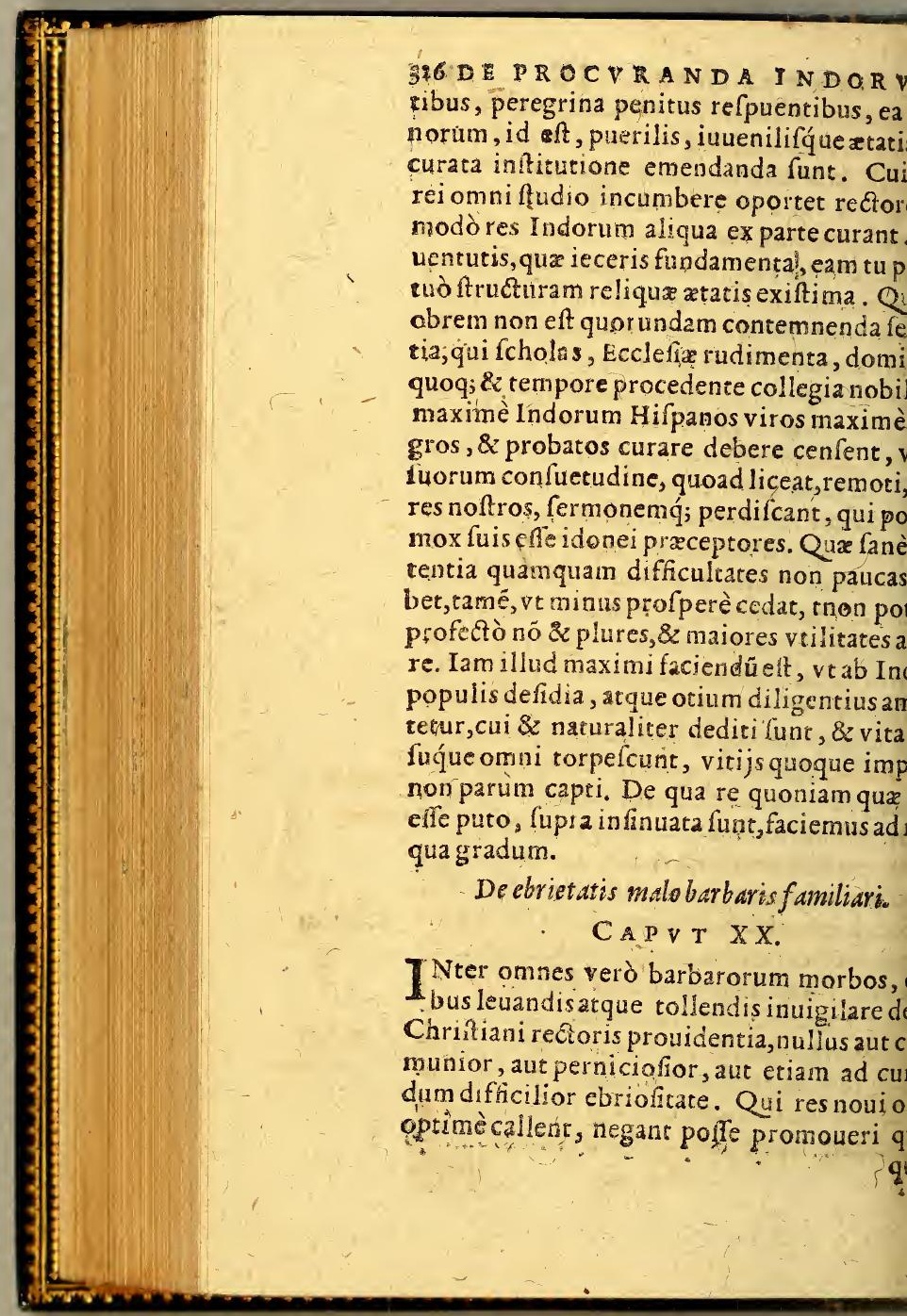


$S$ A I V T E. II BER III. n religione, ac ne in qualicunque quidem tione politica, nifi malum hoc latiffimè $\mathrm{s}$ ab Indorum finibus exterminetur. Ac tò mirabile eft in tot tam vaftiorbis naus repertis, cùm nullus vini v fus, nulla pe otitia extiterit, temulentix tamen vfque itium omnibus effe commune, vt pro raaculo fit, fi qui fobrietatem non odio, \& inia profequätur, id quod de Tucumanis, burdam alijs fane paucis accepimus, neffalsò . Quanquam v num illud ebrietatis $n$ incredibile eit dictu, quot artibus, quàm quàm exquifitis procuretur. Ex oryza $\mathrm{Ae}$ $a, \&$ Sinas expreffo quodam ac decocto reebriofas fibitemperare potiones vulga Noftri indigena plerique ex fruge fua anfa fermentum aqux inmergunt atq; exint,alij putrefacta potius vtuntur, vode So. pfis dicta efficitur, quouis falerno potenQuidam ex ramulis quibufdam arborum ptis fua vina conficiunt. Alibi ex palmulis fus liquor ebriecatis mirè efficax, quem eribus in vfu fuifie fcribit Chry foftomus. ani nonnulli ferui faccareum fuccum quiHomilin c.s.Ejai. Im medicamentis ita inficiunt, ve vehemen a potio euadat, quam illi Guarapum nont. Verùm quid attinet innumerabilestetia fpecies referre, vt quod in vna vite nalatere voluit, id peruería ars ad tã multa trã rit? Sed neque noum hoc eft, neq; noftrobarbarorú proprium. Scribit Plinius grauis $L^{2}$. 14. c.2a fuiffe Occidẽtis populis fuã ebrietaté fruadida, Pluribuf́́; modis, inquit perGallias, paniafớ, nominibus alijs,

$$
x^{4} \text { Hifpa- }
$$

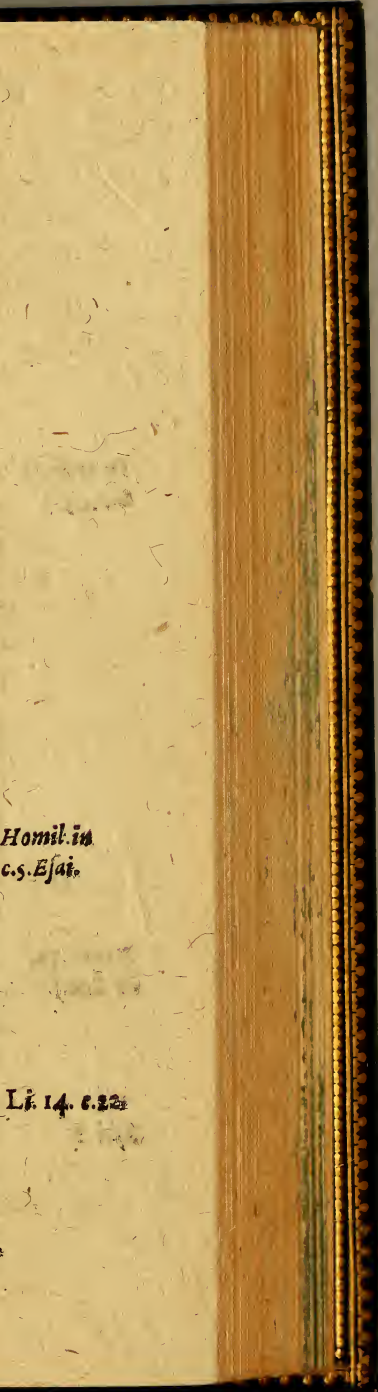




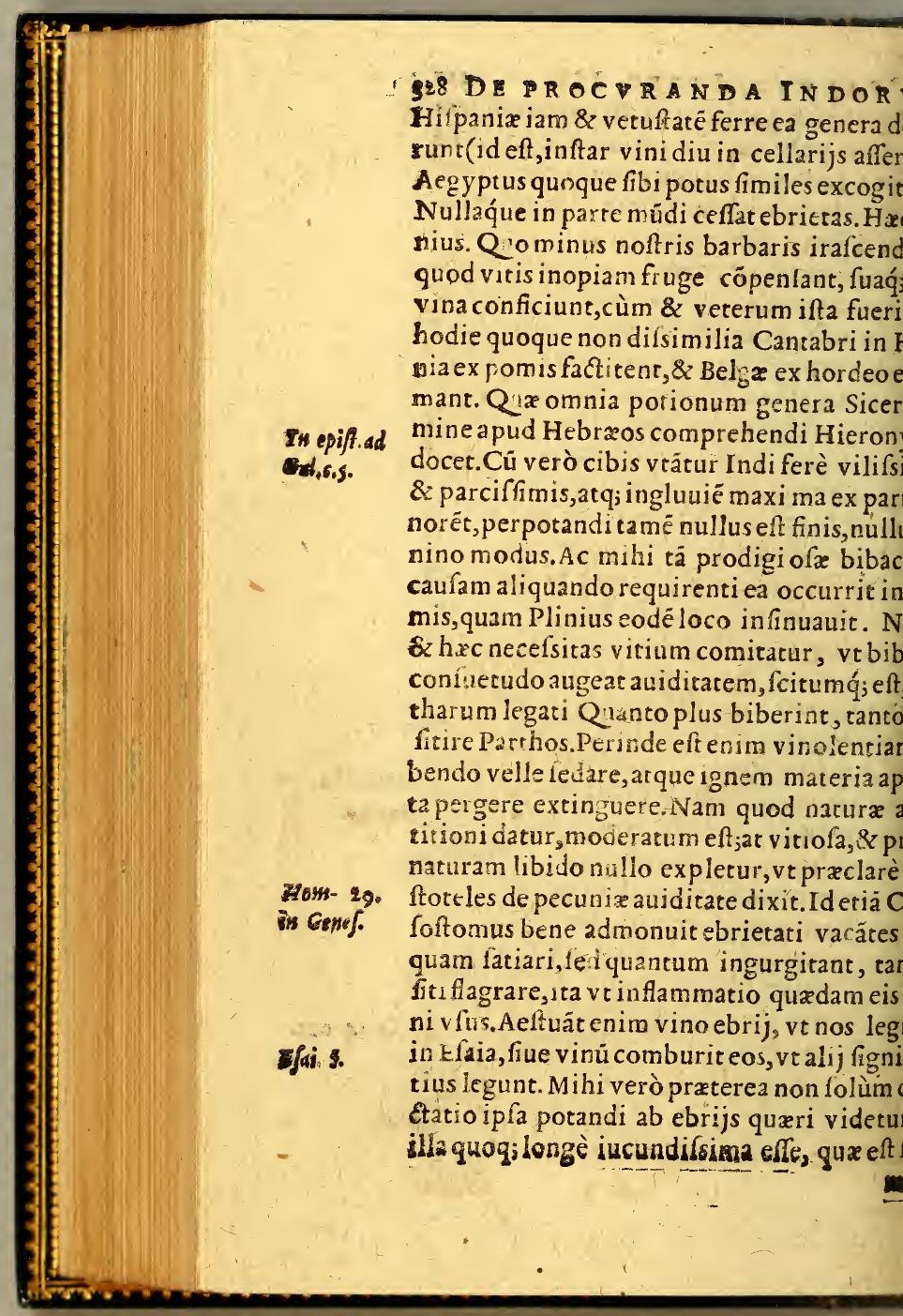


SA L V T E. LIBER III. felicitas, mentis emotio.Senfus illam cali\& noctem offufam cerebro, dulcem fibi effe ipfi barbari iaktant, $\alpha$ rebus ipfis corobant, cùm potionibus interdum vtanrquàm acerbis, interdum ne potioné quillam adhibeant, fed fucco pigmentifue naefumptis, in quo nulla effe poteft faporis tas, ebrietarem accerfant. Nam in quadam cùm nauigationis commoditatem expe, didici ex Tabaco contufo (genus id herad permouendum cercbrum mirè efficax) AEthiopicos naribus exorbere vim loliauemq́ue fibi ac diuturnam inde temulenxcitantes, pro magnis delicijs ducere, vt inis plagifque $a b$ ea confuetudine auelli t. Verùm præcipua caufa tam effufarum otationum,tamq́; ardentis frudij, Diaboli us arseft, qui nefcio quibus præftigijs inlamines noctes diefque bibendo confumefumma felicitate, promaxima religione fir. De his planè loquitur Sapiens cú idoarú moros explicat, Tot \& tam magna maem appellant. Aut enim filios fuos facrifi-sap.sef s, aut obfcura facrificia facientes, aut infalenas vigilias habentes, neque vitam, neq; as mundas iam conflituunt, \& catera. $Q$ ofia barbarorum, \& bıbendi canendiq́; v1udines, turbulentalq́; illas pernoctationes exerit, non poturfe melius fignificari diuàı per vigılias infaniæ plenas. Eam quoq: uort m fuiffe fuperftitionem, ve Deos lizos perpotandi licentia celebrarent, nocturcantiones, ac faltationes libidinis furorifá us multo mero dedicarế,, Philonis libri at-
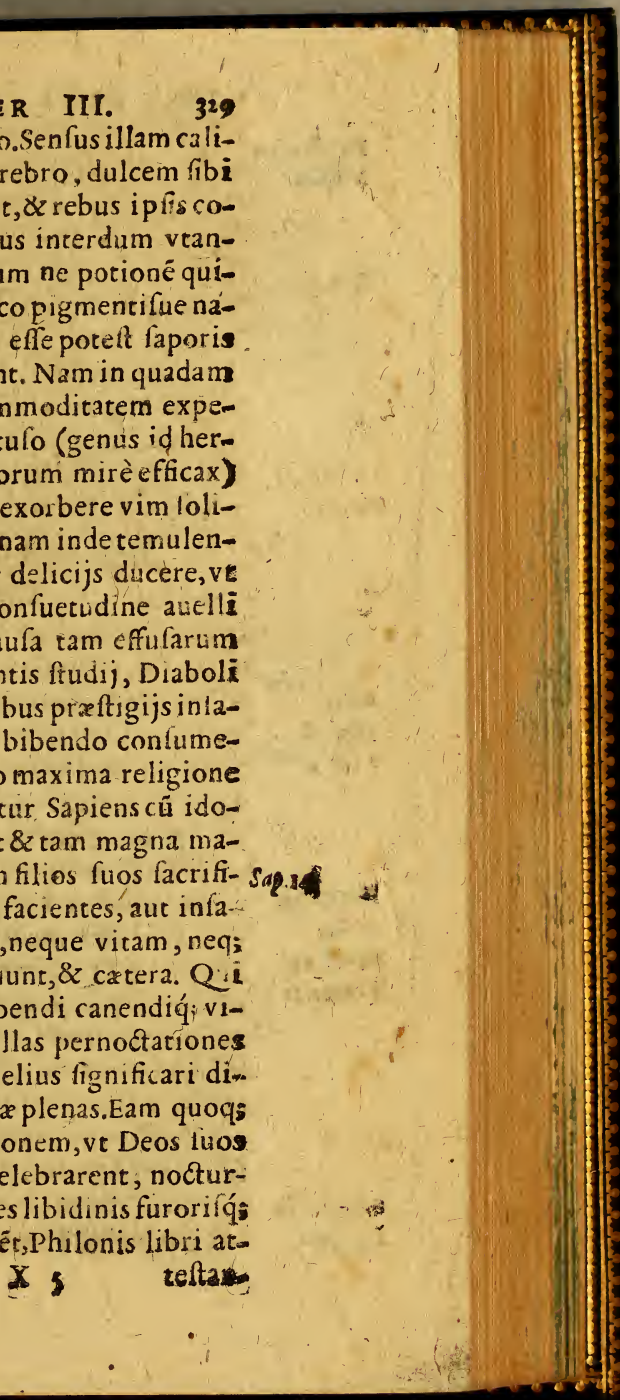


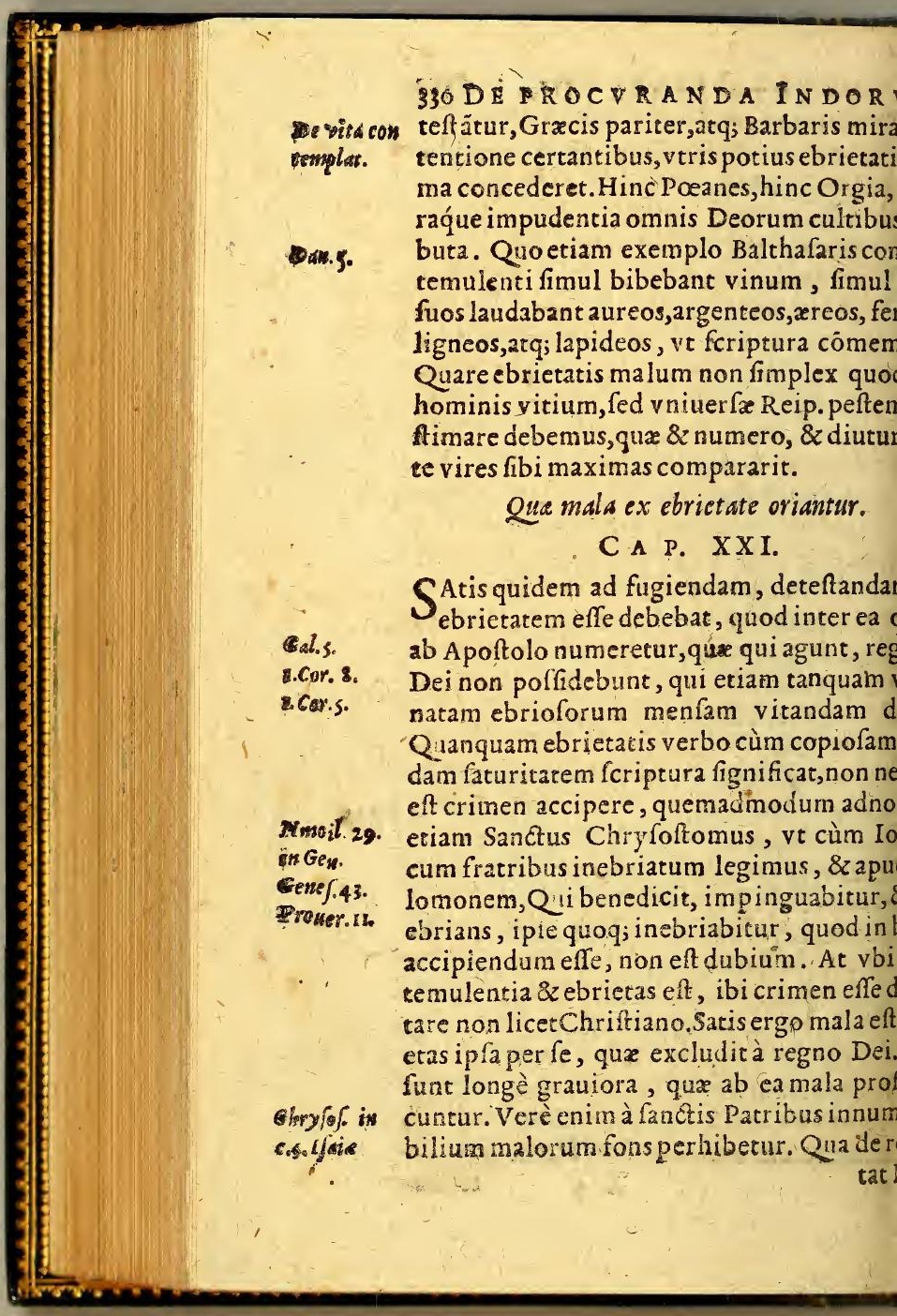




\section{SAIVTE. IIBER IIT. 39 ?}

ni Bafilij elegans fanè, \& copiofa oratio, ntêtias exfcribere, ve fæxp folet, videtur con. Turan fius in libro de ieiunio, \& H\&lia. Tri- 648. o, vt compendio dicam, nocet vehemen-Scot 3.pro etas, Corpori, Moribus, Fidei . Ariftote- ble.s.lib. orbos, \& caufas perfequitur in Proble- 14 c.22. linius in naturali hiftoria. Ex noftris os Hom 1. ad Ioannes ad fuos Antiochenos, Non pau Pop. Anto ed multò plures, $\&$ difficiliores animi, oris morbos immoderata vini parit poafionum bellum, abfurdarura hyemem ionum menti introducens, \& corporis Hliorem, $\&$ folubiliorem efficiens. Non a ter natura vexata aquarum fuperntia continuè diffoluitur, vt corporis lefcit, \& diffluit, \& exilis redditur, vini ntinuò ingurgitata. Cui A mbrofius conHinc phrenefis periculora, hinc calculi De Helia ieiustio $c . \mathrm{I}$. oena, hinc exitialis cruditas, \& reliqua. cuit ifta Sapiens, Sed quàm fufficiens eft, Eccl.sk , homini erudito-vinum exiguum, $\&$ in ndo non laborabis ab illo, \& non fenties . Vigilia, \& cholera, \& tortura viro infrumnus fanitatis in honine parco, \&c. Qux ifint, veriffima eorum mihi fententia viui immaturos plurimorum obitus in hac e nimix ebrietati tribuunc. Sunt etiam rgraues, qui hanc inferiorem, ac ma$\mathrm{m}$ oram olim Indorum populis refer$m, \&$ numerofiffimam, nunc adeò imm, ob id inter alia fentiunt, \& prædijuod polt Hifpanos ingreffos effrrenatè eræ, \& quidem exitiali maximè indulargumento effe, quod montanos, quia.

\& par.

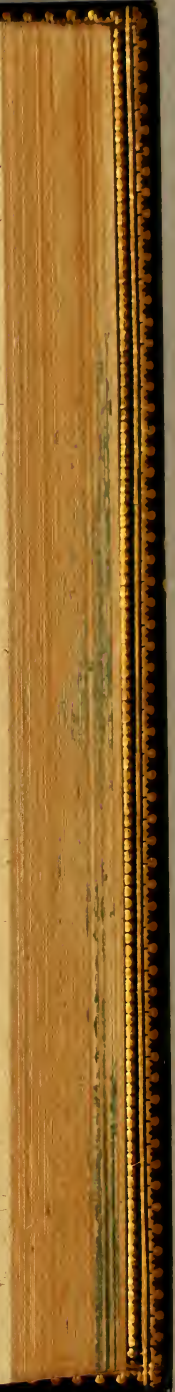




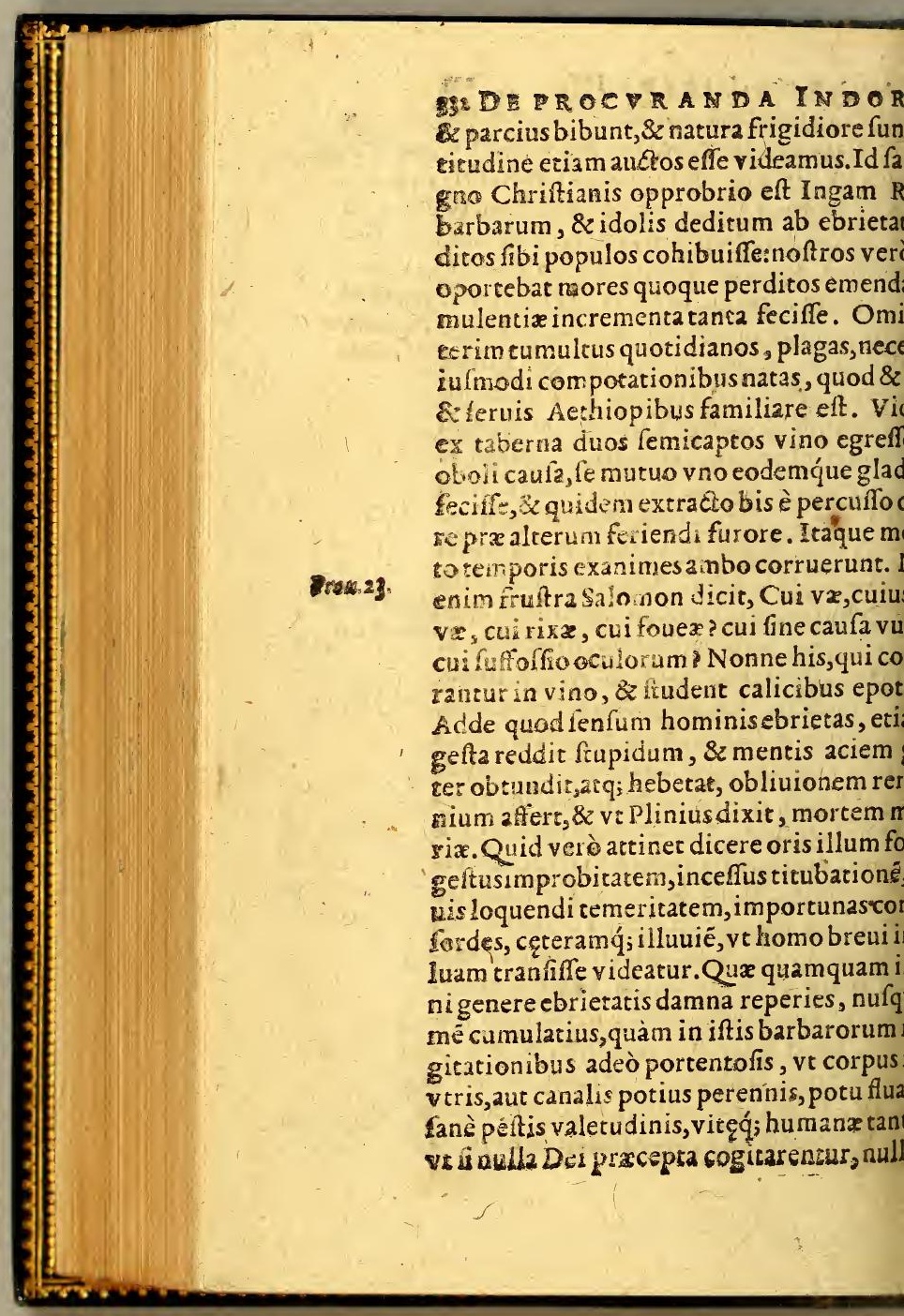


SA I $\nabla T$ E. I I B ER IIT. intentata fupplicia, tamé ob Reipub.indiligentiffimè cuiuis legiflatori, $8 \mathrm{mz}$ i cauenda, relegandaq́; fit. Cor pora igiit at ebrietas, an imos verò quid ? Nemp. t morú corruptela maior. Audi, fi vacat, $m$ in praclara de ifta ipla pefte concione, $s$, inquit, Dremon eft voluntarius ex voanimabus noftris inditus, ebrietas malier eft, virtutis inimica, fortem virum - laxaces. gnauum,ex temperato facit lafciusm, iu ignorat, prudentam extinguit. Et polt 12 , Quid opus eft reliquam perturbatioteruam enumerare, morum peruerfitate, citudinem illam ad iracundiam,ad quere rem ac repentinam animiad omnia mu$\mathrm{m}$, ftrepizum multum, ac tumultum, facidolos deductionem, ad omnes ira motus derantiam?Voluptatis verò incontinenhis ex vini fonte originem, vimq́; habens, sad omnem impuritatem, atque intemiam ruit. A nimalium omuium libidinum tem fuperat, cùm bruta naturæ leges in nere nof cant, atq; obferuent : ebrij ranti e foeminam, in foemina mars m querunt, tane. Hæc Bafilius, aliaq́; complura, qua gendx orationis fudio, fed quoridianz entize obieruatione prolata funt. Obfider onftrum, atq; infeftat v niuerfum terrará , verùm nufquam grauius fæuit, quàm ince barbaros, apud quos éa eft rerum omperturbatio, v textremá,obfcænitates, \& a flagitia compotationis furore adminta in laude ponantur. Canicur more folennis niunt fine vllo diferimine omnis xtas, fe-

ธूर्ड 


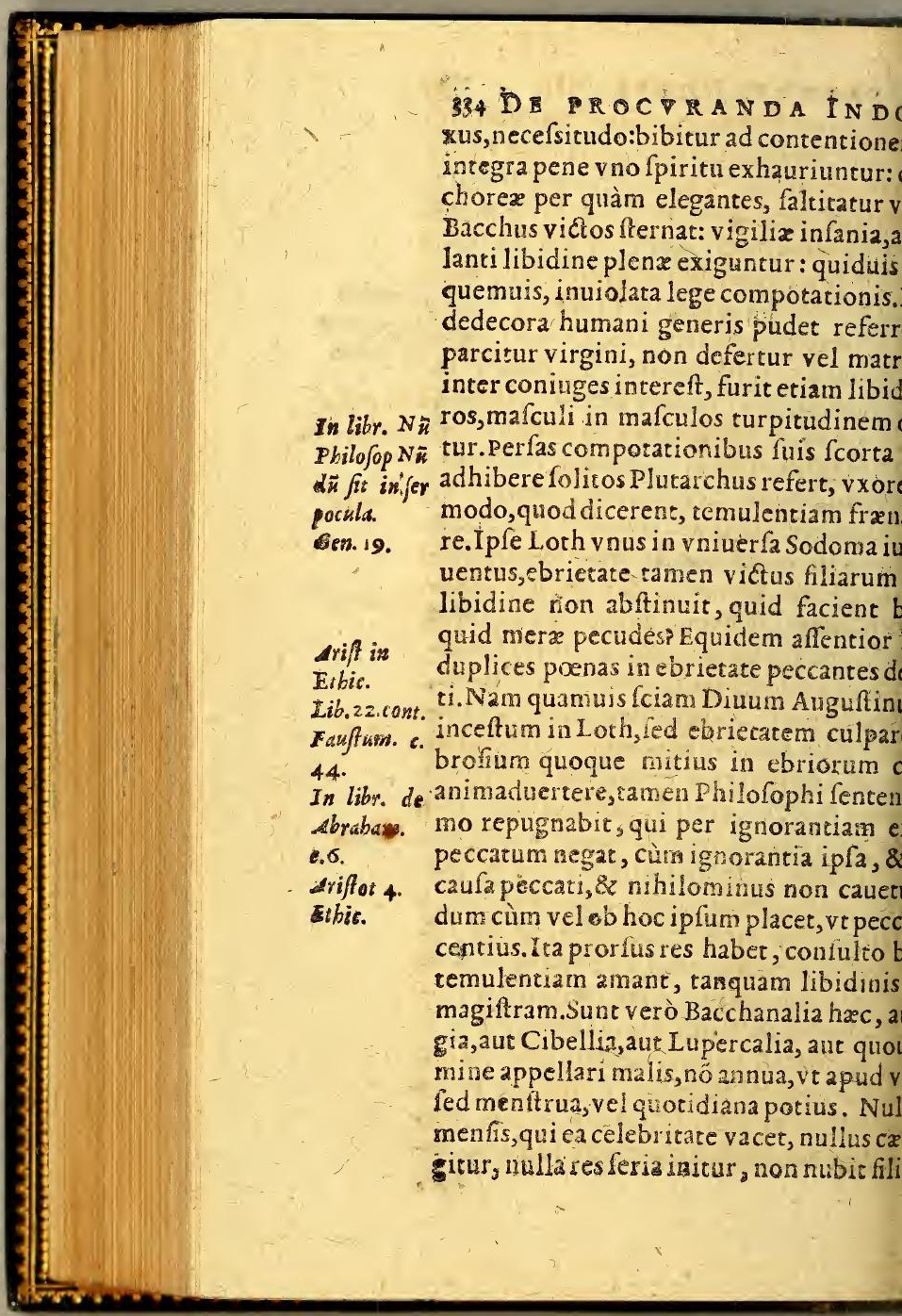


S A L VTR. LIBER III: \$3; ecus, non foditur ager, non Deo facrifica: ebrietate optima duce pręeunte.Vnailla as, priuatafó; res ornat, \& magnificentix, gionis argumétum: Mifera prorfus ftultominum feruitus, qui cùm ipfi natalibus à brutis abfint, ftudio, arq; opera omni có it, vt birutis quog; deteriores fiant. Mores $n$ tales ebrietas efficit: Fidei verò ianuam ludit, ết q́; rèligionisChriftianæ inter-Inftis fruiffima.Praclarè Beatus Ambrofius De Helid ebrictatem effe perfidiz matrem, contim Fidei, quod perfpicuèdocet fermodiSedit, inquit, populus manducare, \& bi- Exod.32. z furrexerunt ludere.Quem ludum intelquis ignorat? Vituli aurei adorationem ant Parres, \& panlus ipfe, Neque idolofficiamini, ficut quidam ex ip fis, ficut fcri eft, Sedit populus manducare, \& bibere, exerunt ludere. Certiffimum eft ebrietafacrilegium plerumque coniunetum. Nö althafar facra vafa popofcit, ac profanè Dar. eft, quàm temulentia imperauit, tum fuos cuique laudandi certamen exortum uera vinum, \& mulieres a poffatare faciüt Etcl.1 fapientes . Incredibili verfutia Diabohoc orbe omnem fuum cultum ebrietate uit, omni viciffm ebrietati aliquid de Itu adhibendum docuit . Experientiffimi m Indicorum pro certo confirmant nulf́e paulo celebrioré compotationem, nulilias ftatas, quin peculiari fuperftitionis, rilegijgenere imbuantur: Huiufq́ue fcebleruata eft tanta calliditas, vt non aliter ntiquum fuum errorem \& idololazriam 


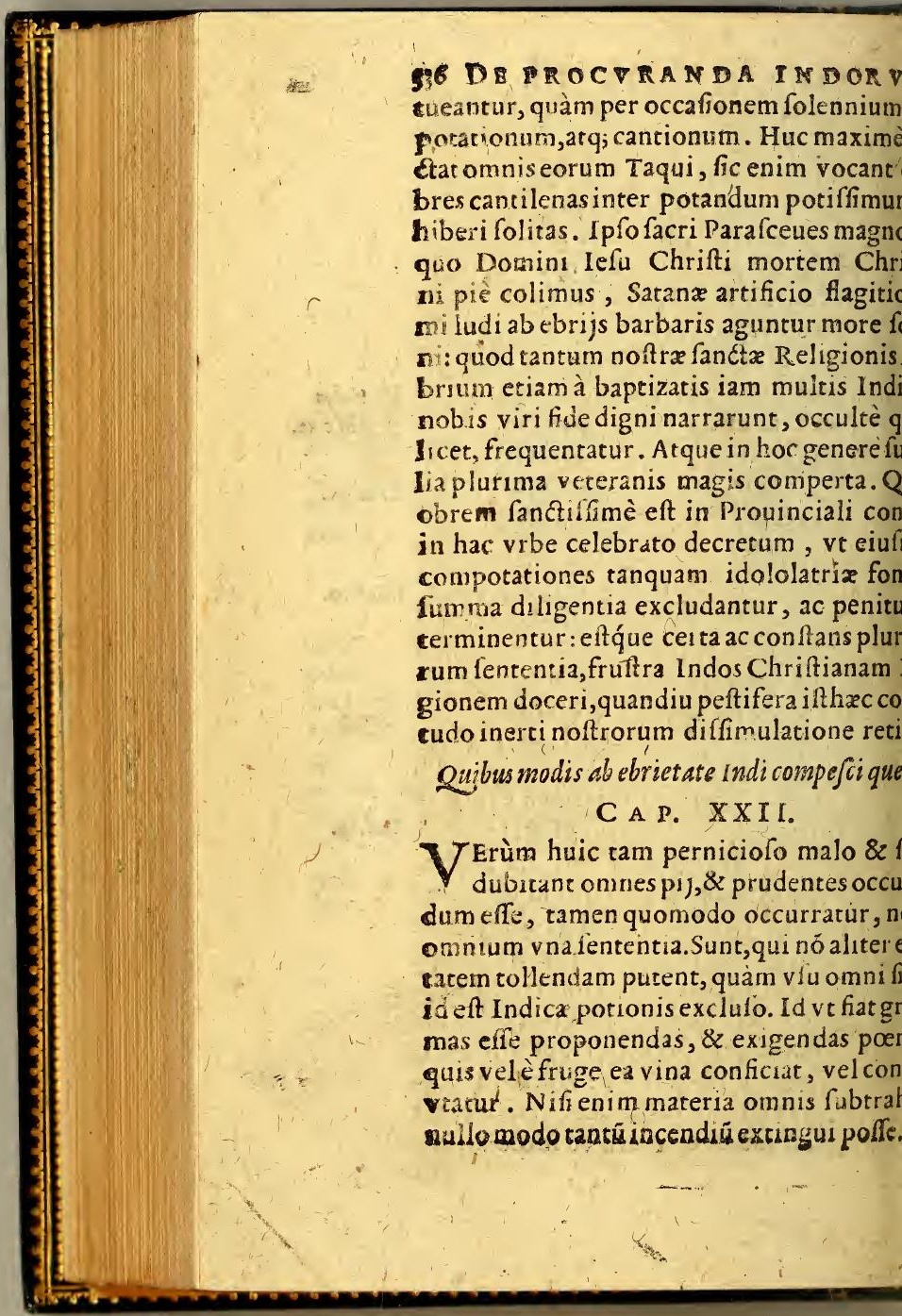


SAIVTE. LI IER IIT.

ox nihil propemodum ab eorum fenteni abeffe videtur, qui non ita pridem cum no Pontifice feriò agendum exiftimarunt, erali Ecclefiz decreto vinex omnes ab oriftiano extirparentur, relictis tantùm in vfus neceffarijs, quòd per vini immodera$\mathrm{m}$ incredibilia mala dicerent euenire, idSeptentrionalibus præfertim Europæ ponult is magnifóue documentis demovitraed facilè horum eft explofa fententia. $\mathrm{Ne}$ im, vt fcitè dixit Chry foftomus, vino, fed chryf. boma ntix fræna adhibenda funt. Eadem certè 31 in 1 ad \& pecunias nullas efle iubebunt, vt auari- cor. currant, \& pretiolos pannos, vt faftus reur, \& fóminas ipfas fepelire oportebit; idine concitentur viri, quin potius oculos \& linguam adiment, netanta peccemus. no nihileft adeò fanctum, adeò bene prodiuinirus, quo non in perniciem fuả abuit humana malitia. Et re vera ficut vinum er, \& fobriè vfurpatum; $\&$ valetudini, $\&$ : ; \&z latitix confert, quæ qui detrahit, iniuei prouidentix facit infignem, emendare s qux ille fapienter fecit, ita planè ficer $x$ potiones vitilitates habent non contem$s$, quis qui prorfus adimit, non mediocriferos premit. Nam \& robuftam, \& falubre, efactis non iniucundam effe ficeram (fic iam dudam voco iftam vulgarem Indootionem, fiue Maicio, fiue Cacao, fiue quoo genere conftei)nullo modo negare pola quicumque ifta experti furre, genus verò ho $m$ inops, \& tenue nullas alias delicias agns, hos rnoadiumento prituare velle, in hu- 


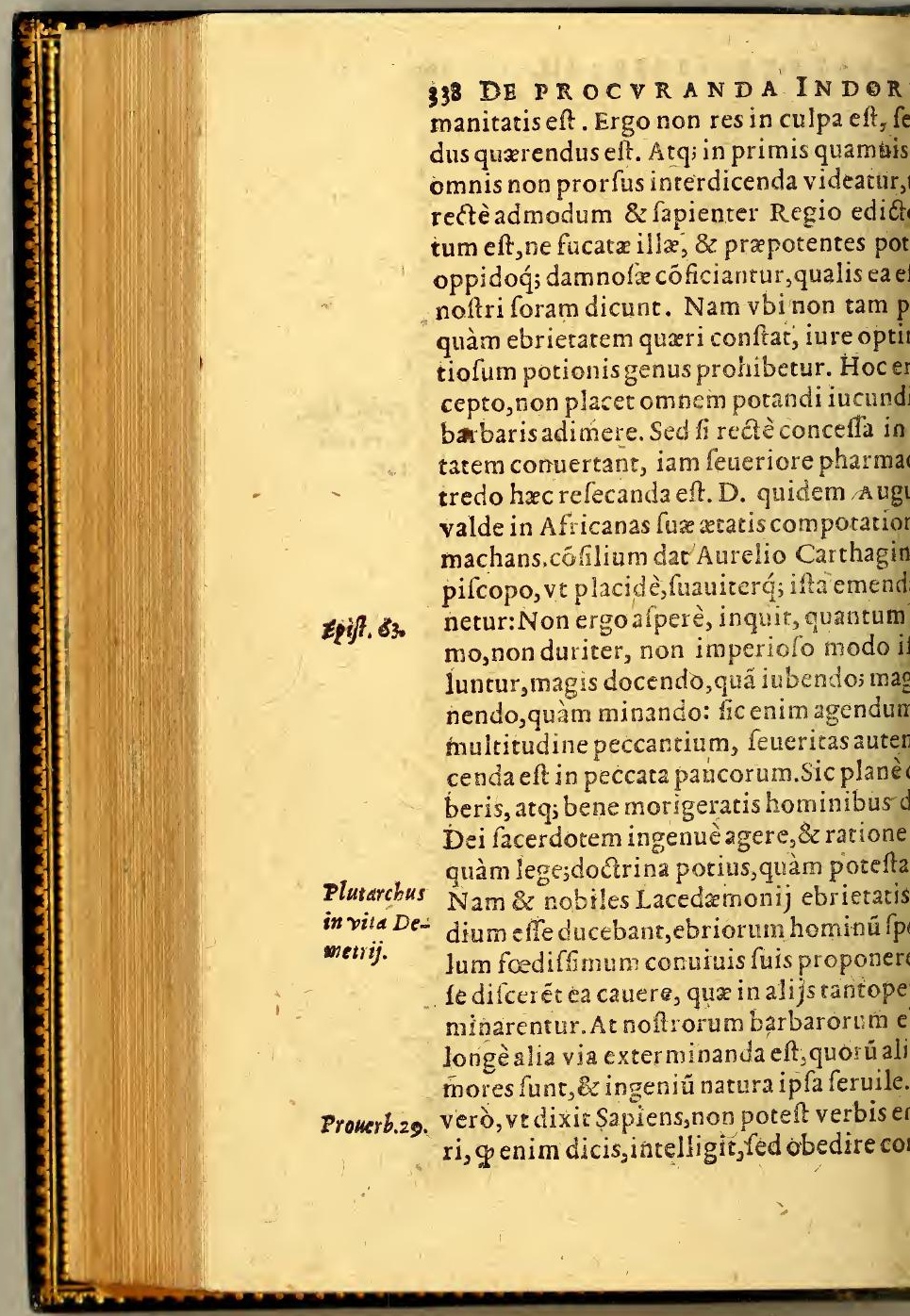


SAL V.TE. I.IBER IIT 339 \& fi exempla proponenda funt, $\&$ fi facerdo commonitiones, atq; comminationes ceffain debent;tamen vt in vetuft is v lceribus fit, iore medicamine faniessifta radenda eft. seft poteftate ciuili, opus eft feria animadone in temulétos, ac nifi lege agatur, fruftra $s$ verba fient.Verùm fi putredo hxc refecan , \& tamen materia non demitur, quidnam drj effe potefl?dicet quifpià. Audiui ex viro iffimo, eodemq́; totius rei Indicæe peritiffplerifqu videri difficilé, \& per moleftam eẩ sendi barbarosabebrietate proulinciâ: fibi perfacile, \& iucundam.Cú me tâtre rei poltione nö mediocriter erexiffer, fubiecit pre onem \& mihi, \& vt opinor, cuiuis prudenti probatâ. Vituperabat ille cos, oqui bibendi letudinem, aut ad certos calices definirent, riuatis méfis magnoper ènter dicerêt.Cenq́; potius quãdiu intra priuaros parietes pri a ipfi biberent, etiam fi fortafis excederent, iffimulâdum effe, vel fi proderentur, nỏ adtm rigidè excipiendum. Atrompotationes icas, ftatas, ac celebres, eas fummis virib ${ }^{9}$ ef turbädas, ac profligådas:idú; \& expedire ơn \&z faciu nó effe difficile. Vtriufq; fua afer$s$ caufas affere bat egregias. Nã prinatim v:uiufq; perpotationem infente perfagui tuin cile eit, quod iacebras domenticas, atq; horas ortunas, $z$ inufitaras varietates pervieftigare o polfit:tü verò nimis fioc ardim, \&zafper ü c meritò verendum eft, ne qui nimium emü- Provierb. 3 . liciatetiam fanguinem Quamobrem B.Au- Epif. C $_{3}$. quanquam ebrietati infextuffimus, cenfebat $A d$ Aurelino aliqua ex parte conninendum, fed feranus

$$
\mathrm{Y}: \mathrm{h} \text { : }
$$

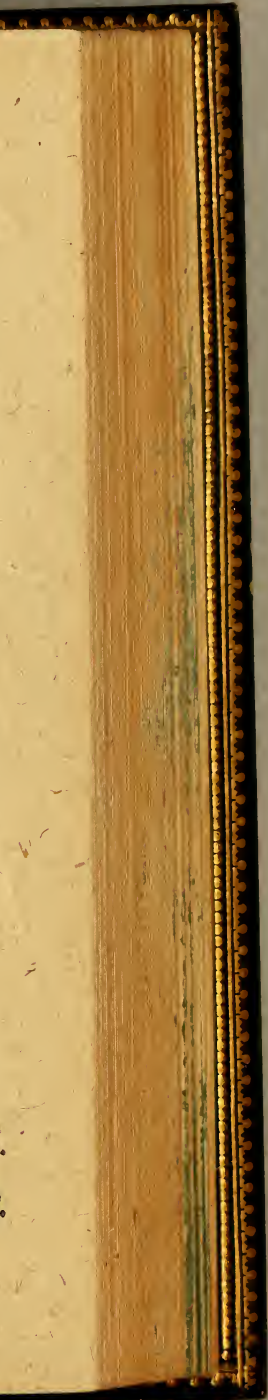




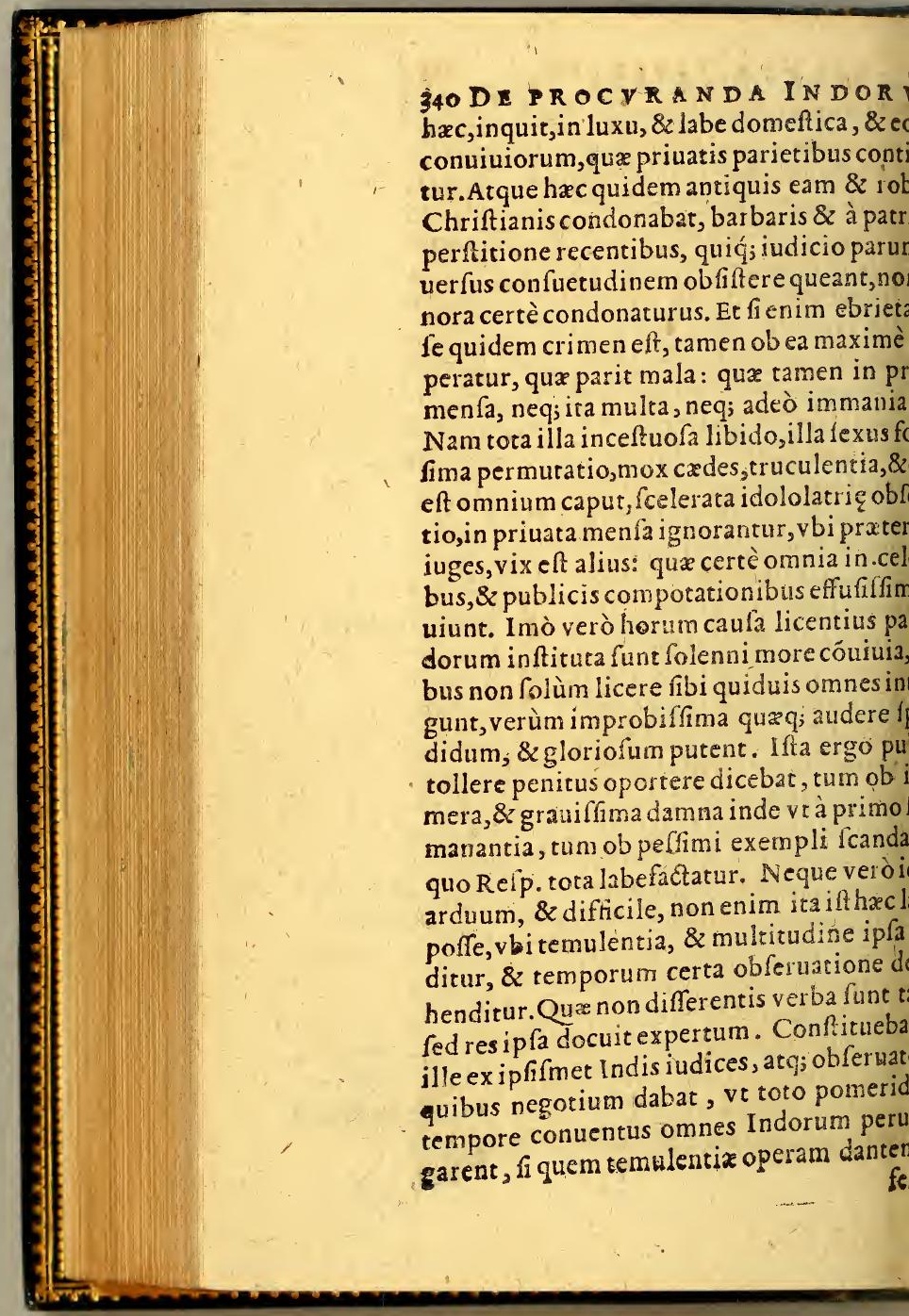


SA LVTE. LIBER IIT. ent, ad fefe continuò deferrent, fin vel neter indagarent, vel inuentum fcelus diffient, poenas minabatur acerbas non temufed obferuatori, qui non quafiffet, aut in$t$, negligentix, aut malitix conuictum obrem pro concione femel, atque iterum ri iubebat, tertio opus non erat, tanto om errore commotis, vt deinceps in detegen ijs folertiffimi effent. Iam verò cùm oborum cuiufquam induftria delata effet es,eò conuolabat, recenti, ac fiagranti debnoxios capiebat:primùm leuiore aliquo cio contentus, fecundò, ac tertiò augebat aliquot ex primoribus verberatis, aut etine deton fis, quod Indis acerbiffimæ iniuo eft. Affirmabat, cùm Prætoris Cuzquennere fungeretur, quæ vrbs omnium caque altera noftris Indis Roma fuit, breui bus effeciffe, vt ne veftigium quidem etis relinqueretur, in remotiffimas quoque acias temperantiz exempla à maioribus anfmiffa Indi cateri fequerentur. Sed netia, \& focordia fuccefforum rem tantam $\mathrm{fl}_{2} \&$ ad priftina temulentia fudia redife. Idem, cum Chuquifacx effem, fufcepit rtante, peffimum illum morem abolere. viciffim à me,vt in concione ea de re vererem, reique foeditatem exprobrarem: ipum, quo vtebar linguz Indica bene doonuocata ad fe Indorum concione legem blicis compotationibus abolendis promul perfuadereque iuber: obferuatores deinde quibus oppidi regiones diftribuit, fefe rem, nifi grauiker vapulare malint, mature

$$
\text { Y } 3 \text { facere }
$$

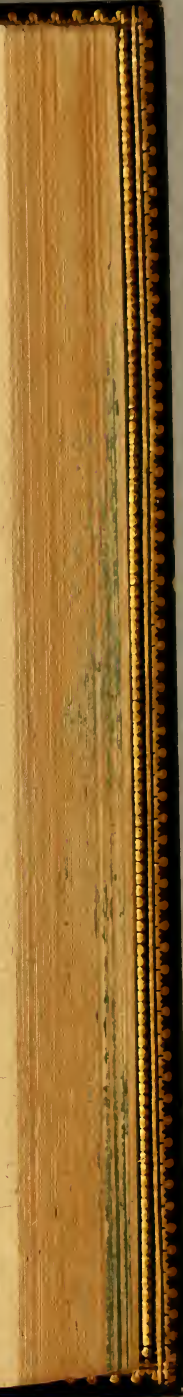




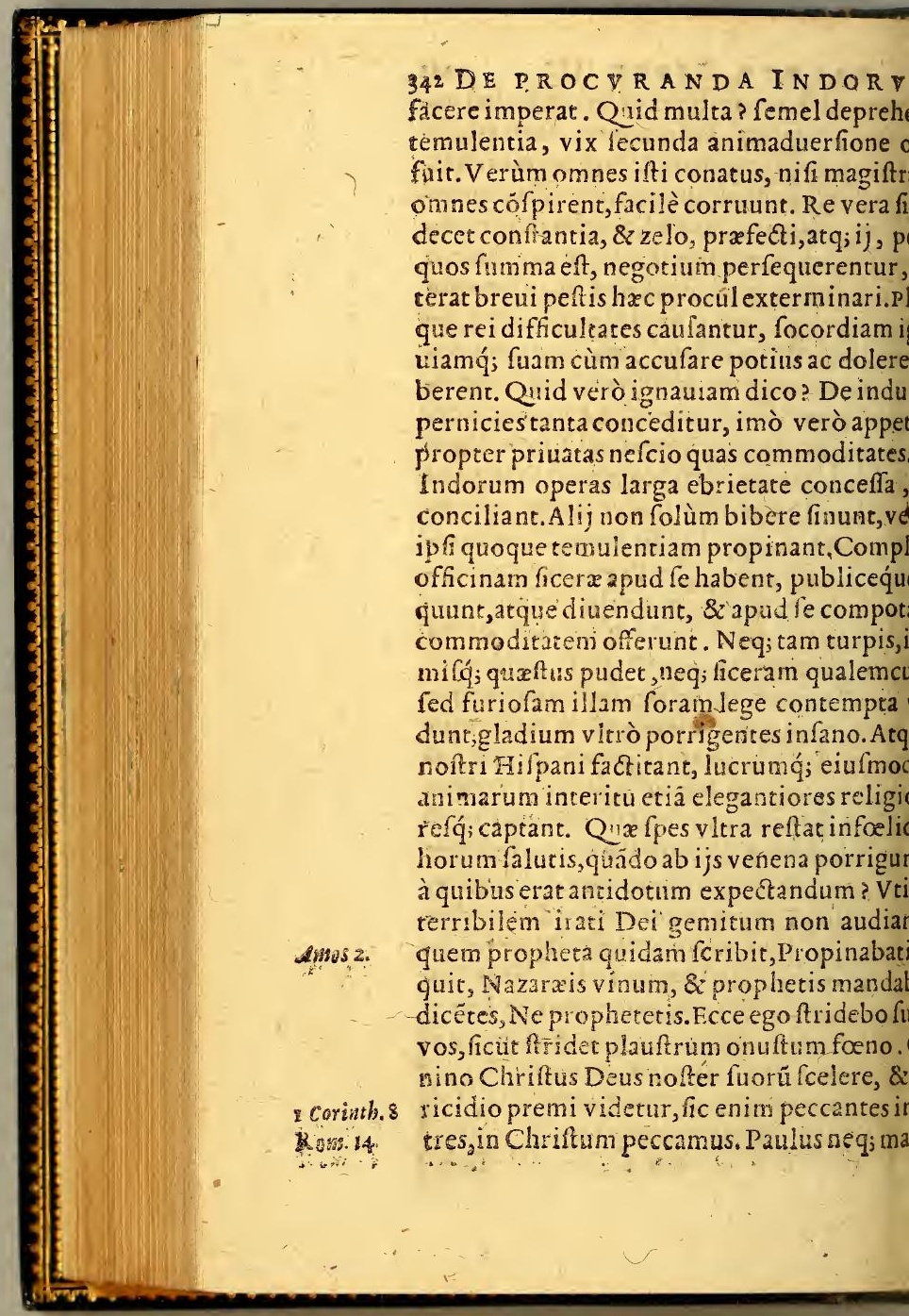


S A LVTE. ILI'B ER III. rnes, neq; vinum bibere libenter fufcipit, fratrum faluti confulat: nos vino etiam fito fratrum animas enecare pergimus, vt vndecunque radamus. Hæc tota populi ani ignominia, frue eo, quo diximus, monduftria, frue alijs artibus qua ab alijs piè trosè excogitatx funt, omnino releganda publicæ poteftatis miniftros, \& diligétifinda eft opera, $v t$ publica faltem , atq; $\mathrm{fa}-$ barbarorum temulentiz, terrore, minis, acerbitate modis omnibus propulfentür. m fibi perfuadere debent, nihil neq; relineque difciplinę in Indorum animos inoffe, nifi omnium malorum fons ebrieftruatur.

\section{Pratoribus Indorum. C A P. XXIIT.}

has igitur difciplinæ Indica feueriores ges exequendas, quoniam \& neceflaria 10 funt, \& nifi ferio in przuaricatores aniertatur, fuperuacaneus erit labor omnis, facerdotum eft ita feuerè plectere, vt fuo icemus, videtur multis, mihiq́; ipfi perutipræfectos, indicefue peculiares dare.Cùm curia frequentiaq́; noftrorum Magiftralongius ab fint, pleraq; oppida, nifi fuos ipores habeant, quos timeant, quos obferacilè aut delicta latebunt, aut impunita reentur, crefcetq́ue impunitate ipfa quiduis trandi temeritas. Nam neque facerdotals eft ifta vlcifci,cùm præfertim erit aliquid ius vindicandum, neque Patronorum cur $x$ ommiti pofiunt, à quorum potentia, 8 invt defendantur, indigent fapè publica au-

$$
\text { I } 4 \text { thoritare! }
$$




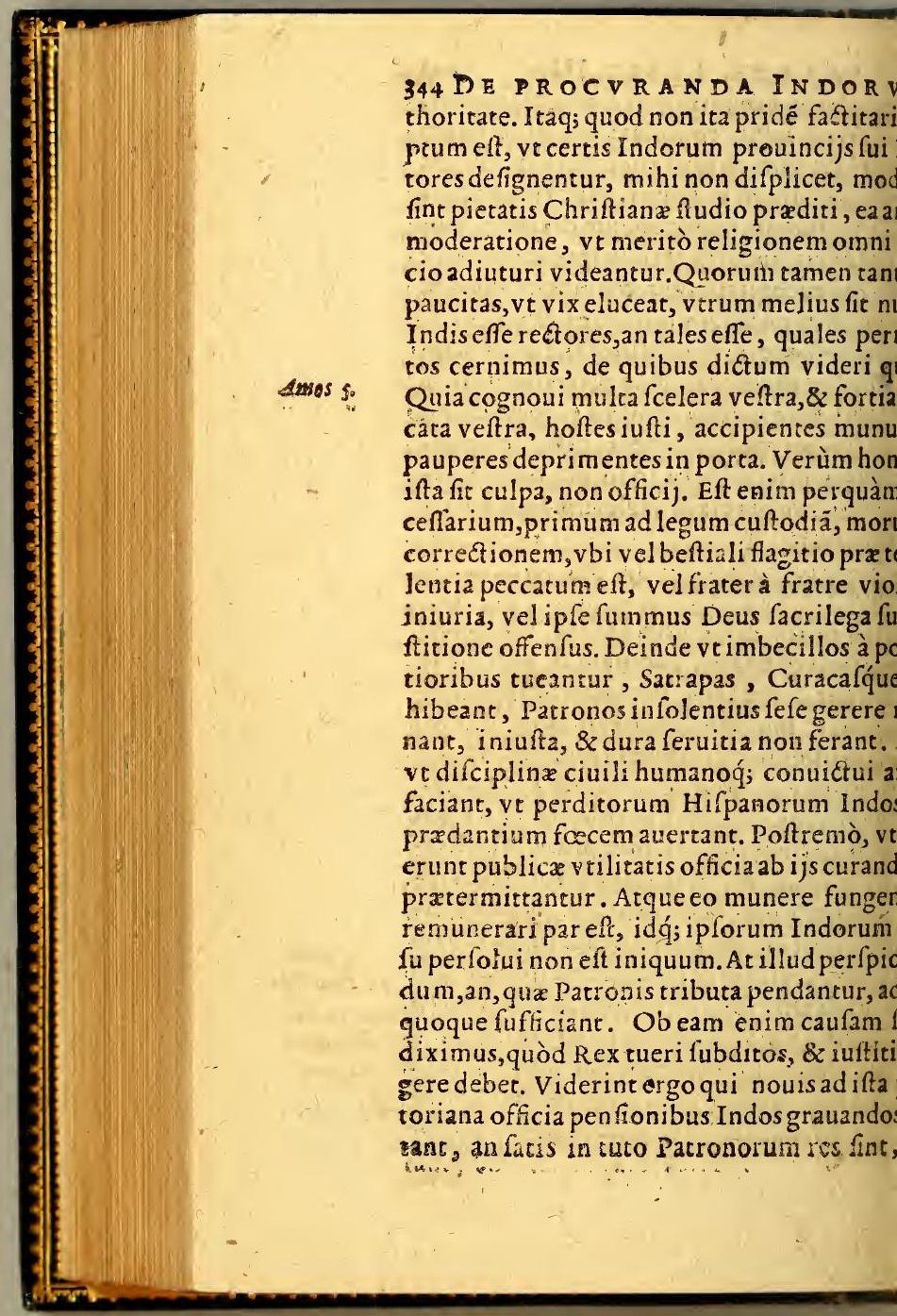


SA'IVTE. II BER III. 345 tanta emungant, parum ipfi, aut nihi! ciuiminiftrationis clientibus præftant. Hune æfecturis Indicis locum antequam præter$r$, admonendifunt præfecti ipfi, ne tam fe es, quàm parentes exhibeant, neq; prórfus in cæteros feueritate vtantur.Pueris fe poudi magiftros, quàm forenfes iudices cogiNeque iuris illa ftricta norma vbique fera, fed frepitu omni remoto, ex æquo \& 2 boerum q; iudicandum, id quod etiam falutaedicunt Regix leges, qux fcripta, \& refcrirè adimunt, $\&$ pretium, fi quo horum opus cipere vetant. Caufas more patris familias poner e, \& pro arbitratu agere, fxpè tutius, commodius, nifi atrox aliquod facinus acquod rarum eft, cùm pleraque nugarum, \& ilium concertationum fimiliora fint. Qua illud viris grauibus vehementer difpliceinaduerti, quòd ab Indis teftimonium iuando exigitur, cùm conftet eos facillimè are, vtpote qui, neq; ipfius iuramenti vim ant, neq, veritatis ftudio tangantur, fed teonium co modo dicant, quo credunt iudici ffimum fore, aut à primo quoq; fuæ factioomine edocti funt. Hos igitur iurare comre, $\&$ ip fis exitiofum eft propter infinita, \& idiana periuria, \& cauf $x$ ip fi valde incomum, cùm firmitudo veritatis nulla fperetur. torum ergo fententia eft in Concilio Pro- In Con. Taiali edici oportere, ne ab Indis iurifurandi jio flagitetur, idque lege lata caueri debere. im fi pueri \&zinfames à teftimonio dicēdo, ramento interponendo iure arcentur pro- eft. ron.ca. 34. Summopere id cauturs. iudicijinfirmitatem, falfitatifque fufpicio-

$$
\text { I } 5 \text { nem, }
$$




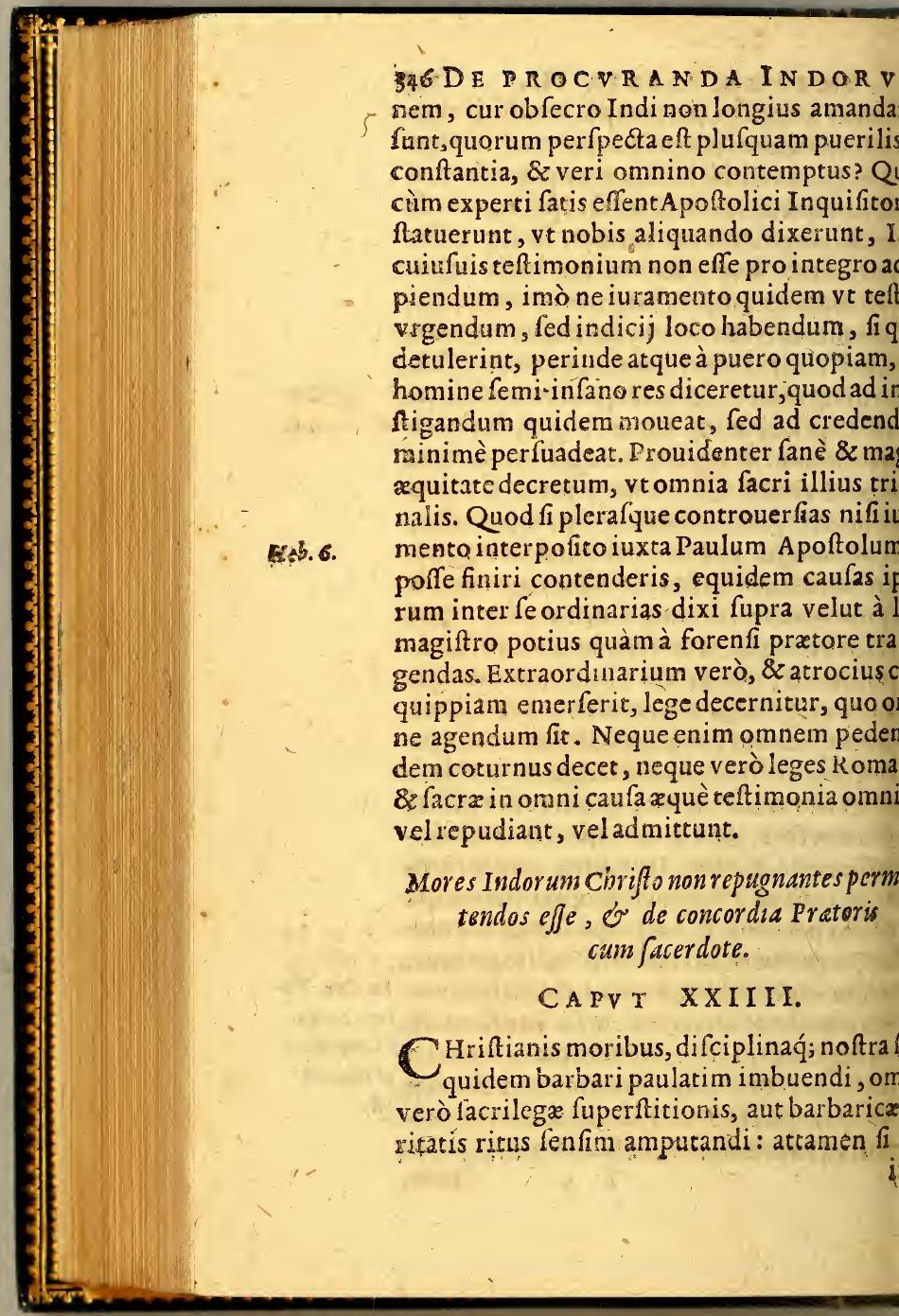


S A L V T E. LI BER III. illorum mores à religione, \& iuftitia non epant, non exiftimo facilè immutandos, fed is, ac gentilitias confuetudines ab æquo tbhorrentes retinendas effe, \& fecundum sdicendum, quemadmodum Indici fenaegia decreta continent. Qua in re valde turà multis vel propter ignorantiam mualium obferuationem, velob nimium, \& aturum communicandi noftra feruorem. non morabor Plutarchi philofophi illu- In Politice ræceptum de gubernanda Repub. appone- ad Traiant ertere fe ad mores ciuium cognofcendos o$t$, atque eorum penitus exploranda, atqùe inda ingenia. Erenim ftatim mores, \& ingeonari murare populi, nouifq́ue ea legibus rari extemplò velle, non modò non facilè, n ne tutum quidem omninò eft, vt res qux o tempore, \& ingentibus viribus indiget. leducit ex vino perpulchrè, quod initio, atis arbitrio regitur, mox fenfum calefaciominem com mutat, $\&$ vertit ad fe. Quamm multa diffimúlanda funt, nonnulla étiam anda : quæ tenacius hærent, \& perniciofus nt, ea dexceritate quadam in bona fimilia mutanda. Cuius rei authorem luculentum grium magnum profero, qui rogatus $a b$ uftino Anglorum Archiepifcopo in frmili Lib. 1o. Rea, ita fcribit Mellito, Dicite Auguftino Epif- gif.epift 7. , quod diu mecum de caufa Anglorum cois tractaui, videlicet quia fana idolorum dein eadem gente minimè debeant, fed ipfa, in eisfunt idola, deftruantur; vt dum gens eadem fana fua non videt deftrui, de corde rem deponat, \& Deum verum cognof́cens, 


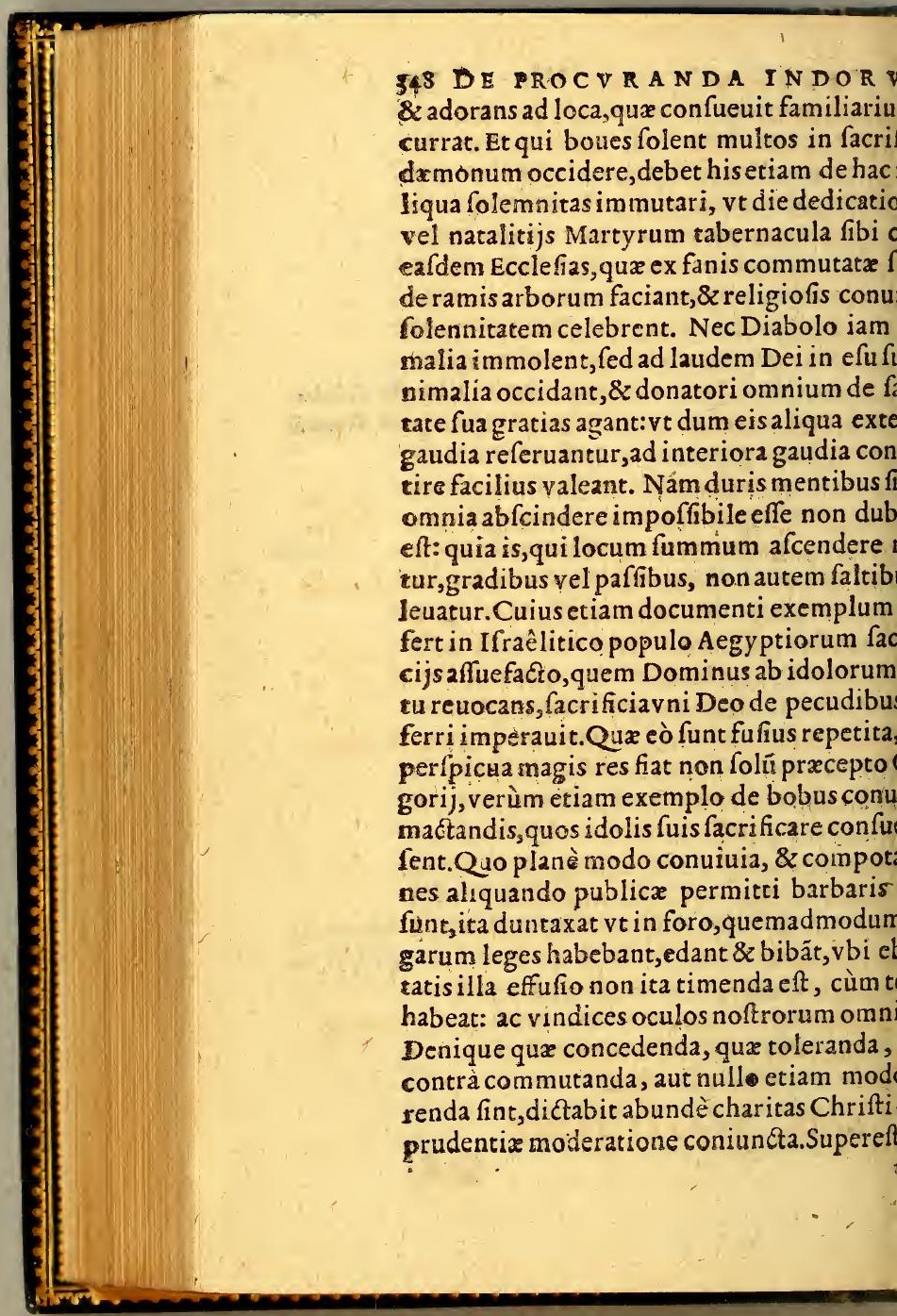


S A I V TE. LIBER III. ve ciuilem omnem poteftatë admoneamus, adminiftranda Repub. Indorum cum Ecaftica germanè coniungatur, fitq́ue Prætor doti, quod Samueli Dauid, quod Hieremiz s, quod Efaiæ Ezechias, quod Sylueftro Cóinus, quod Theodofius Ambrofio. Facilè vis perficietur, fi gladius v terque confente$c$ vaginam eandem induerit. Contra, nihil erturbat, labefactat, enertitqú religionem, umq́ue doctrinam, ac mutua inter facrum, anum q́ue contentio.Scriptum eft, Vnus $x$ - Escl.340 ans, $\&$ alter deftruens, quid proficit eis nifi ?̇Ec rurfus, Non eft diffenfionis Deus, fed 1, Cor. 14 s.Et alibi, Si quis videtur contentiofus effe, 1.Cor. 11. alem confuetudinem non habemus, neque efi Dei.Et væ certè eft illi, qui vnum fcan- Matth.ı\&. zauerit ex his pufillis, qui credunt in Chri. Omnia ergo in charitate fiant, omnia fe- s.Cor.16. ùm ordinem,omnia in vinculo pacis. Ni- Ephes 40 er contentionem, neq; per inanem gloriam. qux fua funt, finguli confiderantes, fed ea, Pbilip. aliorum. Et fi funtigitur officia diftineta, \&z e facerdotem decet arma tractare, neq; ium facrificia offerre, tamen idem animus, seadem, idem perducendi omnes ad Chriftudium. Itaque fibi mutuo adiumento vt omnibus modis curandum eft:atq; alter quiin ijs, quæ ad Deum, alter in ijs, quæ ad hoes magis occupatus, vterq; Dei oues pafcant, falutem fuorum quærant, non quærentes $\mathbf{u}_{1} \mathrm{Cor} \cdot \mathrm{jo}$ quod fibi vtile eft, fed quod multis, vt falui fiant.

LIBRI TERTII IINIS. 


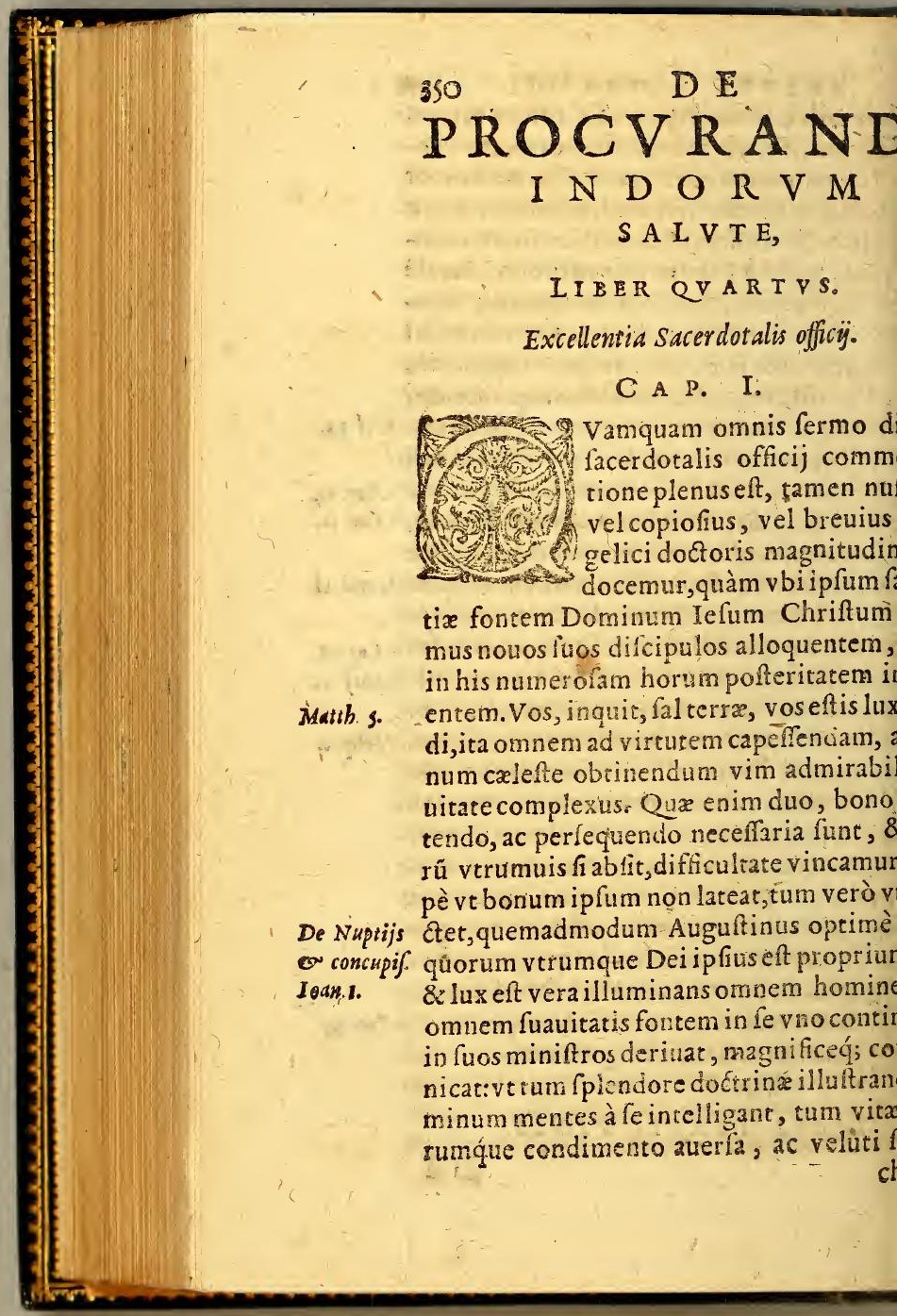


\$ A V TE. IIBER IIII. 3\% ntia mortalium fludia non folùm virtutis idio leuent, verùm etiam propenfius exciItaque quod veteri prouerbio tritum eft, \& fale nihil effe vtilius hominibus, id in Egelico facerdotio veritatis fuauitate perceatque guftata, fitum effe nemo non fentit. am fui muneris excellentiam tanti facitApous Paulus, vt datam fibi gratiam ad illumi- Ephef.zz das gentes, \& prædicandas inueftigabiles diaschrifti, toto orbe fole clariorem oftendat; ebras noctemq́ue omnem procul depellens, fe fo! mam, atq; exemplar publico fpectacu- 1. Cor. 1 \% roponat, ita alios fui imitatores efe cupiens, ple fic Dei. Salis nimirum copiosè functus phil. 3. cio laboribus, fudoribufq́; cófumptus, ve di im faporé alijs impertiat. Nifi enim liquef$8 x$ à fe deficiat quodammodo, catera condire . .... st : nequit. An verò quifquamaliud quàm falem itct, cùm audit illa dicentem? Puto quòd us nos A poftolos nouiffimos oftendit tanim morti deftinatos, quia fpectaculum facti r.Cor. to us mundo; $8 z$ Angelis, $8 z$ hominibus. Nos ti propter Chriftum, vos autem prudentes in rifto;nos infirmi, vos autem fortes; vos nobinos autem ignobiles, $v$ fq; in hanc horam; \&z rimus, \& fitimus, \& nudi fumus, \& colaphis limur, \& inftabiles fumus, \&z laboramus opetes manibus noftris;maledicimur, \& benedinus; perfecutionem patimur, \& fuftinemus; fphemamur, \& oblecramus, tanquam purganta huius mundi facti fumus,omnium peripa vfque adhuc. An non hîc liquefcit, \&z toaे fe deficit Paulus, ve lefu Chrifti gufu audies fectatorefó; fuos imbuat ? Quid illud ? Etfi Pbilip, immo- 


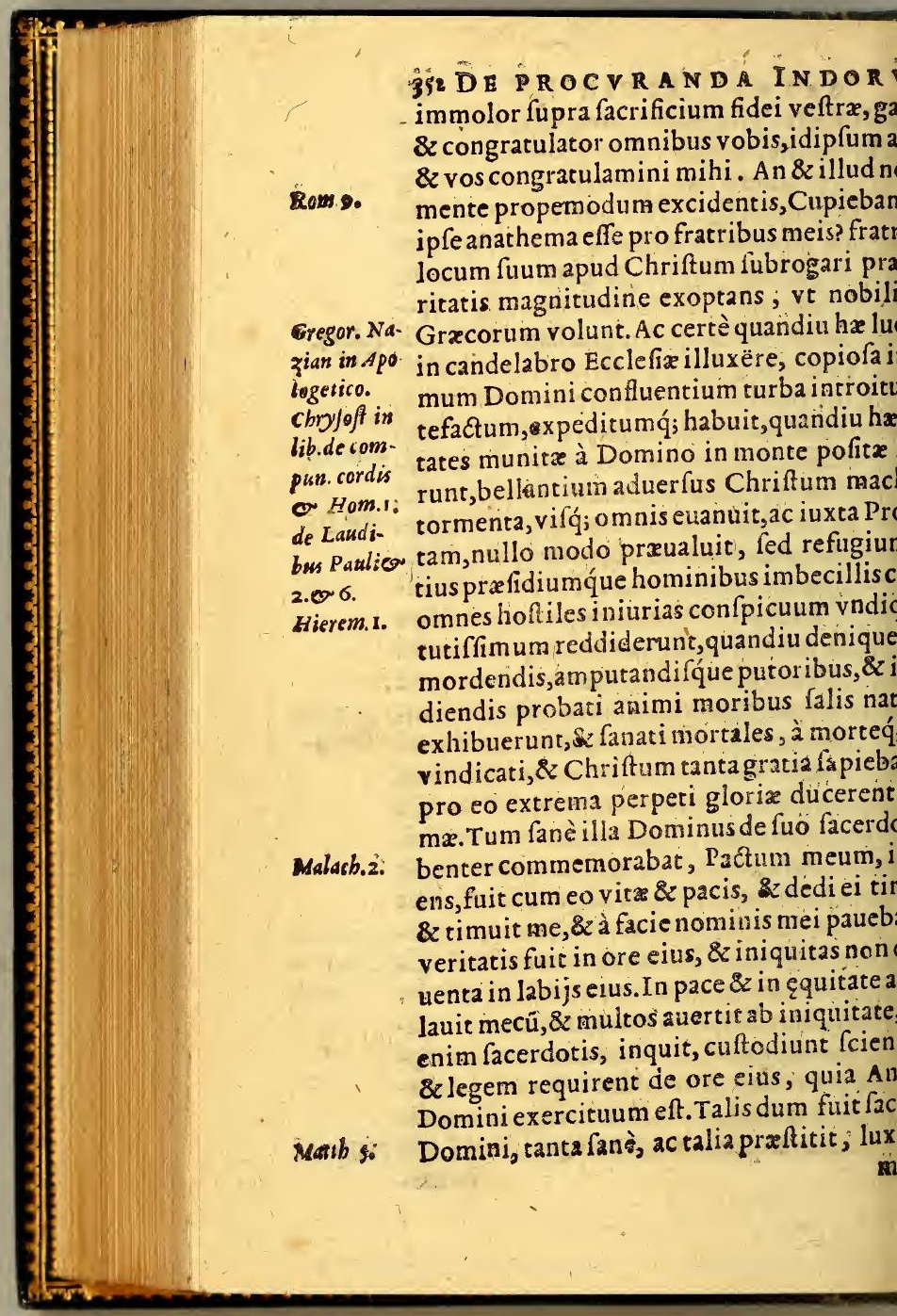


\$A I T E. LIBER IIIT. 353 di, fal terrx. At fi fal euanuerit, quid fequiquo falietur?Ad nihil valet vltra, nifi vt tur foras, \&x conculcetur ab hominibus. Si os is efie definat, qui iubetur, cæteros quidé ate fua priuat, cxterùm ita fe ipfe perdit, ecuperabilis fit habêda quodammodo eius \& defperanda curatio. Neque in fterquilitantim proijcitur, fed hominum quoque dibus proculcatur. Quàmaptè prophetile fermoftatim Euangelica ifta fubtexuit, utem, ait; receffiftis devia, fcandalizaftis mosin lege, irricum feciftis pactum Leui, Dominusexercituum. Propter quod $\&$ ego os contemptibiles, \& humiles omnibus lis, ficut non feruaftis vias meas, \& accep:ciem in lege. Infinitum efret cxtera perfeux contra hos fatuos Principes Tanaos, có- Efazie Io. ftores fultos, vel potius idola paftorum, Zach.1I. a le iplos potius paicentes, contra vafanos Ezech. 34 . letas, contra lacerdotes contemptores, atq; Soph. 3. antes, contra fercus foleunitatum, contra Malach.2. aris plaufus captatores, contra inexplebi- on. cunia gurgites, caterafq́ue peftes Prophefermo declamat. Vixalias fancti Patres plebus velis feruntur in pelágus, quàn cùm de lotali contumelia oratio eft. Gregorins vterque, \& Romanus, \& Nazianzenus, tam è, \& copiosè, vt nihill lupra. Huius'Apolom, Paftoralem iHius nemo eft, qui fine trepidatione legere queat, modò fenfus id habeat. AuguRini iam presbyteri plenos Epift. $4 \%$. egemitus ad Valerium Epifcopum fuum ine pudore vfurpacià fe nominis facerdos t? Cunctarionem recufarionemó; facerdoZ tij apud

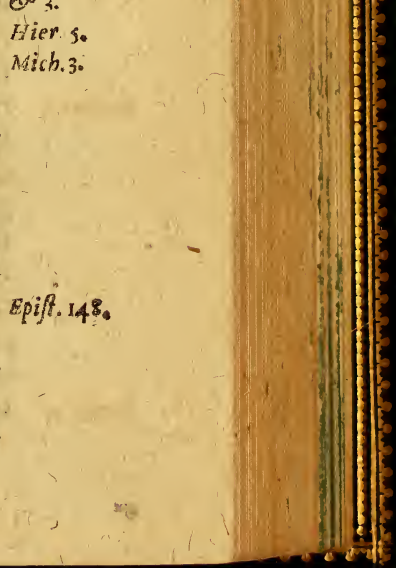




\section{DE PROCVRA NDA IN DOF}

Inlib. de fa- tijapud Ioannem Chry foftomum quis fi $\mathrm{v}$ cerdotio. infpiciat, non mirerur? fin orationis vim In epiff. ad quatuor libris attendat, non affentiatur? Io anme Hie- Hierony mi nimia pene modeftia, a tque hu rofolym tra tas Epiphanij literis conteftata, qui diuà tr ducta ab ipfo do altaris my terio celebrandoabftinuit, Hierongmo. cùm in monafterio verfaretur, in quo mulc fratrum nullum aliumpresbyterum haber cepto Vincentio, qui eadem verecundia ne quidê facra faciebat?Verùm, nifi fallor, ho. nes ficut antiquitatis authoritate; itaorat fublimitate, \&z grandiloquentia quadam fu revidetur Diony fius magni Praceptoris Epif 8.ad nus ipfe difcipulus. Is in epiftola quadam a temophilū mophilum indignos munere fuo facerdot Moxacbum. verbis obiurgat, Si igitur qux illuminat, dotum eft fancta diftinctio, proculdubio facerdotali ordine, \& virtute omnino prol: eft,qui illuminans non eft; multoq́ue fanè gis, qui neque illuminatus eft. Atque vt quidem videtur, audax nimium huiufmodi facerdotalia munia nibi affumit neque me neque veretur ea, qua funt dinina prater $r$ tum perfequi, putatq́ue è latere Deum, rum fibi iple confcius fit, \& fe Deum fallere fimat, quem falfo nomine ap pellat parrem detóue fceleftas blafphemias fuas (neque preces dixerim) facris aris inferre, eafque f figna illa diuina ad Chrifti fimilirudinem re. Non eftifte facerdos, non eft, fed infeftu trox,dolofus, illufor fui, \& lupus in pomini gregem ouina pelle armatus. His plura aut iora de Euangelici minifterij, $\&$ culmine, $\& z$ cipitio qui expectat; cuiǵue ad refipifcen 
$S$ A L V TE. LIBER IIII. ta fufficiunt, infaruatum fe iuxra Domini atiam, \& nullo vnquam fale faliri pofie de- Matth.s. trat.

Indos maximè faccrdotes preftare oportere.

\section{A $\mathrm{P}$ V T II.}

vulgáris ef, inquiunt, ithec facerdotalis ficij cömemoratio, vecus ifta querela ef?; declamas. Eft ita fanè, non difentior. Ve ufquam æquè necefiaria commonefactio, ine magis excellentia illa flaysitanda, quàm qui animas verbo Dei lucrifaciendas Chri. cepir, \& animas infidelium, idque apud hoceft, vbi adiumenta habiturus fit pau edimenta quàm plurima. Vbi quo praclapusaggreditur, tanto in maiore periculo ur,ne dum quarit alios, iple pereat, imò e \& fe, \& alios perdat, quodvtinam non rè, \& crebrò vfurparet fermo diuinus, Laruinæ populi propheta. Vtinam va illud ofeeg. veritatis non audiremus, $V æ$ vobis qui tu- Math .236 lauem fcientia, ip fi non intratis, \& intronon fnitis intrare. Etenim vbinam genla verius Zacharias proferre polfit ignopecoribus occifionis, quęqui polfederant, $\mathrm{Zach}$. $\mathbf{n}_{3}$ bant, \& non dolebant. Et vendebant ea es, Benedictus Dominus, diuites faci fuz'paftores eorum non parcebanteis. Quis on fanetaş iftorum vocesaudit, cùm Deo agunt, quod de facerdotio, \& doofrina um dioti ad patriam argento onufti re?t dicentes, Benedicus Deus, diuires faaus jon tamen parcunt gregi, vt ait fermo

$$
\text { Z } 2 \text { diuinus: }
$$




\section{DE PROCVRANDA I NDOR}

diuinus.Sed voment aliquando, qux malè

Zach II. tierunt, \& gement, quinunc trinmphant. vlulatus paforum (ita enim $\int$ quitur)quia ta eft magniticentia corum, vox rugitus leo Et ego non parcam, ait Dominus, fuper hab testerram. Tota ergo delolatio terra inde 3.Reg.4. fectò venit. Propter nefaria admiffa Oph Phinees, ip fiquidem intereunt, populus a fanctus turpiter tergavertit, \& quodef d dum, arca Dei ab hoftibuscapitur, \& lud Ezech.22. haberur. Quarit Dominus virum, qui ftet fitus pro domolfrael, nefcio an inueniat. I Hier.10. res,inquit, ftultè egerunt, \& Dominum nor fierunt, propterea non intellexcrunt, \& 0 eorum grex difperfus ef. Nulla ergo alia quarenda ef, cur Domini greges in his fal difperficrent, quam verorum paftorum n penuria in tanta mercenariorum minimè l arcentium copia. Neque fruftra Paulus cù

2.Tim.2. prædicando Euangelio praceptadat, Timo dilectum monet, folicitè cura te ipfum prol lem exhibere Deo, operarium inconfufibi Fhilip.3. rectètradtantem verbum veritatis. Suncen 2 cor.u. perarijmali, fubdoli, qui nonem Chrift Rom. 16. uiunt, quàm fuo ventri. Hi multi \&z multip Hicrem. 12. nomine paftores, re vera ver fipelles lupi d 2. Corinth 4. liti funt vineam Domini Sabbaoth, caupo 2.Cor.2. tes verbum Dei fecundùm Apofolum, magnitudinem Evangelici prxdicatoris a rans, \& pondus Apoftolici officijexpenden hementer exclamat: Et ad hac quistamidor Verèenim Apoftolicos homines poltulat ftolicum munus, Crucem Iefu Chrifti \& ve \& factis annuntiandi, \& in illius obfequiun bem 
SALVTE. LIBER IIII. 357 vniuerfum redigendi. At nos aliter cenfere nus, Et ad hæc quis non idoneus? Ad Indos ndos quis nö fufficit, etiam fi liter is vacuus, fi moribus non ornatus? Quò minus miumeft, fi vbi fementis faciendx cura conitur, nullus ibi, aut rarus fructus appareat. fanè iam dudum certa, 8 z fixa fententia eft, Meffis inopiam operariorum vitio, non is fterilitate contingere.

ontra eos, qui Indorum tarditatem accuSant:

\section{A P. I I I.}

Eque eos audiendos puto, qui quam in fe de berentagnolcere, ac dolere culpam, in Incijciunt, illorum ingenia nufquam non viantes, nofq́; dum contra afferimus, rudes $n$,imperitos, tyrones, infantes clamant, qui a quada pietatis fpecie facilè decipianur: eranos, expertos, fcientes, facto periculo, \& explorata proferre. Qui mihi Sibæil- 2.Reg.16. quem Kegum hiftoria narrat, calliditatem rividentur, quiclaudum Miphibofec heuum, dum pro fe non potef occurrere, $\&$ commenta diluere, accufans, proditionem in illius criminationem vertit, atq; hocam de omni fundo depellere pergit.Sed Do- P Pal.14 \$. serigit elifos, \& foluit compeditos, \& ilnat $c x c o s$, pupillum \& aduenam iple fufciAccufant igitur Indorum tarditatem ad caFidei mylteria, obtulos $\in$ fle, hebetes, trunui nihil prater fua farra, cibofq́; craffos coequeant, ad coelefia, \& fpiritualia cognora ftupidi, brutiqúe fint. Fruftra in ijs edo.

$$
\text { Z } 3 \text { cendi }
$$




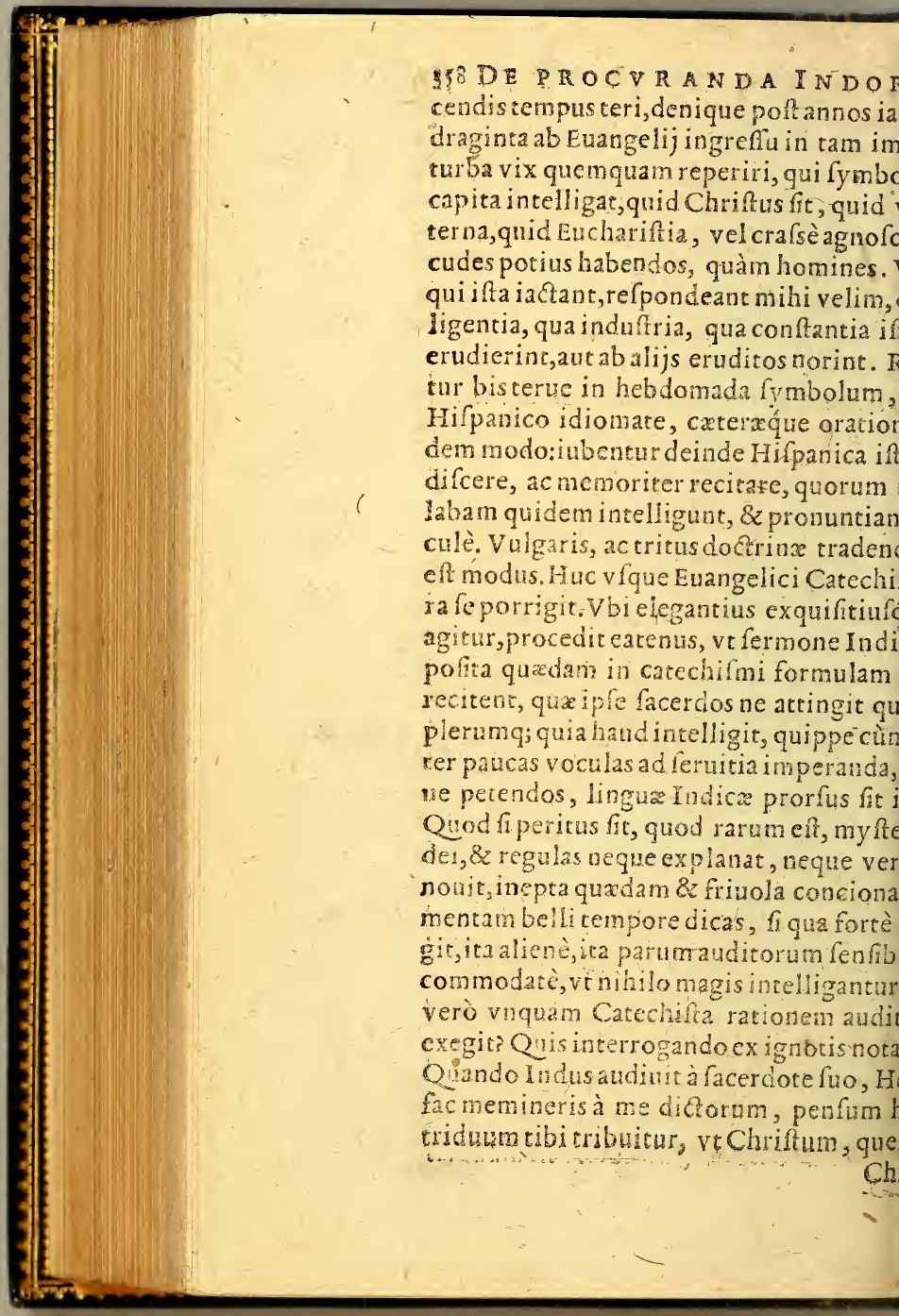


SAIVTE. LIBER IIIT. Itiani adoramus, quemq́ue illic imagine exum vides, \& Deum effe fcias regnantem in , ex omnixternitate, $\&$ hominem factum rris propter donandum nobis regnum cœm.Si rétè refponderis, laude, $\&$ pramio afris, fin perperam, publicèlues? Quid fimile Iam factitatum? Denique perinde Indis doa traditur, atque cùm à mendicis ftipiscoldx caufa precationes, aut verfus ali qui canatur,qui illud tanțum fpectant, vt dicendo $\mathrm{d}$ finem $\mathrm{v}$ fque perueniant carminis, vtrum auditores, vel attendant, vel delectentur, nia iam accepta, non admodum curant. To. go catechizandi ratio vmbratiliseft, \& lufimilis. Ego verò fi homines ingenio acer, 8 difcendi percupidi tales praceptores effent, nihil aliud quàm vi duplo ignorans euaderent, doceri ifto modo arbitrarer. $\mathrm{n}$ in $\mathrm{y}$ mbolo addifcendo, 8 intelligendo, erijf́́; Fider agnofcendis viri ingenio praes, \& literatura celebres diu in catechumem ordine tenebantur, cùm Ecclefraftica diina vigeret, neq; ante ad Fidei Sacramẹtum ittebantur, quã multas ab Epifcopo de fymconciones audiffent, diu \& multum cum caifta contuliffent, poft quas omnes curas, $8 z$ itationes, magnum erat, fi recta fentirent, entanea refponderent, quòd religionis nomyfteria altiffima, vt re vera funt, ac difficil intellectu haberentur: \& nos valde fupiri, of citantes grauiter Indos vituperamus, tarac ftupidos criminamur, $\phi$ ea non teneant, neq; tradidimus ipfi, neq;ab alijs illi accipetuerüt, fublimia prafertim, \&zab eorú fenfu

$$
Z_{4} \quad 8 \mathrm{cos}-
$$




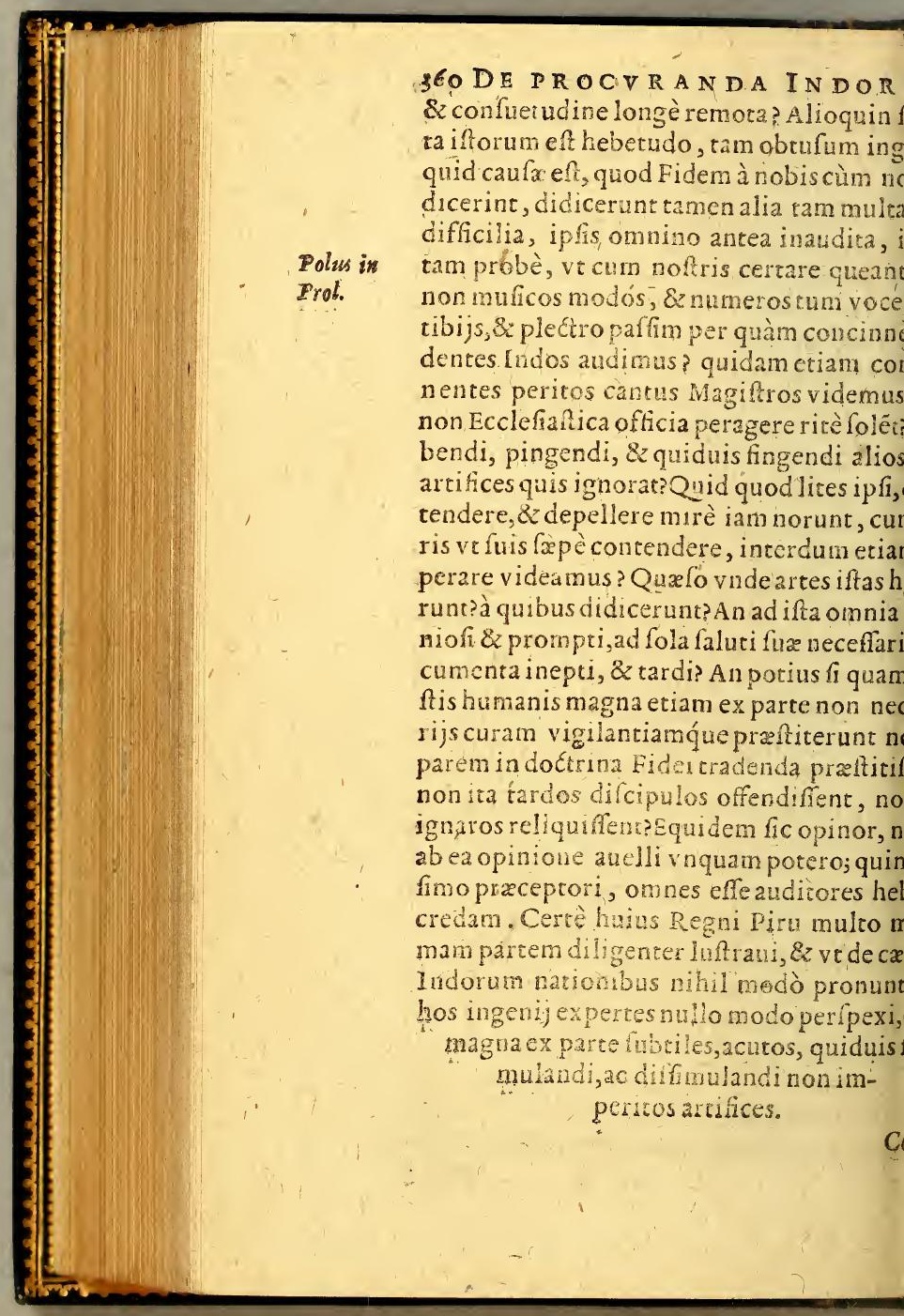


S A L $\checkmark \mathrm{T}$ E. LI BER IIII. tracos, qui peruerfitatem morum Indorum Fideinon recepte cousam afferunt.

\section{CA P V T IIII.}

a habere cùm pleriq; fateantur, tamen al orum accufatione non recedunt:fed alia ex eosadoriuntur, ve ignorantiam non fuo, torum vitio tribuendam probent. Aiunt aquidem effe, neque ingenij expertes: venatura prauos, ad malum proclines, boni shoftes, fapientes, vt faciant malum, bo- Hier.4. autem facere nefcire:tanea peruerfitate faia fibi faftidire, vt non folùm ad incelligen\& difcendum nihil laborent, fed etiam ftaefpuant, atque auerfentur, ita nihil illis hxnemoria', nihil intelligentia percipi, proa quod voluntate ad Chriftiana omnia aliena funt. Argumento efie manifefto, quòd Ptianorum confortia diligenter euitent, ad fias non nifi inuiti coêant, patres fpirituaos, fi paulo accuratius eorum mores emenpergant, confpiracione facta per falfas criitiones ab fe depellant, nihil pium, \& faluaifi per vimagant, prafente tantùm SacerChriftianos fe fimulent:clanculum vbi daacultas, auitas fuperfitiones fudiofifibeant. Denique ipfoscultiores, 8z eleganinter noftros nutritos, quos Ladinos apire folemus, quos oportebat magis Chriis moribus pollere, decuplo cateris effe pe$s$, cuinluis fceleris egregios fabricatores. os, quiad [peciem pij, probiqúue fint inter os, vbi primum fead fuos receperint, ne

$$
Z 5 \text { gultum }
$$
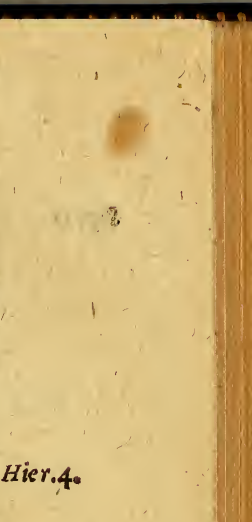


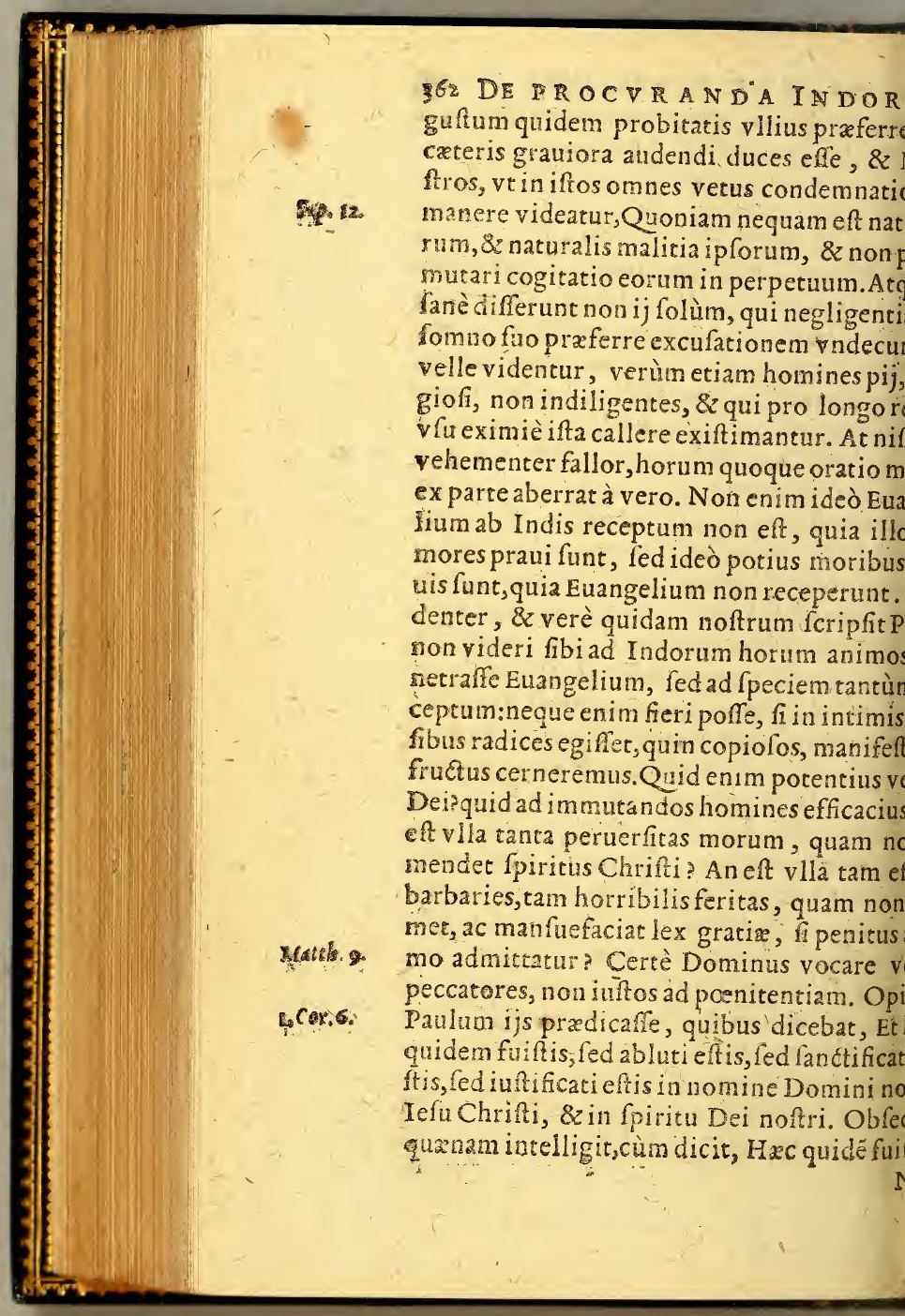


SAIVTE. LIBER IIIT. folùm egiftis, verùm etiam confuctudine a veluti verfi eratis. Quæ illarRelege fupe. Nolite errare, neque fornicarij, neque iferuientes, neque adulteri, neque molles, e mafculorum concubitores, neq; fures, neuari, neque ebriofi, neq; maledici, neque ra$s$ regnum Dei poffidebunt. Et hxc, inquit, is. Non video qua his horribiliora noltris aris obijci poffint.Et tamen ex illis frcibus, nta fentina mundauit Dominus fibi popu- Tit.8 acceptabilem, fectatorem bonorum opeIn ouili Dominico Leonem, \& pardum, \& $\mathrm{m}$ fimul cum oue, vitulo, \& agno futuros, \& i feritate depofita eodem pabulo pafcendos Efaie ut us Propheta defcribit. Quin etiam venenonnes beftias lufui potius, quàm horrori fu, cùm primum paruuli manum fenferint. Ec tabitur infansab vbere fuper foramine a$s$, \& in cauerna reguli, qui ablactatus fuerit, um fuam mittet. Non nocebunt, \&z non ocat in vniuerfo monte fancto meo, quia reeft terra fcientia Domini, ficur aqua maris ientés. Huic igitur falutari aqua diuini feris, huic lauacro puriffimo, \& foecundiffimo eft tam peftilens plaga, qux non cedat, moim illius admittat. Et qui ftat in fignum porum, ipfum gentes deprecabuntur. Ee mox pauca; Et leuabit fignum in nationes, 8216 iders; ugos Ifraël congregabit.Tanta ferarum, \& enatorum commemoratione quid aliud figat Spiritus Sanctus, quàm nullius natioaut gentis quamuis noxios, quamuis maos mores Euangelicæ gratia obfiftere pofed cedere, cùm primùm illius Paruuli de radice

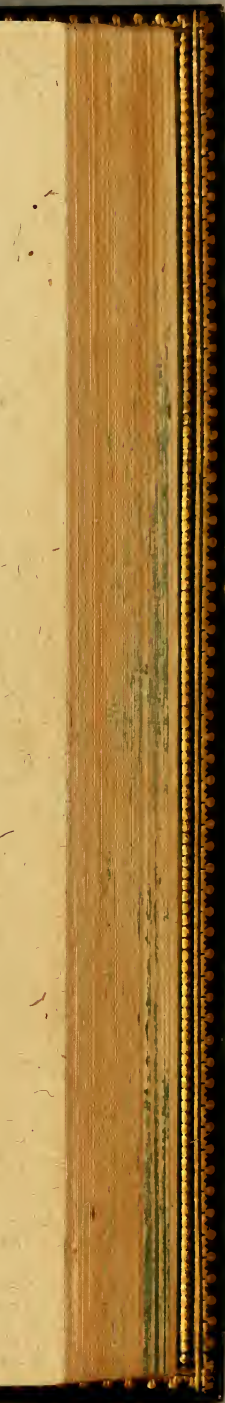




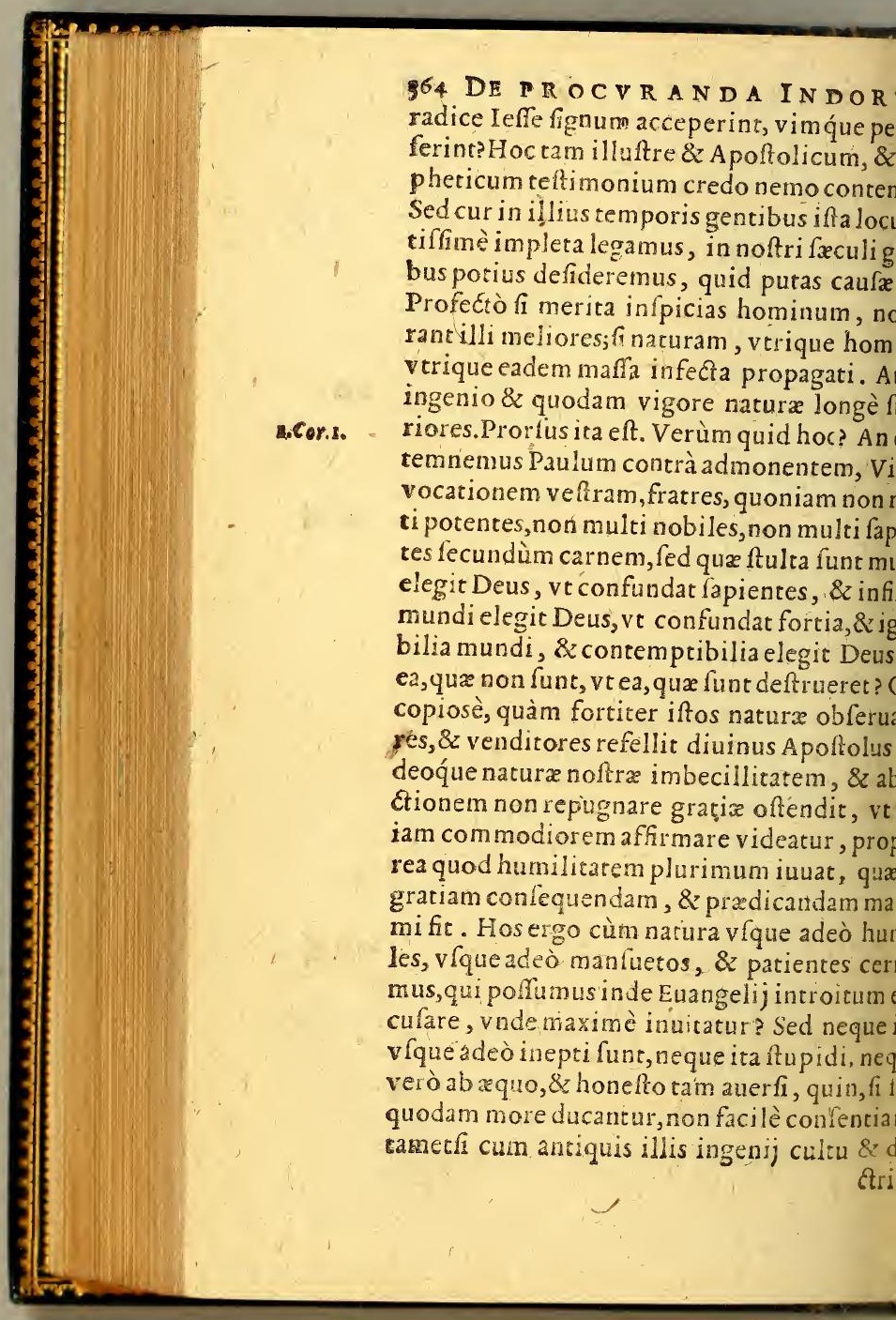


S A L V TE. LIBER IIII. $36 \%$ $x$ exercitatione nulio modo fint comparanur ergo illorum tanta melfis, horum tam te$\&$ inops 2 Expende omnia fubtiliter, $\&$ ad rem reuoca intelligéntiam, inuenies porifm caulam in coeffe, quod diuinis, \& occuladem, fediuftis confilijs, antiquis gentiradicatores fuerint pradicatione fua digIm noftristam fint plerig; indigni,ve longe euertant, ac dilfipent, quàm $x$ dificent, atlantent. Itaq; præcipua caufa ad miniftros m) idoneos redit. Qua namque eft prædicaoftra?quæ fiducia? signa certè non edimus, lanctitate non eminemus, beneficentia non amus, verbiac fpiritus efficacia non permus, lachrymis, ac precibus à Deo non immus, imò ne magnopere quidem curamus. ergo noftra querela eff ?quze tanta Indorum atio? Pudere nos potius deberet vitæ nohorrori effe tantus Dei contemptus, odio am fupina fratrum noftorum pereuntium io. Et cùm ad Apoftolicum hocce munus bus Chriftum Euangelizandi deberemus etiffimi, fapientia, \& fanctitate mirabiles, nus fordidilfimi quique $\&$ omnibus rebus mi, vbi illud eft: Patati omni pofcenti vos 1.Pet. 3 em reddere de ea, qua in vobis eft, fpe?vbi id. Difciteà me, quia mitis fum $\&$ humilis Matth r. ? \& Filius hominis non venit animasper- Luca 9. fed faluare? Atque illud fixum, ratumq́ue at fine vlla dubitatione, quod Indi non innt Chriftum maxima ex parte miniftroum negligentix, tum improbitati effe tridum.

Meffene 


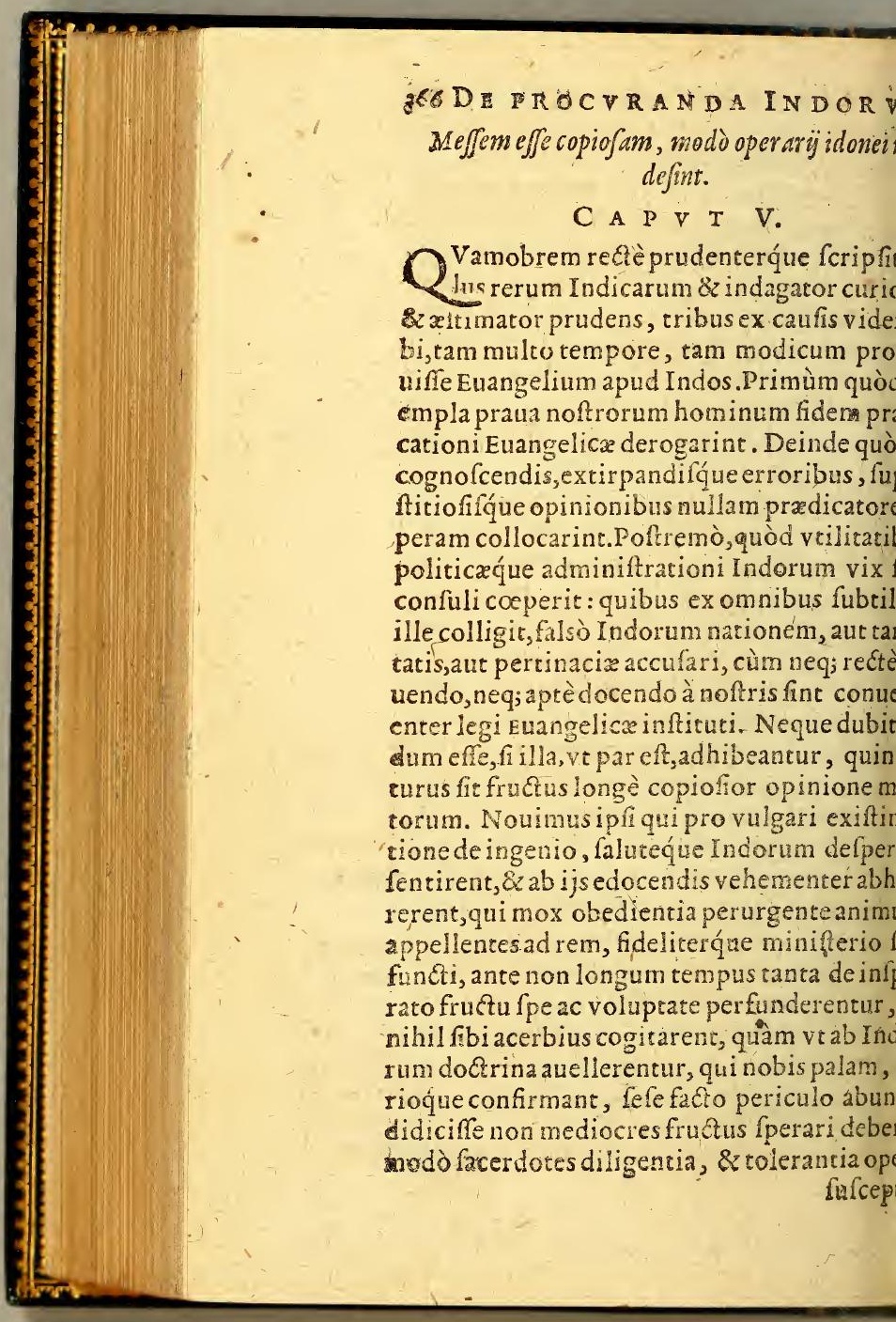


SALVTE, IIBER IIIT: pto non defint. Neque verò ita nihilef̂ahactenus, neque labor omnis ante actus aaffus \& irritus, quin fi \& tempora tumul. plena cogitentur, \& curre minifrorum, ciffimè dicam, fua magis, quàm Chrift ntium, non amplius effectum fir, quàm eferitò expectandur. Neque tam funt Iudi sinfideles, neque vfque adeò à Chrifto aliauerfi,vtplerique iaflant. Nouit Domidi funt eius. Profectò Ianaconz noftri, id di nobis familiares, fiquemadmodum fiftra affuefiunt, ita etiam mores Chriftiaectarent, non dubitandum effet, quin ficut notitia religionis Chriftiana cæeteros Intunlunas longè excellunt, fic etiam morü itate fuperarent. Sed quæ vident, difcunt: credentes vident, credunt $\&$ ipfi rectè:im agentes vident, difcunt \& ipfi improbè a Egocertè opinor non folùm xtate noftra, perioribus quoque patres noftros in genridiores, \& magis aे vero auerfas incidiftificafre tamen copiosè, quod diligentia; patientiaq́; fua difficultates omnes eui- Legar qui volet antiquos Anglorum mo- Beda is bx riores nofris Indis inueniet: at Augufi- Ro.dugla urentius, Iuftus, Mellitus, cæteriq́ue à San egorio miffi quanta effecerunt, quàm glo$n$ Infulæ illius conuerfione? Turingos, 8 es, aliafq́; nonnullas Germaniæ nationes leò barbaras extitiffe olim, vi nihil magis rum Pontificum Gregorij fecundi, \& ter- In teption má; Zachariæ refponfa A poftolica fatis mo conciliso. nt. Ab vnotamen Bonifacio à fede A po-rumprope prædicationis caufa miffo quãta multitu. initianso. do fub

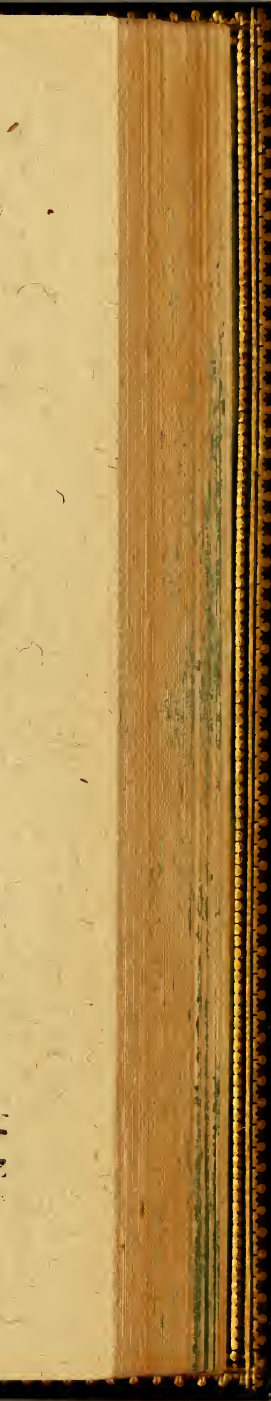




\section{DE PROC R A N DA IN DOR}

Greg tertius do fub lene Chrifti iugum ceruices dedi inepift vli centum millia hominum non longotemp ma ad Boni- dem Pontifex fcribit facro baptifmate ab facium.

Quid noftri Hifpanienfes Afures? quidC briolim? An non perviros Dei mantuefá feritate exuta, humanitati quodammodo diti funt? Quid de Malachia, quem librop D. Bernar. in commemoraui?quid de cateris dicam, qui 1 vit. illiws.

lùm Græcis, \& fapientibus, fed barbaris qu 8 infipientibus Euangelium falutis xtern pertiti funt? Quod fi magis recentia, \& $n$ proxima defiderantur, nó obfcurę famęeft quid in Prouincia Veræ Pacis Dominican miliz patres egerunt, cùm Indos filiorum haberent, $a b$ ipfis verè parentes agnofcere illeq́ue in primis Frater Ioannes, nifi fallo mine,vir Sanctus, \& Prophetia fpiritu cl Eodem mado, \& Minorita, \& Heremita,cx q́ue, vel monachi, vel clerici zelo Fidei, \& tis animarum fuccenfi, non exiguam apuc laudem, apud Chrifum etiam cumulatum mium labor is fuiconfecuti funt. Noftros quid attinet dicere in India Orientali, quo fudores pro Chrifto foliciffmi extiterunt ad fines vfque terra bonum Chrifti odorem fundentes, vel ipla commemoratione rerun Lib.3. de vi. ftarum animos Dei amantes exhilarant, a ta Ignatij. cap.

Litera $P A$ trum focieta tisex inäia orisnsali. imitandiftudio vehementer inflammant. $C$ rum Dux Sancus Magifter Xauier Apoft temporis fplendorem, \& claritate fignorum rerum magnitudine, \& laborum toleranti nouafe videri poteft. Quid huius fectat Magifter Gafpar in India citeriori, Colmas" res in Iapponia, loánnes Nobrega in nobis 


\section{SA L T T. LI BER IITÝ.}

Brafilea, reliquiq́q; patres fpiritu feruẽtes, Rom.1\&ీ? profratribus a nimas ponere, $\&$ fe ipfos $1.10 \mathrm{an} 3_{0}$ idere,ac fuperimpédere Euãgelio Chrifłı? 2. Cor..12. cêre non pauci.Omnino fit tales Indorum is diuino dono Miniftri contingerent, mef ent inuenturi lætiffimam. Verum Paulus olus illo iam tempore, quo primitiz Spiancti effur $x$ funt, dolet, ac deplorat omnes $\mathbf{p h i l} \mathbf{z}_{\text {. }}$ e, qux fua funt, non qux Iefu Chrifti, \& vum Timotheum vnanimem, \& fynceoadiutorem habere, quid nos dicenus, fxes mundi incidimus, quando \& charilrorum refrixit, \&zveniens Filius homi- Mat.24. fidem in terra inuenturuseft? Attamen Lucse 18. rendum eft diuino præcepto, \& affiduis, ibufq́ue precibus roganduseft Dominus Mat.10. vt mittac operarios in meflem fuam, qui

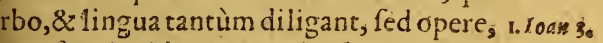
tate fe splos idoneos noui reftaments m:- 2 .Cor.3. præbeant. Atqueid quidem, vt Pater midiarum, \& Deus totius conlolationis InEcclefir largiatur, plena fiducia fperant, quia fine illo nihil pofiumus facere, qui ult, ponit, vt eant, \& fructum plürimum nentemq́ue afferant. Sed quod noftra inquales efie oporteac tãti operis miniftros, rei bene gerenda fpes omnes fitas effe rauimus, iplo Deo noftro adiunante, acdeinceps perfequemur.

De peritia Indicalingua necefjarid.

$$
\text { C A P. VI. }
$$

$A$ in omni Chrifi miniftro, qui Indo n falutem fit curaturus, quarenda funt,

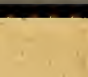

.




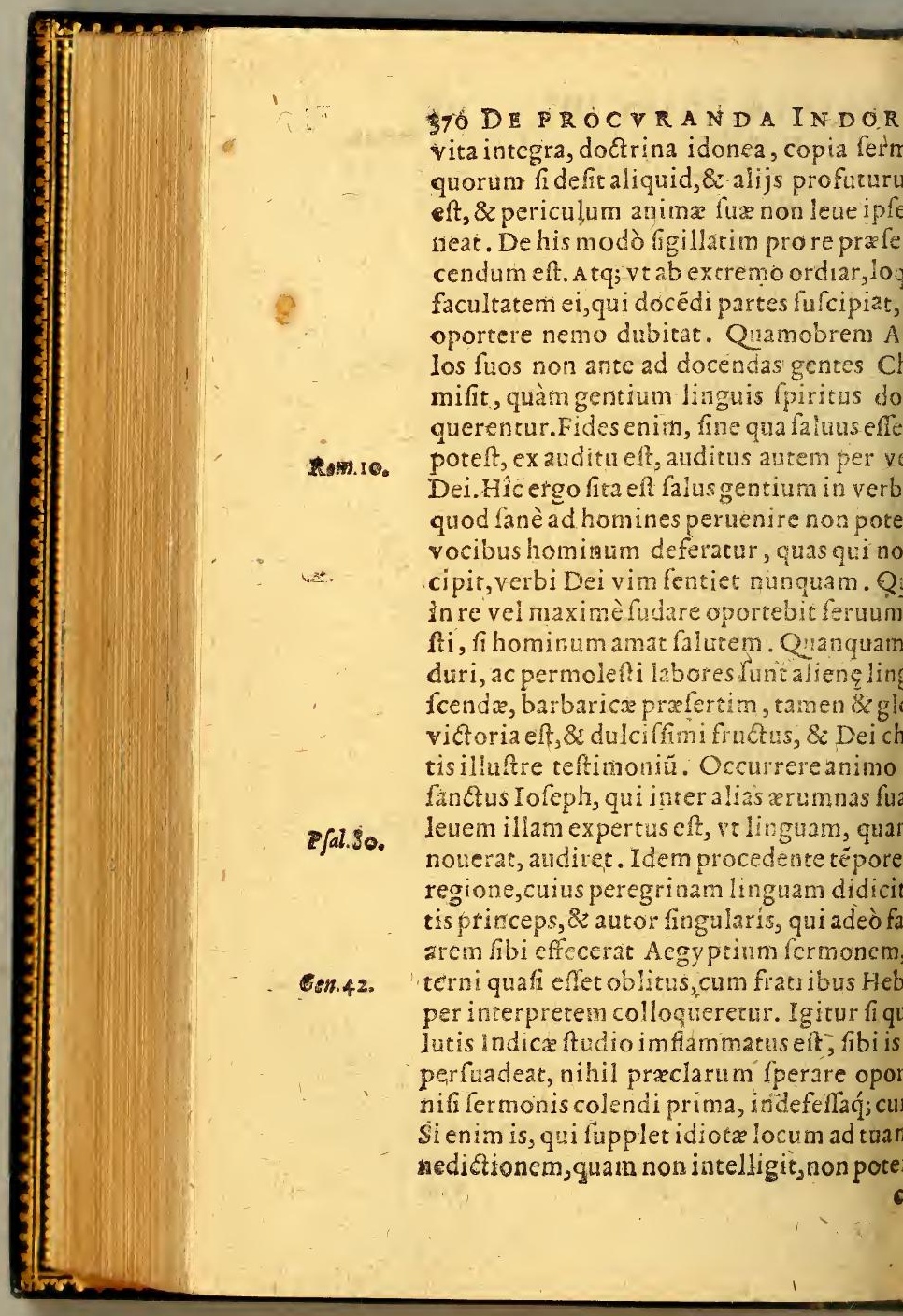


SA'T V TE. LIBER IIIT. $37 \pi$ Amen : quamuis enim tu bene gratias agas, Cor.s. le nihil $x$ dificatur, quonam modo conciotibiquamuis mirabiliter,quamuis diuine rifto, populus ignotæ linguæ, $\&$ profundi nis refpondebit in corde luo Amé, hoceft, prabebitaffenfum:Quomodoquamuis tu oquaris, edificabirur ad Fidem $\&$ dilectio rater, cùm vocestantùm fparguntur in vêc more Babylonica conflionis qui fermodiffident, nequaquan fenfu animilque cót? Mihi attentè frpe diuç; de falute Indorocuranda cogitanci nihil commodius, nitius venire folet in mentem, quam vthoprobati, atque integri, fermonis Indici fufciperent, familiarifimam confuetuhaberent, copiamq́uead dicendum fibi nt cum arte, tum exercitacione diuturna. enim mihi perfuadeo ita fururum breni, gelium chrifi adanimosiforum pene\& vires fuas expromeret, quod in hodier iem plurima ex parte tantum auribus Innfonuife, non etiam intima cordis penepulfafie videtur. Neq; enim alia via orb is um reliquusadgratian chrifti peruenit, verbi Dei forti inflantić; prædicatione; Actis A poftolorum lape legimus, \& Ecticæ omnes hiforiz tradunt. Neque verò ditus, aut alia via nationi Inchorum ad um aperienda eft, quàm affidux efficacis accommodata prædicationis verbi Dei. ecus opinatur, etiam atque etiam errat: præter documenta diuina plurima eagrauiffima, atteitatur nobis copiofiffimè A 2 2 rei

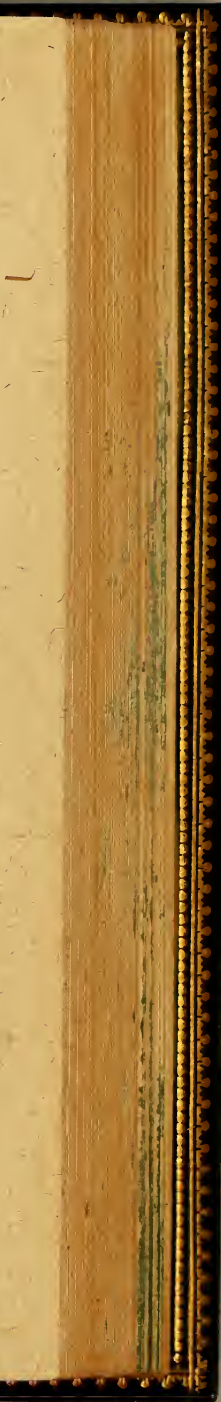




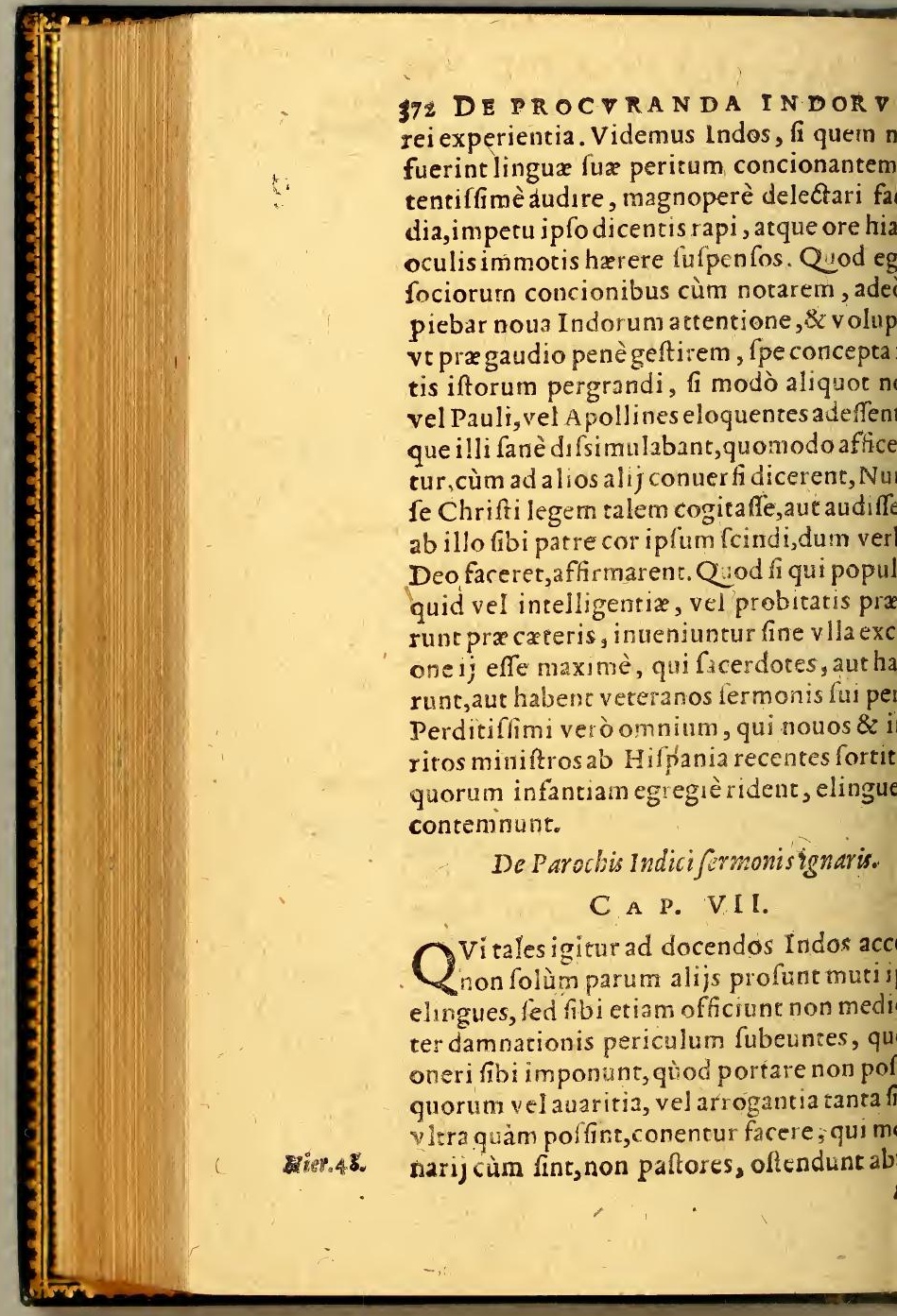


SA I V TE. L I B ER IIII. 373 lad fe pertinere de ouibus, propter pugil- rodn 10.' ordei, \& fragmen panis animas viuifican-Ez̧ecb.ız. ura non viuunt. Sunt huius generis hodie uàm multi, qui iniuncto muneri doctrinx rum copiosè fe fatiffacere exiftimant, Ora en dominicam, \&z Symbolum, ac falutatioAngelicam,tum præcepta Decalogi Hifpaidiomate identidem Indis recitantes, eoinfantes baptizantes, mortuos fepelientes, imonio iuuenes collocantes, \& rem facram diebus facientes : Hæc fumma doetrinæ de parochi officio fungi fatis fuperq́; opiur, neque interim confcıentia, quam veıná eriatam non habeant, mordentur, quod dife fint oues Domini, eo quod non fit paftor, Ez̧ecb. 34 que fint in deuorationem omnium beftiaagri,errentq́ue in cunctis montibus, in om1le excelfo, neque fit, qui requirat quod peec qui reducat abiectum. Nam quomodo o fidei reducent, qui linguam non habent? us vocibus lupos arcebunt, ouefq́ue nomin vocabunt, qui nullo modo, quid loquanntelliguntuı? Oues, inquit, vo. ern eius au- Ioan.rø. t. At vocem audire non pollunt, quam paproferre non nouit. Atque accipiat licet is, vt volet, quod dicam:rigidum \& moroappellet, nihil moror:ego eum facerdotem, inguæ Indorum ignarus eft non nifi cùm afliz iactura Parochi officium fufcipere iam pridem, \& opinor, \& affero, quodetiã ifefta ratione demonitro. Duo funt de necef falutis, Fides, \& P Penitentia.Fidem docere xdicare non poreft fermonis expers: PœniSacramentum adminiftrare non poreft, A. 3 qui 


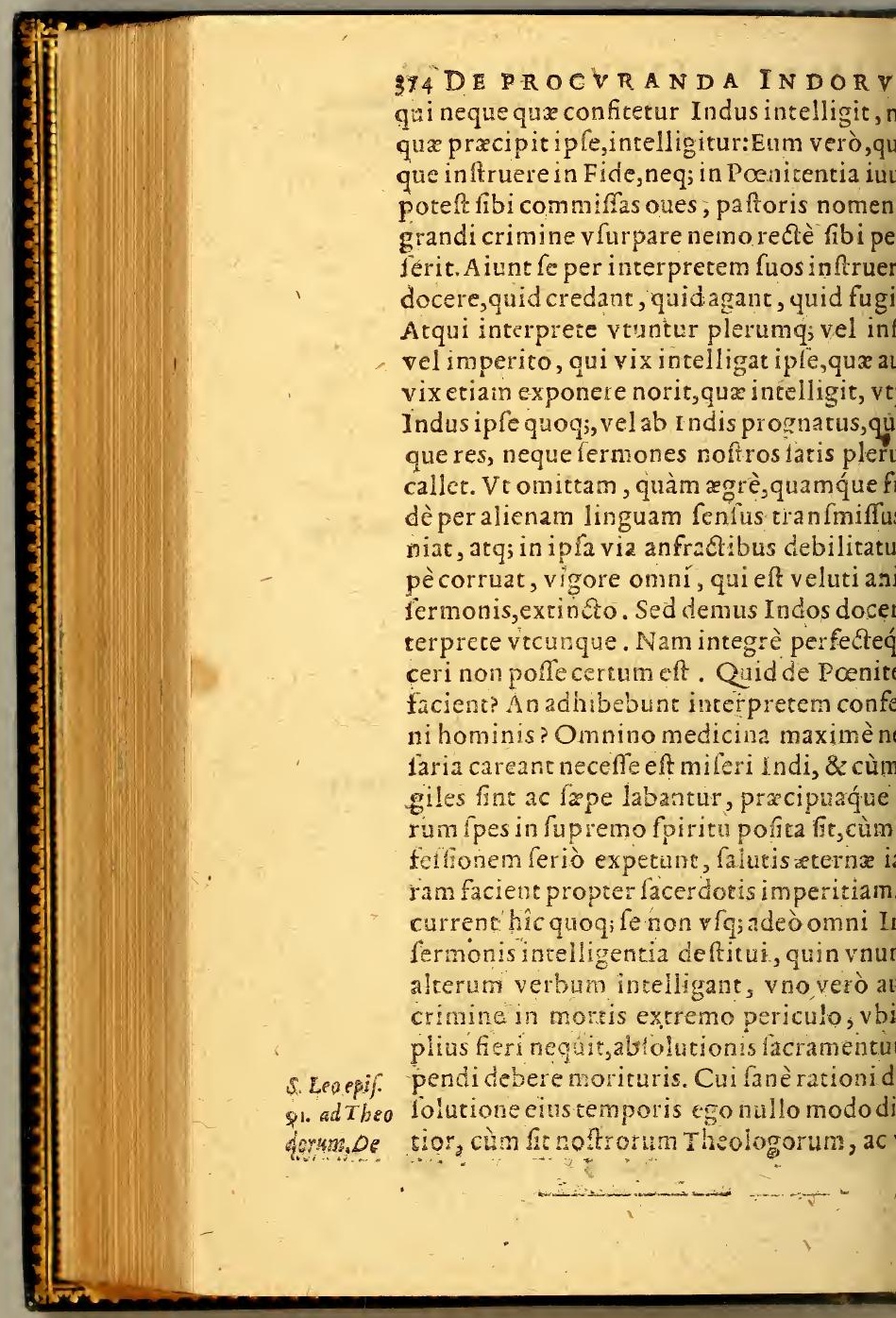


SALVTE. II BER IIIT. yoque patrum certa fententia. Attamen tum eo in difcrimine excufant, nullo mo. ilem licentiam, vbi nihil tale vrget, fai concedunt. Cùm ergo omnes polt bapm lapfi ex diuino pracepto etiam citra iaftico verò quotannis, quomodo pote?t cutionis commercium nullu haber? Q 10 d De Panitent id, quod mihi ex hifce quidam aliquan- tijs c.Ompondit, fimilia inquirenti ex eo, fecon- nis. Conci. nes fuorum audire, cùm nonnulla percipi- Trid. feff. q; id fibi faris effe, vt abfoluant. Ego fanè 14.cap.5. a affirmo, cùm confeffionis integcicas ex $\delta$ efl 14 . c. liuino fir,eum non effe idoneum Poeniten- $5 . \sigma^{2} 6 \overline{.} .7^{\circ}$ inifrum, quem propeer imperitiam dimi\& eo amplius neceffariò latet, perinde eit, ac fi tantundem non sudiret, quàm effe ram, 8 idoneam confeffionem præter is periculum nemo vecunque doctus exit. Denique vbi Parochus non ea facultate vt fubfantiam faltem, quaq́ue iudicium. sequirunt, pofficintegrè affequi, neque $\int_{a-}$ Ponitentis proratione perfon $x$, \& crimineceffaria documenta adhibere, nullo. o eft ad audiendas coufeffiones reputandoneus. Qui verò l'œenitentia facramencommuniter adminiftrare non potelt, hune Parochi officio tuta confcientia fungi neDamnas igitur, dicet quifpiam, omnes \&; chos, \& Epifcopos, \& Patronos Indorum, illis nullo alio confulunt modo, quàm hofacerdotum prẹidio, qui noui,rudefó; Inidiomatis ex Hifpania aliundeuè aduenA2 3 \% t210\%

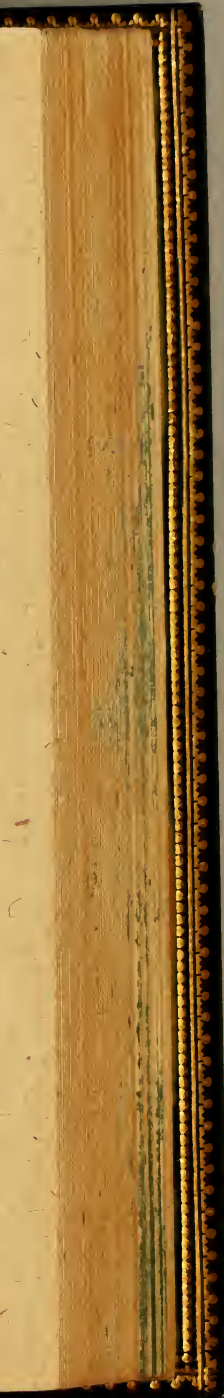




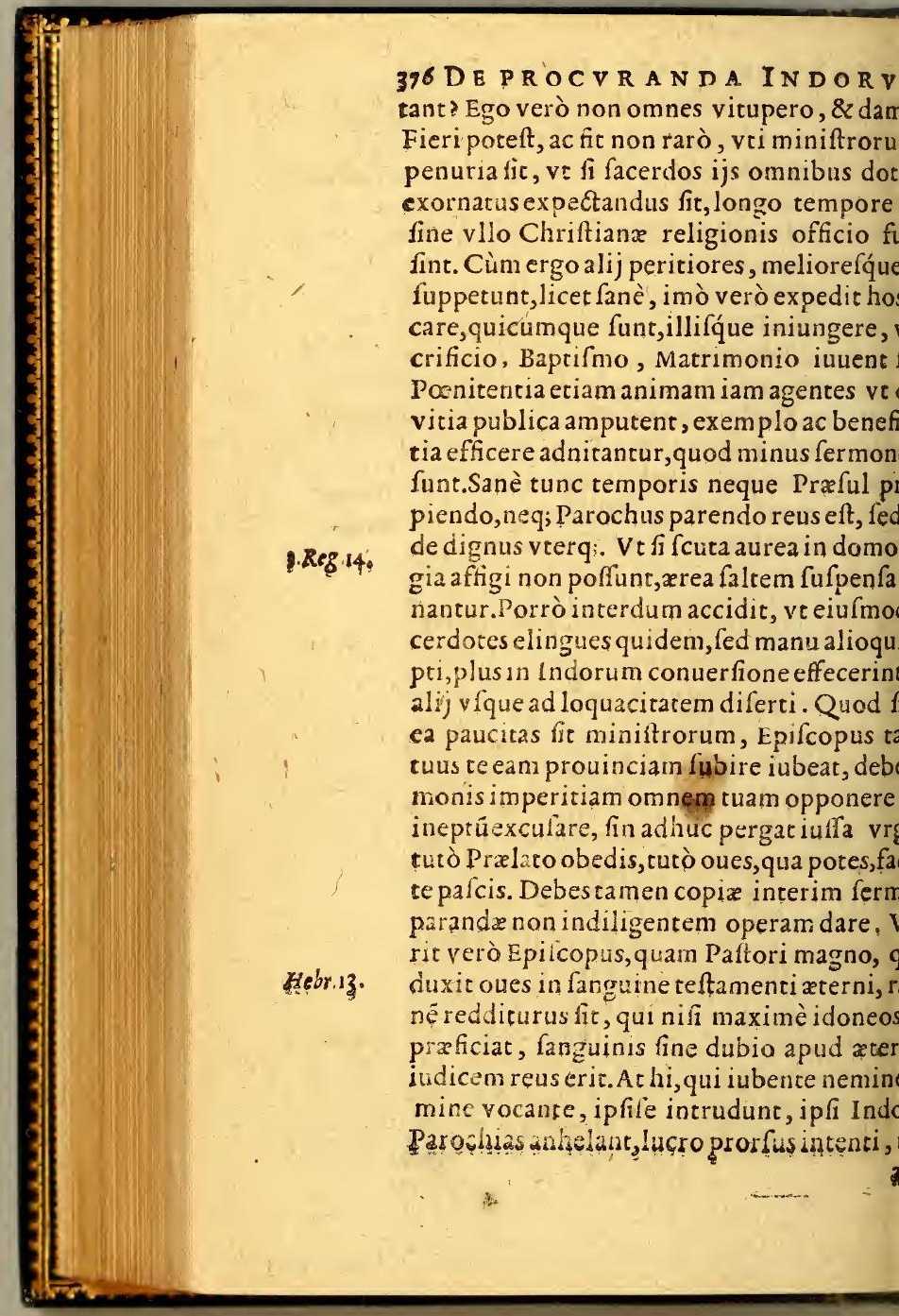


SA L VTE. LI BER IIII. ,quàm quxftum exiftimantes pietatem, cü ${ }_{1 .}$ rim.6. lioqui ineptiffimi, muti, elingues, qua rati2 lege excufentur, quod fpecularores fe cô- Ez̧ech. 3. erint, qui clamare non norunt,alij iudicent. ertè tantam temeritatem, tantum Dei aniimq́ue contemptum excufare nec volo, nec $\mathrm{m}$, cùm liceat videre paruulos deficere vul os in plateis ciuitatis, atque exhalare aniuas in finu matrum fuarum, cú planè quos umaffectum, \& curam præ fe ferre opor, ftruthiones potius voraces, atque crude- Thren.2. periantur, atque ita fiat vt lactentium in folingua palato adhæreat, quod doctrinx Thre.4. a vel claufa, vel arida inueniant, \& gran- ofe.g. uli panem petant, cùm fit tamen nemo, rangat.

od quidam non recte infcitia fermonis Indici confulant.

\section{A P V T VIII.}

Tque hæc de neceffaria notitia fermonis ei, qui animæ fux interitum auertere cupit, di unt:quæ tamen eam,quam optamus, \& quęis, idonei Dei miniftri menfuram minime lent. Nifi ergo linguæ vulgaris egregiè peiri, doctrinæ atque inftructioni tor popu$m$ operam dent, mea quidem fententia paadmodum promouebit opus Domini. Vnus nodi,cui Dominus linguä eruditan dedet fiar laffum fuftentare verbo, $\&$ infirmü de affumere, centum iftis triuialibus cateis anteponendus eft, cùm folus vnica conciplus efficiat, quàm illi multi toto fxculo. rénam tales dono verbi afiucnces, finon Efai.sQa

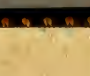

.




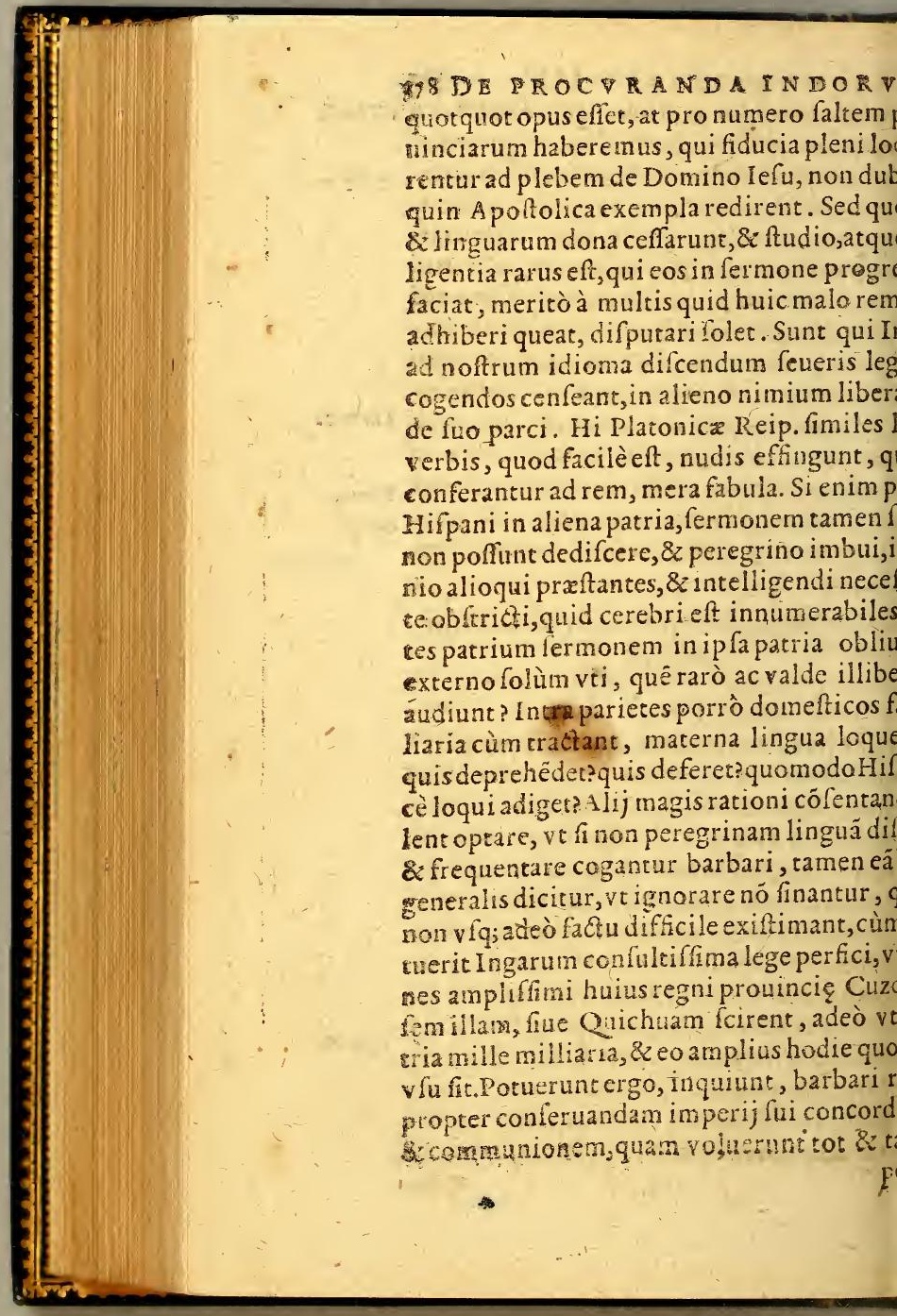


SALVTE. LIBER IIII. lis linguam dare, non poterunt verò Chriprincipes propeer religionis vique adeò ariä caufam, efficere, vt eadem illa lingua rcrebrefcat, vt omnibus vfui fit? Etfi enim ores Indorum illä ferè callent, vulgus tamulicrum, puerorum, eorumq́; , quos ipfi runas vocitant, genus hom inū agrefte, vix uam fatis illius norunt. Qua ex re, \& prxdo verbo Dei, \& confeffion ibus audiendis dimenta fiunt fanè grauia, cùm idiơmatú altiplex fylua fit, vt in his locis, qux iple fus fum, exiftimem plufquam triginta linnumerari, eafó; valdè $\&$ inter fe abhorrenad difcendü difficiles. Cui tã maguo incófi quo pacto polfit occurrere noftrorum ratorum vigilantia,optimè de Indicana fa neritos pofteritas omnis laude celebraret. ü hxc vel fieri nequeunt, vel certè non fiüt, Indorum informatione, noftrúip fi non de us informare fermonem, quoniam chariege,illos à nobis patius quari, quă ab illis ecet. Sunt igitur (in quorú me numeroalido fuiffe confiteor) qui faluti Inçorú eduos,praficiendolá; ex Indigenis Hifpanorụ magiftros arbitrencur. Hanc efle compẽdiviam, propterea quod hi fermonis abúdè funt, cui ab incunabulis afuefacti funt, dquiduis explicandum familiari vtiqueefu verò \& religione Chriftiani integri \&z 1, cú ab Hifpanis progenitoribus fide Eccle camq́; confuetudinê hęreditario ferè iure eant,idq́; prosúma gloria ducant. Ac plaicüq; ex his probatę diuq́; fpectatę virtutis ti fuerint, doctrina quoq ; non expertes, in

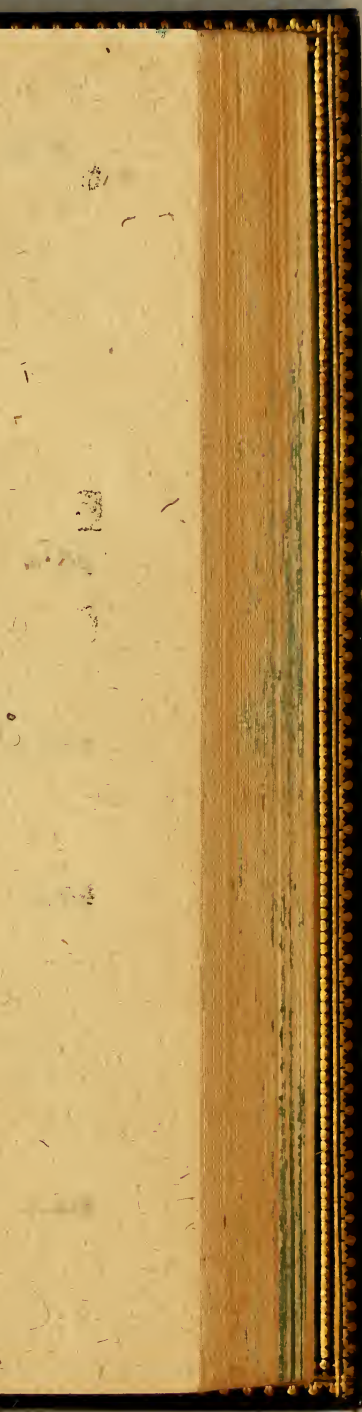




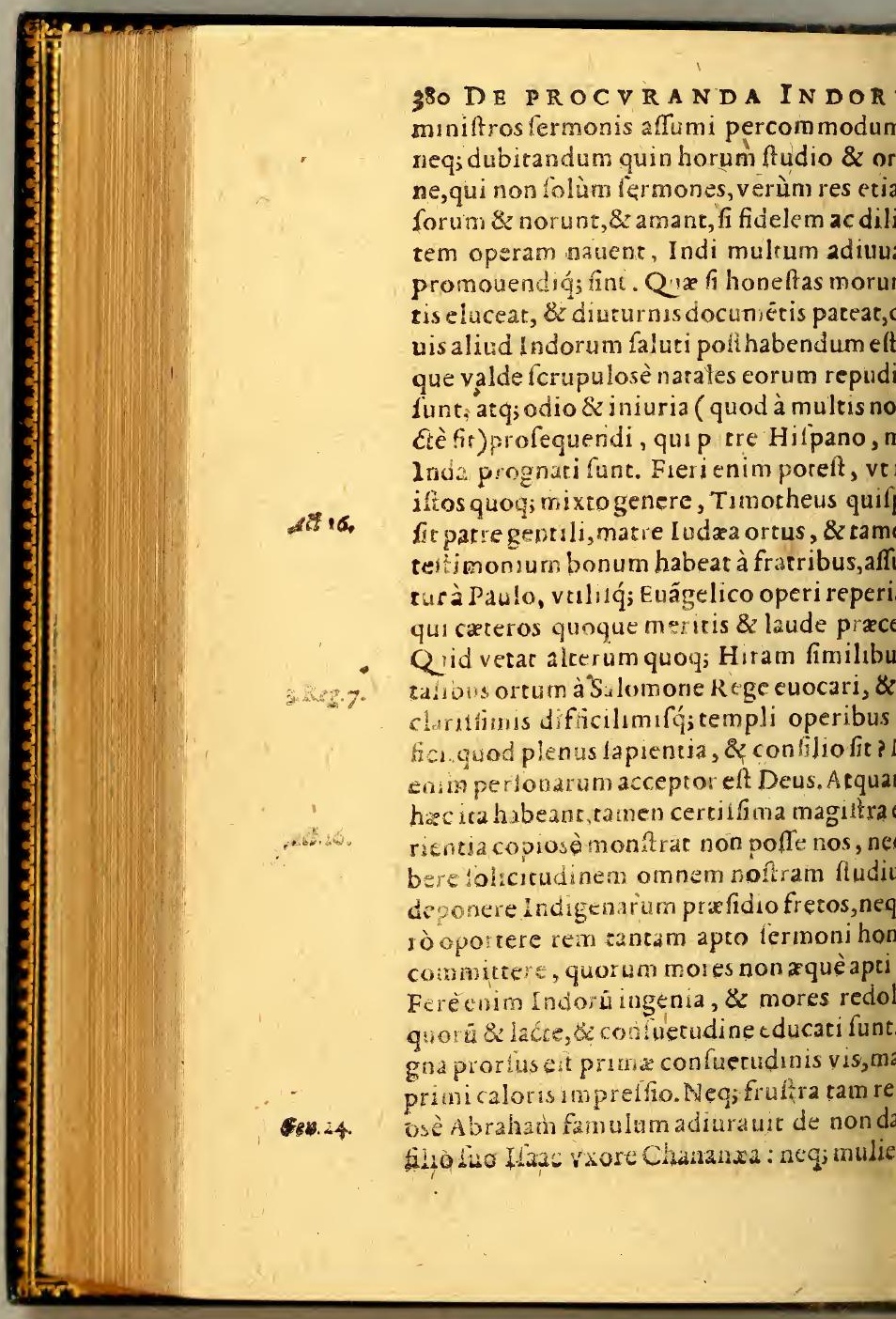


S A L V TE. LIBER IIIT. $\quad 38 t$ non potius fapienter Sancta Rebecca He-Gere..2\% foeminę coniungi Iacob fuuri adeò exhort vitam mallet amittere. Sunt proprijcue regionis mores, quemad modum \& natictus non ijdem vbique, fed varij. Cietenmpermendaces, malix beitix, ventres piettimonium Poëtx veterifert Apoltolus, vera icriplerit. Itaque folerter ingenia inenda funt hominum, morelq́ue diu probanPatrix minus temperat $x$, confantis, vel lafciuz, \& leus opinionem quis cluat. ulo certa compertum eft ex iftis plerolque beffe r or upeis moribus, quàm verbotano ere.Quamobrem ita iftorum loquendi opnitas contemnenda non elt, vt tamen inge2 moribus nifi pieniffimè probatis, non es tanta,tamq́ue periculofacredatur.

doporteat ad Indos venientes praducatores

Indicum idioma diligenter

difiere.

$$
\text { C A P. IX。 }
$$

que laborandum nobis eft, \& quod vnum tat ex omnibus, fudio \& tolerantia, fermo cultas paranda.Id quamuis difficile, \& nefum fit, non tamen fierinequit. Videmus ines in Hitpania natos, atq; educatos, qunfetiam de noitris Theologos non obfcuri ro s, qui obedientia duce ad has regiones vent, charıtate illuftrum conau ü autore imnte, tanta fe dilcendo idiomati Indicocura liffe, ve non minus facunde 8 copiosè Ingaermone concionentur, quam materno pofjento 


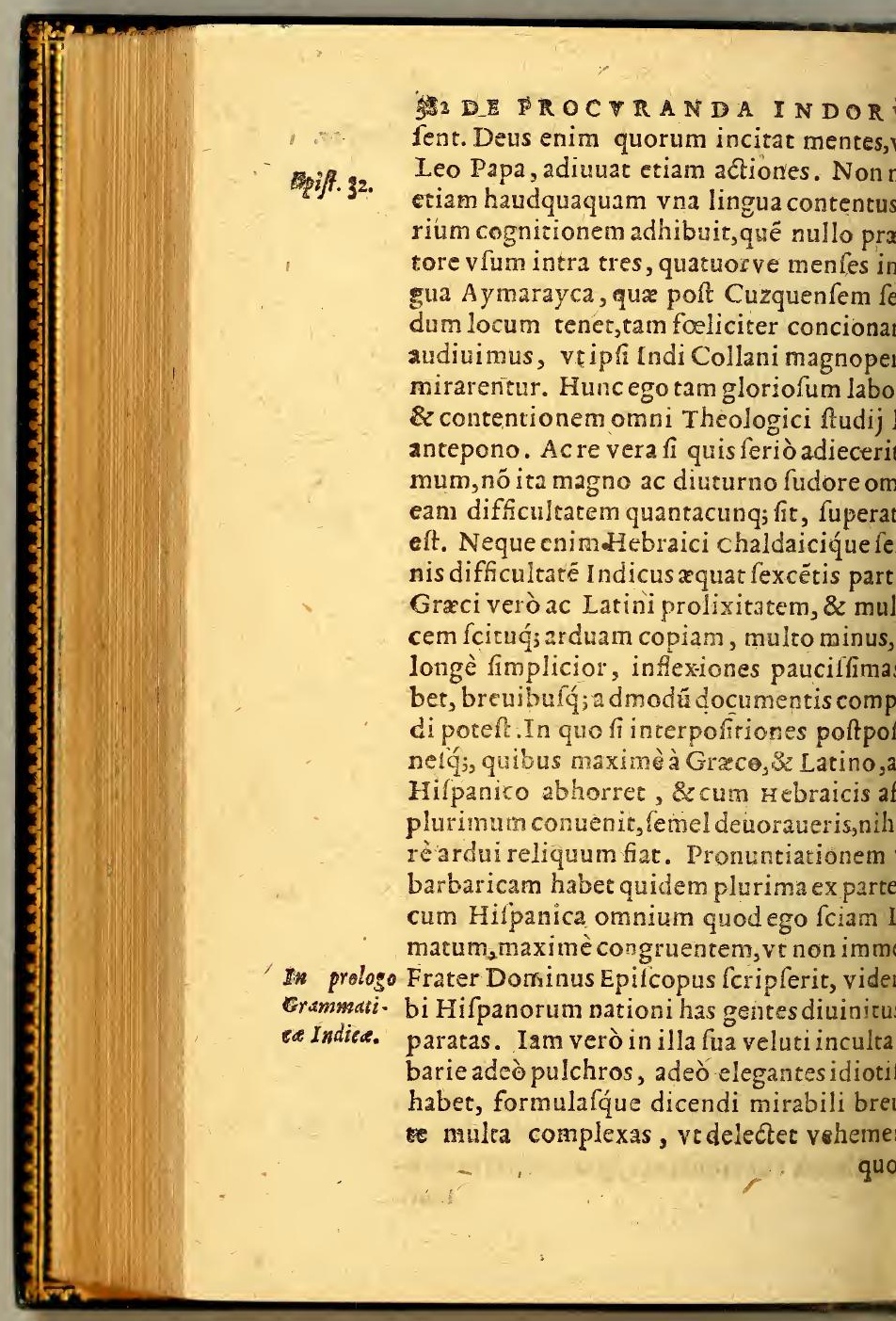


SAL TE. LIEER IIII. - - 383 um vnius vocis vim 1 Latinus, Hifpanufue imere velit, pluribus ipfevix polfit. Séd tualium \& philofophicarum rerum, ficuti tia plurimum carebant, vtpote barbari,ita orum Indicorum penuria maxima eft. At Hifpanicas voces Indicas fecit. Vtenime$\mathrm{n}$, bouem, vinum, triticum, oleum, multaid genus quia non wouerant, $a b$ Hifpanis folum res, fed vocabula quoq; acceperunt, quibus nos quoque alia Europze vel anitium vel frugum genera ignota mutuatifi: ita equidem cenfuerim non magnopere randum, fi Fides, fi Crux, fi Angelus, fivirtas, fi coniugium, fi pleraque alia non fatis cè ac propriêreddi polfit. Licebit enimex anico mutuari, \& propria facere, vfuq́ue linguam locupletare, quod $8 \mathrm{z}$ omnesfecềtiones, Hifpanica maximè, vt aliena copia ditefceret, qwod prudentifimus quifquis yachac, id ef, Indici fermonis Magifter uentare iam folet. Pronuntiandi vero diftas vbi veluri infartis affurifque multis bis plerxq; dictiones in longum crefcunt, poted non effe molefta paternx præfertim itati affuetis, multoq́ue illa alteragrauior, ligendi Indos ftridentes. fxpè ore potius, $n$ loquentes, fed'deuoranda eit tandem ve ipfóatque exercitatione vincenda. Cxquippe facilia valde. Eft autem ad certa epta neque multa, neque diffieilia redacta mnis Indicæ lingux:qua in re primis foripous, et fi multa falso, multa impropriè \& abè præceperint, tamen gratiæ habendæ funt im $x$, multum enim adiuuat ars, methcdufq́: traders.

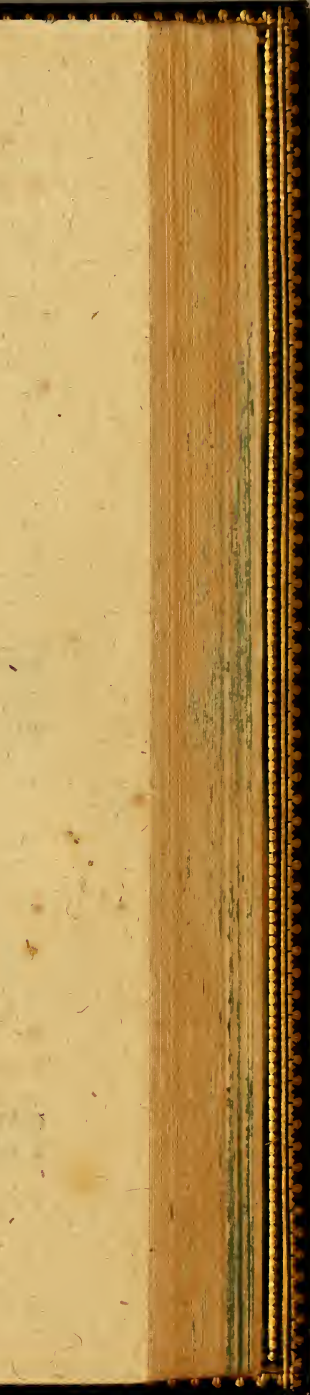




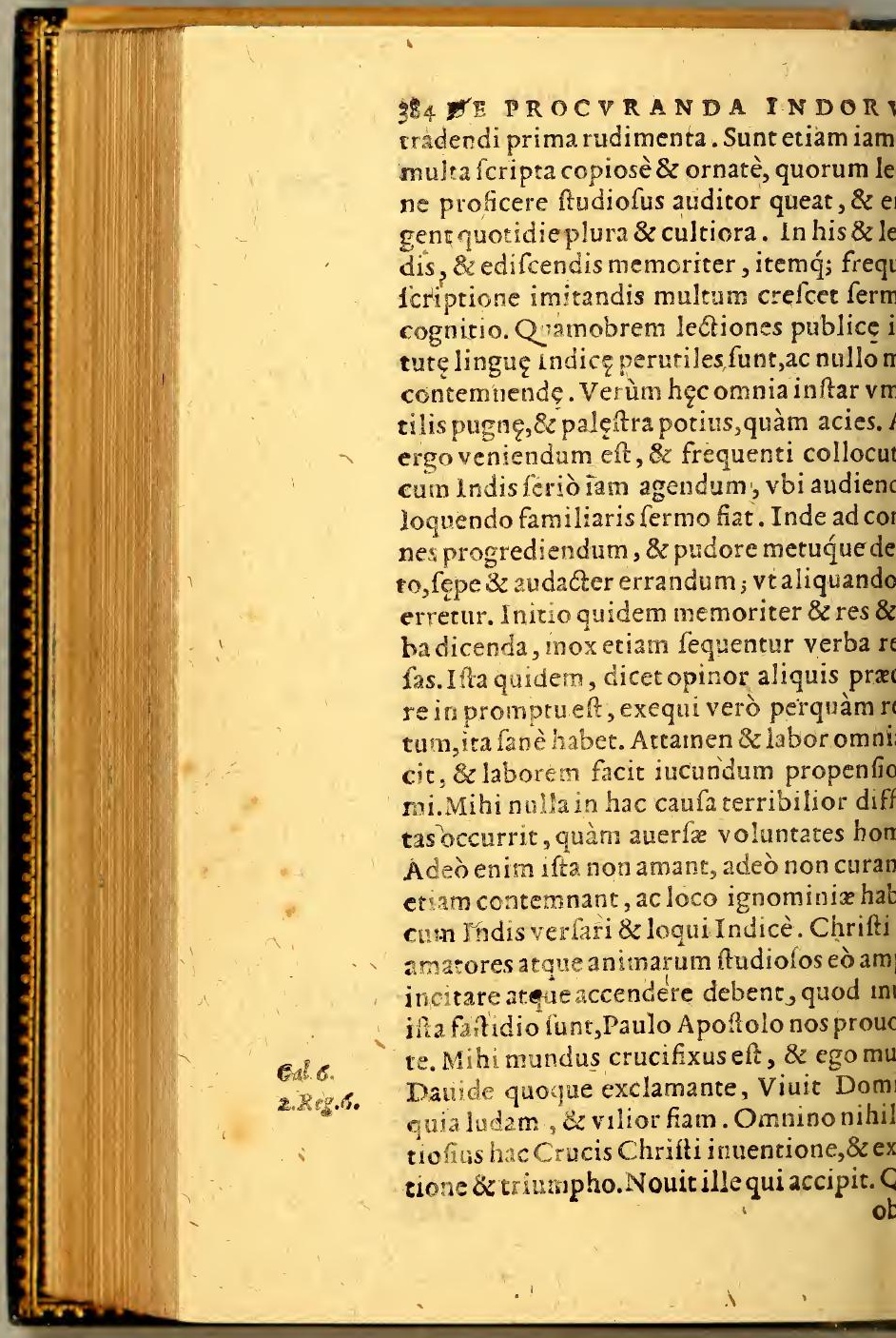


SA L V TE. L I BER IIIIİ. fi facerdotes, miniftriq́ue Euangelij mulpud Indos proficere cupiunt, illud modis bus curent, yt recentes ab Hifpania anteferuor ille, \& fitis animarum intepefcat, alia re occupentur, ac difineantur, quàm atiffime ftudio difcend $x$ Indic $x$ lingu $x, \&$ uam didicerint exercendx. Hoc nifi fiet, iquid fiet, quod experimento compertum nus.Sapienter ergo \& religiosè Dominicanilix patres in Guatimala prouincia, ve ide dignus vir folebat narrare, inuiolabili o venientibus ab Hifpania totum primum $\mathrm{n}$ nihilaliud quàm fudium fermonis innt. Anno integroexasto ad fructificannittunt, quod vtinam omnes fequeremur plum, fieret paucis annis fine dubio plufeffectum eft plurimis. Neque enim focie- Par.4.Conf. oftræBeatus Fundator Ignatius Indic lin cap. 12 . or Etiones publicas fruftra pręcepit, vbi vti- Declar. lit. derentur, neque vfquam neceffarium ma- $B$. od Regulx habent, vt Regionis, in qua defermone loquantur omnes, funtenin per neceffaria omnia ifta prafidia, vt facultas dr verbi diuini gentibus annuntiandi. At fi vel per occupationes vigentes, vel per $s$ folicem ingenij fortem tanta connequeat, non contunuo deber fibi $a b$ hoc opere vacandum xift mare, filentioq́ue agere.Poteft mult:s u odis fucultat is fux itatem adivuare. grinum fi doctus ipfe it \& probata virtut s focio vtatur fermorito, guen iplefeuten an feorfum doce-

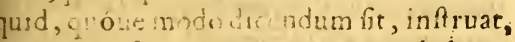
ue vt Moyles Aaron interpietem habeat, $\mathrm{Bb} \quad$ vt per

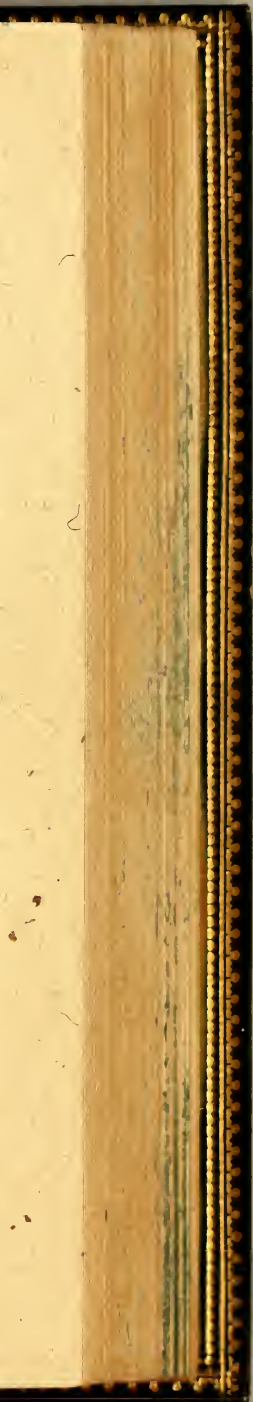




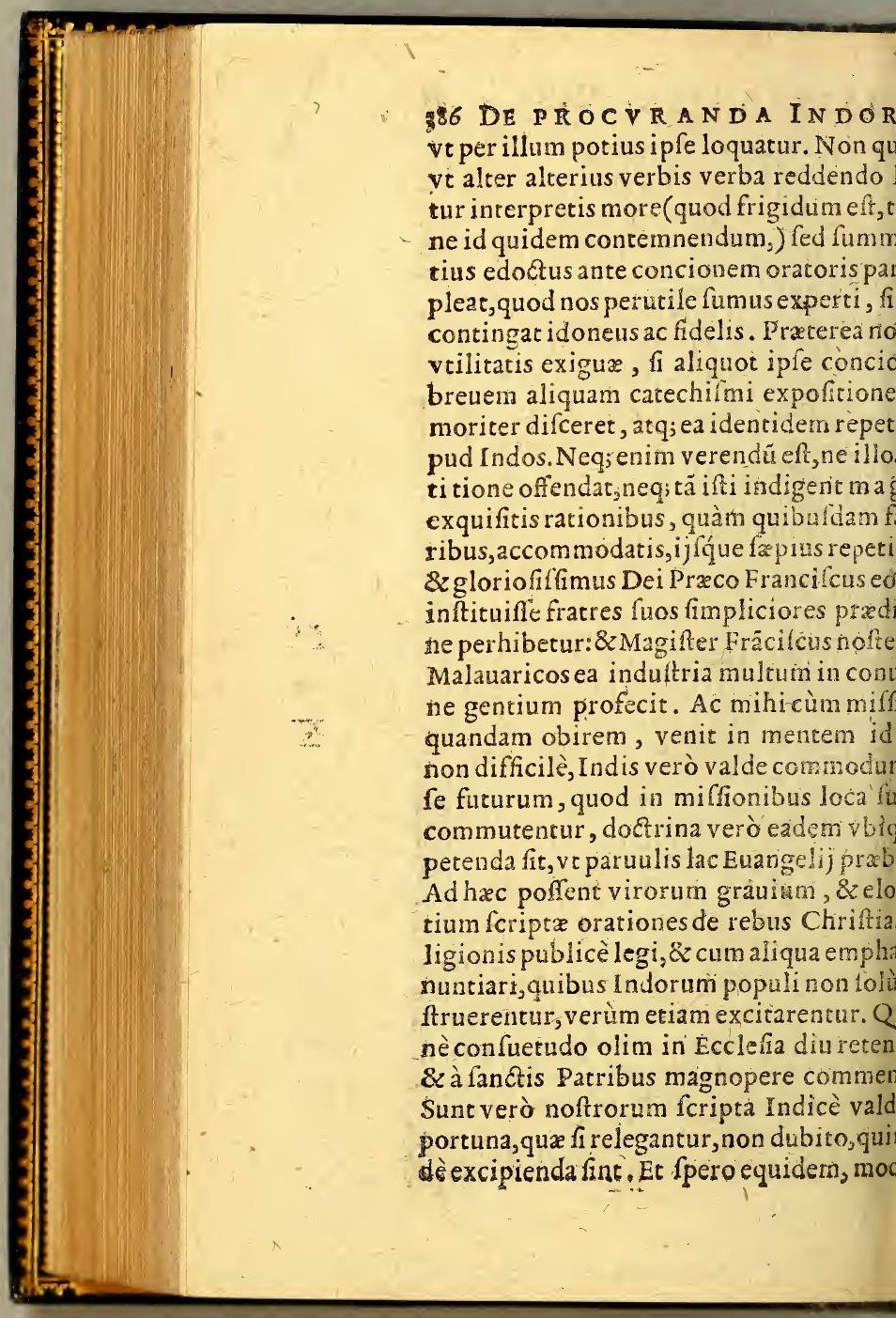


S A L V TE: I I BER IIII. on defit fpirizus Chriftum, \& Chrini parcomplectentis, his alijlq́ue rationibus, dem fpiritus commodè fuggeret, magnos falutisque Indica prouentus aliquandé Iros'.

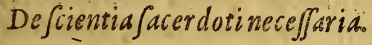 \\ C A P. X:}

2V I T V R fcientia, qux tam propria erdotisef, vt pectori infculptam Doctrieftare lex iunerix, fignificans Dei ferum Exod.18\% rem efle oportere cæterorum, quorum ir curam, ne, fi fcientiam à repulerit, reur iple viciffim à Domino, ne facerdorio tur,atque ita pariter, \& propheta, \& popu- ofiof rruat. In plebeio homine habet ignoranam fortalfis excufationem, at in facerdoLeo Papa fcribit, vix ferenda eft excufatic; ratendat infcitiam, imo vero, vt in alia e- Epilcopos a fcribit, in ijs, qui prasut, infritianecex- sicili. one digna eft, neevenia.Quatenus autem Epif.2z. am efie oporteat facerdotem, fatis Patrum res indicant.Si pradicandi quidem verbi angitur officio, cum fic hoc proprium Pa$n$, atq; Doctorum eum effe oportebit, qué s defcribit, Amplefientem fanè eum, qui dùm Doctrinaın; eft fidelé fermonem,vt is fit exhortari in doctrina fana, \& eos, qui adicunt,arguere:qui hxc praftare non poemerè Doctoris in Ecclefia v furpat locum, fibi fuxta Iacobum Apofolum iudicium Dif. $38 . F^{-}$ in laisis.

Leoep $8 z^{\circ}$ Tit.1. as. Quod cum tantre magnitudinis tanti periculi fit, nemo fatis praftare poteft; $\mathrm{Bb}$ a nifi

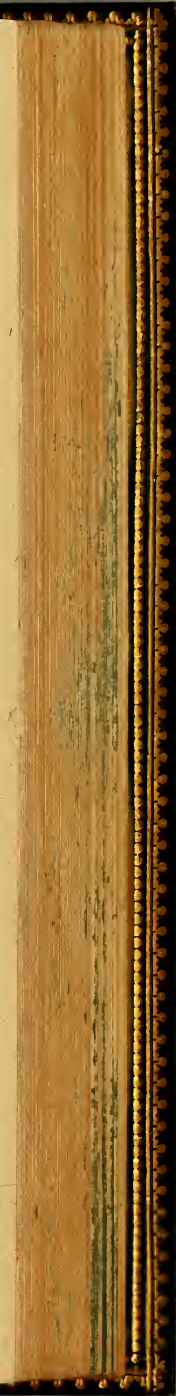




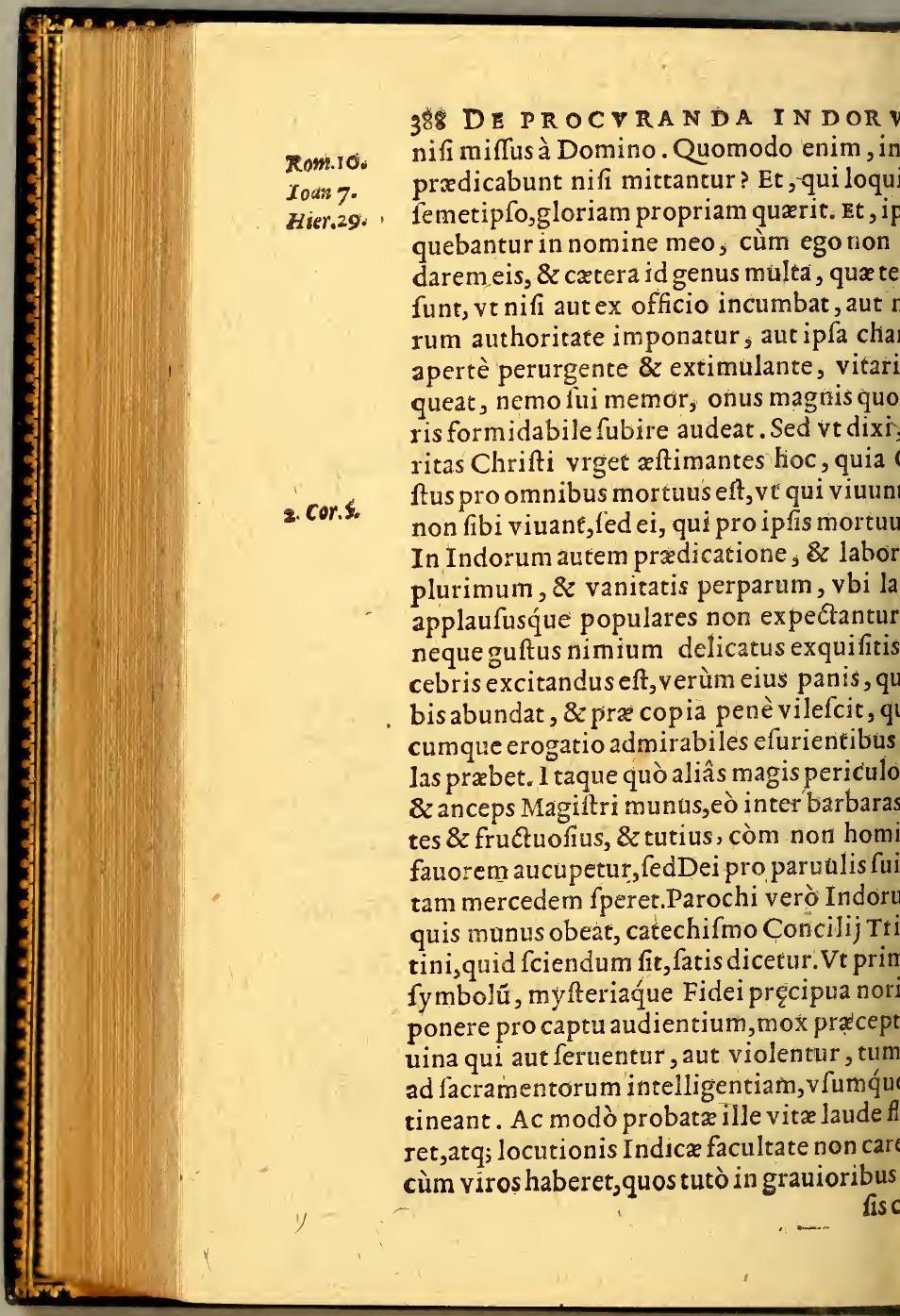


SA L V T E. I I B ER IIII. afuleret, non magnopere ego fcholarum ap um, reconditamq́; illam doctrinam in eiufIndorum Parocho defiderarem, quippe munus magis prudentia quadam, atque in, morumq́ue Indicorum peritia confter, fubtiliori literatura.Vt enim Magifri noum in religiofis domibus eliguntur, virtudentiaque præftantes, ipfoq́ue vfu rerum ualiú,propterea quod ea ars artium cú fit, m paginis euoluendis, quàm internis $f$ pinotionibus difcernendis paratur (tameti undamentum iftud iacitur vitæ purioris fus exercitati ad difcretionem boni, \& anctorum patrum lectio vt Gregorij, Ba3ernardi, ac cæterorum, Diuinæq́ue fcripræfertim meditatio plurimum adiuuet:) inè in moderatione Indorum, qui nouitij $\mathrm{m}$ funt religionis Chriftianæ, \& $<$ quidem somnia diuina, \&z Ecclefiaftica valde node inufitata occurrant, exoptanda effet exuædam vitæ fanctitasin miniftro Dei cum rudentiæ ac dexter itatis laude coniuncta: iæ verò is modus eaque menfura, quæ com er opportuna eft, vt fciat quę forma catei feruanda, quis ordo facramentorú tenendantum fibi liceat in abfolutione, quæ fint ata crimina, quæ præuilegia Neophitofummis Pontificibus data, cæeraq́ue talia, m notitiam ex Concilio Prouinciali Lipetere potelt. Ritus verò Indorum, auifuetudines, \&z fuperftitiones, modumm his agendi, \& verfandi, nó nifi longo vum difcere poteft, hinc cùm pendeat vilis iftratio facerdotij Indorum, valdę dolen$\mathrm{Bb} 3$ dum 


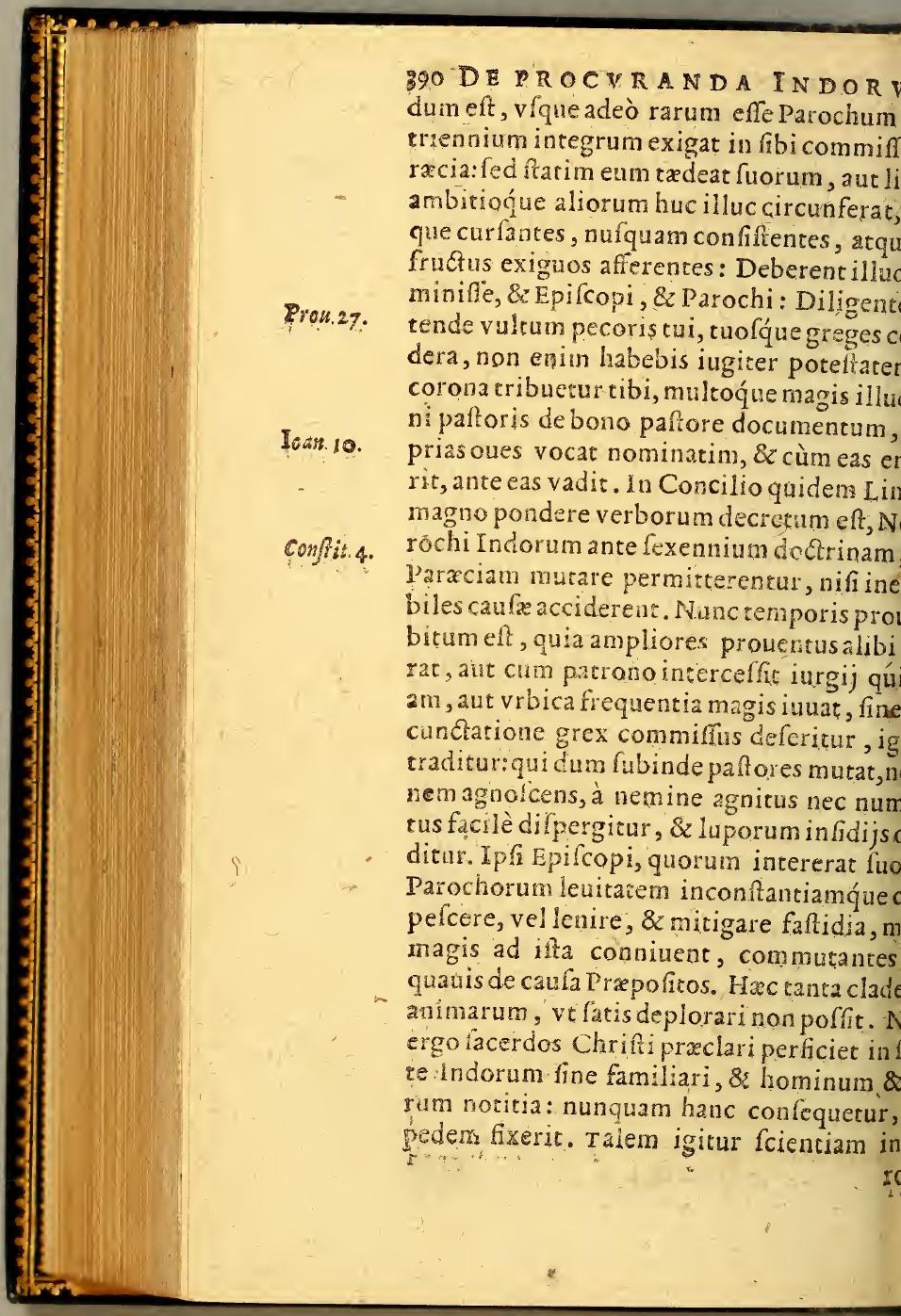


SA L V TE. I, I B ER IIII, , Indorum plurimi facimus, illam verò eatam Theologix cognitionem nullo montemnimus,

cortere in nouo orbe aliques effe praftantes

Theologos.

\section{A P V T XI.}

in potius tamet $f$ in plerifque mediocris uędam doctrina fit fatis, tamen eos, ad quos unt cærteri,à quibufó́; velut à fonte hauriam effe oportet abfoluta Theologix faculiftructos in nouo orbe, vt nufquã gentium us. Id ita effe, qui rê accuratius animaduercertis indicijs deprehendet. Primú enim, ides Chrifti recens fundata eft, tamq́; ims fpatij s longè lateq́; propagata, ibi fanè \& eres pellendos errores, 82 ad nouả tuendá onem Theologiæ doctrina magnoperè neia eft, cuicus partes Auguft. effe docuit, vt Fi r2.de Tr aluberrimä gignat, nutriat, atq; defendat. củ audiffent A poftoli, quia recepiffet Sa-ACl.8. verbú Dei, miferunt ad eos, non quofuis, trú \& Ioannem Apoftolor ú facilè primos. lob causã putamus?nifi gr religionis Chriexcrdia, præcipua quadam tapientia in$t$, induftria, diligentia, quemadmodú in no erumq; ftirpibus videmus accidere.Deinnouo hoc Orbe noua effe negotia oportet, mores, leges, contractus, rationes denique niuerfas longè alias: militiæ, mercaturæ, cę,totius Indicx adminiftrationis difficul ccurrút quotidie noię $2 z$ magna, quib ${ }^{9}$ iędod̂rinę lux adlit, eaq́; copiofa, in magnis âtiæ tenebris, ac certo periculo falutis fux $\mathrm{Bb} \$$ boni 


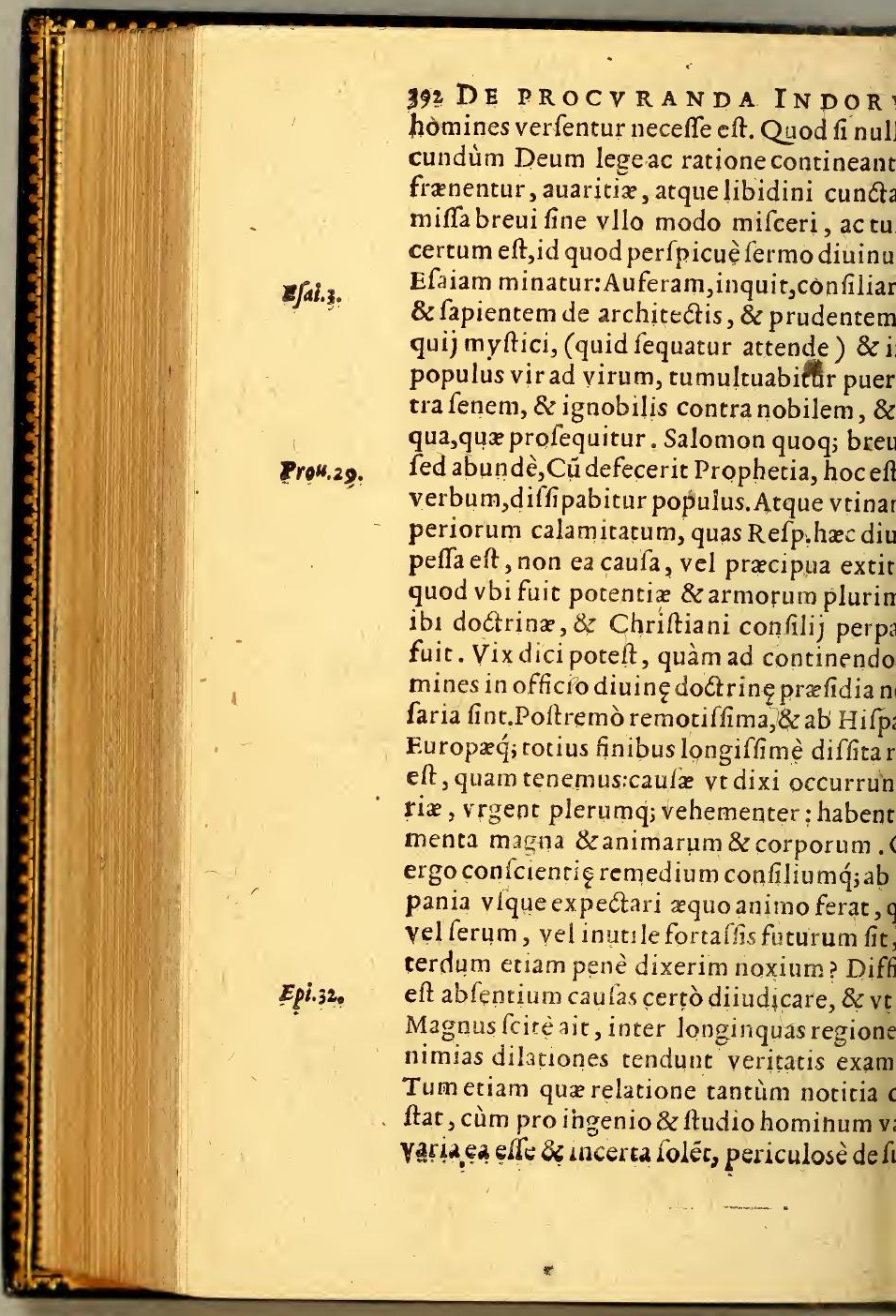


S A L V TE. LIBER IIIT. Chriftianx falutis negotijs adhibet cenfuuam. Euenit crebrö, ve quemadmodum me tiam petitiffimi abfente ægroto confulti, neq; morborum caufas, neq; hominis con ionem fatis perfpectam habent, grauiter tur, \& fallant:ita etiam noltri Theologi anienfes, vtcumq; illi celebres, \& illuftres ui fint, tamen de rebus Indicis non medioerrent. Q i verò cominus ifta con fiderãt, sluftrant, ac veluti manu tenent, etiam fi speriti illi fint, tamen longè certius, $\&$ foe philofophentur. Paulus certè A poftolus quam multa Corinthijs præf cribit abfens, ma tamen tunc fe difpofiturum promittit, fuerit apudeos. Multum omnino confert ta experientia, \& magnas fapientiæ occas præftat. Quamobrem nifi qui cæteros fo, atq; illuftrent fplendore doctrinæ , abloliqui, \& præftantes Theologi fint, dubiü $\mathrm{ft}$, quin magnam religionis totius caufa in bus Indicis iacturam factura fit.

robitas in miniftro Euangely quòd $\mathcal{O}$ à Deo or ab hominibus requir atur.

$$
\text { C A P. XII. }
$$

tæ verò fanctitatẽ in facerdote (quod erat $x$ tribus primum ) etiam nomen ipfum adt eximiam effe debere, quod non folùm faiteras vbiq; fonare, fed etiam prophanas nendare fribit B. A mbrofius, qui Pythago. a illud ad facerdotes propriè accommołat. munem, atq; v fitatam populo viam non ef1. Cor, II endam, quod ab Hebræis, quorum \& genus Ie vult,accepiffe afferit. Nihil enim in faB b 5 cerdo. 


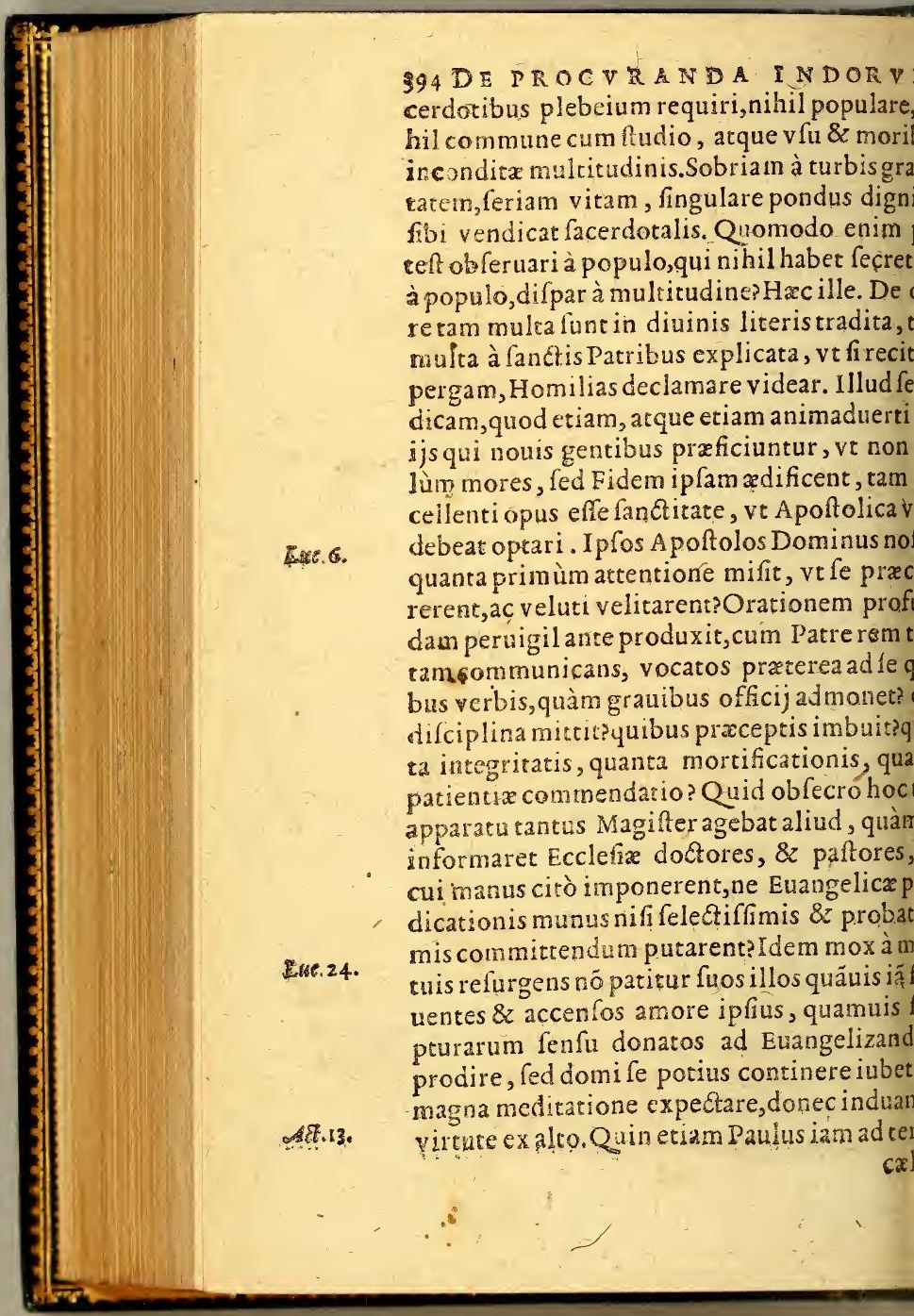


A I T T. II BER IIIT: raptus, \& mira operatus, non prius cum a deftinaturad gentes, quàm fanctis fraieiunantibuss, \& miniftràntibus Spiritus eos fibi ad opus hoc fegregari iubet. nam profectò vitæ immàculatæ probaApoltolicum hocce munus efflagitat. ipfegrauiffrmè de eligendis fideliü praadmonet Titum, ve conflituas per ciui- Titris resbyteros, ficut \& ego dilpofui tibi, fi le crimine eft. Oportet enim epifcopum imine effe, ficut Dei difpenfatorem, non um, non iracundum, non vinolentum, rcufforem, non turpis lucri cupidum, fed alem, benignum, fobrium, iuftum, fancontinentem. Miniftros quoque præcipit 1.Tim.3? robari prius, \& fic miniftrare, nullum criabentes. Quæris, cur tanta exigantur in elij miniftro. Dicam equidem breuiter, reque Deo, neque hominibus, neque veipfi fatisfacere vllo modoqueat, nifitaitufq́ue fit. Etenim Dei graţiam etfi cerIt nullis proprijs meritis præueniri,tamen quoque indubium eft, iuftorum fanctitate cibus, præpofitorum præfertim, effici fole fubditus populus Dei largam in fe benediem, \& gratiam ex periatur. Id'q́; multo main initijs fidei, vbi nulla poffunt eorú, qui itur, merita inuitare, \& multa poffunt criobftare. Scioequidem Deigratix prorfus , ve tot millia I udaorum Petri exhortatioenitentiam agerent, $\&$ in Chriftum crede- $A$ Aftor.16. vt tot millia gentium Pauli prædicatione o 17 . rum vanitate reiecta Deum viuum, \& ve-

\section{ARE. 2.0 4:}




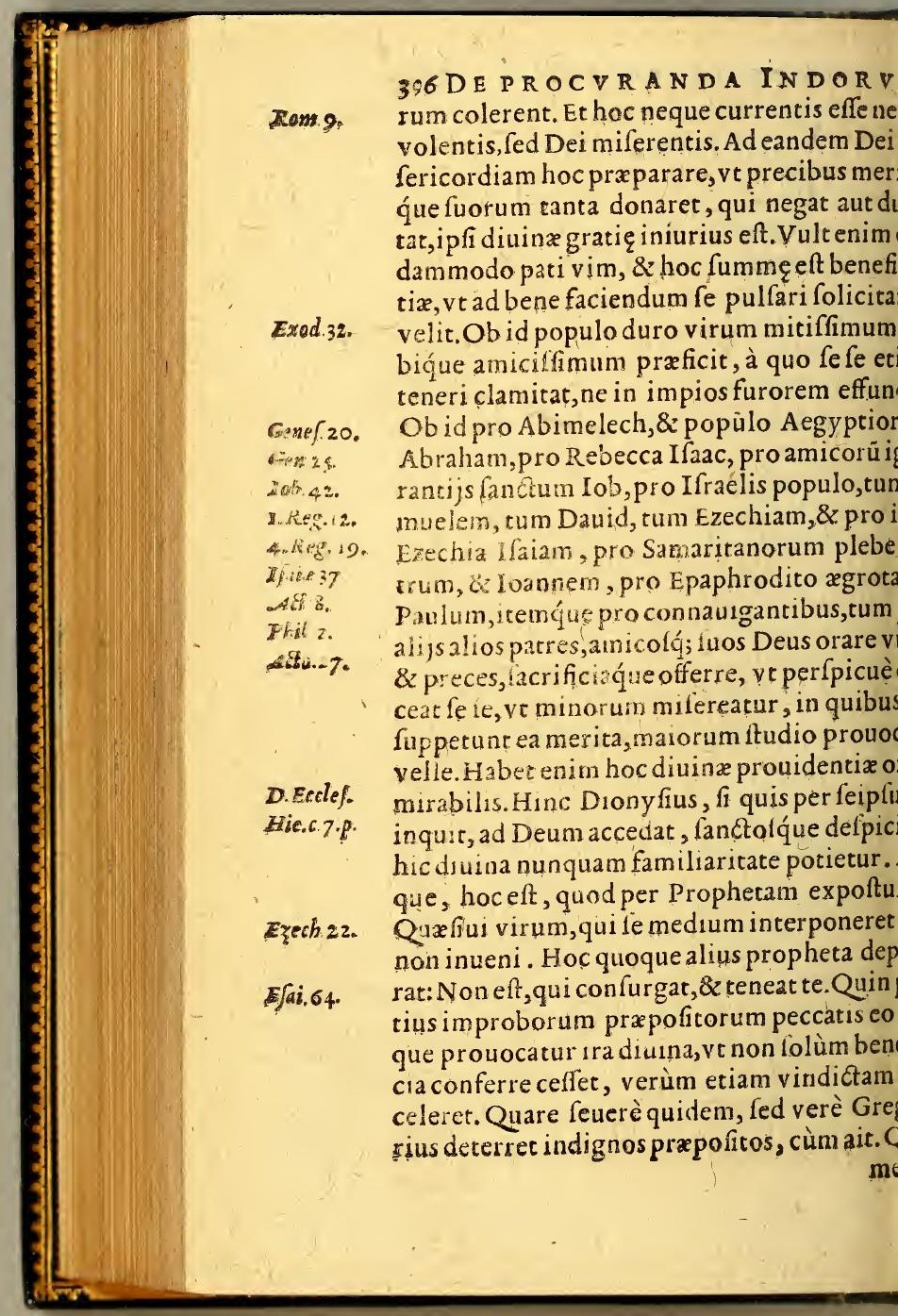


SALV TE. LI B ER IIII. उंभ re apud Deum interceffionis locum pro po- 2 part. arripit, qui familiarem fe eius gratia effe Paff.c.lto vitæ merita nefcit?aut ab eo quomodo alijs am poftulat, qui vtrum fit fibi placatus, igt? Qua in re eft etiam formidandum, ne qui tre iram poffe creditur, hanc iple ex proprio I mereatur.Cuneti enim liquidò nouimus, cùm is, qui difplicet,ad intercedendum mit ,irati animus ad deteriora pronocatur.Que ita fint, verendum profectò, ne Indorum de exigui progreffus, in multis etiam initia facta noftris malis meritis coram Deo æqua e refpondeant. Quò enim hi magis à Deo ii , \& à cxlefti luce feiuncti, eò facerdotis, atris merita illuftriora effe oportet, vr quod $t$ illis, apudoptimum patrem Deum iple ciat, Dixi praterea hominibus fine vitx initate prodeffe vix poffe, quia re vera regnum non eft in fermone, fed in virtute, plufq́ue 1.Cor.40 mouet vita pura, quã oratio culta . Contra, es corrupti doctrină faná facilè cuertunt, \& lem reddunt. Sergius quidem Paulus pro- AẼo 13. ful vir prudens tunc credidit admirans fudoctrina Domini, 'cùm verbis vidit facta edere. Nos verò prodigia; quibus Euangel1voces confirmemus, nulla producimus, neverờ eft opus:vita vna reftat ad plenä confirionem, ve ait Chryfoft, qux fi defit, cæerera Hom 33, in nt, neceffe eft. Indorum verồ ingenium effe 1. Cor. iffe me memini, vt incredibili attentione de is maiorum pendeant, illa obferuent vigitiffimè, inde hos iudicant, \& aut contemit, aut fufpiciunt, \& pro Deo habent. Cuius ò vita defpicitur,neceffe eft, vt etiam prædicatio 


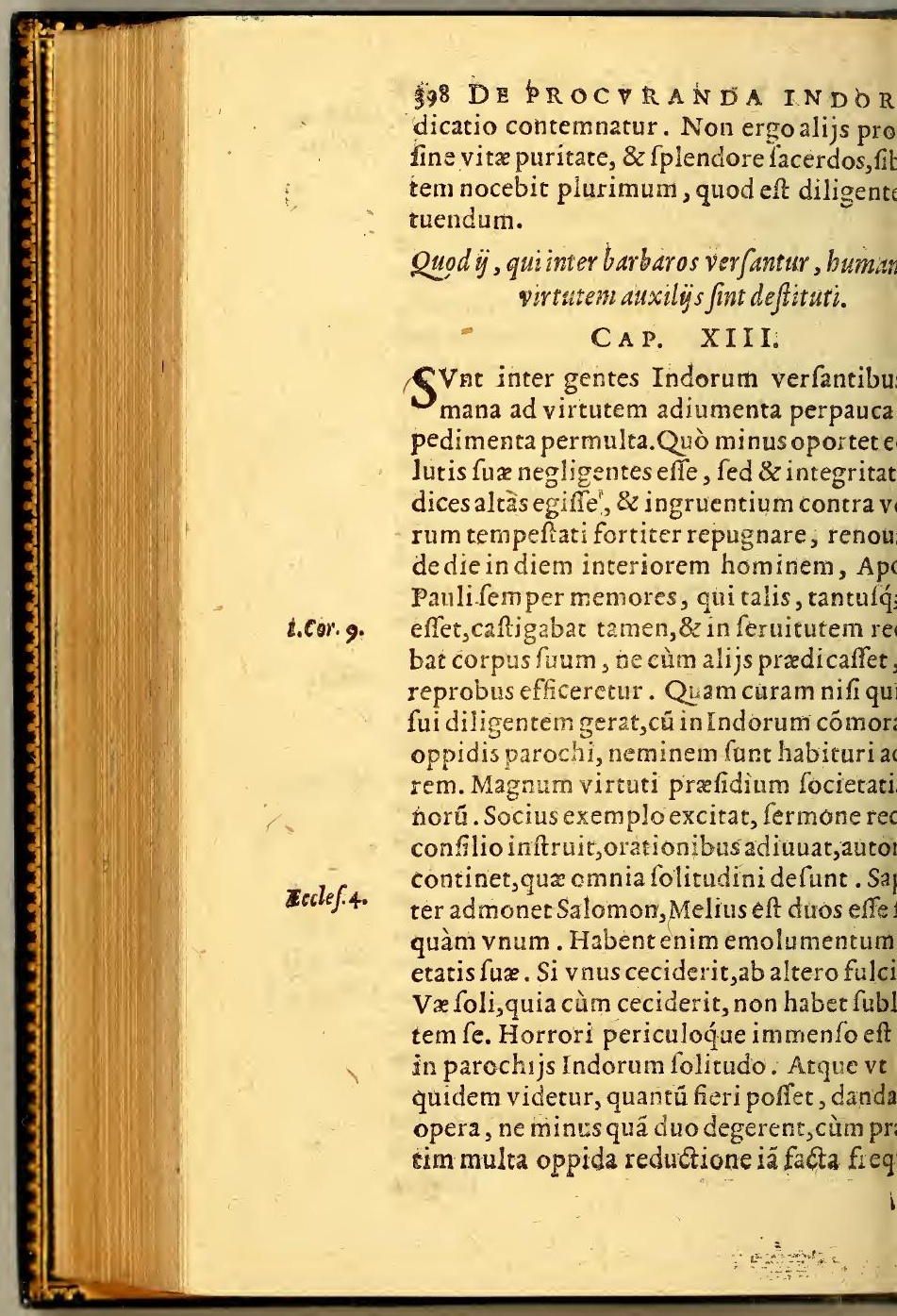


S A IVTE L I BER IIIT. 399 quibus vnus minimè fufficiat, Etenim Chri Matsh. I th Dominus difcipulos ad predicandum binos ; cùim poffent tamen finguli plures populos e.Sed præceptor nofter tum confolationi, cautioni fuorum ipfafocietate confulenputauit, tum etiam ædificationi fecuritatiexternorum. Quam formam tenuêre poftea Atoli, cum Petrum \& loannem mitterert, Barnabam \& Paúlum, cùm Iudam \& Sylam, rfus Barnabam \& Marcum, Paulum \& Syatque ita pene perpetuò. A pud noftros verò elij miniftros mira folitudo. Ex qua primû dia paulacim oritur:deinde licentia, cùm fíefe peccetur, reprehenfio nulla timeatur, remò iam lapfi fera, \& difficilis refipifcenùm medico cat eat. Hinc in malo confuetuboni præterea omnis obliuio, denique vitæ oris delperatio. O quot ita miferè corruêre, neritò vlulare debeat abies:cùm viderital. mas ac nobiliffrmas cedros Libani cecidiffe. loquor antiqua, non repeto Herones, Terianos, Origenes, Nicolaos, Salomones, catee documenta veterum. Recentia \& quotia intueor. Et quid obfecro prodeft homini, fi dum vniverfum lucretur, animæverò fuæ imentum patiatur? Imò verò qui fibi hemeft, cui bonus erie vnquam ? Omnia ergo Zach.za: Aี6.8. AE.13. A.t.15. umenta \& præfidia humana, quæ ex aliorum , moribus, doctrina, authoritate proficifcundefunt propemodum parocho Indorum. onam igitur modo nifi multum in virtute fecerit, fuçque ipfe difciplinæ cuftos integer us ac vigilantiffimus fit, fufcepto muneri fir ngenti fuo damno fatiffacere queat?

Mattb, 16.

Eccli.14. 


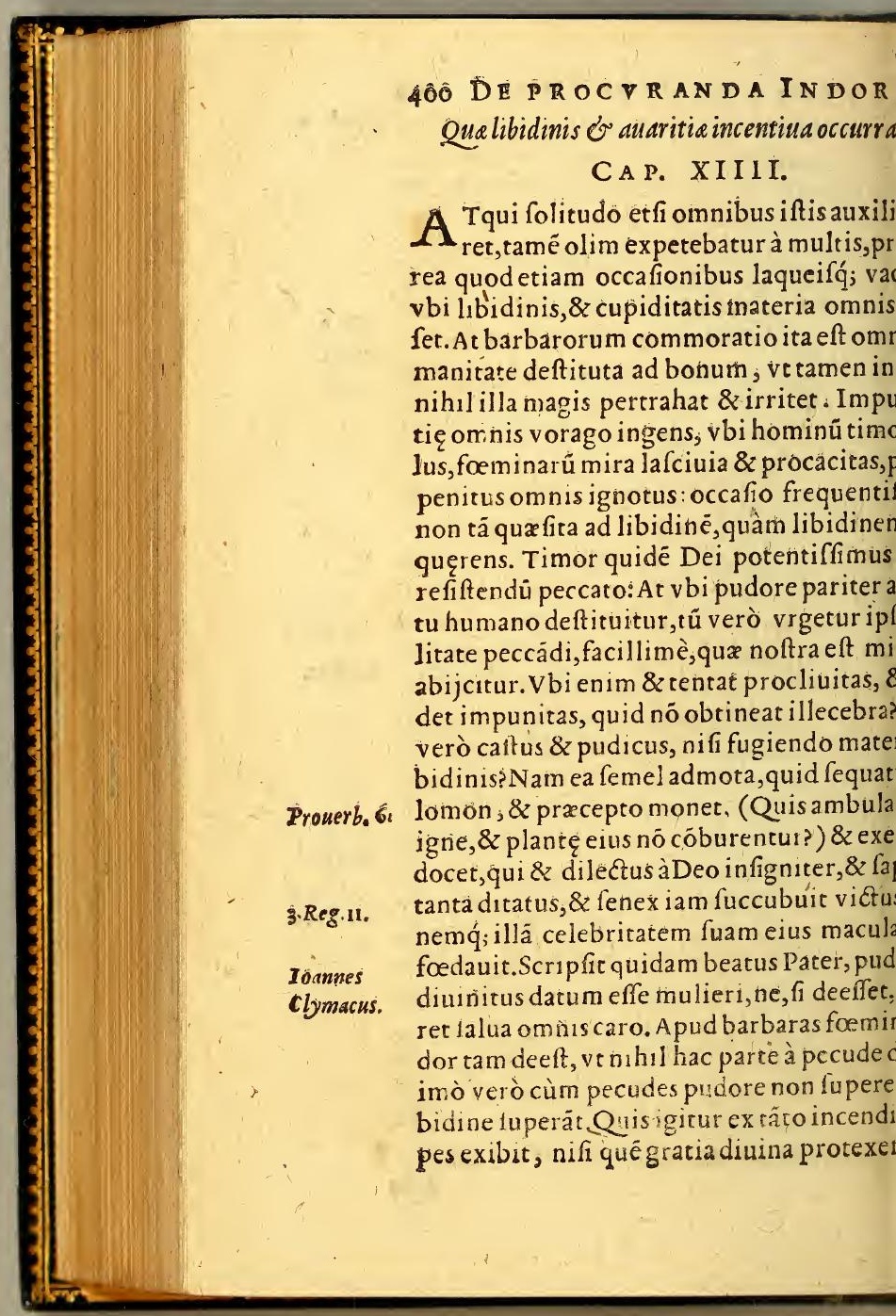




\section{S A T $\nabla T E$. LIBER IIIT.}

diana carnis mortificatio vallauerit? $E$ aoque tentatiograndis, cui fine magna aninftantia refifti non potelt, cominatum exdi in Indos, quorum naturalis atque vfitaiectio, \& nulla ad refítendum audacia, as facilè tollit rectori, vt quicquid collibear, unctationead rem conferendú putet. Sunt qui dominántur fidei fuorum, qui cum auate imperant, $\&$ fas omneac nefas pro fuo racu ftatuunt, verè ab A poftolo delcripti rij, qui deuorant, qui accipiunt, qui extol- 2 Cor.n. $r$, qui in faciem credunt, qui Deo non fer- Rom.i6. ; fed fuo ventri. Qui ita tenere primatum $t$, vt non recipiant quofuis alios, quamuis probatæ, \& doftrinz 1 anz, \& in opere Dei itatos. Inde faftus quidam inlolens: Quod is frater verbum exhortationis habeat ad em, ingratè prorfus accipere, inuidiam itare, nihil iuris alijs facere. Neque ignoro' omplures, qui coadiucores in Dei opere olum accipiant, fed vehementer etiam efent. Inde quoque cupiditatis habena lanæ cum campus latè patens occurrat, vbi quid quxftus exerceri velit, nemo fit concturus, opera prompta Indorum ad quidSifcelera maiorum diffmulare pergat, arquiduis corrader, fi mulclare pecunia, fi ria imperare obfequia òmnium parata. Deabfoluti cuiufdam imperij \& auaritiæ tam effufa materia, vt nifi quis temperatiffmo animo fit, virtute iam confirmata, in

tranfuerfum breui agi poffit: C. 


\section{DE PROCVRANDA IN DORV}

Contra alufus Indicorum Parchorum.

\section{A P V T X V.}

PRxclarè veì àgeretur cum rebụs Indor fifacerdotumea faltem modeftiaefiet, vi siorumoccafionibus humanè op pugnatentu non quarterent etiam ipfide induftria vita $f_{e}$ tioris licentiam, accerlertes vit'to fuadan Eap s. poncntes fponfionem cum norte, \& tot \& 5op.14. magna mala pacem exiftimantes. Neque el - Jaqueos diaboli effugiunt, forminas confo. 4clli. 42. fuo \&vita vfibusadhibentes. Quod fi à veft it totinea, \&à muliere iniquitas viri plocedit, poteft effe caftitatis tanta cuftodia, qua hol perpetuò infidiantem, domo, Jare, \& indiui confuctudine accipiat? Aitunt frbi nec cibos quere, neccatera feruitia parare debere, ad vfus fneminas necchariò achibendas effe. Q $\pi$ vesò, \& viri ifla pranate non polf nt, lndip fertimadomnia obfequia prompriffini. Al foeminarum onnino muditias cupiunt, $r$ poffint anus, quæ neq; igrem neq; fumi:m, vt citur,pariant, reperice. Netcio an alia in re: iore cura laboratum fit ab antiquis parribus, plures aut feucriores canones legas, quàm $\backslash$ bj agitur, ne cum formin is habitent clersci. In $\mathrm{C}$ 5iff. 3z.e. cilio magno Nicęno quàm grauiter de fubint: Incerdixit. ductis mulieribus clerico vitandis cautum : conc. Aquif. nemo non nouit. Omnes prouinciales fync granc. c. 32. plena funt. Patum decreta vehomenterclam Jucink fara inufó; Hieronymus fatis tfe poteft vfo; ad i inepife ad e. uidiam hocloco decertans. Hofpitiolum tuu pifropos $G_{\text {al }}$ incuit, foribensad Nicporianum clericum, a

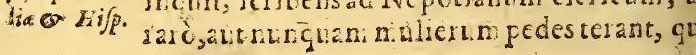


SA L V TE. IIBER IIIT. 403 poteft cum Deo habitare, qui foeminarum Conc. Th fibus copulátur. Fomina confcientiam fe- ron cap. 7. pariter habitantis exurit, nunquam de mu- in 3 lib. de$m$ formis difputes, forminx nomen tuum crit.tit. de ant, \& cxtera. Nulla profętò excufario cobabitatioadmitti poteft, $v$ bi fi minus confcienti $x$, fa- ne clericon̈ aitem fua conlulere debet parochus. Nego- or mulicrä. onem verò facerdotesexercere, atque ví. fuper quarere, omnium conciliorum, arg Nepotian,ad ificum, Leonis prefercim vocibus interdi- Ruffic ad ificum, Leonis prælertim vocibus interdi- Paulinum, eft, $\&$ Pauli ipfius, vel porius Domini, quod ov ad ocea. nt omnium malorum radicem effe cupidi- nü. Gratian. n, \& facularia negotia militian Dei plur - fub moteximpedire. Hîc ego quid commenorem ex- iu coniunga itas mammonx artes, emptiones, diftractio- $d .32$ c $\mathrm{Ho}$ lie rerum, pacta \& conuenta fecreto inita, fpitiolum. ntum ad negotiandum inftitoribus datim, ${ }^{34}$ quaft. 4 . Im foenore redear, quod plerumque meritò oroniam im redit, \& forte quoque excluft, $\mathbb{R}$ adione, mulit. efe eorum fidei dedunt, qui impolturam fan Leo epif?. clerico indulgentiam putane? Iam veì a cap. 3 . 4 . Conci Eli$m$ argento permutationes, $p$ fiulqúne arg en bert.c.39 ea obati, \& puri cum impur indufriam tem- zo.dif. \&8. obferuantem, \& fidelium oblationes ven- per totam, et em, cum Patronis mutua fub certa lege, \& $l_{i b}$.3. decrsealias auaritia fraudes recenfere longiff- ta tit. viti. eft. Iraqueillx potiffrom Parácia In-mo. mappetuntur, \& magno fapeambitu, \& o obtinentur, qua licet proncncus habeortafie minores, negociandi tamen comitates vberiores prabent. A facerdotevfd Propheram omues auritix fudent, air Hierem.6. 0 diuinus. En Indici facerdorij Charib\& syrtes, ad hos fcopulos miferanda, \&z C. 2 guoti.

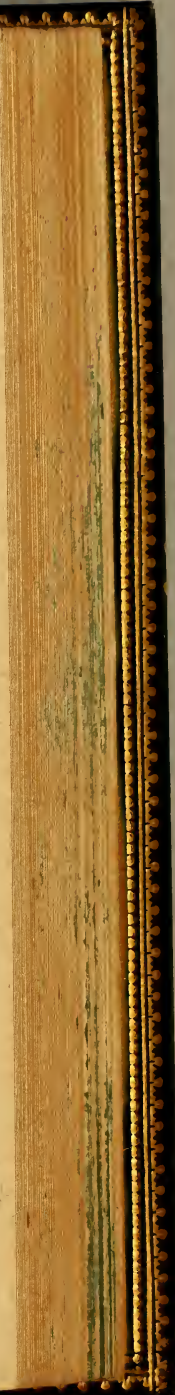


904 DE PROCVRANDA INDOR V In 6. s,n. quotiỏiana naufragia. Quid verò de aleatorib gener ca so. Et hos grawifnmè damnant Canones, fed fruf difi.35. c. $\dot{E}$ - quantum video,ad nos. Ponitur menfa fortu pijcofws. diesnoctef́q;alea iacitur, collufores, vead ca Efaic $65^{\circ}$ ner vultures, vndique accurrunt, fi morantur jam accerfuntur. Populare eft in facerdotis mo ludendum. Integri anni fipendiavno f: iacu raduntur. Faftidia pleriq; folicudinis 8 tijobtendunt, qui egroti confeffionem, aut ri catechumeni infructionem, fi quartam h partem excedat, molefä, \&z prolixam accul Infomnes nodte, multo iam diefacra peragh idq́uecurfim, vt mirum fireos pilas chart pro facris paginis non referre. Non inueho quidem, neq; maledicendi animo ifta depro Sed cogor vicem noftram dolere, qui fabula t. ludibrium facti fumus vicinis noftris. Alijv venaciones, aut aucupia exercere honeftifim ducunt, plus fxpè in venaticis canibus infum tes, quan pauperibuserrogãtes prafepia ad c quitandum plena, accipitres magno fudio re,greges Indorum poff fe trahere, montiun ga frequentius terere quà Ecclefia limina. In Synodo Francica, eo sueßionenji, o ituro c. nis, idem, \& facerdotes, \& prafules, \& mona Forofu- actitamus. Reprehendi iamilla non pofunt, licnj cap 6 .

De clerico

Denatore.c. Epifsopim ex Conc. Au ralianenfi. uerfus has ineptias multa quocue fancita in cilijs larrum, Gallicanis pralertim. Sed co pfaeft iampridem difciplina Ecclcfiaftica communia funtomnibus. Itague is cui paft lis Incorum cura commitritur, non folum tra Diaboli machinas, \& natura incenciua gnare debet, fed iam etiam confrmata hom confuetudini \& tempore, \& turba prapotent fe obijcere, \& ad excipiendainuidorum, ac leuolor 
S A LV TE. LIBER IIIT. 405 lorü tela fortè pectus opponere, qui fi quid ofano fuo inftituto abhorrentem viderint, ditorem, hy pocritam, hoftem clamant. Hæc o, quæ breuiter attigi, \& in alijs curare, cum um fortè confeffiones audierit, \& in fe caueonus Chrifti minifter debet, quod vt pro ditate præitet, quanta opus fit gratia Dei, quanitæ obferuantia, ipfe perpendát. Adijciam ique ad calcem fancti Ifidori fententiam de rdotij fanctitate, vt hunc totum locum amis de Parochi vitæ integritate cócludam. Sed d plura fubijciamus?inquit. Si enim is, qui in sbyterio, vel epifcopatu pofitus mortale alid peccatum admiferit, retrahitur: quanto gis ante ordinationem, fi peccator inuentus cauédum eft, ne ordinetur. Quapropter quia Etymo lib. peccatores à facerdotio remouet, confideret 7.6.6. nufquilque, \& f ciens, quia potentes potenter menta patientur, retrahat fe ab hoc non tam 10re, quam onere. Qui enim erudiendis, atq; truendis de virtute populis praerit, neceffe vt in omnibus fanctus fit, \& in nullo reprefibilis habeatur.

De Orationis prafidio Euangelizanti neceffario.

\section{A P T XVI.}

Valem oporteat effe miniftrum falutis Indorum, dictum eft hactenus, dicendum deeps, quibus prafidijs hanc, quam expetit, Inrum lalutem confequetur. Mihiad tantam ré iciendam quinque omninò neceffaria videri lent; vt vir Euangelicus oratione Deum fibi nciliet, Exemplo homines moueat, beneficen-

$$
\text { Cc } 3 \text { tial-: }
$$


De diuin

Nomi.c.3.

Luce 1 .

P.ol: 43
406 DE PROCVRANDA IN DOR V ria alliciat, Carechifmo inftruat, facramétis cificet, qux fanè figillatim parochos, paftc que Indorum, quoties res incidit mihi ho confcientiastractanci, rogare foleo, quan memini, \& commendare diligenter. De qu etiam vberius modò differendum puto. Ig vniuerfa facerdotalis cure, negocijáue ger caput orarionem effe non dubito, modò ea uens, affiduaqúu fit. Etfi enim omni negotio rituali inchoando, \& profequendo orati præfidia prima pracipuaq́; funt authore Dic fio, vel potius Chrifto, qui femper orare mo neq; vnquam deficere, tamen vbi de conue ne animarum agitur multò maximè, quòd tize restota fit, qua impetrari precibus po meritis praueniri no potett. Q iod fi non de uis converfone reseft, fed de prima, de max de dificillima, quando vocatur infidelis ad dem, quando non affectum folum, fed ip. quog; fenfum iubetur exuere, $\&$ fefe penitus negare, vt in obfequium Chrift captiuo in ledtu eat, tam eft profecto orationis fingu prafidium, vequi catera omnia adhibeat, fi omitrat, nihil acturus fit, in hafa \& clypeo niens, non in Domino fiduciam habens. Ne enim in gladio fuo poffederunt terram, \& $t$ chium corum non faluauit eos, fed dextera Domine, \& illuminatio vultus tui, quia com] caitti in eis. Plus longè, fine vlla dubitatio Paulus orationibus egit, quàm coñcionibus, lachrymis, \& gemitibus, quàm exhortationit Itidemq́ue Perrus, 8 Ioannes, cxteriqú mili ser de bono Chriftianx duces. Orationi Stephani Saulum Eaties.

matum vult Martyr Cyprianus, ficut Mon 
S A L VTE. LIBER I III. $40 \%$ is lachrymis regenerationem fuam magis otam fert Auguftinus, quàm Âmbrofij con- Lib.confo ibus. Q iamobrem antè omnem diuini veratationem orandum ardenter monet idem is Pater, deoq́ue dicendum ex animo, In a tua Domine lumus $\&$ nos, \& fermones noIdcirco pro infidelibus tam diligenter farLibro 4.de Doct Chrift. c 15: or 30 ater orat Ecclefia, vt ijdem Cy prianus, Aunufq́; notarunt, quod eos tenebris fuis proiffimè immerfos lucem diuinam afpicere mè liceat, nifi fol iufticiæ fedentibus in rev mbræ mortis clementer illuxerit. Ego P. cifcum Xabier, tot millia hominum Chrieperife facundia non puto, qui eciam in rno fuo fermone non admodum eloquens ibetur à notris, ne dum in aliena lingua arica verba vix frangens pocius quàm prois; ied feruentiffimis certè precibus, ardenlachrymis, gemitibus, fufpirijfq́ue ex imo is, in quibus totus erat noctes integras per, quibus multò fortius, \& continentius Deư bat, quàm homines vlla dicendi vi. Atq; in pfo Regno nouimus, qui fimplici quidem one $\&$ imperito, fed f piritu Dei ferués plus nuerfione Indorum effecerit, quàm multi lari locutores. Immenfum effet antiquæ $æ-$ exépla narrare. Vnus Paulus A poftolus pro ibus effe poteit, cuius in orando incredibile um pro verbi victoria nullus hominum fiignim putaret, nifi Spiritu fancto tefte eum tirinon poffe cognofceret. Euolue ex. ordilius omnes epiftolas: inuenies, ad Romanos m fibiteftem aduocantem, quod fine inter- Rom. fone femper in orarionibus luis memoriam

$$
\text { Go } 4 \text { corum }
$$


408 DE PR OCVRANDA IN DOR V 1.Co\%. r. corum faceret:pro Corinchijs fempergrati. Ephef. 3. gentem Deo: pro Ephefijs genua fiectentem Chrifus habitaret per fidem in cordibus h Thilip. 1. proPhilippenfibus omnibus femper in cut orationibus cum gaudio deprecantem: $\mathrm{Co}$ coloff 1. fentibus non ceffantem poftulare, 8 orare, $v$ 1.Theff. nitione Dei impleantur: I hefalonicenfum moriam facientem in orationibus fine in 2.Tim. x. milfone:Timothei difcipuli memorem, \& Phila. 1. defiderantem nocte $\&$ die:Philemonis quo \& domefticx eius Ecclefix in orationibus . permemorem, quod de Tiro quanquam tace men debemus accipere, qui maior dignio apud Paulum erat. Nam Hebræorum, quibi hac re nihil videtur fignificare epiftolx exo paululum commutato, \& propter argum magnitucinem, \& fublimitatem ftylo pene torro magisquam epiftolarivfus, ad kom

Rom.10. fcribens, an memoria excidiffer fibi, fatis cat, cum tritticiam fibi magnam doloremq́; tinuunirefert, adeo ve feparari à Chrifo Rom 10. dammodo pro illis cuperet, pro quibus quamuis obfinatis \& dur is oblecrationem t à fe fieri lalutis caufa. Galatas, vtne hos qui prxtermuttamus; quanquamacriore oration tendum ratus proneceffaria obiurgatione, uitatem illam orationum premendam exift rit, tamen quantum orationibus adiumaret, bus lachyms prolequeretur non folùm i difcimas, quod folicitudinem fuam alibion 2.Corn. Ecclefiarum perhibet, verum eriam quod terno quods m affectu flebiliter conuenit ho lioli mei, yuos iterum parturi, donec form Chriflus in vobis. Omnino Rupore dignur dem 
S A L V T E. I I BER IIII. 409 q́ue omnem propemodum fuperans, tot Ecarum, tot domorum, to hominum memoperpetem in vno Paulo hærere, quos fem- Gal. uos fine intermiffione, quos in cunct is orabus etiam iurifiurandi religione interpofii fcribit effe præfentes. Ego Pauli charitaChrifto deriuatam, qui omnes, cùm oraret, inatim recordaretur electos, eo modo ingo, quo immenfum pelagus in finum alique num influit, atque hac orandi diligentia, tanta peregerit, defino penè mirari, qui inerim orationi nihil effe difficilè. Itaq; vt ntarum feptuaginta fex animarü vita mordonata eft Paulo precanti, ita innumerabi- $A$ Etor. 2 Fo $^{\circ}$ vita animi zerna. Quid Petrus, cuius tan-2. Pet. $\boldsymbol{l}_{\text {. }}$ rdor extitit, vt etiam poft obitum fuum freiter fuos apud fe habiturum polliceatur? AC verum effe mihi perfuadeo, quod D. Chrymus fcripfit paftores Eaclefiz folere prius efudiofius fuorum in oratione meminiffe, $n$ fui. De Polycarpo Ioannis difcipulo Eufe-Eccl.bift.lito narrat, cum à lictoribùs quareretur, marty - 4.c. 19. áue fuum adeffe cerneret, impetrato oranatio duas horas in commemorandis Chrifti libus nominatim fibi commiffis exegifle, fui affe mentione vix habita. Tanta erat in fuos citas prifcorum illorum Patrum, tantus atorandi.Et eft prorfus verum, quod ad Auguum beatus Innocentius fcripfit, plus nos pro Epift. $97^{\circ}$ re alternis, \& communibus orationibus, m fingularibus, $\&$ priuatis. Poltremò qui in atione gentium laborat, meminerit fe A poorum fungi officio, qui alia alijs omnia aandantes, duo tantum fibi fumplerunt, vt o-

Cc s ration

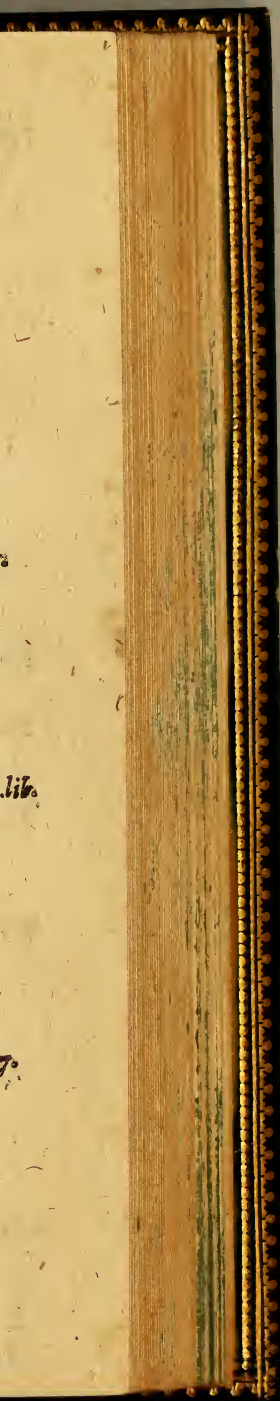




\section{TODE PROCVRANDA INDOR}

AfRor. 6. rationi \& minifterio verbi inftantes effent duabus funcionibus oratione ad Denm, \& tione ad homines Apoftolica cura definit: quas fi quis feiungat, ac diftrahat, tam fier quit, vt optatam fratrum falutem acquirat, $q$ fi longum pelagus enauigare contendens nulla vela furpendat, vel plenis velis nauim tione non foluat. Qui velit igitur in Indi vinea fructuosè operari, orandi fudium quam fibi intermittendum perfuadeat, $f e$ ip verò iuge facrificium offerens, lachrymis, 1 bus, ieiunijs, vigilij fq́; crebris, atque omni pufculimaceratione Deum fibi propitium dat, vt Euangelium crefcat,atque fructificet niuerfo mundo. Opinor fanè in illogenere moniorum multa verfari inter Indos, qux atare 9. niff ieiunijs, \& orationibus eijciantur. Inter nia verò venerabilis illa agni immaculati v ma principem locum tenet, quam Patri quot immolet toto mentis affectu, plenaq́ue fidu fidentiffunè poiftulans, vt eos, ad quos legati fungitur, filij fui cohęredes, \& concorporale fe dignetur, pro quibus ille fanguis effufus Fieri non poteft, vt $t a l i$ oblatione tam bene quber.2. nizz preces ab eo, qui diues eft in mifericol $\&$ propter nimiam charitatem fuam, cùm \& effemus mortui, conuiuificauit nos Chrifto, pulfam ferant.

\section{De vita exemplo. \\ C A P V T XVII.}

$\mathrm{E}_{\mathrm{X}}^{\mathrm{X}}$ frequenti cum Deo confuetudine, $\mathrm{v}$ quoque diuinz guftus quidam efficitur 2.cor.s. qृuâuis fobrijalijs effe pergant, qui alioqui $m$

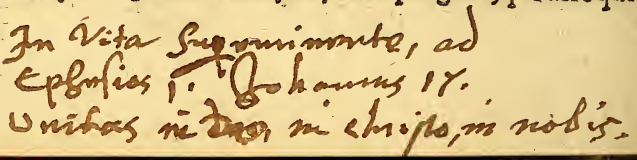


SA L T E. IIBER IIIT.

$4 \pi$ cedunt Deo, \& illius cellarijs fxpè internon poffunt tamen non ebrietatis illius, at- Cant.5. ulcedinis abundantiam eructare, Deumq́; Pfal.104.4. ere.Vt quicquid Moyfes caput obuelet, ne Exod. 3, ris magnitudine $p$ ! ebis oculos per?tringat, $n$ ex confortio Dei ita eum immutatum reeceffe eft,vt ne ipfe quidem fe agnofcat,ig'́f faciem fibi alterä, portquam diuino colo potitus eft. Itaq; orationis præfidio non $n$ alijs Dei gratia impetracur, pro quibus odipfe quoq; nouo igne fuccenditur, vt vioeleftem, Deoq́; dignam inftituat. Vitæ venfpicuam puritatem in Fidei praceptore Indos fummoperè neceffariam effe vt doproficiat, 8 aliàs $f x$ pè iam diximus, $\&$ eft $s$ adhuc repetendum, cùm nulla alia maior, rtior fpes fit falutis Indorum incorrupto paftoris exemplo, contra nulla validior peulti paftoris peffimo exemplo, quem pulfermo propheticus idolum potius paftoris Zach. lat. Agat ergo fedulò minifter Chrifiti, vt fum vita ipla teftetur, ve cognof cant amlius difcipulum, cuius dostrina gloriatur. à Chrifto manfuetudinem, difcat humili, difcat perfectam illam, \& maximam chaem, vt vitam etiam pro ouibus promptè exat. Memineritoperibus bonis ita lucere conominibus, vt videntes glorificent Parrem colis ef. Hoc effe omnium ad perfuadenpotentifrimum miraculü certò fciat, quod ex tot tantifó; illius primæuæ Eccle fiæ relifit, indefefio ftudio conferuare debemus. us quidem à Domino paftor Ecclefiæ vni- 1.Pet. S. conßitutus paltores admonet, obfecratq́a

vile

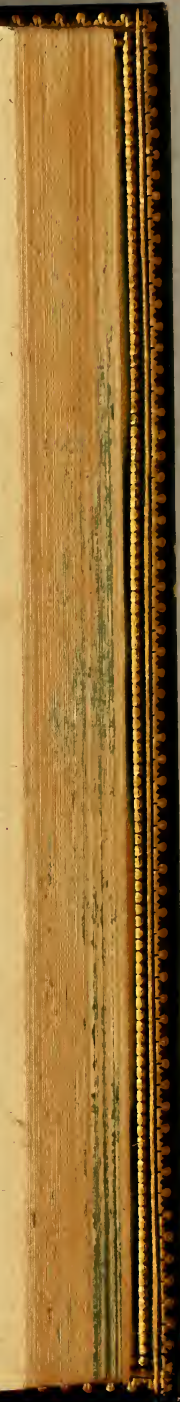




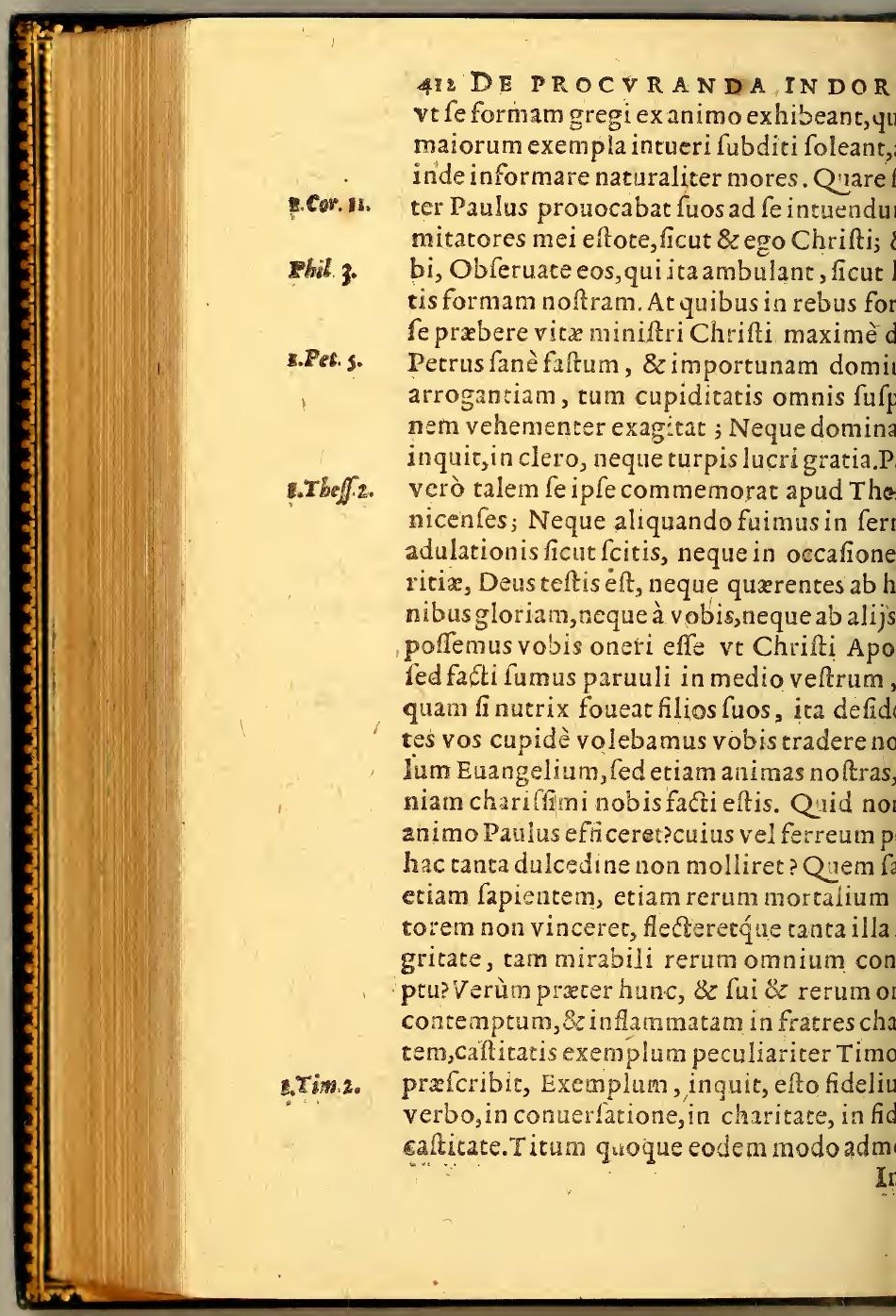


SAL̀TE. LIBER IIII. $4 \times 3$ nibus te ipfum prabe exemplum bono- Th. perum, in doetrina, in integritate, ingraNon folum caftitarem omnibus notam efo et, fed integritatem quoq; \& grauitatem, illeuitatis in eo norari queat, non oculus or, non vultus fractior, non verbum petu$s$, nihil lafcium, nihil impudici cordis in redolens exter, fed afpeclus ipfe, inceflloquia omnia plena iucund $x$ cuiufdá gras. Illud fenis Hieronymi obferuet: Quicle te probabiliterfingi potef, ne fingatur, euita. Denique in his duobus, continentia $\mathrm{m}$, \& pecunix contemptu etiam opinioiominü captet. Multa quidem alia A pofomina obiecta ab aduerfarijs fidei Chryfos dicit, cæterùm cupiditatis, aut impudici iam ab inimicis, \& mendacibus nunquam In I. Tim boss.60. incufatos, quod in his omnes vellent noleftimonium veritati dare cogerentur. Id in Chrifo Rege noftro aduertere eft, cùm tinuidiofiffimè, $8 x$ iniqquiffimè oppugnaac profcinderetur ab impijs. Mihiad hos proficifcéti fapienter quida minofter fugfrater in Orientali India diutiffimè ip fe tus, non folùm veritatem in hac parte, fed opinionem fudiosè effe quxrendam, vt te im me illealloquebatur)hypocritam ageerdum minimè poniteat. Vt enim virgifama, fic facerdotale decus finiftra furpifacilè violatur.Ita ergo fefe comparet miEuangelij, vt omni momento fpectacue effe Deo, \& Angelis, \& hominibus cogi- 1. Cor. \&s 


\section{ArADE BOCVRANDA INDOR? De Beneficentia. \\ C A P V T XVIII.}

Reneficériam tertio loco numerabamus. uis autem ip@a verbi Dei impartitio be centiæ fit præclariffimæ, neq; tam fulti fimt panem quo venter efurientis impletur in mofyna genere praferamus Dei verbo, quo Cat.rud. difcentis infruitur, ve Auguftinus admo oul4. tamen eam modò beneficentiam propriè ne no, qua fratrum faluti fortunifque confulit Hãc in omni Rectore aduerfus fubditos ma! 2.lib.Paft.c. perè necellariam eleganter Gregorius ofte zo: Egentis, inquit, mentem dootrina fermo nol netrat, fi hunc apud eius animum manus $\mathrm{mi}$ cordiæ non commendat. Tunc autem verb men facilè germinat, quando hoc in audie pectore pietas predicantis rigat. Nam quafi $i$ vediximus, à percipienda prædicatione gr animus frangicur, fi cura exterioris fubfidij: fore negligatur. De hac externorum bono: communicatione, \& proaidentia Petri Apol

1. Fet.g. vocem illam accipiendam dicit: Pafcite, qu vobiseft gregem prouidentes non coactè,

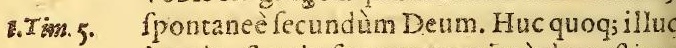
iungit, fi quis fuorum maximè domefticol curam non habet, fidem negauit, \&eft infi deterior. Et certè hunc fuifie ab A poltolistr: tum morem longa $x$ tate retentum, ve Eccl pafores de Ecclefix bonis, deć; fuis ipforur gerribus omnibus opportuna fuppeditarent rus eft, quàm vt Conciliorum decreta innu: rabilia, * Ecclefiafica gefta referre opus fit.I ¿av. o. obaufam Diaconos inter alia creatos ab A 
SAIVTE. I IBER IIIT. SIS conftat, ve men fis pauperum ninift rarent, ; Agape illa culta eft tunc, quæ poftea pauelanguit, \& quafi veftigijs tantum conferft, vt nullus inter eos egens effe fineretur. rouidentia Ecclefiaftica, parernaćue mifelia in pauperes plena funt literæ fanctoimbrofij præfertim, atque Chryfoftomi, cò procelffife fcimus, vt nonnulli pontifia omaia diftraherent, quidam fudoribus uperes alerent.Paulinus Nolanus Epifcot magni fcriprores fideq́; digni referunt, m quoq; vendendum tradidit, feruitutifó, etio inufitata milericordia alterius calafuccurrit. Longum efr, \& minimè necefantiquorum patrúvel facla narrare, vel a relegere, qui eofdem voluerunt, $\&$ verbi pafcendas animas effe minifros, \& bonodferuanda corpora diftributores. Quare Aeconomos Chrifti vorandos cenfuerü. em vera fi nihil in hac parte nos a diuuaret itas, tamen ipfæres morefó; Indorum farempore fudiofos Dei miniftros admo. excitarentq́;, vt fi fructum fpiritualē veriant, beneficétiam nullo modo fibi perire tur. Nam fi lucra animarum fitimus, nulla compendiaria viabeneficentia. Beneficen mos facilè expugnat, atq deuincit, quicult copiosè perorat,atq; pérfuadet. Nam perioribus libris dixiffe me opinor,idè i A poftolorumq́ue figna, tam ad Fidem am fuêre potentia, $\not$ omnia penè vtilitati ú impenderentur. Inde facilè, ac libenter ati animi hominú falutis conflia ab opti e meritis bauriebãt. Mortuos, inquit, fuઈ Luce 10.

Gregor. 3. Dial. cap.: Ang de civos

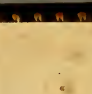

Gregor. 3.
Dial. cap."
Aug. de Cis


ATGDE PROCVRANDA INDOR citate, leprofos mundate, in firmos curate, de nes eijcite, $\&$ ad cumulum omnium, gratis a piftis, gratis date. Hoc extremum fi fyncer Euangelio digna in Dei praconibus gentes nerent, quamuis barbar $æ$, quamuis fer $x, b$ profectò manfuefcerent, omniq́ue illa fer depofita leniffimo Chrifti iugo victa colla mitterent.Et canes \& pifces, \& ipfi immanes nes beneficia fentiunt, \&zea gratitudinis fur gumenta hiftoricis confcribenda dederunt, homines nififlectant, faxeos monftrent. prorfus, \& improba fententia multorum ef dos nihilbeneficia fentire, humanitate non gi,gratitudinis ne veftigium quidem oftenc quo in cos clementior beneficentiorq́; fis, teriores reddi. Sed quamuis nonnulla ex de barbarorum feruili ingenio, \& minimè i nuo, ita exiftimare procliue eft, tamen quo cohibenda humanitatis, \& beneficentiæ in officia attinet, nou fatis vigilanter ifta dicur Namque apud eos, quibus fe non fatis Indic mittunt, quorum fidem fufpectam habent, $t$ fanè vulgaris ifta opinio locum. Libenter e beneficiutn accipiunt, breui obliuifcuntur a ptum, raro, aut nunqua $m$ gratiam referunt. fa eft natura ipforum imbecillitas, 8 timid Vtenim canis alienus nec menf $x$ tur affuefa obiectam offam, aut fruftum rapit, atque ita fi plura non videt:at menfæ herili afluetu eft alicer;herumque iam fibi notum fequitu profectò barbarı natura alıeni à coniortio humanitate non fecredunt tibi etiam Sene énti,timentque adhuc potius quàm amant. lóngo vfu didicerint te fibi beneuolum v prof 


\section{SALVTE. LIBER IIII. AIT}

tò \& grati funt, \& fe ipfos etiam dedunt. t fanè Hifpani, qui Ianaconas experti $\mathrm{a}$ fit genus hominum oblequentius, heroodeuotius. Dicant Patroni Indorum, an rdotem fibi beneficum, \&z commodum res. i funt, non excedentem deplorent, ac reit, a pud patronos prefuleló; etiam conteeo Patre nullum fibi effe chariorem. Dierdotes ipfi, qui in eos fuêre liberaliores, I fentiant ad quauis obfequia promptos, Dei verbutn videant eos libentius fufci$\&$ animum ad noftra germanè accommovos certè ipfi exigum quiddam beneficij titi, tamen excedentes, $8 z$ lachrymas illoidebamus, $\&$ clamores exaudiebamus, 8 am longo itinere nos confectantes vel intinebamus. Quod fi illam nottrorum hon vrbanitatem, verborumó'; elegantiam, animi grati fignificationem officiolam, $\mathrm{n}$ Indis minus inceniunt, apud ingratos beneficia collocari iactant, falsò lanè in ica confuetudine mores cultioles quauos ne apud ruiticos ģuidem fuot Hifpasivnt. Quod fi couftatem aftimationem eritorum Jibrantem omn1a iuftiffma lefiderant, num tha ittud eft in ijs praferui nos longè fit idurintes, quàm humanispertifunt. Sed cl rumen lenlus beneficiapud Indos, qui ce ferts qudem deeft, falcommodirates in cogitantes eos libendant, quos de le bentuerno vident. Bene do fogur mirum ad conciliandas aures sć; tu retiopuoficitur. Quodfinihulaarte Che...tan numinis honornos maxi$\mathrm{D} s \mathrm{me}$

\section{Indos do- mefficos, 8 .} ne familia. 


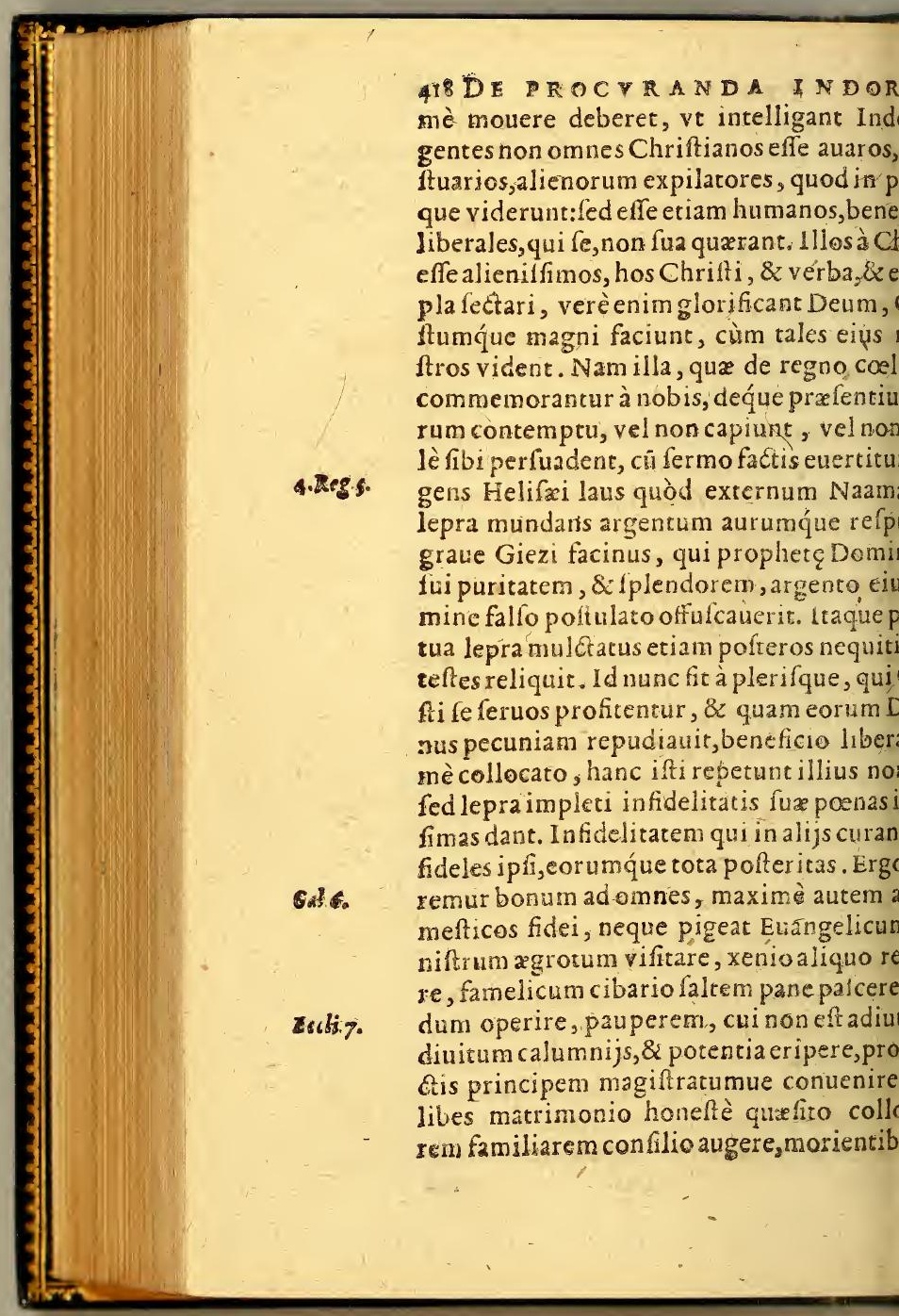


A L.V T E. LIBER IIIT. benignè aftare, fepulturam curare, $\cos _{3}$ runtur $2 \mathrm{~d}$ mortë, eripere, lites $\&$ diffidia ere: omni deniq; officijgenere cumulaqui, fiquidem certiffimè fciat Chrif́o inxq́; religioni honoré maximü,ad fpiri trum faluté viam apertam, fibi pramiú m parari, fi verum illud eft, qnod veritas. nod minimis ift is feciftis, mihi feciltis: Matth. 21\% De correptione do difiplina.

C A P. XIX.

verò Chriftianæ dilectionis fit non mo. onfolari pufillanimes, fedetian corri- 1. Theff. uietos, hanc quoq; beneficent parte peram admilfis corrigendis infiftit; mii pratermittendá parochus exiftimare c ficubi difciplinæ feuerioris cura adhi: 7, ea profect ò opus eft maximè in naticrum, quod \& natura feruili, \& noribus que puerilibus fint, quifefesta companifi timoris ftimulis excitentur, facil defledant, aut pigri confítant. Redie Salomon fcripfit, Virga \& difciplina fapientiam. \& alibi : frulritia colligara rde pueri,fed virga difciplinx fugabie urfus, Non emendabitur verbis fervus eruus non poteft verbis erudiri. Paulus A poftolus non fo'ùm manfuerudinis fpi Properhisos Proh. 22.

Provier.29. c. Eor.4. ed virgam quog; prafert interdum. Sed o \& quatenus caftigatione veendum fie ti Dei,id certè quæritur.Plerique perfua er vim \& metum nihil fe apud Indos e, vfque ad plagas defauiunt, neque veDeo lacratas manus, in colaphos fuorum Rem prorfus inhoneftam, \& facercotal

$$
\text { b) } 2 \text { ato- }
$$

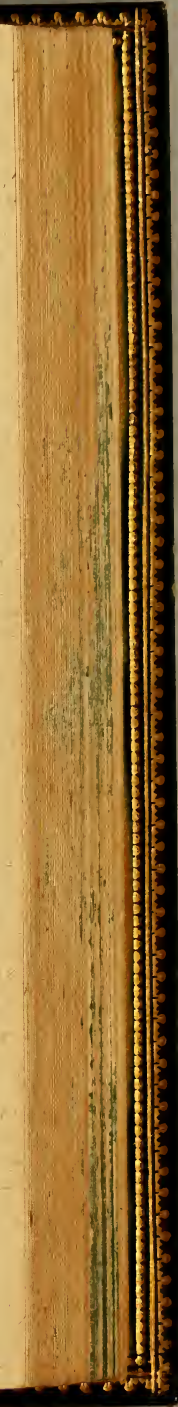




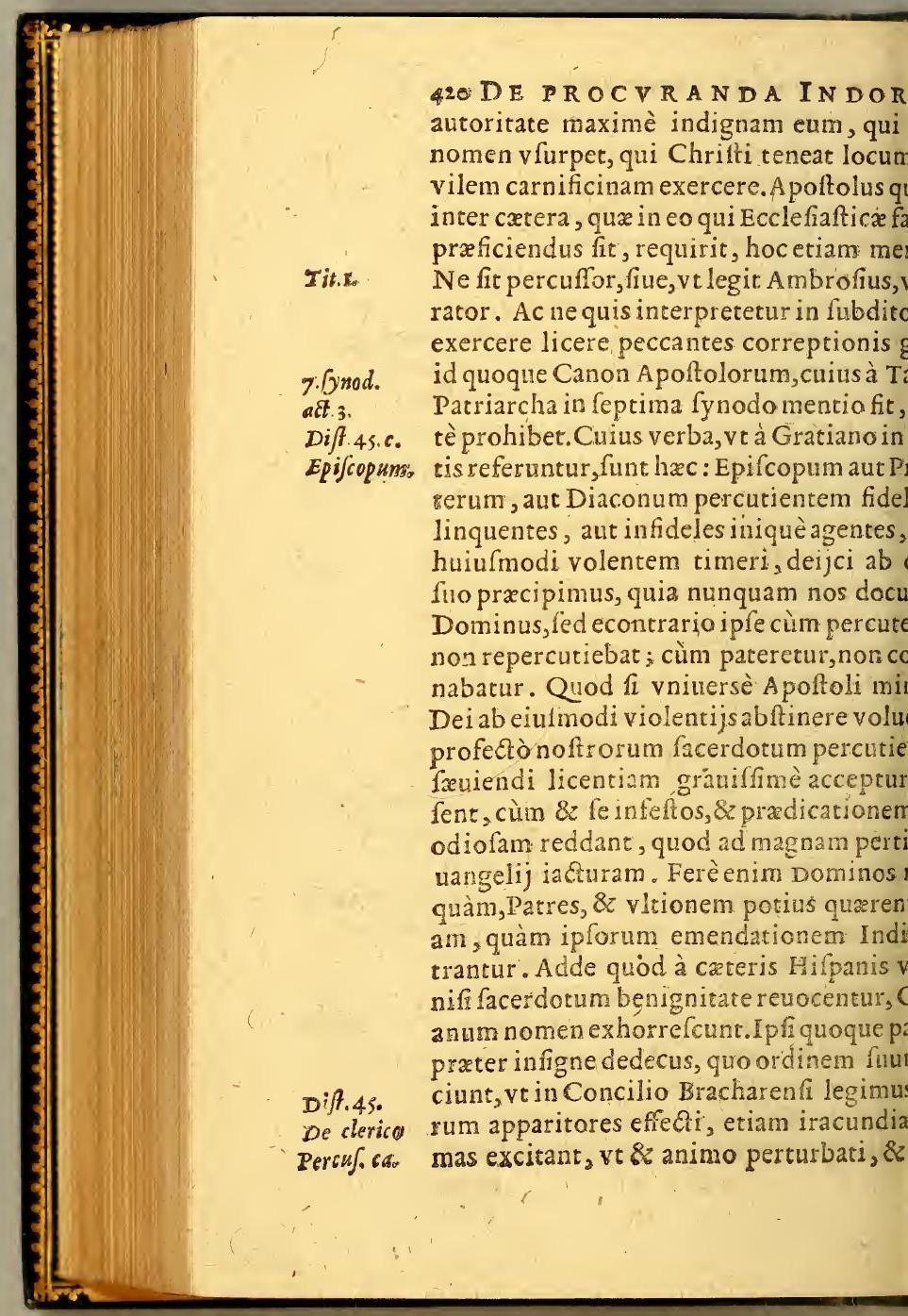




\section{SA L V TE. I I BER IIIT.}

Idecori paffim tumultuentur. Quibus ex siquis. ex mnibus prouidenter in Concilio Limen-Conc. Aganni crde, verberibus, detonfione comx, thenf. que in Ind'as defignari folitis abftinere Cap.n6. ii iuffi funt, muletandi, fi fecus faciant, a prefulum arbitrio. Hic iam vociferanrimi fibi omnem docendi, \& emendandi cultatem eripi, Indos nifi facerdotem ti, pro nihilo illius monita habere, facilè utemnere, fi impunè fe abituros intelliihil boni f ponte facturos: quò liberalius agitur, eò deteriores reddi. pueros effe Is, \& ingenio, puerorum more tractanii nifi præceptoris flagellum præ oculis $t$, neque difcere, neque parere fciant. mùm Indus intelligat nihil fibi à parotimendum, neque ad miffam venire dieis, neque ad doctrinam conuenire, neque iones curare, Chritianæ omnia religiociaflocci facere, ebrietatem inuerecundè , infanire in foeminas, fuperfitionem que antiquum repetere, ariolos fuos con. fimulacra adorare, omnem difciplinam, lenique ipfam funditus perire. $\mathrm{H} x \mathrm{fe} \&$ upertos, \& quotidie experiri certiffimè. facerdotum manus qui à fupplicio Indohibent, nihil aliud quàm Indorum manus somne diffoluere. Quorum profectò non contemni oratio, aut omnino conficta reQuamuis enim illi pulfando cædendoó; ut, tamen hi cùm digna frepe vindicta adt, tum nifi vindicetur, facilè verba connt. Indigent ergo feueriore interdum difb, indigent prorfus. Horum verò crimina Dd 3

2ut

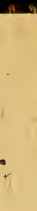


428 DE ROCVRANDA INDOR aut negligentiam fpirituali gladio (quode clefix proprium) vlcilci minimè expedit interdicta Ecclefiaftica, excommunicatic cenluras fi pro vindicta iubeantur,excipe cilè paruipendent, quia harum vimn neo dent neque agnofcunt, $8 \mathrm{z}$ ad fuperftition tenebras, facilè funt redituri Ecclefiæ luce dicti. Vt ergo belluas caftigare folemus infligendo, quæ multum fenfus ac doloris ant,periculi minimum,efferq́; reprehenfic gniffimus, fi quis phrenerico aut infano ptionis gratia gladium iugulo admouer mucronem pectori opponeret, ac non verberibus tutò fauiret in furas aut fca quòd illic mentis inops, necem citius, correctionem admitceret: hîc contra falut fa dolor iple fierer: 1ta fanè in nouos $\mathrm{E}$ paruulos minimè oportet cenfuris ager rum difcrimen fine emendatione adiren gifqúc corporeæ ac fenfibiles ponæ infi funt, quibus $\&$ lęduntur nihil, 8 multum no adiuuantur. Eam ob caufarn fanctiffin mani Pontifices cùm Hifpanos interdi excommunicationis caufa teneret obft peculiari priuilegió neophitos hos m comprehendi voluerunt. Coufequenser vt corporalibus poenis in officio barbari nendi fin:. Eas verò à facerdote irrogari fum eft lupra. Quid igitur? Non parux runt anguftix, cum hinc facerdocalis di \& paterna beneuolentia neceflariò con! da, inde difciplinæ neceffitas, ingeniumá wile concertent. Primùm igitur, quod fup libro diferebam, pratore ac iudice fach 
SA LVTE. I IBER IIII. 483 le ad difciplinam Indorum, hic profectò verum fit, dilucidè patet. Horum enim iè intereft ifta vindicare \& $x$ plectere. Hos adminiftros effe facerdotú æquiffimü eft, icquid durius defignandum erit in noxios, ari potius manu intentari. Deinde quoniá etoresomnibus populis adefie non polsüt, currunt quotidie peccata leuiora, qua corone quidem indigët, fed non illa alperior diciaria, vt cùm ad rem facram non venit, techifmo abfuit:tum etiam funt quadam, fæcularibus vindicari nullo modo debér, illorum forú reculent, vr cùm Quadrageem confeffionem Indus neglexit, cum immēta matrimonijnon dixitfciens, cùm renis Chriftiana 1 itum contempfit, cum arus \& veneficos cófuluit, $\&$ multa talia, túc facclefiaftico iudicio in tales animaduerti tebit. Ac mea quidem fententia taxatasia finitas ponas decreto publica efie oportelibus criminibus, qux fciret Indus fefe cer biturü,cùm illud aut illud admitteret. Fieoc modo vt plus timoris poena iã propoficuteret, tũ minus odij cótraheret parochus utioni mandans, quod effer lege decretum. enim ram ipfe tunc vindicare, quàm lex vitur,atq; ita \& terrori effet fupplicijirroga32 minus infeftus, qui imperaret. Quam ob am in fynodo Prouinciali ponas elfetaxaertis criminibus credo, tametfi parum ea intur, fed fum potius parochus quilibet iuum fequitur, aut eriam iracus dix legem.Pomò fiue publico canone fint poenæ decreza, priuata lententia decernantur, illüdmodis Dd 4 ousto

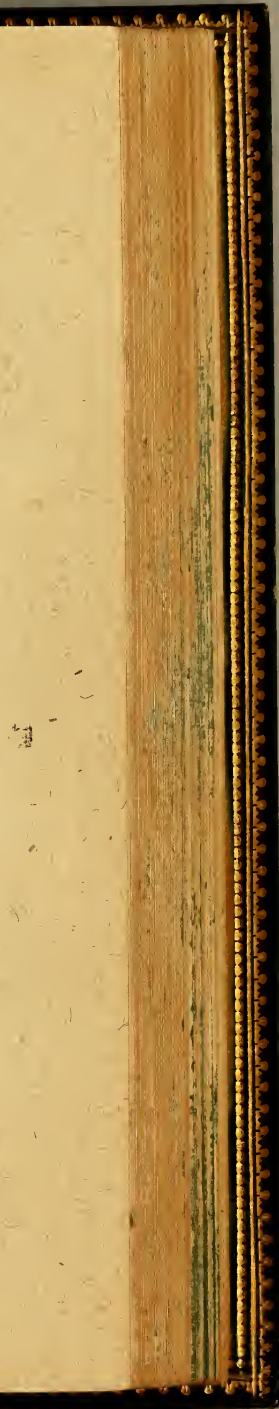


424 DE PROCVRANDA INDOR V omnibus obferuandum eft, vt nihil paroc manu propria vindicet. Id enim \& odiofum $\&$ indignum, \& valde periculofum. Iubeat ipfe quid facto opus fit: Apparitor autem filcalis,aut Lictor,aut Guatacamaius iuffa ceffar.

Quid obferuandum in correptione Indorum

$$
\text { C A P. XX. }
$$

VA in retria pręcipienda funt.Vnum vi Cas vindictre exponat, \& intelligant ipfi corripiuntur, mitius fecum agi quàm pron to. Et ne tam iracundiam, quàm difciplinam terpretentur, non irafcatur \& fauiat in fuis in Dei offenfis. Turpe enim elt valde, vt, fi atque Indum mulæ fuæ fonum ferre ceffan viderit, aut non promptè imperatoscibos a rentem, nimis fruiat: eundem mox $8 z$ adu rum, \& idololatrâ fciens vix contingat. Hir dia exardefcunt in parochos, hincomnis d plina contemnitur. Magnopere ergo curan eft, ve caftigatio difciplinæ caufa adhibita, vltionis, auc iracundiæ impetum prafeferat cunda praceptioef, ve confeffonis Sacran to, \& exifimationi diligentiffmè confula Ea enitn funt ignorantia ifti,vt facilè fibi fuadere poffint, cum ad confeffiones facier accedunt, Patrem, qux ex illis audiuerit, act poftea vindicaturum, ac propalaturum. Ita hoc timore correpti fimul confcientia fux nera non admodum curantes, facile ficta mendolas confelfiones facient, rarè verita integrè a perient lacerdoti.Q $\mathrm{Q}$ etfi multum pands in tanto facrilegio forent, tamen quod 
5 A I V TE. IIBER IIIT. 425 non poffumus, ex duritia \& imprudentia chorum occafionem non exiguam tam maui exitij haberent. Hoc ergo quod eft omgrauiffimum, in facerdotali feueritate inmodum modis omnibus cauendum eft. Ac tat óm nino difciplinę neruum tantifper deari, \& infringi, quàm tam falutaris, tamq́ue frarij facraméti exiftimationem prodi. Sed t vtriq; rei confulere prudens charitas, fi effionis forum longè diuerfum effe $\&$ verre fape perfuaferit, fi nihil in confeffione tum, etiam alioqui cognitum plectat, vt ma ylum quàm proditionem confeffionem $\mathrm{ef}-$ gnofcant, fi blandè illic, \& parernè fegerat, tante confelfionü tempore à feueritate $\mathrm{ab}$. at, fi fe grauiffmas poenas daturum docetenuiffimam auditæ culpæ reuelationem. emò perfpiciendum eft, vt fupplicij mos fit, qui lemper paternam \& Ecclefiaficam entiam redoleat. Argenti modica quadam ta, coniectio diurna in compedem, plagx lot interdum inflidx, fruiffrmum omnium um detonfio, quछextremx ignominix a. Indos loco eft. Neque mirandü, aut ab Ecfitico inftituto aliênú exiftimandum, fỉ id $s$ poenx adhibeantur, cum facris $\&$ anciquis Dif. As.e. nibus nò rarò verberum mentio fiat. Ni- cumbeasus. nim quod ad continëdos in officio homines e poteft, Ecclefiafica cura à fe alienum pued quicquid in hac tam magna quaftione ipitur, imbecille eft, \& ieínum, nifi vnctio tus accedat, qua doceat de omnibus. Magenim eft doctor Charitas, vt fanctus Chry- Hom. 33 in mus ait. Hac cùm fyncerè $\&$ germanè falu- 1. cor. Dd 5

tem

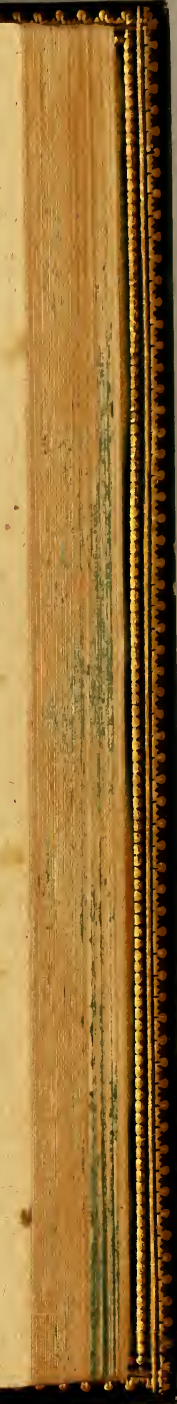




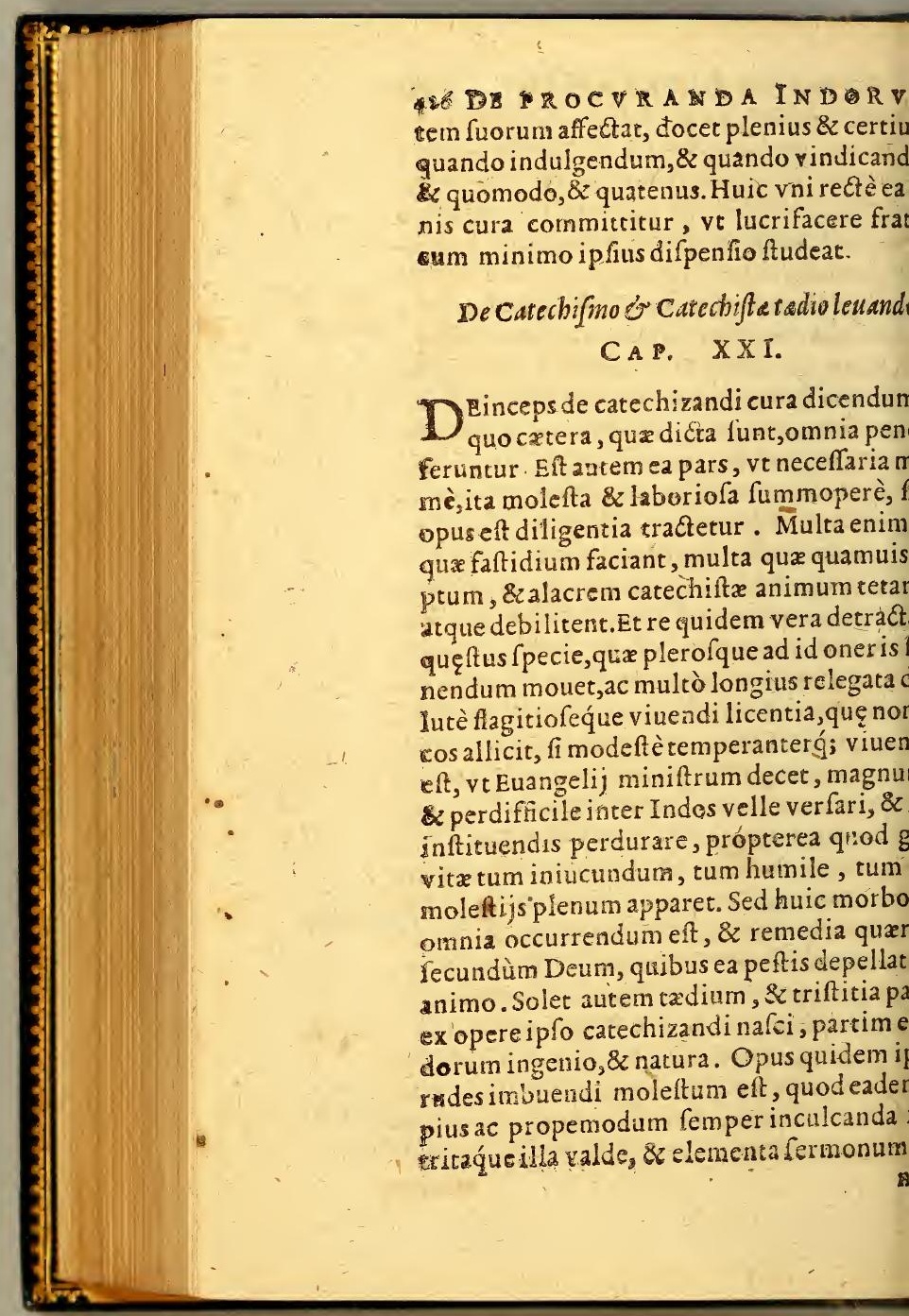


SA I T E. I I B ER IIIT. 427 ue his omiffis ad perfectiora ferriconcedi, fed lac femper paruulis in Chrifto oportet e. Huius autem ægritudinis leuandæremeex nullo alio melius petere poffumus, quàm Beato $\mathrm{A}$ uguftino in eo opere, quod de hociprgumento, id eft, de catechizandis rudibus ipfit, vbi inter alia fic ait. Iam verò fi vfitata paruulis congrueñtia fæpe repetere faftidiCat.Rud. $s$,congruamus eis per fraternum, paternum, ternumq́ue amorem, \& copulatis cordi eonetiam nobis, noua videbuntur. Tantùm e$n$ valet animi compatientis affectus, vt cùm. afticiuntur nobis loquentibus, \& nos illis centibus, habitemus in inuicem, atque ita, illi qui audiunt, quafi loquantur in nobis, 8 in illis difcamus quodammodo quod doce1s. Nonne accidere hoc folet cùm loca quam ampla \& pulchra vel vrbium, vel agrom, qua iam nos frpe videndo fine aliqua votate præteriebamus, oftendimus eis, qui annunquã viderant, vt noftra delectatio in eom delectationis ncuitate renouetur, \& tanto gis, quanto funt amiciores ? Quanto ergo madelectari nos oportet, cùm iptum Dominum $n$ difcere homines accedunt, propter quems cenda funt, qua cunque difcenda funt, $\&$ in eo m nouitate innouarı?Huc accedit ad cóparanm latitiam quod cogitamus \& confideramus, qua erroris morte in vitam fidei tranfeat hoo.Idem in eodem opere, Cogitemus quid no- capese $s$ prærogatum fit ab illo, qui demonftrauit bis exemplum, ve fequamur veftigia eius, i cùm in forma Dei effet, femetiplum exiniuit formam accipiens $\&$ catera, vfque ad

morteme

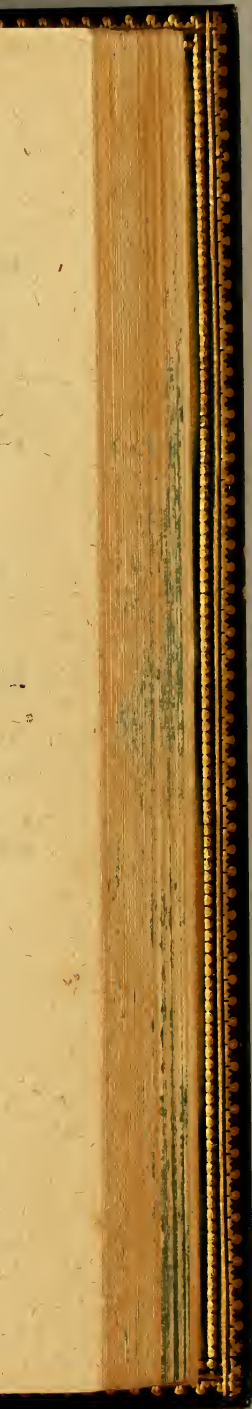




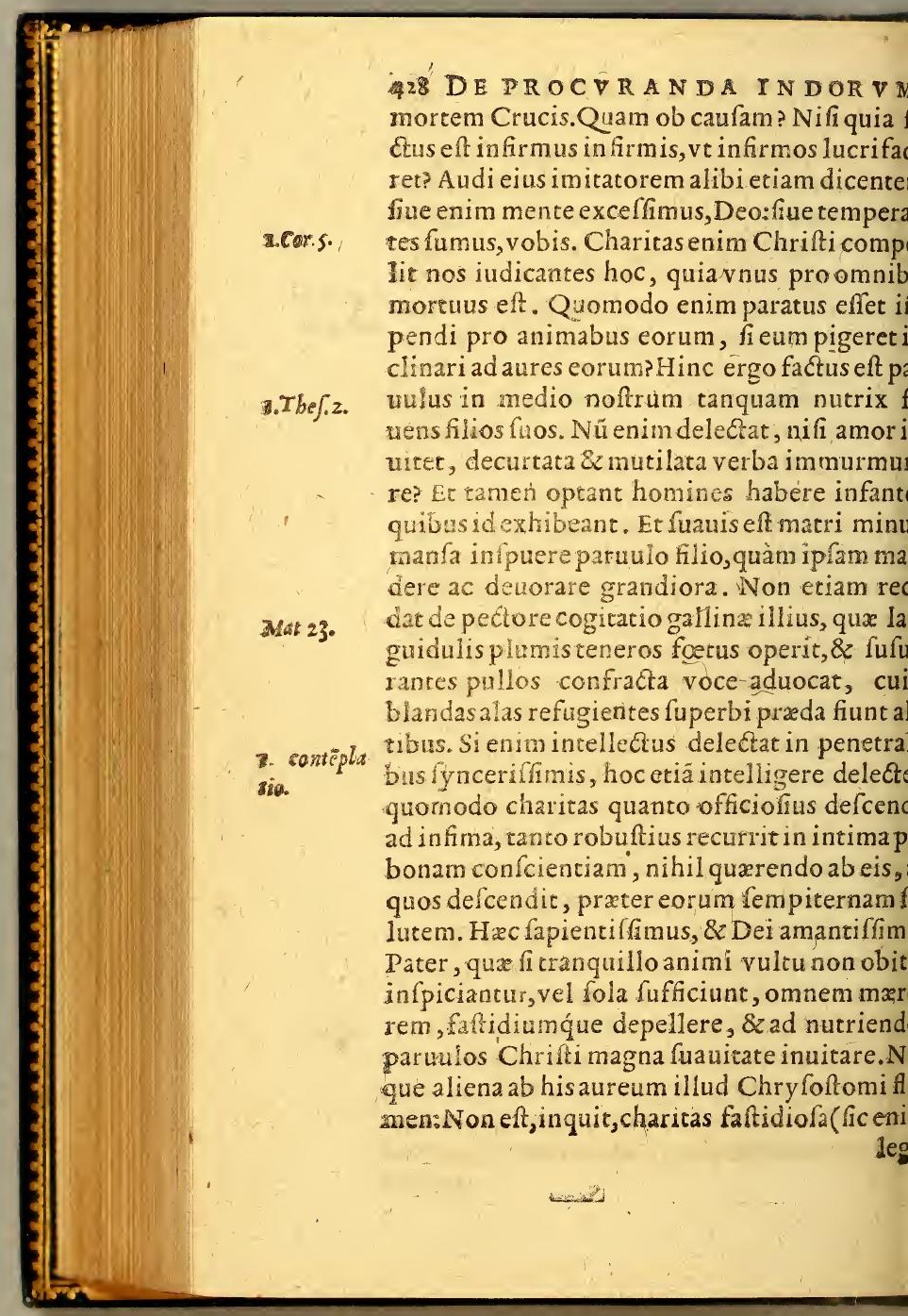


SA L V TE. LIBER IIII. it ille in Paulo, quod nos: Nó eft ambitiofa) Homil. 33 iores natu videmus fapientiaprzellétes vi- ins.Cor. cú liberis fuis fẹpe balbutire: $\&$ id cü faciüt, 1.Cor.13. reprehendit cos quifquã, neq; ipfos rei illius let, fed digna laude adeò videtur, vt quan$\mathrm{m}$ improbi funt, qui inftituuntur, perdurent en ipfi hortando, turpia caltigando, horum s nihil pudet. Non eft enim faftidiofa charifedalis aureis omnium quos complectitur, a tegit.Ita Chryfortomus charitatis ingen:exprimit. Quare néque infantilia dedigna, neq; affidua repetitione tædio afficitur.Eaenim repetere mihi quidem non pigrum, Pbilip. 3o uit, vobis autem necefarium. Nonne vide\$ artifices eadem ipfa cùm faciant, 8 modo em repetant, nihil tamen faftidire, fed lucro ius intentos vehementer delectari ? Nam $8 z$ harædus, \& cantor, \& grammaticus, \& ludigifer rudimenta eadem inculcare non moè ferunt, quod ea docendo quåtum ampliofaciunt. Et prorfus in doctrina Chrifi, quz ceffente iarn aut defeffo dicuntur, quaq́; ipet languida putat, ea fæpe vehementius Deo agente, auditorum animos permouent. Quonobis accidit, cùm confeffiones peccatorú imus, \&, feffiam alios atque alios excipis,tả nobis frigidè loqui videri, \& faftıdiosè, ipfi nobis difpliceamus, \& tamen illa ip fa guens, vt nobis videtur, \& toties fingulis reita exhortatio, præter fpem noftram, lacrysac fingultus intimos excitat, declaratq́ue re a poenitens, noua illa fibi $\&$ mirabilia videri? hi quidem frpe ita euenit, \& tamen fæpe concum mihi ardenter agere viderer, $\&$ ad fle-

cten-

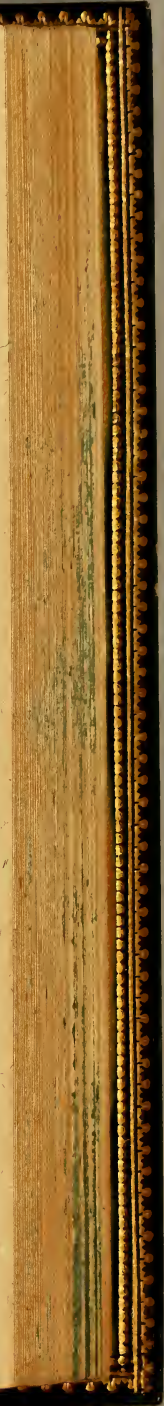




\section{Rom. I.}

2. Tim.2.

1

Ift: 2

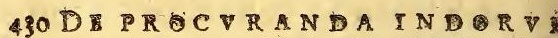
Etendum quoque lapidem efficaciter loqui, suens vultum auditoris, deprehendi ofcitan ve fatis mihi perfuaderem, neq; qui rigat e aliquid, neq; qui plantat, fed eú quiadminift femen ferninanci, $\&$ dat fructum, cùm vult.I fum ergo repetendi, $\&$ inculcandi eadem tad magna mercedis eft, \& fructum habet copi fum. Quòd frabicetum \& indignum nobis pu rilia ifta tractandi munus reculamus, præterq quod $\&$ charitatis vacui, \& fuperbix pleni, $n$ bis fufpecti effe debemus, \& ftulti prorfus $q$ certa lucra non amemus, incerta magis \& pe culis plena fectemur, hoc igitur vt omittä, qu fo honor \& dignicas, apud quem tandem 2 matorem collocanda eft? Deumne, an homin iudices intuebimur? Siquidem hominum iuc cium refpiciamus, nihil abiectius pauli of cio, quippè cùm pro magno diceret, Non er befco Euangelium, $\&$, Noli erubefcere teftim nium IefuChrifi, neq; me vinctum eius. Talis rat apud homines exiftimatio pradications uangelij. At apud Deum? Nihil A poltolatu m ius in terris. Principes conftitues eos fuper of nem terram. Paruulos igitur Chrifi Euange lacte nutrire, vile: Indos, gentem defpectam fordidam erudire, virograui indignum. Ita nè müdus exiftimat. At apud Deum nihil fub mius, nihil gloriofius, \& reuera in Ecclefia $D$ nihil Apofolicum magis. Hoc enim proprit Apoftolorum eft. Neque enim Paulus tanti fuum effe putabat fapientiam loqui, fed pai id quidë $\&$ rarò, nec nifi incer perfectos. Cx $r$ is vero quid? Nihil, inquit, mearbitracus fu Ceire inter vos nif Iefum Chriftum $\&$ hunc

cil 
SAIVTE. LIBER IIII. SGं um. Ne ergo vile habeatur officium, quod Angelis modò commifit, fed \& Chriftus ipfcepit .Quantoq́; quis maior eft, tanto eum is decet ad ifta defcendere exemplochrift, uguftinus optimèadmonuit. Quod fapienùm fecum reputaret parens nofter Ignaticietatis Iefu inftitutor firmiffima ac perpeonfitutione fanxit, vr quicunque profefem facerent, quigradus eft in noftra fociefublimior, cæreris votis fuis conceptis \& Parz exprefsè adijceret. Et promirto peculiarem cons. m circa puerorum eruditionem. Vt norint i omnes rudimenta Chriftiana dostrina folùm viros, quibus difcere opus fit, fed etiä os docere tam effe fuum, vt nifi fide Deo vi, huic muneri deeffe non polfint. Itaque no on iam de laude, \& palma cogitandum eft, ad rudes catechizandos accidimus, fed de potius liberanda. Euangelizandi enim par$s$ neceffreas nobis incübit, \& vænobis ? $_{2}$ neuangelizemus.

e fructu ex catechizandis Indis perando.

\section{A P. XXII.}

Ihil tamen $x q u e ̀$ laborem catechizandiatsget \& txdium, ac ea cogitatio, quod oper ium non fuccedat. Hoc etiam Auguftinus rtit. Facit, inquit, loquenti tædium auditor

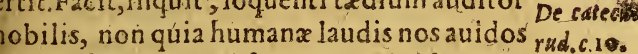
decet, fedquia Dei funt, quæ miniftramus, uanto magis diligimus eos, quibus loqui, tanto magis cupimus, vt eis placeant, quæ orum porriguntur falutem:quod fi non fuc$t$, contriftamur, \& frangimur, quafi fruftra ram conteramus. Huic moleftiff́ma cogita. tioni

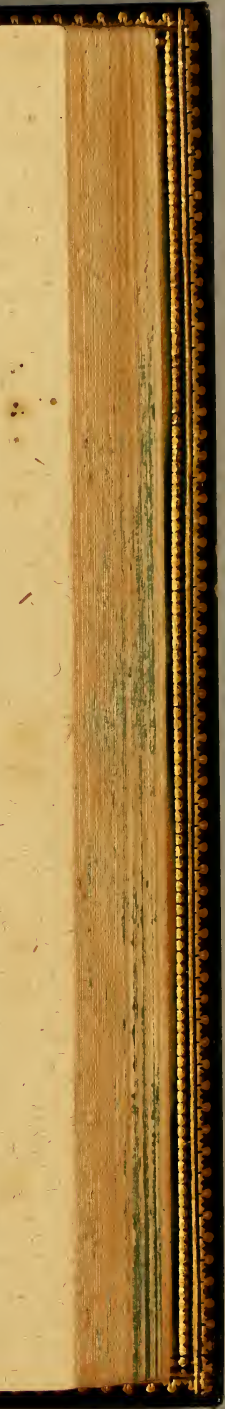




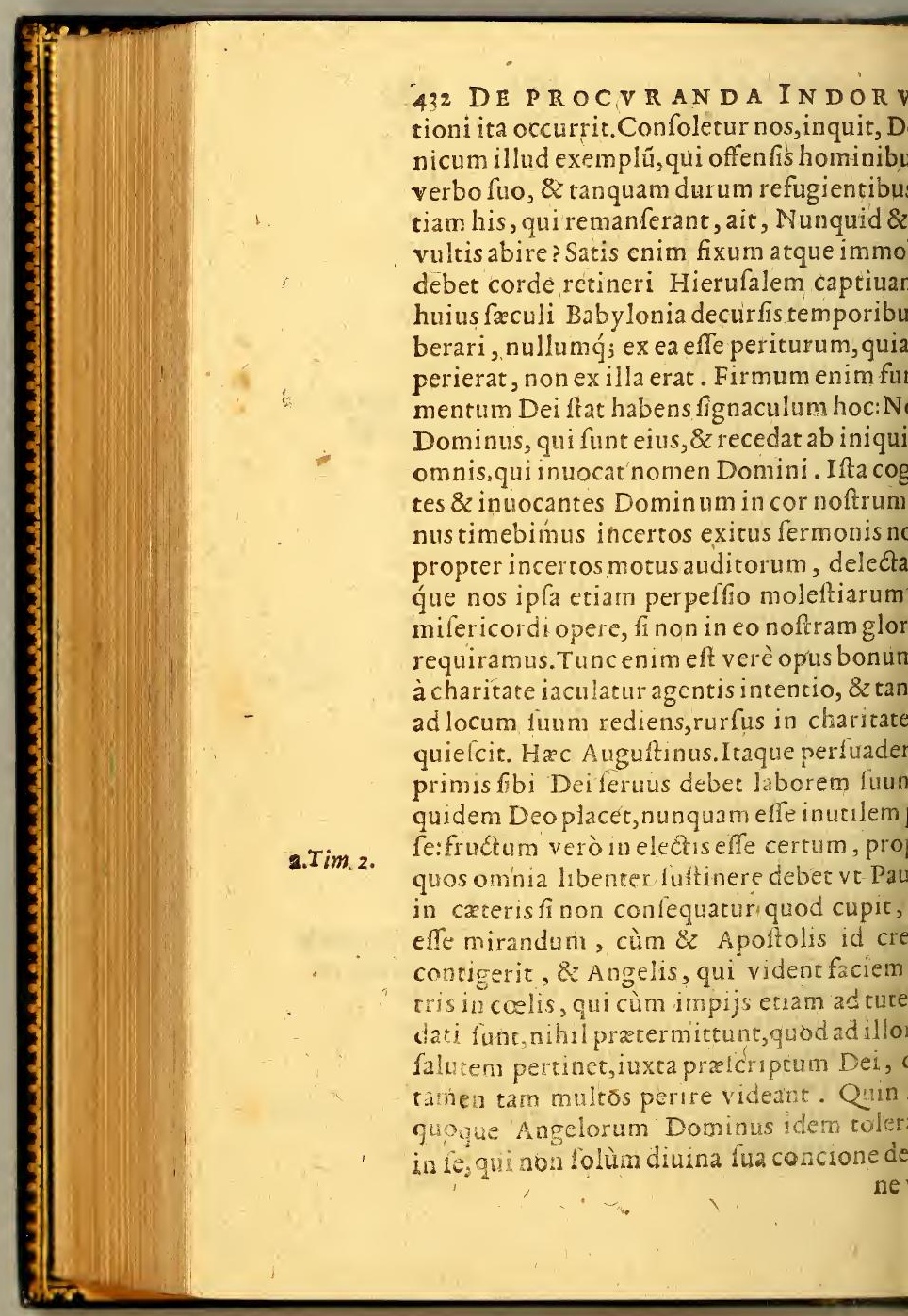




\section{SAIVTE. ILBER IIIT. 433}

itx non fexit animos hominum, fed etiam, eorum prauitas eft, magisalienauit à $\mathrm{fe}_{\mathrm{a}}$ Con tem vei ò Dei prádicatorem docens, \& non inum gloriam quarentem, conuerfus ad reos dixit, Nunquid \& vos vultis abire? Vt in- Ioan, 6. gamus ardorém quidem proximos lucrandi imum effe debere, fed tamen cùm per te non rit, quominus vota fuccedant, fummè quieatque tranquillum. Non enim, ve dixi, periteft charitatis opus. Hac igitur humiliter ùm cogitanda funt. Deinde quoniam deber, trat, arare in fpe fructus percipiendi, certò 1. Cor. 2 erfuadeat catechina, frucius futur os maxiatque mirabiles laboris fui. Nam fi opiniovel fegnitie, vel ambitione ortarum caligo ttur, letenilq́ue oculisres Indicæ iudicenon eft dubitandum, quin labore, \& moleongè maior appareat qua ftus a nimarú. Hoc folùm viri religiofiores, \& experiuntur, \& licant, verùmetiam prudentilfimus quifq; larium, qui diuturniorem vifum horum hapotuerunt. Et furgit quidem paulatim, fed idie maior copiofiorq́ue meffis, ac pro ip0 , \& natura iftorumetiam gratia ipfa lento f́penla quodamnodo videtur, re tamen ven ceffat. Tolle auaritia $m$, adhibe vita inteexemplum, procaptu Indorum opiniones m vanas refelle, viam veritatis demonfira, e his diligenter infife minifter Enargelij, go te fruar Domine Iefu Chrifte, vt copiomeffem, \& \atam futuram intelligo. Sed nos operando ceflamus, \& properatas, ac plenas esfatim volumus. Non eft autem rale RegDèi, prerfus ron eft tale, fed guale Chrifus 亩 expofuit,

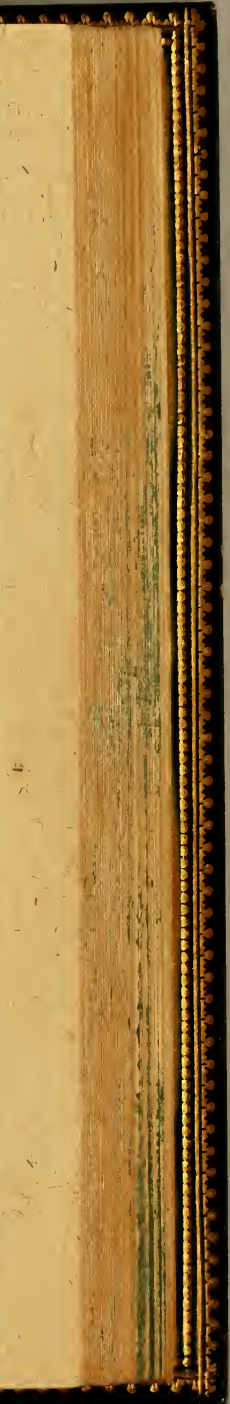




\section{DE PROCAR A N DA IN DOR V}

Marr.4. expofuit,Sic eft, inçuit, Regnum Dei, quen modum 1 homo iaciat fementem in terra, \& miat, \& exurgat nocte \& die, \& fe men germi $\&$ increfcat, dum nefcit ille. Vltrò enim $t$ fruclificat primùm herbam, deinde fpicam, inde plenum frumentum in fpica. Aduerta obfecro nof rum effe fementem iacere in te Eceldit jdq́ue iuxta Ecclefiaften mane, \&z vefpere faciendum, quia nefcimus quid magis oria hoc an illud, \& fi virumg; fimul, melius erit que etfidormiendum eft aliquando, \& va dum Deo, fed tamen nullo modo abopere fandum, fed furgendum nocte, 82 die. Er lice menfepultum lateat, neg; nos laboris noftri ceffum videanus, fuftinendum tamen eft, nobis etiam nefcientibus femen germinat, 8 crefcit.At neque properandum eft nimium, ftatim plenx maturxq́; fruges expectandix. primùm herbam quandam cuiufda extern $x$ ciei,\& fignificatæ Chriftianitatis gratè acci mus, mox calamum vifuri robuf ier is fidei 'Aremò plenos gratia, \&ucharitatis frucrus de temus. Hoc non in vno quou is homine tanti uator nofter voluit intelligi, fed multò mag ipfa hominú multitudine, quá Euangelici i nis iactus attingit. Senfim enini vocatio $D$ tes fuas ederit, \& euulfis tribulis, \&z cardu rorum preparatur terra futuræ fementi $F$ fenfimq́ue ccelitusaffuente diuini fauoris bre, noutum germen in Chrifto oritur, cre inaturefcit in frugem. Ergo coeleft is oraculi fpicua promiffone confirmatus Euangelici perårius certiffmè intelligat laborem fuut effe jnanem, fed magna emolumenta faluti 


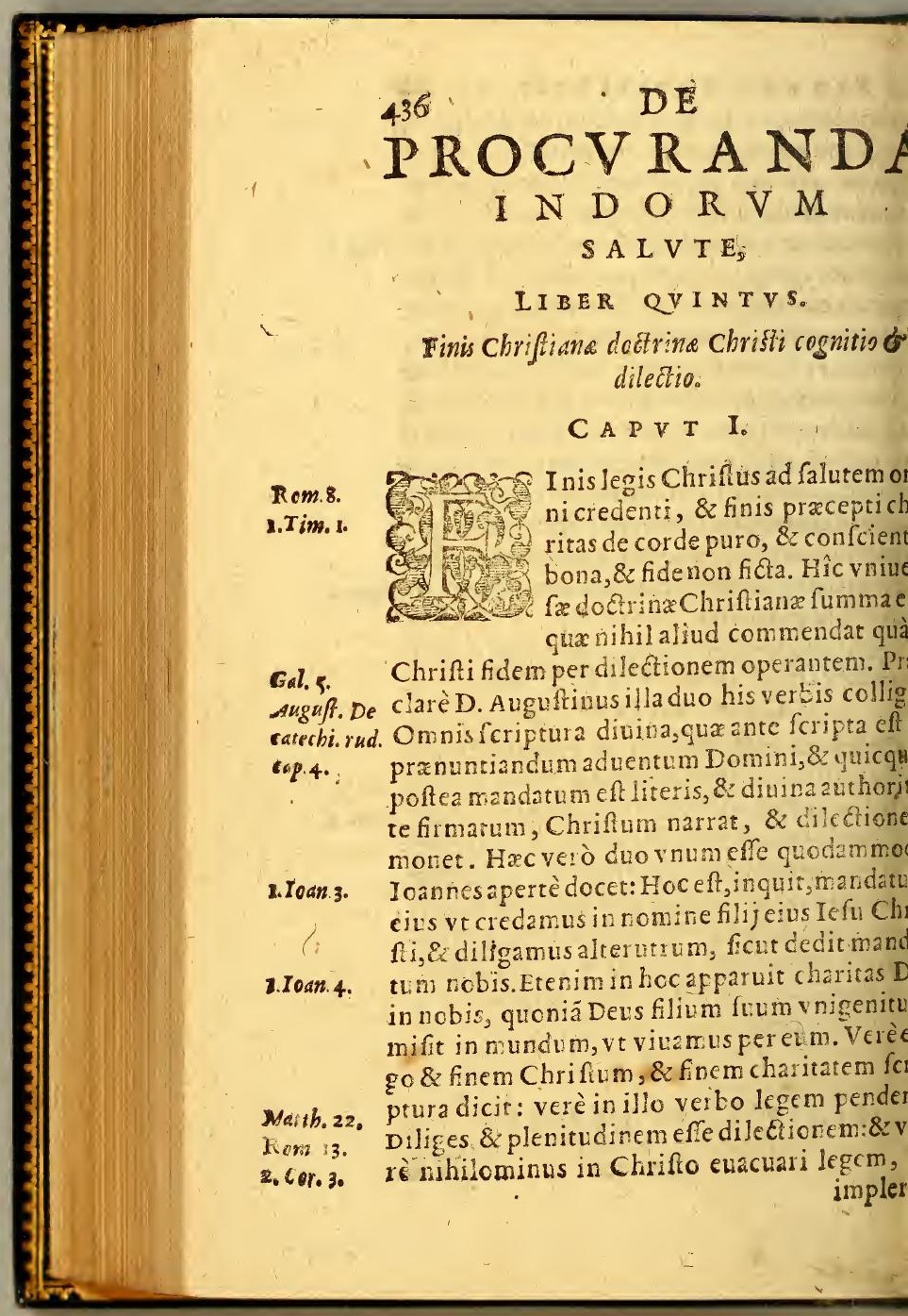


S A L V T. L I BER V. 437 leri omnia, fiquidem nullus eft alius diuin $\boldsymbol{x}_{\text {, }}$ itutionis fcopus, quàm Chriftus cognitus \&: ctus, Etenim vita æterna eft cognitio Chri-1.Toas.3i era \& perfecta. Nam qui dicit fe noffe eum, sandata eius non cufodit, mendax eit. Quo$\mathrm{n}$ igitur duæ funt rationalis naturæ paries: nitio, 8 appetitio, duæ humanæ vitæ ratiocontemplatio \& actio, duo quoque funt donæ Chriftianæ lumina, cognitio Chrifi, \& atio, neceffe eft duas eciam effe doctoris $\mathrm{E}$ gelici functiones, docere, $\&$ exhortari,atque rinę omnis, \&z cognitionis finis eft Chriftus, is exhortationis, \& adionis finis eft chariPorrò cognitio Chrifti, quam Fidem dici, fymbolo traditur, charitatis omnis actio alogo continetur. Ergo pradicatoris Chrii elt, \& Fidem dxcere, \& mores inftruere. A verò inchoandum eft, fine qua impolfibile $\mathrm{Heb}_{\mathrm{r}}$ ' lacere Deo,cuius author, \&z confummator Heb.is. hriftus. Quamobrem illa prima, ac præcicura effe debet miniftri Euangelici, vt gens Chriftum annuntiet, cùm fit nullum aliud en fub coelo datum hominibus ad falutem $A E T$. equiendam. Neque verò poteft quifquam a- 1.Cor:3. fundamentum ponere, neque eft aliud o- Ioxn.10; $n$, neque via alia ad viram æternam. chrifus aruulis, cibus grandibus. Chriltus Alpha, Apoc.r. , \& principium fapientize totius $\&$ finis. nat Chrifti minifter quarere quid artud doquàm Chriftum, qui factus eft nobis fapien- 1. Cor. 1. \& iuftificatio, \&redemptio. Abfint procul ticorum calumnię. Chrißum nobis effe omìm dicimus, 8 zihil prater hunc fapereoere, non tam fumus fulti, vt iccirco manen-

$$
\text { - Ee } 3 \text { dum }
$$

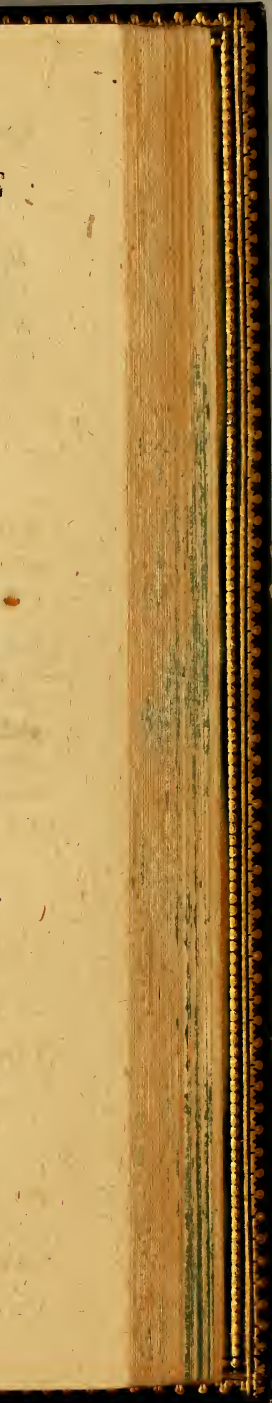




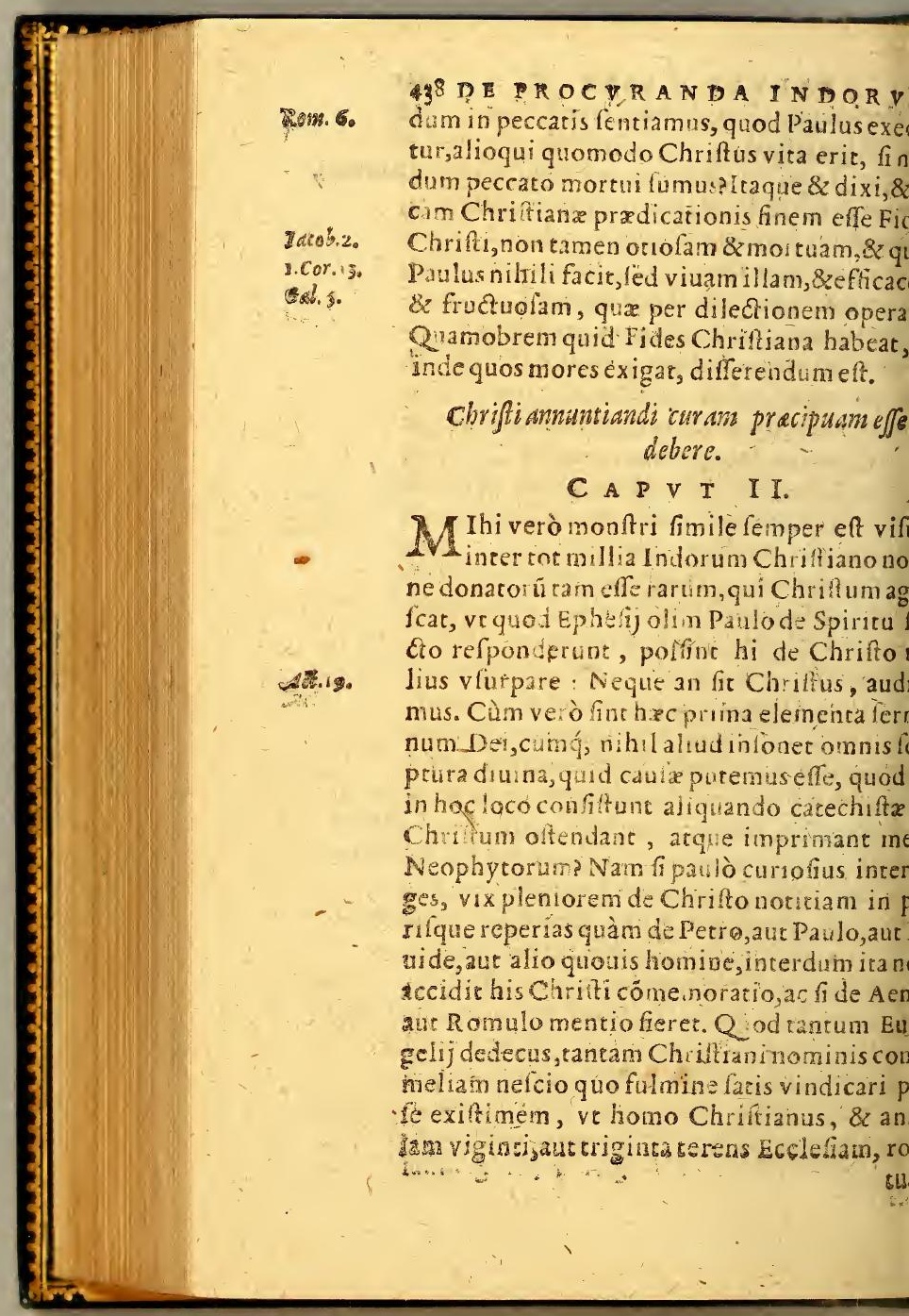


SAIVTE. IIBER V.

le Chrifto, neque quis fit, neque verò an fit, rus íncelligat. Ac docent multi nefcio qua ola, quidam præpoftera omnino, plerique iftum quidem annuntiant, fed ita cur fim, \&\% urè, ve nihil hîc magis Indus con fiftat aniquàm in cæatelis omnibus. Hæc ergo prima axima.Euangelici catechiftæ præceptio fit, leophytus Chriftum teneat, 8 memoria, ac llig̣entia menteque tota, quantum capax eft, at. Et quamuis res notiffrima fit, quá loquor, ifq́ue teftibus egeat, tamen dignum eft priEuangelijpredicatores contemplari, quid uerine, \& quò omnis eorum fpectarit oraA chrifto inftructi, \& redempti nihil alịud m Chriftum Magiftrum, 8z Redemptorem petuò loquebantur. Siue enim A poftolorum cipem Petrum cum plebe, cum principibus orum, cum gentibus differentem, fiue Stenum, frue Philippum, fue Paulum, \& Barna- Atto.13 16. adgentes, fiue folum Paulum ad gentes $f x-17$. erba facientem, fapè ad populum Hebrzo- Atc.2s.26. 1, fiue cxteros omnes parentes, \& pracepronoftros fpętes, ne vnam quidem concionem enies, in qua Iefu Chrifti Dei noftri annunio non vel totum argumentum orationis $\mathrm{fit}_{z}$ certè præcipuus fcopus, quò cæatera tandem rancur. De Epiftolis fuperuacaneum eft di, cum quxuis illarum pagina Chrittum lotur. Cur hoc? Nos predicamus Chrifum cru- 1, Cors. xum, Iudæis quidem fcandalum, gentibus auIfultitiam, ip fis autem vocatis Iudzis, atque ecis Chritum Dei virtutem, \& Del fapienn. Hæc eft, inquit, virtus Dei ad Jaluandum, Joan. \$ Dei fapientia ad docendum, fiquidem, oz graEe $4 \quad$ sia, 


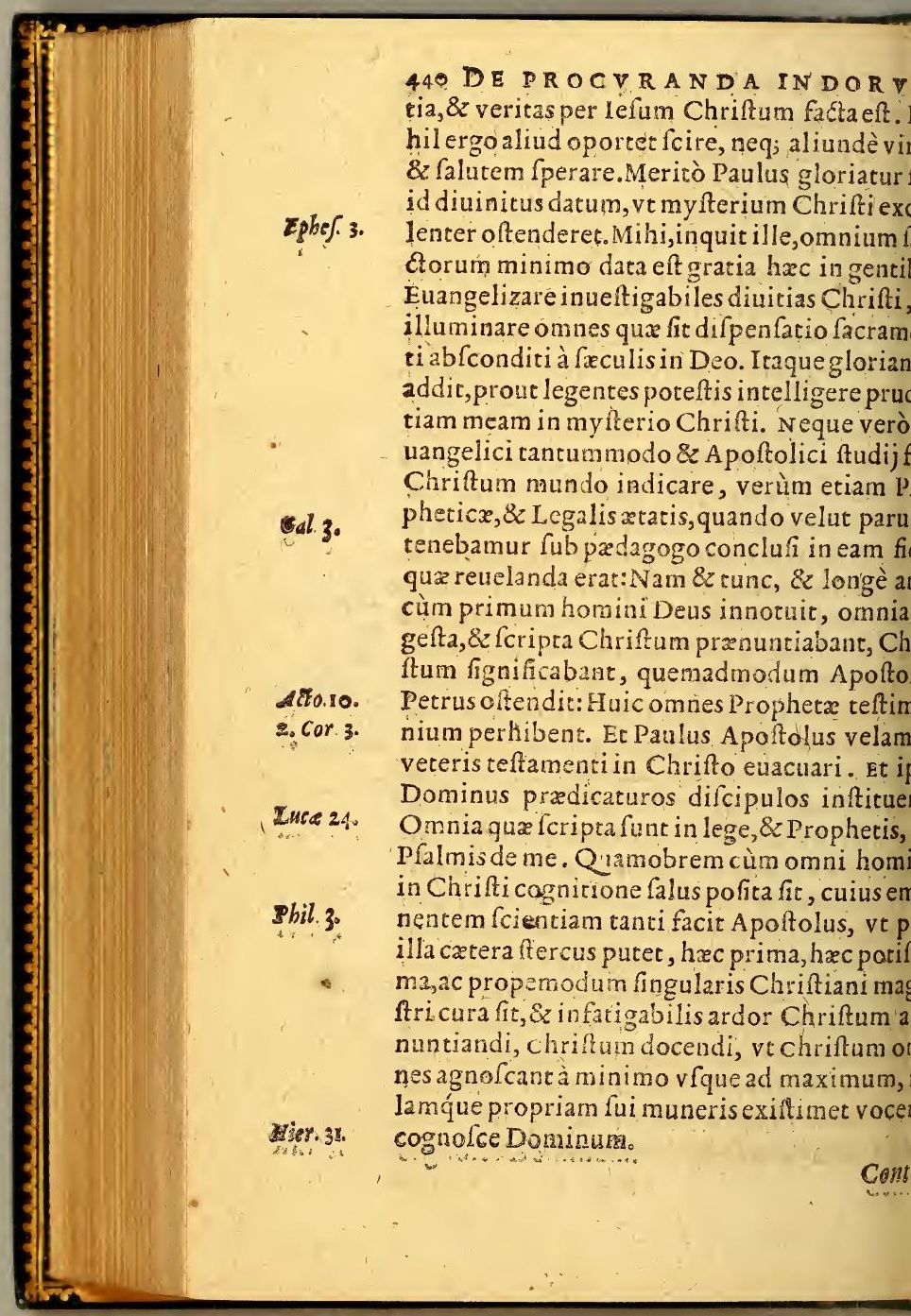


SALVTE. IIBER V. $44 \pi$ tra opinionem eorum, qui fine Christi noti: tia poffe aliquem faluum effe volunt.

\section{A P V T III.}

Væc cùm ita habeant, vix fatis mirari poffum, quid pręceptoribus quibufdam fchola$s$, viris certè grauibus noltri frculi in menvenerit, vt nunc quoque temporis poft taneuelatum Chrifum fine Chrifti notitia fan cuiquam xternam contingere poffe conent.Qiorum opiniotam mihi femper vifa c modo quoq; videtur abfurda, vt nullo moubitem antiquos parres Augutinum præ$m$ in homine Chriftiano nedum Theologo eftè id accepturos fuiffe, ac nefcio fanè an etfeueriore cenfura temperare potuiffent, a tamen propter authorum $\&$ eruditionem, $\& 2$ tem abftinendum nobis eft, quorum veftiotius folemus fequi. Sed illud \& liberè 8 dicendum eft, non dignam Theologo effe ntiam, qua nihil in facrisliteris, nihil in is Patribus firmitudinis habear, tantùm huquadam fufpicione introducta propter eoinfinitam multitudinery, qui in hoc nouo tâ longa ætate Euangelij luce caruêre, quiditus in coelum omnis pracludi videtur, fi lutem fuerit Chrifti notitia neceffaria, quã $s$ humanis ita labentibus confequi nullo o potuerunt, cùm haberent nullos Fidei ones. Qinid igitur?inquiunt . An his omnimpoffibilem effe falutis viam fentiendum quorum poteftate non fuit Oceano traieburopa prędicătores accerfere?iplos verò

$$
\text { E. } 5 \text { fponte }
$$

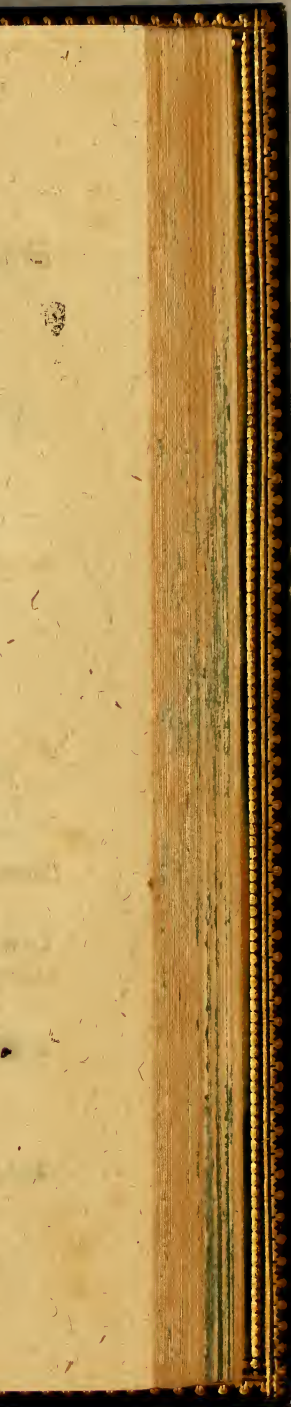




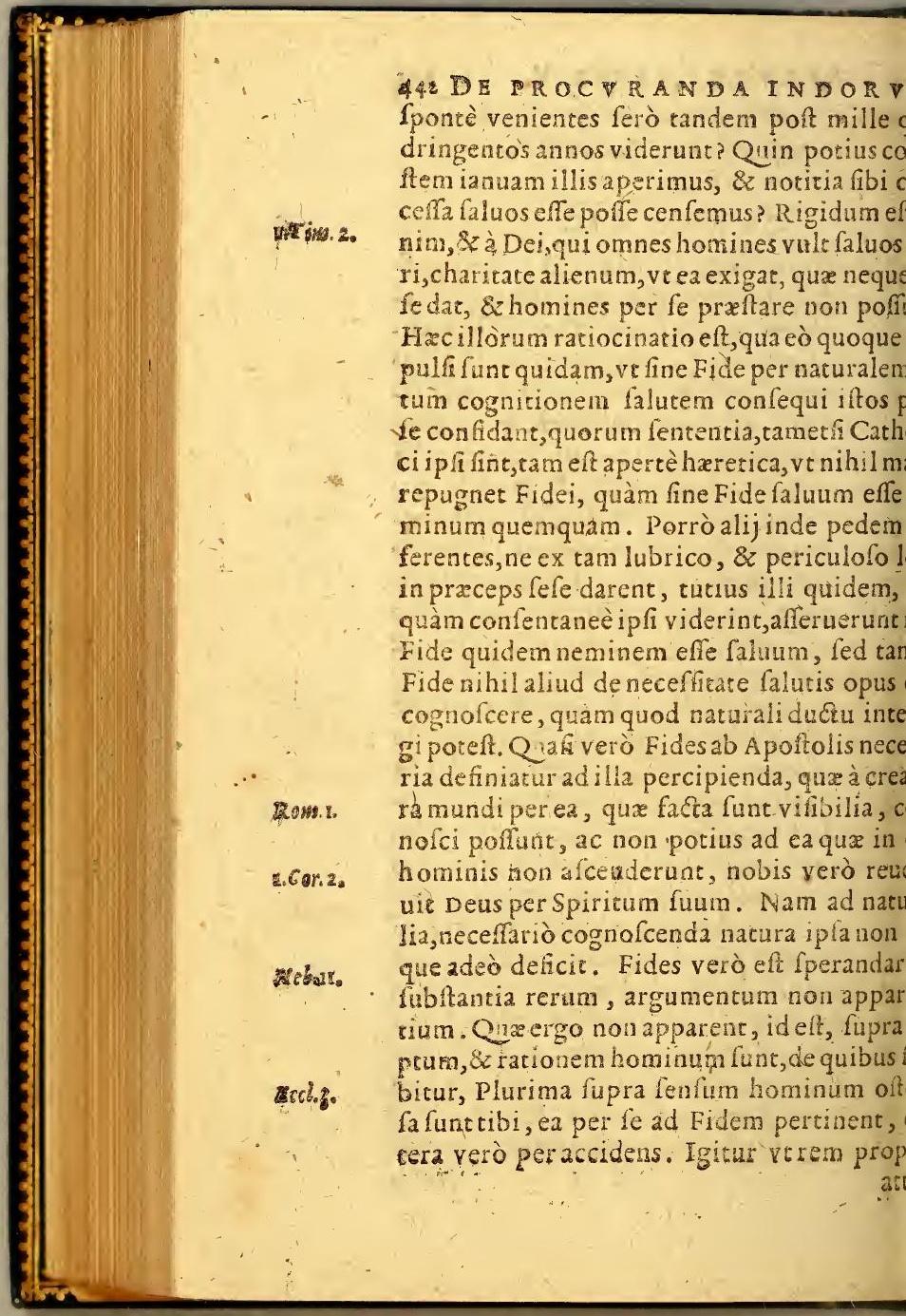


ngam, poft noum hunc eundemóue vaimum orbem inuentum noftri theologitacepêre $\&$ docere, $\&$ fcribere, cùm per mildadringentos annos, neque in lacris, neque cholafticis Dodtoribus veftigium eius fenix extet, quod equidem fiam, quin omconfentienter affirment fine explicita Fihrifti neminem effe faluum. Hanc autem n fententiam ex quadam Sancti Thomx o- In 3.d.2. 2. one confirmandi occafionem libenter arterunt, de primùm veniente ad vfum ratioquem ad Deum conuerti, \& yoffe, \& debeult, atque è veftigio fi faciat, gratiam incationis accipere. Ex quo colligunt nihil modi puero opus effe atia cognitione quàm $i$ honefti, quod proilla xtate potent agnof- Horum, pro Indorum falute patrocinium bentius amplecterer, quò me huius caufre iofiorem profiteor, nifi valde reuocaret, dad Patrem nemo venit nifi pèr Chrifum, loan. 6 . d nulla alia eft via, qua eatur, nullumaliud $10 a n .140$ um, quo intretur ad vitam. Acrequidem loak, $10_{0}$ , fi poteft fine Chrifti notitia falus effe aut itia, ergo gratis Chriftus pradicatur. FruA poftoli mitcuntur in orbem, fruttra prastur : Qii crediderit, \&z baptizatus fuerit, is erit. Non fruftra, inquiunt, Chriftus antiatur. Nam \& plures \& facilius, \& vbelaitut en confequuntur. Ego verò exıltimaChrifti annuntationem, hoc eft Euahgen, non ve plures, \& melius falui fierent, neariani fle, fed vt omnino poffent homines ten conlegui.lta fanè exiftimabam, imò ve0 ał exiftimo, fed tari ccrtò, \& apertè mihi perfua:

Marc. 16.

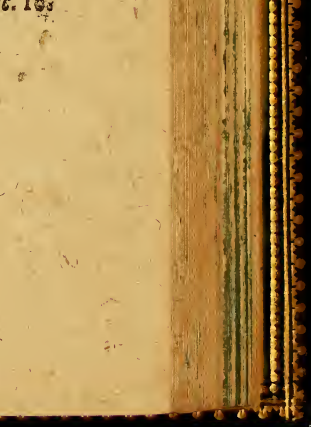




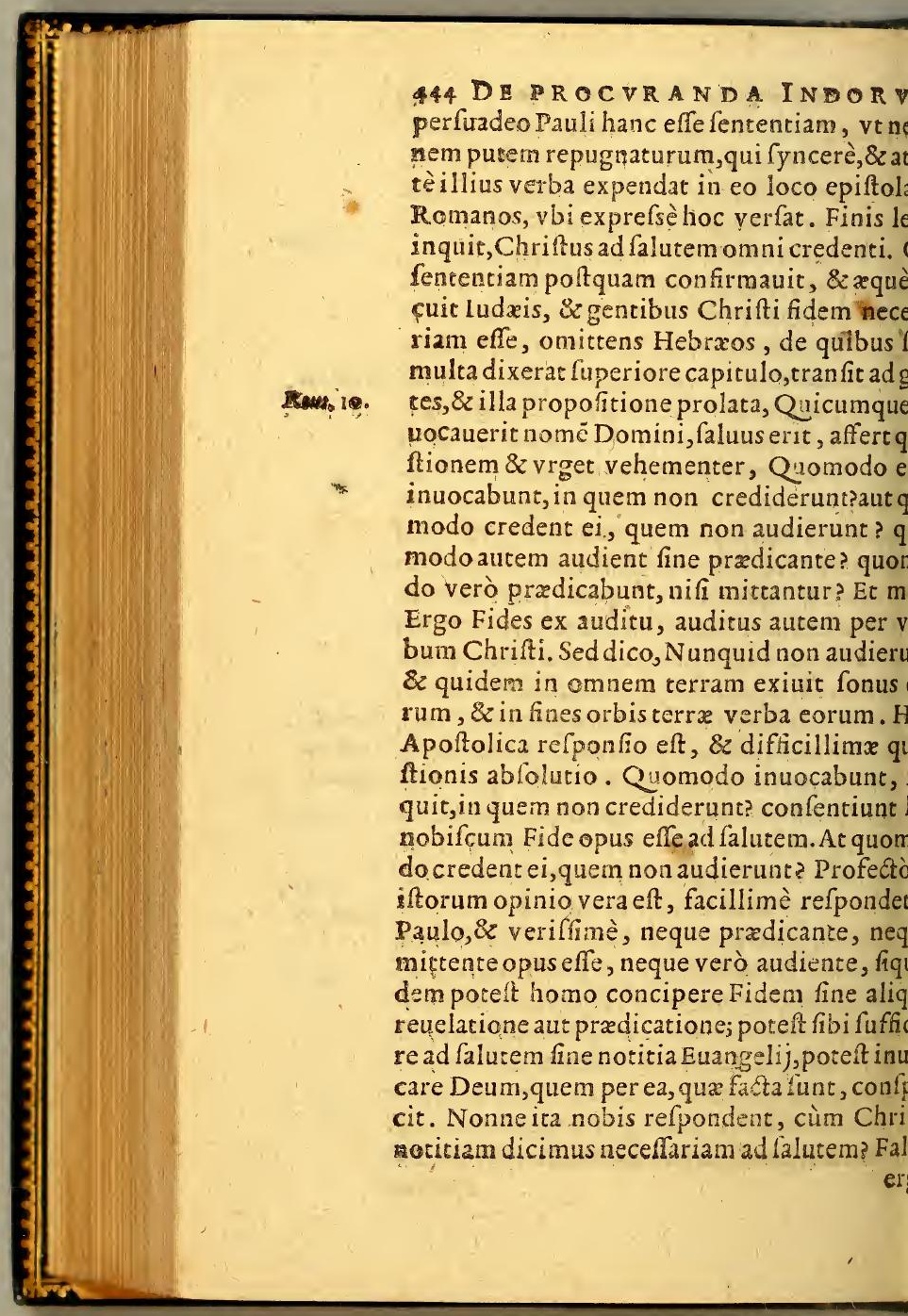


SA I V TE, LIBER V. Paulus docet neminem fufficienter inuo\& credere ad falurem, qui non audierit Eelicam pradicationê, fi vera ilta funt. Quod lus falli non potef, profed ò ifa vera non Si pergas Paulum interrogare, Quid de ijs; unquam audierunt Euangelium? refpondet In omnem terram exiuit fonus eorum, 8 os orbis terræ verba eorum, nimirum icationem eorum faluti, qui falui futuri ex gentibus, toto orbeterrarum non defu$\mathrm{n}$, qui verò ex ijs perierint, fuorum fcelenon ignorati Euangelij poenas daturos. Diurum hoceffe, \& afperum, at memineris ab tolo cos reprehendi, qui iuftitiam fuam vo. Rem.la sftatuere, juftitix Dei non funt fubiecti. enim hîc agitur, durum ne hoc, \& feuerum benignum, \& liberale, fed vtrum verum e. Aliogui eadem pietatis fpecie cogentur parualis corum, qui Euangelium audire otuerunt, fine baptifmo falutem dare per cumque Fidei proteftationem parentum, in fiebat in lege natura? Cur enim paruuli uangelico facramento falui efe non pof\& tamen grandiores fine Euangelica lege nt? Quod fi farcntur Euangelica lege iam ulgata nufquam gentium ad iuftificandos los antiqua facramenta facis effe, $\&$ pro ijs bus v num duntaxat valere baptifmum(nenim hoc fine aperto errore negari poteit) quxfo rationis habet, maioribus notitiam naturæ ad falutem poffe fufficere? Etenim uid contra nitantur, fateantur pariter neeft, modò fine Euangelica lege homines faluari, quod qui non putar ablurdum, cum 
446DE PROCVRANDA INDOR co ego amplius minimè difputem. Paulum fectò apertius loquentem nemo deficeret: $\mathrm{Cl}$ omnes fancti expofitores fenfum efe, quem xi, probant, maximè Beatus Thomas, cuins $\mathrm{cl}$ mentationem afferre non moror, cuius fe hi i thes. lete 3. ptores in primis authoritate tuentur. Poft en anc c. 10, ad ratum ergo locum Apofoli, ita dubitat. N Ea: quid illi, ad quos non peruenit pradicatic uangelij, vipotè fi fuerunt nutriti in fyluis, culationem non habent de peccaro infidelita Ad hoc dicendum eft, quòd fecundùm fent riam Donnini, qux habetur Ioannis $16.111 \mathrm{i}$ loquentem Domisum, vel per fe, vel per dif - pulos fuos non andierunt, excufationem hab de peccato infidelicatis, non tamen benefici conlequentur, vt fillicet, iufificentur $a b a$ peccatis, quix vel nafcendo contraxerunt, malè viuendo addiderunt, \& pro his damnabı tur.Si qui tamen eorum feciffent, quod eft in Dominus fecundùm fuam mifericordiam $p 1$ uidiffet mittendo eis pradicatorem Fidei,

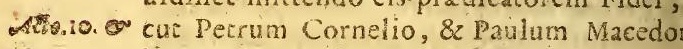
ซซ. bus.Hadterius Thomas. Augufini autem de ! retameitapertafentencia, vtnullo modo iu terfugi quẹat. Adeò enim Chrifínositiamad lutem neceffariam vult, vt ijs etiam, qui ex ge tibus ante temp us Euágelicum feruati funi, $n$ nimè id contigiffe dicat abfque reuelarione nius mediacoris Dei \& hominum Iefu Chrif Nam vicatera mifa faciam, ita fcribic in lib. Axg. Tib. 18. de ciuitate Dei, Diuinitus autem prouifum fut de ciuitreq. Fe non dubito, vt ex hoc vno fciremus (loqueb 47. turaùtem de fancto $\mathrm{Iob}$ ) etiam peralıas gent effe porviffe, qui fecundù, Deum vixerunt, 6 qúue pl]

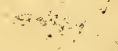


SA L V TE. IIBER V. placrerunt, pertinentes ad fpiritualem Hiew lem.Quod nemini concentum fuifie credenef, nifi cui diuinitus, reuelatus eft vnus meor Dei, \& hominum homo Chrifus refus. cundo quoque libro de gratia Chrifti idm multis confirmat. Neque tamen difpli. nihi illa quorundam temperatio, vt impliquiden fides Iefu Chrifti,explicita verò vmediatoris fatisfuerit ad falutem confedam ante Euangelicum tempus. Tunc e- 26. , vt ait Paulus, tanquam paruuli cuftodieur inclufi in eam fidem, qua reuelanda cAt pof renelatam fidem, patere alicui $v i$ anuam nifi per reuelatam, \&z expreffam ific cognitionem nullo modoaffentior, omIs \& antiquis, \&z nowis feriptoribus hac eftautibus præter paucos quoldam fchela. $s$, qui neque ratione ali qqua firma, neque rum authoritate, fed fua potius fufpicioucuntur. Neque verò extremam falutem ùm, fed iufitiam etiam primam fine Euancognicione poft promulgatum orbi Euanum cuiquam contingere exiftimo, in quo minus molefiè, fed tamen falsò contradi- Neque Auguftini alium fuiffe fenfum $A$ Sh. quid hi contenderint dem on trabutut. Non Pred jas. o Cornelij (quoniam hoc loco vrgent) ea- Eor.c. 7 . caufa ef, \& infidelíum huius temporis. E$\mathrm{m}$ quemadmodum Iudæis fides vnius meoris tunc temporis fufficiebat ad iuftificaem, antequam Iefus Chriftus euangelizareita quoque Cornelio Iudxorum, \& libris, nfuctudine inftructo fufficere potuit, vidum à Petro difceret Chriftum. Nunc vésò pors

Aug.lis. 2. de gratia chrificap. $24.25 .0^{5}$

. . 
448 DE ROCVRANDA INDOR rò poft quam toto orbe terrarum Iudaica, $\&$ \& facramenta prorfus abolita funt, vt non sua foltim, fed etiam mortifera fint, om nir uangelica menfura quærenda eft fidei, fine nemo, quod fatis eft, credit, cŭ lex fidei fola i ficet, id eft, nullum aliud falutis initium fit ter fidem I efu Chrifti . Quod fu quis pergat rere. Ex quonam tempore explicita fides $C$ fic coperit effe neceflaria ad iuftitiam, equi refpondebo ex illo ipfo, cùm primùm pron gatum eft orbi Euangelium. At Indisnon hactenus promulgatum, inquis, ita cgo fan bitror, vertim nihilad rem. Neque enim promulgatione fer mo eft, quæ cuiuis ignora nis locum nullum relinquit, fod de ea pot qux cù $m$ folennis fit, \& prolegiflatoris vo tate conueniens, cmnes contrarias legesab gat, contra ¿lufó; diffoluit . Scimus igitur fa menta omnia, \& legis, \& natura abolita effe, mus Euangelicam $\mathrm{tg}$ gem, qux eft fides lefu $\mathrm{fi}$, omnes mortales aliquando coepiffe ebl. re:quo verò primùm temporefufficienter 1 mulgata fuerit, alijs aliter ftatuentibus, nos cimus. Cornelij certè tcmpore nondrim pl propalatum fuife Evangelium Gentibus, ve fe Petrus teftis eft, cui ea de re erudiendoco fti vifione opus fuerit. Nunc ergo cùm $æ$ què notum, vel ignotum fit Gentium populis effe aliquem mediatorem diuinitus prouif fue hurc effe folum Iefum Chrifum, non

Trajentit apertè D.Gre ger.bom.in szech.9. cur fin e Euangelij notitia remilfio peccator alicui tribuatur. Alij fentiunt Cornelinm verè iuftificatum effe coram Deo antè Petri dication em, cùm \& animali immundo com ret 
SAIVTA. LIERR V。 $\&$ audita remiffione peccatorum per Chri eciderit Spiritus fanetus, neque ab ea fenvalde abhorret Chryfoftomus: verùm lifficile eft, qué fcriptura religiofum, \& $x$ :im Deum, \&zacceptum Deo \& operantem am dicit, nó eundem verè iuftificatum inere, commodius explicatur accerfendi Pefed vt Euangelicam gratiam ea plenitudiirmitare, qua per Iefir Chrifti fidem côfeir . Modò verò polt latè pradicatum Euann eiufdem neceffitatis putamus credere; Chrifum credere, fine cuius my fterij fide cari neminem \& olim beatus Thomas, \& Tho. 1.2. q0 fancta fynodus Tridentina decreuit. Sed 113 ar. 4 , ad agemus de infinitis hominum millibus, 2. or 3. que audierunt Euangelium, neque verò au $C_{q}$. Tri.feffo otuerunt? An eorum neminem faluum effe 6.6.6. cenfebimus? Minimè verò. A fîne miracum doceri non poffunt. Primum miraculú on debet Dei peculiaris prouidentia vel um, vel hominem definantis, vt Euangei, qui quod potef, praftitit. Nam vt rarum , 8 rarifsimum vt in natura iam obfcuragrauiffimè faucia ad tam praclaros quifconatus affurgat, idque fitse proueniente uxilio facere nequit, ita prouidentia fingu on deftituendum ipfa ratio confirmat, cui ngulare contigerit ftudium boni. Quod if - miraculum vocandum perftant, quid de ne digladiandum ef? Certè hi tanquam odi opera Deo grauia aut angufta $\&$ inufiotent, ita parcè $\&$ arctè cohibenda putant. on ad ipfum illum Cornelium, \& $A$ ngeFf

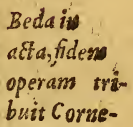




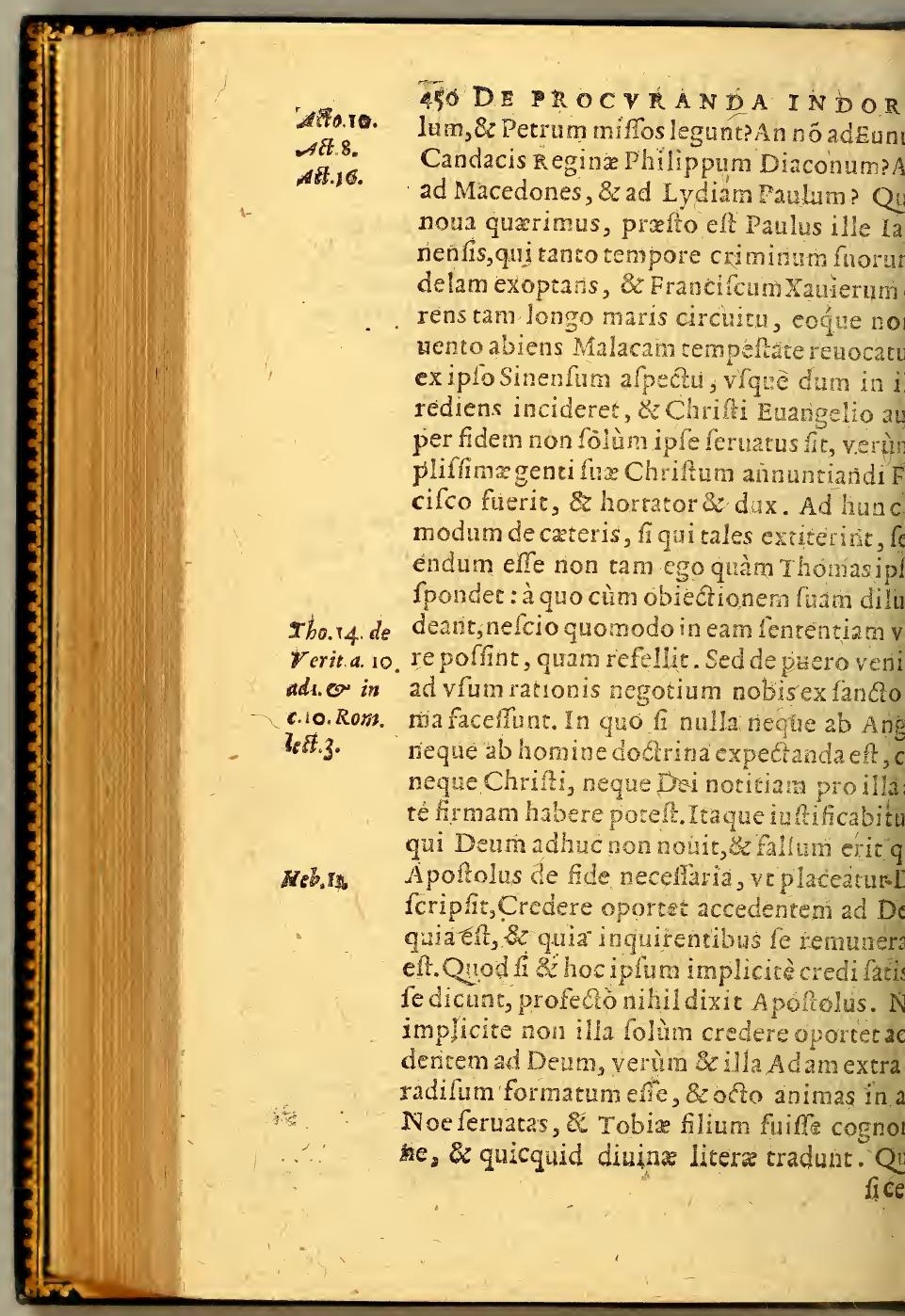


S A L V TE. LIBER V. aliqua fidei menfura defignanda eft, \& fir tem de Dei maiefate 8 prouidentia conprofectò à quo hanc fonte puerulus hauteft nulia doctrina imbutus, nulla experiluctus, ab eodem facilè hauriet, \& Chrifi rium, cum verumque vel diuinitus, vel itus edocendas fit. I taque vel opinio illa oma non vfq; adeò tenaciter eft tuenda, etiam illius plerique difcipuli non fatis rfuadent, vel fi retinenda eff, ad eum moxplicanda eft, quem antiquiores illius diffequentur, ve etiań pueri iuftificatiouelatio Chrifti antecedat. Neque enim incertas opiniones dogmata debemus eferere. Cum ergo fides infufa neceftaria vt credat homo, fed vialiquid credat, id is tam propter actum quàm propter obiequarenti quodnam fit illud, whil aliud it, quàm quod Patres tradunt, vecreds- cồ. Trid: ra elie, que divinirus revelatest promina fef. 6.6 .6$. q; illud in primis à Deo inflificari impiú itiam eius per redemprionem, qux est in o Iefu. Quamobrem myfterim Chrifi mac porifimum docere debermus, fillientiam fequi volumus, qui duscebat, N1- i.certzo d arbiratus fum melcire-inter vos nifi Chrifum, \& hunc crucifixum.

errorem illius, qui cbriftionos rudious the Fide explicita chrifiafferuit pofje faluari.

\section{CA P V I III.}

7 autem habet oquod nemo fripto Eह 2 - उस 


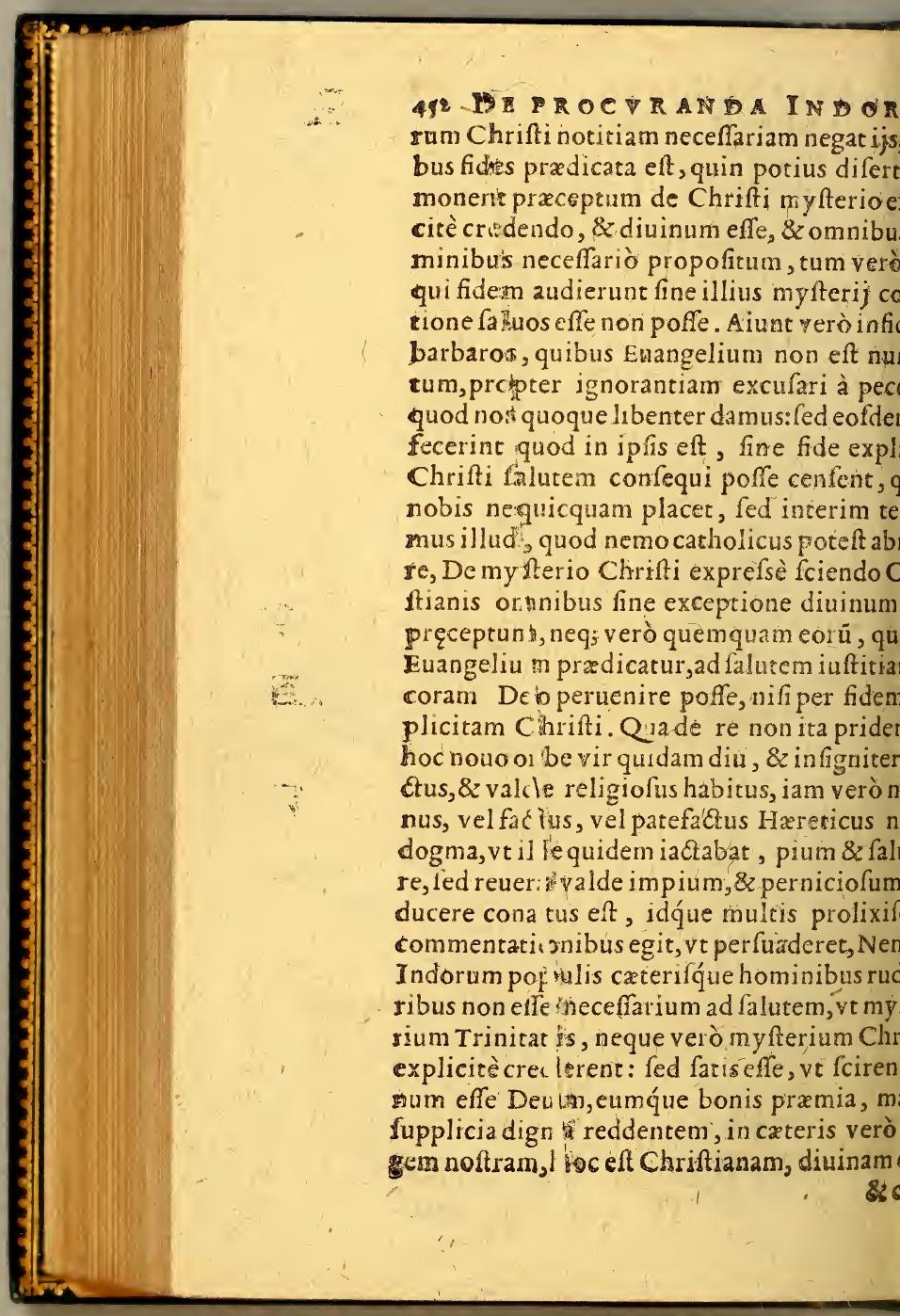




\section{SALVTE. LI ER V.} tò tenendam. Denique præter illa duo niud quàm vt crederent communiter \& è,quarenet Ecclefia. Quamobrem hxc ïplis prxdicanda effe, cxtera non ita magnouranda. Caufam huius fai dogmatis ille bat, quod Deus ad impoffibile neminern et:effe verò tam obtufo \& abfurdo ingen is fque, vt neque myfterium Trinitatis, neq; rium Chrifti percipere polfint, quos fi co-hxc explicitè credere, nihil aliud agas, qua li ingrelsú miferis occludas. Addebat por$n$ diu de hac re fecum iple deliberaffet, ata fentiret, vt dixi, diuina fe reuelatione pe confirmatum vfq; adeò, vt Paulum ipfum olum per reuelationé dixiffe affirmares, oribus non effe neceffarium ad falutem cre hriftum effe hominum faluatorem. Quis feudopaulus ille, 8 peffimus damon fuegelus lucis haberi volés, fatis iam ac p.jus quàm veliemus, innotuit. Sed autore miffum dogma tractemus, eoque accuratius ${ }_{\text {, }}$ iugulum ipfum Euangelij ferire conten. mnis penê pradicationis Indica labor $8 \mathrm{e}$ ollatur neceffe eft, fi vera illa fint. Paucis on folùm impiam, fed ftultam quoque ionem perfpicuè demonfrabo. Quideimpium magis,quàm $\&$ aperţ Domini ntiæ, \& gentium faluti per Chriftum obticontradicere? Ite, inquit, in mundum vni $\mathrm{m}, \& z$ prædicate Euangelium omni creatuicrediderit $\&$ baptizat ${ }^{9}$ fuerit, faluus erit erò nó crediderit, condēnabitur.Euangeliū ufcipere \&z credere omné creaturam opor \{alua effe v

$$
\text { Ff } 3 \text { motitio }
$$




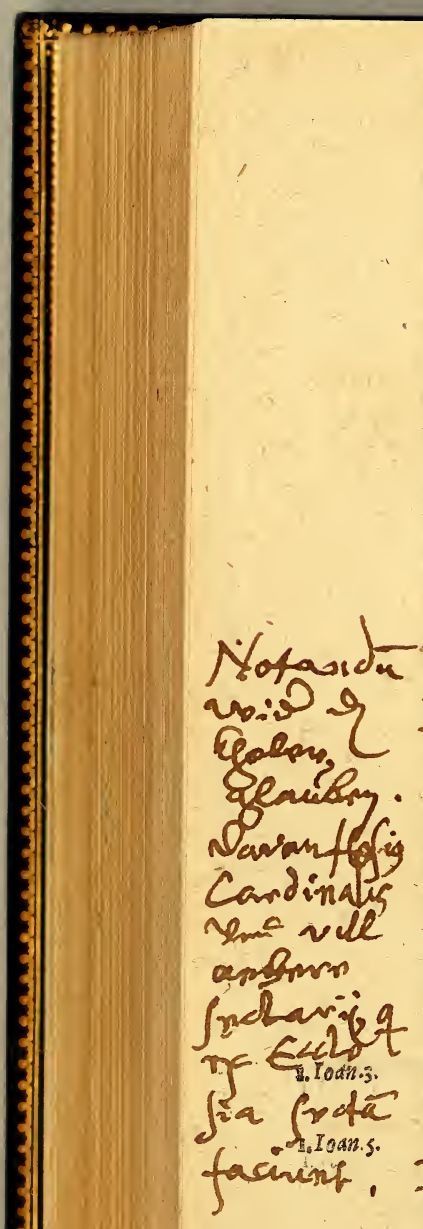

954 DE PROCVRANDA INDOR notitia nomine quidem funt duo, re ip $f_{p} p$ rusidem. Quomodo enim Euangelium no qu: Chriftum non nouit? Ex quo planè app quàm Rultè illud dicatur, vt is, qui fidem tianam habet, Chrifum tamen ignorare $p$ Nam fi quis Aeneidaaur Odyffeam tenere diceret, neq; tamen Aeneam aut Vlyffem v audife, quis obfecro rifum tenere poffer? $\mathrm{Pr}$ rea qui nouit fe fieri alt efle Chriftianum, 8 Iudxum aut paganum, qui Chriftum non uit? Qromodo eam legem profiteri potelt quid lex habeat, ignorat? Omnis Chriftia quatenus Chriftianus eft, Chrifum profite itaque docere quemquam Chriftianum effe bere, fi faluus effe velit, neque tamen opus vt Chriftum agnofcat, nihilaliud eft quàm ratione infanire. Ad hoc quäinepè $\&$ fatu becur Induscredose, qua credit Eccle fra, qu esen Chriftum ignorare permittitur? Om repugnat vtrumque Etenim Ecclefiam nifi gregarionem fidelinu chrifum verè tene intelligas, non magis Ecclefix credit quàm. gogz Iudeorum, aut fcholæ Achenienfum, Chrifoenimecclefia neque effe, neq; intel posef. Siue ergo Ecclefia moses, fiue Chri noum legen, frue frdelium cortum, uif $\mathrm{C}$ Ium Liadus agnofcat, Ecclefix myfterium fo nö poteft Vtullud præteream, quantæ infania myferium Eeclefix myfterio Chrifti prapo rein necelficate fit fer explicitæ. Ioannes Apofolisica colligit. be hoc ef mandatú ei itcredamusin fin jeius lefu Chrift hrecel, ait, vice qure vincit mundum, $f$ Hoftca. Quxatem fit fides nofira, fatin adi 
SAXVTE. LI B ER V. $45 \%$ his eft qui vincit mundum?nifi qui credit, Iam Iefus eft filius Dei.lgitur eiufdem prę,eiufdem neceffitatis eft Chrifianocredein Chriftum credere, eadem fides Chriftiafides Chrifti. Docendi ergo funt Indi, \&z somnes myfterium Chrifti, \& qui genus a$\mathrm{d}$ hominum inde excipit,grauiter errat, ne icum apertè dicam, quod tamen nonnulli sutores intrepidè affirmant. Sed homo duseft, inquit, rudis, hebes, fenex eft iam pitus, æthiopseft trunco fimilis, Vrus eft

Dominicus Soto in 4. uicquam a pecude diftans. Hofne atque ho fimiles Trinitatis myfteriú difcere coges, eft $v$ fque adeò difficilè magnis etiam \& ptis ingenijs? Myfterimmne Chrifti, quod im fuperat mentis humanx ex tam ftolido exiges?Ego verò myfterium Chrifti (nam . teris dicam poltea intelligere neminem , quod eft paucorum, credere verò omnes edico, quod nemo non potef . Nemo eameft ablurdus, qui nequear vtcunque coe Deum \& hominem. Doceri ergo poteft, factus homo, hic eft Chriftus Ielus, áddat, 1 fit factum, vt nos prorfus à peccatis eripei: \& vitam confequeremur, atque ita diffe vnicum faluatorem noftrum. Mox ordiquoque doceatur, quod conceptus fit Spiriincti opera ex virgine, \& natus, \& cruci\&z poit mortem refurgens in vitam immar 2. Hac profeciò cogitatione percipere non mpolfibile, quin potius fi Paulo Apolto- Rom 10: edimus, propè eft valde verbum inore no, 2 in corde noftro, hoc el verbum Fidei, pradicamus, quia fi confitearis in ore Ff 4

t부오.

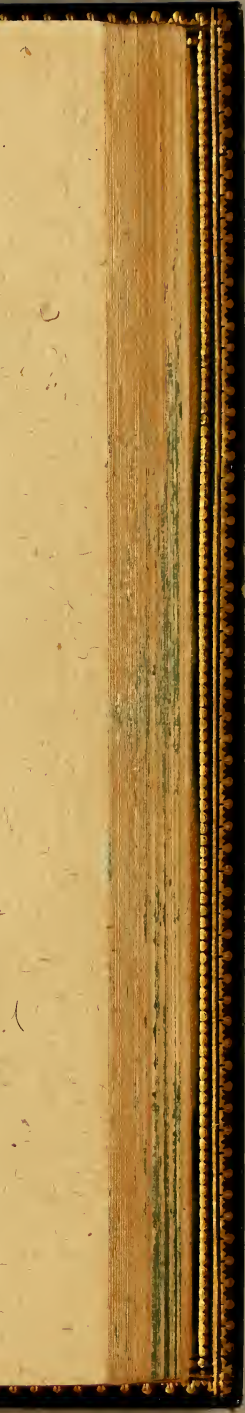




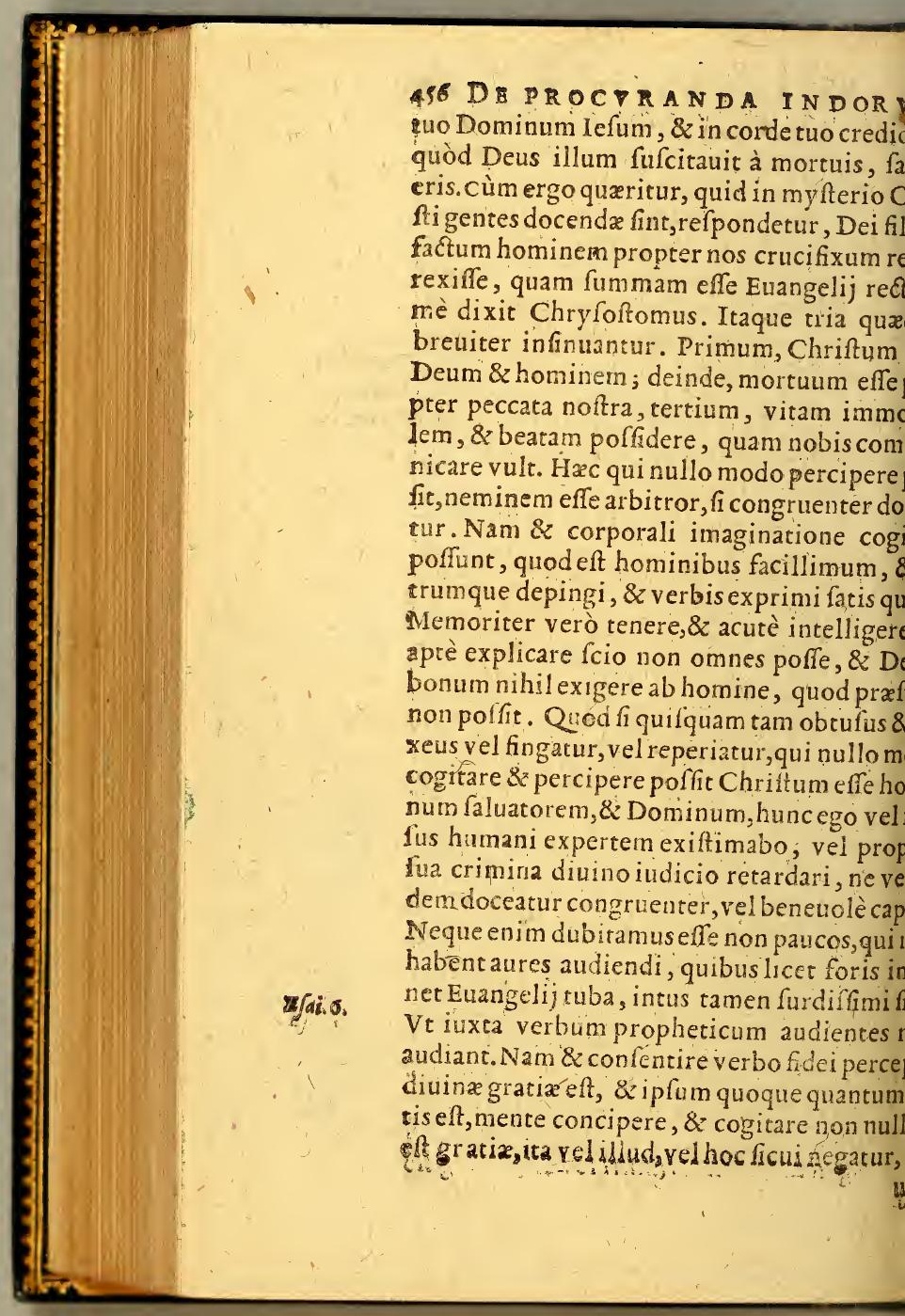


SALVTT. I TBER V. $455^{\circ}$ iudicijeft, cuius effectus cùm fape cernacaufas tamen planè ignoramus. Deniq; quiue diuinitusad fidem Chriftianam idoneuș catur, fine qua falus \& iuftitia effe non poidemad myfterij Chriftiagnitionem,quan fatis eft, idoneus exiftimandus eft, quam fi eglexerit, vel affecutus non fuerit, oftium æternæ nondum inueniffe fine vlla dubitae exiftimandus eft.

pracepts cateramyfteria, qua continentur in fymbolo, scire ommes Chriftiani conftrin-

gantur.

C A P V T V.

Yfterium verò Chrifti nemo poteft perfectè, \& vt par eft, cognofcere, nifi myfteriú que 8 Trinitatis, \& Ecclefiæ doceatur. Nam s Chriftus Dei filius de Spiritu fancto conus eft, mortuus eft autem, vt fuo fanguine daret fibi populum acceptabilem, fectato- Tit.\& bonorum operum, in quo eflet remiffio pec rum, \& falus æterna per fidem, \& facramenhrifti. Itaque tribus hifce myfterijs, Chririnitatis, Ecclefiæ, Chriftianæ fidei fumma ita eft.Quamobrem ab A poftolis tribus vepartibus ly mbolum diftributum eft . Et qua lem ad naturam diuinitatis pertinent, in pri oco patri attributa funt, quæ verò ad difponem redemptionis nofra, fecundo loco filio lefu Chrifto : porròqua ad fidelium iam \& fanctificationem, ea tertioloco Spii fancto afcripta funt. Neque veró illorùm nodò error refellendus, qui plebeio \& rubomini fatis effe putant, vt fe tenere profigf s

teatur,

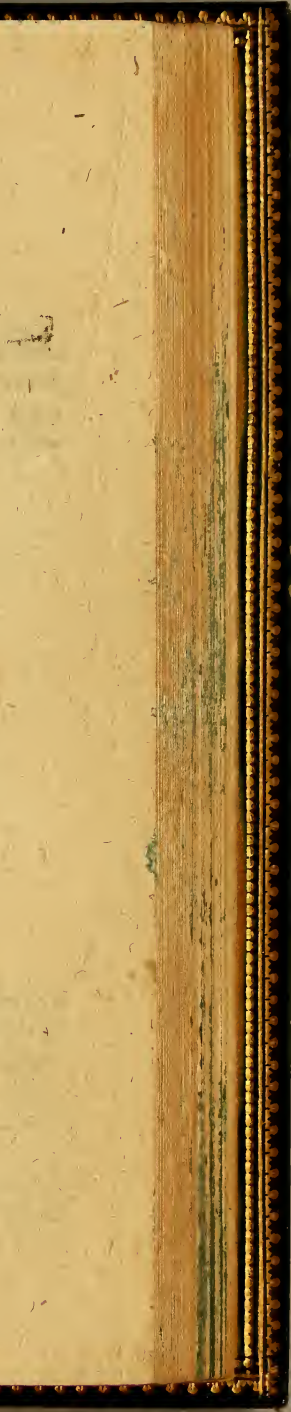




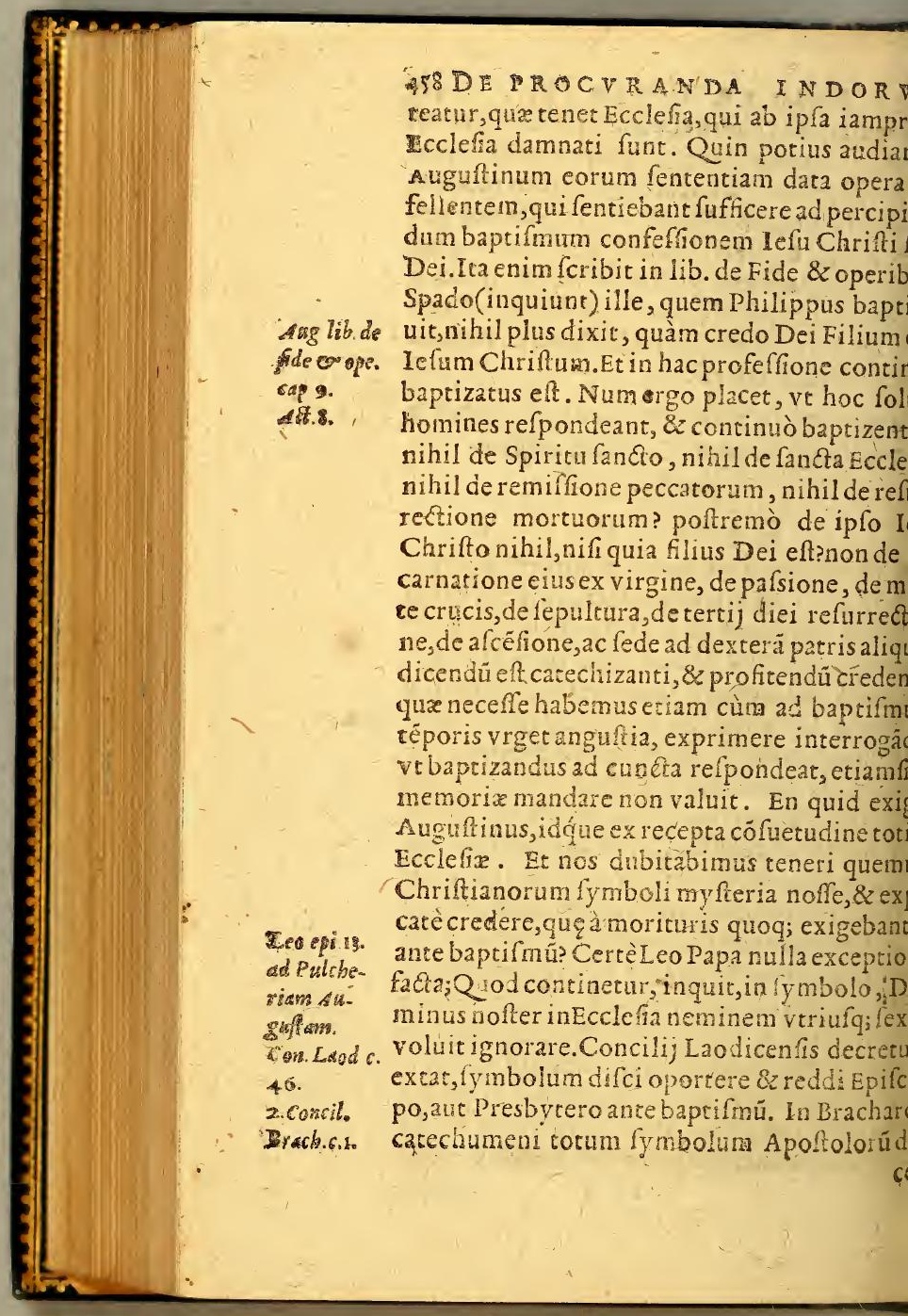


SA I V T E. LIBER V. ubentur. Sed notior reseft, quàm veteftimo quæ fuat plurima, indigeat. Igitur omnes fiani nemine excepto fidei capita, qua cóur in fymbolo, quảntum illorú captus fert, catè tenere diuina autoritate cogútur, qua friptôres quidam dosii nó doctè profectò ant, quorú de hoc diuino pracepto refellé t cohibendofententia, vix in op inionú nureferri poteft, cùm noftri $\&$ multitudine, coritate multis partib? fuperiores fint. Quo Tho 2.2.q. verò ea, qux cốmuniter pracipiuntur,pro- 2.art. 7 \% vrgétes aliquas cau fas excufari nónunquam $8 . \mathrm{Mag}$. in 4 . nt, non eft dubitandum, quin temporis an- di sof fho$x$, aut fenfus hebetudo, aut minus idonei do lafici ibi. s facultas, fepe imbecilliores excufet, fi nô in $3 \cdot d i f .2 g$. equaq; omniailla fidei myfteria norint. Si baptifmi percipiendi, itemq́; Eucharifiz ndæe, \& côféfsionis peccatorü Chriftiano ndæ, cùm iuris diuini præcepta fint,tamen f nonnunquá homo excufari, vel miniţro t5e, vel ipla materia, vel fua ip fus impotéloquendum, velalijseriam ex caufis, neq; $n$ fi voto $\&$ animo praftet quod poteft, cùm corde Deum quarat, excludetur à regno, profe 20 eft, cur quamuis diuinum de fide $i$ ipuis myferijs ab A poltolis traditis cogno dis, \& exprefsè profitendis praceptum fit, excufari \& abfolui non pofsint multi, quofenfustam éftexiguus, ve non vfquequaq; ciat, aut atas grauis, aut praceproris inopia, lind extrinfecus obiecum impedimentum. ue enim contemnet hos, qui fecit illos, quo. Sap. 6 . pufillum \&z magnum ipfe fecit, \&zqualifilli cura de omnibus, neque deerit Domi-

aนs

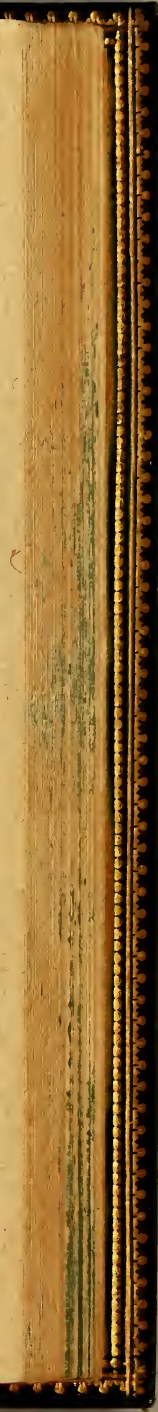




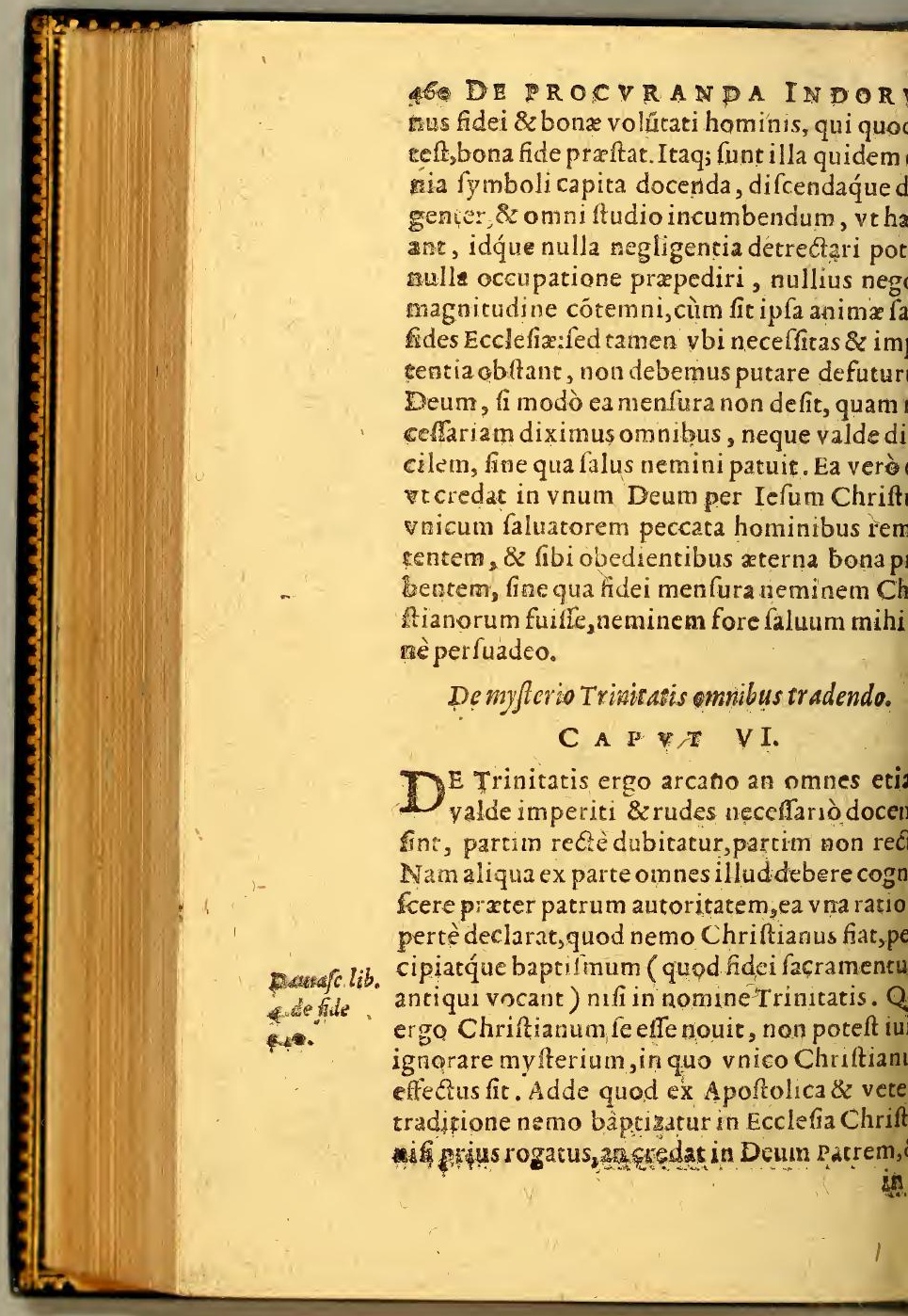


SAIVTI, IIBER V. 46I efum Chriftum Dei Filium, \& in Spirimm tum, refponderit firmiter fefe credere. Que uis ergo hebes fit, fi iudicij aliquid habet, $\mathcal{Z}$ ogatur, \& ita relpondet, prorlusqúue ita exsè credere iubetur. Namque implicitè $\&$ intè non ilthac folùm, fed quxcunque diuins a produnt, credit, de quibus tamen non om s interrogatúr, quod ea exprefsèfcire onilli minimè opus fit. Præterea càm nemo imperitus Chriftian $x$ difciplin $x$ fr, quin $8 z$ res cęteras fignare falutariter doctus fit in ine patris, \& Filij, \& Spiritus fandi, quomodo ei ignorare fas erit, quod quoridie dentat? Nihil ergoeft, cur propter Aethyopü rumue barbariem noum dogma cudatur, rinstate non necefiariò docenda, quod plurauioresque Theologi,\& Ecclefia ip fa, nilor, in Athanafij fy mbolo fatis redarguit. ubtile eft, inquiunt, myfterium, \& valdeféTbo. 2. 2. T. 2. Jcholafioi in $3.0 .25^{\circ}$ humanum excellens: iflorum verò fenfus eft obtulus, vt ne cogitare quidem Trinitaqueat. Primùm qui ita differunt, veliman le ifis cogitare poffe refpondeant. An prater s a definitos loquédi modos ex Ecclefiæ, \& logiæ regulis fumptos, quicquảamplius in Cublimi arcano Theologi noruntâNihilopiNam de me certus fum equidem.Quidenim endum, \& quomodo enunciandum fit, ruftiteratus præftat:quid porrò id fit, \& quomos gitandü, nihil propemodum inter vtrum intereft. Non ergo intelligentia, quæ valde orü eft,tanti myfterij, quã non tam lectione orum, quàm diuinitus luce perfufa mens ca- $A$ ug. $l i b .14$ it Auguftinus optimè docut, fed fimplicem de Trim. fynce- 


\section{DE PROCVRAN DA INDOR}

Aug li 14. fynceramq́ue Fidem poftulat fancta mater $\mathrm{E}$ de Trim. fia, à qua cur alienare quoluis homines del musomninonon video. Qiremadmodum en - facrificia olim offerebantur Deo pia populi grone, quorumtamen vim, \& fignification pauci admodum latis perciperent, \& nihilo nus à luis Dens ifla exigebar, quod in ijs, qua debant, a, quęnon videbant, protefabantur: planè in nouotefamento, vbicruentxabol funt vi@ima, \& vituli acceptiffimi süt labia fitentium Domino, vult profectò Detis fide fuos offerse, \&zcordis, \& oris confeffionem cundùn fpiritum Fidei, ve latrem, \& Filium Spiritum fanctum adorent, \& colant, quam quid ore proferant, quid mente credant, vix p rique percipiant: Nam \& ipfa Fides eftargun tum non apparentiun, quan etiam lacrifici Fbil.a. quodaniloco vocat Apoltolus. Sed premunt huc uonnulli hęc iṕa amplius. Trinicatis my rium in hoc effe arunt, vetres cituinæ perfonx vna eademq́ue efentia credantur. Atqui inue es quàmplurimos, qui neque quid fit diftinc perfonarum, neq; quid efentic vnitas cogit queant.Ego fanè talss effe nó in India \& Aech pia folum, fediu ipra Hifpanię, \& Italię cu Hofius lib. de Fitale c. 2 .

plurimos arbitror. Hos ergo excludenus ex n tia Trinitatis?Minimè vero. Quin potius doct fimi Cardinalis Hofrj, \& de Catholica Eccle optimè meriti fentétiâ, valde probo. Diftinet né, inquit, petfonarum \& vnitatem fubitant. fi qui funt rudiores, quâ vt compiehendere $p$ fint, non ef adeò necefrarium ad falutem om bus explicatè credere, ve fi quis minus hęc fue affecutus, decius falute dubiradum fic. Re prot 
4

SALVTE. LI BER V.
C piè. Namq; vt rudiores myferiútrifus ac piè. Namq; vt rudiores myfteriú Tri-
tis, quantum fatis eft, credant, fatis omnino llis, fi verè̀ credát in vnum Deum Patrem, \&z um, \& Spiritum Sanctum. Neq; opus eft ifta osè premere apud tales, qua fi fubtilius exantur, de fllorü exiguo fenfu elabuntur.Tet ergo vnum efre Deum omnipotétem, om$n$ rerum creatorem, teneant hunc effe $\mathrm{Pa}-$ 2, \& Filium, \& Spiritum farictum. Quod fi erea facultas fuppetat, doceri poffunt has efre diftinctas perfonas, \& aquales peromed Deumomnino vnum, propter vnameäque omnino fubftantiam. Quicquidenim oc myfrerio lenriendum elt, Ecclefia breuiofuit, Vt in perfonis proprietas, in efentia as, in malieftate adoretur rqualitas, ad qua Auguftinus confert omnia à fe difputata aindecim libros in ea epiftola, quam fcriEnodio, fed ficut religiola diligétia ifta pleponentium laudanda eft, ita improbanda undam importuna morofitas de diftinctioerfonarum, de vitate effentiz à rudiffimis inibus rationem extorquentiam, qua neq; prehendere faris póflunt, \& cùm vicumque prehendunt, penirus explicare non poffunt, ortè verbis conceptis memoriæe mădarine, Ivt in puerili atate non eft inutile, ita non um eft intimi fenfus indicium. Opus ergo tomnes doceantur credere in v num Deum em, \& Filium, \&z Spiritum fanctum, quemodum religio Chriftiana veneratur, idqúue dibusfatisef, \& pro eorum tenuitate non offibile.

\section{Aug. epipo.} 102.

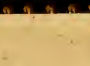

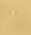




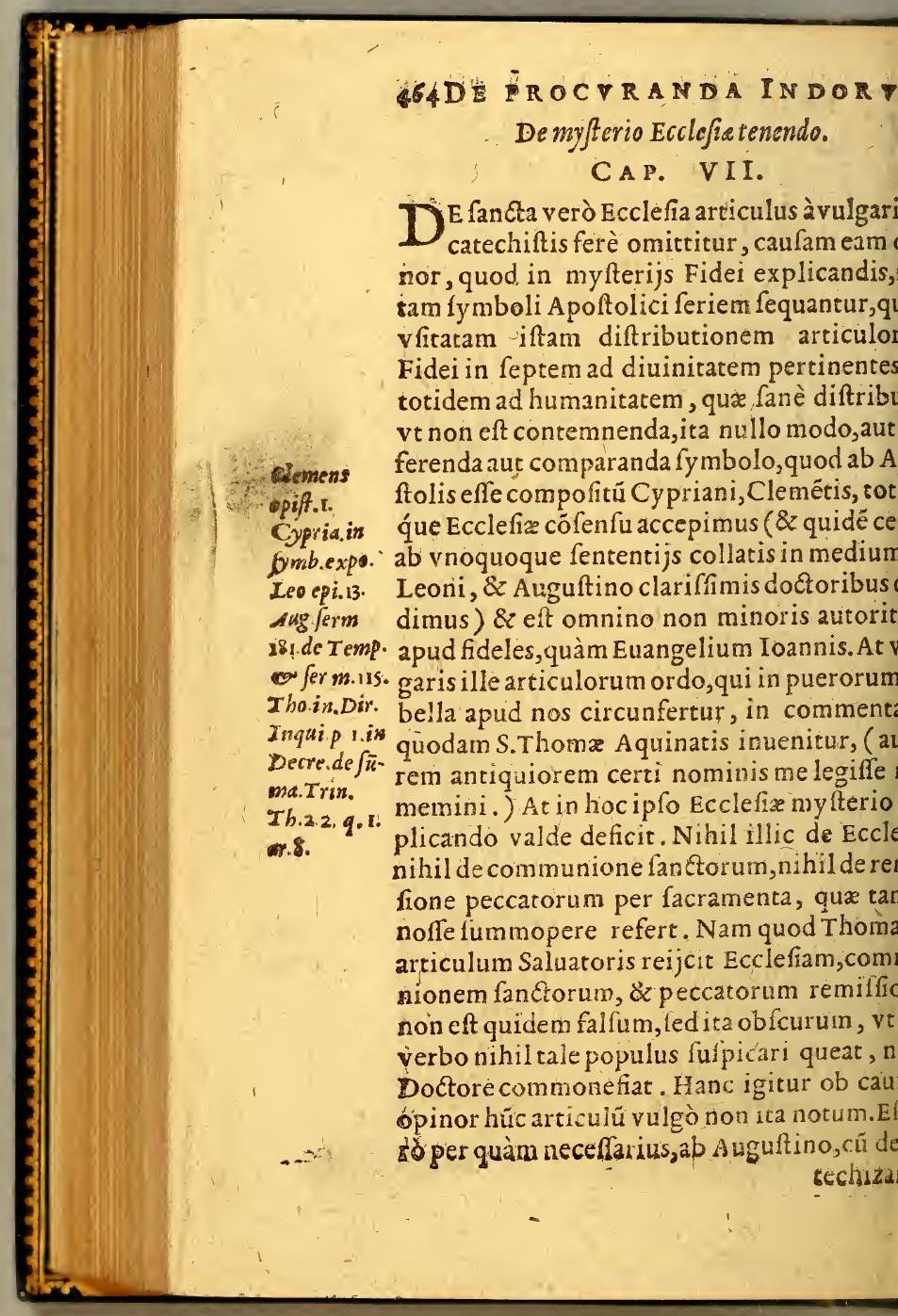




\section{S A L V T E. LI BER V.} iizandis rudibusagit, ac fxpè alıâs, vfque a. Auguft. Sepé commendatus, ve dicat lapius \& planiùs in contra Do. pturıs facris cie fancta Ecclefia, quàm de ip fo ratiftas. ifto prophetatum. Adde, quod ab hoc vno, $\sqrt{1}$ diffentiat Chriftianus, quamuis in cateris è labarur, Chriftianus effe non definet: huic fi fefe fubtrahat; Fidelis effe non poteft. Eft n Ecclefia Domus Dei viui, columna, \& firnentum veritatis. Doceantur ergo Indi de efia tria pracipuè.Primum, quid illa fit, con zatio certè hominum Chrifum, doftrinam Chrifi profitentium, non Hifpanorum, auc arorum, aut nationis, \& gentis cuiufdam nu$0, \&$ forte definita, omnia terrarum fparia, lestemporum fucceffiones cóplectens. Ho $c$ 1 eft aliud quàm iple populus Chruftianc,finguli enim, ve prxclarè Auguftinus dixit, Ang queft. fumus, \& partes Ecclefia, omnes verò fimul, Euang.lib. met mater Ecclefia. Huius verò caput effe c.p. 18. na.a vrbis Pontificem Petri fuccefforem, ifti vicarium, pleniffima ipfius in terris auitate pollentem, cuicxteri omnes Chriftia iam Reges, \& Principes pareant. Hoc eft Ecam Catholicam credere, 8 vniuerfalem.Sedum, hanceandem A poítolicam, \& fanctam Nimirum huius Ecclefia do frinam à Deo profectam, neque vnquam errate, errareue : quicumqque verò ab ea rec fferint, fine vlia itatione grauiffichè errare: praterea in hac effe falutem, vt nemo, qui abea alienus fir; us effe poffit, quocumque ille religionis no. eglorietur, itaque foli populo Chrifianopatere colorum aditum. In ea quogue licec imi reperiantur, peruerfis moribus, effeta$\mathrm{Gg}$

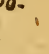

o.




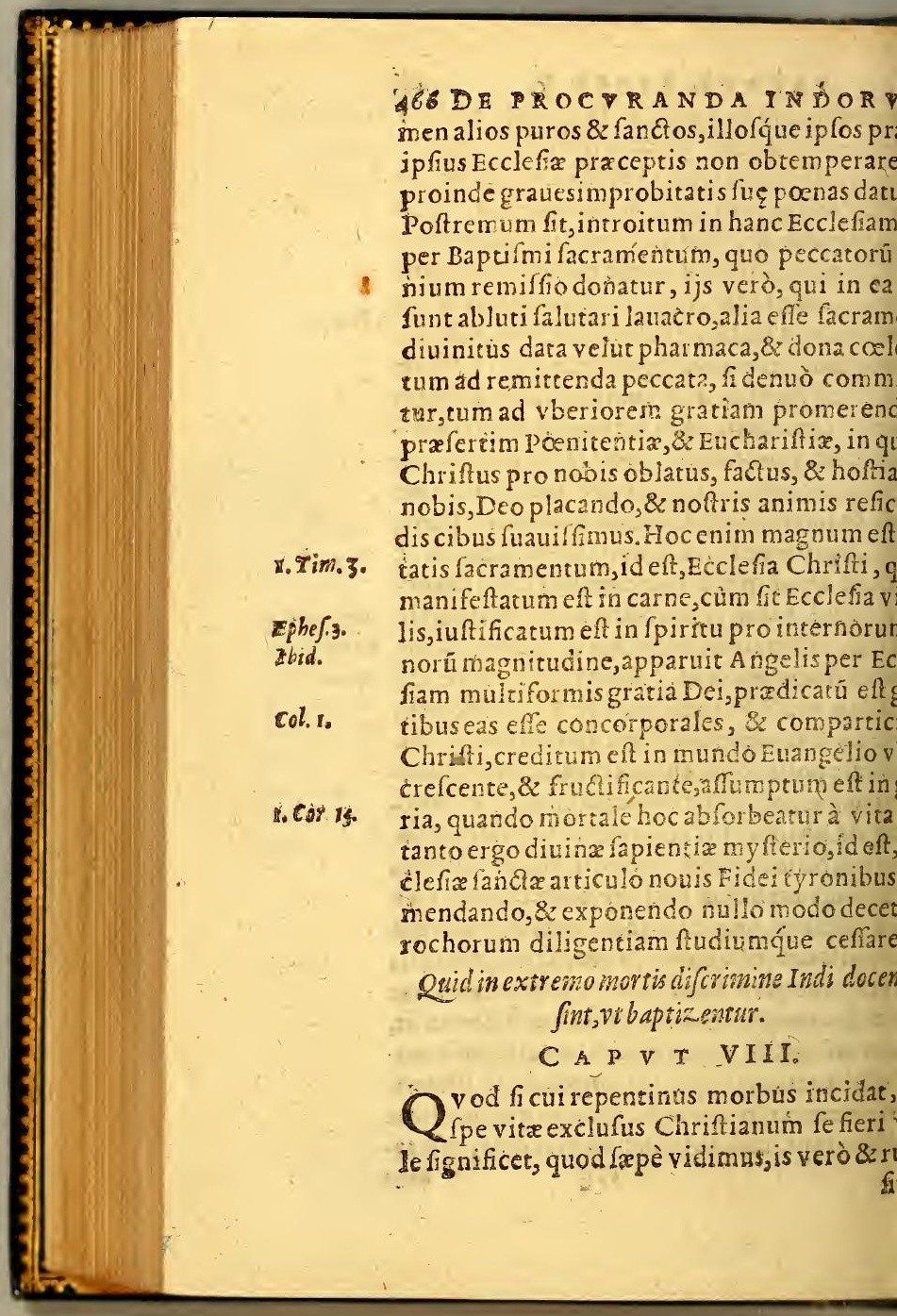


SALVTE, LIBER V.

itemporum impediatur anguftijs, ne Chri $1 x$ doctrinx rudithenta fatis accipere poffit, itò quaritur, quidnam fatis effe exiftimanfit, ve falutari lauacro perfundi poffit. Auin. quidem etiam in tanta temporis coarctaDe Fid. of opser.c.9. e, de omnibus fymboli articulis interrogari hominem, 8 fic baptizari, quod fanè in eo chumeno, qui aliquandiu res noftras audion eft difficile, vt rogatus, \& ore, \& corde ondeat. At fi rudis fit omnium, \&ad imbuenmora fit breuis, quid fit agendü adhuc quz, ne aut homini falutis aditus prxcludatur, aptifmus detur indigno. De qua re in fynorouinciali Limenfi decretum eit, ve quàm Synod. Lלेmen.6. $3 \frac{3}{3}$. t breuiffimè pracipua tantùm doceatur. rum primum eft, vtcredat in vium Deum em, \& Filium, \& Spiritum fanetum : fecun, hunc effe omnium creatorem, \& eundem iam bonis xternam preftantem in coelis, \&z s fupplicia fempiterna:tertium, à peccatis inem liberari nifi per Iefum Chriftum Dei m hominem factum, pafum, \& mortuum ter nos, hunc effe Dominum \& redempto. noftum, \& fpem vnicam, qui regnat glorio. coelis:quartum, Huius Iêfu Chrifti homifieri feruum per baptifmum, in quo omnia ata remittuntur, $8 z$ vita donatur aterna. Hęc poteft \& credat, \& confiteatur, roganduseft, rè præteritz vitz criminum poeniteat, pra èidololatriæ, \& an in pofterum velitrecte refecundùm Dei, \&̇Chritiani populi leges e pracepta.Si fe \& preterita dolere refpon;\& futura adimplere cupere ex animo, non fferédus, fed Chrifto ex aqua \& spiritu fan̈$\mathrm{Gg} 3$ atore

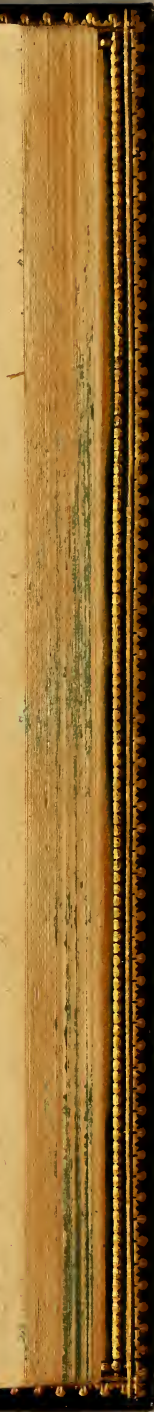




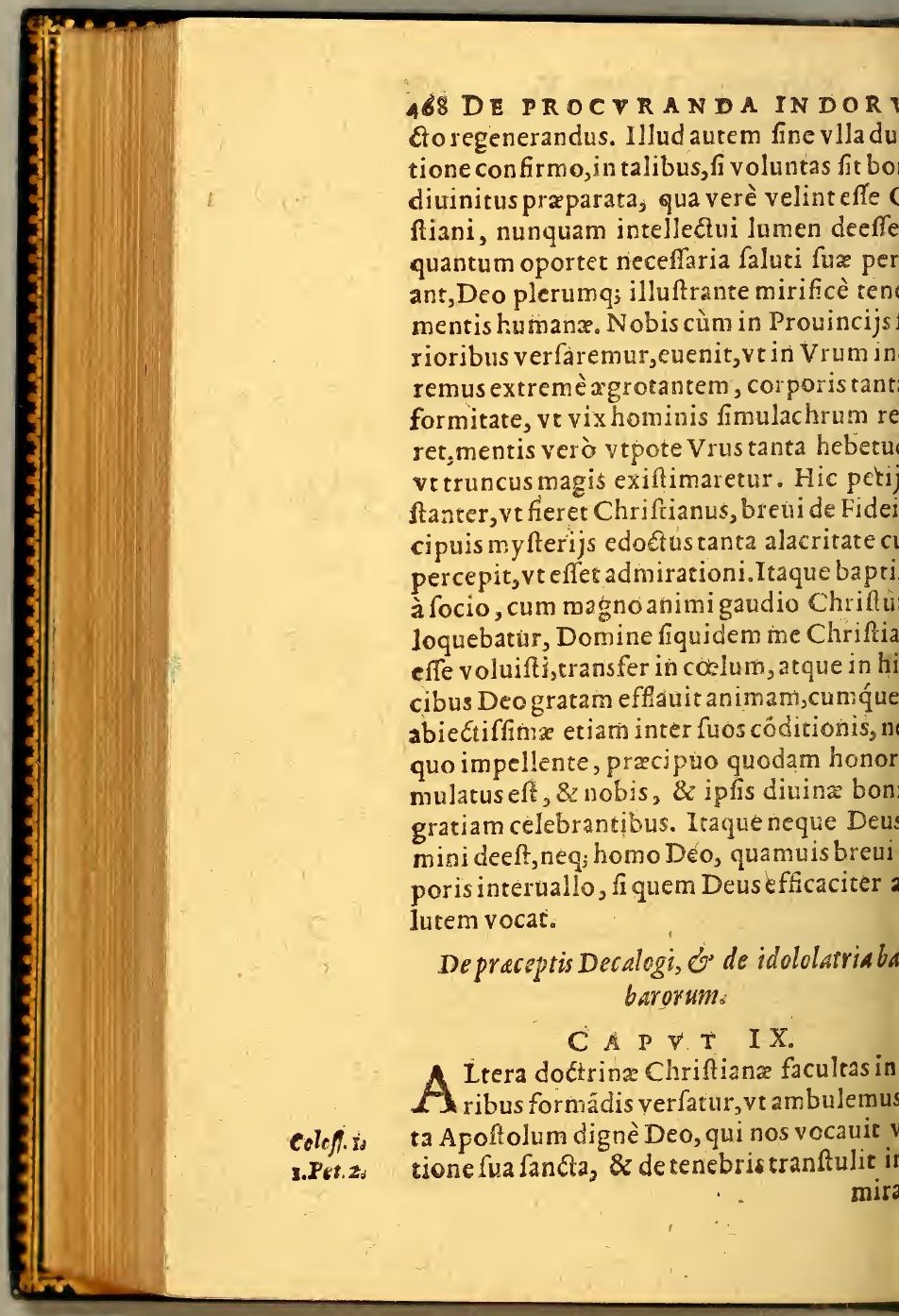




\section{SA LVTE. LIBER V.}

bile lumen fuum. Omnis autem vitx Chrix ratio ex charitate dependet, qua Deum 2us \& proximum, illum colentes, huncadius ve poffumus. Huc ergo fpectare debet omatechiftx noftri labor, ve Dei vnius verum $\mathrm{m}$, hominis quoque in hominem officia opuna perfuadeat. In primis nihil eft æquè landum, nihil tanti faciendum, quàm vtex 0 , aut iam facto Chriftiano omnis idololaamor \& fenfus penitus euellatur. Nã \& omea peftis perniciofiffima exiftit, cùm fit, ve Sap. 14a ens dixit, omnium malorum initium \& fieræ religioni omnibus modis obfiftens, $8 r$ eft in humana conditione miferabile, nulvirus ita intimis vifceribus hxret, cùm eft lebibitú, nulliusturpiter amantis in fcoruum tam infanusamor, quàm eft idolola$n$ idolum defixus an imus, Quamobrem for-Hierem. 2.' ionis meretricigque cuiufdam amoris no- Ezech.16. fcriptura facrá idololatriä frequenter no- ofe. 4 . uius cacum quemdam furorem, pertiña- Pfalios. ue contentionem multarum rerum comoratione demonftrat. Id quàm verè fit in is literis commendatum, noftri barbari fafe declarant. Nefcioequidem quibus vergnificem non tam imbutos, quàm in idoloim penitus transformatos iftorum animos, que in otio,neque in negotio, neque in pure, neque in priuata quicquam peragant, dolorum fuorum prius fuperftitione adhiNon latari in nuptijs, non lugere funus, pulum prabere aut accipere, non denique, edem efferre domo, aut operi manum adere fine facrilegiogentili. Vfque adeò Dia$\mathrm{Gg}$ 3. bolus

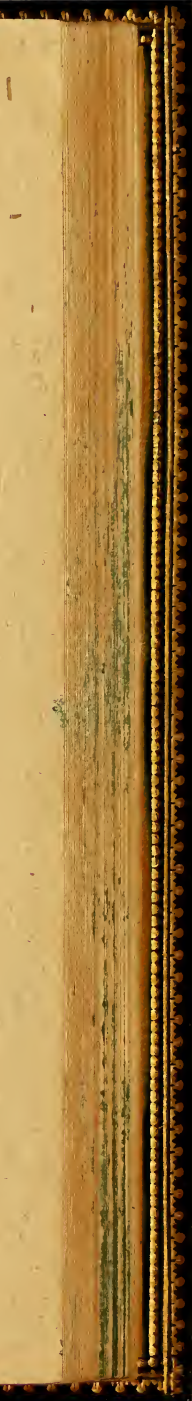




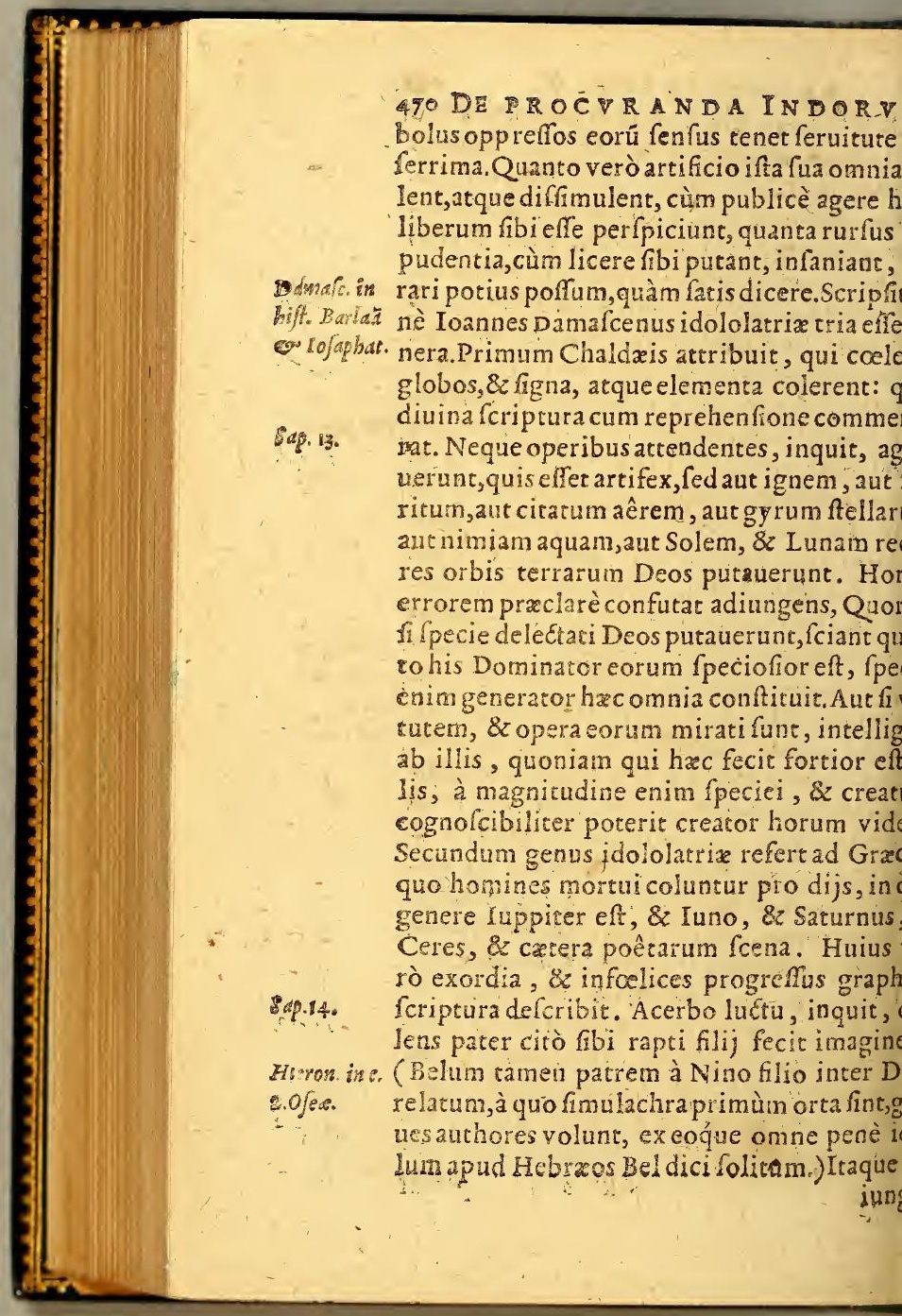


S A L T E. LIBER V.

sit, Et illum, qui tunc quafi homo mortuus at, nuac tanquam Deum colere cœpit, \& tituit inter feruos fuos facra, \& facrificia. ade interueniente tempore conualefcente ua confuetudine hic error tanquam le: cuitus eft, \& tyrannorum imperio colebanigmenta. Et poft pauca, multitudo autem inum abducta per fpeciem operis, eum, qui tempus tanquam homo honoracus fuerat, Deum æftimauerunt. Et hxc fuit vitæ hu$x$ deceptio, quoniam, aut affectui aut Re- Theologit $s$ deferuientes homines incommunicabimen lapidibus, \& lignis impofuerunt. Tergenus addit Damalcenus Aegyptix idolo$x$, qua non folum fidera, aut homines haur proDijs, fed animantia quoque fordivilia \& faxa ipfa, \& ligina fenfus expertia no honore afficiuntur. Nam \& bouem, \& um, \&z canem ipfum, atque mufellam, \& $\cos , \&$ lapides inter Deos retulerunt, Ofy \& Typhonem, \& Orum, \& mille alia comta fabulantes. Hoc totum idololatriæ genus iffimè infectatur Sapiens, Nam ybi men-Sap.18 em illorum fecit,qui folem, 8 fidera colue, fed adhuc, inquit, in his minor eft queInfelices verò funt, \&z inter mortuos fpes um eft, qui appellauerunt Deos opera ma$\mathrm{n}$ hominum aurum, \&zargentum, artis in. ionem, \& frmilitudinem animalium, aut lam inurilem opus manus antiquæ. Hos vea refellit: Non erubefcit loqui cum illo, qui anima eft, 8rprofanitate instrmum depre. Ibsidez r, \& provita rogat mortuum, in adiutorium. ilem inuocat, \& pro irinere perir ab eo, qui

$$
\mathrm{Gg} \& \text { ambu- }
$$

Ang lib. 22 ; contra Faus. fiumc.87. Nazianzorat. 2. de

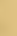




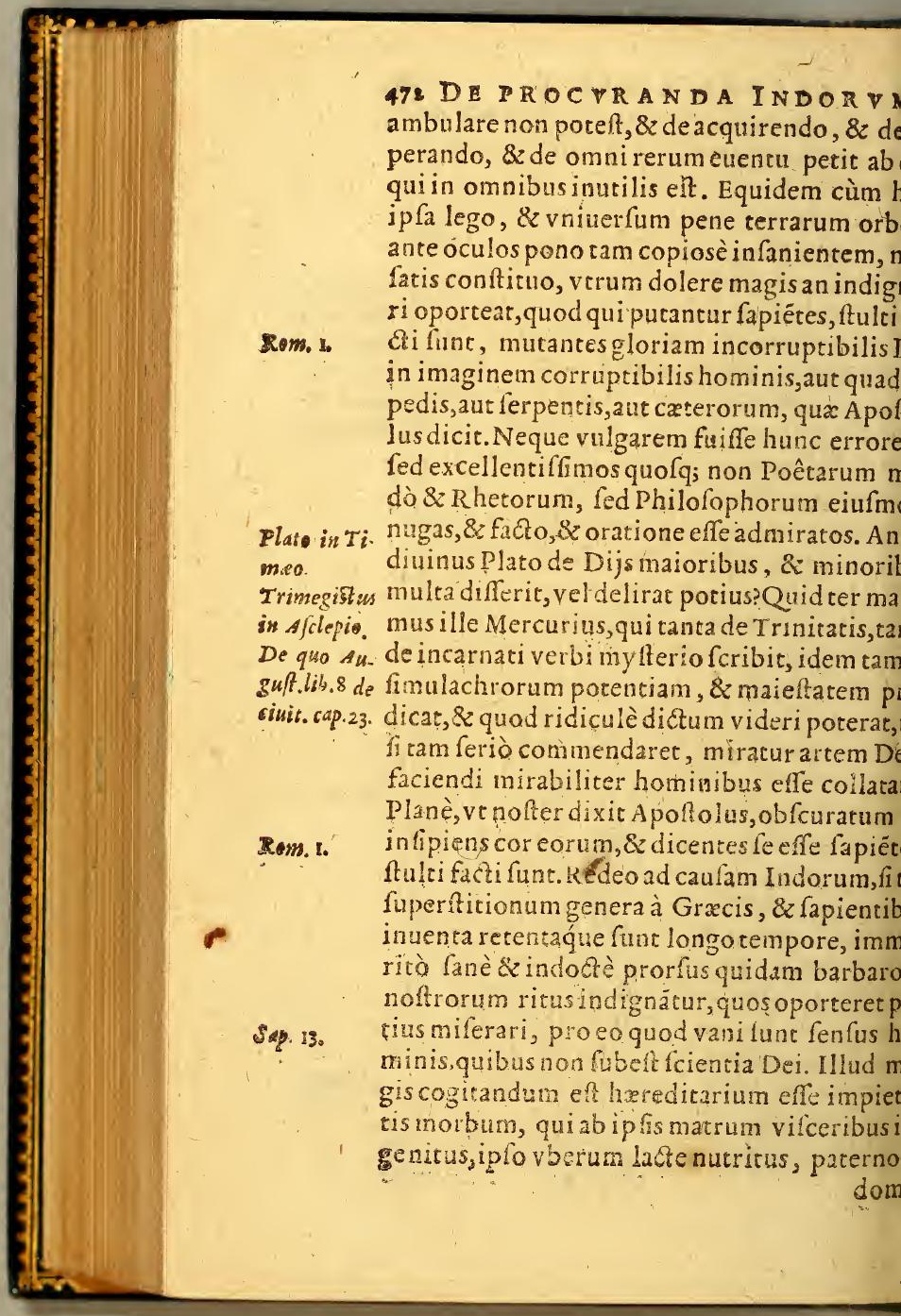


S A L V T E. L I BER V. neftico exemplo confirmatus, tum diuturna fuetudine $\&$ legum publica authoritate muus, nullo modo nifi copiofo Chriftianæ gramunere \& magna doctoris Euangelici, atque efeffa cura fanari queat. Quid igituraccufas barbarorum in idololatria deferenda tardim, \& cunctationem, cùm debeamus potius træe defidix iralci, qui pauca quædam, \& fria, contra Guacarum, \& Homorum fuperftinem fufurrantes, victoriam ftąim canimus, rorfus infecta. Hìc hîic ergo oportet catechin prudentem pedem figere, \& $2 \mathrm{~d}$ idololatrix imas fibras euellendas ex Indorũ animis omn cogitationem, indufriam,operamq́ue conre. Nam omnia à nobis eius genera commeratà apud barbaros vigent maximè. Solem dem noftri Peruenfes in honore primo hat, fecundum eum Tonitru, i!lum Punchaum, a Illapam vocitantes. Quillam quoq;, id eft, am, Cuillor, id eft, fidera, terram quoque $\mathrm{Pa}$ mamam, \& mare MamacochamChaldęorum re venerantur. Porrò Reges fuos homines ecipui nominis diuinitate donatos colunt, orum etiam corpora admiranda arte integra, viuida adhuc vfque confemant, ita primum ngocapam, \& Viracocham, \& Ingayupangü, Guaynacapam, \& cæteros fuos progenitores igiofiffimè ftatis feftis, \& facrificijs profeebantur, cùmeis ifta licerent, vt cum omni xcia ingenio certare poffent in conferuand 2 iorum fuorum memoria. lam verò quod ad ġyptiorú fuperftitionem atrinet, tä latè patet du noftros barbaros, ve prorfus enumerari neeant facrilegiorum genera, atque Guacarum, $\mathrm{Gg} 5$ fiue

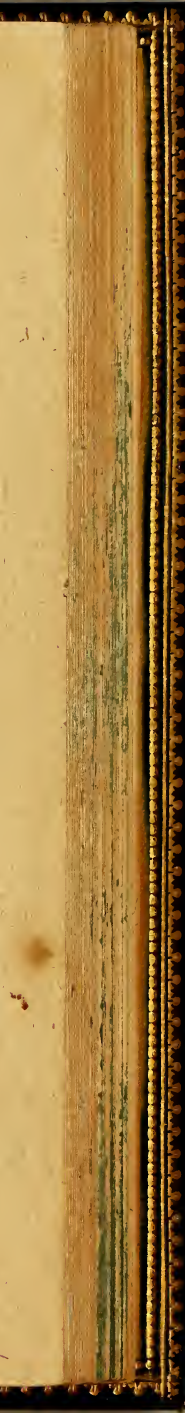




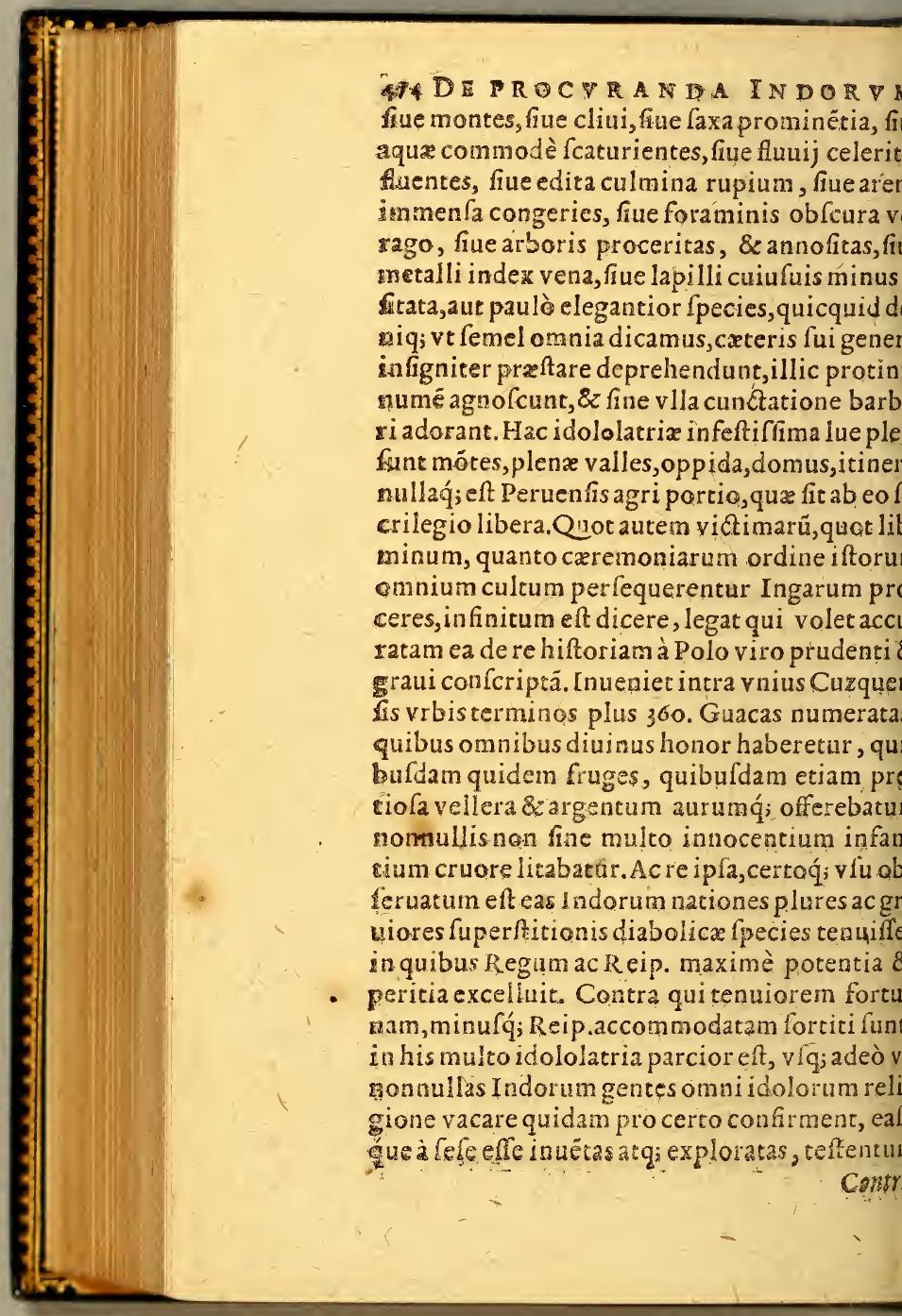


S A R TE. IIBER V.'

Contra idololatriamremedia.

$$
\text { C A P. } X \text {. }
$$

Vius verò curandi morbi illa plerifque noftrorum expedita ratio vifa eft, ve fimula\& Guacx, cæteraq́ue fuperftitionis Indicæ numenta inuenta quidem extorquerentur inis, atque ferro \& igne abolerentur, vt inueentur verò, fi fateri verbis Indi recufareat, beribus certè, vt proderent, effe agendum. $q$; hoc militaris modo turbæ inftitutum, fed Etiffimi, atque optimi cuiufque facerdotis reiofum confilium fuit. Quod planè, fi in no$o s$, id eft, iam baptifmo donatos tantùm defiatum effet, poterat certè ferri, tamerfi ita ea in peccetur quotidie, vt qui religionen Chrianam commendatam \& confirmatam volunt, ail aliud maximè agant, quàm vteam odion reddant, propterea quòd qux de manibus dorum idola eripiunturinuitis, ea in animis orum amplius in figuntur, verùm id in Chrianis non eft alienum à ratione ve fiat. In ijs rò qui Fidem Iefu Chrifti, neq; profeffi funt, q; fatis perceperunt, neq; verò edocti funt, cori per vim ante idololatriam auferre, quá fpon Euangelium fufcipiant, mihi certè cum graffrmis ac prudentiffm is viris nihil aliud vide r,quàm aditum Fidei Chrifianæ precludere, em maximè aperire cótendunt. Sxpe enim eit tum, \& eft etiam $f x p$ è dicendum Fidem effe lentium, neq; quemquam Chriftianum fieri bere per vim. Quamobrem praclarè Augurt. afmodi factü reprehendit, $8 z$ grauiffimè docet ius effe idola de cordibus paganorü auferēda, quนàm

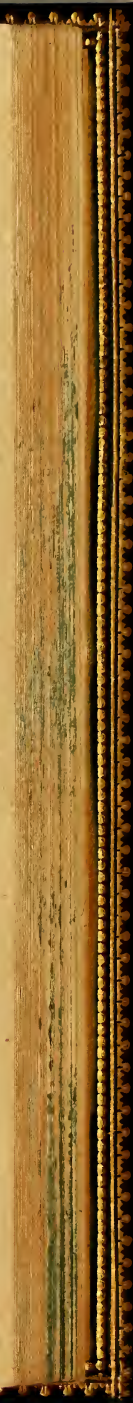




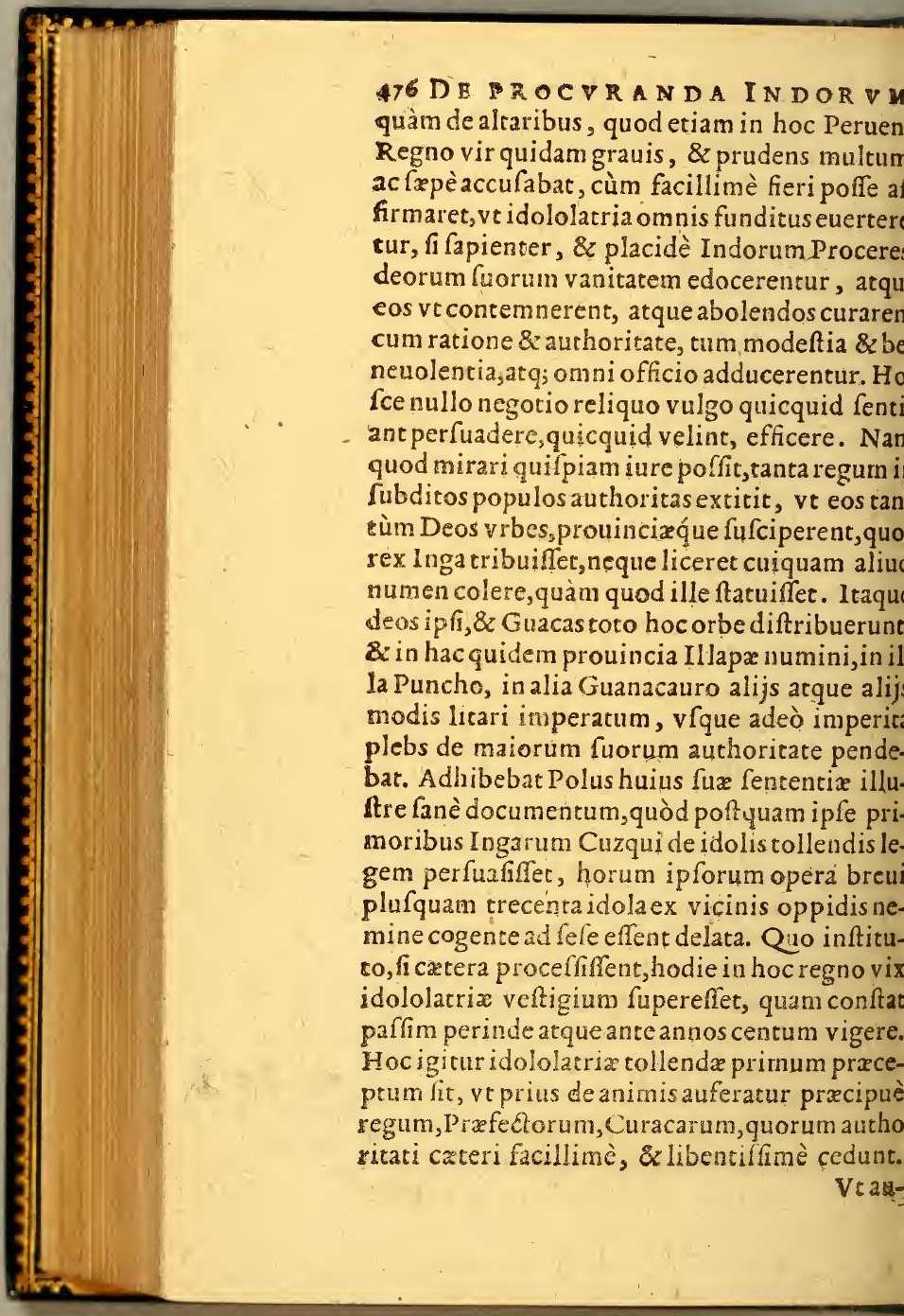


S A L V T E. IIBER V. $477^{\circ}$ tautem id nofter Catechifta perficiat, \& fimucrorum non folùm contemnendam vanita$m$, fed etiam execrandam peftem perfuadeat, n erit illi opus apud hofce barbaros exquifitis modum philofophicifque rationibus, neque ementis Alexandrini fromata, neque Theoriti Cyrenfis morborum Græcanicorum cutiones plurimi faciet.Sed breues, faciles, 8 ar oculos on nium pofitas obiectiones proferet, fque repetendo, exaggerando, auditorum iprum experientiam interrogando, in animis dorum infculpet. Argumenta huic rei idonea fquam melius \& plenius quàm in diuinis litc s, in fapientia prafertim Salomonis toto capidecimotertio, \& decimo quarto, \& in Ifaia opheta capit.44.8\&46.8 in Hieremia cap. demo. Pulcherrimè autem, \& ad vulgarem fen$\mathrm{m}$ accommodatiffimè in Propheta Baruch ido rum vanitas confutatur. N otum, inquit, fit $\nabla 0-B_{\text {aruch. }}$ caps $\delta$, quia non fune dij, nè ergo veneremini eos, $f_{i}-\sigma$. ir enim vas hominis confractum inutile efficir, tales funt dij eorum. Conftituris illis in doo, oculicorum pleni funt puluere à pedibus troeuntium. Lucernas autem accendunt illis, $x$ quibus nullam videre poffunt, funt autem fiat trabes in domo, nigra fiunt facies corum à mo, qui in domo fit. Supra corpus eorum, 8 per caput corum volant noctux, \& hirundies, \& aues etiam fimiliter \& cattæ. Vnde fciat is uia non funt dij. Si ceciderint in terram à feetip fis non confurgunt, ficut mortuis munera lorum apponuntur illis. Hoftias eorum venunt facerdotes $\&$ abutuntur. Vnde ergo vocanar dij.In domibus eorũ $f_{2 c e r d o t e s}$ fedent. Neq \&quid

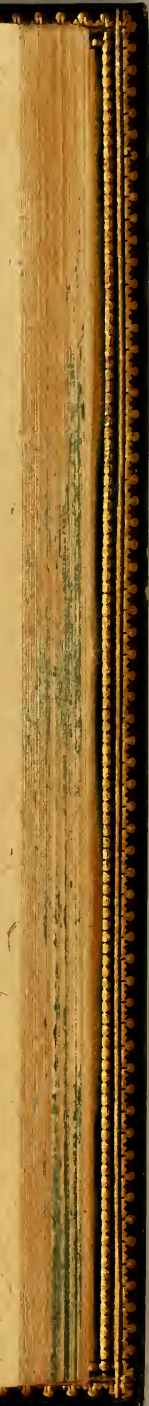


478 DE PROCVRANDA INDOR I fi quid mali patiuntur ab aliquo, neq; fi quid $b$ ni poterunt retribuere. Neq; regem conftitue poffunt, neq; auferre, fimiliter neq; dare diuiti poffunt, neq; retribuere. Si quis illis votum v uerit, \& non reddiderit, neq; hoc requirent. $H$ minemà morte non liberant, neq; infirmum potentiori eripiunt. Lapidibus de monte fimi! Sunt.Quomodo ergo æfitimandú eft eos effe dec A fabris \& aurificibus facta funt, nihil aliud er nifi id, quod volunt effe facerdores. Nunquid go pofiunt ca, qua ab ip fis fabricata funt, effe d Quomodo ergo fentiri debeat quod funt dij, q nec de bello fe eripiunt, neq; de malis fe liberâ si inciderit ignis in domum deorum, facerdot quidem ipforum fugient, \& liberabuntur, ip verò ficut crabes in medio comburentur. Qu modo ergo xfimandum, aut recipiendum quò funt dij? Non à furibus fe liberabunt, quibus in qui fortiores funt, \& reliqua. Tria ergo hinc a gumenta ad idololatriam confutandam caper poteft minifter Chrifti. Irimü ex natura $\&$ fub Stantia Deorum.Siquidem ligna,aut lapides, au metalla funt, quibus artis humana acceffit indu frria facerdotum auara prędicatione munita, ay regum violento imperio. Deos autem facere ho mines nequeunt, cum fint ip fis meliores rebus fe fabricatis.si idololatria circa coelefria, aut na turalia corpora verferur, fubftantia illorum fa cta, \&z motibus varijs fubiecta oftendi facilè po reft, quodà Dei natura alienum eft. Quod fi rege prifcosadorant homines barbari, eorum corpo ra nihil fentire, \& tabe iam confumpta docer poflunt, neq; à cxteris quicquam differre. Alte sú argुumentum eft ex impotentia \& ignorantia

Simu 
S A I V TE. LI BER V. nulachra quippe fe ipfa defendere nequeüt ab is, aur latronis, autruinæ iniuria, neque verò vident, aut fentiunt, aut mouere fe omnino flunt. Naturalia autem corpora nullo fuo arratu mouentur, fed leges fibi ab authore praas femper tenent. Tertium eft ab humanarum um prouicentia,quod præcipuum eft. Vbi ip. arbarorum experientia compungenda, $\&$ in dium producenda eft. V'trumne in morbo, aut lo, aut fame deorum fuorum vtilitatem aliam fenferint? Vtrum religiosè illos colentes, pro nihilo facientes melius habuerint? Quot quanta ma la perperf, neq̣; tamen à dijs adiuti, euatique fint. Ad hxc autem omnia plenius firmanda; quoniam fapèaliqua figna fenfus vocis in fimulachris apparent, interdum etminæ, \& præcepta exaudita, docendi funt bari, cùm res ita tulerit, diaboli ea omnia effe nmenta, tum verò quis diabolus fit, qui illits ellites damones, quid agant, qua illorum in mines inimicitix, \& fraudes, \& nequiria, vt lorem in horum porius odium conuertant. c enim commune apud omnes pene barbarros , vt Deum quidem omnium rerum fuprea m,ac fummè bonum fateantur, fpiritum vequorundam peruerforum non obfcura opifit, qui à noftris barbaris Zupay vocari fo. t. Igitur \& quis ille fummus idemq́ue femernus rerum omnium opifex, quem ip eta $n$ ignorantes colunt, \& quem nos annuntiais, per omnia doceri debent, mox quan$\mathrm{m}$ abillo illiufque fidelibus miniftris Angeabfint gens peffima cacodamonum, ho inum generi infeftiffima, accuratè \& dilu-

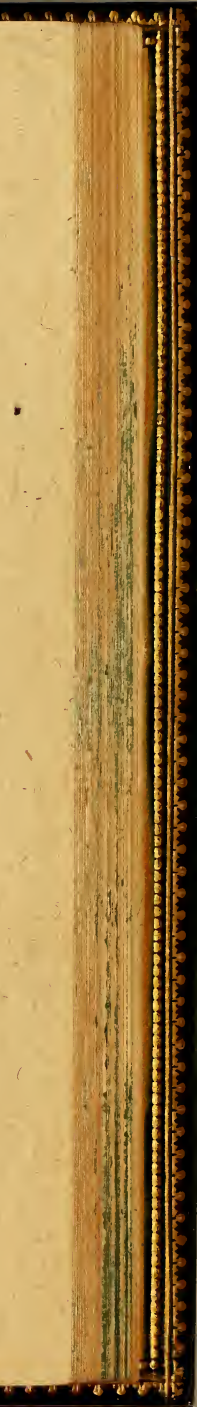




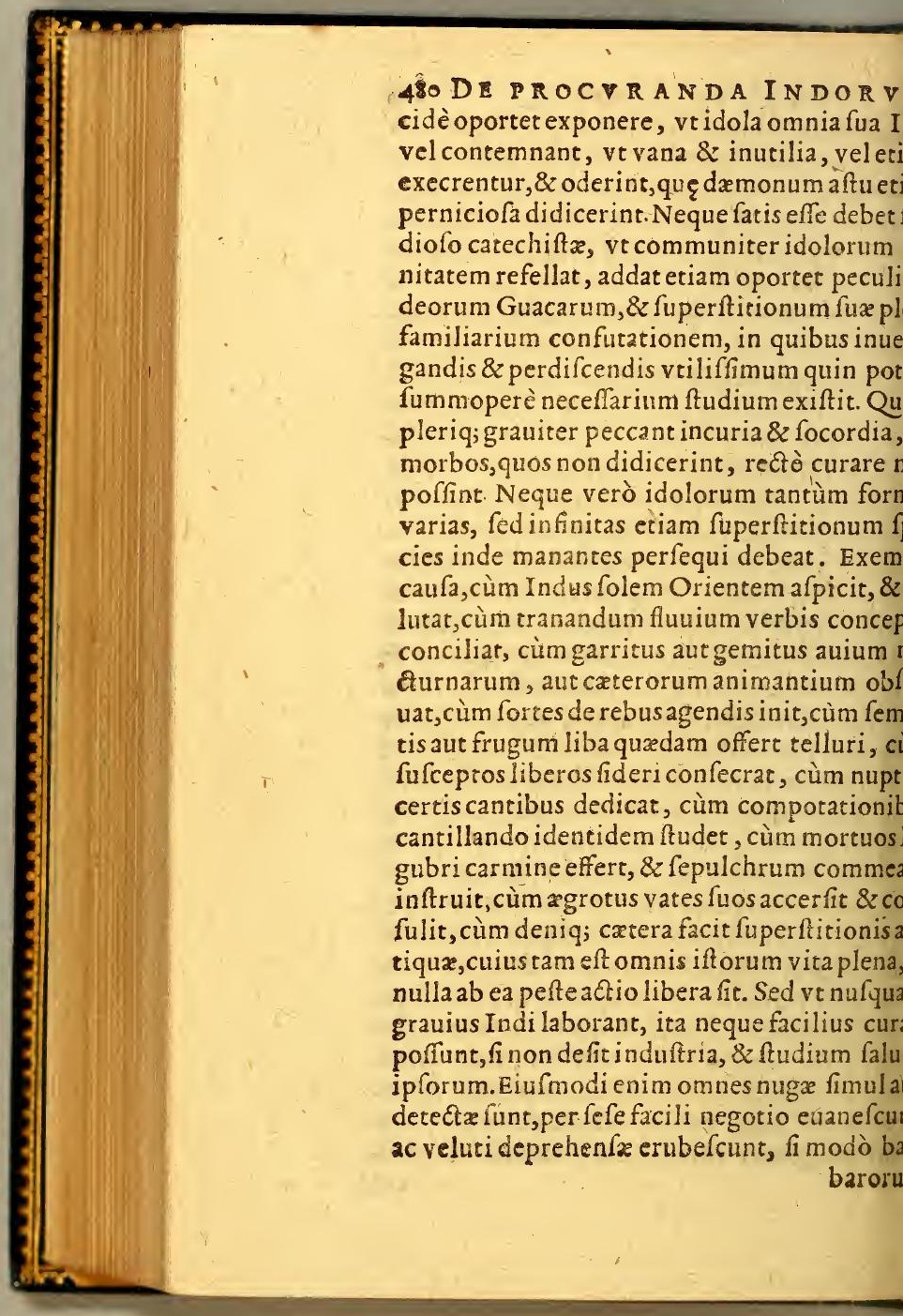




\section{SALVTE. LIBER V. $48 \pi$} orum præfectorum, maiorumq́; fuorum $2 u$ ritas compefcatur. In confeffionibus verò iendis omni cura incumbendum eft, vt hxc nia minute ac figillatim, vbi opuseft, facerinterroget poenitentem, \& confeffum doatque deterreat. Ferè quia negliguntur, ocint: eadem adhibitæ curationi non difficilè int.

De euertendis idolorum fignis ơ templis.

$$
\text { C A P. XI. }
$$

Vamuis autem prima effe cura debeat fa. cerdotis, vt idola de auditorum cordibus auntur, idq́ue docendo \& exhortando maximè tamen vt de oculis quoque atque vfu remotur, nullo modo negligendum eft.Q. a in re Deut.7. $n x$ hiftorix illuftria \&z documenta, \& facta 12. onunt. Aras, inquit, eorum deftruite lucof-3. Reg. Is. fuccidite. In quo genere mirificè $A f_{2} \&$ lo- $4 . R_{\text {eg }} 23$. celebrat facra hiftoria, quin etiam ab Eze $2 . P d r i 4.0$ rege Moylis ferpentem illum æneum con- 34 . fum cum non parua laude commemorat, 11 \% 4 . Reg, 1 . rgo, \& facerdotes, \& principes fludiosè cudebent, vt idololatria omnisetiam lufpicio eatur. Quod duobus modis rectè \&z ordine ₹ lecundum Chriftiana legis difciplinam. ùm in ipfisiam Chriftianis, qui baptifmo uff funt, in quibus gentilitiz fuperpitionis umentum aliquod ferrı minimè debet, fed olatria fpecies omnistum acriter infectandeprehendatur admifá, tum præcauenda di nter omnibus illius fignis fublatis. Hoc Au- Serm o. de inus, \& à fe factum com meinorat, \& fieri de verb. Domì demonftrat. Hoc cuiufdam Concilij Canon $n i$ Ang. $\mathrm{Hh}$ difertè

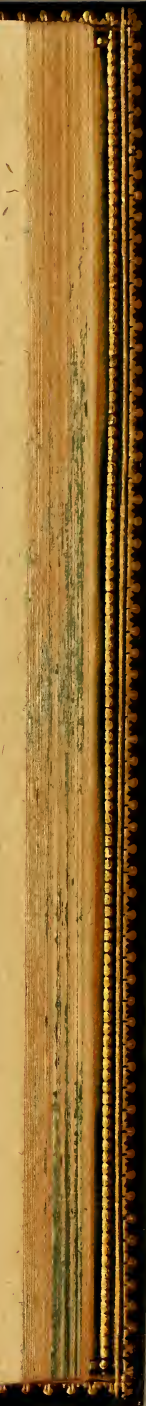




\section{4? DE PROC RANDA INDOR}

Comill.Nak- difertè precipit illis verbis, fummo decert netenfe sa. debent ftudio Epifcopi \& eorum miniftri, vt 20. bores dxmonibus confecratx, quas vulgus co $8 z$ in tanta veneratione habet, vt nec ramum, 1 furculum inde audeat amputare, radicitus ex dảntur atq; comburantur. Lapidies quoque, q in ruinofis locisatg; fylueftribus damonam dificationibus decepti venerantur, vbi \& v vouent, \& deferunt, funditus effodiantùr, atq tali loco proijciantur, vbi nunquam à cuito bus fuis venerari poffint. Etomnibus adnunt tur, quantum fcelus fit idololarria, \& qui hre neratur, \& colit, quafi Deum fuú negat, \& $\mathrm{Ch}$ fíanieati abrenuntiat, $8 x$ talem pocnicenti: debet fufcipere, quafi idola adoraffet, omnibu interdicatur, ve nulles votum faciat, aut canc lam, vel a liq̨uod munus pro falute fua rogatur alibi deferat; nifi ad Ecclefiam Domino Deo fi \& catera. Quem canonem libëter recitaui,qu videam in eius generis ritibus, 8 moltum Ind iam baptizatos labi, \& parum à facerdotibus al maduerti. Non folùm ergo fimulachra ipfa,

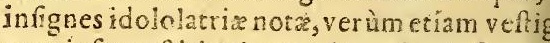
quaru is fuperfitionis veteris eradenda funt. A que eam ad rem imperio, $\&$ anthoritate, fi op fit, vtendum erit.Ethac ad Chrinianos Ecclef filios. Ad infideles verò quid’prorfus diftingu da caufa eft.Si enim ita fuos ritus, \& caremoni agunt, vt fidelibus fcandalo non fint, fed vnu quifq; lege fna viuere facilè fnnatur, permittei di funt cacitati fure v fque dum ab altiff mo illi

2.Cor.s. minerrur. Huc enim pertinet illud. Eos qui f ris funt, Deus iudicabit. Quod fi Ecclefia princ pibus fubfunt, \& Chriftanis hominibus fcar 


\section{SALVTE. LIBER V.}

funt, profeclò tolerandi non funt. Quo in Be B. Augufitinus laudat Conftantini magni $s$, quibus Paganorum templa claufte, \& idola xit, jitemq́ue Ambrofusaduerfus Symman vrbis prafectum, Fortuna aram à Curia ana eiećtam magnis viribus eloquentixe deit. Concilium quoque Eliberinum, vedoferuorum idola comminuant, edicit.Atque nodo in fubditis infidelibus, cùm præferouis fidelibus nocent paganici ritus, atque latria per poteftatem auferri \& poteft, \& $t$, nifi maiora inde incommoda, \& cumultus equi fapiens adminiftrator iudicarit. Sed lummoperè curandum eft, vt pro noxijs us falutares introducantur, \& cxremonijs nonix obliterentur. Itaque \& aqua benevfum, \& imaginum, \& rofariorum, \& gram, \& cercorum, \& palmarum, \& cateroquaz Ecclefia fanct a probat ac frequentat; hytis perquàm opportunum effe fibi perant facerdotes, atque ea omnia in concioniopularibus mulcis laudibus profequantur, o vereri fuperthitione nouis religiofifó; fimbutos affiefaciant. Ita fiet, vt melioribus elegantioribus occupati obfoletam fecta perftitionem de manibus ac de mente det.

\section{Derectadileatione fui:}

\section{A P. XII.}

It Dei veri cultú traditum, fupereft, vt promi dilectio explicetur. Eft verò vnicuique mus diligëdus, frcut ipfe fibi. Se autem ipemo, vt oportet, diligit, qui animi corpo-

Hh 2 rifóque

Aug epif. 48.ad Vincent. Amb.lib.s. epiff. 31.ad $V$ alentinia. num Auguff. Corc. Elik. G. 41.

\section{6.}

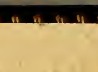




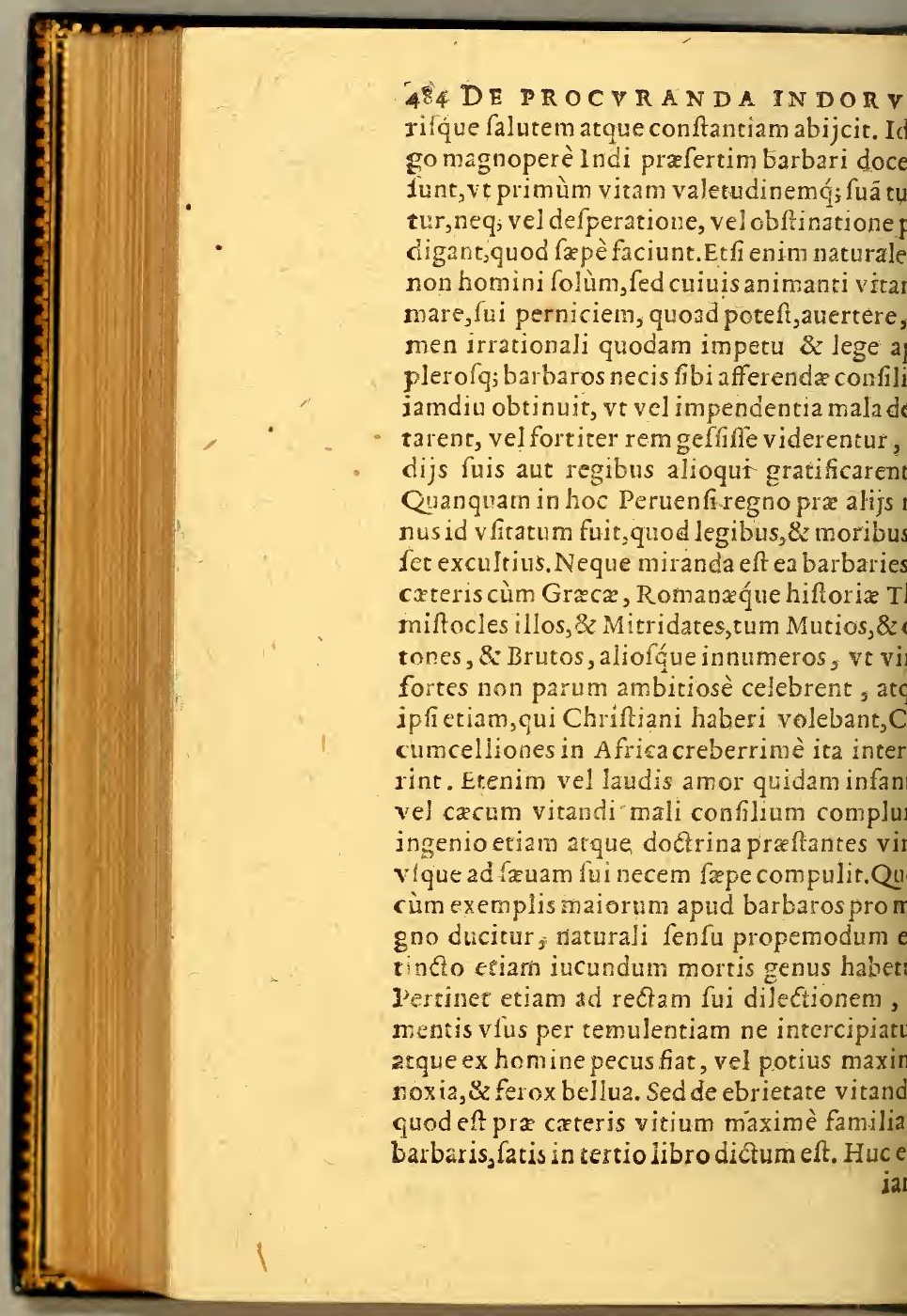


SA L V TE. LIBER V. 488 pertinet, humanarum carnium efus, in quo tam defuncto homini, qui nihil aut fenfus loloris capit, quàm ipfi humanæ naturæ infit. Idenim naturali legi ita repugnat, vt a, quantum ego fentio, famis inopiaue caufa Victorid res' e poffit. Affentior enim doctiffimo Theolo- ledt de tem: a fentienti,quanquam alij aliter fapiant.Gé-perantia $n$. utem hoc vitij apud Indos Carybes dictos, 500 fed es funt Brafilienfes, \& Chunchi, \& Chiri- Caict. 80 enfes, \&z alij plerique in vfu \&z pretio habi- $\begin{gathered}\text { Abr fentiunt. } \\ \text { tenti- }\end{gathered}$ facrofanetx literæ grauiter auerfantur, qux sap. 12. res illos idolorum adoratoresinter catera um accufant, tanquam humanorum vifcecomeftores. Philofophia quoque ferinum e docer a pud Arifotelem, qui eiufmadi fa- Arifot. $\%^{\circ}$ inter extrema opprobria actionum huma-Etbic.c. so m numerandum putat. Quare vt feminis unifundendi honefta caula effe non potet io corporis, nifi alioqui matrimonio legi, etiam fi ex eiufmodi humore coacto inis confequatur, ita profeclò neque ex hucadauere epulas quantacunque famis dendæ necelfitas iuftas effe permittet. Ad nunis quoque natura dilectionem fpectat, fundtorum corpora non violentur, atque ne fepulchra quidem effodiantur, in quod tiæ, \& inhumanitatis genus leges impera, \& Pontificia acerbè animaduertunt, "\& conc. Tol.4" c regno Concilio Limenfi feuerè admo- c. 45 . noftrorum hominum licentia coercetur. Con Meldes: $m$ in quo réctam fui dilectionem barbari $c .72$. dunt maximè, minimeq́ue id putant, illud Conc. Lim. lod ab A poftolo Paulo vno verbo luculen- cap. 113. t dictum, quòd contumelijs afficiunt car- Rom. bo $\mathrm{Hh} 3$ pora

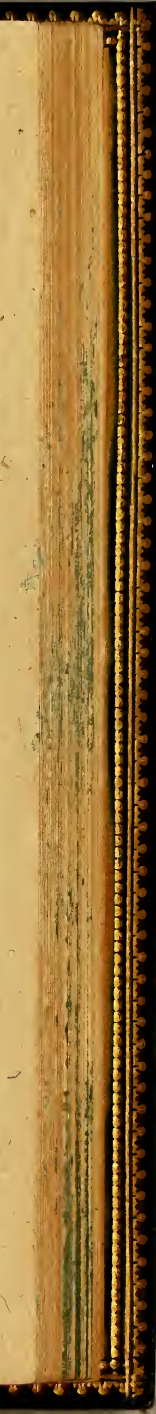


486 DE PROCVRANDA INDQR VM pora fua.Ita enim omnes impudicitiz \& libid nis prapoftera fordesexpofirt. Atque eftill quoque ab eodem veriffimè oftenfum idolol tria fcelus omnia flag:tia ftatim confequi, ta 3ap. i4. quam riuulos primum fontem, quod elt à Sapi te fapienter etiamanimaduerfum. In hoc gene funt concubitus cum maribus, cum befijs, $\mathrm{cu}$ ipfis lignis, inceftuof amplexuscum fororibu cum matribus, cum filijs apud quofdam barb ros non concelfi folù $m$, fed interdum lege fanc ri. Noltros Ingas non nifi fororem legitimo fi coniugio copulare folitos conftat, ex quibus d ad fidem conuerfi \& baptizati in antiquo mat monio permaniere à prafule quodam permi feruncur, factumć; Paulum quartum Pont. ma grauiffmè culiffe, verbifque feueriffmis obiu gaffe fama eft. Verè̀ Sapiente fcriptum eft, In S.p. tium fornicationis eft exquifitio idolorum, adinuentioillorum corruptio virz eft. Et po nonnulla:Neg; vitam,-neq; nuptias mundas ial cuftodiunt, fedaliusalium per inuidiam occ dit, aut adulterans contriftat: 82 omnia commix ta funt, fanguis, hómicidium, furtín $8 x$ fictio, co ruptio \& infidelizas, \& catera, inter qua natiu tatis immutatio, iuptiarum inconfantia, ino dinatio moechir, \& impudiciria. Infandorume nim idolorum cultura omnis mali caufa eft, initum, \& finis. Hxc Sapiens. Qux omnia carn flagitia à carechifa affiduè \& grauiter in lecta dafunt, \& fenerius cum violacoribus legis nat ralis agendum. Inter ea verò fornicationem, qu ferègentes licere putant, multis modis legi $D$ \&z natura ipfi contrariam docere debent, atq; perfuadeanc, non doldm facra auchóritates pro ferenda 
SALVTE. LIBER V. AE end $x$, verùm etiam humana argumenta, quxe erunt: illudque præcipuè ab opinione iftorenouendum, ve foeminas rion ante matrinio fibi iungendas arbicrentur, quàm in fos periculum fecerint, qua ex caufa concubiprius penes fe retinent, quàm ealdem ducant res. Quin etram adeò virginitas vilis eit foeis, vt opprobrio propemodum detur, fi qua huptias nondum corrupta perueniat, tan$m$ fui amatorem antea inuenire nequiuerit. atque id genus alia barbaricæ fultitie mondiligenter $a b$ hominum fenfu, \& vitz vfu ad liceat releganda funt, $\&$ docendiomniorbari, vt fe iplos, fenfum, corpulque fuum gere \& conferuare congruenter natura dif.

Dedilectione proximi,

\title{
CAP. XIII.
}

Zoximumeft, vt qui fe rećtè diligit, fratrem uoq; vt fe ipfum diligat. Quod lanè fit duomodis. Vno, vt ne cui omnino nocear, fue $v i$ corpulá; lædendo, frue vxorem violando, $\sqrt{1-}$ ortunas contrectando, fiue exiftimationem ionemq́ue imminuendo, quibis proximus e aut verboladitur. Et ve fit perfecta iuftquibus perpetrandis abitinet, $a b$ ijfdem etper libidinem affectandis fefe cohibeat. Hoquippe omnium lex nacuraliter hominum rta atq; impreffa aniniseft. Vt quod tibi ab Matth. \% fieri nolis, id in alterum ipfe ne facias. Alte- $T o b .4$. uoque modo diligimus proximum, cùm non lò non lædimus, verùm etiam opportunè admus atque adfumus. A tque hîc planè omnia $\mathrm{Hh}^{-4}$

Chriftiz-

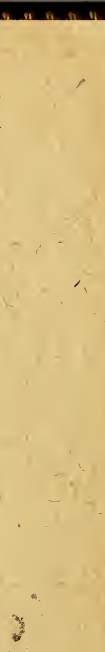




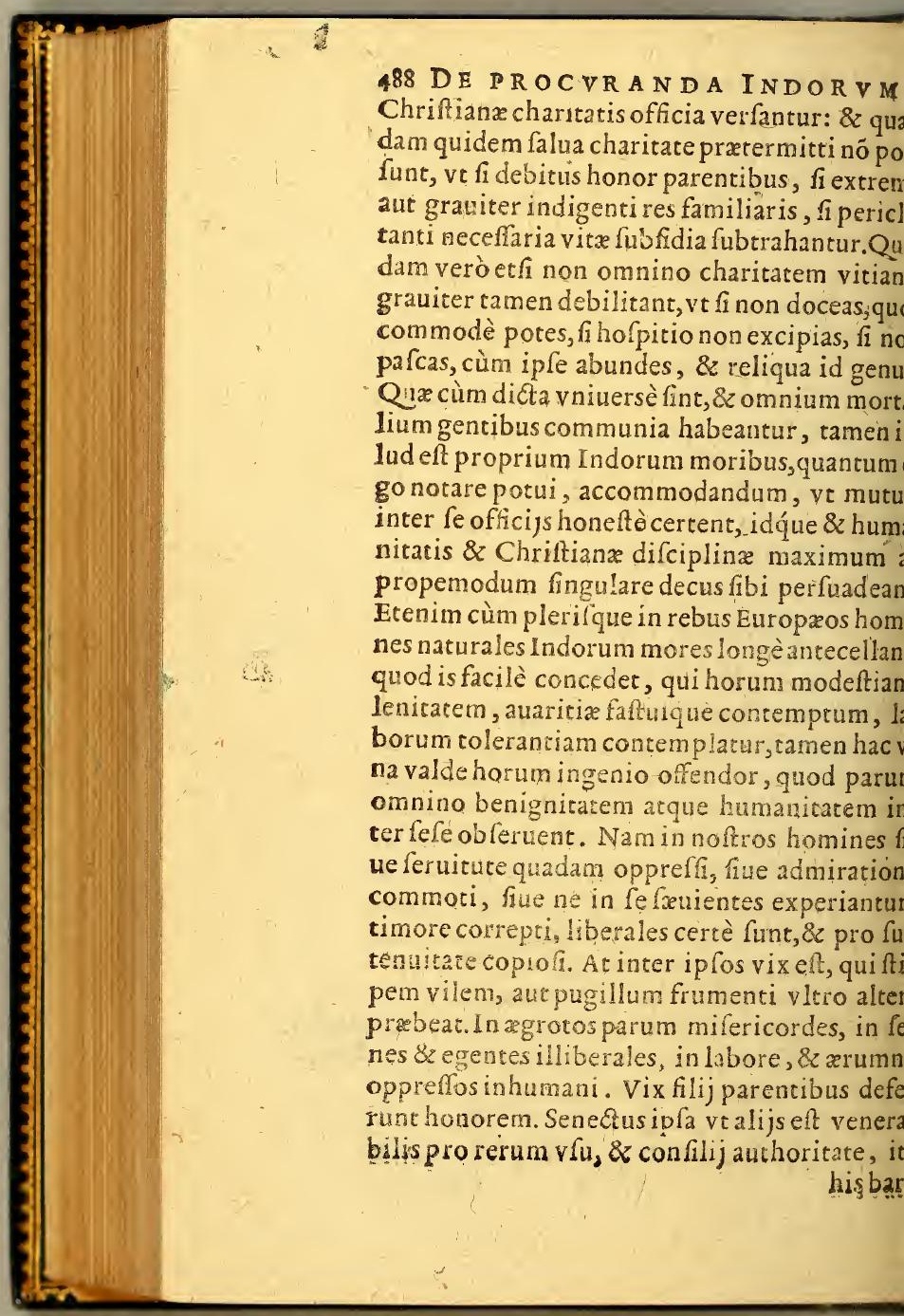


S A L V T E. I I BER V. 489 arbaris vulgo faltidio, \&z opprobrio habeitaque plerique fenesatque anus, quoniam entand $x$ vitæ rationem inueniunt nullam, bus deftituti, \& ab alijs contempti, eam pomum ineunt, vt fortibus, augurijs, diuinaibus, veneficijs ftipem colligant, \& fuam acæteros opinionem tueantur. Obferuatum viris valdè prudentibus nullos effe in naIndorum iftarum fuperftitionum artifi\& architectos, nifi hominesabiectos, in$s$, decrepitos, qui omnibus alijs rebus exclueas fe artes vulgò conuertunt. $\mathrm{Ob}$ feruatum $\mathrm{m}$ parentes filijs in nullo efle pretio fi indint,agrotis nihil ferè opis adferri: defunctis Ita prodigi, quæ fi viuis concederentur, diueffent in vita retinendi. In noftris verò niperinde barbari fufpiciunt, \&admirantur, il æquè apud fe commemorant, \& laudibus unt, atque mutuam beneficentiam, \& libetatem, cùm prafertim eam ad fefe redundaerfpexerint. Verum eft enim Saluatoris elom:In hoc cognofcent homines, quòd difci-Iod\%.14 i mei eftis, fidiledtionem habueritis adıuia. Hanc ergo Chriftianæ charitatis partem, e in beneficentia fita ef, excolendam atque ftrandam, \&z verbis, \& factis fibı præcipuè utare debet minifter Chrifti. Et certè difat barbari humanitatem, difcunt mores fuares, difcunt effufam etiam in fuos liberalita. $\mathrm{m}$, fi diligenter $\&$ crebrò ea de re commo-i nefiant, \& exhortationibus facerdotum paria exempla non defint.

Hb S De

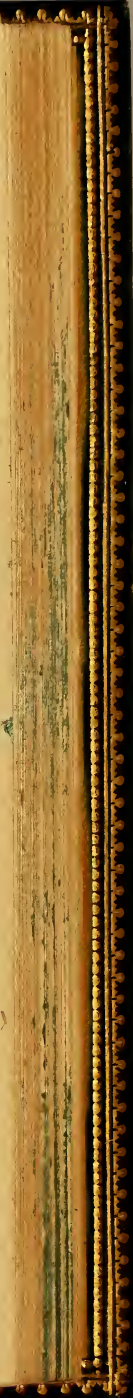




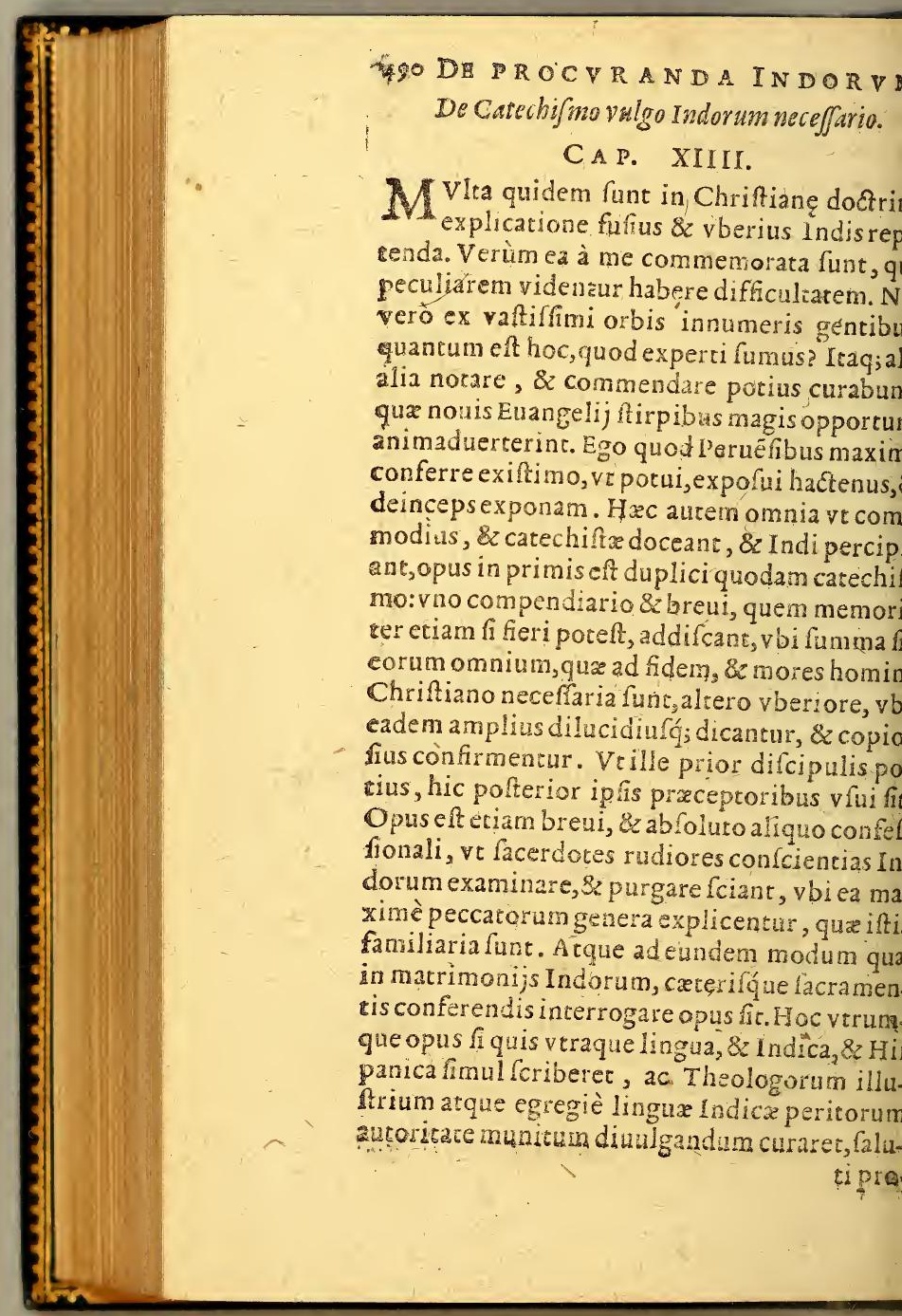


\$ALVTE. LIBER V. rofectò vniuerfæ Reip. Indicæ immortale eficium conferret.

In infructione Indor um diu effe perfeuerandum.

\section{A P V T XV.}

$M$ verò de refidentia Parochorum, deque niffionum auxilio, vt hanc de catechizandis dis partem abfoluamus, dicendum deinceps Neque magnopere modò incumbendum eft, paftoris prafentiam omni quidé gregi in pris neceflariam, etiam Indorum populis deeffe llo modo debere monfremus. Nam vt paftor endat valtum pecoris fui, fuofque greges con Prow.2\%: eret, vt requirat abiectum, \& infirmum con-Ezech.34. ctumq́; alliget, \& forte cufodiat, vt proprias lom.10. es nominatim vocet, \& vadat ance eas, \& lu$s$ arceat, 8 feipfum, fi opus fit, pro ouibus rifti exemplo offerat difcrimini, cateraq́; filia, quorum nos diuina literæadmonent, hic xcipuè defiderari res perfe ipfa quouis etiam cence loquitur. Q ma fiant, non minus experimur nos, quá faCanones pradicant, atq; ille præfertim Conlijparifienfis, inter catera, inquit, qux religio Chriftiana aduerfa funt, hoc nihilominus có. arium, \& periculofum extar, quod quorundä xlatorum temerario aufu Ecclefia fuis ad tem is viduantur facerdotibus: $\&$ poft pauca, Non tendentes quod eorum abfentia, \& loca Deo cata fibi cultu debito priuentur, $\&$ homines $f$. cófeffione, \&infantes fine baptifmatis regeratione plerumque moriantur. Quamobrem Darochos fedes fubinde commutances, $\&$ pr $x-$

, $.2=$

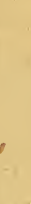




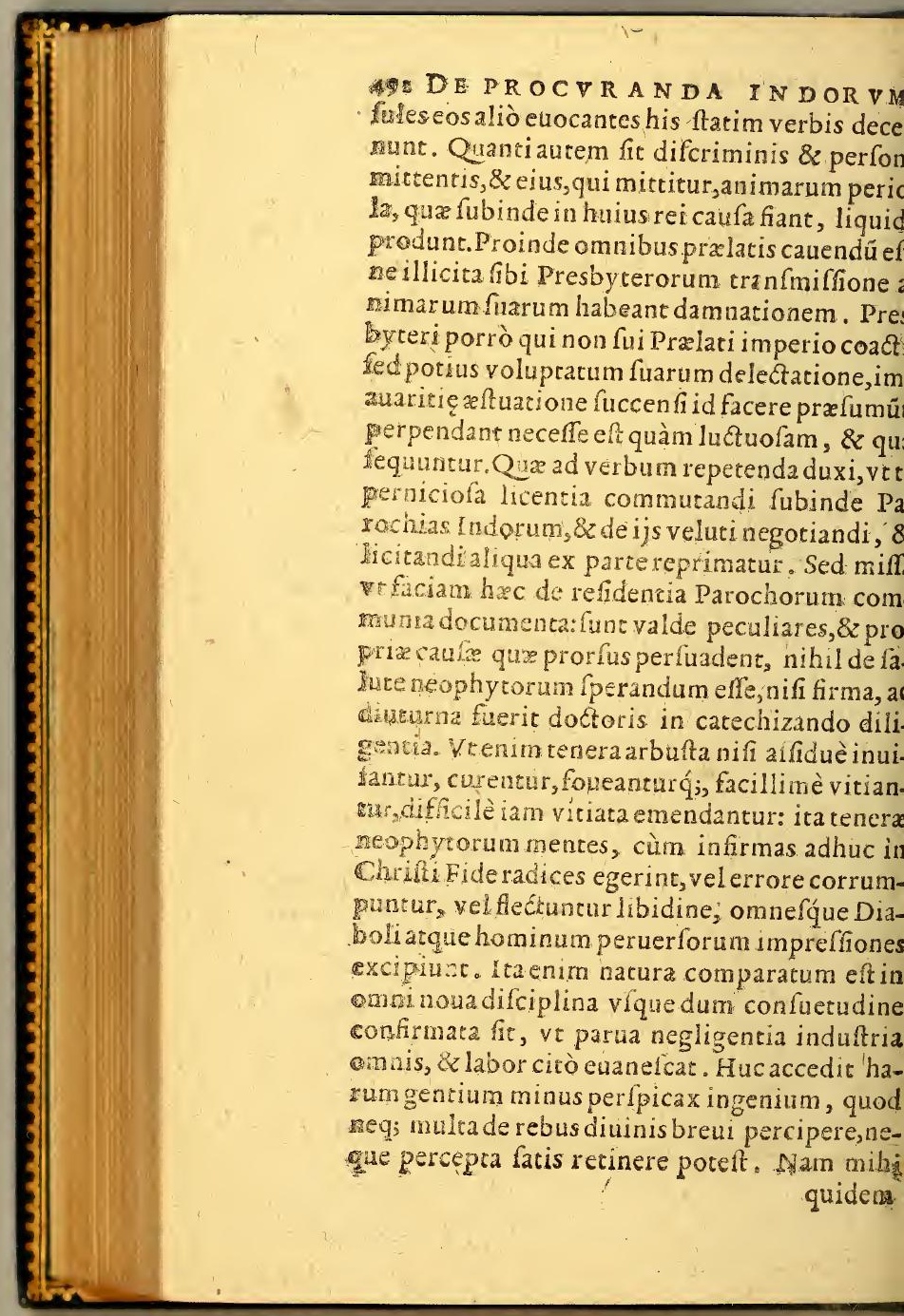


SA L V T E. LIBER V. idem Indi fxpè videri folent ijs perfimiles, i vel xtate,vel morbo ftomachum habent delitatum,ægrè coquentem cibós ingeftos: quom fi aut craffitudine, aut copia obruantur, illiacefcit, \& vitio cruditatis vires potius fran,quàm confirmat. Opus ergo eft, quod medirum ars habet infirmo ftomacho parum, $8: f_{z-}$ alimentum inftillare.1ta enim \& $z$ vincit, \& ad endum excitatur. Haud ergo promitrat fibi if quam exigui cuiufdam tempóris labore maos ex Indorum populis fructus, neque exift:emus bis aut ter de tora Fidei caufa edoctos nö aplius indigere doctore. Quin potius \& affiè differendum eft $\&$ modicè, vt qux audicat, percipiantatq; conferuent. Sic enim Chrius ip fos fuos difcipulos inftrucbat, præceptosorbis terrarum, multa habeo vobis dicere, rowen. na non poteftis portare modò. Prater has aute mmunes ferè infirmitatis humana rationes, illa maxima, 8 certiffima natiuæ cuiufdam orum leuitatis, quicùm primùm fibi relinruntur, mirè lubrici omnia accepta deponunt, aut veteres fequuntur errores, aut fin obusum odque, prout forstulerit, feruntur, ficut parli fluctuantes, \& circunferuntur omni vento Epbef.4: ctrinæ. Quamobrem, ne in his fruftra laboreus, \& ne excidant in fimplicitate Fidei corruis ferpentis aftu fenfibus, neue ab ijs, quiconadicunt veritati, confentiunt veró iniquitati anfuerfiagantur, infinitis modis neceffarium $t$, vt in ijs docendis, arguendis, exhortandis, nfirmandis, tuendis, \& gremio denique ipfo 2. Corr II Itandis, nutricis diligentia ne momento quim abfit, hoc eft fpirituales magiftri, \& patres

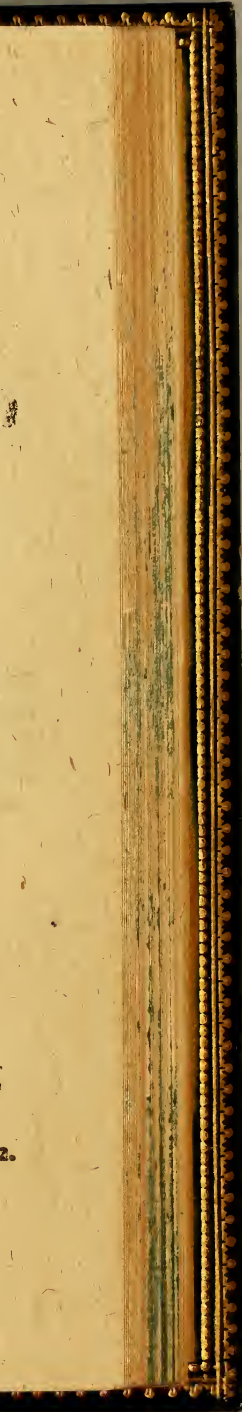

apud 


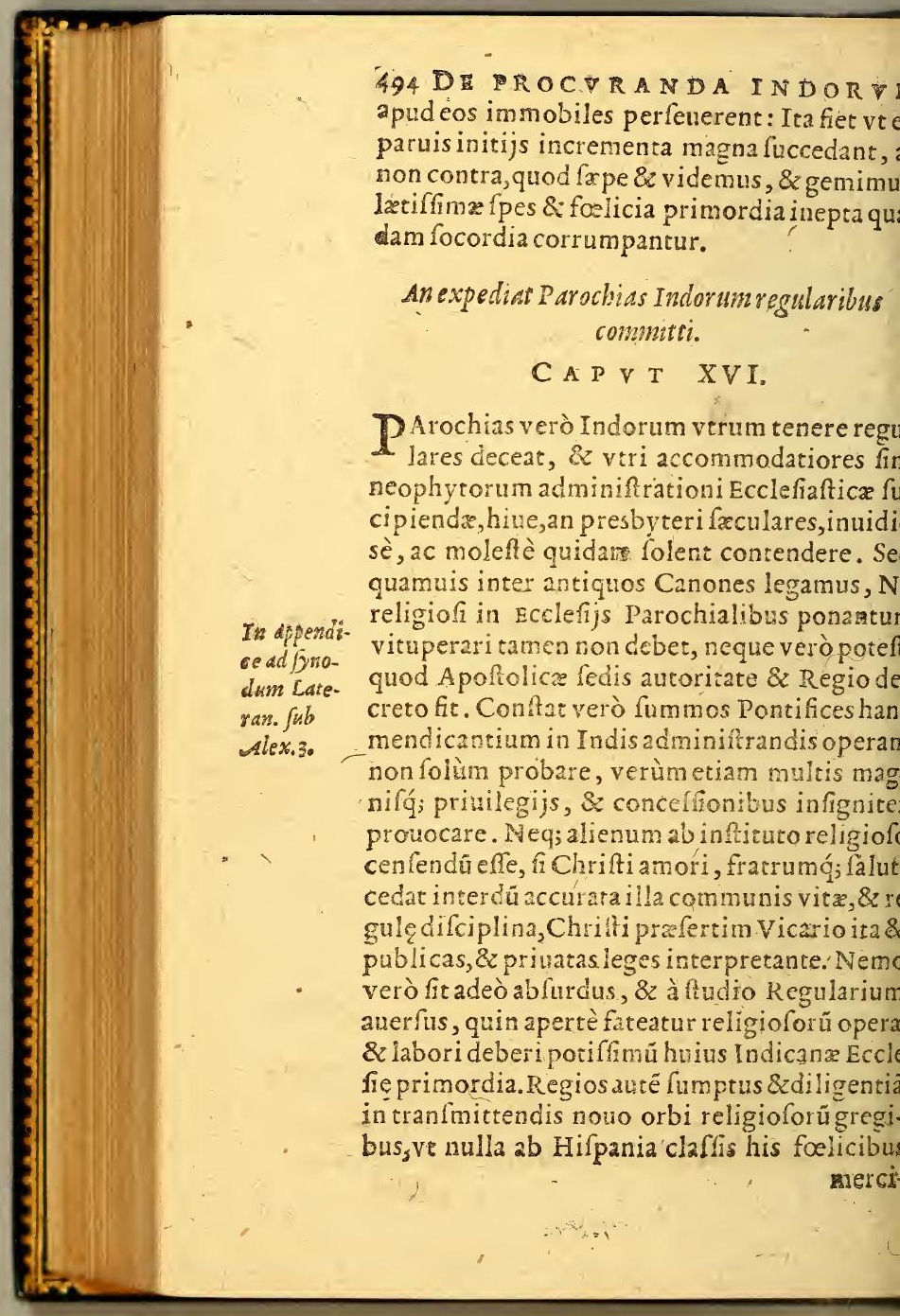


SALVTE. IIBER $\dot{V}$. rcibus vacua foluat, quis tā erit incptus', qui orfum interṕ́etetur, quá vt curam Indorü hi iffrmü fufcipiant,regiam ớ confcientiã, quolicet, exonerent?Pręterea ne illud quidem ne i poteft à religiofis, religiofius accuratiufq́; phytos inftitui, fereq́; vitę exemplo magis, im à fæcularibusadiuuari. Nã vê nihilaliud, a habitus profeffio cohibet, vt caftius vitam tituant. Qux cùm ita fint, ns eft cur ab officio fare monachosf folu facularibus parochias nes Indorum quifquam concedere velit. At er has omnes tot \& tàntas cómoditates duo hi videntur incómoda.Vnum eft illud ipfum d regularibus, cum priuilegijs fuis exempti , nô fat is bene cum Epifcopis conuenit in ad niftrandis parochijs Indorum. Hinc quanta la profecta fint, dici nó potêt. Primùm enim a oficio funt negligentes, Epifcopi , quorum - munus eft proprium, fuis occurrere non pof t parocho, aut caftigato, aut commutato, fidem neq; vifitare, neq; plectere, neque amoe malè meritos poffunt. Præfecti verò Prociales fubiectos fibi Reguiares corrigere qui n poffunt, fed cùm oues alienx fint, vix ad ilferò tandem querela peruenit. Et omnino ha nefcio quid perturbationis Parochum Epifo fuo nó fubeffe, ac duplici veluti capite reHinc porrò diffidia acerbxáue contentiones er Epifcopos, \& Regulares cum Indorum cer nagno malo. Hinc querela Epifcopor ü, quod es fibi commiffas fatis pafcere nequeant. De1, veftem ex lana linoq́; contextam, \& aream dë vario femine afperfam,videre eft fimpli- Deu $.222^{2}$ ati Euangelica, \& fumminiftrationi lpiritus, Lcwit. 19 quam

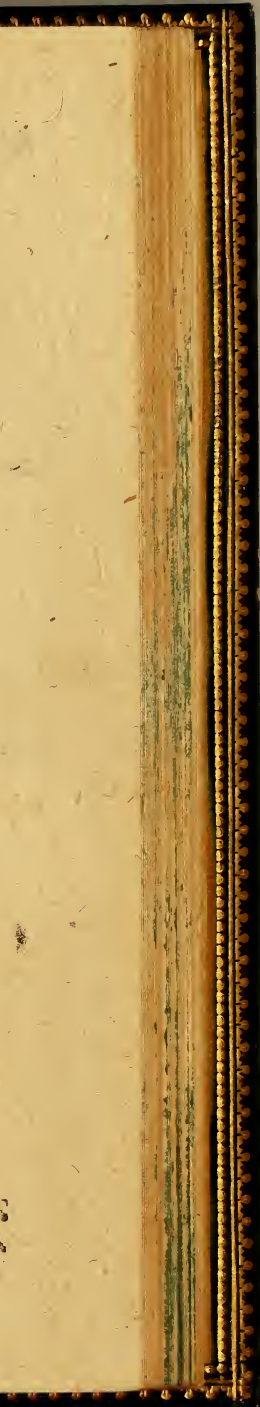




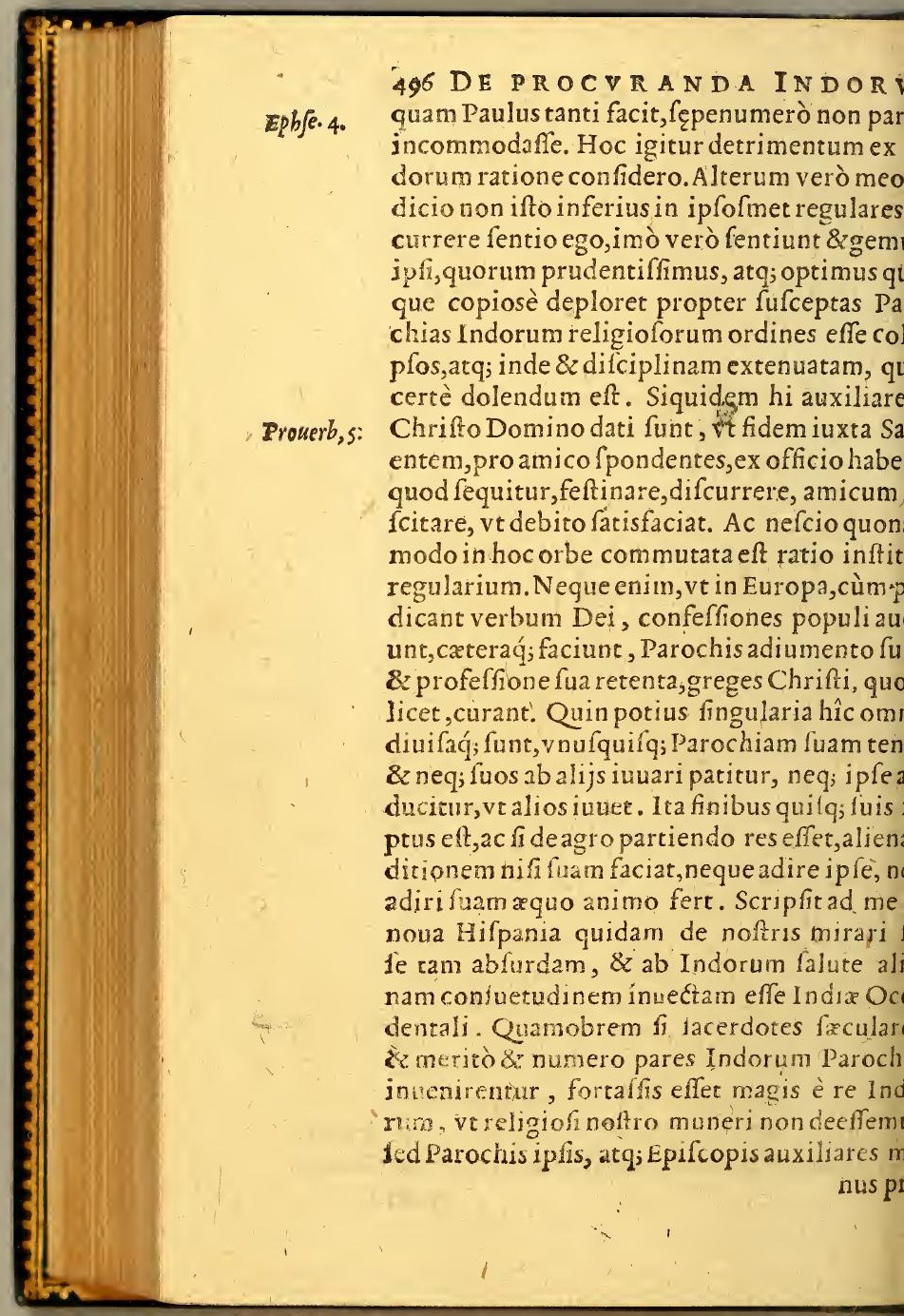


S A L T T E. L I B R V. praberemus, \& cum fumma eorum beneuoia verbum Dei inter Indos diffeminaremus, eos audiendis confeffionibus,cæteroq́; ornfficio profequeremur. Quod fi hoc vniucrsè nequit,vt certè nequit, profectò qui ex reli is hoc infituti genere militare poffunt,omplurimum caufa Indorum conferre putan ant.

tem Indorum focietati Iefu pro riribus effe procurandam.

\section{A P V $\mathrm{T}$ XVII.}

cietatis autem lefu eò potiffimum inftitu, vt in miffonibus obeundis pervarios orerrarum tractus Ecclefiæ Deiferuiat, hoc eft proprium munus, vt nihil magis. Atq; id lem quanquam vbiq; gentium præftare depro fua virili, tamen nufquam æquè arq; iniationes Indorum, ad quas Deo concilianorxcipuo, vt ego fanè opinor, ftudio diuininftituta eft. Acdabunt mihi xqui omnes liter veniam, fi quandiu fum Indorum feruus, orificem minifterium meum. Itag; fi in hac e vel cefret difficultatibus victa, vel defidia eat focietas, non mihi dubium eft, quin grapræ cateris \& Dei, \& hominum incurrat nfam. Etenim quo alio pertinet familiare ilin proferfionibus folennibus votum, quod quartum folemus vocare, de parendo Poni circa milfiones? Quorfum toties facta men a facris Bullis inftruti profectionis ad InQuid in beati Patris noftri Ignatij conftituibus, tantoperè repetitum, \& commenda, quàm vt prompto alacriq́ue animo præfto Ii vnuf- 


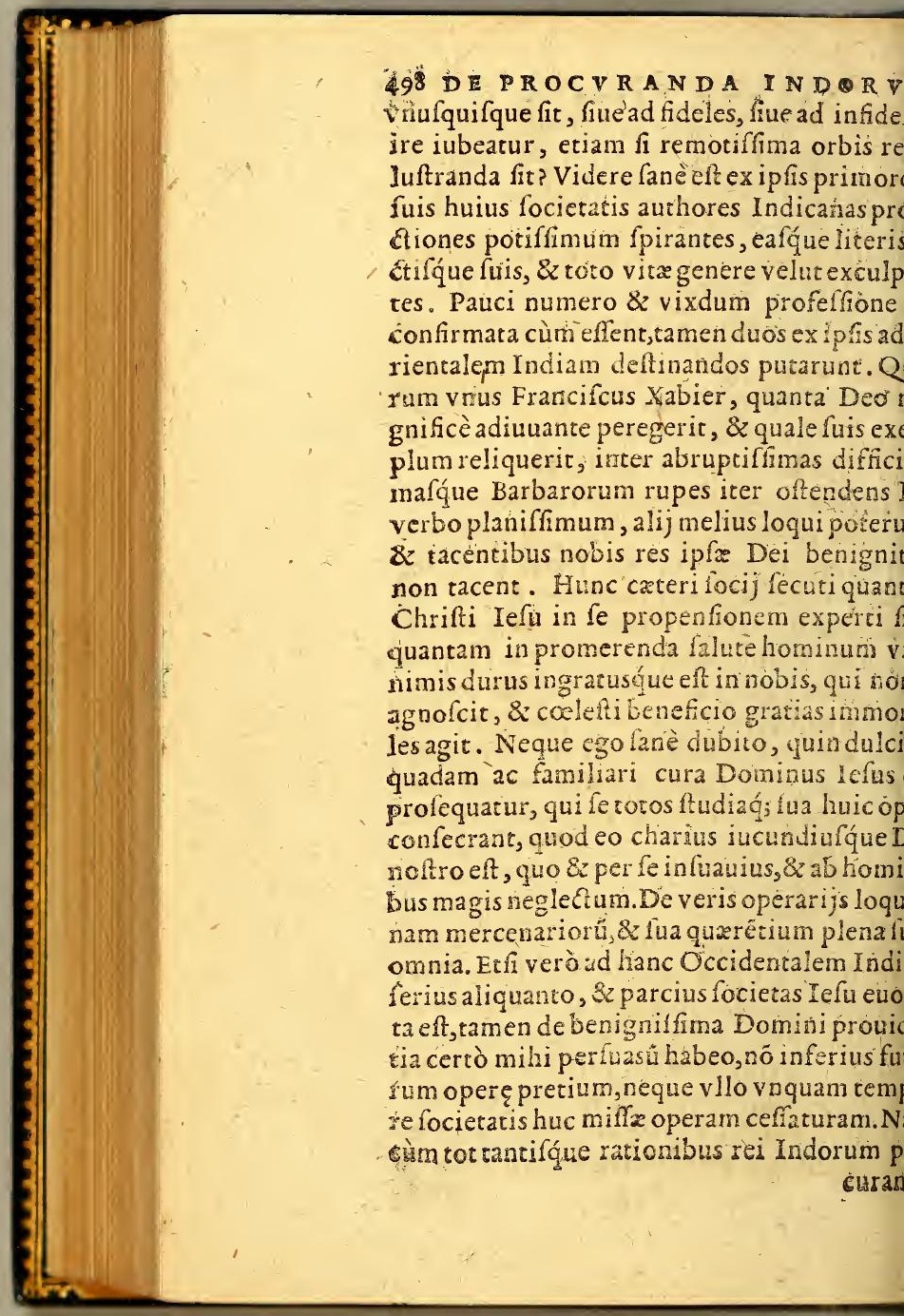


SAIVTE. LIBER V. dx cóftricti teneamur, militix defertores etiam proditores habeamur neceffe eft, fi mnes neruos in hoc opus Domini,vel praiffis cæeter is contendamus.

multis videatur focietas Parocbias Indorume deberefuscipere.

\section{CA P. XVIII.}

oniam veró in hoc orbe nulla alia Euangeizandi ratio hactentis fufcepta eft prater quam Parochi fuis adhibere folent, videnultishuius focietatis homines nifi ParoIndorum ipf $v$ fitato more fúfcipiant, nifalutem neophytorum conferre polfe, vni mój; corum adisentum ex Europa effe produm fuperuacancum putant. Itaq; cenfent omnino onericeruices fubijciendas, curam ndorumpropriè fubeundam. Cumque in arte cunctationem nofram viden indulam nobis deliriafque obijciunt, quod deto labore \& vita agreftiori, vrbanam freciam amemus. Quidam timoritrepidatiooftrx fubftomachantur, amico illi quidem o, fed voce libera obiurgantes, fi Patres fois Iefu parochias Indorum fibi vitandas i, de Iridorum defperanda falute ferre fen$\mathrm{m}$. Quis erim, inquiunt, difcrimini huic iet fele pro falute fratrum, $f i$ vos Patres detis, \& $x$ tergiueriamini, quo um alioqui anim ftudium, \& inflammata in Deum pietas eEta eft ? Quorfum veró miffionem tantam itis, tancum terræ pelagique emen fi ad igterras traijcitis, fi Indorum caufam deferiut qua ratione profeffioni, nominique ve-

$$
\text { Ii } 3 \text { atro }
$$

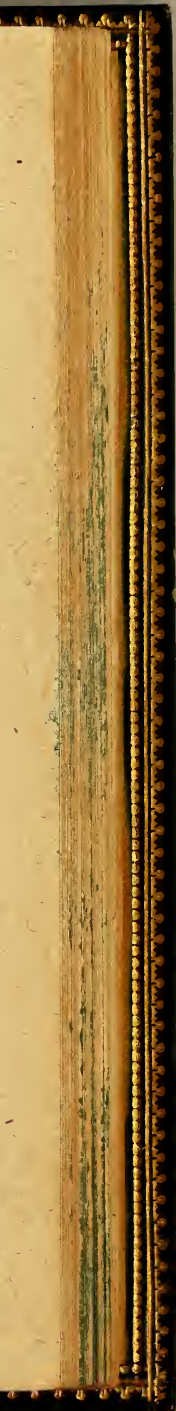




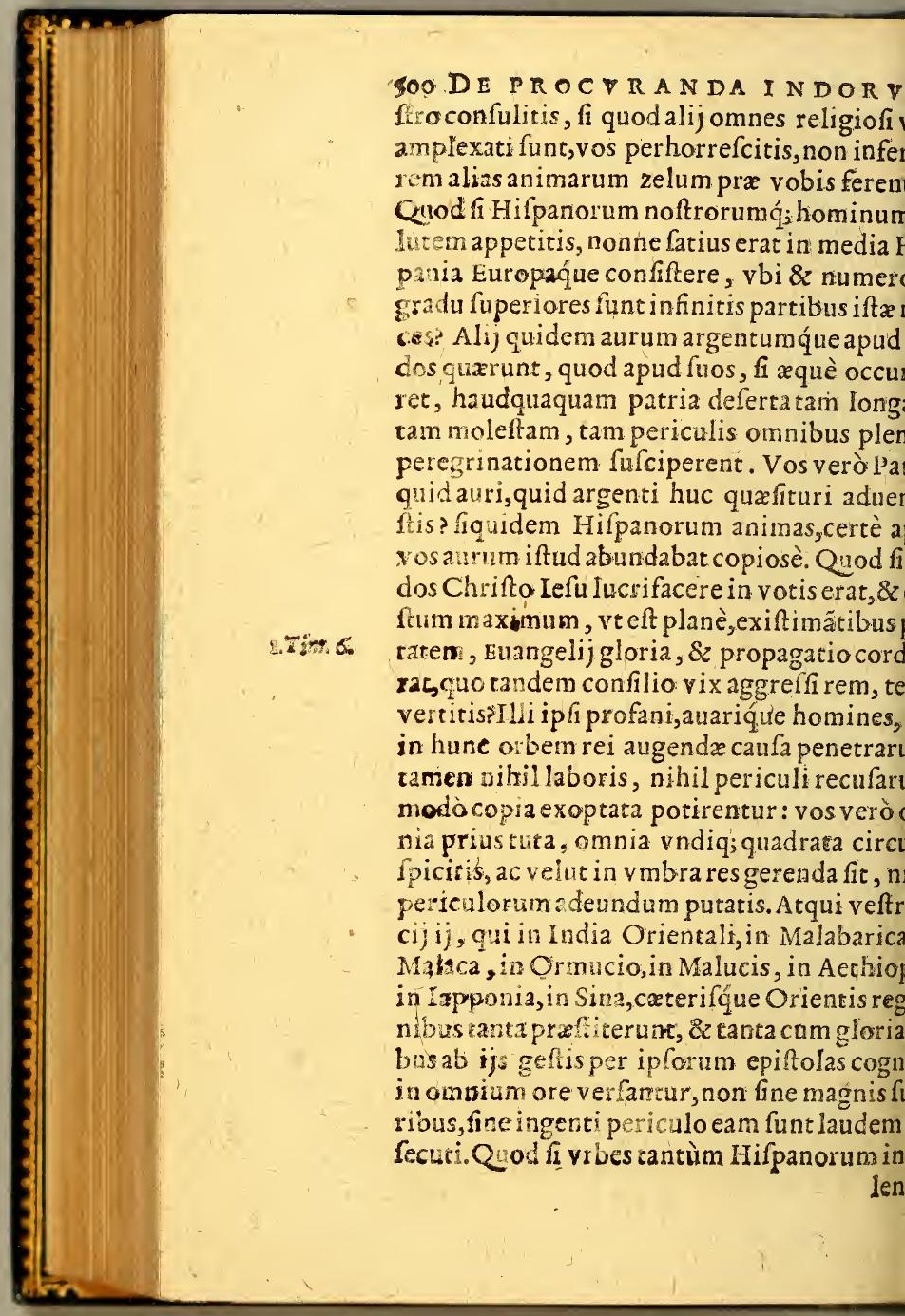


SAIVTE. LIBER V. 5OR las vobis exiftimatis, fi Mexicum, Limam, cum, ac non in medijs Indorum populis fefigitis, fi Carãgas, Collas, Sacacas, Yauyos, rafque prouincias barbarorum vitatis, $\mathrm{vm}$ ilis tantùm ac ludicra veftra omnis de Indis curatio fit neceffe eft. Quomodo enim eam em chrifto expugnare poteritis, apud quá m figitis nullam, nulla certa prafidia conitis, nullas moras ducitis? cùm nulla alia erinde opus fit ad falutem Indorum proculam, atque perfeuerantia \& improbo quolabore. Sic enim habetote Patres, quantum veteranos, \& mores horum barbarorum urno vfu edoctos caufa admonet, nifi per1ò, ac conftanter verbum vitæ, \&z curam fas harum gentium meditemini, vanos omnes ros conatus \& tela Penelopes fimiles prorfuturos.

cerationes à $\int u$ cipiendis Parochüs Indorum focietatem deterreant.

CAP XIX.

Aec atque horum fimilia expoftulare nobifcum folent, qui caufa Indorum fudiofi, feores nos in fufcipiendis Parochijs accufant, rú me oratione ita fæpenumerò perculfum or, vt propemodum victus cederem, omniaalia faluti neophytorum pofthabendaexiarem, atque equidem penè contemnerem. contemni profectò non poffunt, cùm occur$t$ nobis tot viri religiofi 8 z pij, qui pó minus ico, \& fynceroanimo trepidati nem noftrá ufcipiendis Parochijs vehementer probent, firmentó́; fe longa experiétia didicifle reli-

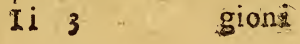




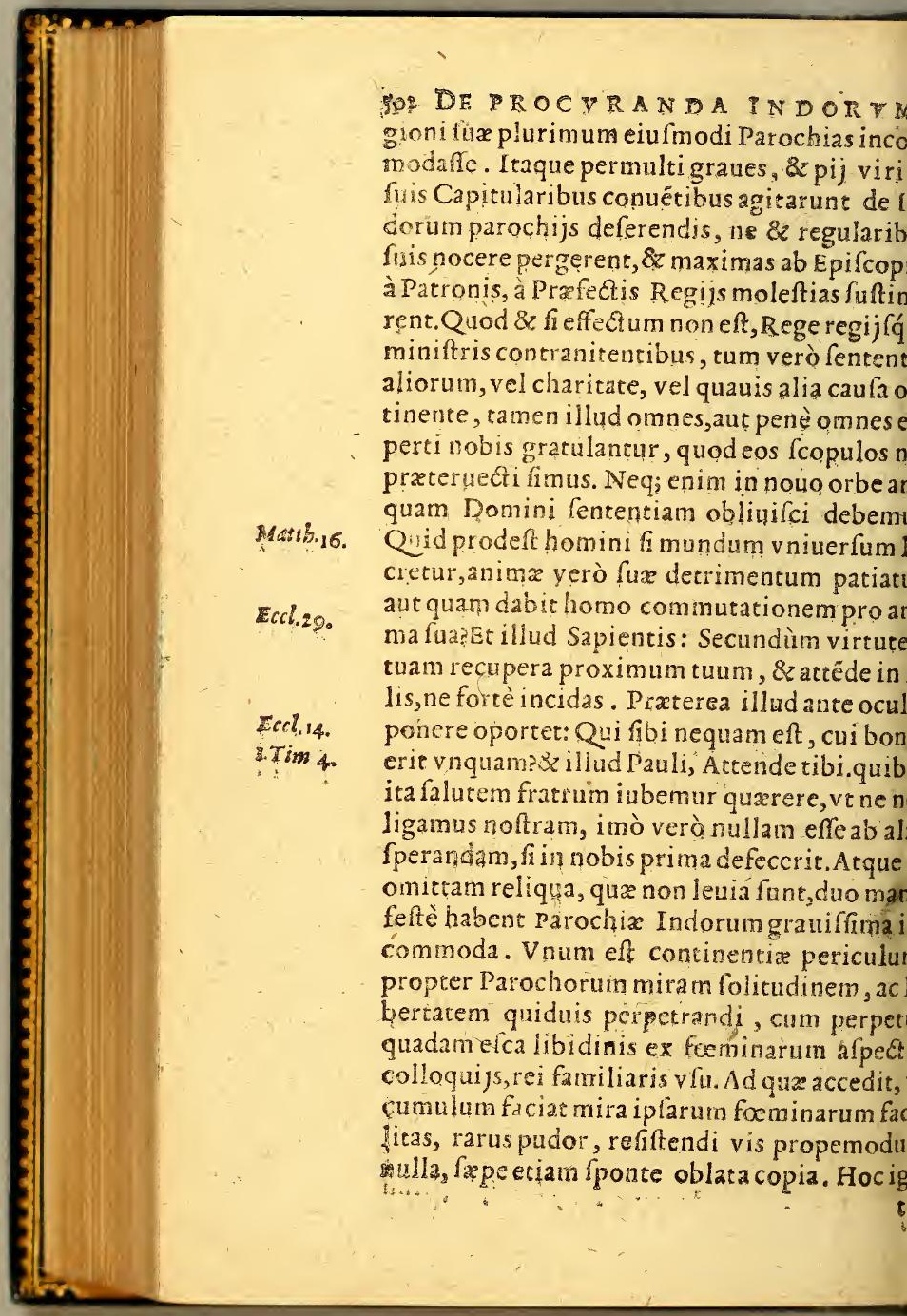


SA L TE. IIBER V: - vnum eft: alterum verò non leuius iudicia o, quod ex lucri fpecie nafcitur, \& cupiditapinione fiue vera illa, fiue falfa fit,omnia $\mathrm{Pa}$ hi ftudia refpergit, propemodumq́ue corrúNâ \& victus fuppeditari folet ab Indis, quod Camaricum dicunt, \& à Patronis Dominif́, orum falarium penditur. Hîc cùm Indis imando, exigendo, commodiffimum quodque rendo, minus copiofum Camaricum reculan quanta turbatio inter ipforum fraudes, \& $\mathrm{Pa}$ hi cupiditatem. Itaque omnem ad Parochi efum vel fallendum fi polfunt, vel fi nō pof$t$, explendum, falutis fux curam, cogitatiooq́ue conuertunt. Cum Patronis rurfus Indo , cum Prætoribus, quæ tragoediæ quotidie? t iurgia, \& lites, quibus Regia fublellia alficrepant. Hinc fimultates, hinc odia acerba, c calumnia graues. Coniurat cum Curaca ronus aduerfus Parochum, \& quiduis v obat, tertes habet ad votum. Hæc qui non vidit xaggerationem fortaffis cumulata putabit? interfuit, \& rem totam oculis perluftrauit, um fide inferiora teftabitur. Igitur vel concitiæ naufragium, vel fxua certè tempeltas ounda elt, tum verò auaritia gurges ipfe fi $e$ ur,fpecies profectò auaritix, \&z exiftimati s iactura euadi nullo modo pofie videtur.

ure in fuctipiendis P.arochïs moderatio adbia bendafit.

C A P Y T XX.

NTER has verò tantas difficultaces, illa hacte us fententia mihi magis probata eft, vfque $\mathrm{Ii} 4$ dum 
504 DE PROCVRANDA IN DOR V dum melius, \& certius aliquid eluceat, Par chias Indorum, neq; èflefocietati noftræ tem rè complectendas, neque vfquequaq; tamen pudiandas. Sed fiquidem duobus illis incomm dis incontinẽtiæ, \& auaritiæ fatis occurri que tum verò Epifcoporum pace, \& amicitia reté cxtera omnia officio aduerfus Indos effe po habenda. Sin verò vitari nulla ratione quea pro certo effe intelligendum aliam effe adiuu di has gentes quxrendam viam, neque dubita dum hanc vulgarem diuinitus noftris effe pr clufam. Nam præter communes Euangelizan legès eft illa focietati noftræ, vel prima, vel m ima, vt minifterij fui impenfi in proximos n lam omnino patiatur mercedem, mercedif fpeciem ad fe redundare. Itaque quodalijs va dè, \&z licet, \& fanctum eft, eleemofynas pro $m$ fa dicëda, pro funere, pro concione, $\&$ acciper $8 z$ petere, noîris etiam vitrò oblatas admitte nullo modo fas eft, idq́ue $\&$ conftitutionum Jiterarum A poftolicarum praceptis difertè, fape cautum eft. Quarénihil eft quod tantope quidam mirentur, is Parochias Indorum Cam rico, \& falario infructas minus cum noftra pr feffione congruere exiftimemus. Verùm ea, qi dixi,incommoda vitari fatis poffe videnturm hi in ijs praccipuè Parochijs, qua vel in vrbb Hifpanorum fita funt, velab ijs non admodu remotx, qualis hrc Limenfis eft S. Iacobi, 'qua noftricenent. Nam \& fubefie poffent Recto collegij, qui Indorum dostrinx dant operam, queillorum religioni \& modeftix fatis confu potef, cùm vita omnis illorum, fuperiorum o Jis fubieqa fit, qui $v t$, \& fibi \& officio fatisfaci 
SA L V TE. LIBER V., 505 , facilè curant. Vitæe ergo liberioris licentia eriorum cura propè inuigilantium in homi. us alioqui probatæ integritatis, fatis fublata eri potef. Etenim \& magnum Indorum fru$m$ ita experimur, $\&$ incommoda omnia facinteuertimus.Sed quoniam facerdotes doctri$\&$ adminiftrationi Indorum necefarij fine nptu $\&$ quidem copioso vbi frequentes illi t, ali non poffunt, non eft recufandus modeus, \& congruens victus, dummodo illud inuibile fit, ve ab Indis ipfis nihil exigatur, neque $\mathrm{m}$ præfectis ipforum fordidæ concentiones de $x$ ftu aut mercede concitentur. Id vt fiat,cent pleriq; magno adiumento fore eam conftiionem, quam noua lege iam videmus editam, de publico ærario facerdotibus annui prouen stribuantur, quod fi fyncerè, \& candidè ob:uetur, non dubium eft, quin honeftis, $\&$ reliofis hominibus percommodum, \& iucundum :ipfi verò adificationi, \& faluti neophytorum agnoperè conducat. Hoc genus ergo Parochia m collegijs Societatis vicinarü mihi $j$ ss, quas xi, conditionibus fufcipi minimè difplicet. d quoniam maius aliquid homines in focietarequirunt, neque eo modo fat is velexpecatii de fe conceptæ, vel harum gentium extrem ceffrtati noftri faciunt, ne illud quidem omitndum eft, quod nos admonuerunt opportun iri primarij. Effe quafdam prouincias Indorú equentes, vbi collegia focietatis erigi poffent, que inde facerdotes prodire ad parochias proarandas, qui tamen fuperioris, \& curæ, \&zocuis penè fubeffent, \& religiosè iuuari, \& inuif, zommutari cùm effet opus, facilè poffent. I ta Ii 5 enim 
$506 D E R R O C V R A N D A T N D O R \nabla$ enim fieret, $v t$ Indorum rationibus confuler eur ordinaria noftrorum præfentia, \& ipfis rel giofi inftituti nihil deperiret. Atque hoc gent doctrinarum, vt vocant, plerique regulares m ximè probant, quodeft in noua Hifpania v fit: rum, vbi monafteria, ve audio, in oppidis Indo rum paffim redificata funt. Et in hoc ipforegn Perufunt non pauca huius exempli. Quanquat \& diaboli inueteratęinuidię, \& hominum frag litati nihil eft vnquam fatis tutum. Verùm in ardua arque vadique difficultatibus plena, que periculo longius ablunt, ea pro tutis confilia re putari debent.

Mißsionum $v$ /us in Ecclefia antiquns of frequens. C A P. XXI.

I quid in parochijs tenendis minus Indorum $S_{\text {faluti præltamus, certè Miffionum commodi }}$ tate copiosè rependi poteft. Miffiones verò in telligo eas excurfiones, \& peregrinationes, qua oppidatim verbi diuini caufa fulcipiuntur, qua rum $\& x$ y fus $\& x$ autoritas logè maior eft. Et latiu. patet, quàm homines opinantur. Etenim in pri. ma illa florentiffima Ecclefia videre cit hoc du plexgenus Euangelizantium. Alij certas plebe moderandas inftituendasq́ue cura propria a perpetua fufcipiebant, de quibus Paulus A pofto.

7it.t. Jus loquitur. Huius rei caufa reliqui te Cretæ, vi conftituas per ciuitates presbyteros, quos etiam Hierofolymam adiens ex Ephefo euocauir Mi48.20. letum. Actedite, inquir, vobis, \& v niuerfo grẹi, in quo vos poluit Spiritus fanctus regere Ecciefiam fuam, quam acquifuit fanguine fuo. Hos 7. Pet. quoque Petrus alloquitur:Seniores pafcite, qui in vobiseft, gregem Dei ${ }_{2}$ non turpis lucri gratia, 

que dominantes in clero. Hos loannes in fua ocalypfi Angelos falutat, Smyrnę, Ephefi, Phi Apo.2. elphiæ, \& cæterarum vrbium. De quorum petua refidentia apud plebes fibi commiffas a multa fancti Canones edicunt, ve facra $\&$ an ua concilia relegentibus tędio penè fit eadem fatoties ac tantopere repetita. Hunc ergo lo$n$ in Ecclefra Dei parochi tenét Indorü certè uis foribus perneceflarium \& falutaremn. At $t$ alterum genus in Ecclefia fancta Dei miniorum, qui non firmas fedestenerent, fed prout npor is opportunitas, \& fratrum neceffitas po laret, varias Ecclefias obirent, in ijs pro re ras traherent, proprios paftores iuuarent, inmos confirmarent, fortes perficerent, omni ra ne Chrifi rem promouerent. Nam ve in excitu fapienter inftrueto pręter militares copicerta lede difpofitas, quibus nihil magis curæ , quàm vi locum fuum ne deferant, cùm in eo otoria fit, vt caput potius ponant, quàm femel um pedem referant, funtetiam auxiliares piæ leuisq́ue armaturę equites, quorum fit ntra munus huc illuc dilcurrere, vbi difcrien fit, promptè adefle, labantem iam militem nfirmare, hoftem irrumpentem excipere, nni negotio adeffe, quorum fidei \& diligene plerumque victoria accepta referenda fit: prafecto in hac militię Chriftianze veluc caorum terribili \& ordinatifima acie, duo nt ordines, vaus eorum, qui certo loco dertant, alter eorum, qui per omnia difcurrunt, omnibus opem ferant. Quod militia genus nti in Ecclefia factum eft, $v t$ duces noftros mmos, id eft, Apoftolos fibi fumpfife videamus. 


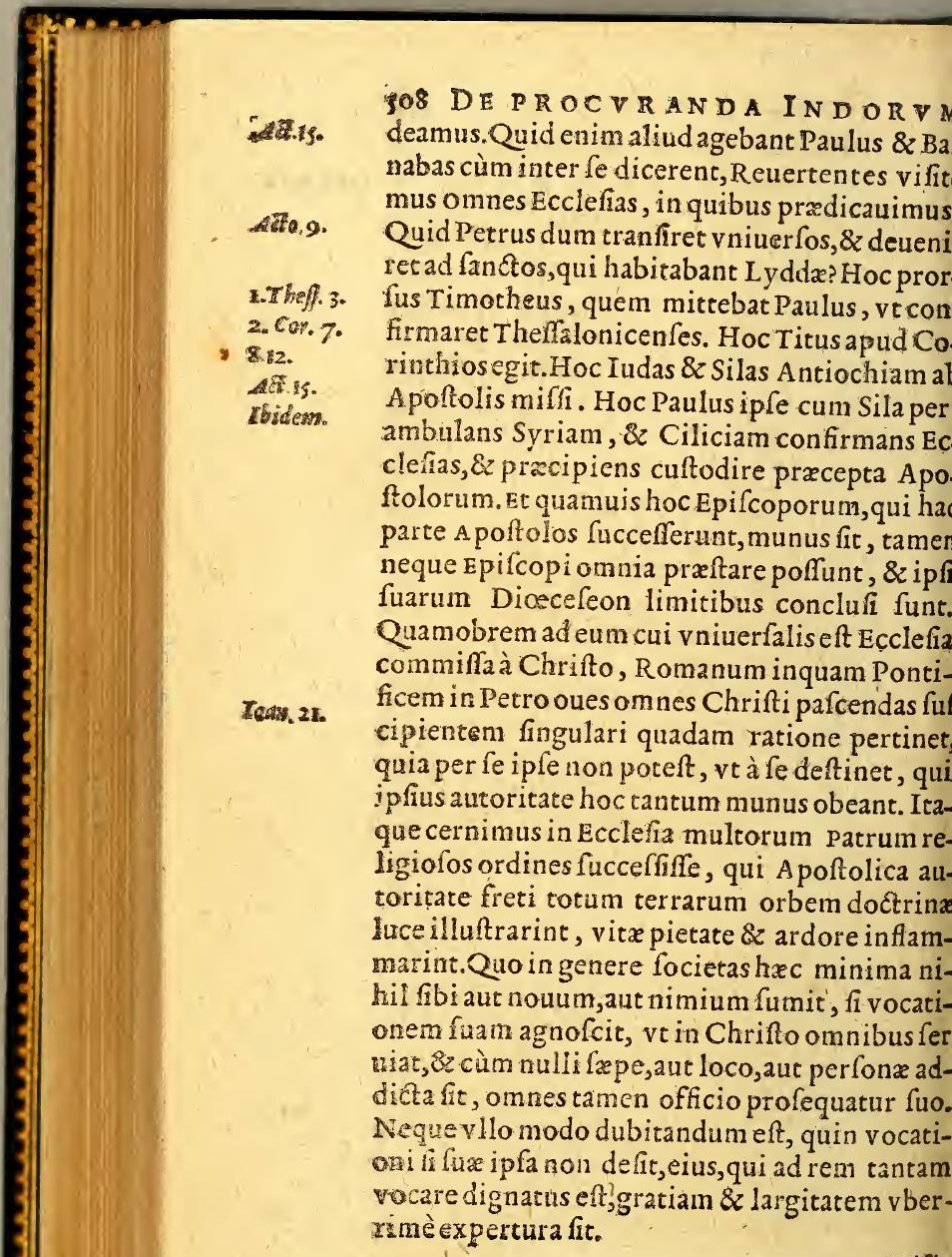

Mijsio 
SAIVTE. LI BER V.

Mißionum vtilitates inter Indos.

C A P. XXI.

Iffonum autem vtilitates inter Indos mul. 1 tæ magnæq́ue funt. Prima quod omni cupitatis occafione procul remota, cum neque mifterij fui mercedem exigant, neque fructum ium expectent, quàm falutem Indorum, neque poftulando Camarico molefri fint, deinde cónentiæ, \& integritatis lumen pra fe ferant,adirabile dictu eft, quàm in'fui doctrinxq́ue fux mirationem \& fudium Indos rapiant. Neque im, quod ixpe dicere foleo, illuftriora mirzla ad Euangelij commendationem Indisadhi. ri veffunt, quàm ve neque auaririx occafione, que libidinis finifro rumore, dactrina miniri euangelici decoloretur. Secunda, quod cùm uerius obiurgare \& malefacta vindicare ad pa chos propriè pertineat, miffionum verò ratio fit, vt potius confolandi, intercedendi, ac bee de omnibus merendi partes, fibi fumat, valde noftros ftudia Indorum excitantur, \& ficaniorum magna coniunctio: ex qua \& fidem diis facilè cor modant, \& $x$ fe fuaq́; omnia libenfimè impertiunnt,atque communicant. Tertia inc quoq; manat, \& $z$ eft copiosè vfu comperta, uod ad confeffiones noftris faciendas, etiam ge crales, etiam ingentium fcelerum, ac diutifiè contectorum, vitro ipfi non inuitari veniüt, ui tamen parochorum omnium vna fententia, arò verum in confeffione facramentali ipfisaeriunt, quip pe qui parochos pertimefcant. Eo mni metu odioque fublato ad noftros, quos fii experiuntur beneuolos, nihilǵue læfuros certò fiunt,

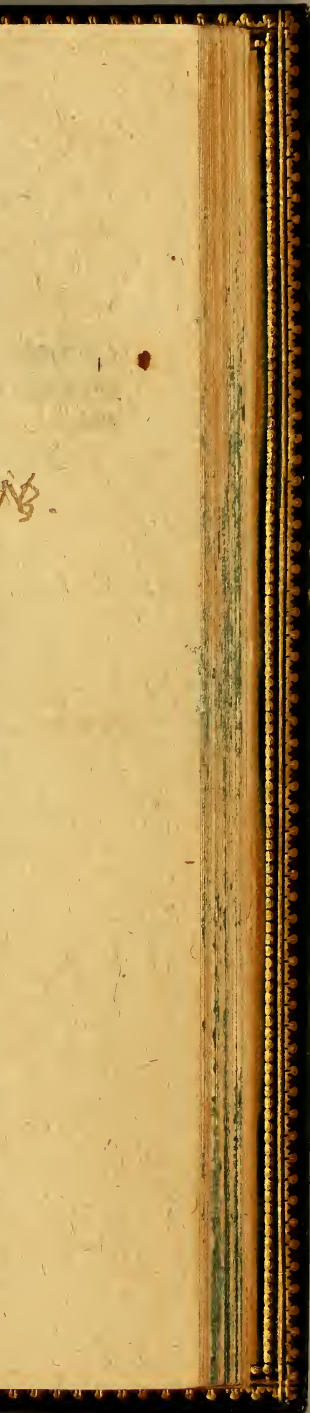


- cozririd. fel.2s cap. se.
SIO DE PROEVRANDA INTORVI có f́ciunt, certatim accurrunt, crimina omnia a periunt, vitæ confilia libenter accipiunt, fumm deuotione imperata exequuntur. Hæc vna com moditas miffionum, quam in prouincijs fupe rioribus cùm verfaremur, abundè fumus exper ci, tanci elt a pud me, ve fi nullus alius miffionun fructus expectaretur, fola fufficeret. Ac quemad modum in facro Tridentino Concilio propte fragilem muliebrem fexum fanctimonialium pudori \& metui patres ita confulendum putarunt, vt prater ordinarium voluerint aliquotie extraordinarium illis confeffarium dari : ita equidem Indis etià confulendum arbirror, quo rumeft fides infirmior, \& duriores in fe parochos experiuntur. Itaque eo miffionum auxilio mirificc corum infirmitas recreatur. Quartam

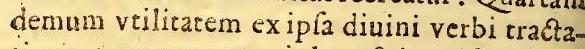
tone numero: qua triplex eft in miffionibus. Vna,qua pueri \& rudiores fimpliciter, \& memo riter catechímo imbuuncur, idĝ̣ftatis diebus \& horis partim canendo, partim recitando fructuosè admodum fic. Altera, qua docentur, \& inftruuntur familiariter pro fuo quil q; captu tam in my fterijs fidei percipiendis, quàm in moribushoneftè inftituendis.Poftrema eft ea, qux a d exhortarionem fpectat, qua pro concione excicantur ad falutaria om nia, ac vi ipfa dicendi dicentif́que autoritate flectuntur. Hic mirificè $\&$ capiuntur, \& $z$ cedunt, fi concionatorem lingux bene peritum, \& appoficè dicentem nacti funt. Quod cum rarum in parochijs fit, $v$ nus eiufmodi Indicè bene doctus, miffionum excurfione multis parochijs prodeffe poteft. Atque ad has duatuor exempli, Beneficentız, Sacramenta ad-

ringes: 
SALVTE. I I BER V. SIB iniftrandi,poenitentiam prafertim, \& verbi niq; diuini diffeminandi redigi cateræ pofit vtilitates, qux ad Indos pertinent.

od Parocbi Misiones vtiliter or libenter-abcipiant.

\section{A P. XXIII.}

ST alia quoq; his non inferior vtilitas miffionum, cum adparochos iplos beneficium iuatur. Paulus quidem dicebat, Deoautem cias, qui femper triumphat nos in Chrifto Ie ${ }^{2 . C o r}$. \& odorem noticix fux manifeftat per nos in ni loco, quia Chrifti bonus odor fumus, quod quoque modo viurpare poffunt, fi qui funt curfus A poftolici fectatores. Noftri certè exti funt fxpenumerò parochos ipfós vitx con tudine colloquijlq́ue captos ad Chrifum iraffe, neque parum ad virtutis officia comtos efie. Nihil enim vitx exemplo porétius, efertim in morum quadam fuauitate, tum ipamiliaris collocutio fudia fimilia parit. $\mathrm{Cu}$ fefe adiuuarià noftris fedulò nulla interim rcede expedtata vidét,atọ; cnere ipfo nô paleuari horú opera,beneficio allecti de fe bemeritos amant. lam verò cùm ad confcienm fuam fructum hunc deriuant, ad fuos londiffundunt exemplo inftructi, xmulatione itaci, fructu provocati. Ad hæc omnia illud edit, quod cùm fape binæ ac terña auteo ares parochize valde inter fe etiam difiunctx ius parochicura commifia fint, atque adeo yue baptizare, neq; confeffiones audire, neq, doctrinainftruere omnes fuos commodè pofit, vt maximam anni partem oues paftore prorfirs

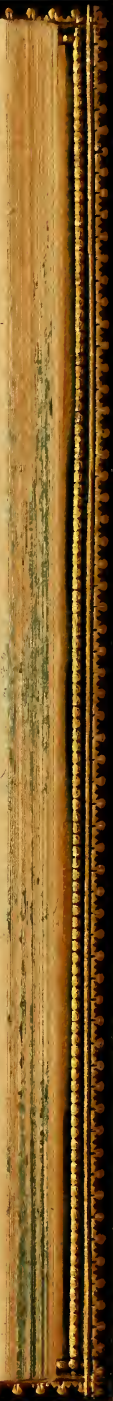


512 DE PROCVRANDA INDOR V prorfus careant, qua ex re quot millia periclit tur, imò verò manifefè intereant, dici non $p$ teft. Polfunt ergo qui Miffionibus vacant, bo temporis partem in ea parochia confumere qua parochus abeft, \& omni boni paftoris of cio perfungi, quæ res nó folùm eft ipfis Indis lutaris, verùm etiam Epifcopis, parochis, patr nifóf; gratiffima, quibus omnibus eiufmodi fu plementa magnam confcientix quietem affer Quamobrem à multis iam agitatum eft, vt co legia Societatis, aut refidentix in frequent maxima Indorum collocarentur, vnde tanqua ex munita arce fubfidiarij milites regionem o nem opportunè excurrerent. Ad hæc, vt fili nobilium Indorum à pueritia inftruendos ed candofq́ue fufciperent, in qua vna re totius ge tis falus vniuerfa pofita eft. Neque ego fanè di fido futurum breui, vt his omnibus modis atq rationibus focietas noftra faluti Indorum pro curandæ, quod tantoperècupit, feliciter op ram nauet.

\section{Quid cauere oporteat in Missionibus.}

$$
\text { C A. P. XX IIII. }
$$

A $C$ miffionum commoditates ex ferè fun A quas expofui. Vt verò in om ni prxclaro n gotio euenire folet, non carent fuis quoque no leuibus difficultatibus. Primùm enim inuid paftorum, \& plebis contemptus eorum præ no ftris diligentiffr mè cauendus eft ea vna ration vt omni, \& verborum, \& rerum fignification teftétur fe nullo modo effe parocho fuperiore fed hunc verum legitimumá; paiforem, fe ver tantùm illius adiutores, 8 adminiftros. Itaqu 

Inem honoris in illum fignificatione ne pręmittant, vt \& spfe intelligat nihilab ijs amiosèagi , \& populus factionem nullo modo ditetur, fed fubditus fit per omnia parocho . Vix dici poteft, quãtopere incer Indos obdetur is, qui cateris imperat, \& praeft, vt ftaoculos in ipfum Apo,vt illi vocant, animúconuertant. Qua ex re nifi humilitatem noin finuent, \& circum pectè parochorum auitatem tueantur,atque commendent, certum inuidia, \& calumnia on nia facim bona fucorrumpi. Praterea 82 illud omnibus modis andum, ne odiofi parochis fimus, dum vel iam integritatem oftentamus, vel reformaam acceniorum partes importanè affumi- Meminiffe potius illud oportet à Spiricu to dictum, Noli effe iuftus multum, neque fapias quàm neceffe eft, ne obftupefcas.lie. illud A poltoli, Omnibus omnia faceus fum, 1. cor 9. mnes facerélaluos. Et illud Dominidicıte: huic domui, \& ibi manete comedentes, \& Matt.10. entes, qux apud illos funt. Denique vnulquif proximo fuo placeat in bonoad adificatioEtenim Chrifus non'fibi placuir. His alijf-

Rom 15o diuinæScripturæ fententijs docemur, ita re. onis diciplinam conferuare, ve charitati rum multum demus. Multa toleranda fune omine prefercim faculari, fape eriain prononnulla interdum concedenda falua conutia, 8 z ita agendum, vi conluetud nis fuaui alliciatur potius, quam alperitare offenfus iat fatim. Itaque neque vifitatores, nequa ores, aut Monos aliquos vel Sycophantas imare nos debet, fed fibi amiciffimos, \& hu $\mathrm{K} \mathrm{k}$ manif-

\section{Eccle 7 .}


S14 DE PROCVR.ANDA IND ORVM inaniffimè affectos. Nouimus ex prudenti dif mulatione non paucos egregiè captos tande Dei verbo manus dedifie: quos fi nimia feue tate offenderis, mille concionibus reuocare no poteris. Verùm ita humanitatis leges feruan funt,vt neg; religionis exiftimatio ladatur, que confcientiæ coram Deo puritas offufcet Nam \& virum religiofum \& Apoftolicum m nus obeuntem nihil,ant leuitatem, aut faftu aut lafciuiam redolens decet. Quoniam verò ad aperiendas confcientias fuas in confeffio parochi accurrunt, imploranda impensè eft uina gratia, vt $\&$ officio non defis tuo, $8 z$ frat animam grauiffmè interdum fauciam à mo reuoces. Ego fanè in confeffionibus audien nihil aquè formidare foleo, quod facerdotu quotidie coelefía facramenta tractantium v medicina vlla morbi curari poflunt, cum fem coperint peruenire ad cor durum, atque ill Gregorij plerunque, cùm eiufmodi duritie ereg.lib.2. contemplor, venit in mentem. Pleriq; corun expofi.in 1. Domino in impoenitentis cordis caliginem $p$ Reg.c.3. ifciuntur, \& nulla hominisadhortatione refip fcunt. Ergo in primis illud tenendum eft, vepl

Ezech.13. cendi voluntas, \& humanus afiecius nullo in do dominetur, ne puluillos fub omni cubito, ceruicalia fub omni capite fatuamus, iuxta pr pheticam comminationem, quin potius verit in omnibus domineeur, \& prafit, propter $q 1$ fi homines aliquando fcandalizantur, non $\mathrm{m}$ Deut.1. gnoperecurandum eft. Deienim iudicium e ait friptura. Itaque $f$ is, qui parochus nom natur, concubinarius fit, fi aleator, fi fonerato if fimoniacus, filitigator, fi turpis lucri fect: 
SAL $\backslash$ T E: LIBER V. , fi officij fui negligens, fi fermonis Indici peritus, \& contemptor, veritatis falce refeda funt vitia,ac nifi tibi ipfi in Domino fatis eris peruidendum, ne alienis peccatis ipfe mmunices, manus poenitentiæ citò imponês. 1.Tim.s. terùm hac ipfa etiam letalia, $\&$ vetufta vlce. oleo fimul foueri poffunt, atq; itavino perdi,vt pariter, \& mordeantur, \& ferant. Attin , inquit, à fine v fque ad finem fortiter, \& difnit omnia fuauiter diuina Sapientia. Opus te, modum fuauem effe oportet. Multum ineft, qua manu, qua dexteritaté vulnuschirurs infligat. Non imperiosè, non duriter, magis Aug.epift. nendo, quàm minando;magis iuuando, quàm 64 . ad Aso endo, ve ait Auguftinus, ifta tolluntur. Vi- reliums. nus fxpe facerdotum confcientias deplora, de quibus ego planè diffideram eò quodad durum perueniffe mihi viderentur, \& iuxta eremiam propter multitudinem iniquitatis Hiere. $30^{\circ}$ ra facta cle peccata, minifterijs tamen nois, vel porius diuina gratiæ ita ceffife, ita reaiffe, ita ad cor redijffe, vt magnificas Deiboari gratias ageremus, \&lpen non vulgarem nciperemus, fociétatis noftrę homines, quorú at parochi penè omnes, value fudiofi, pracla fimos fruetus in lucrifaciendis Domino eiufo di hominibus allacuros. Hẹc in parochos ob-uanda.Porrò Indi, ipfi quoq; curam quandá diocritaris efflagitant. Vrenim eos oderunt, i nimij in exigendo funt, ita etiam à fe auerputant, qui ab ipfis oblata repudiant. Accipida ergo funt humanè munufcula eorú, \&zbegnè vel eadem, vel plura fi liceat, pauperibus mmunicanda.Quod fi ipforum opera interdú Kk 3 Sap. 8. Ang.epift.
o4. ad As
reliums. Hiere. 30 : 


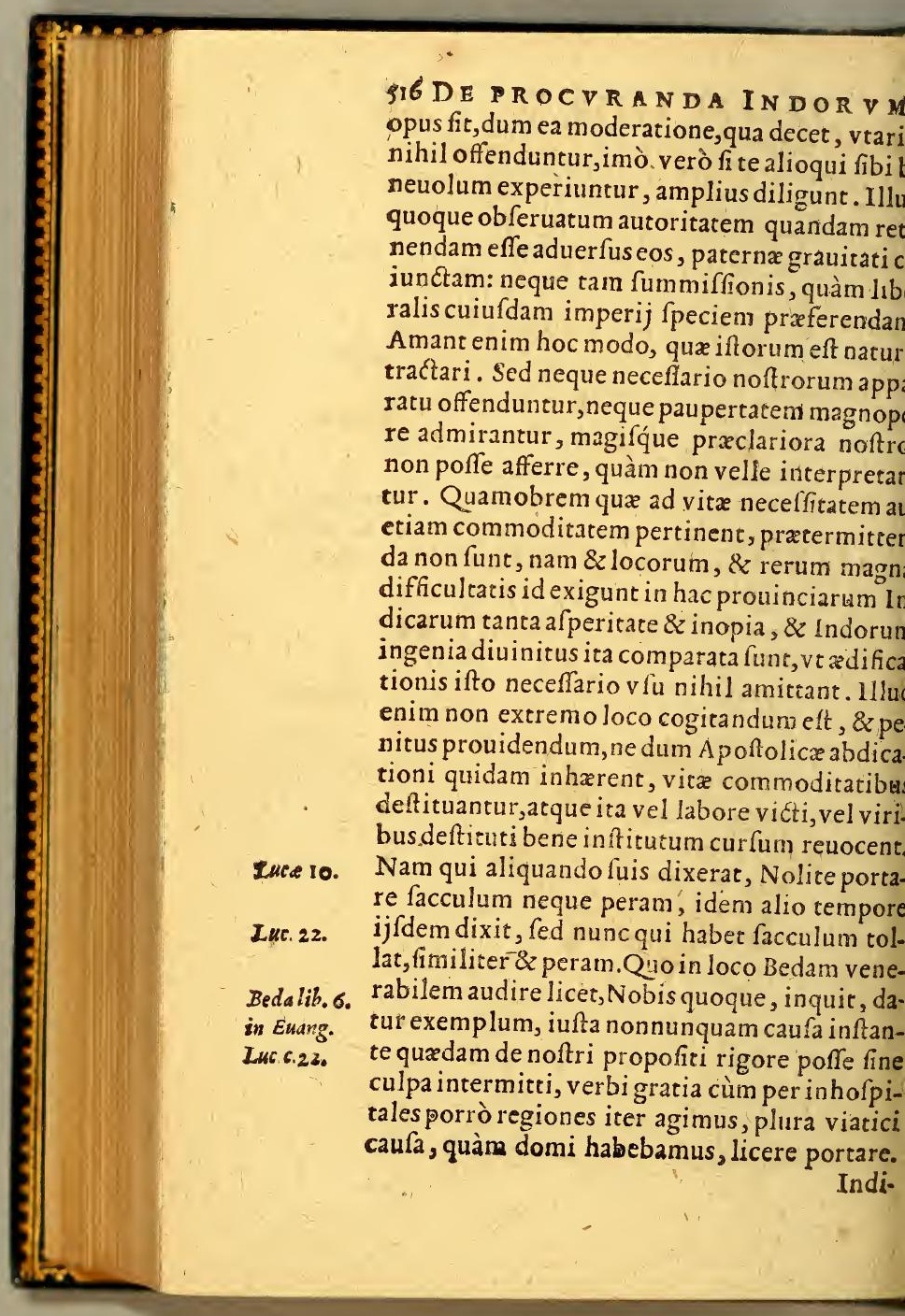


SA L T E. IIBER V. licas fanè peregrinationes notaffe videri po- Atque hæc ad difficulcates Indicarum mifum confiderandas hacienus dixiffe fit fatis. ad poltremò adijciendum puto, Indicas 82 moditates, $\&$ difficultates non ex aliarum ionum lege aut confuetudine, fed ex fua ipim effe metiendas, \& Dei zelo præeunte tum erò experientia duce, illud in omnibus intuendum, vt non quæramus quod nobis vtile eft, fed quod multis, vt falui fiant.

FINIS LIBRI QVINTI.

$\begin{array}{ll}K k & \text { DE }\end{array}$

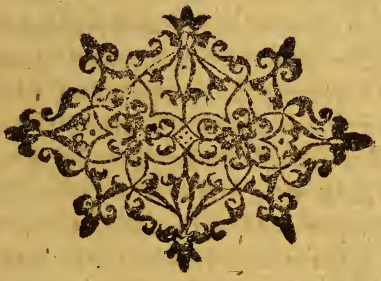




\section{S18 DE \\ PROCVRANDE

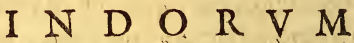 \\ $S$ A L V T E,}

L I B E R S X T Y S

Quatenus modo de Sacramentis agendum fit.

C A P V T I.

E diuinis Sacramentis admi
trandis, quod vnum ex ijs,
propofuimus, reftat, fi pro arg
menti dignitatedifferendum
fet, magnum opus exifteret, cùm ipfum per fe tantum fit, meritò quodar modo indignaretur. At nos rem tantam nu. modoaggredimur, qui de Sacramentis cont impudentes Nouatorum calumnias, \& ab i Ecclefia in magno \& ocumenico Concilio T dentino copiosè grauiterớ; de finitum, \& ill fres noftr $x$ ptatis fcriptores nufquam aut vb rius, aut frelicius quàm in illis afferendis, exp candis, commendandifó; elaboraffe, "non ign remus. Igitur cum Hæreticis res nobis mo non eft, led ne catholicos quidem antiquos, in religione conftantes admonendos, cohorta dofue exiftimamus, quorum illud infignem e ditionem, hoc dicendi facultatem non vulga requirit. Tantùm breuiter, ac pene cur fim ea Sacramẹntis attingemus, quaz rudibus Ind orv 
SA L TE: IIBER VI. STO oul is neceffaria videbuntur, atq; in ijs maxè infiftemus, quæ per imperitiam, aut incuriả orundam contra veterem \& Ecclefiafticam ciplinam inter hofce neophytos obrepfiffe, percrebuife notauimus.

lta in bis regionibus contra Ecclefiaconfuetudia nemgeri.

\section{A P V T II.}

JA $M$ exquo tempore obedientia duce ad has regiones Indicas venimus, non pauca Sacramentorum functione minus conueniter Ecclefrafticis inftitutis, nonnulla perturtè prorfus atque ineptè geri, \& diū mirati fuas, 8 dolenter fæpe commemorauimus . Caumihi cogitanti nulla certior occurrit, quàm od Euangelium non tam prædicatorum, quã ilitum manu in has nonas orbis nationes inue um fit:quorum focordia cum imperitia connćta multa abfurdè peperit, qua accedente cố etudine confirmata tanquä legitima habétur. a priores pofterioribus errandi viam munient,ve vix liceat doctis \& $z$ pijs hominibus vete $\mathrm{m}$ totius Ecclefix confuetudinem reftituere, beanturq́; rerum Indicarum imperiti, qui regionem \& facramenta Ecclefiæ integrè,ac pro gnitate Indis tradere cupiant.Quid plura? Cú Prouinciali Concilio Limenfi ab omnibus eruen fibus Epifcopis, cxterif́́; grauibus viris dea vitia emendanda multum operæ $\&$ ftudij ollatum fit, atgj; edita extent egregia decreta de eformatione permulta, nihil tamen amplius erfectũ en, quàm di ab otiofis nautis de repul

$\mathrm{KK} 4$

mode- 


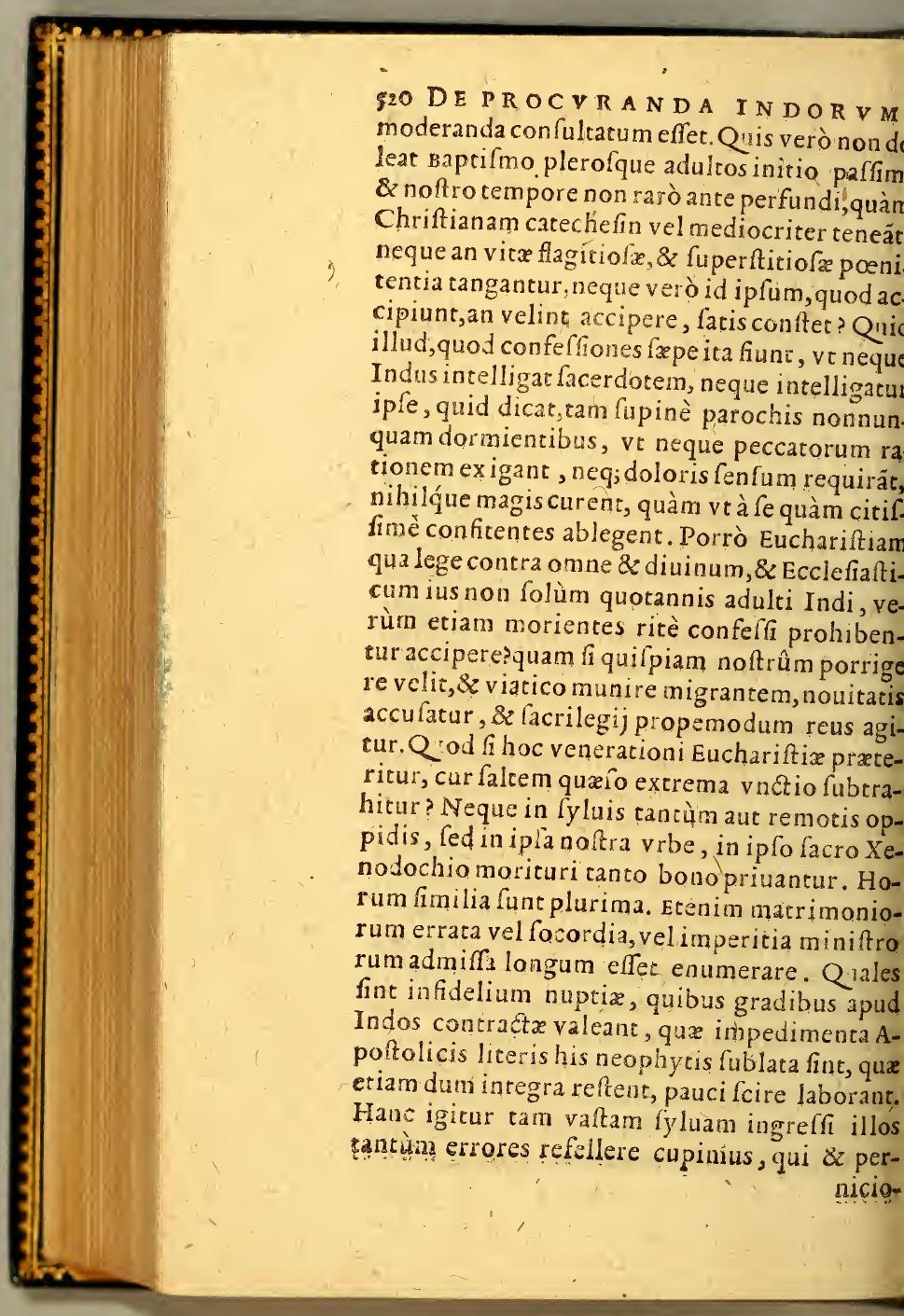


S:2: DE ROCVRANDA INDOR TM exponant, \& Fidei temerè fufceptæ defertore certiffimo exitio afficiát. Non enim tales, vt ef in Decretis Patrum, inuici faluandi funt, fed vo Conc. Tol. 4.ca.55.d. 45. De IHw2is.

lentes, vt integra fit forma iuftitiz. Equidé cen ferem Prouinciali Concilio nihil grauius dece nédum fuiffe, ac fore deinceps, nihil etiam feue rius vindicandum, quàm vt Indi adulti ante bap tifmum perannum, aut etiam amplius, nifi dif crimen mortis vrgeret, in Fidei myferijs per difcendis, \& voluntate bona confirmanda dift nerentur:ita fieret vt ferius impetratam baptif mi gratiam pro magno haberent, $\&$ diligente conferuarent, quemadmodum in concedend Euchariftia vfu veniffe cernimus. Sed quid agi. mus de ijs, qui contra falutare hoc Ecclefix init tutum baptizati funt? Certè fi nullam habuiff voluntatem perfpicerentur, atque omnino in uiti \& repugnantes, \& contradicentes baptizat De baptif funt, nullo modo Chriftianum characterem ac mooveius cepiffe exiftimandi funt, quemadmodum eft ab effec. c. $M a$ - Innocentio tertio definitum, neque enim fin iores 5 item fufcipientis voluntate facramentum conftar gite. potelt, quod accipere non poter, qui non præbe vtcumque confenfum. Verùm fi voluntas non. nulla non defuit, tametfi vel vi,vel minis extor. ta, quia re vera charadere Chrifi infignitus eft cogenduseft Fidem femel fufceptam conferua. Ibidess. re, ne Chrifti facramento magna fiat iniuria, profanum per licentiam reddatur, quod eft etia ab codem Pontifice fecundù Toletani Concilij decreta declaratum. Illud autê habet quaftio né non facilem, viruin cùm barbarus baptifmun prorfus ignorat, \& tamen non contradicens bap cizatur, verè Chrifianum characterem accipia 
SA L V T E. I T B ER V.

ene. Nam rei ignoratæ voluntas effe non poIt, cùm nihil ametur nifi cognitú aliquo modo. aq; qui interrogatus, an velit in fe fieri, $\phi$ fit in ijs, aut etiam nihil interrogatus, baptifmo perindrtur, nihil inter baprifmü, \& profanam aquá fcernens, nihil ibi religionis agnofcens, is pro ctò quomodo velit, quod nunquam cogitauit, on facilè poteft dici. Cùm v́erò facricanones ihil aliud tradant obltare baprifmo, quàm vointatem baptifmo renitentem, \& contradicenem, cumq́; hoc loco hominem nihil diffentire, ihil reclamare ponamus, iteare poftea baptifaum, fi ille faluus effe velit, difficilis exempli pparet. Qiam quaftionem ne quifquam otioam putet, iciat apud nosefie frequentem in ijs ræfertim Aethiopibus feruis, qui ex Cabouerde fportantur. Hos enim fi conuenias, an Chriftiai ham fint, audies non rarò, fefe cum effent imuberes fimul cum alijs plurimis in naui, aut ittore deprehenfos baptizatos effe, cùm certè uid fecú ageretur, ignorarent, nifi quod multi imul à clerico,a ut milite quopiă aqua alpergeantur, \& exinde Chriftianos fe fieri audiebant, ùm neque hoc etiam ipfum quid effet edocerëur, neque rem iplam penitus intelligerent, \& tomines barbari, iụmétis fimiles, minimè quid illid effer fcire curarent. Digladiantur quidam, 968 ar. 7 . vtrum fi neutra voluntas detur, baptifmus fit ra- Sot. in $4 . d$. us. Diuus quoque Auguftinus non parum haret g.art.7. in fine librorum de baptifmo, vtrum baptifmus D. Aug. lib. per iocum \& non feriò collatus habendus fie cer 7 . de Bapus ac conftans. Vbi ita fcribit, Solet quari, v-tifmocontra trum nihil interfit quo animo accipiat ille cui Donatiftas datur, cum fịmulatione, an fine fimulationê: fí cú cap 53 .

fimu-

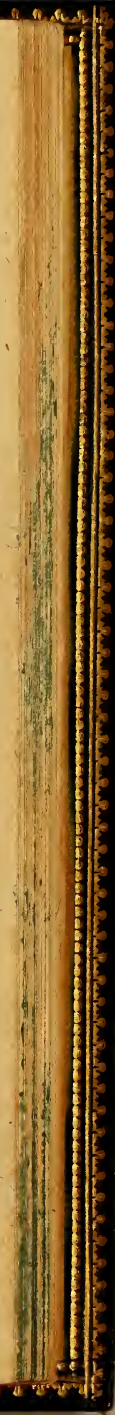


\$24 DE PROCVRANDA INDORVI De Conf. $d$. fimulatione vtrum fallens an iocans ficut in $m$ 4.6. follt.

mo.Et quibufdam interpofitis, quibus fe Eccle fix iudicium expectare ea de re proficetur,adiu git: Nequaquam dubitarem habere eosbaptif mum, qui vbicumg; \& à quibufcumq; illud ver. bis Euangelicis confecratum fine fua fimulatio ne 8 cum aliqua fide accepiffent, quanquam eis ad falutem fpiritualem non prodeffet, fi charitate caruiffent, qua Catholicæ infererentur EcI clefix.Et mox, vbi autem, neque focietas effet v la ita credentium, neq; ille, qui ibi acciperet, ita crederet, fed totú ludicre \& mimicè, \& ioculariterageretur, vtrum approbandus effet baptifmus, qui fic daretur, diuinum iudicium peralicuius reuelationis oraculum, cócordi oratione, \& impenfis fupplici deuotione gemitibus implorandum effe cêferem. In hac ergo dubitatione cum de voluntate Indi, aut Aethiopis temerè baptizati quæritur, illud mihicertum eft, fi faris me minit $f e$ fine fimulatione, \& cum aliqua fide, vt Auguftinus dixit', fufcepiffe baptifmam, hoc eit, incellexife llud efie ritum aliquem Chriftianorum, atque ita in fe fieri permiffe, quamuis cætera Chriftianx religionis non fit edoetus, approbandum effe baptifmum, minimeq́ue repetendum. Re enim vera confen. fiffe putandus eit, qui cü videret in fe fieri quod adChriftianam religionem pertinere vicumq; fciebat, non contradixit. Quod fi nullo modo quideffer baptifmus, agnouit, neq; illum à profana \& quacumq; alia afperfione difinxit, penitus Chrifti, \& Ecclefix Fidem ignorans, non magis voluiffe intelligendus eft, quàm fi dormaiens, aut amens baptizaretur, cùm nulla antea 
SA LVTE, LIBER VI. J25 is fignificatio extitiffet.Quem fanè nullo mobaptizatum effe ego non dubito, quemadmome illum quidem, de quo Auguftinus valde bitat, qui per jocum prorfus, aç nó feriò bap aretur. Nam \& diffentire, atq; abnuere putãseft, qui cótra vetus inftitutum fuum aliquid u i prorfus ignarus acciput: \& fatis eft eũ nul$n$ baptifmi voluntarem habere, neque expref$n$, neque interpretatiuam, quam in aduleis ad ftabtiam facramenti requiri fanior, \& cerDoctorum fententia habet. Acfaris id doDebapiifmo. c. Maior. 6 . item quarj. unr.

iffe Innocentius III. videtur, cùm de baptifdormientis aut infani improbảdo, fi antecentis voluntatis figna non extent, fententiam it . At verò cùm neque barbarus iple fatis ezratam habet præteritam voluntatem fuan, que notitiam illius temporis, neque verò inijs manifeftis percipi res potelt, quod freens eft in hac fuperiorum temporum perturione, 8 barbarie, falutare confilium Alexan111. fequendum eft, \& condirione adhibita tifmus iterum conferendus. Poriò volútaté entum in baptifmo paruulorum fuorum ad ftantiam facramenti necefiariam efre, quamafferant quidam, ref́è tamen afferi non poIbidem. - Sed tamen parentibus inuits, fi infideles D.Th.2.2. , eorum paftulos non efre baptizandos, quan- 9.10 ar 12:mon fine patrocinio nobilium autorum Con, Lim. inq; in fcholis res agitatur, tamen Thomę fen tia \& Ecclefire confuetudine \& Concilij pro. cialis autoritate longè praferenda eft, dumdo in mortis periculo confticutum paruulü la expectata parentum voluntate baptizare firmat conc. re $\&$ decere quoq; concedamus, quod autores 2 im. Conft.

De baptifmo cap. De qui bas.

Dur.in 4. diff. 4. $q .6$. Pal.c. 4 . contra ferstiuntCai.3.p. q. 08 ar. 10. con Sor. in 4. Conft 27. Sot.in 4 d. 5. ar.10.in fine idem cö27. qui-

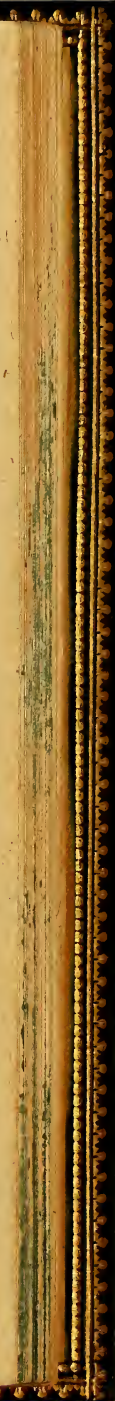




\subsection{DE PROC $\forall$ R NDA INDOR V}

Conc. Tol.4. quidam pij \& docti pro illorum falute defe c. 61.28.q. dunt, \& à noftris aliquando cum laude factu 1. Iudai qui. meminimus. Cùm verò ex duobus parentib alter filium paruulum chriftianum fieri vult: rero repugnante \&z contranitente, iuxta Conc lij Toletani, \& Lintenfis decreta, baptifmo f: uendü ê, \&zillius ius pręferendum, qui de fil falute melius cogitat. Atq; hac de voluntate ba tifnum fufcipiestium obiter ateigife fit fati De Fidle of Penitentia ad baptifm gratiam $n$ ceffaria:

\section{A P V T IIII.}

Air 20. Fldem ver ò in Dominum Iefum Chriftum, 2. 2 . Poenitentiam in Deum, quam Paulus prædi cabat ingentibus, Petrus ab Hebræis exigebat neceflariä effe, vt baptifmus non folùm Chrif militem faciat, fed gratiæetiam \& falutis dona tiuo afficiat, nemo eft tam ineptus, qui dubite! Verùm qux Fidei menfura exigenda fit in cate chumeno, \& quibus modis agendum, ve fatis in ftructus, \& firmus veniat ad lauacrum Chrift fatis eft in libro fuperiore explicatum. Pceni cenciam autem, hoceft anteact $x$ vita veram de reftationen, atque in pofterum firmum corri gendzconfilium, rarus eft certè in Parochis quu pro dignitate requirat. Nam \& priftinæ fu perftitioni vulgo hraent, \& cócubitus nefario retinent, \&rebriofitaté fuam non deponunt:ple riq; honoris caufa baptifmum ambiunt, ne ab Ecclefia arceantur, nonnulli ve Hifpans Domi nis ea in re gratificentur, at que eiufmodi fictio. nibus apud barbaros plena funt omnia, noftr: certè maxima ignauia, qui fupini, atq; of citãte éa de re cogitamus, digni certè, qui tanti facrile 
SALVTE, LTEER VI. jpornas luamus. De hac vita emendatione cunda $\&$ exploranda in competentibus multa tiqui Canones, multa noua fỳnodalia decreta xclarè prxcipiunt: led facilè omnia contemintur $a b$ ijs, qui quxfum amant, falutem hoinum, \& Chrifi digniratem non amant.Itaq; antiqua Ecclefix confuetudine perquàm cóodum mihi videretur, ve catechumeni alidot dies, fi menfes longum effer, ieiunijs $\&$ pre bus alijlq́; pijs operibus pro facultate fua excerétur ante baptifmum, tum verò vt teftimo ium ferrent temperafle fe à flagitiofo concutu, ab omni fuperftitione gentilica, pracipueue ab ebrietate, Ecclefiam quoq; frequentaffe; omni officio vitæ fuperioris emendationem eclaraffe. Ita fieret, vt paratiores venirent, $\&$ uã tandiu probati gratiã adipifcerentur, non $a$ facilò reuè fi ad vomitum corrupturief?ent. e qua re legi Gratianus poteft in quarta diftin ione de confecratione, \& cateri, qui de catelefi, \& præparatione baptifmo neceffariacoiosè fcriplêre.

e ̈̈s, quifebaptizatos vel negant vel ment butur. C A P. V.

Eijs verò, qui baptifmum vel datum fibieffe mentiuntur, vel acceptum iam à fe negát, ùm fit vtrum q; paris facrilegij \& periculi, meitò fynodalia decreta cautos effe parochos iuent. Sunt enim qui reuera baptizati non funt, ùm tamenChriftianis nominibus appellentur, Ecclefiaftica myfteria conuentulq́; frequenent. Hoc ex temporum fuperiorum perturba-

tione

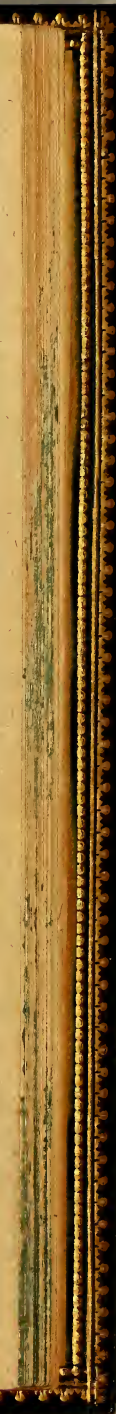




\section{DE PROCVRANDA 'INDOR V.}

tione accidifle conftat. Atque in horum aliqu nos incidimus, qui cùm diu Chriftiani habere tur, \& Ioannes, aut Francifci, aut Petri vocare tur, tandem concionibus noftrorum permo fimulatione depofita baptizari fe poftularun $\&$ re diligenter difcufia, inuentum eft eos no fuiffe re vera Chriftianos, fed à parentibus Ind fubtractos per Hifpanicos Dominos eiufmod noninibus fuife donatos. Nonnulli quoque $\mathrm{Ae}$ thiopes cú frpe confeffiones annuas peregifsét rogatı aliquando ea de re fe nunquã effe baptiza tos apertè confeff funt. Erit igitur adhibend. non exigua diligentia præfertim erga aduena. $\&$ ignotæ regionis homines. Contra alij ea occa fione fe baptizatos fape diffimulant, baptif mumq́, fupplices petunt, quem revera iamac. ceperunt, eo fanèconfilio, vt vxores nous ducere liceat, cùm veteres difplicent. Eum fucum prudentiores Parochi deprehendere folent. Ne igitur, velgrandi facrilegio iterato facramento contaminentur, vel à neceffario excludantur, vigilare facerdotes oporter. Et cùm res liquidò conftare non poteit, atque is qui baprifmum petit, a foqui teftimonium habet integritatis fux, Leopif. 34 probabilique verinque ratione dubia, prudenti c. I De cionf. d.4.cumita. que. Jidem in epi. 90, ca 16 De conjd. 4.c.Sinulla. virocaufa fit, Beati Leonis decretum falutare feruandum eft de ijs, qui in captiuitate pofitis parentibus nati funt, \& baptizatine fint, certum effe non potelt, quorum potius faluti confulendum docet lauacro regeneratio ,nis adhibito. Quia quod non oftéditur gelíu, ratio non finit, ve videatur iteratum. 
S A L V T I.' LI B ER VI.

De Sacramento Confirmationis of illius materia.

\section{A P V T V I.}

Aec pauca de baptifmo Indorum:neque verò plura de facri Chrifmatis facramento dida funt. Ac bene habet fanè, quod Confirmam is facramento neophyti noftri priuati non tametfi partim penuria Epifcoporum, par fortaffis negligentia, rarò eam gratiam Inonfequantur. Illud hoc loco, pro infituto ro dicendum eft, materiam huius facramenDoctoribus, \& Florentino Concilio tradi, ifma ex oleo, \& balfamoab Epifcopoconatum. Dubitant verò multi, an balfamum re a ad effentiam facramenti pertineat: $\&$ pleue affentientibus, Sotus, \& Caietanus graues hores negant, qui fi de vero balfamo loquunomnino tenendi funt, cùm eorum fentenfatis A poftolica fedes confirmaffe videaExtat enim inductum à Pio Quinto Pone maximo Epifcopo Tucumanenfi datum, d nos ipfi in autographo vidımus, vt in hac identali India, liceat in confectione Chrifis proverobalfamo fuccum quendam alium ibere, natiuum his regionibus, qui balfami rem, \& fuauitatem maximè refert. Non ir'verum balfamum de effentia eft facramen. , nifi malis materiam facramentorum Ecclefia fubdi, quod emnes viri doctirepudiant.

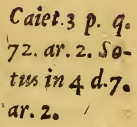




\section{DI PROCVRANDA INDOR V}

De Euchariftiapercipienda diuinum effe preceptum.

\section{A P V T VII.}

Equitur vt de Euchariftix perceptione dic $S_{\text {mus,à qua genus Indorum latil finè exclufur }}$ adhuc homines docti, \& pij fruftrà conqueru tur. Quem totum locum vt commodius exp cemus, dicendum erit de ipfo iure diuino, \& $\mathrm{E}$ clefiaftico percipiendi Euchariftiam : tum qu de confuetudine huc v que feruata fentiendu fit, \& de falute eorum, qui fine viatico coelefti vita decedunt:poftremò quid deinceps fieri e pediat,admittendine fint an excludendi à fact myfterijs Indi. Ac primùm non parua quæet eft inter Theologos, Vtrum re ipfa fumere $E$ Bona.in 4.d. chariftiam iuris diuini præceptum fit. Quida s2.art.vit.q. enim non aliam, quam Ecclefiaftic conftututi -Alexand. nisvim agnofcunt, quorum potef videri n Hales 4.p.q improbabilis fententia, quod videamus Eccl 51. memb. 4. fram quibufdam dare, quibufdam negare euch caieta 3.p.g. riftiam, etiam cùm fupremus agitur fpiritus: 8 art.21. $O$ quare $\&$ antiqui Canones complures funt,

32.

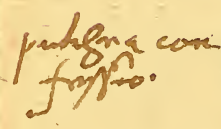
quarundam hodie quog; prouinciarum mos el vt ij, qui per publicos magifratus ad fupplic ducustur, nan communicentur. Atquiiusdiu num Ecclefia tollere, aut immutare non pore Non ergo iuris diuini eft, vt homines etiam vitz fine Euchariftiam accipiant. Adde quo verba Chrift, quibus maximè apud Ioanne neceffaria ad vitam æternam carnis \& fanguin Chrifti perceptio perhibetur, xquè de o mnib loquuntur,adultis, inquam, \& paruulis, vt A guftinus fxpiffimè aduerfus Pelagianos conter dit,pra 


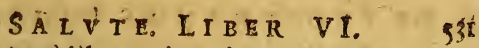

præcipuè libro primo de peccatorum meri- Aug.lib. ide remiffone, quod etiam Innocentius priin epiftola ad Concilium Mileuitanum aper nèdocet. At verò paruulos facramentóaltambui, quicquid Græci, 8 z Boêmi Hæretici radicant, $v$ lque adeò non eft necefe, vt conia potius confuetudó teneatur in Ecclefia 8z olim fi qui Patres paruulos communicanoutarunt, nulla id falucis neceffitate feciffe, controuerfia credendum eft, vt Synodus Triina commonuit. Hac igitur cogitanti mi- fejeat.c. 4. am verò ad huius occidui orbis Ecclefias o-

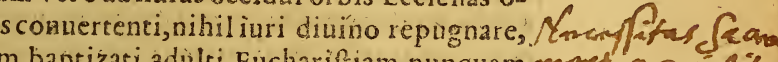
$m$ baptizati adulti Euchariftiam nunquam moreq se mpiph

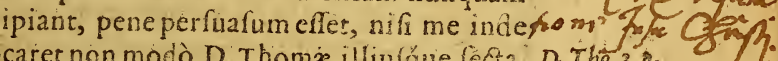
caret non modò D. Thoma illiulque féta- D. Tho. 3 p. $m$ authorıtas, quęa apud me valet plurimum, q. so.unt. r. tiam perfpicua atque efficax, quantum ego Domin. Sols o, ratio. Si enim facramenti cuiufque necefex ip fius fignificatione intelligenda eft, $v t$ efix conferfus docet, \& ba ptimum idcirco tam receffarium ominino fatemur, quod fpi lis generatio fit, nemo autem viuere queat, afcatur: Ponirentix quoque facran entum farium agnofcimus lapfis polt baptifmum, in eo per claues Ecclefix ianua aperitur icceleft is, qua occlufa nemo introire pofregnum : cùm Euchariltia cibus fit anima, e cxipla materia, \& inftitutione Domini. iffmè confter, qua obfecro racione exifl inpoftumus, nifi infanimus, tam pretiofum, falutarem cibumà Saluatore noftro infi. $n$, \& commendatum fidelibus, quibus taliberun fit vel nunquam illum ore conIt 3 . singers? in $4 . d .12 . \%$. 1.ar, $1, p_{e}-$ irses Sot. De Eucbar le de. 9. Pal in 4 . d. 9 q.1.i ritis cap. 20. Invo l. epif? foripio ad Conc. Mil. Concitrids Peccat.me- 
932 DE PROCVRANDA INDOR VN tingere? An eft minus neceffarius vitx tuend cibus, quàm medicina letali languori cura do? Nam qui vt hinceuadant, Chriftum mand cari fpiritualiter à fidelibus poffe aiunt, etian facramentaliter non manducent, atque eo cil vitam animæ ali, vera illi quidem afferunt, $f$ nihil de argumentationis robore imminuunt. tenim fpiritualis Chrifti manducatio etiam v teribus Patribus communis fuit, $v t$ A poltolus

2. Cor. 10. nè confirmat, Omnes, inquit, in mari $\&$ in nu baptizati funt, $\&$ omnes eandem efcam fpiritu lem manducauerunt. Attamen populus $\mathrm{Ch}$ ftianus in nouo teftamento ficut ad vitæ gen rationem accepit baptifmum, ita etiam ad vi iam acceptæ alimentum accepit Euchariftia Ipfum ergo Chrifum facramentaliter fume debet ad vitam fpiritualem conferuandam, fic in ipfo Chrifto per baptifmum neceffariò nafo tur. Neque mihi placet, vt re ipla atque actu a cipere hunc panem ad vitam anima fuftenta dam opus fit; fatis effe non dubito, ve voto acc piatur abeo, qui noneft idoneus actu acciper dummodore ipfa, atque actu aliquando fufc piat, quemadmodum de baptifmo, \& Confelfi ne facramentali Fides Catholica fentit. Etenil Iot*.\%. ficut de baptifmo dictum eft à Domino, $\mathrm{Ni}$ quis renatus fuerit ex aqua \& Spiritu fancto, no poreft introire in Regnum coelorum, ita erias

Itus 6. ab eodem de Euchariftia dictum eft, Nifi mar ducauer itis carnem filij hominis, non habebit

Nach. 28. vitam in vobis. Et ficut illic legimus, Ite, docet omnes gentes, baptizantes eos in nomine Patri 4.6\% . n. \& Filij, \& Spiritus fancti:fic etiam hîc, Hoc fac te in meam conmemorationem. Nam quod ill Domin 
SAIVTE. LIBER VI. $\quad 533$ mini verba, de Fidei manducatione tantumdo intelligenda quidam volunt, grauiter \& iculosè labuntur. De vtraque enim manduone \& Fidei, \& facramenti Chriftum loqui ipfe contextus apertè docet, tum Ecclefiæ holicæ confenfus conftantiffimè confirmat, teftimonijs illis ex fancto Capite Ioannis oftrinam Euchariftix confirmandam perpein Concilijs 8 decretis v fa eft.Verè ergo locur chriftus de facramentali manducatione, tantùm Fidelibus baptizatis in hac vita poconuenire poteft:beatis\& ântiqux legis pa. us conuenire non poteft, qui tamen Chria fpiritualiter manducauerunt. Quòd fi hac luftria Icripturæ verba nulla effent, fi nulla $m$ cibi fignificati ratio haberetur, illud tame ndè effe deberet, quod Ecclefix preceptum ommunicando ex Concilij Lateranenfis tëlegimus, vfum verò \& perpetuum \& vnia lem ex ipfo spiritus Sancti aduentu cerni, fentire verò fidelibus liberum fuiffe tunc itus à communione abftinere, vel ad id huo non diuino infituto vocatos effe, magnx fectò imperitix eft. Neque enim Ecclefia de amentis percipiendis folet ferre leges, fed ous temporibus neceffario funantur, \& qua one definire, id adfe pertinere propriè agnoEft ergo, eft iuris diuini præceptum, vt omadulti iam baptizati aliquando communit. Tempora autem percipiendx Euchariftix Concil Nica præcipuè fancta mater Ecclefia definiuit : $\mathrm{v}_{-}{ }^{\mathrm{c}} \mathrm{an} .13 .26$. a cùm quis mortis anguftijs, aut periculo pre q. 6. De his ur, tunc viatico neceffario iunandum facri ones ftatuunt: alcerum quotannis in Domi-

L1 3 nice tba.4.c.77.

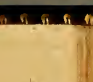


534 DE PROCVRANDA INDOR V M Cone. Late e. nico Pafchate, de quo praceptum extat Latera 20. Con Coxk.Tri.fef. verba,Si quiș negauerit omnes, \&z fingulos $\mathrm{Chr}$ 33.c.g. fifideles vtriufque fexus, cum ad annos di cretionis peruenerint, teneri fingulis annis $f a$ tem in afchate ad communicandum iuxta pra ceptum fanctx Matris Ecclefix, anarhema fit.

\section{q hóc capinto merg $D$ ifteofra}

Quiod quamuis dirinumpracepium fit de com. wnunic ando,poßic tamen Ecclefia proiu: dicio fuo commanionem negare. C A P. VIII. a cospar tad gro Colana rec Wmosos? pojita fun Damore - feruato huc vque more in hac noua Occident I a f. li Ecclefra fentiendum fie, vbi Indi adulti ia

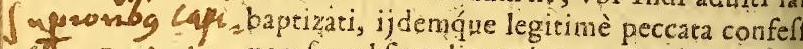
27itg Anhtia neq; femel fingulis annis, neque verò mortis v Lelf an whem gente difcrimine communicantur, adeoq́; id v L Jofu, $\mathrm{chm} / \mathrm{h}$ ue fandalum homines putent. An debet confu mima gug. ad $7 d$ - rudohæc ioter eas numerari, quas Auguntinus rabile sab iamepi. pienter pro varietate locorum varias efe in cechlat. clefijs feruandas docet? Ac ille in ijstantùm 'ea cchy ac Roma facultatem tribuit, qua non funt contra Fide nat fren w Catholicam, \& Conciliorum Generalium d con fun fund in creta, quale de communicandis adultis omnib

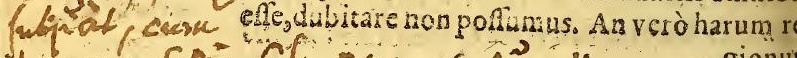
(1) Lemers refig 
SA I V TE. IIBER VI. onum hominestandiu abfurdè contra Ecclefticam difciplinam, \& Euangelicam legem erTe arbitrabimur? At multi præfules, \& dores fapientia, \& religione præftantes eiufdi morem, vel probarunt, vel certè diffimuunt. An potius quod hactenus factitatúm eft, non penitus improbare debemus, vt corrigi nen $\&$ in meliorem v fum transferri oporteat. hi fanè ita videtur: vt $\&$ modeftè de hac Ecfia noua fentiamus, \& 2 tamen veritatem $\mathrm{E}$ igeli), faluti præfertim Indorum tantoper ceffariam afferamus. Quod ve facilius intelliur, oporter illud diligenter aduertere, quòd amuis diuini \& Euangelici iuris fit, vt Chrianus aliquando communicet, potelt nihilonus illum ecclefia à communione fufpendenon folùm ad definitum tempus, fed etiam totam vitam, \& quod mirabile ef, ip fo morvrgente periculo poteft priuare viatico, neq; nen vlla ex parte ius diuinum violatur. Id ita e complures antiquorum Conciliorum Canos apertiffimè monftrant, quibus propter va$s$ caufas etiam verè pcenitentibus cùm de viexeunt, non effe concedendam Euchariftiam simus. In vno Elyberino Concilio omnium cancelybe? opemodumProuincialium antiquiffimo, pluf rinum in am feptem aut octo canones ob varia commif tomo. neq; in fine communionem accipiendam effe cernune. Ac nequis-vel Prouincialis Concilij choritatem, non magni faciat, vel peculiarem cuius regionis \& Ecclefiz eam feueritatem pu , legat beati Innocentij Papre epiftolam ad actum Exuperium Epilcopum Toloffanum, epi.3.64. ius verba recitare placer: Quafitum eft, in-

$$
\text { L1 4 quit, }
$$

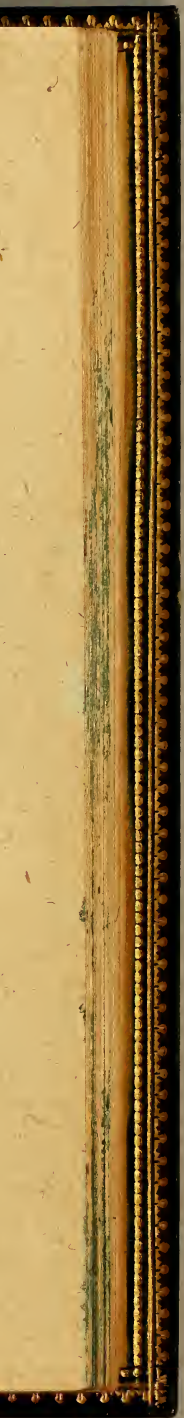




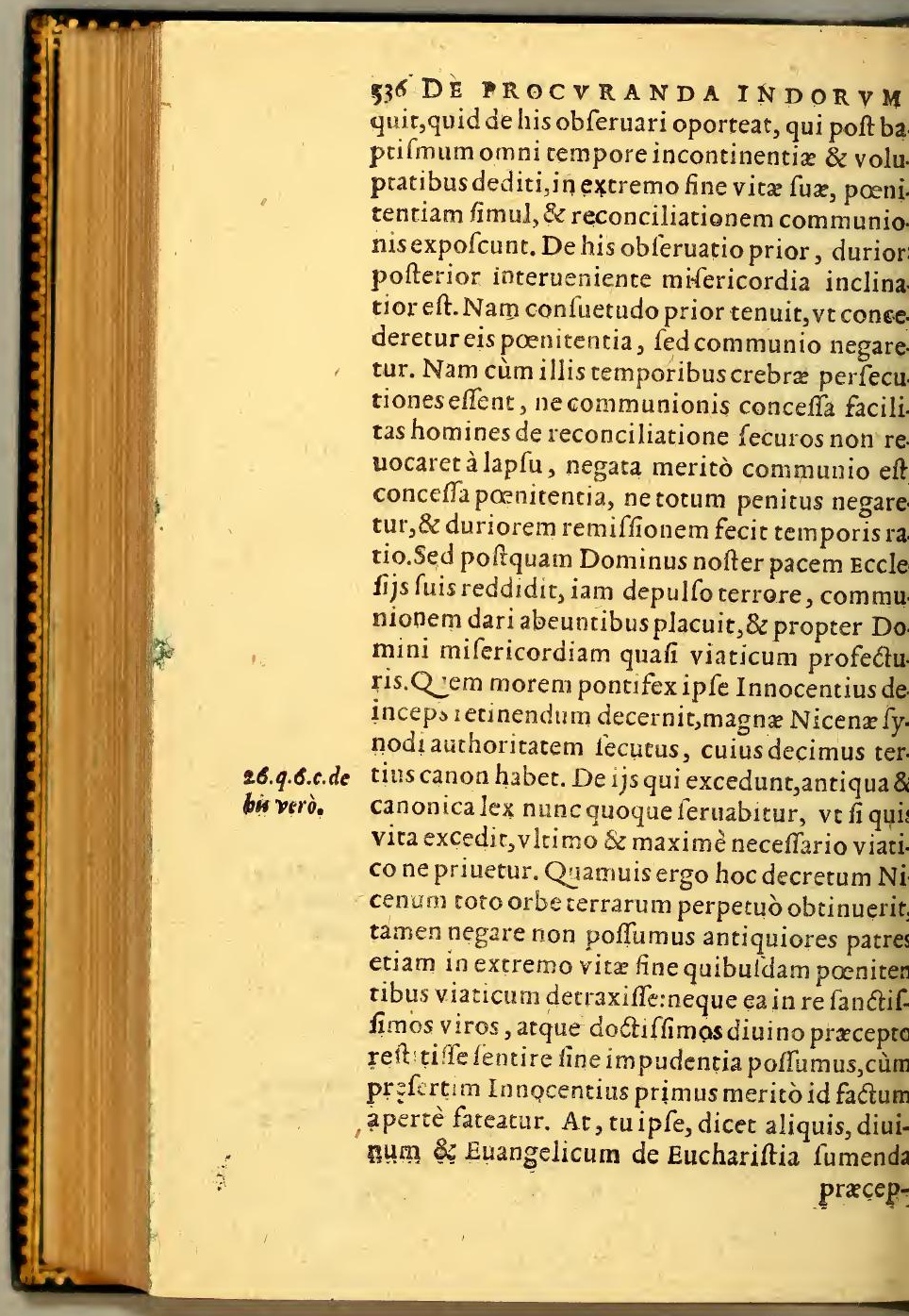


S A I V TE. LIBER VI. eceptum ftatuis: ftatuo fanè, fed ita tamen vt riftus Dominus Ecclefix fuæ commiferit, indo, \& quomodo, \& à quibus Euchariftia furetur. Itaque poteft illa legitima ex cau $\{a, \&$ apus prorogare, \& omnino fufpendere aliem à conmunione:ficut potuit eadé aliquaninfantes communicare probabili ex caufa, \& x id prohibere ex caufa:potuit plebem vtraq; cie communicare, \& mox id ipfum lege vee. Nam vbique quidem illa in difpenfatione ramentorum poteftatem maximam habet $\mathrm{di}$ itus datam, fed nufquam ita illufrem atque fpicuam, atque in hocomnium diuiniffimo ramento, quod profectò præclarè docent Tri- seff.21.c. zo ntini patres, illis verbis: Præterea declarat nc poteftatem, perpetuò in Ecclefia fuiffe, vt facramentorum difpenfatione falua illorum oftantia ea ftatueret, vel mutaret, qua fufcientium vtilitati feu ipforum facramentorum nerationi pro rerum, temporum, \& locorum rietate magis expedire iudicarer. Si quis ergo me prefsè, \& fcholafticè quxrat, qualenam fie Euchariftia percipienda diuinum pracep$\mathrm{m}$, illud fine dubio refponfurus fum, vt omnes arifti corpus ab Ecclefia datum accipiant. Nee enim iubentur arripere ipfi, fed de manu iniftrorum fumere:à quibus $\&$ petere debent, cùm illitribuunt, non poffunt perpetuò reere, nifi diuino iure violato. Neque verò, in 10 quaftionis eft nodus, propterea miniftri Ecefia, \& difpenfatores facramentorum Dei coutur, aut omnibus, aut omni tempore porrigeEucharifiam, fed fuo iudicio Ecclefia vti dinitus finitur, vt det vel fubtrahat in tempore

$$
\text { IL } 5 \text { tritici }
$$

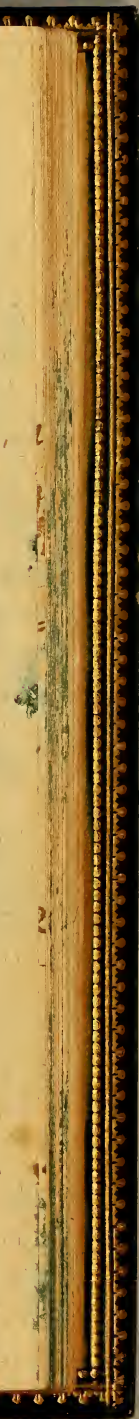




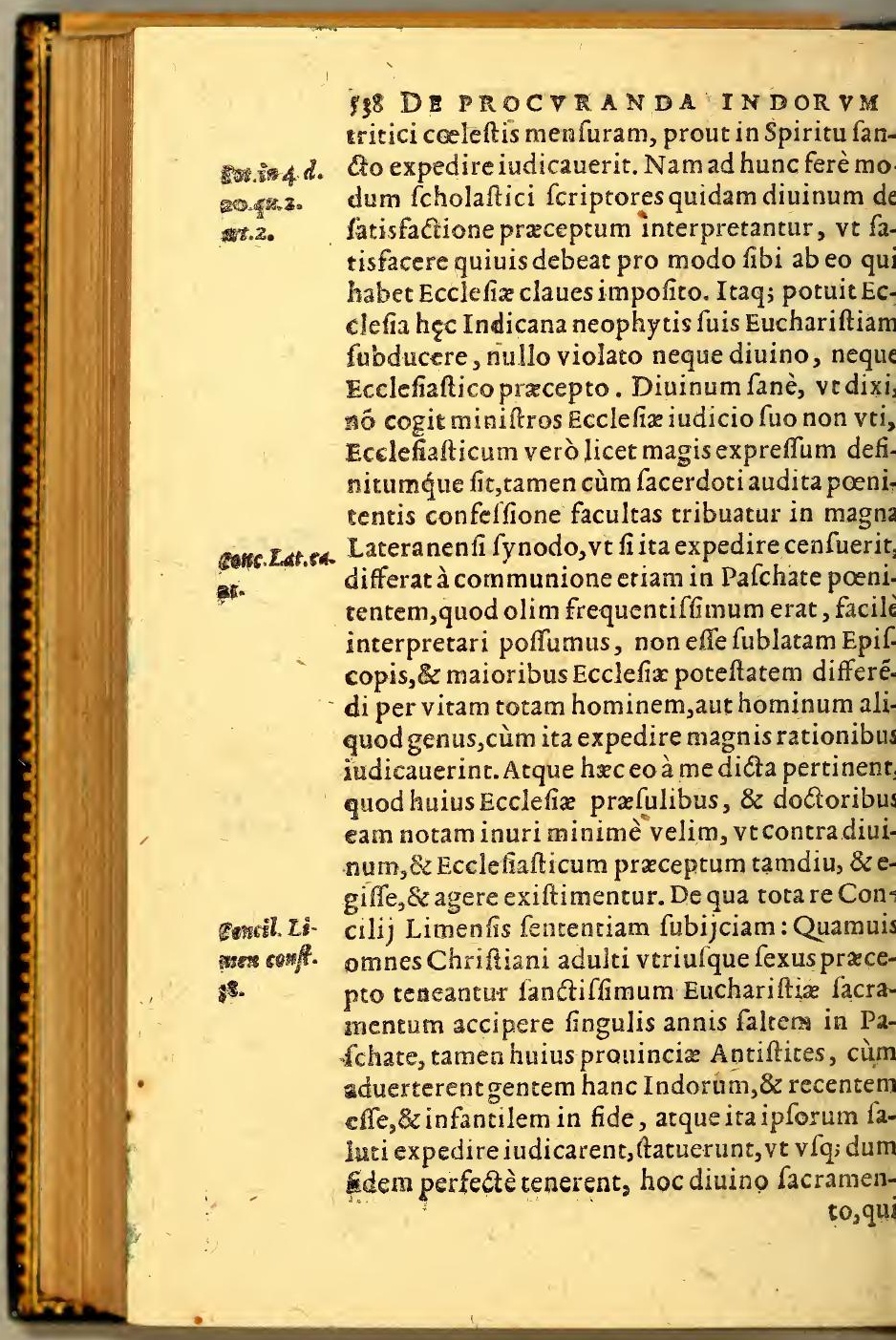


SALVTE. IIBER VI. $530^{\circ}$ Q, qui eft perfectorum cibus, non communicaentur, excepto fi quisei percipiendo fatis idoeus videretur.

Quod ommino expediat priori confuetudime emendata, Indos fideles communi-

care.

\section{A P V I IX.}

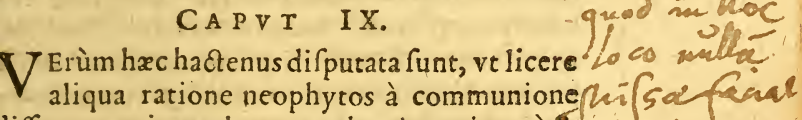

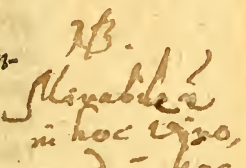
differre non improbemus: at hoc ita vniuersè perpetuo fieri, vt in his regionibus ferè fit, nullo modo probare poffumus. Itaque corrigenda eft prorfus confuetudo ifta, \& tam antiftitum autho cnen tamsn ritate, quàm virorum literatorum doctrina ab hoec fot jpso hoc nouo orbe exterminanda. Quamobrem in illo codem Concilij Prouincialis decreto, poItquam prior confuetudo aliqua ex parte excufa-m peipry m gitur: Quoniam verò complures iam Indorum Eadern cort cügs fidei Chrıftian $x$ doctrinam melius percipiunt, fii. $58_{2}$ atq; hoc diuinum facramentum non folùm deuotè cupiunt fuícipere verùm eriam petunt

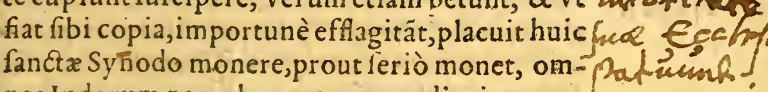
nes Indorum parochos, vt quos audita iam con. feffione perfpexerint hunc coleftem cibum à reliquo corporali difcernere, atq; eundem deuotè cupere \& pofcere, quoniam fine caufa neminem diuino aliméto priuare poffumus, quo tempore cater is Chriftian is folent, Ind is etiam omnibus adminiftrent. Quæ pia fanè, \& fatis confulta conftitutio nihilo magis, ex quo edita eft annos iam noucm obferuatur, quiã reliquo retro

tom 
540 DE PROCVRANDA IN DOR VM tempore: $v$ hinc fatis appareat, non veneratio. nifacramenticceleftis aut neophytorum falut plerofque facerdotes confulere, fed otio \& ignauiz indulgere, cùm religionem, $\&$ prudentiam in neganda Euchariftia perquàm ambitiosè prærexant. Quàm ergo magnoperè expediat nouos Chrift milites communicare illo pane, qui cor hominis verè confirmat, etiam fir rudes illi fint, 8 tyrones, oftendit in primis torius Ecclefix Catholicæab ipfis primis exordijs confuetudo, qua Spiritu fancto duce omnes Chriftiani ex ipfo fonte Baptifni ad facrolansta myfteria percipienda perducebantur. Adeò in Ecclefia Dei cer tum fuit, quibus effet lauacrum regenerationis legitimè datum, eis colefte alimentum concedi debere. Teftes multi produci poffent, fed vnus Dionyf. de nobis Diony fius Apoftolici, \& temporis, \& SpiEccl.fier.c. ritus fatis erit, is facros ritus baptifmi enarrans, 2.p. \&. ita fcribit, facerdotes illum veftem baptizati munditiz congruam induunt, ficque indutum rurfus ad Pontificem ducunt, ille diuino ac dei-

* fico prorfus vnguento virum figaans facratiff64.2.pa 3. mæcommunionis participem facit.Et mox tractata intelligentia baptifmi myftica,ita rem abfoluit: In fine autem omnium Pontifex ita perfectum ad facratiffimam Euchariftiam vocat,atque confummantiumilli facramentorum communioné deificam tradit. Hæc Diony frus. Quod vfqueadeò in Ecclefia feruatum eft, vt eos etiam quos minus confideratè baptifmo ablutos effe conftaret, ramen à communione non prohiberent, tanquan fuo iure id exigentes. Conftat hoc Come Tol.4. ex Concilio Toletano, vt alia omittamus. Qui cop. ss. autem iampridem ad Chriftianitatem venire coacti 
S A L V TE. L I BER VI. acti funt (ficut factum eft temporibus religio(fimi principis Sifibuti) quia iam conftat eos cramentis diuinis affociatos, \& baptifmigraam fufcepiffe, \& Chrifmate v nctos effe, \& cororis Domini, \& fanguinis extitiffe participes, crtera. Hac fanè Ecclefire confuetudo inuiota fuit, quod nimirum fancti Patres cenferent ne Euchariftia neminem effe perfectum Chriianum atque conftantem. Adeoq́ue id verum t fententia illorum, vt beatus Atiguftinus eós, ui non communicant non plenos Chriftianos, d femichriftianos, aut nondum chriftianos efinire videatur : Ita enim fribit in loannem: dixerimus Catechumeno, Credis in ChriAug.trate. II. in loans. um, refpondet, Credo, \& fignat fe cruce Chri$i$, portat in fronte, 82 non erubef́cit de cruce omini fui. Ecce credit in nomine eius interroemus eum, manducas carnem filijhominis, \& ibis fanguinem filij hominis?neficit, quid dicius, quia lefus non fecredidit ei. Et poft pauca: cceffic ad illos Iefus, facit in illis falutem, quia fe dixit, Nifi quis manducauerit carnem meâ, loan. 6 . biberit fanguinem meum, non habebit in fe itam. \& mox, Quò traijcit per baptifmum ieis, cuius figuram gerebat Moyfes, qui per maetraijciebat? quò traıjciebat?ad Manna, quid It Manna? Egofum, inquit, panis viuus, qui de olo defcendi. Manna accipiunt fidelesiam traeti per mare rubrum. Significabat mare illud ubrum baptifmum Chrifti, quò ergo perduit credentes \& baptifatos? Ad Manna. Et neciunt Catechumeni, quid accipiant Chriftiani, rubefcant ergo, quia nefciunt, tranfeant mare abrum, manducent Manna, vt quomodo crediderunt 
44E DE PROCVRANDA INDOR V M diderunt in nomine Iefu, fic fe ipfis credat Iéfus. Hactenus Auguftinus. In eorum ergo numero reponendi funt, qui non accipiunt cœlefte manna, quibus Iefus fe ipfum non credit, hoc eft inter femichriftianos, \& qui Catechumenorum - dinem non exceffere.Quantopere autem referat ad fidem confirmandam, ad fpem augendam, ad charitatem dilatandam, ad omnem denique Chriftianx vitæ rationem promouendam, coeleftis illius panis frequentatio, nemo eft prorfus qui dicendo fatis confequi poffit. Vnde oblecro tantus fidei ardor initio nafcentis Ecclefia, E4itor.2. rant, inquit, perfeuerantes in doctrina A poftolorum, \& orationibus, \& fractione panis. v nde ad calcandum mundi faftum, vnde ad fuftinenda martyria inuicta virtus? vnde ad glorificandum Chriftum inter gladios $8 z$ ignes tanta illa alacriChryf. bom. tas animorum?Ex illa, ait Chryfoftomus, menfa - adpop. tanquam Leones ignem fpirantes ipfi diabolo Ant. Cypr.libr.r. epifiz. formidabiles difcedamus.Quid Cyprianus?Idoneus effe non potef, inquit, ad martyrium, qui ab Ecclefia non armatur ad prælium: \& mens deficit, quam non recepta Euchariftia erigit, 8 accendit. Multum planè, $\&$ fupra quàm dici poteft baptifmus homini confert, multum cærera facramenta : fed fine hoc omnium facramentorum fummo, imperfecta cxtera funt, neque vitam Chriftianam, quam inchoant aut promouent, perficere pofunt. An nōDiony fius idoneus author eft,cuifidem habeamus? At ille fic fcriDiony?. de' bit, Dicimus ergocæatera facrarum rerum figna, Ecel.Her. c. quorum nobis focietas indulgetur, huius diuinis sip.s. profectò confummantibufq́; muneribus perfisi.Neq_i enim famè fas eft facerdotalis muneris 


\section{SA L V TE. LIBER VI.}

yferium aliquod peragi, nifi diuinum iftud chariftiæ auguftiffimumqú facramentum com eat.V fq; adeò fancti Patres nolunt Chriftianos cramentis creteris effe contentos. Quid ergo ss tam ftolidè, vel querimur, vel miramur Inrum gentem nondum firmas in fide, \& relione Chriftiana egiffe radices? Baculum panis Eq̧en. ferimus, vt propheta loquitur, 8 imbecillitam miramur? Famelicis alimenta diuina fubahimus, \& maciem greffulq́ue titubantes accumus?Propheta fe percufum, $v t$ foenum $\&$ a . Pfalı $10 t$ iffe cor fuum dolet, quod oblitus fit comedere nem fuum:quid agent, qui nunquam illum etm deguftarunt? Nos tamen nihil tot in Chrifto ruulorum feruitutem interitumóg; dolemus. ùm deficiat paruulus, \& lactens in plateis op- Thres.s. di, hocef, cum recens in Chrifto nati nobis ectantibus, \& tacentibus in media Eccle fia inreant præ fame, $\&$ quidem cùm infént ipfi,ate auidè diuina facramenta pofcant, non eft i porrigat, omnes dedignantur, omnes auerntur miferos, vt verè videamus impleri, quod mo dininus ftatim adiungit, Matribus fuis dirunt. Vbi eft triticum \& vinum? cùm deficent quafi vulneratí in plateis ciuitatis, cùm exlarent animas fuas in finu matrum fuarum. uod fi panis hic coeleftis propriè cor homi. $P$ S2l. s confirmat, fi fenfum mentis illuftrat, fi adrfus pericula \& hoftiles impetus munit, fi deque vnus vitam fpiritualem conferuat $\&$ percit, quid aliud quærimus, curdeficiente pae corruant ifti vnufquifq; ad proximum fuum, Eqech.4. contabefcant in iniquitatibus fuis? Re vera eficiunt in via Domini, quia contra Domini Aarc.go prace: 
$\$ 44$ DE PROCVRANDA IN DOR V præceptum finuntur abire ieiuni. Contra qui Pal.4.", cunque hoc cibo reficiuntur, à facie frument multiplicantur, \& vires quotidie nouas fu munt.Docuit hoc vfus ipfe copiosè. Nam quot quot ex Indorum genere à noftris ( qui con tradicentibus cæeteris id aufi aggreffique funt communicantur hactenus ea puritate, co anim robore,eo fidei fenfu, ijs denique vitæ vniuer fæ Ptudijs, cæteris præftant, vt meritò facerdote ipfi mirentur, atque ingenuè confiteantur am pliores, \&illuftriores huius fupercoleftis pa nis fructus in neophytis cerni, quàm in cæteris neque immeritò. Nam $\&$ fide \& deuotione no vincunt:quod nos ip fi abundè fumus experti. Fe rè commune prouerbium Indis eft, eum, qui fe mel Euchariftiam acceperit, nullum ampliu crimen debere committere: quod fi quando hu mana fragilitate admiffum fit, tanto animi do lore tanta in feipfum indignatione commotum ad pœenitentiam venire Indum confpeximus, \& tam duras de fuo fcelere poenas exigere, $v t$ ar dorem fidei admirati fimus. Neque enim tantam inuenimus in Ifrael. Scimus aliquot per fimula tionem diuino obrepfifie conuiuio non indutos vefte wuptiali, fed abeant fimulatores:nos de ve. rè abrahæ filijs loquimur, quos non dubitamus

Matth.8. ab extremo hoc Occidente in menfa Domin cum Abraham, \&zlfaac, \& lacob praclarè re. cumbere. Certè Euchariftia ipfa pro fua benig. nitate, \& magnificentia nouos menf $æ$ fuæ con. uiuas largius locupletiulq́ue videtur excipere. Quare cùm perpetua totsus populi Chriftiani confuetudine, cùm maiorum noftrorum ac fan. ctorum Patrum authoritate, cùm ratione ipfa perfo 
SA L V TE. II BER VI. rfpicua, cùm teftatiffima experientia doc $\$ 45$ nouis Indorum gentibus fuper ur nouis Indorum gentibus fuperfubftantiale nem communicare, quis deinceps tam erit elefti beneficio ingratus, ta $\mathrm{m}$ negligens falufratrum, tam ipfius Chrifti Iefuglorix inui$s$, qui non inepto hoc more longiffimè releto, facram Euchariftiam auidè płafertim tentibus fratribus arbitretur effe tribuen $m$ ?

\section{Confutatio opinionis contraria.}

$$
\text { C A. P. } X \text {. }
$$

T perfectorum, inquiunt, paniseft ille cœleftis, cibusgrandium, vt Auguftinus auגit, crefcant, \& manducabunt. Imò verò man. cét, vit crefcant. Neq; enim ego A ngelorü pa$\mathrm{m}, 8 z$ fuperfubftantialem virorü atq; perfeorum cibum effe nego:verùm idem cibus eft rulorum, idem infirmorum alimentum. non diuina fapientia poftquam ædificauit prouer.9. i domum, \& excidit columnas reptem, \& imolauit vidtimas, \& mifcuit vinum, \& propoit denique menfam fi am, ita alloquitur conuas fuos. Si quis eft paruulus veniat ad me, 8 fipientibus locuta ef, Venite comedite pam meum, \& bibite vinum, quod mifcui vos, relinquite infantiam, \& viuite \& ambulate $r$ vias prudentix? Paruulos ergo alloquitur, ruulos inuitat ad coleft is men fx conuiuium. am cùm diuites illi ac prapotentes varijs ex Luc.14。 ufis venire vocati recufaffent, Rex qui lautas fplendidas epulas appararat, feruos luos, vt Matt.23. $\mathrm{Mm}$ 
S46 DE PROCVRANDA INDORV debiles \& claudos , \& pauperes accerferént, $m$ fit, vfque dum conuiuis domus regia impler tur:atque illud folum in conuivis expoftulaui quod quidam veltem nuptijs dignam non att liffet. An non verò quos Dominus libenter ve cat, \&z gratos habet, hos miniftri iure faftidian Cer tè fancti Pares, qui panem hunc perfect rum, $\&$ virorum in Chrifto cibum effe volun ijdem debilium, \& paruulorum viribus auge dis, \& confirmandis, \& medicinam, \&zalime tum effe aptiffrmum copiosè teftantur. Non e go quoniam minus perfecti in fide, \& charita neophytifunt, repellendi funt, fed multo mag inuitandi, \&zalliciendi, ve vfu iplo panis huiu: qui cor hominis confirmat, perfecti fiant. A:l ftoliditatem \& imperitiam barbarorum nob obijciunt, indignum effe dicentes, fi canibus: porcis margaritas proijciamus. Sed qui Chrif lauacro purificatil legitimè funt, canescertè, ? fues illi no funt. Quod fi fenfus horum exigut eft, netales quidem à fe repellit benigniffm: Tbom. 3p. Dominus. Diuus fanè Thomas tantæa autoritat 9.80.a.9. virijs,qui debilem habjent vfum rationis, no effe denegandum hoc facramentum, apertè fr. - bit.Vt enim fenfu $\&$ ratione parum valean multum tamen prafiabunt amentibus, \& phrs neticis, quorum fi anterior deuotio teltata fi inftillandam illis atq; infundendam Euchar: conc. Car- ftiam, fanderum Patrum Canonesiubent. V fo tag. $4 . c_{7} 6$. 26.q.6.Is adeo pluris fuit fructus, quem ex hoc facramet to homines percipiunt, quam fpecies quadar qui in infir- religionis, quam multi hoc tempore præ fe fo mitats. tunt. Acrevera non eft tam Indorum fenfu exiguus ad percipiendam Euchariftiam, quàr 
SAIVTE. LIBER VI. rochorum magna defidia ad porrigendam; m vecuram laboremq́ue docendi, \& præpadi plebem à fe reijciant, ruditatem \& impeiam iftorum obtendunt. Non fatis difcernic dus inter cibum facrum \& profanum, inquis: quîpoteít ille difcernere, fi tu nunquam hoc cuifti ? Non eam deuotionem affert, quam ortet. Quomodo verò afferet, fi tu ad coelefte ramentum nunquam inuitas? fi neque dignim commendas, neque immenfam vtilitatem es? Omnino experti fumus ipfi, quàm vehenter excitentur Indi, cùm hæc illis commerantur, quăm omnia \& polliceantur, \& $x$ præa, velicear eis de illo pane edere. Quanta veinuidia, quo dolore pulfentur cum intuenHifpanos communicantes: quod fi quem rum hac menfa dignatum conlpiciunt, om. m ftudia ardent, atq; ad fefe diffundi eam lialitatem vehementer efflagitant. Itaq; ad do dam fidei catechefin, \& ad rurpia quadam vi profliganda, ebictatem præfertim, nullum sedium præfentius experti fumus, quàm vt a communio pramium proponeretur $i \mathrm{j}_{2}$ \& fidei dogmata optimè tenerentatque exmerent, \& mores Chriftianosatque honeftifos pra fe ferrènt. Certane ineer fe, cùm ifta liunt, \& gratilfimum habent,cum admittun, refectiớue femel cibo coelefti puritatem ntis, 8 corporis miultò fudiofius quàm $\mathrm{H}$ ifii conferuahe, ve redire liceat ad menfam $\mathrm{m}$, ardenter exoptant . Hoc parochicomres minus credunt. At nos non longè pe. loquimur, faciant ipfi periculum, fi zeDei habent, ac non negligentia pretex. $\mathrm{Mm}_{2}$ - tunt

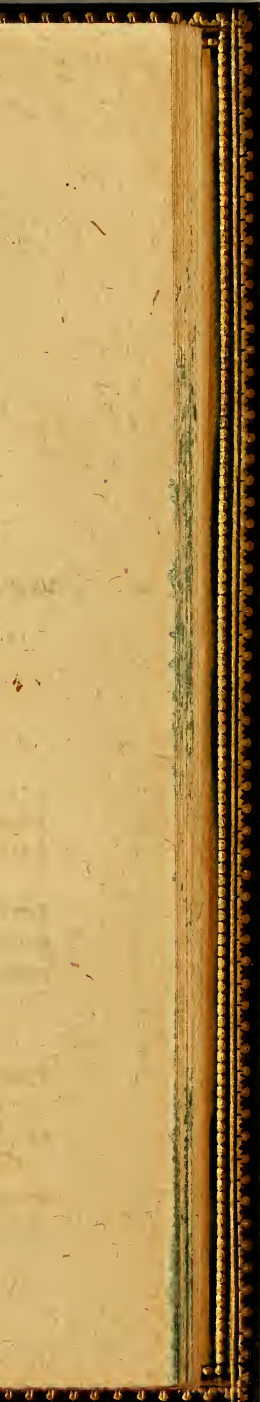


\$4 DE PROCVRANDA INDOR M tum quærant. Sed qui grauius \& probabiliv videntur morem iftum fuum defendere, illu obijciunt, quòd non tutò prabeatur Euch siftia neophytis, quippe qui veterem fupe Ationem non fatis exuerint, fierique poffit, indignum aliquid in Chrifti corpus defignen cü nó conftet fatis animo an fint fideles. Iftoru flagitia v fitata commemorant, for des præfert carnis, \& $z$ temulentix. Talibus porrigere facr mentum nihil effe aliud quä in cloacam aut fe tinam proijcere. Quibus equidem refponde non abfq; probatione, \& examine panem illu prabendum effe neq; nouis, neq; veteribus $\mathrm{Ch}$ 8.Cor.j. ftianis. Quod fi quis eft fornicator, aut ebriofi aut idolis leruiens, cü eiufmodi etiam comm nem cibum capere Apoftolus vetat, nedü coele menfa communicare. Verùm hoc neq; omniu neophytorum eft, neq;ifillorútales funt aliqu do morbi aliter in illis curandi funt, quá in ça ris fidelibus, quorum nouimus corruptos mor \& vitam admodú flagitiofam legitima poenit tia \& confefsione detergi, atque ita falubri fat factione purgatos, vt ait Leo Papa,ad commun

Ioos. De gerit.d.1. c.mulrip. nem admitti. Cur igitur nó idem apud Indos dulgentiæ erit, quibus eo magis cùm labütur v nia danda eft, quod ignorácia potius, \& imbec litate quadam, quàm animi peruerfitate labor Itaq; velad ipfa iftorum vitia amputanda $8 z$ lenda fingularis remedij $\mathrm{eAt}$, diuiná cômunio ijs, qui ab ebrietate $\&$ cæteris fordibus diligê cauent, præmium ponere. Neque enim vbi pe fpecta eft fuperftitionis antiqua aut ebriofitat aut fœed $x$ confuetudinis macula, ad altare Ind 
SA L V.T E. LI BEK VI. ebet admitti, nifi contraria opera illam manieftè $\&$ diligenter eluerit. Nametfi veniam $\mathrm{Ab}$ loni filio, Ioabo interpellante fapientifsimus auid negare non potuit, ingreffum tamen Hieufalem à fuo confpectu per biennium abfinee iufsit. Intelligant Indi quod communione riuantur non effe nationis, fed criminis: $8 z$ vnierfum Chriftianis concedatur, fed non Chriiano dignis moribus fubtrahatur. Neque ego imiam modò frequentiam Eucharifix in Inis probo, fortalsis enim facilitas contemprum ariet. Sed illud cótendo, vt quotãnis nifi ex cercaufa communicentur, ve Ecclefia pracipit, um præcipuè,vt cùm de vita exeunt, \&z ritè faerdoti confefsi funt, viatico neceffario ne prientur, quemadmodum habet Nicenus Canon. uinam autem indigni, ineptiue fint, quibus ngelorum panis præbeatur, facerdotum ipfoum audita confefsione cxterifque perfpectis, udicium efto.Sacrilegiorum verò, qua quidam ut metuunt,aut infimulăt, profectò periculum ullü êt, aut perquã rarum. Neq; enim Indi luæorum more auerfi funt à my fterio Chrifti,neue eft timendum, ne contumelia afficiant fumtam Euchariftiam, quam reuera venerantur, eque eius generis exempla hactenus certa vidi nus, quin potius quod ad externum cultum atínet, multò quã veteres Chriftiani ad religioné ropen fiores funt. Q:od fi pueris olim,\&phre2eticis Euchariftia dabatur, vt Ecclefiaftic hitorix copiosè teftantur, neque id contra religio nem cenfebant fancti Patres, cur illi facramento fat iniuria, fi pauperes \& egétes iuxta Pfalmum dant, \& faturentur, qui fi iudicio aut doctrina P $\mathbf{S} a l_{.2 \xi_{0}}$ 


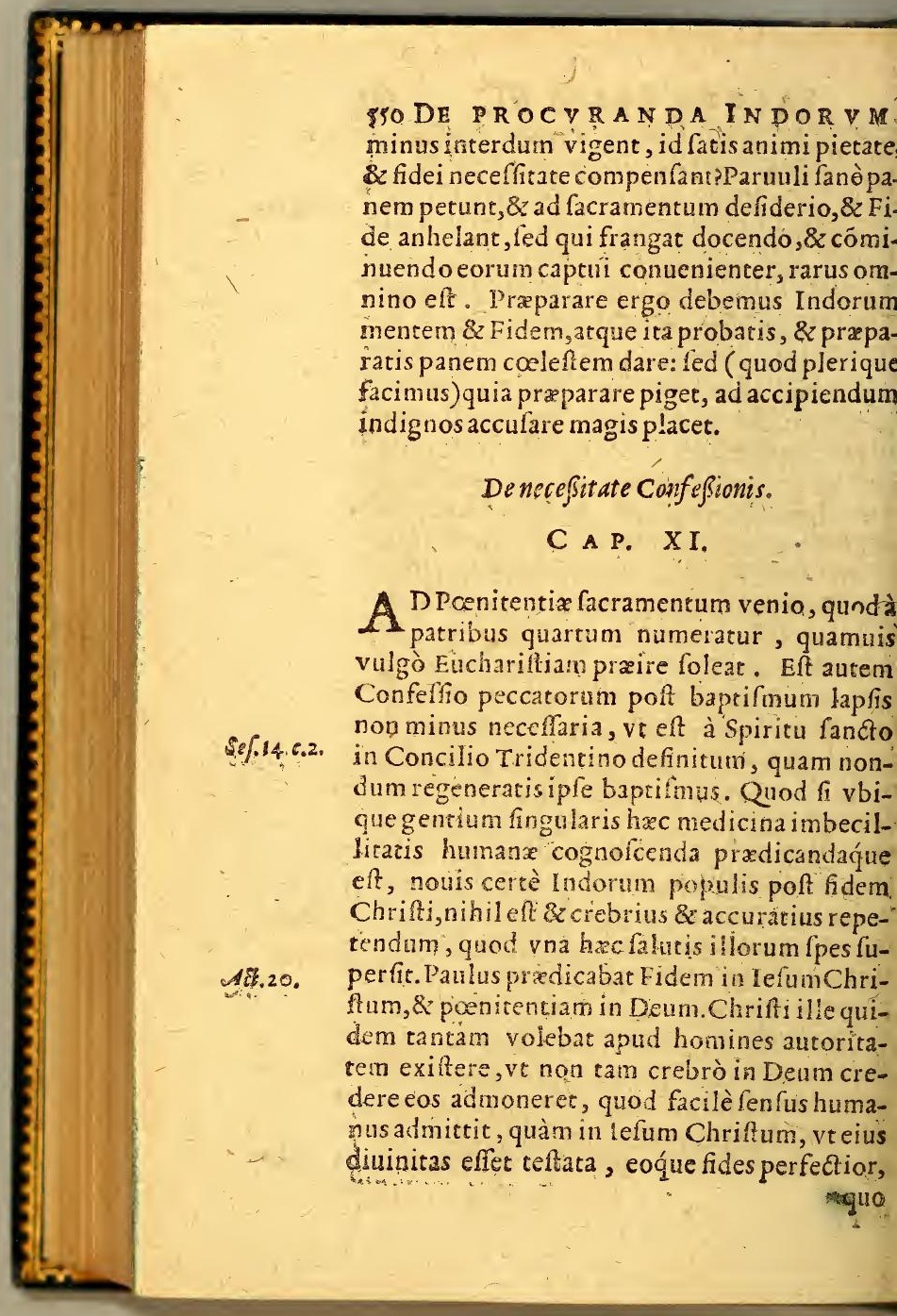


5 A L V TE. LIBER V. o fenfu humano fuperior. Contra, Poniten$\mathrm{m}$ in Deum maluit dicere quàm inChriftum, cùm criminum quifque fuorum meminiffet, um ipfum, non hominem folùm, fibi offen$\mathrm{m}, \mathrm{\&}$ iratum cogitans, vehementiùs doleret, loniam verò pœnitentiam etiam ante bapmum ita neceffariam effe confat, vt tamen fibaptifmo vel re vel voto fufcepto non fuffi$t$, confequens eft prorfus, vt qui primam renerationis ftolam maculauit, \& pcenitentia ligeat, \& per clauesEcclefiæ gratix reftitui de at, fine quibus falutis aditus nemini poft bapmum lapfo patere poteft. Barbaris auté, quon eft fenfus natura imbecillior, Fides vèrò $n$ admodum excitata, rarum eft valde, vt pertus ille dolor, quem contritionem dicimus, criminibus commiffis hæreat, quo magis di$\mathfrak{x}$ medicinæ auxilio excipiendi adiuuandiq́; t, vt quod hominis operi deeft, coleft is famenti vis fuppleat, Nam quod Abfolutionis aeficio dolor ille non vfquequac; perfectus, ì plerifq; attritio, à nónullis imperfecta cótio vocatur, valeat ad falutem \& primam iuficationis gratiam confequendam, tam mihi tú eft, vt inter catholica dogmata propemomumerandum puté. Neq; obfcurè Tridenti Patres id docuiffe videntur, cùm eam attritio $\mathrm{m}$, qux per fe non iuftificat, ad iuftificationis tiam in facramento Pónitentiz impetran$\mathrm{n}$ valere declararit. Mihi verò \& ratio a perperfuadet, cùm per claues Ecllefix detur ra abfolutio culpx, idque per $f e$ \& ex proia inftitutione, cum fitetiam morbi letalis me cina pręfens, fit leprę oftéf ę purificatio opera-

$$
\mathrm{Mm} \& \text { toria, }
$$

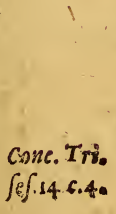


5\%2 DE PROCVRANDA INDOR VM toria, fit deniq; mortuæ animæà morte peccat excitatio, quemadmodum fanctorum Patrum literæ produnt:tum maximè me confirmar quo tidiana diuinze operationis experientia, fi ta men occultæ operationis experientia dici de bet, fiducia quadam de multorum hominum fa lute certiffima. Cernimus planè innumerabile animas minus perfectò dolore pro fcelerun magnitudine commotas ad hoc facramentun accedere, quibus poltquam quod in nobis fitun eft, praftamus, \& de Dei immenficate confifi fa cramentum abfolutionis impendimus, ade cceleftium donorum, quantum homini conjjce re datur, teftimonia non obfcura fuccedunt, $v$ Matt 18. nihil aliud cogitare poffimus, quàm quod veri Iow3.20. frima bonitas dixit: Quæ folueritis in terris, in coelis foluta erunt. Qua mobrem non eft cu: quifquam de Indorum falute defperet, nequi corum tenues conatus, $8 z$ examinationes con. fientix, \& minus accuratas peccatorum enu. merationes, $\&$ doloris non vfque adeò expreff: figna, \& cxtera pro eorum captu non magn: Rom.14. Contemnat:fed quantum poteft, ip fe adiunet fra trem, \& infirmum, ve ait Paulus, in fide affumat agat denique quod potert, id verò omne, quoc Sap. 6. Ejai. 28. Efabi,so. reftat, diuinæ clementia committat fecurus, qu: exiguo facilè concedit mifericordiam, \& labo. rantem ac laffum reficit, $\&$ hoc habet ipfe refrigerium, fi reficiamus agrotum, \& fciamus ani. mam laffam fuftentare fermone, $\&$ de tenui of ferentem Domino, quod habet, non afpernemur. Equidem horum miferorum confeffiones impéritas fecurius audio, quã hominum præpo. tentum expolitas, \& magna doloris fignificatione pro- 
SA L V TE. LIBER VI. 593 e profufas. Cùm ergo in hoc facramento vnica t fpes falutis Indorum, præ omnibus \& dilientius $\&$ crebrius meditandum prædicandújue erit.

Confeßsionis peccatorum vfum Indis in fua fuper. . fitionef uiffe.

\section{A P T X XII.}

Llud autem meritò mirari quifíam poffit, Confeffionem peccatorum etiam occultoum, \& grauium celebri vfu apud hofce barbacos longè ante Chrifti Euangelium auditum, requentatam. Erant facerdotes non pauci huic pfi muneriaffignati, qui plebis audiendis confeffionibus vacarent. Atque ad fingula depromta peccata ex manipulo quodam foniculum frangens facerdos, $a b$ eo videlicet crimine liberum pronunciabat. Vnde apud fuperiores Prouincias Ychufyres eiurmodi facerdotes vocabantur. Ac vt mihi quidem narrabant Chucuiti. Parochiarum præpofiti, non omnes omnium criminum abfoluendorum parem poteftatem habebant : fed grauiora quædam facinora apud primarios veluti Pontifices deponere vfus erat. Hanc ergo confuetudinem inter idololatras barbaros religiosè obferuatam mirari, vt dixi, meritò poffis. At illud non admirationem, fed ftuporem mihi propemodum affert, valuiffe santum Diaboli hominumqúue mendacium apud homines, vt non folùm occulta crimina proderent, fed fęuas etiam poenas fibi pro ijs iniungi æquo animo paterentur. Iubebantur fa-

$\mathrm{M} \mathrm{m}$ s peex- 
54 DE PROC R R N DA I NDOR V M pe expiandiadulterijauralterius fceleris caufa; duriffimo faxo ad fcapulas tundi fortiter, interdum à iuuenibus diu virgis cædi, non rarò fi fce Leris magnitudo acerbius aliquid portulare videretur, in excelfam atque omni folatijgenere deltitutam rapem fecedere, \& longum ibi æuŭ, ferarum more traducere. Complura iam eius generis narrant, quæ fabulis fimilia videri poffent, nifi nobis fuperfites ad huc fenes, quofdam decrepitos eo munere olim apud fuos functos viri fide digni oftendiffent . Caufam ego huius confuetudinis barbarorum illam potiffimum probo, $q$ Diabolus per omnia in Dei fimilitudivê etiam nuncinfaniens, ficut fe Deú adorari \& falutari mortalibus illufis perfuafit, ita Dei veri facramenta religiofaque inftituta transferre adfe falfa quadam imitatione contendit . Nam quo alio fpectat, quod in Cuzquenfi vrbe Ingarum imperio celebri, Euchariftiæ noftræ vmbram quandam \& fimulachrum adhibendum curauitecùm ex maffa facrificij nefcio cuius fanguine afperfa buccellas quafdam folennes fingu Li acciperent, atque comederent, quibus Principis Ing $x$ fidem, \& focietatem frbi cordi effe vfque ad fundendum pro ipfo fanguinem teftaren cur. A tque ad cum modum fefto quodam die peregrini prxfertim atque aduen $x$ communicabant. Prxtereo Trinitatis imaginem in Tanga- eanga apud Sacacas veteri more cultam,omitto alia complura, qux curiosè huc accerfere poffem: quibus cum fidem olim barbari haberent, minus dificules ad credendum, cü noftra narra mus, fefe præbent.sed diffimulari profectò non potelt, quàm nobis erubefceadun fit, quod a $\mathrm{Sa}$ -

i tanas. 
SALVTE. IIBER VI. $\$ 5 S$ anæ miniftris fuperemur,cùm ad falutares ix liuinitus inftitutas confeffiones perfuadendas igriores fimus, quàm illi ad fxuas illas fuas arni ficinas. Gratulandum verò eft in tanta méis humanæ cæcitate, effe aliquem fcelerum fenum, nonnullum confcientix aculeum, quo tran juillitatem fuam occulto veneno expofito queere quodammodo cogitur. Et quia vera remelia minus occurrunt, falfis fe faltem, vt poteft, ecreat, atque fuftentat. Tanta eft culpx intus laentis vis. Quò magis fidere debet Chrifti ferus, \& veram peccatorum omnium medicinam genitentiam per falutarem confeffionem often lere. Facilè fibi perfuadent Indi Confeffionis acramentalis vfum \& vim, neque recufant cerè medicum (etfi pleriq; contra calumniantur) nodò eum effe perfpiciant, qui verè̀ medicus it, non infeftus carnifex, aut auarus prædo aninarum:

e peritia Indicalingus Confe Sionibus audiendis neceffaria.

\section{A P V T XIII。}

V A L E M verò effe oporteat medicum, quo falutis animarum zelo feruere, qua eritia a periendis curandifóue vulneribus prelitum, fatis vt arbitror, fiupra dixi.Attamen fernonis Indici peritia quantopere defideretur, $10 \mathrm{c}$ maximè loco ap paret. Cùm neque pœnientiú crimina agnofcere neq; falutarıter prouiere niff lingux minifterio poffit. Cuius qui exers fit, turrum Babelicam, non Euangelicam is adifie

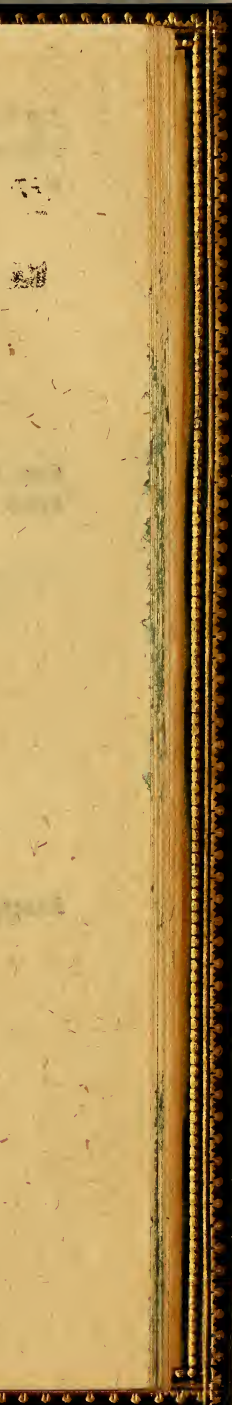


\$द6 DE PROCYRANDA INDORVM S. $\boldsymbol{T}$. re redificet, neceffe eft. Et quamuis inter viros Theo

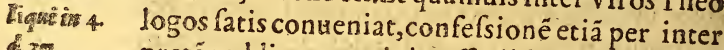
6.27.

pretê reddi, atq; accipi poffe, ijdem tamen æquè confentiunt, nulla aut diuina, aut Ecclefiaftica lege homines ad eum confefsionis modum compelli, quippe cùm lex Dei fuauis $\&$ æquitatis ple na nolit cum tanta fua moleftia ad confitendum peccatorem cogere, cùm præfertim pudore metuque humano, qui vbi tertius adeft teftis aut arbiter, maximè vrget, ne confefsiones integra Conc, Lim. fynceræçue fierent, meritò verendurn effet. Quãceres. obrem confultè fatis in Limenfi fynodo Patres ne Indorum confef siones per interpretem Parochi exciperent,graui propofita mulcta veruerut. Quod tamen decretum non eò pertinet, vt non liceat fponte fua volétes Indos per interpretem confiterimorbo præfertim periculofo oppreffos audire, vbi facerdotis Indicè docti copia deeft, atque eo faltem modo horum faluti confulere, quod à quibufdam religiosè factum nouimus, \&ratio ipla monet, vbi poenitens iple iacturam eam omnem præ falutis fuæ défiderio cótemnit, non oportere fpiritualem medicum labori, vel

Eeep. 78. fuo,vel illius.parcere. Neque verò hoc Sancti Leonis antiquo Canoni contrarium eft, qui folùm reprehédit, \& vetat. Ne populi auribus profeffio publicè recitetur, cùm reatus confcientiarum fufficiat fol is facerdotibus indicari confelfione fecreta. Nam \& nonnullas confeffiones cum alij plures intereffent $a b$ antiquis ChriRuanisfactas effe hiftorix produnt, \& hi ipfi barbarifcelerum fuorum notitiam fallis facerdocibus reddere frequente corona non verebantur. Verùm quia hoc $\&$ rarum ef, vt poeni- 
S A I V I E. I I BER VI. $\$ 57$ tens libenter accipiat, \& qua neceffitate fiunt, præter legem funt, nullo modo pateft falua confcientia Parochi munus vfurpare, qui per fe ipfum Confeffones populi fibicommiff, hos eft fine interprete audire non polfit. Quod fi bona fide prafecturam non tam à fe quxfitam quàm ab Antiftite fuo fibi impofitamagat, \& quamuis non omnia optimè intelligat qua poenitens loquitur, plurima tamen \& communiora \& grauiora non ignoret, atque ipfe viciffim opportuna confilia adhibere mediocriter poffit, non erit deterrendus ab eo officio facerdos, cùm peritiores præfertim defunt, \&z zelo ipfe fpiritus fermonis inopiam abundè compenfat. Damaf. Tutiffima res obedientia eft, \& fola,vt Damalce $H$ iffor. nus ait, citra periculum.

\section{Deprudentia Sacerdotum of tolerantia.}

\section{CAP. XIIII.}

SErmonis ergo Indici peritum oportet effe fa$S_{\text {cerdotem:verum non minus morum } \& \text { inge- }}$ nij Indici peritum. Idololatriæ genera \& flagitiorum $\&$ cæterorum, in quibus frequentiores funt, vel experientia ipfa difcet, vel aliorum commemoratione cognofcet. Sunt etiam nonnulla commodè literis commendata. Ex quibus omnibus ipfe fibi Indicem conficiet, ad qué con feffiones examinet, quatenus opus effe prudentia perfuaferit. Neque enim omnes eodem ma do examinandi erunt. In eum vfum tum ab alijs, tuim à noftris nuper Confeffionalia quxdam perfcripta funt, vtraq; lingua his region:bus 


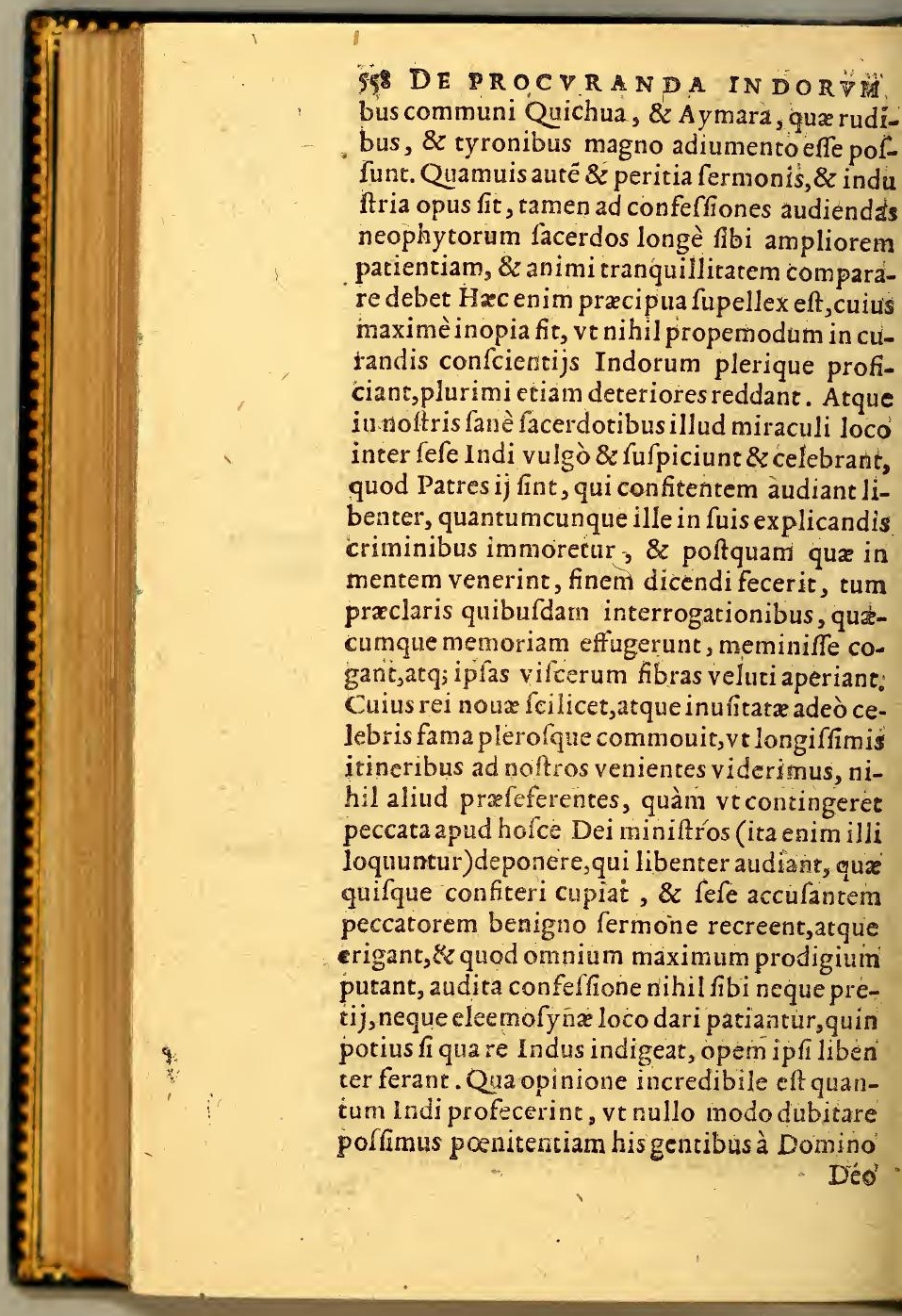


SA E TE. LI BER VI. S. Deo datam, minifrorum culpa fuife minus hactenus fructuofam, eandem futuram fruetuofiffimam, fi vel mediocrem animialacritatem in excipiendis infrmis medici fyirituales præfeferant. Sunt ergo Indiaudiendi toleranter, funt inuitandi benignè, erigendi fapıenter, funt denique in omnibus æquo animo ferendi. Charitas enim omnia fuftinet, omnia fuffert, \& in fpiritu lenitatis pręoccupatum aliquo delido initruere docet.

Quod confeßsiones non fyncer a fiant, potius facerdotum, quism Indorum fieri

culpa.

CA P T XV.

Vibusex rebus facilè intelligere poffumus, quod plurimi Indorum malignè facramento poenitentix abutantur, non fy nceras, neq; integras peccatorum confeffiones facientes, fed fucatas ad fpeciem, 2 mutilas, non ram ad iplorum referendum effe malitiain, quàm ad Parochorum fruos mores, 8 imperiofam quandam aufteritatem, qua infirmum \& frabiofum pecus faftidiứt, \& calce abijciuút, qui errátes oues funEzech.54: da potius \& baculo terrét, quá fabylo leni colligüt, immemores prorfus illius magni paftoris, qui dixir: Sibilabo eis, \& congregabo illos, quia zacbs. redemieos. Profectò fi fideles Hifpani cófelfariú nact i efsét talé, fruienté,\& magis finire pro perantem, quả andire omnia curanté, rarus effet omnino, qui integras cófeffiones faceret. Metus ergo Parochorú, \& quod ex metu oritur odium, cogit Indos nihil veri \& fynceriapud illos dice re. 
560 DE PROCVRANDA INDOR MS re . Cuiris rei nullo alio teftimónio opus eft quàm quod facerdotem nacti benignum patier ter audientem, \& commiferantem potius, quàn fuperbè indignantem certatim ad Confeffione faciendas nullo vrgente accurrunt illi ipfi In di, qui Parochis fuis vix vi poft annum, vecon fiteantur, adduci poffunt. Incredibile eft quo millia confeffiones generales fecerint apud eosreligiofos, quos fibi verè patres arbitran. tur, quàm fponte, quàm apertè, quo animi dolo. re,qua fui deteftatione infandiffima etiam fce. lera totius anteact $x$ vitx detegant, quibus la chrymis, quo gemitu, \& fingultu corpus fuum acerbè tundentes ac vellicantes, \& fefe totos intimo morore conficientes, quod iam tandem Parochi nó pauci, \& agnolcere, \& admirari cœperunt. Quid oro eft, Cur Indus cùm ita ægro tat, vt mortem fibi impendere exiftimet, vltro accerfit Parochum, \& intimas confcientix plagas exponat? Profectò Fidem fuam fatis Indus, cùm fingere nihil eft opus, oftendit. Itaque moriturus libenter crimina omnia etiam immania prodit,quod tamen folpes fape facere recufat. Hîc quis non videat metum hominis metu mor tis fuperari?quod $\mathbb{f}$ fanus, \& faluus hominis afperitatem \& minus fibi æquum animum minimè offenderet, facilius ac libentius res ip fas ve funt, proditurus effet.

Contra errorem illius, qui fripfit Confeßiones ab Indis effe tollendas.

- C A P. XVI.

Vo magis ridenda êt (fi modò rifu ac non potius acri dolore tam abfurda bla fph emia

exci- 
SȦZTE. I I B ER VÍ. Só́ xcipi debet) Theologi illius fententia,qui opti è confultú iri Indis $\&$ dixit, $\&$ fcrip fit, fi conffionum obligatio tolleretur: Ne tot, inquit, $8 x$ Im grauia facrilegia perpetrare cogantur, $\hat{o}$ ultam hominis vocem, qui cùm fibi fapienter adorum faluti confulere videatur, nihil aliud gat, quàm vt illos interire vnico fublato remeio cogat . Si peruerfis remedio quouis abutenbus ifta ef ratio medendi, tolle matrimonia, e adulteria fiant, aufer Ecclefias \& facra omia, ne facrilegi fint, denique nullum fit humaimbecillitatis remedium, ne malitia cótuer$t$ in virus. Quin potius apud rętè ac fapienter Atimantem omnia, pluris eft quod pauci electi er medicinam fanantur, quàm quod plurimi probi per illius abufum deteriores fiunt. Atde hæc quidem ita dicuntur, quafi confultatio is humana effet de Pcenitentix Sacramento enfere:cùm verò, ve facrofancta Concilia tra- Conc. Tri. unt, totiufq́ue confenfus Ecclefix, diuini iuris fer.ı4.can $\sigma_{a}$ lud fit,diuinæ autoritatis, neq; aliud polt bapfnum lapfis remedium fupereffe Chriftus Do inus fanxerit, quàm infanè, imò verò quàm xeticè prorfus dicitur, vt confeffionis faciidæ obligatio abrogetur ijs, quibus nulla eft ia falutis relicta fpes? Quin nos ip fos potius cufamus, atq; emendamus, $8 z$ animarum meci efficimur, \& patres nos, non fatellites effe meminimus? Hæc enim expedita, \& cer-

ta ratio eft ad euitanda facrilegia,

qux in confeffionibus Indorum perpe-

trantur.

$N n$ 
\$62 DE PROCVRANDA I NDOR VM Quas fatisfactiones Indis iniungere oporteat.

\section{CAPVT XVII.}

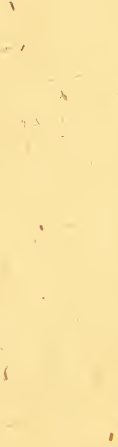

Q Vas autem fatisfactiones iniungere conueniat, prudentia docebit. Cum intimo ipf fcelerum fuorum dolore pulfantur, vlero pergraues fibi imponi flagitant: 2 fi facerdos indul gentius fortè fe geferit, ip fi eas arripiunt. Adco feruor fpiritus, vbilemel accenfus eft, magnos conatus excitat. At plerique imbecilliores funt, neque ea animi frmitudine, vt tam graues ponas de fe exigant. Qiid ergo?abijciendine erüt? an expectandum vique dum fpiricusita incalefcat, vt pares delictis poenas exoluere velint? id quidem el, \& Dei potius dono, quam hominis induftria fperandum. Ergo quod Chrifus oui erranti praftitit, ve vix dum abertore conDionep. S. uerfam, ve Diony frus dixit, in humeros facros attolleret, id iplum Chrifi imitatori faciendü eft, fi falutem hominum amat, vt non plus imponat oneris, quàm ferre illum pofe viderir; atque in fe, quod frarridcel, fuppleat \& peraconc.Tri. gat,adimplensea, qua defune paffounm Chrift $\int e f .14 .6 .8$. Matt.23. promembroipfus. Ivam ficut alienorum peccatorum participes efficiuntur, qui leuiffmas fatisfactiones pro grauiffmis delictis iniungunt, vt fancti Patres tradiderunt:ita l'harifro. rum eft, alligare onera gravia, \& importabilia. Chrift fanguinem non infideliter difpenfare is credendusef, quifefe viribus pcenitentium accommodat, cùm prafertim non tam animi prauirace quàm infirmitate quadam maiora non audent, mitiora libenter tubeunt. Salutares igitur 
SA I TE. LIBER VI. itur fatisfactiones Indis iniungere oportebit; $x$ ijs præfertim, qux aut confuetudine, aut com. loditate freti non mendaciter fefe peracturos olliceri videantur: ita prorfus vt excitentur otius quàm terreancur, ne odio in facramenun concepto, cùm opus deinceps fuerit, redire Imedicum perhorrefcant.

\section{De Extrema vnctione.}

\section{A P. XVIII.}

Nfirmatur quis in vobis, inducat presbyteros Ecclefix, \& orent fuper eum vngentes eum in omine Domini, \& oratio fidei faluabit infirum, \& alleuiabit eum Dominus, \& fi in pecatis furerit, dimittentur ei. Hoc facramencum xtremæ vnctionis à Patribus Sacramentum Idc.s. Ex Conci Tri. $\int e f_{12}$ c.1.0 c.2. de Extre. xeuntium vocatum eft, $8 x$ totius vitz Chriftia- vnct. x confummatiuum exiftmatum, quo Domius clementiffuus finem vitx tanquarn firmilmo piafidio muniut. Nam etri aduerfarius ofter occafiones per omnem vitam quærat $8 z$ apter, vedeuorare animas noftras, quoquomoo poffit, nullium tamen tempus eft, quo vehenentiusille omnes verfutia fux neruos intenlat, ad perdendos nos penitus, \& à fiducia etiä, i poffit, ditnine milericordix deturbandos, quàm cùm impendere nobis exieum vita perpicit. Vnctio ergo hæc lacra delika, fi qua unt adhuc expianda, ac peccati reliquias abtergit, \&z ægroti animam alleuiat \&z conirnat, magnam in eo diuina mifericordix iduciam excitando, qua infirmus fubleuarus, $x$ mali incommoda, ac labores leuius fert, \& $\mathrm{Nn} 2$ tentz- 
364 DE PROCVRANDA INDOR V i rentationibus Dæmonis calcaneo infidiantis $\mathrm{fa}-$ cilius refiftit, \& fanitatem corporis interdum, vbi faluti anima expedierit, confequitur. $\mathrm{H} x \mathrm{C}$ funt qux Fidelibus omnibus ex tam falutari fa cramento pie fufcepto bona conferri fancta Synodus Tridencina docet: à quorum confortio $\&$ fructu cur obfecro excludantur noux ftirpes Indorum, cùm baptizati fint ficut \& nos, \& Fidem eandem profiteantur, \& in mortis difcrimine fibi $a b$ Ecclefia auxilium praberi vehementer cupiant ? Magnæ hoc inhumanitatis in fratres genus eft, cùm præfertim fi qui omnium mortalium, hi maximè cùm extrem i tem poris tenentur anguftijs, præfidio Ecclefiaftico indigeant.

Rx concil, Etenim idolorum pontifices $\&$ venefici, quoLim. conf. rum hodie quoque magna copia fupereft, qui 75 . fummopere Chriftianæ religioni obfiftunt, caterolq́que decipiunt, ij omni opera $\&$ ratione $x$ grotis periclitantibus perfuadent, vt iuxta prifcam fuam fuperftitionem apud ipformet confiteantur,atque idolis fibi placandis \& conciliandis facrificia offerant:multaque alia impie \& facrilegè præcipiunt miferis, qui vt funt natura timidi, minufq́; ad Diaboli fraudes cognofcendas infrueti, tum antiqua confuetudine alliciente, 8 mortis periculo territi faeilè eiufmodi fallacibus promiffis animum adhibent . QuamAE 13. obrem aduerfus hos filios Belial, veritatis ini2. vet.2. micos, qui vias Domini rectas non ceffant pernertere, \& alliciunt animas inftabiles in xternam damnationem, opuseft Chrifti tyronibus firmiffimo aliquo præfidio : nullum verò excogitari poteft diuino Extremæ vndtionis Sacramento praftantius. Quibus rebus adducta Synodus 
S A I V T E. L I B E R VI. 565 us Prouincialis decernit, \& præcipit, ve facer- $\operatorname{con} f$ t.750 otes nullo modo Indos fideles iam ritè confefs, aut fi minus id licuit, contritionis figna præ ferentes fine hoc tam falutari remedio de viexire patiantur. Et decretum quidem totius cclefix ad omnes fideles in generali Concilio gimus, peculiare verò ad Indos fideles in Proinciali fynodo repetitum, \& magnopere comhendatum cernimus: vtrumq; verò re ipfa vfueadeò neglectum,vt pene facrilegij loco fit, quis de Indo in firmo vngendo cogitet. Neque go fanè intelligo quoufque tam ftolida noftroum confuetudo ferenda fit.

\section{Defacerdotio. CAP. XIX.

$$
\text { is }
$$

E Sacerdotio inter Indos pauca fanè præcipienda funt. Nam quod ad ipfos attinet, fat ciunt ordinem effe miniftrorum à Domino intitutum, vt \& Deo feruiant, \& populo prafint, $11 \mathrm{i}$ ad altaris facrofancta myfteria, huic ad renittenda peccata, $\&$ verbum Dei proponendú, autoritate diu initus data. Atque vtinam vt hi fa cerdotium venerantur, \& tanquam munus cœlefte fufpiciunt, ita nos vitæ fanctitate tanto muneri pares effemus. Illud autem prudenter eft à maioribus conftitutum, ve nemo ex Indorum genere, facerdotio aut gradu aliquo Eccle-Conc. Lim. fiaftico donetur, neque facras veftes in minifte- conft.740 rio induat: tantùm vt liceat Indis fidelibus inferuire altaribus acolythorum more in choro pfallere,"xdituorum officio fungi, fuperpelliceis inter hæc tantummodo indui. Nam infesiora hxc ad eos cohortandos, \& in religione Nn 3 chri. 
566 DE PROCVRA N D IN D OR VM Chrifiana confirmandos plurimum valent. Mirificè his delectätur, \& primores ipli libentiffimè filios fuos Ecclefrafticis minifterijs, \& literis imbuendos tradunt, idq́ue progloria non parua ducunt. Quod verò ad fuperiores gradus facros prafertim Indos euehere minimè oporteat hac xtate ecclefix antiquiffima inftituta fatis dor.Tim.3. cent Paulus Apoftolus vetat neophytum Ecclefir præfici, ne in fuperbiam elatus, inftar DiaAdrian. 2. in epift.ad Taraficin 2. Nicrena bin。

Sap 14. 3. $R \operatorname{lgg} .13$. boli corruat ex alto. Sacra Concilia vehementer deteftantur ordinationes eorum, qui in fide tyrones funt. Nam cum ipfis tum populo damnum fit, tum verò minifterio ipfi non leuis iniuria. Quocirca admirabile eft, quàm feuerè facra literæ reprehendanc facerdotes factos de face populi, idćue cùn agatur non de facerdotibus veri \& fummi Dei, fed falforum porius:quia tamen Deorum nomen etí non numen habebant, ijs attributos effe ininiftros plebeios, \& viles, pro magno fcelere ponunt, quemadmodum iurifurandi religionem etiam dijs mendacibus non feruatam exdem diuinæ liter $x$ damnant. Sic enim fcriptum in libro Regum legimus: Non eft reverfus Hieroboam de via fua peffrma, fed è contrario fecit de nouiffmis populi facerdotes excelforum, quicunque volebat, implebat manum fuam, \& fiebar facerdos excelforum. In quarto quoque libro de Samaritanis loquens E4.eg.r7: Scriptura, Fecerunt autem fibide nouiffmis facerdotes excellor $\ddot{\text { }}$ \& ponebanceos in fanis fublimibus, 8 cum Dominum colerene, Dijs quoq; feruiebant iuxta confuetudinen Gentium, de Guibús tranflati erant Samariam. Quod planè do cumentum non ad hoc folurs valet, ve Indi non inicien: 
SA I VTE. LIBER VT. 567 nitientur, cùm fint $\&$ in fide noui, $\&$ generi obcuri, verùm etiam qui ex harum fœminis 8 Iifpanis viris concubitu prafertim flagitiofo ignuntur, quoad fieri poteft à facris myfterijs ontrectandis abftineant, ne facerdotium vile abeatur, nifi cùm vitæ diu probatæ grauitate, $\&$ gorum fplendore natalium obfcuritatem fupeant.Tales effe nonnullos negare non poffumus, ui \& vitæ honeftate, nof ris pares süt, \& fermois Indici cómoditate fuperiores. Verú rari hoc xempli eft. Quamobrem antiqui Canones $\&$ rouincialia decreta feruanda funt, vt facerdos mni ex parte populo fpectabilis \& honore dinus exiftat.

De ritibus Matrimoniorum apud Indos.

C A P. XX.

N matrimonio tractando lacior campns occurrit, in quo parocho multa/neceffariò conofcenda erunt, non folùm quod fit Ecclefix icramentum excipiendæ, \& fanandx mulcorum nfirmitati neceflarium, fed quod infideles quoue fua coniugia habeant, quorum vfum $\&$ rium, abufum quoque \& errores cognofcere oorteat, ne quod non rarò contingit, aut vera natrimonia dirimantur, aut pro matrimonijs lagitia teneantur. In omnibus docendi funt, ve Heb.13. uftodiant immaculatum torum $\&$ honorabiles uptias. Vfum autem \& vimconnubiorum apud if fideles, fromnia dicenda fune, oratione comlecti, moleftiffimi negotij eft, cùm in tanta bararorum illuie non polfint non infinti efte Nn\& \& \&in

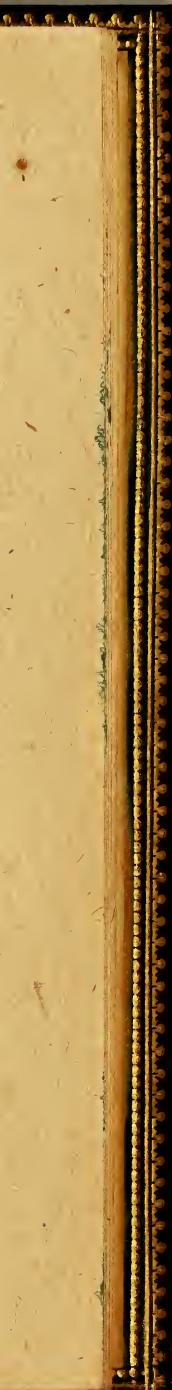




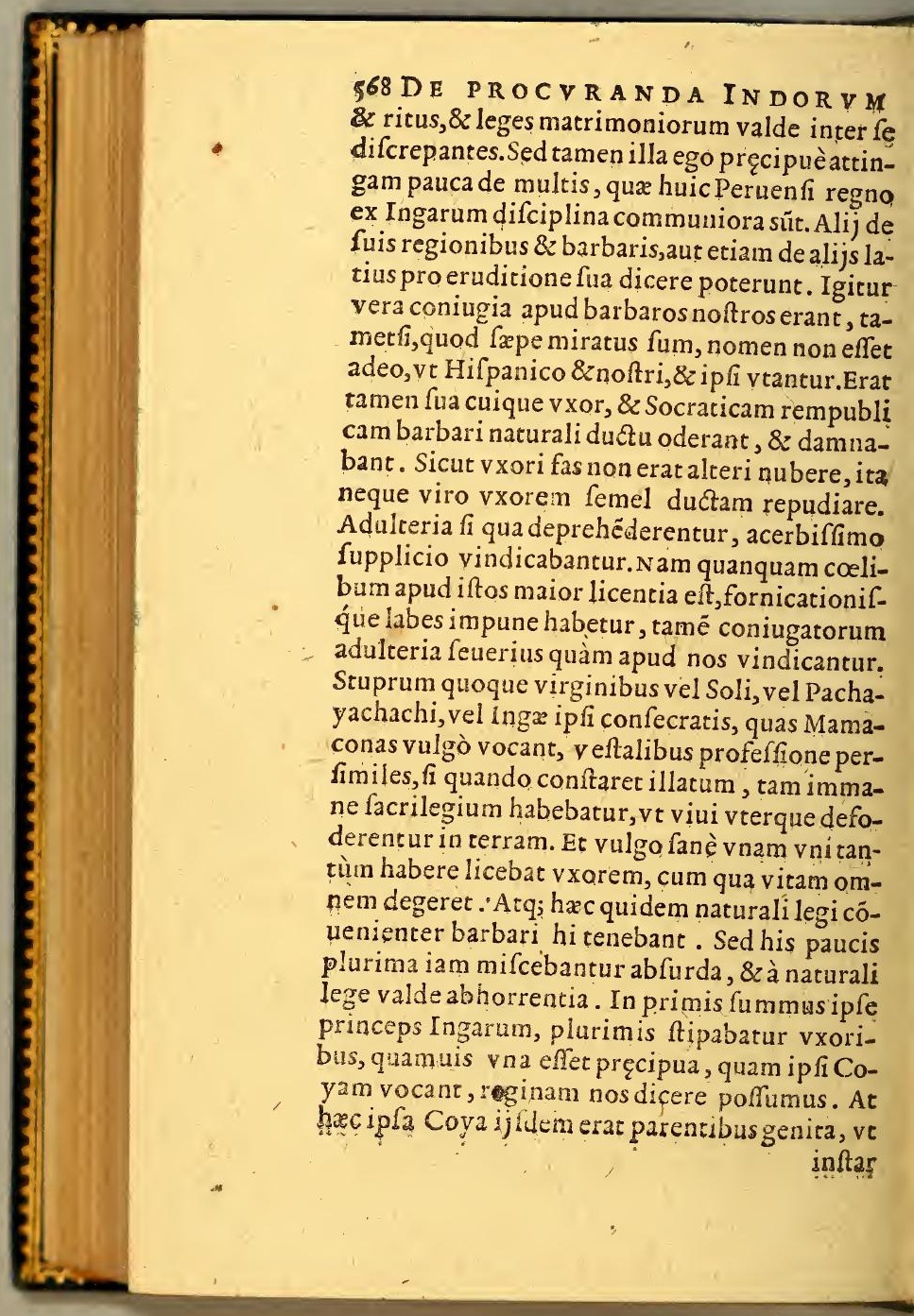


S A L V T E. LI B ER VI. ftar Iouis Iunoni, regis eadem effet, \& $z$ foror, coniux. Adeò fanctum erat, vt præcipua vxor, dern effet fanguine coniunctiffima.Cęteri veproceres, \& ipfi plures fibi coniugio copulaint, præcipuamque eandem fi non fororem,at nfanguinitate maximè propinquam habebát. at enim id regium. Vulgus reliquum vnam, vt xi, nifi priuilegio Inge ob aliquid fortiter,aut renuègeftum, plures liceret accipere, vxorem bebat. At illam non pro fuo quif́que arbitratu igebat:fed aut Principis, aut Ducum illius,aut opuli ipfius volútate capiebat fibi affignatam. q́; intra fuam femper tribum $\&$ familiä, quod yllo vulgo dicitur. Ex qua priftina confuetudiinfidelium, duo apud fideles abfurda manant:vnum vt Curaca fiue primores Indorum, o arbitratu fuo fuis vxores dent, neq; liberam lis eligendi facultatem permittant: alterum vt ix de alia tribu aut gente vxorem audeant Indi cipere,eamq́ue ob caufam fre confanguineas at etiam forores, \& nouercas violent provxobus. Quæ fanè incommoda diligentium paro1orum ftudio magna ex parte abolita funt: $\mathbb{2}$ oncilij animaduerfione plerique vigilare cœerunt. Fuit miferrima feruitus Peruen fium fub garum tyrannide, vt neque vxorem ducere, Conc. Lims: Conft. 64: eque ficeram bibere, neque cocam mandere, eq; carnibusvefci fune illius voluntate fas eflet. Iunc verò qui in libertatem Euangelij vocati ant, gratias agunt, \& duriffmo iugo excufo, uem Chrifti farcinam alacriter portant. Eft iam peffimusquidamerror, \& ex errore maimusabufus coniugiorum, (monftrum dicere $\mathrm{Nn} 5$ poffis) 


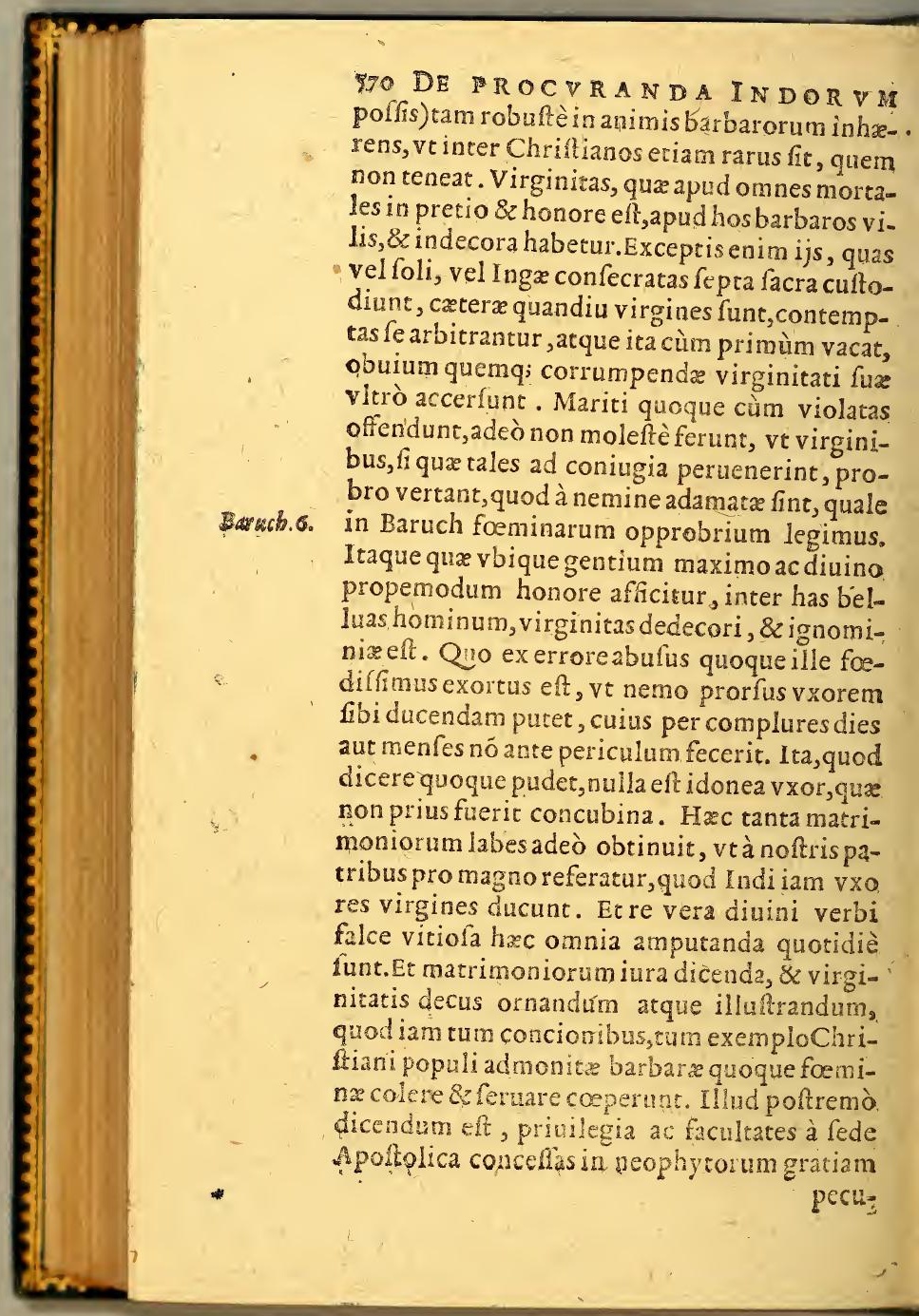


SA L V TE. L I B ER VI. 572 eculiarifudio debere cognof́ci, ne cùm aliâs epe, tum in marrimonijs iungendis Indorum abi contingat. Neue per imperitiam prxpofiorum imbecilles Indi ea cogantur feruare, qua ortes $\&$ antiqui Chriftiani vix feruant. Nam ùm multa ijs fimilia quæ diximus, barbari $n$ fua fuperftitione feruarent, ne religionis notra moribus contrarijs prorfus deterrerentur fide, Romani Pontifices nonnihil de Ecclefifticarum legum rigore imminuendum exiftnarunt, imitati profectò Gregorium illum mag num, cuius erga recens conuerfos A nglos pa- Regift,epio erna indulgentia literis ad Augufinum datis $3 t$. expreffa tenetur.

2uid agendum fit de coniugïs infidelium, cìm ad filem catbolicam comertuntur.

\section{CAPVT XXI.}

SED habet frequentem apud nos, \& dignam fcitu quæfionem, cùm infidelis coniugatus fide noftra fufcepta baptizatur, quid de illius matrimonio fentiendum fit. Ac primùm, eum qui Chriftianus effectus elt, non polfe vxorem cenuò ducere infidelem, neq; fidelẽ infideli nubere,fine vlla dubitatione ex Ecclefiæ vfu, \&z có fenfu certifimum eft. Nam $\&$ fcelus ingens com mittitur, \& matrimonium nullum éft iuxta no- Ambr.28.q. frorum doctorum concordem fencentiam, ta- Ang. eadens metfi, qua illi recitane, A mbrofij \& Auguftini, qu.c.sio carteraq́; decreta, non id fatis efficiant. Sed con- enim Con. fenfus, vt dixi, Ecclefix facis eft. De eo verò qui Chalc.c. 14. ante 


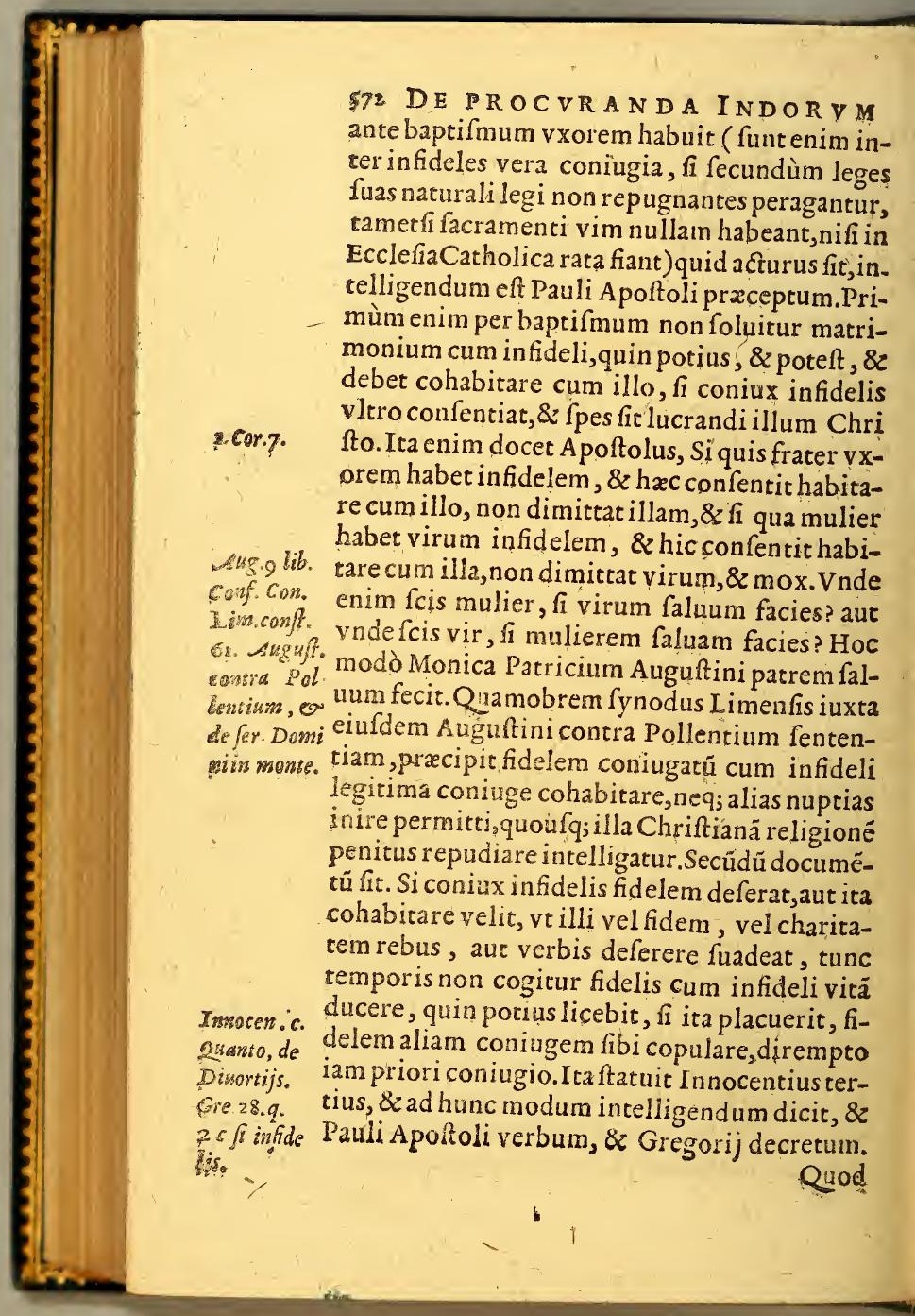


S A L V T E. LI BER VI. God fi infidelis difcedit, difcedat, ait Paulus: on enim feruituti fubiectus eft frater aut foror eiufmodi:in pace autem vocauit nos Domius.Tertium quoque fit. Cùm dubium eft, an cöax infidelis fideli impedimento futurus fit, \& n potius illú peruerfurus à vera religione fit; uàm $a b$ ipfo lucrifaciendus, quidnam agendü It? Nam neque contumelia creatoris manifeftè pparet, neque fpes etiam fatis elucer illum falum faciendi. Huic dubitationi, occurrendum xiftimarunt Patres hoc modo: vt coniux infielis admoneatur, quantum fatis eft, vt religioem Chrifti fufcipiat, quod fi conuenienter ad1onitus, omnino renuerit, intelligatur obftina effe voluntate, \& fidelem confortio fua pous lædere quàm ab illo adiuuari. Itaque fepaandum effe. Ad hunc modum Toletanum Coniliü decernit, Iudæi qui Chriftianas mulieres coniugio habent, admoneantur ab Epifícopo iuitatis illius, vt fi cum eis permanere cupiant; hriftiani efficiantur.Quod fi admoniti noluent, feparentur. Huius Concilijaucoritatem feuti Patres in fynodo Limenfi, ita præcipiunt, alter coniugum baptizari renuerit, Sacerdos dhibito notario, \& teftibus illum admoneat, $t$ intra fex menfes Chriftianus fiat, \& baptizeur, atque eandem admonitionem repetat fape atra illud temporis fpatium faltem femel finulis menfibus. Quod fi tranfacto iam femeftri empore, adhuc baptizari renuerit, exinde iam fua fecta obftinatus reputandus eft . Quambrem Antiftitem fuú Parochus certiorem faiet, vt iple ftatuat, quid facto opus fit. Separaonem autem illam Concilij Toletani ego non folùm 


\section{DE PROCVRANDA IN DORVM}

Sorm in 4. folum quoad torum intelligo, fed etiam qunad d.39.q $\mathrm{k}$. vinculum. Itaque licebit, ve graues quoque au2.004. Aug.28.q. 1.c. 2xor. Inno.c.gas demusde dinortijs. tores confirmant, fideli iam tunc alias nuptias conciliare fibi. Contumelia enim creatoris, \& periculum fidei intelligitur, cùm animusconiugis infidelis adeò eft in fua fuperftitione obfinatus. Praterea illud ex eodem Innocentio animaduertendum ef, nuptias infidelium non teneri Canonicislegibus, quareilla folùm matrimonia irrita evunt, qua cum lege naturali pu$*$ gnant, quemadmodum apertè repugnat pluralitas vxorum, atque etiam repudium prima, vt Matro. Euangelium \& Prophetz docent.Quamuis inInciro. Malach.2. eptus quidam Theologus, ve multa alia, etiam hoc hæreticè \& ftultè afleruerit, Indis plura litem vxorum effe concedendamin Ecclefia. Repugnat etiam naturaliter matrimonio primus gradus originis, vt cum forore, cum nouerca, ac mulco magiscum natre, aut flia, nepte aut auia. Quamobrem in Concilio Prouinciali ex fenten tia Pauli quarti Pontificis omnia ifthrc matriConc. Lim. monia infidelium, cum Chrifiani funt, irrita conft.38. fieri decretum eft. At verò qux lege folùm Ecclefiafica prohibita funt, ve fecundo aut tertio gradu contracta, ea rata fieri, cum vrerque baprizatur, Canones facri iubent. Cùm verò plu-

C. Gavdemus de di. res habuit vxores, fi verè ve vxores habuit, adhimortijs. bitis caremonijs, 8 ritu patrio nuptijs adhiberi folito, illam tantummodoretinebit, quam primam effe meminerit, aut fi ignorat, quanam conft.37. fuerit prima, accipiet ex Indulto tauli.ertij Conc. Iim. quam ex omnibusiple delegerit. Quod fi etiam primailla abeft, \&:baptizari differe, licebit ex alijs, quá velit, fumere, ita cócedente Pio quinto Ponts: 
S A I. V T E, LI BEŔ VI. 973 ontifice Maximo, quinullo modo Innocentio Eodem ca. ertio contrarius eft.Quandocunq; autem̄ vxor Gaudemsis, nfidelis ad fidem conuertitur, fi nondum alian Chriftianam accepit, tenerur illam fidelisacciere. Hæc pro rezionum harum difficultatibus x landintum Pat um decretis perfirinxifie fuficiat:plura $\&$ clariora autores iradent.

De impedimentis Matrimon $\ddot{y}$ explicandis, do iusembus collocandis.

\section{CAP. XXII.}

$A M$ verò in matrimonijs celebrandis fummo pere Parochi curare debent, vi impedimenta cclefiaftica lape \& proponantur, \& explicétur equod crebro fit, per ignorantiam illegitimas ndi nuprias iungant. Quod fi guando de induiria \& malitiose in pedimentum diffimulatú, tut tectum effe deprehenderint, ve Prouincialia lecreta habet, grauicer in reosanimaduertant; rafertim Curjcas caterof́ćue primores, quoum nequitia folent incefuolæ nuptia frequen er conciliari: vereliqui exemplo áfperiore do. ti difcant in folennibus monitionibus aut Banis explorata impediméta manifếra facere. Süt utem montiones in facroConcilio Tridentino ræceptæ, inter Indos potiff mum obferuand t nuptiæ publicétur eorú qui coniugari volüt, nter ens, quibus maximè noti funt. Impedimëa verò apud hos figillatim exponéda funt,quius \& ignotú eft ius, \& pro vetufa cófuetudine requens eft prohibita coniugia appetere. Itaq; xplicabit Parochus, quod faciü peritiores, qui ous gradibus confanguinitatis, quibus etiä affinitatis, 
576 DE PROCVRANDA IND.ORPا nitatis, quibus fpiritualis cognationis nefas fie coniugia inire. Maximè verò infiftet in declarädo, impedimento ex fornicatione primo,aut fecundogradu admiffa. Vulgare quippe eft Indis earú forores, aut neptes, aut materteras, aut con fobrinas ducere, quas flagitiosè polluerút. Atq; equidem perquàm optarem, vt in ijs gradibus, Seff.24. ficut duo reliqui, à Tridentino Concilio fublati eap. 4 .

S. Angelus sylueft. lif funt, effet penes Epifcopos Indicanos difpenfan di facultas cum neophytis, præfertim cü effent iā matrimonia cótracta, \& aut vterq; cóiúx impedimentum neficiuit, quod fieri poteft, aut faltem vnus eorum. Hos enim iubere prorfus fe có tinere, aut Romam vfq; petendæ difpenfationis caufa proficifci nimium profectò eft. Atq; in fecundo faltem gradu ex fornicatione occulta Epifcopos noftros difpenfare, quia fedes Apoftolica commodè adiri non poteft, \& periculum eft penf 9.9.

Nauarr.

22.n.86. in mora, autores non ignobiles fentiunt, quorum nosiudicium fecuti Archiepifcopo Limé fi, vt nonnunquam difpenfaret, perfuafimus.I1lud quoq; experientia docet Indos à prima adolefcentia æate collocare percômodum effe, ac multo magis adoleícentulas Indas, quod re ipfa compertum fit, maritatas fcominas omnium effe caftiffimas, quæ fi coeperint ante nuptias libidini fræna laxare, per reliquam ataté pręcipites ferantur neceffe eft. Erit ergo non mediocris of ficij, vt Parochus honeftas nuptias fuadeat atq; conciliet, parentes de liberis collocandis admo neat, metum omnem Curacarum adimat: iuuenes ipfos conueniat, \& Chrifian i coniugij fanctitatem doceat, fidei \& catechefis Chriftianz sationé expofcat, peccata ritè côfiteri moneat: ftatim 


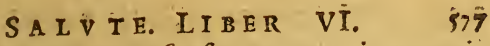
im ve mutuo confenfu contraxerint matrisium, in Ecclefia folennesbenedicticnes imdat, ve fimul, quemádmódum eft à noftris fulibus ordinatum, \& nuptia fiant, \& ab Ecconft.68. ia benedicantur. Mox ve nuptialia ominia lemè peracta fuerint, omni illa fuperftitiofa ulentia \& compotatione amputata, in qua poloper fuos Areitos, aut Taquies initianhonefta tantùm religiofi conuiuij lartitia ceffa paternè grauiterçue monere, qư fret iftiani matrimonij leges, qua difciplina dotica,quomedo Ecclefia frequentanda, manè efperiquotidie orandum, filijeducandi in , \& timore Domini, vt quamuis pauperem am degant, multa bona habeant, fi timuerint $\mathrm{m}$, \& illius mandata feruauerint. Hoceft eomnis homo, reliqua omnia vanitas vani- Eccli 12: mactenus de facramentis Indis adminindis, pro infituto noftro pauca de multis: e certè proexplorata harun regionum conione magis opportuna exiftimauitous.

uibus ex rebus Indorum falus maximè pendeat, peroratio.

\section{A P T XXIII.}

$\neg V M$ de procuranda Indorum falute fatis multa, vt potui, dixerim, tanen illa omnia n magni ponderis futura fcio, nifi tria quxm veluti capita vniuerf huius inflitu, $i$, pro i dignitate feruentur. Primi m, vt Chrlasti incipes \& Prafecti, \& Magifta arus Chriftivin fuaue, $\&$ onus leve Indis ad fidem fe reci-

$\mathrm{O}$ () pientibus; 
$\$ 73$ DE PROCVRANDA INDOR V H pientibus, vreft, effe permittant, id eft, vt tribu torum, exactionum, laborumq́ue onera valc moderentur, fciantq́ue Barbari fe ipfos potil quam fua quxri, \& quod habent Caroli Cafar regia edicta, rebusipfis intelligant, Chrifian dominatu fe porius leuari, quàm premi. I ges qüoque non prorfus duras, \& infuetas ba baris ferant: fed quead per Chriftianam, \& n turalem legem liceat, finantur inftitut is fuis v were, atque in ijs ip fis, \& dirigantur, \& perfic antur. Etenim perdifficile eft omnes leges, confuetudines patrias, \& gentilitias mutare: fatis profeclò eft, vt illa abrogare cogantur, qu funt Euangelio \& Ecclefia Chriftiana. contra ria, qux in tam corruptis moribus, in tantis ig norantia tenebris fatis multa funt. Catera protinus auferre contendas, ac non tempori ip fi optimo magifto viemendet committas, red des Chrifianifnum odiofum \& graucm. Omi to quod prudentiffmus quifque $\$$ rerum In dicar um peritilfmuseiufmodi notias leges, 8 mutationes cenfet ipf Reipub. temporali, 8 Indorum, \& Hifpanorum admodum pernicio fas, quòd barbari neque noftra tenent, ncque fu finuntur agere:ex quo rerum omnium perturba tio confequatur neceffe eft. Sed vt hoc omittam certè fides, 8 amor Chrifi cum dura tributo. rum, \& operarum, \& legum feruitute Chriftia.

Thren. r. nitatis pratextr non bene çonfat. Migrauit Iu. das, idef, fideiconfeffo, vt fancti parres interpretantur, propter affictionem, \& multitudi2.201.1\%. nem feruitutis.Sefaci Aegyptio regitraditi funt dininitus Iubai, vifrant, ait Deus, difantiam Seruig, 
SA L V T E. I I B ER VI. ditutis meæ, \& feruitutis regni terrarum. $\mathrm{Ni}$ go Chriftianis principibus \& magiftracibus na cura fit falutis Indorum, ac non prouenm cenfufque regalis ( nam honeftè ifta quoquæri poffunt, fed fecundo loco) parum adlum apud Indos religio Chriftiana profiHoc igitur primumeft. Deinde illud, vt fules Ecclefix Indicanæ ij præficiantur, qui im Dei habeant, \& filijs potius thefaurizent, 2. Cor. 12 on folùm fua libenter impendant, fed fe ipetian fuperimpendant pro animabus fuo, licet plus diligentes minus diligantur à Deniq; quorum effet infigne verbis rebufexpreffum, Non veftra, fed vos. Qiod fi Is, vt apud Prophetam loquitur, daret pafto- Kierem. 3. iuxta cor fuum: Epifcopos inquam \& 2 Paro- I. Tim.3. $s$, quales defcribit A poftolus, plurimos ac le- Tit.l. mos greges ex hoc agro Indicano pafcua leftia quotidie exciperent. Ve effent autem ores eiufmodi, (nufquam enim tantopere otet effe lectiffimos) examinanda eflet doetriexplorandi mores fine auaritia, perfpicienanimarum zelus, \& laborum pro Chrifto toantia.Verè enim in his nouisEcclefix populis iqui temporis \& A poftolici paftores effe deent. Poftremò, religiofi qui ad has regiones regia liberalitate \& fide, copiosè tranimitaus, non fortuitò, aut pro libidinè, aut etiam aritia cuiufq; fed colefti vocatione ducti veamus, quantum referat, vix dici poteft. Nihil rinde nocer huic Ecclefia atque mercenario$\mathrm{m}, \&$ fua quærentium turba.Quid verò in cau- Iud. Deiagant homines animales, fpiritum vix ha$\mathrm{O}_{2} 2$ bentes? 


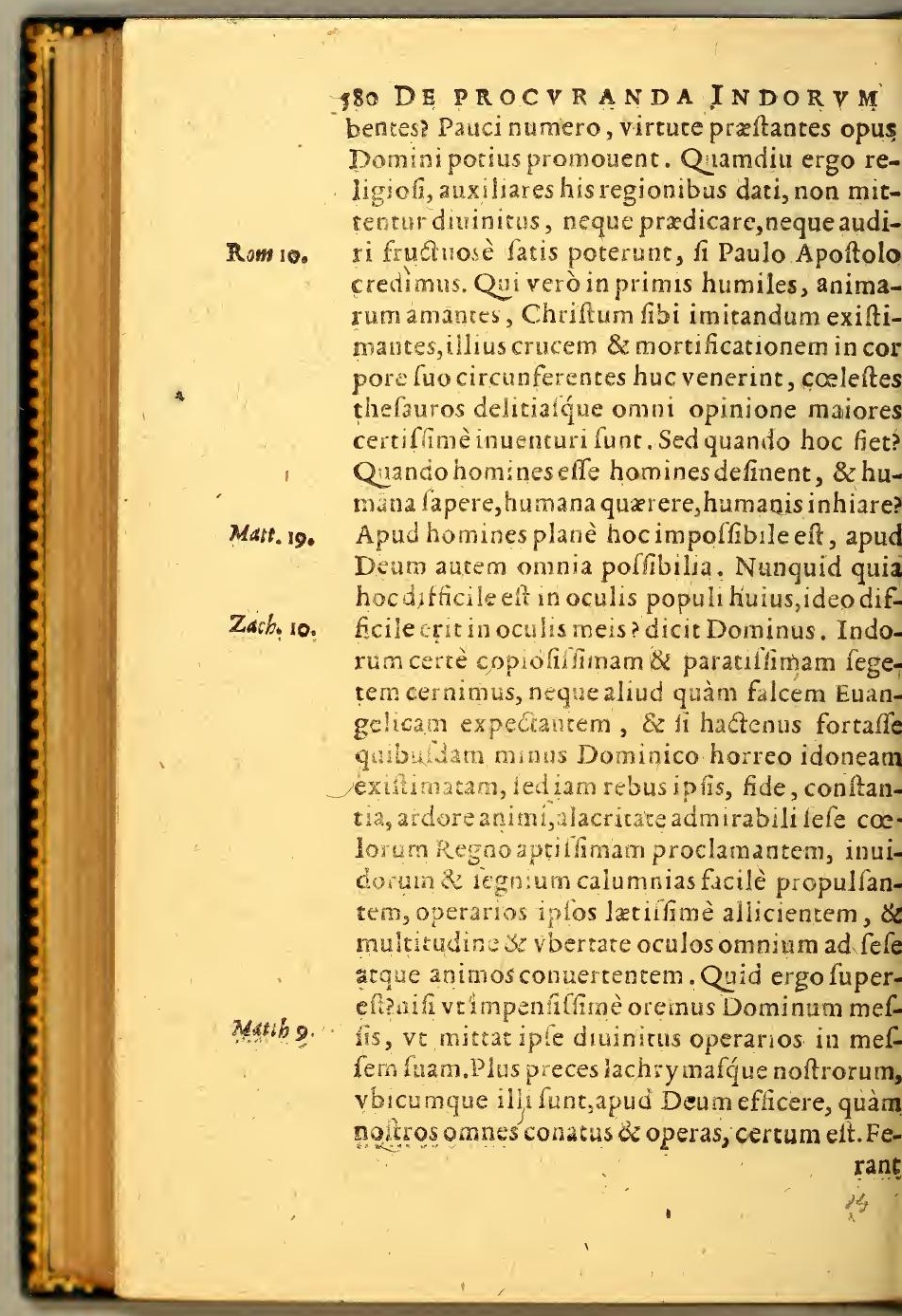


SA L V TE. IT BER VI. S̈I ant igitur opem quiciamque Dei amantes, $8:$ lutis hominum fudiofi apud benignum Reemptorem haberi volunt, $\&$ quibus polfint mo is, facrificijs, precibus, lachrymis; tuin confilio, opera,fudoribus, 8 fanguine iplo, fi opus fit, chariffimam Chrifto Iefu, tot gentium falutem profequan.

tur.

$$
F \perp \mathbb{R} \text { IS. }
$$

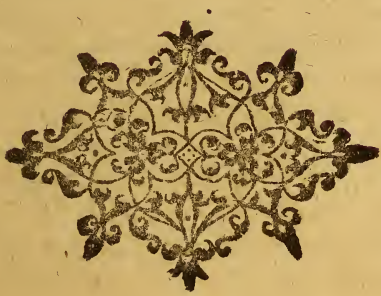




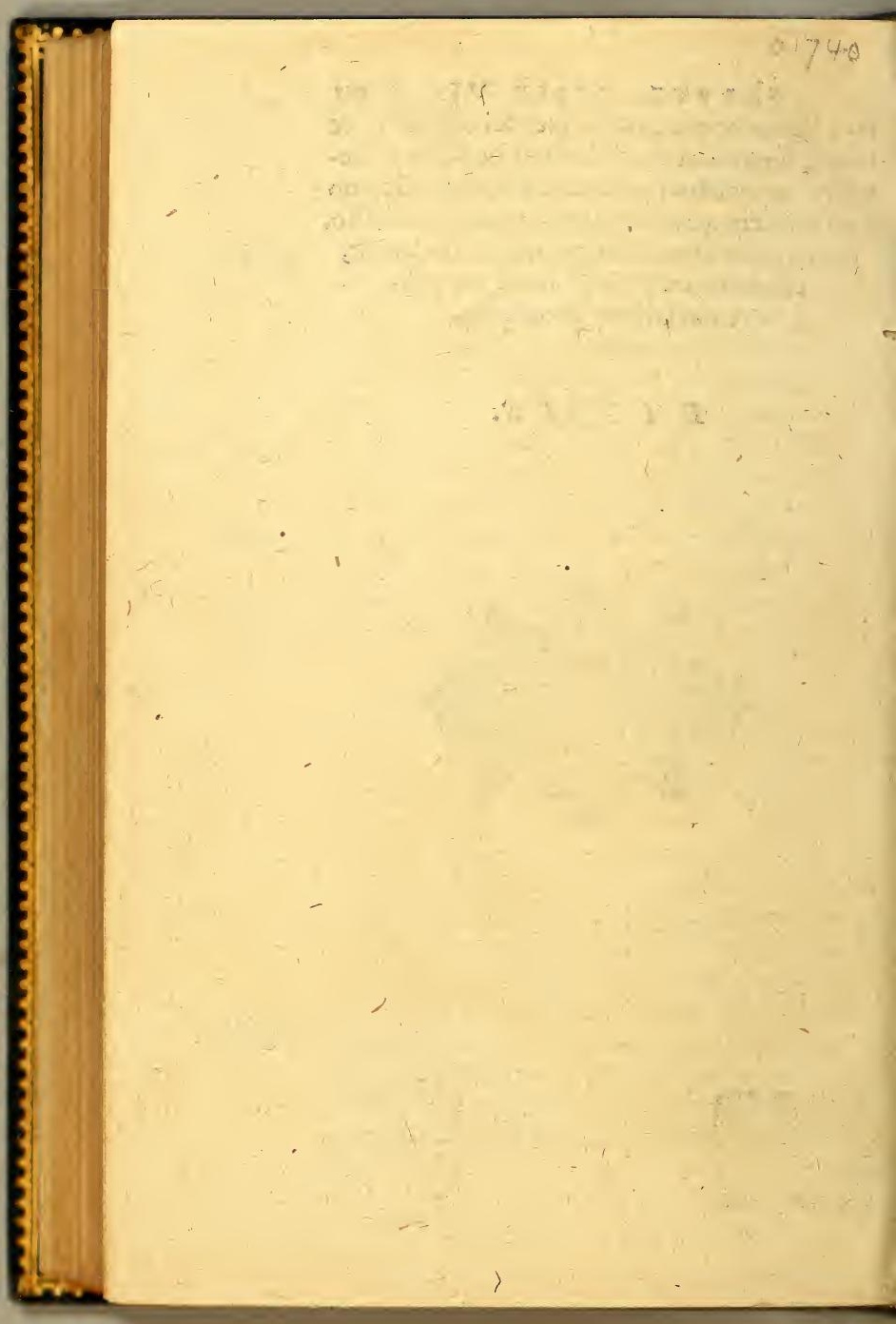





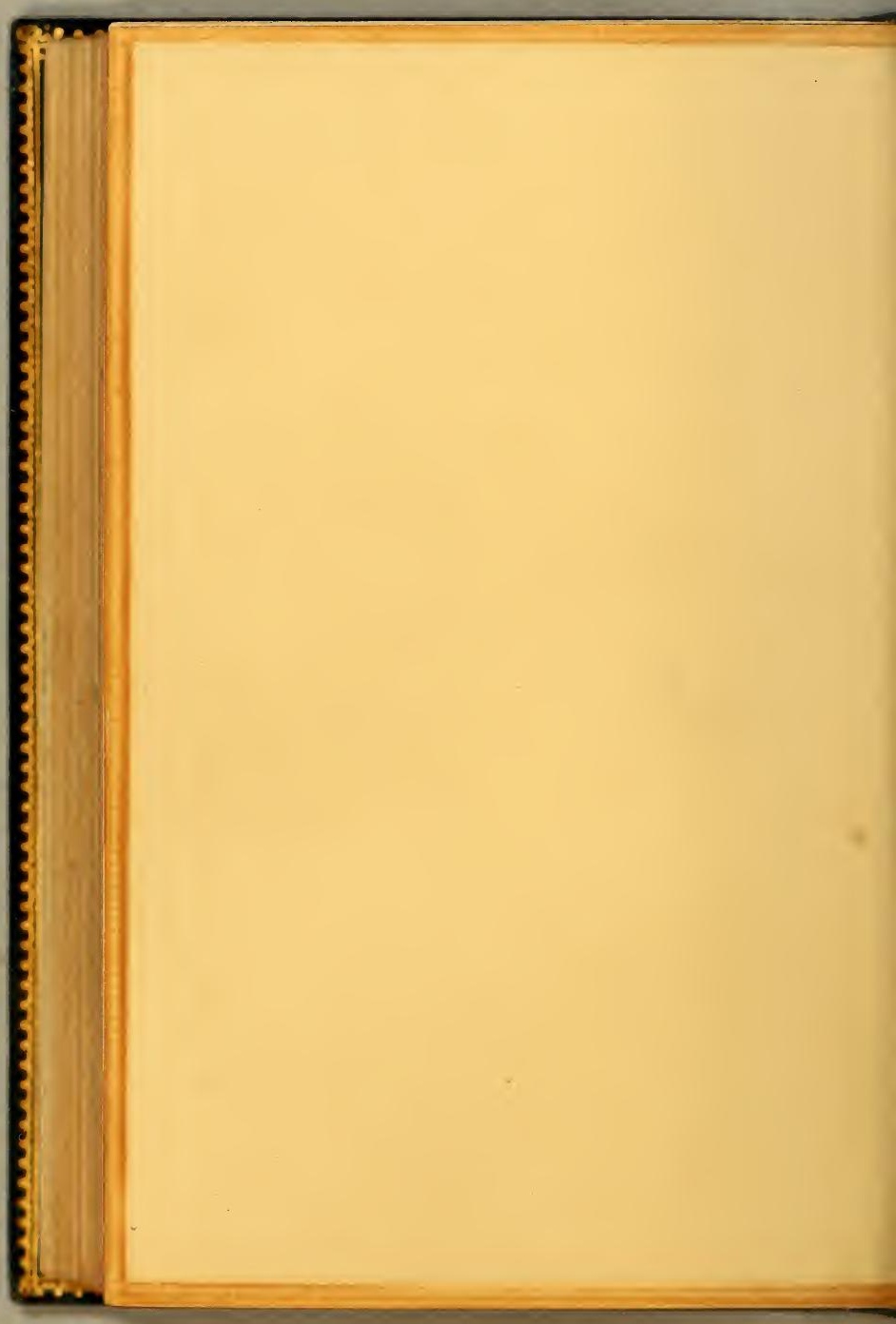




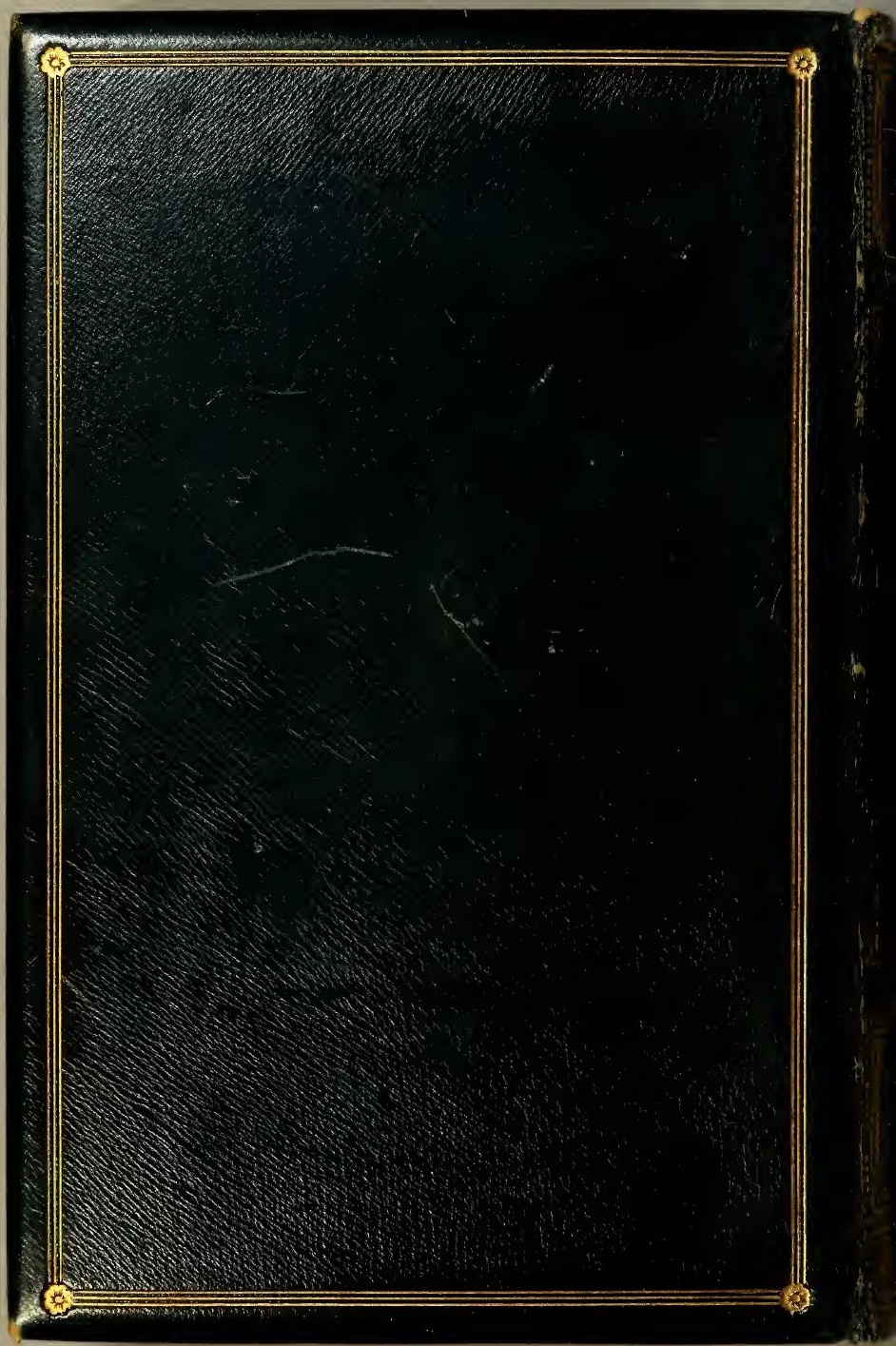

